\title{
Preventing medical malpractice and compensating victimized patients in China
}

Citation for published version (APA):

Yu, X. (2017). Preventing medical malpractice and compensating victimized patients in China: A law and economics perspective. [Doctoral Thesis, Maastricht University]. Intersentia. https://doi.org/10.26481/dis.20170215xy

Document status and date:

Published: 01/01/2017

DOI:

10.26481/dis.20170215xy

Document Version:

Publisher's PDF, also known as Version of record

\section{Please check the document version of this publication:}

- A submitted manuscript is the version of the article upon submission and before peer-review. There can be important differences between the submitted version and the official published version of record.

People interested in the research are advised to contact the author for the final version of the publication, or visit the DOI to the publisher's website.

- The final author version and the galley proof are versions of the publication after peer review.

- The final published version features the final layout of the paper including the volume, issue and page numbers.

Link to publication

\footnotetext{
General rights rights.

- You may freely distribute the URL identifying the publication in the public portal. please follow below link for the End User Agreement:

www.umlib.nl/taverne-license

Take down policy

If you believe that this document breaches copyright please contact us at:

repository@maastrichtuniversity.nl

providing details and we will investigate your claim.
}

Copyright and moral rights for the publications made accessible in the public portal are retained by the authors and/or other copyright owners and it is a condition of accessing publications that users recognise and abide by the legal requirements associated with these

- Users may download and print one copy of any publication from the public portal for the purpose of private study or research.

- You may not further distribute the material or use it for any profit-making activity or commercial gain

If the publication is distributed under the terms of Article $25 \mathrm{fa}$ of the Dutch Copyright Act, indicated by the "Taverne" license above, 
PREVENTING MEDICAL MALPRACTICE AND COMPENSATING VICTIMISED PATIENTS IN CHINA.

A LAW AND ECONOMICS PERSPECTIVE 



\title{
PREVENTING MEDICAL MALPRACTICE AND COMPENSATING VICTIMISED PATIENTS IN CHINA.
}

\section{A LAW AND ECONOMICS PERSPECTIVE}

\author{
Dissertation \\ to obtain the degree of Doctor \\ at Maastricht University, \\ on the authority of the Rector Magnificus, \\ Prof.dr. Rianne M. Letschert \\ in accordance with the decision of the Board of Deans, \\ to be defended in public \\ on Wednesday 15 February 2017, at 14.00 hours
}

By

Xiaowei Yu 
Supervisors:

Prof. dr. M.G. Faure

Prof. dr. N.J. Philipsen

Assessment Committee:

Prof. dr. G.E. van Maanen, chairman

Prof. dr. H. Nys, KU Leuven

Mr. dr. R. ten Hoopen

Prof. mr. dr. L.T. Visscher, EUR Rotterdam

Cover photograph (C) Shanzheng Wang

Layout: Marina Jodogne

ISBN 978-1-78068-468-0 


\section{ACKNOWLEDGEMENTS}

It has been a truly rewarding and life-changing experience for me to undertake this $\mathrm{PhD}$ research, which would not have been possible without the guidance, advice and support from many people and institutions.

First, I would like to express my sincere gratitude to my supervisors Prof. Michael Faure and Prof. Niels Philipsen for the continuous support of my $\mathrm{PhD}$ research, and for their motivation, understanding, and patience. Their guidance and expertise have been essential to the completion of my thesis. Their understanding and patience have helped me to keep a delicate balance between research and family.

Besides my supervisors, I would like to thank the members of the reading committee: Prof. Gerrit van Maanen, Prof. Herman Nys, Prof. Louis Visscher and Dr. Rankie ten Hoopen, for their insightful comments and valuable feedback on my thesis, but also for their challenging questions which led me to widen my topic from various angles.

In addition to the preceding academic support, I gratefully acknowledge the funding received from the Chinese Scholarship Council (CSC). Without its help, it would have been very difficult for me to conduct a $\mathrm{PhD}$ research in the Netherlands.

My thanks also go to those judges, lawyers, doctors, and government officials in China, who were willing to allow me to access court decisions or to be interviewed by me. Absent their support, it would be impossible for me to conduct any empirical research in China.

I really appreciate the pleasant working environment and facilities provided by Maastricht University and thank all my colleagues from the law faculty, especially those from the METRO research institute, for their assistance, stimulating discussions and the fun we had in the last four years. They include Ancui Liu, Anna Berlee, Bo Chen, Catalina Goanta, Chantal Kuijpers, Constantijn van Aartsen, Cuiping Gan, Elke Hundhausen, Guang Shen, Huizhen Chen, Jiangqiu Ge, Jie Wang, Jing Liu, Jingjing Fu, Kelly Shang, Liang Yu, Liuhu Luo, Marjo Mullers, Marina Jodogne, Mark Kawakami, Max Gaber, Mehdi Piri Damagh, Mengmeng Shi, Mengxing Lü, Sarah Schoenmaekers, Shuo Li, Taotao Yue, Tianxiang He, Tobias Heldt, Wen-Cheng Huang, Wenqing Liao, William Bull, Xi Chen, Xiahong Chen, 
Xuesong Li, Yaojin Peng, Yingying Jing, Yleen Simonis, Yu Yan, Yu Zhao, Yuan Gao.

Since my study at the Law School of Southeast University (Nanjing, China) had laid a solid foundation for my $\mathrm{PhD}$ project, I am indebted to all my teachers there, especially Dr. Qingkang Dai, who was my master-thesis supervisor, and Dr. Yuling Chen, who had inspired me to choose the current $\mathrm{PhD}$ topic and the current dean Prof. Yanhong Liu and the former dean Youyong Zhou, who work conscientiously to make the young Law School more and more promising and competitive in China.

Also, I would like to say a heartfelt thank you to my mother Zhangmei Sun, my father Yiqin Yu, my mother-in-law Jinhua Wang, and my father-inlaw Yongling Shen, for encouraging and supporting me throughout the last four years.

And finally to my wife Jiajia He, who has been by my side in the past three years. Without her understanding and encouragement, I would not have had the courage to embark on this journey in the first place. And to Yinran for being such an adorable and good baby in the last thirteen months, and making it possible for me to finish the thesis. 


\section{CONTENTS}

Acknowledgements ....................................................................................

Contents ........................................................................................... vii

Abbreviations ................................................................................................

List of Figures and Tables ......................................................................... $\mathrm{xxv}$

\section{Chapter 1}

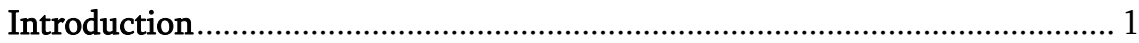

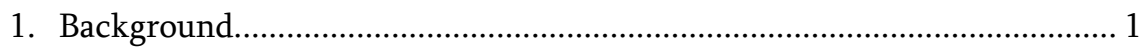

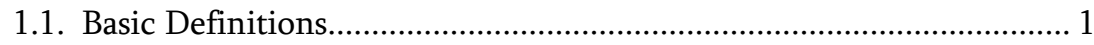

1.1.1. Medical Disputes..................................................................... 1

1.1.2. Iatrogenic/Treatment Injuries ................................................... 3

1.1.3. Adverse Events..................................................................... 5

1.1.4. Iatrogenic Injuries, Errors, and Negligence …………………..... 6

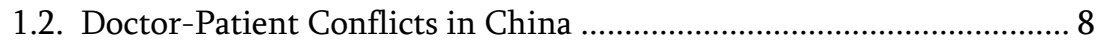

1.2.1. The Frequency of Medical Disputes and Iatrogenic Injuries.... 8

1.2.2. Violence against Doctors ........................................................... 9

1.2.3. Provider Negligence and Medical Disputes ............................... 11

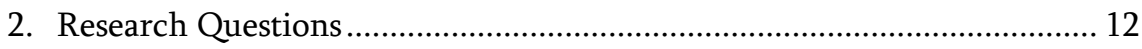

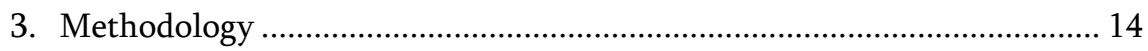

3.1. The Doctrinal Approach .................................................................... 14

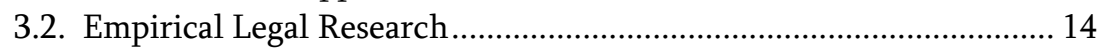

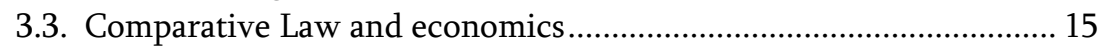

3.3.1. Why Law and Economics? .................................................... 15

3.3.2. The Use of Comparative Law …………………....................... 17

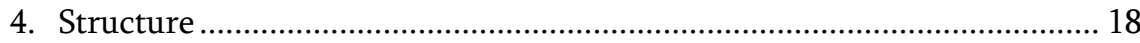

PART I

LEGAL REMEDIES FOR MEDICAL MALPRACTICE IN CHINA .................. 21

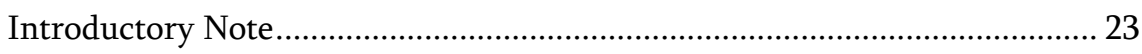




\section{Chapter 2}

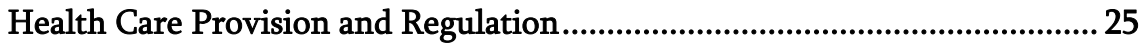

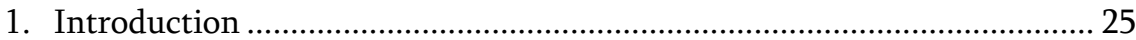

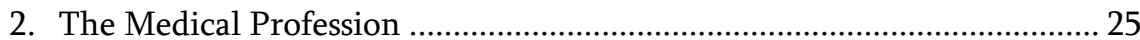

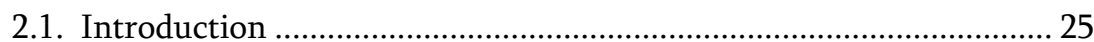

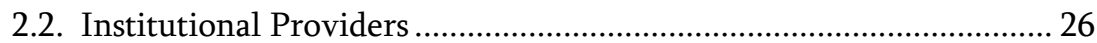

2.3. Individual Providers.................................................................. 29

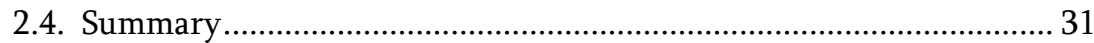

3. Financing of Public Health Care Provision .................................................. 32

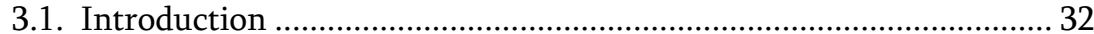

3.2. Health Care Reforms and Financial Burdens on Individuals ............. 32

3.3. Currently Covered Groups and Government Subsidies ...................... 35

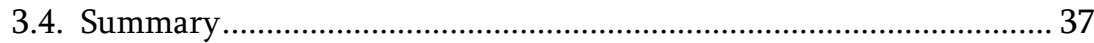

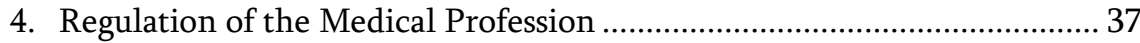

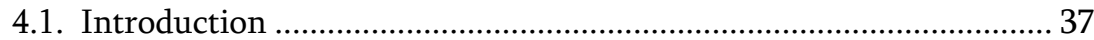

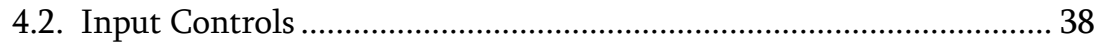

4.2.1. Controls on the Entry of Institutional Providers .................... 38

4.2.2. Controls on the Entry of Individual Providers......................... 40

4.3. Output Controls ................................................................................... 42

4.3.1. Controls on the Performance of Institutional Providers ........ 42

4.3.1.1. Codes of Conduct and Sanctions................................. 42

4.3.1.2. Hospital Accreditation ................................................. 47

4.3.2. Controls on the Performance of Individual Providers............ 50

4.3.2.1. Codes of Conduct and Sanctions................................. 50

4.3.2.2. Periodical Doctor Assessment...................................... 55

4.3.3. Medical Quality and Safety Incident Management................. 57

4.3.3.1. Incident Reporting ................................................... 57

4.3.3.2. Regulatory Threats …………………………….......... 59

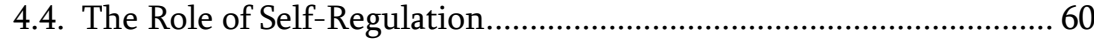

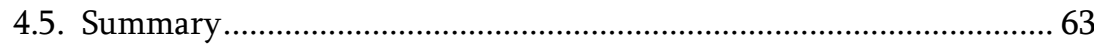

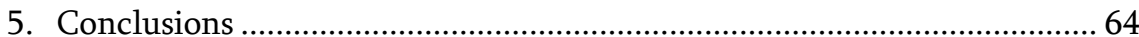

\section{Chapter 3}

Compensation for Iatrogenic Injuries under Tort Law ......................................6 65

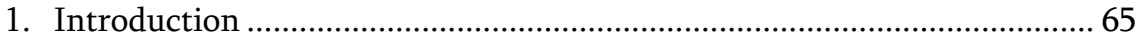

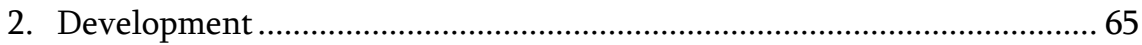

3. The Substantive System of Private Law Compensation .............................. 70

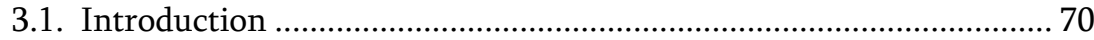

3.1.1. The Relevance of Contract Law .............................................. 70

3.1.2. The General Clause for Medical Malpractice Claims ............... 74 
3.2. Technical Malpractice.................................................................... 76

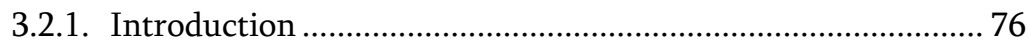

3.2.2. Statutory Standards, Written Treatment Norms, and Unwritten Customary Practices ................................ 77

3.2.3. Proof and Causation Issues ..................................................... 80

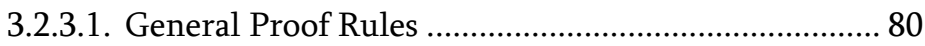

3.2.3.2. Defining Causation................................................. 82

3.2.3.3. Uncertainty over Factual Causation ......................... 83

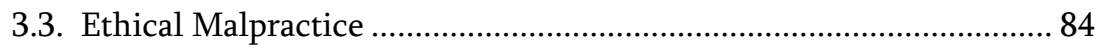

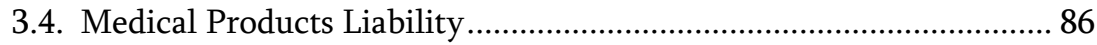

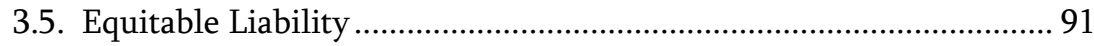

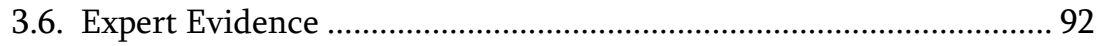

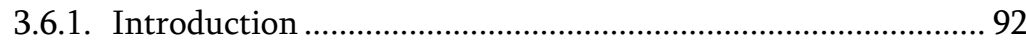

3.6.2. The Basics ............................................................................ 92

3.6.2.1. The MATAS ........................................................... 92

3.6.2.2. The JAS ................................................................. 94

3.6.3. A Comparison and Contrast .................................................. 96

3.6.4. The Two Systems after the Inception of the Tort Law .......... 98

3.7. The Law of Damages ...................................................................... 98

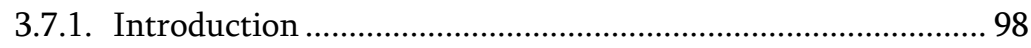

3.7.2. Compensation for Pecuniary Losses....................................... 99

3.7.2.1. The Legal Basis ........................................................... 99

3.7.2.2. The Abstract/Standardised Approach to Future Damage ................................................................ 101

3.7.2.3. Caps on Pecuniary Damages .................................. 105

3.7.3. Compensation for Non-Pecuniary Losses ........................... 107

3.7.3.1. The Legal Basis ..................................................... 107

3.7.3.2. The Measure of Non-Pecuniary Damages................ 108

3.7.4. Uncertainty over Legal Causation ....................................... 110

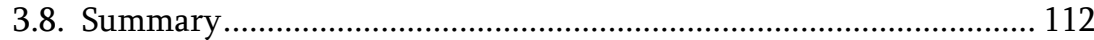

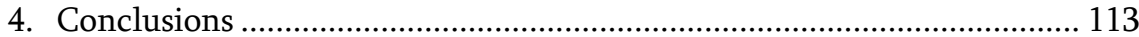

Chapter 4

Medical Disputes, Iatrogenic Injury, Malpractice Litigation, and Patient Compensation: Empirical Evidence .......................................................... 115

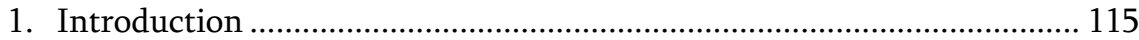

2. Results of the Court Decisions from the Gulou Court ........................... 117

2.1. Frequency and Outcomes of Claims............................................ 117

2.2. Representatives and Defendants................................................ 120

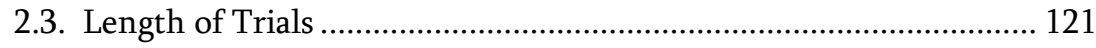

2.4. Causes of Action and Legal Standards Applied............................... 121

2.5. The Impact of Expert Testimony on the Trial ................................ 125

$\begin{array}{ll}\text { Intersentia } & \text { ix }\end{array}$ 
2.6. Pre-Existing Conditions and Specialities Involved.......................... 128

2.7. Seriousness and Causes of Iatrogenic Injuries................................. 130

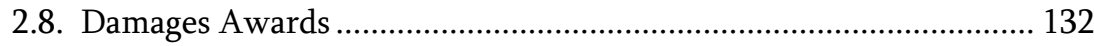

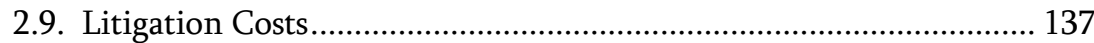

3. Discussions (Supplemented with Interview Results) ............................. 138

3.1. High-Risk Hospitals, Specialities and Medical Disputes ................. 138

3.2. The Role of Expert Witnesses........................................................ 139

3.3. Locus of Liability and Standard of Care ......................................... 143

3.3.1. Locus of Liability................................................................ 143

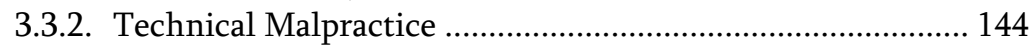

3.3.3. Ethical Malpractice .......................................................... 147

3.4. Causal Uncertainty and Proportional Liability.............................. 149

3.4.1. Uncertainty over Factual Causation.................................... 149

3.4.2. Uncertainty over Legal Causation ....................................... 152

3.5. Defective Medical Products and Substandard Blood........................ 152

3.6. Payment of Medical Malpractice Claims ....................................... 153

3.7. The Time and Money Spent on Malpractice Litigation ................... 155

3.7.1. The Burden of Time............................................................. 155

3.7.2. The Burden of Financial Costs .............................................. 156

3.8. The Impact of the Tort Law 2009 and the Role of Chinese Courts 157

3.9. Medical Dispute Resolution and Violence...................................... 159

3.9.1. Negotiation, Administrative Mediation, and Litigation........ 159

3.9.2. Yi-Nao Incidents ................................................................ 160

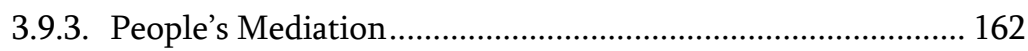

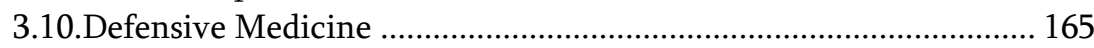

3.10.1. Does Defensive Medicine Exist in China? ............................. 165

3.10.2. The Causes of Defensive Medicine ...................................... 168

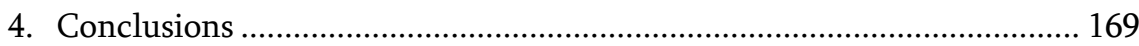

Chapter 5:

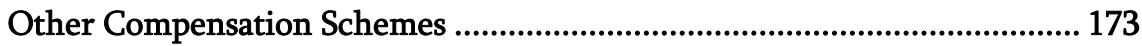

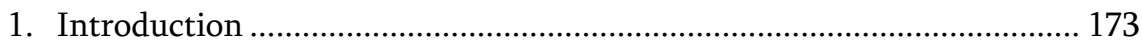

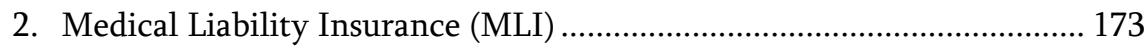

2.1. Introduction ............................................................................. 173

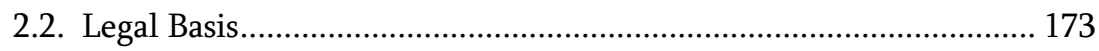

2.3. The Evolution of MLI in China: Local Experiments ...................... 175

2.3.1. Introduction ....................................................................... 175

2.3.2. The Yunnan MLI Scheme...................................................... 176

2.3.3. The Shanghai MLI Scheme.................................................. 177

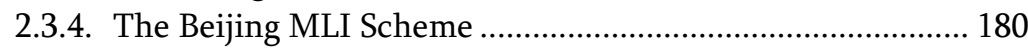

2.3.5. The Shenzhen Medical Professional Risk Insurance

Scheme 


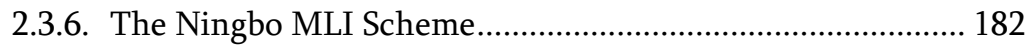

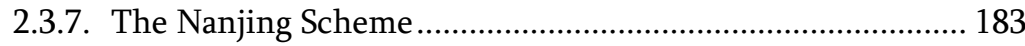

2.3.8. A Comparison and Contrast ................................................... 184

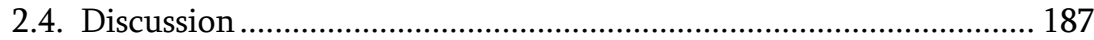

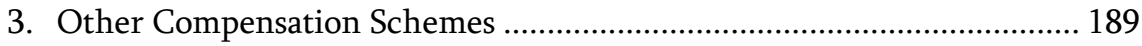

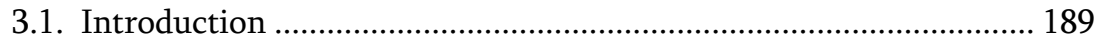

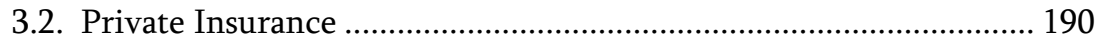

3.2.1. Private Health Insurance .................................................... 190

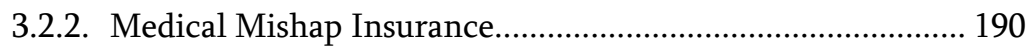

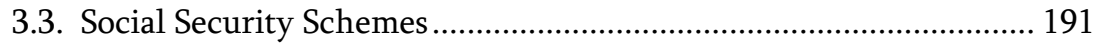

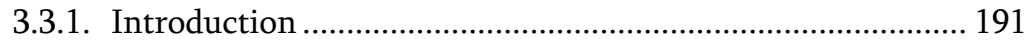

3.3.2. Social Security Schemes Covering Medical Expenses ........... 192

3.3.2.1. The Basic Medical Insurance Schemes ...................... 192

3.3.2.2. The Urban-Rural Medical Assistance System .......... 193

3.3.3. Social Security Schemes Covering Other Losses ................... 194

3.3.3.1. Basic Pension Insurance ............................................ 194

3.3.3.2. Minimum Subsistence Guarantee and Support of the Especially Poor ....................................................... 194

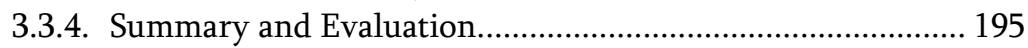

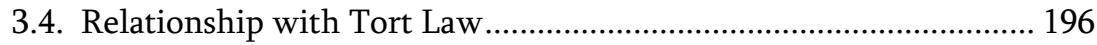

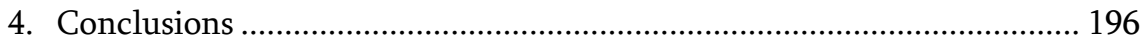

Chapter 6:

A Doctrinal Evaluation and Tentative Conclusions........................................ 197

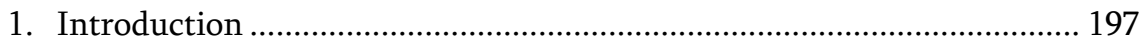

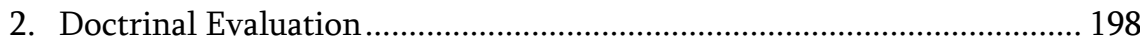

2.1. The Regulatory Quality Assurance System........................................ 198

2.2. The Victim Compensation System: Input Analysis.......................... 199

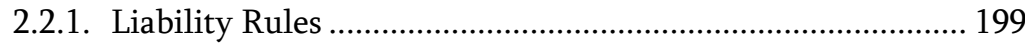

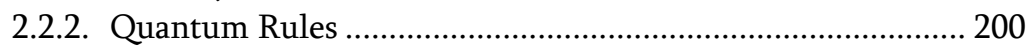

2.3. The Victim Compensation System: Output Analysis ....................... 201

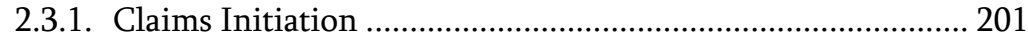

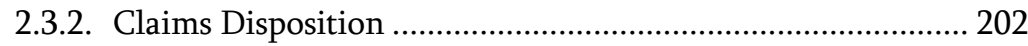

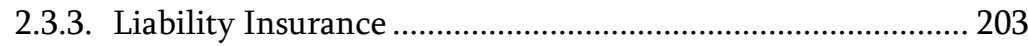

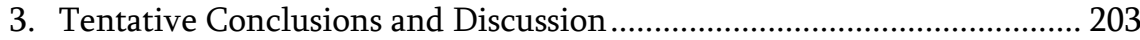

3.1. A Summary of the Doctrinal Evaluations ........................................... 203

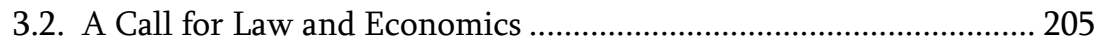

PART II:

ECONOMIC THEORIES AND EMPIRICAL EVIDENCE.............................. 207

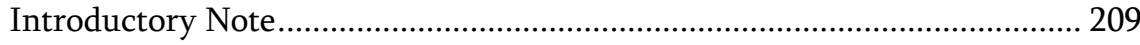

Intersentia $\quad x i$ 


\section{Chapter 7}

Preventing Medical Errors through Tort Law - Theoretical Models ........... 211

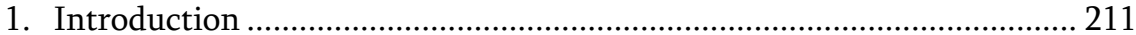

2. The Classic Model of Tort Law …............................................................... 212

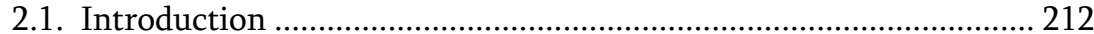

2.2. The Model of Primary Accident Cost Avoidance............................ 214

2.3. Tertiary Cost Avoidance .................................................................... 216

3. Applying the Classic Model to Medical Malpractice.............................. 217

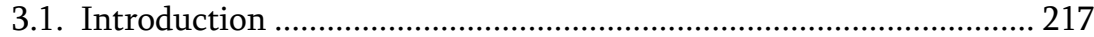

3.2. Features of Health Care Services and the Choice between

Negligence and Strict Liability ......................................................... 219

3.2.1. Product Uncertainty ....................................................... 219

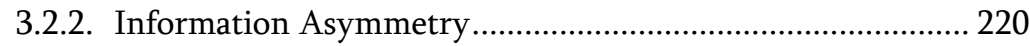

3.2.3. Externalities .......................................................................... 220

3.2.4. Negligence versus Strict Liability ....................................... 222

3.3. The Standard of Care.......................................................................... 223

3.3.1. The Learned Hand Rule........................................................ 223

3.3.2. Prior Precautions and Competence........................................ 224

3.3.3. Uncertainty over the Standard of Care ................................ 225

3.3.4. The Impact of Regulation .................................................. 227

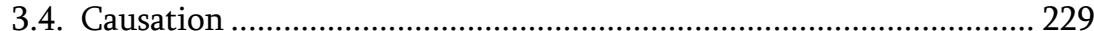

3.4.1. Causation in Fact.................................................................... 229

3.4.2. Uncertainty over Causation in Fact ................................... 230

3.4.2.1. The Potential Inefficiency of the Threshold Approach................................................................. 230

3.4.2.2. The Efficiency of the Proportional Approach.......... 231

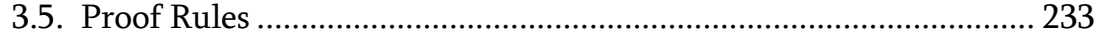

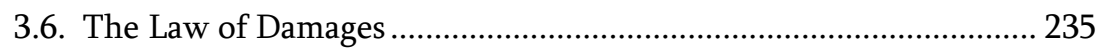

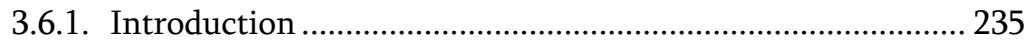

3.6.2. Full Compensation .............................................................. 235

3.6.3. Assessment of Damages ...................................................... 238

3.6.3.1. Objective versus Subjective Methods ...................... 238

3.6.3.2. Compensation for Wrongful Death......................... 239

3.6.3.3. Compensation for Non-pecuniary Losses in Non-Fatal Accidents

3.6.3.4. Collateral Benefits ..................................................... 244

3.6.4. The Off-setting Benefits Rule/Re-stated

Negligence Rule (Scope of Liability) .................................... 246

3.6.5. Uncertainty over the Magnitude of Liability ........................ 249

3.7. Dispute Resolution and Tertiary Costs.......................................... 250

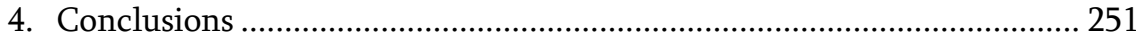




\section{Chapter 8}

Preventing Medical Errors through Tort Law - Empirical Evidence and Updated Models

1. Introduction

2. Empirical Evidence: Iatrogenic Injury, Malpractice Litigation, and Deterrent Effect

2.1. Introduction 254

2.2. Incidence, Severity, and Costs of Iatrogenic Injuries ....................... 254

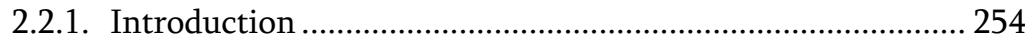

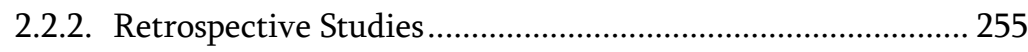

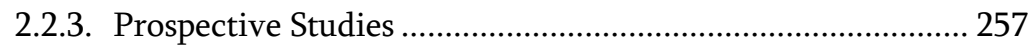

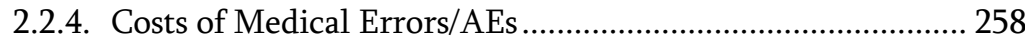

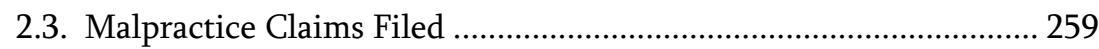

2.3.1. The Initiation of Malpractice Claims ..................................... 259

2.3.1.1. Theoretical Predictions .............................................. 259

2.3.1.2. Empirical Findings ................................................... 260

2.3.2. Trends in Medical Malpractice Claims Filed ......................... 261

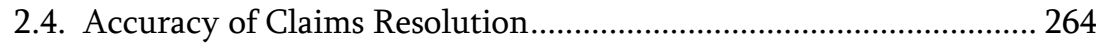

2.4.1. Defining Claim Accuracy …….............................................. 264

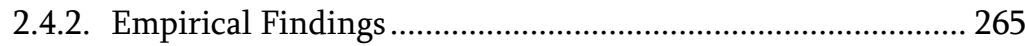

2.5. Does Medical Malpractice Liability Have a Deterrent Effect? ......... 267

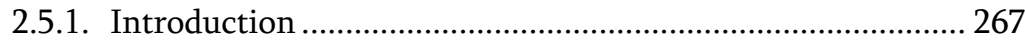

2.5.2. Defining Defensive Medicine ................................................ 269

2.5.2.1. Defining Defensive Medicine ................................... 269

2.5.2.2. Positive versus Negative Defensive Medicine.......... 270

2.5.3. The Extent of Defensive Medicine....................................... 271

2.5.3.1. Different Approaches ………………………............. 271

2.5.3.2. Direct Physician Surveys .......................................... 272

2.5.3.3. Survey Studies using Clinical Scenarios .................... 273

2.5.4. Statistical Evidence on the Extent of PDM........................... 274

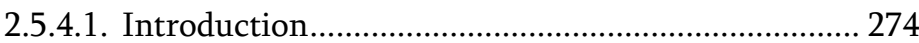

2.5.4.2. Statistical Studies on PDM in the Speciality of Obstetrics .................................................................. 275

2.5.4.3. Statistical Studies on PDM in the General Ailment Setting or Other Specialities than Obstetrics ........... 278

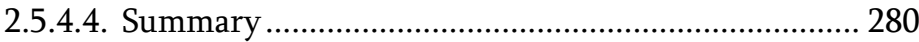

2.5.5. Statistical Evidence on the Extent of NDM ............................ 280

2.5.5.1. Statistical Studies on NDM in the Specialty of Obstetrics ................................................................ 280

2.5.5.2. Statistical Studies on NDM in the General Ailment Setting 
2.5.5.3. Summary

2.5.6. Summary and Evaluation

2.6. Is the Medical Malpractice System Cost-Effective?......................... 284

2.6.1. Costs of the Medical Malpractice System ............................. 284

2.6.2. Deterrence Benefits Compared to the Costs ......................... 286

3. A New Empirically-Grounded Model of Medical Malpractice Liability. 289

3.1. Introduction

3.2. Empirical Evidence on the Causes of Iatrogenic Injuries

3.2.1. Risk Factors

3.2.2. Deliberate or Accidental Negligence?................................... 291

3.2.3. Human Errors and System Failures...................................... 292

3.3. Updating the Classic Model of Malpractice Liability ...................... 294

3.3.1. Patient Safety Investments .............................................. 294

3.3.2. Enterprise (Hospital) Liability ............................................ 296

3.3.2.1. Direct Hospital Liability and Vicarious Liability ..... 296

3.3.2.2. Enterprise Medical Liability ................................... 299

4. Conclusions

\section{Chapter 9}

Preventing Medical Errors through Alternative Regimes ............................303

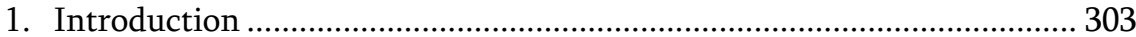

2. The Contractual Approach: A Desirable Alternative? ............................ 304

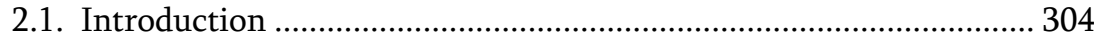

2.2. The Case for the Contractual Approach......................................... 305

2.3. Arguments against the Contractual Approach ............................... 307

2.3.1. Information Problems....................................................... 307

2.3.2. Other Arguments against Waivers of Statutory Liability ..... 308

2.3.3. Other Arguments against Contractual Variation in the

Standard of Care

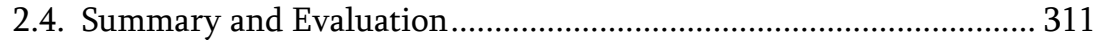

3. Regulation: A General Overview …..................................................... 313

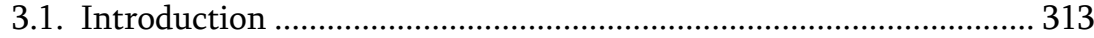

3.2. Arguments for Regulating Health Care Provision.......................... 315

3.2.1. Introduction .................................................................. 315

3.2.2. Public Interest Arguments for Health Care Regulation........ 316

3.2.2.1. Asymmetric Information ...................................... 316

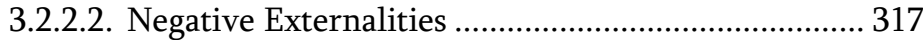

3.2.2.3. Public Goods .......................................................... 318

3.2.2.4. Market Power ............................................................ 319

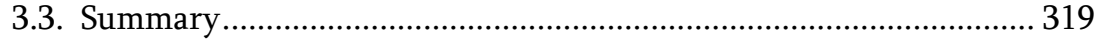


4. Input Controls: Is Licensing a Desirable Alternative?................................ 320

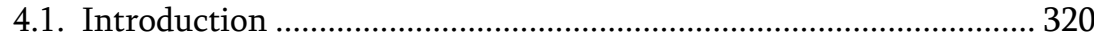

4.2. Arguments for Licensing............................................................... 321

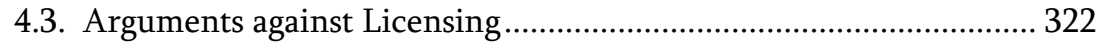

4.3.1. Is Licensing an Optimal Way to Provide Information? ......... 322

4.3.2. Is Licensing an Optimal Way to Ensure Quality? .................. 323

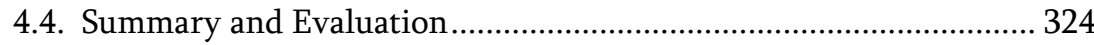

5. Output Controls: Is Quality Regulation a Desirable Alternative? ........... 327

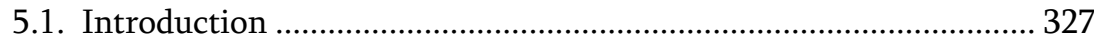

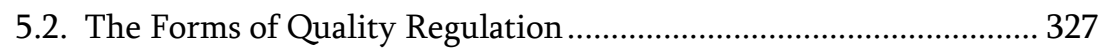

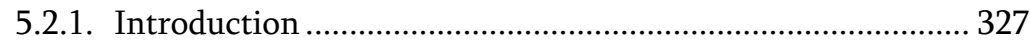

5.2.2. Ex-Ante versus Ex Post Regulation by Regulators ................ 329

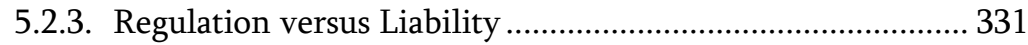

5.2.3.1. Ex-Ante Safety Regulation versus Liability .............. 331

5.2.3.2. Ex Post Regulation by Regulators versus Liability .. 332

5.3. The Choice of Sanctions ..................................................................... 333

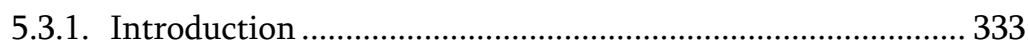

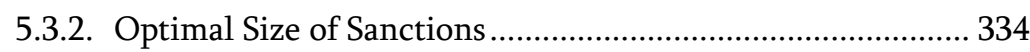

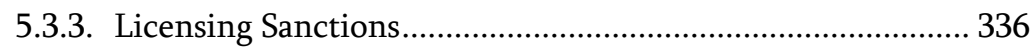

5.3.4. Administrative Sanctions versus Criminal Penalties.............. 337

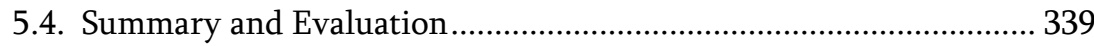

6. Public Regulation versus Self-Regulation.................................................... 340

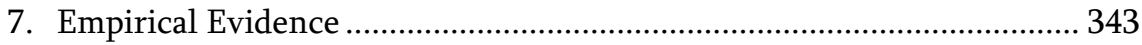

7.1. Detection of Non-Complying Providers ........................................... 343

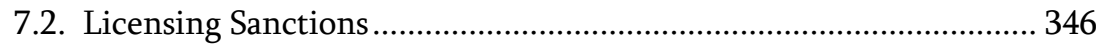

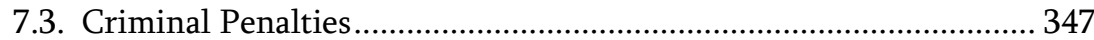

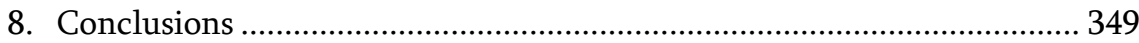

Chapter 10

The Fault-Based Compensation Mechanisms for Iatrogenic Injuries............ 351

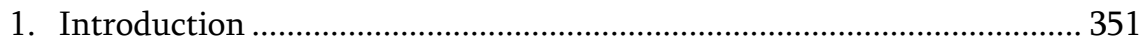

2. Basic Theories of Secondary Cost Avoidance ............................................. 352

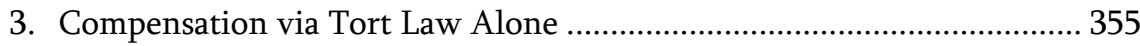

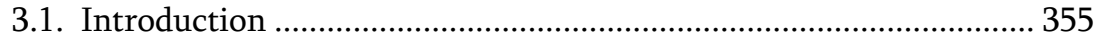

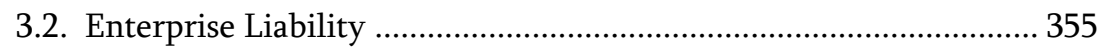

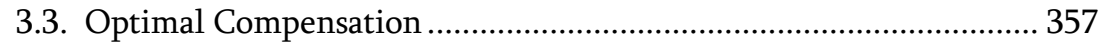

3.3.1. The Insurance Theory ……………....................................... 357

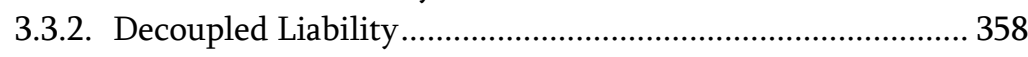

3.3.3. Inefficiencies of Treating Tort Law as an Insurance

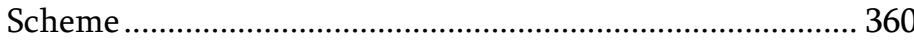

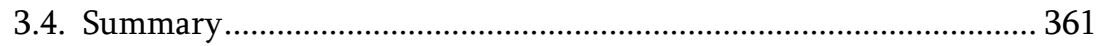

4. Compensation via Liability Insurance …………..................................... 361

$\begin{array}{lll}\text { Intersentia } & \mathrm{XV}\end{array}$ 


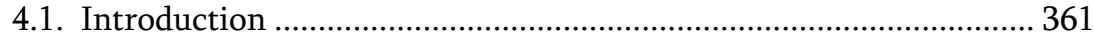

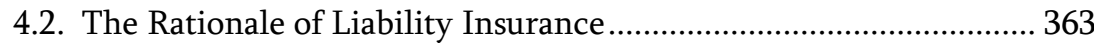

4.2.1. Loss Distribution and Private Insurance................................ 363

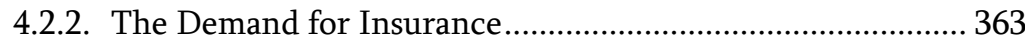

4.2.2.1. Risk Aversion and Insurance ..................................... 363

4.2.2.2. Demand for MLI under the Negligence Rule........... 364

4.2.2.3. Institutional Providers ................................................. 365

4.2.2.4. Coverage for Non-Pecuniary Losses.......................... 366

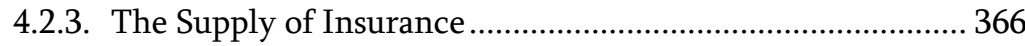

4.2.3.1. Pooling, Re-insurance, and Co-Insurance................. 366

4.2.3.2. The Insurability of the Medical Malpractice Risk ... 368

4.2.4. Informational Problems in the Insurance Market.................. 371

4.2.4.1. Moral Hazard ............................................................ 371

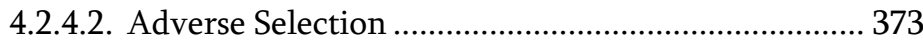

4.2.4.3. Risk Differentiation.................................................... 373

4.2.5. Impact of Special Liability Sub-Rules on Insurability............ 374

4.2.5.1. Causal Uncertainty ................................................... 374

4.2.5.2. Channelling under EML............................................. 375

4.2.5.3. Retroactive Liability .................................................. 376

4.2.5.4. Financial Limits on Liability ..................................... 377

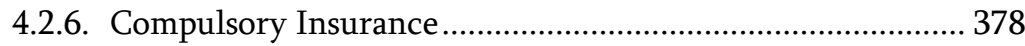

4.2.6.1. The Case for Compulsory Liability Insurance........... 378

4.2.6.2. Some Warnings........................................................... 380

4.3. Empirical Evidence ……………………………............................ 381

4.3.1. Rating and Partial Coverage …............................................. 381

4.3.1.1. Risk Differentiation in Practice (Experience Rating) ....................................................................... 381

4.3.1.2. Why Is Detailed Risk Differentiation Not Widely Accepted?............................................................... 382

4.3.1.3. Partial Coverage ...................................................... 384

4.3.2. A Typical Case: The American Malpractice Crisis ................. 384

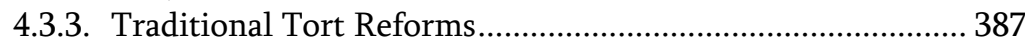

4.3.3.1. Content of the Reforms.............................................. 387

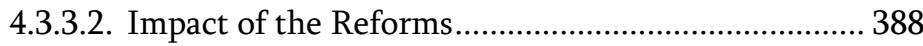

4.3.4. Other Causes of the Malpractice Crisis.................................. 389

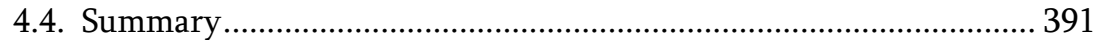

5. Self-Insurance: A Perfect Alternative to Market MLI? .............................. 392

5.1. Inter-temporal Loss Spreading and Self-Insurance .......................... 392

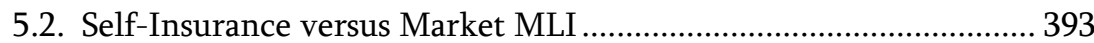

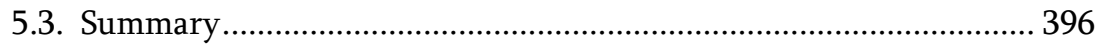

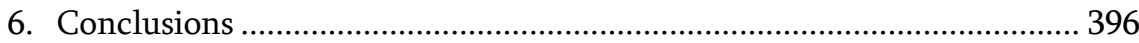


Chapter 11

Medical Compensation Mechanisms Not Based on Fault

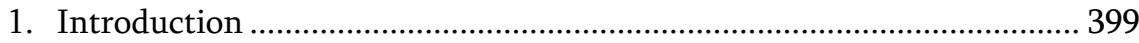

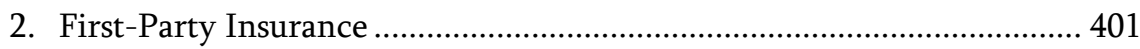

2.1. The Rationale of First-Party Insurance ............................................. 401

2.2. The Relationship with the Fault-Liability-Insurance System (FLIS)

2.3. Empirical Evidence Concerning the (Voluntary) First-Party

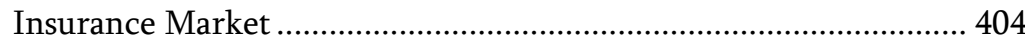

2.4. Solution: A Compulsory First-Party Insurance Scheme? .................. 405

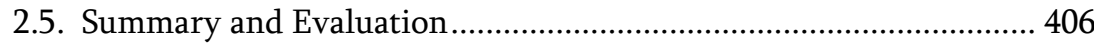

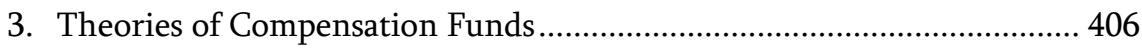

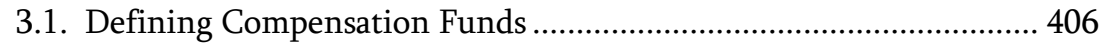

3.2. Fair and Efficient Compensation ...................................................... 408

3.3. Causation: How Should Iatrogenicity Be Defined? .......................... 409

3.3.1. Defining Iatrogenic Injuries .................................................. 409

3.3.2. Iatrogenicity versus Due Care ............................................... 410

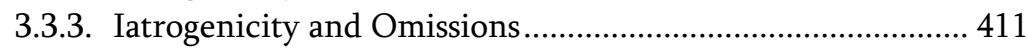

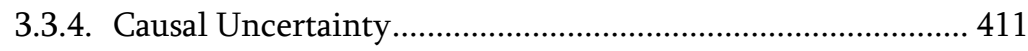

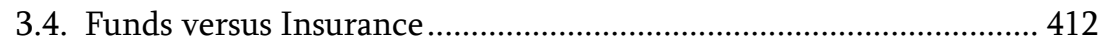

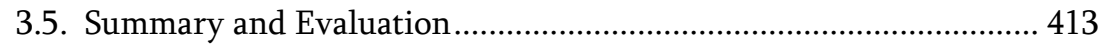

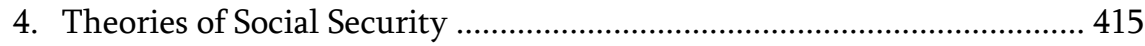

4.1. The Rationale of Social Security ....................................................... 415

4.2. Distinction between Social Security and Tort Liability .................... 417

4.3. Interplay between Social Security and Tort Liability........................ 418

4.3.1. Compensation Models ........................................................... 418

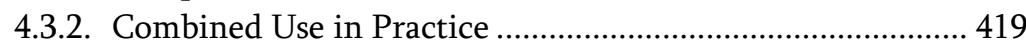

5. Empirical Evidence on No-Fault Compensation Schemes in Practice .... 421

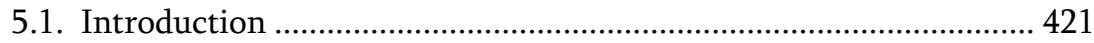

5.2. Core Features of the NFCS: A Comparative Analysis........................ 423

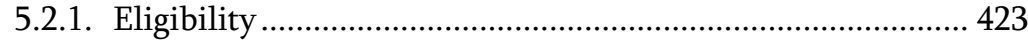

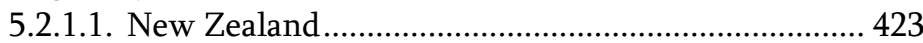

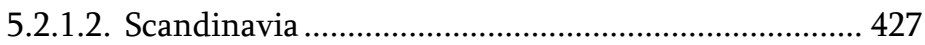

5.2.1.3. Comparison and Summary ........................................ 432

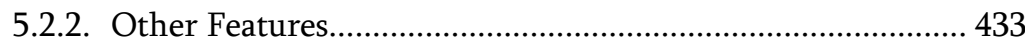

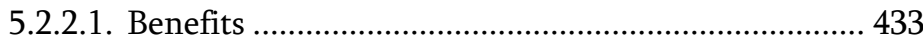

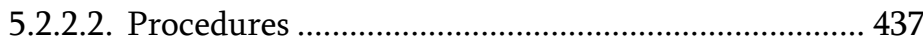

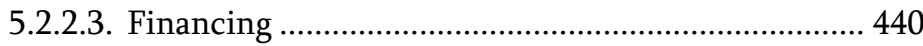

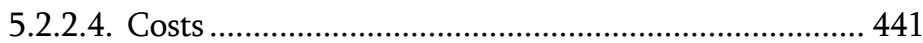

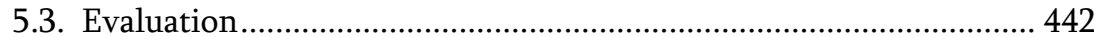

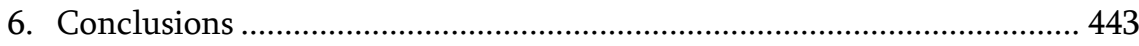

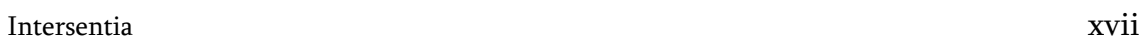




\section{PART III}

APPLYING THE ECONOMIC OBSERVATIONS TO CHINA

Introductory note

\section{Chapter 12}

An Economic Analysis of the Chinese Medical Malpractice System............. 449

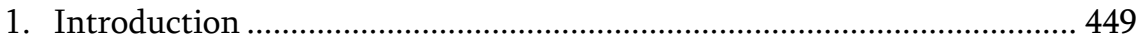

2. Tort Law: Prevention (Deterrence)........................................................ 451

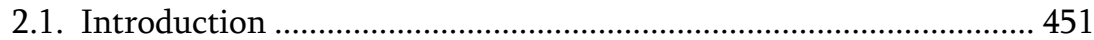

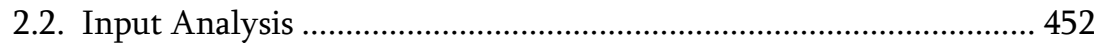

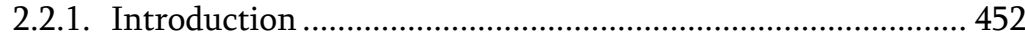

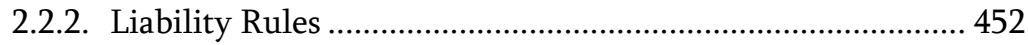

2.2.2.1. Negligence versus Strict Liability .............................. 452

2.2.2.2. Standards of Care........................................................ 453

2.2.2.3. Feasance versus Nonfeasance....................................... 456

2.2.2.4. Causation and Proof Rules ........................................... 457

2.2.2.5. A Contractual Waiver of or Alteration to Tort

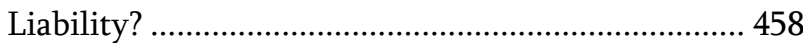

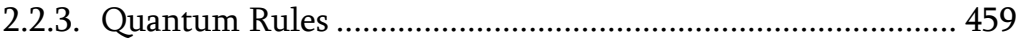

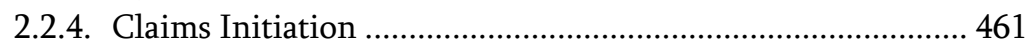

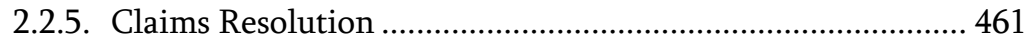

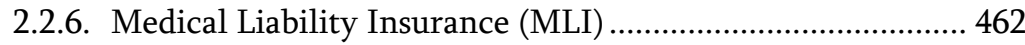

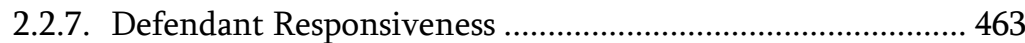

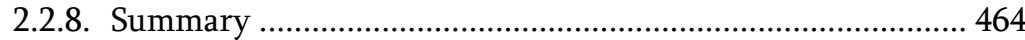

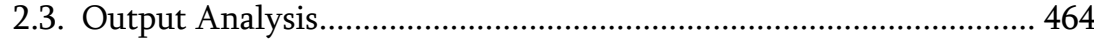

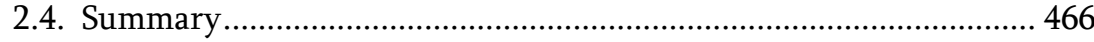

3. Tort Law: Compensation ...................................................................... 467

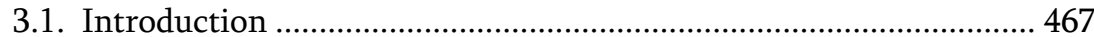

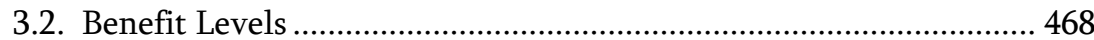

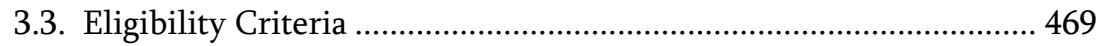

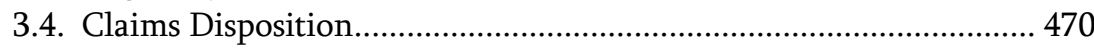

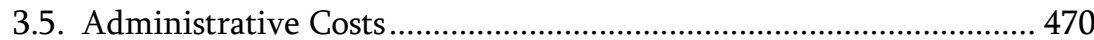

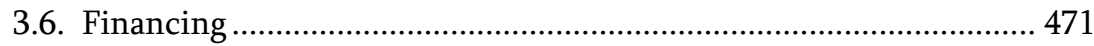

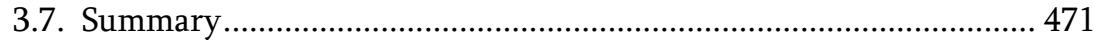

4. Penal and Regulatory Alternatives: Prevention (Deterrence) .................. 472

5. Alternative Compensation Mechanisms: Compensation .......................... 474

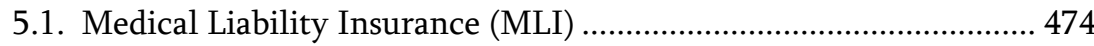

5.2. First-Party Insurance and Social Security ............................................. 476

6. The Impact of Yi Nao Incidents on the Malpractice System .................... 476

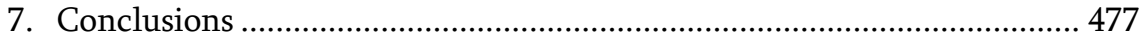




\section{Chapter 13}

Concluding Remarks and Policy Recommendations ..................................... 479

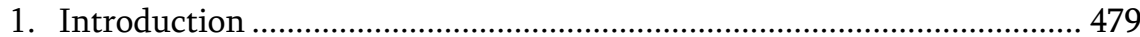

2. A Summary of Main Findings .................................................................. 480

2.1. Sub-Question 1-a: What Are the Legal Remedies Currently Available in China That Are Aimed at the Prevention of Medical Malpractice and Victim Compensation? ........................................... 480

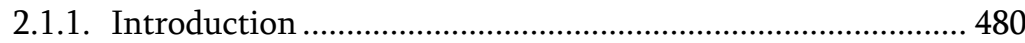

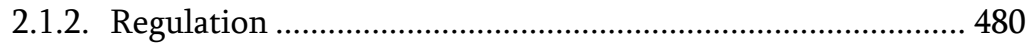

2.1.3. The Medical Malpractice Liability System ............................. 481

2.1.4. Medical Liability Insurance (MLI) ........................................ 482

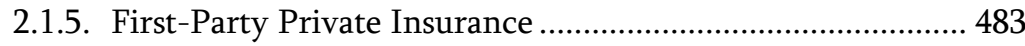

2.1.6. Social Security Schemes......................................................... 483

2.2. Sub-Question 1-b: Are These Remedies Sound according to Legal

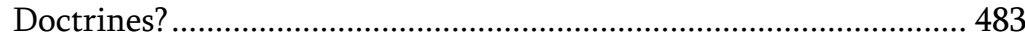

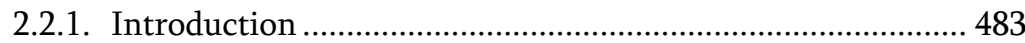

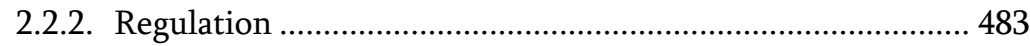

2.2.3. The Medical Malpractice Liability System ............................. 484

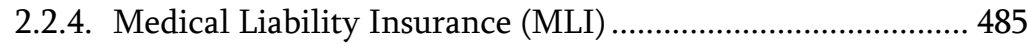

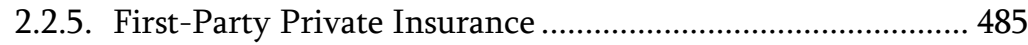

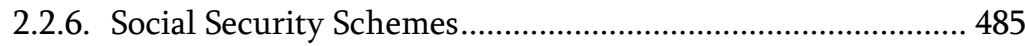

2.3. Sub-Question 2-a: How Should the Legal Remedies Be Structured in Order to Prevent Medical Malpractice and Compensate Victims for Iatrogenic Injuries Efficiently in the light of Economic Benchmarks and Available Empirical Evidence? .............................. 486

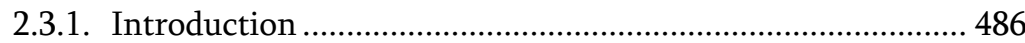

2.3.2. How Should Legal Remedies Be Designed in Order to Prevent Medical Errors (Medical Malpractice) Efficiently?. 487

2.3.2.1. Tort Law .................................................................... 487

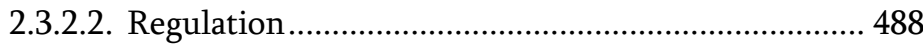

2.3.2.3. The Contractual Approach......................................... 489

2.3.3. How Should Legal Remedies Be Structured in Order to Compensate Victims for Iatrogenic Injuries Efficiently?.

2.3.3.1. Tort Law Per Se ......................................................... 490

2.3.3.2. Liability Insurance....................................................... 490

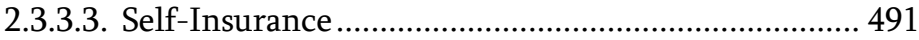

2.3.3.4. First-Party Insurance.................................................... 491

2.3.3.5. Compensation Funds ................................................... 492

2.3.3.6. Social Security ........................................................ 492 
2.4. Sub-Question 2-b: Are These Legal Remedies for Iatrogenic Injury Prevention and Patient Compensation in China Efficient as Well? 493

2.4.1. Legal Remedies for Injury Prevention 493

2.4.1.1. The Medical Malpractice Liability System.............. 493

2.4.1.2. Regulation 494

2.4.2. Legal Remedies for Victim Compensation. 494

2.4.2.1. The Medical Malpractice Compensation System..... 494

2.4.2.2. Medical Liability Insurance (MLI) 495

2.4.2.3. Social Security

3. Policy Recommendations: How Can We Improve These Systems? (Main Question 3)

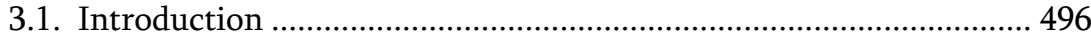

3.2. Reforming the Tort and Relevant Systems Piecemeal ................... 497

3.3. No-Fault Compensation Schemes................................................... 503

3.4. A Comparison of the Different Reform Plans.................................. 505

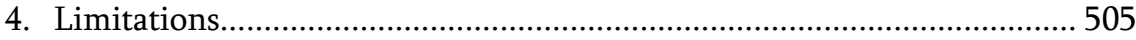

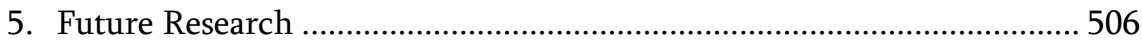

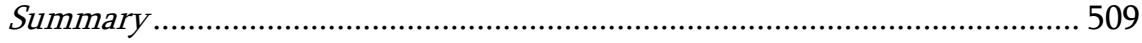

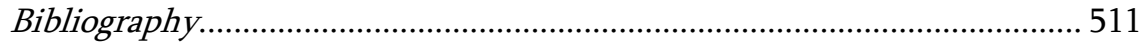

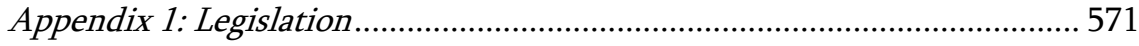

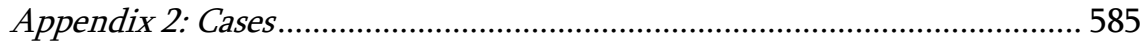

Appendix 3: Semi-Structured Interviews................................................. 591

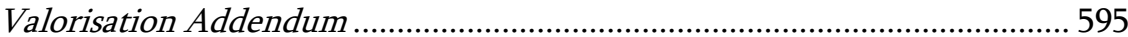

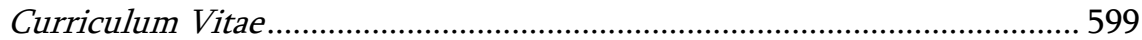




\section{ABBREVIATIONS*}

ACC

Accident Claims

ADR

$\mathrm{AE}$

AM

AMA

AR-

BBC

BMIE

BMIF

BMIS

BMIUR

BMJ

BPIS

CHA

CIMP

CMA

CMA

CMDA

CME

$\mathrm{CNM}$

Contract Claims

CPD
Accident Compensation Corporation

Disputes over Compensation for Injuries Caused by

Medical Accidents (医疗事故损害赔偿纠纷)

Alternative Dispute Resolution

Adverse Events

Administrative Mediation (行政调解)

American Medical Association

prefixed to any administrative regulation (行政法规)

in China

British Broadcasting Corporation

Basic Medical Insurance for Employees

(职工基本医疗保险)

Basic Medical Insurance Funds (基本医疗保险基金)

Basic Medical Insurance Schemes

(基本医疗保险制度))

Basic Medical Insurance for Urban Residents

(城镇居民基本医疗保险)

British Medical Journal

Basic Pension Insurance Scheme (基本养老保险制度)

Chinese Hospital Association (中国医院协会)

Crime of Illegal Medical Practice (非法行医罪)

Crime of Medical Accidents (医疗事故罪)

Chinese Medical Association (中华医学会)

Chinese Medical Doctor Association (中国医师协会)

Continuing Medical Education

Crime of Negligent Manslaughter (过失杀人罪)

Disputes over Medical Service Contract

(医疗服务合同纠纷)

Certificate for Practising Doctors (执业医师资格)

This list does not include abbreviations of statutes, cases, and interviews. For these special abbreviations, see Appendix 1 (Legislations), Appendix 2 (Cases), and Appendix 3 (SemiStructured Interviews). 


\begin{tabular}{|c|c|}
\hline CPG & Clinical Practice Guidelines (临床诊疗指南) \\
\hline CPI & Consumer Price Index \\
\hline CPN & Certificate for Practising Nurses (执业护士资格) \\
\hline CPP & $\begin{array}{l}\text { Certificate for Practising Pharmacists } \\
\text { (执业药剂师资格) }\end{array}$ \\
\hline DHEW & US Department of Health, Education, and Welfare \\
\hline DMI & Designated Medical Institutions (定点医疗机构) \\
\hline DR- & $\begin{array}{l}\text { prefixed to any departmental/ministry rules } \\
\text { (部门规章) in China }\end{array}$ \\
\hline EAG & Expert Ascertainment Group (专家鉴定组) \\
\hline ELR & Empirical Legal Research \\
\hline EML & Enterprise Medical Liability \\
\hline ERP & Extended Reporting Period (追溯期) \\
\hline Ethical Malpractice & medical ethical malpractice (医疗伦理过失) \\
\hline FLIS & Fault Liability Insurance System \\
\hline GAO & General Accounting Office \\
\hline GFMCS & $\begin{array}{l}\text { Government-Funded Medical Care System } \\
\text { (公费医疗制度) }\end{array}$ \\
\hline GR- & $\begin{array}{l}\text { prefixed to any local governmental rules } \\
\text { (地方政府规章) in China }\end{array}$ \\
\hline Harvard Study & Harvard Medical Practices Study \\
\hline HDC & Health and Disability Commissioner \\
\hline HFPC & $\begin{array}{l}\text { (local) Health and Family Planning Commission } \\
\text { ((地方)卫生和计划生育委员会) }\end{array}$ \\
\hline HHS & US Department of Health and Human Services \\
\hline Injury Claims & $\begin{array}{l}\text { Disputes over Liability for Iatrogenic Injury } \\
\text { (医疗损害责任纠纷) }\end{array}$ \\
\hline JAS & Judicial Ascertainment System (司法鉴定制度) \\
\hline JI- & $\begin{array}{l}\text { prefixed to any judicial interpretation (司法解释) by } \\
\text { the Supreme People's Court in China }\end{array}$ \\
\hline LIS & Labour Insurance System (劳动保险制度) \\
\hline LJI- & $\begin{array}{l}\text { prefixed to any local document of a nature of judicial } \\
\text { interpretations (地方司法解释性文件) by local } \\
\text { appellate courts in China }\end{array}$ \\
\hline LPD & License to Practise as Doctors (医师执业证书) \\
\hline LPN & License to Practise as Nurses (护士执业证书) \\
\hline LPP & License to Practise as Pharmacists (执业药师注册证) \\
\hline LR- & Local Regulations (地方性法规) \\
\hline MATA & $\begin{array}{l}\text { Medical Accident Technical Ascertainment } \\
\text { (医疗事故技术鉴定) }\end{array}$ \\
\hline MATAS & $\begin{array}{l}\text { Medical Accident Technical Ascertainment System } \\
\text { (医疗事故技术鉴定制度) }\end{array}$ \\
\hline
\end{tabular}


MDPM

MIAS

MLI

$\mathrm{MoH}$

MQDS

MQSI

N-

NDM

NFCS

NHFPC

NPC

NPE

NPR

NRCMC

NTOCP

NZ-NFCS

OLMI

ONIAM

Ordinary Claims

OTA

PCE

PCI

PCP

PDA

PDM

PMC
Medical Dispute People's Mediation

(医疗纠纷人民调解)

Medical Injury Ascertainment System

(医疗损害鉴定)

Medical Liability Insurance

Ministry of Health (卫生部)

Medical Quality-Safety Dissuasion-Conversation

System (医疗质量安全告诫谈话制度)

Medical Quality-Safety Incidents

(医疗质量安全事件)

prefixed to any non-enforceable other normative

legal documents (其他规范性文件) by various state organs in China

Negative Defensive Medicine

No-Fault Compensation System (or Scheme)

National Health and Family Planning Commission

(国家卫生和计划生育委员会)

National People's Congress (全国人民代表大会)

Norsk Pasientskadeerstatning (Norwegian System of

Patient Injury Compensation)

National Public Radio

Neo-Rural Cooperative Medical Care

(新型农村合作医疗)

Norms of Technical Operations in Clinical Practice (临床技术操作规范)

New Zealand's No-Fault Compensation System (or Scheme)

Operating Licence for Medical Institutions

(医疗机构执业许可证)

National Fund for Compensation of Medical

Accidents (France)

Disputes over Compensation for Iatrogenic Injuries

(医疗损害赔偿纠纷)

US Office of Technology Assessment

Per Capita Consumption Expenditures

(人均消费性支出)

Per Capita Disposable Income (人均可支配收入)

Patient Claims Panel

Periodical Doctor Assessment (医师定期考核)

Positive Defensive Medicine

People's Mediation Commissions (人民调解委员会) 


\begin{tabular}{|c|c|}
\hline PSN & $\begin{array}{l}\text { Pasientskadenemnda (Patient Injury Compensation } \\
\text { Board) }\end{array}$ \\
\hline PSR & Personskadereglering AB \\
\hline PVK & $\begin{array}{l}\text { Potilasvakuutuskeskus (Finnish Patient Insurance } \\
\text { Centre) }\end{array}$ \\
\hline PVLTK & Potilasvahinkolautakunta (Patient Injuries Board) \\
\hline RANE & $\begin{array}{l}\text { Regime of Assistance for Non-paying Emergencies } \\
\text { (疾病应急救助制度) }\end{array}$ \\
\hline RCMCS & $\begin{array}{l}\text { Rural Cooperative Medical Care System } \\
\text { (农村合作医疗制度) }\end{array}$ \\
\hline RSTR & $\begin{array}{l}\text { Regime of Standardised Training of Residents } \\
\text { (住院医师规范化培训制度) }\end{array}$ \\
\hline QALY & Quality Adjusted Life Years \\
\hline rural PCE & $\begin{array}{l}\text { Per Capita Annual Living Consumption Expenditures } \\
\text { of the Rural Residents } \\
\text { (农村居民人均年生活消费性支出) }\end{array}$ \\
\hline rural PCI & $\begin{array}{l}\text { Per Capita Net Income of the Rural Residents } \\
\text { (农村居民人均纯收入) }\end{array}$ \\
\hline SIA & Social Insurance Agencies (社会保险经办机构) \\
\hline SIMC & Shanghai International Medical Centre \\
\hline SPC & Supreme People’s Court (最高人民法院) \\
\hline SPP & Supreme People's Procuratorate (最高人民检察院) \\
\hline Technical Malpractice & medical technical malpractice (医疗技术过失) \\
\hline urban PCCE & $\begin{array}{l}\text { Per Capita Consumption Expenditures of Urban } \\
\text { Residents (城镇居民人均消费性支出) }\end{array}$ \\
\hline urban PCI & $\begin{array}{l}\text { Per Capita Disposable Income of the Urban Residents } \\
\text { (城镇居民人均可支配收入) }\end{array}$ \\
\hline URMAF & $\begin{array}{l}\text { Urban-Rural Medical Assistance Funds } \\
\text { (城乡医疗救助基金) }\end{array}$ \\
\hline URMAS & $\begin{array}{l}\text { Urban-Rural Medical Assistance System } \\
\text { (城乡医疗救助制度) }\end{array}$ \\
\hline VSL & Value of a Statistical Life \\
\hline VSLY & Value of a Statistical Life Year \\
\hline WTP & Willingness to Pay \\
\hline
\end{tabular}




\section{LIST OF FIGURES AND TABLES}

\section{LIST OF FIGURES}

Figure 1.1: The Relationship among Basic Concepts ......................................... 7

Figure 4.1: Cases Closed in Different Ways during the Period 2003-2013

Figure 4.2: Cases Resolved in Different Ways by Year of Decision ............... 119

Figure 4.3: Admissibility of Expert Testimonies ............................................ 128

Figure 4.4: Frequency of the Top-Ten Specialities Related to Adverse Events (AE)

Figure 4.5: The Trend of Awards in (Consent) Judgements by Year of

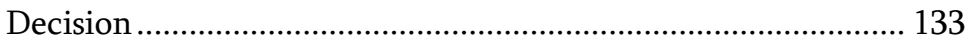

Figure 4.6: Distribution of Causative Factors ................................................. 134

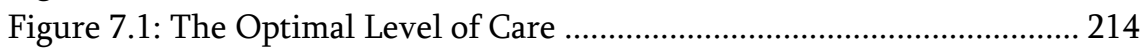

Figure 7.2: The Total Primary Accident Costs Faced by Injurers under

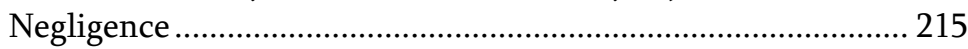

Figure 7.3: Iatrogenic Injuries and Damages ................................................. 237

\section{LIST OF TABLES}

Table 2.1: Three Levels of Hospitals in China..................................................... 47

Table 2.2: Three Grades of Medical Quality-Safety Incidents.......................... 57

Table 2.3: The Distribution of the Reported MQSIs in Jiangsu Province....... 58

Table 3.1: Medical Accident Claims versus Ordinary Claims............................... 69

Table 3.2: Similarities and Differences between the MATAS and the JAS..... 96

Table 3.3: Criteria for Measuring Pecuniary Losses in Personal Injury

Claims. 100

Table 3.4: Compensation Coefficients in Light of the Degree of

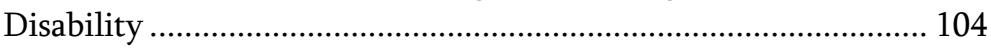

Table 3.5: Degrees of Liability.............................................................................. 111

Table 4.1: Cases accepted by the Gulou Court by Year ................................... 117

Table 4.2: Liability Rules Applied to Medical Malpractice Cases.................... 122

Table 4.3: Quantum Rules Applied to Medical Malpractice Claims .............. 124

$\begin{array}{lll}\text { Intersentia } & \mathrm{xxv}\end{array}$ 
Table 4.4: Outcomes under the Principles 1986 and the Tort Law 2009...... 125

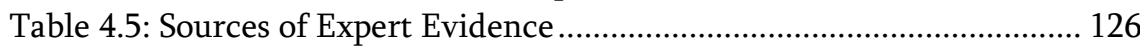

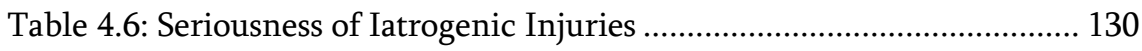

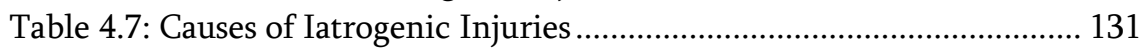

Table 4.8: Mean, Median and Maximum Damages .......................................... 132

Table 4.9: Awards in (Consent) Judgements by Year of Decision.................. 132

Table 4.10: Degrees of Liability in Comparison ............................................. 134

Table 4.11: Damages and Extent of Injuries ..................................................... 137

Table 4.12: Four Categories of the "Medical Standard" Applied by the

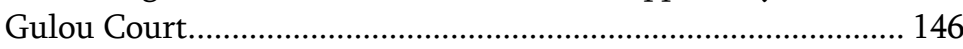

Table 5.1: The Loss Ratio and the Insured Medical Institutions in

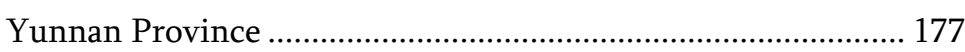

Table 5.2: Premiums Adjustments under the Shanghai MLI Scheme............ 178

Table 5.3: Co-insurance between Individual Providers and the Insurer ...... 182

Table 5.4: MLI Premium Adjustments Used by the PICC Nanjing Branch

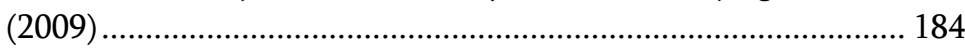

Table 5.5: Six RepresentativeLocal MLI Schemes in China............................. 185

Table 8.1: Retrospective Studies on AEs in the US and Other Western

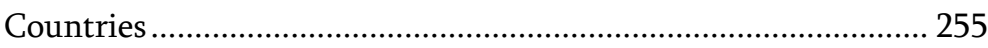

Table 8.2: Medical Malpractice Claims Initiated............................................ 260

Table 8.3: Defining Claim Accuracy ................................................................ 264

Table 8.4: Percentage of True Positives versus Percentage of False

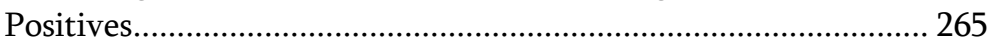

Table 8.5: Statistical Studies on PDM in the Speciality of Obstetrics ........... 275

Table 8.6: Statistical Studies on PDM in a General Ailment Setting or Non-

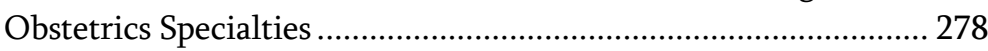

Table 8.7: Statistical Studies on NDM in the Speciality of Obstetrics............ 281

Table 8.8: Statistical Studies on NDM in the General Setting ........................ 282

Table 9.1: EX Ante and EX Post Regulatory Measures for Quality Assurance

Table 9.2: Optimal Sanctions for Medical Quality Regulation........................ 339

Table 11.1: Scandinavian No-Fault Compensation Systems: Cover ............... 428

Table 11.2: No-Fault Compensation Systems: Scope of Benefits.................... 434 


\section{CHAPTER 1 INTRODUCTION}

\section{BACKGROUND}

\subsection{BASIC DEFINITIONS}

\subsubsection{Medical Disputes}

In recent years, what often dominates the headlines in China is the phrase “medical disputes" (医疗纠纷). Broadly speaking, medical disputes refer to all conflicts or controversies between the doctor/hospital and the patient over medical bills, medical ethics, and medical malpractice claims. ${ }^{1}$

The first type of medical disputes is concerned with controversies surrounding medical bills. For instance, patients often complain about everincreasing medical expenses, ${ }^{2}$ roughly $40 \%$ of which cannot be covered by public health insurance schemes. ${ }^{3}$ In China, although the government regulates medical service prices and sets medical charges relatively low, anecdotal evidence shows that many, if not most, hospitals overcharge patients in various illegal ways. ${ }^{4}$ There will be this kind of disputes if patients realise that they have been overcharged. However, this kind of medical disputes is often irrelevant to iatrogenic injuries.

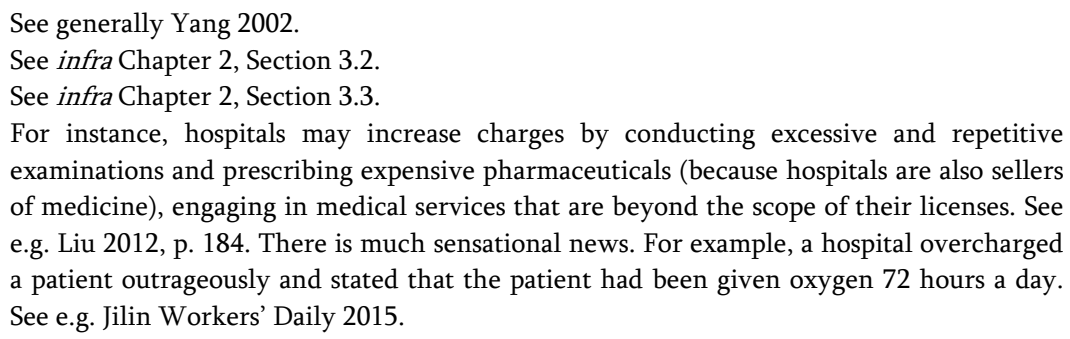


Controversies over medical ethics are the second type of medical disputes. The unique and most notorious one is bribery under the cover of a cash gift, the so-called "Hongbao" (红包). Some evidence shows that it becomes common practice that patients have to offer a "Hongbao" to their doctors. ${ }^{5}$ If patients forget to provide their doctors with a "Hongbao," the doctors will openly demand the "Hongbao." Some anecdotal evidence even suggests that if patients refuse to pay a "Hongbao," they may receive a lower quality of care or may experience more "accidents" during surgeries.7

The preceding two types of medical disputes are normally not resolved by tort law. ${ }^{8}$ Patients may complain to the government about these disputes and administrative punishments (fines or revocation of the license) or disciplinary sanctions (e.g. a warning or reprimand) will be imposed on those hospitals or practitioners who contravene laws, regulations, or codes of ethics. ${ }^{9}$ Nonetheless, these may help to explain why the trust between Chinese doctors and patients is so fragile that a conflict may easily arise.

What is more pertinent to the topic under discussion in this thesis is the third type of medical disputes, which specifically refer to the cases where patients believe that the injuries they suffered were attributable to medical interventions and thus they claim compensation from providers for the injuries. ${ }^{10}$ In China, this narrowly defined notion of medical disputes over liability and compensation is widely used in the Chinese literature and will be employed throughout this thesis, unless otherwise indicated. Medical disputes

$5 \quad$ Liu 2012, p. 43. Bandao.cn conducted a survey of 684 patients, $66.81 \%$ of which said they had offered their doctors a Hongbao, and $77.19 \%$ said their doctors had openly or implicitly demanded the Hongbao. See Bandao.cn 2014.

$6 \quad I d$

7 For example, South China Metropolis Daily reported a case where before an operation, the two surgeons making preparations for the surgery said to the patient, "If you do not provide us with a Hongbao, there will be more 'accidents' during the surgery." The patient, who was poor and borrowed all the surgical expenses (2,400 yuan) from his relatives, finally paid the surgeons a Hongbao of 400 yuan for fear of suffering "accidents." See South China Metropolis Daily 2006. Another sensational example is the so-called “Sewed Anus Incident" (膖肛门). A midwife allegedly took revenge on a woman by sewing the woman's anus after the childbirth because the woman and her husband refused to pay a Hongbao before the childbirth when the midwife urged them to pay several times. See e.g. Xi'an Daily 2010.

8 An exception is that, according to art. 63 of the Tort Law 2009, patients may claim any overcharged expense back from the hospital if they can establish that the staff members of the hospital have conducted "unnecessary examinations in violation of the procedures and standards for diagnosis and treatment."

9 For instance, in 2006 in the Anhui Province, a total of 60 doctors had been subject to disciplinary sanctions because of taking the Hongbao. See Jiang 2015.

$10 \quad$ Yang 2002, p. 123. 
are primarily dealt with by the tort litigation system or alternative dispute resolution (hereinafter ADR), which will be discussed in Chapter 4 .

\subsubsection{Iatrogenic/Treatment Injuries}

A medical dispute normally arises from an "accident" where a patient suffers some injury. In the literature, different types of damage suffered by patients in the health care sector are carefully distinguished. Unlike victims of a traffic accident whose personal injuries are generally caused only by the accident, most patients are already out of condition before they see a doctor, ${ }^{11}$ which is often termed an underlying or pre-existing/prior illness/condition/disease. ${ }^{12}$

During diagnoses and treatment, patients may suffer injuries due to "accidents" that may or may not be related to medical interventions. As Shavell pointed out, the "accidents of special interest are iatrogenic, those which may be imputed to medical treatment itself rather than to a prior medical condition." 13 Shavell further framed the concept of "medical accident," which means "any adverse medical event, whether or not it is in some sense 'accidental' in nature."14

However, it is the notion of an "iatrogenic injury" that is more often adopted in the literature than "medical accidents." According to the Harvard Medical Practices Study (hereinafter Harvard Study), an iatrogenic injury is "any adverse condition in a patient resulting from treatment by a physician or surgeon." ${ }^{15}$ It seems that the notion of iatrogenic injury is almost identical

11 Not all patients are out of condition before going to hospital. For example, pregnant women who choose to deliver at a hospital can be very healthy beforehand.

12 There is a minor difference between a pre-existing condition and an underlying condition. A pre-existing condition is usually defined as an "on-going condition that is symptomatic and has required treatment." See Winthers 2016. Pre-existing conditions are obvious ones which immediately impel patients to see a doctor. In contrast, an underlying illness is "an asymptomatic condition that leaves a party in a weakened state" or makes him/her likely to suffer from another disease. See Winthers 2016. Examples of underlying conditions include: obesity, compromised immune system, diabetes, malabsorption, etc. Schnakenberg 2015. An underlying illness may be a hidden condition that is believed to have caused the pre-existing symptomatic condition, or may not be present with the preexisting condition at all. Right Diagnosis 2016. However, as far as the malpractice law is concerned, both pre-existing and underlying conditions are non-tortious factors that are believed to be within the scope of responsibility of patients themselves, and that are in marked contrast to torts committed by medical providers. Hence, these two terms will be used interchangeably throughout the thesis.

$13 \quad$ Shavell 1978, p. 35.

14 Id. However, it is worth noting that under Chinese law, “medical accidents” (医疗事故) specifically denotes those events with obvious personal injury due to negligence on the part of health care providers.

15 Harvard Medical Practices Study 1990, Glossary. 
with that of treatment injury currently employed by the New Zealand Accident Compensation Act 2001. ${ }^{16}$ A necessary part of the treatment (e.g. cutting the skull in a brain surgery) should not be regarded as an iatrogenic injury; otherwise, it could be counter-productive - no intrusive medical interventions should be conducted in order to avoid iatrogenic injuries entirely.

Iatrogenic injuries may occur in cases where the pre-existing condition is not deteriorating or where it is even improving. Modern medical interventions are usually aggressive and risky in and of themselves, which may generate "therapeutic risks" that are additional to the pre-existing disease. ${ }^{17}$ For instance, there is a small probability that a selected treatment will occasionally cause fatal complications to the patient and there is a large probability that the treatment will cause minor injuries or discomfort to her. ${ }^{18}$ Moreover, few drugs are free from negative side effects. To provide a third example, an underlying condition, which is not present with the pre-existing condition, may combine with the medical intervention to cause new complications in an unpredictable way. In this sense, medical interventions are just the lesser of two "evils." Thus, there is often a trade-off between the benefit of curing a disease under treatment and the cost of suffering an additional iatrogenic injury. Patients should be informed of the benefits and risks of treatment plans and give consent to the treatment. Sometimes this additional harm can be avoided by the treatment, but sometimes it is unavoidable by any treatment in the present state of the art. ${ }^{19}$

16 Section 32(1)-(2) of the Accident Compensation Act 2001 (N.Z.). defines treatment injury as personal injury that is (a) suffered by a person, (b) caused by treatment; and (c) not a necessary part, or ordinary consequence, of the treatment, which does not include (a) personal injury that is wholly or substantially caused by a person's underlying health condition ...

17 Khoury 2006, pp. 51-52.

18 Inman 1986, pp. 44-45.

19 Note that "avoidability" is understood differently in different systems. In legal systems where the negligence rule applies to medical liability, it is only meaningful to establish the causal link between the breach of the standard of care (negligence) and the injury. An injury would be said to be compensable if it could be reasonably or properly avoided by a treatment. Providers ought to exercise due care (the reasonable man standard) but not the best care medically possible (the best man standard). An injury that could be avoided by the best physician but not by the reasonable physician would not be compensable under the fault-based malpractice system. In contrast, in systems where no-fault compensation schemes are employed, an injury that could be avoided by the best physician would nonetheless be compensable. See infra Chapter 11. Since the notion of the iatrogenic injury only implies its connection with medical interventions, but does not suggest any reference to negligence, the avoidability requirement of iatrogenicity will be based on the best doctor standard. 
Iatrogenic injuries may also be the unnatural aggravation of the preexisting condition or failure to stop the medically avoidable natural progression of the pre-existing condition. Errors or omissions during treatment may exacerbate or fail to prevent the natural progression that can be avoided by a proper or best treatment so that the patient's expectations of the amelioration of their pre-existing disease are frustrated. Stauch contended that the failure of a medical intervention could legitimately be counted as harm because the patient's health has not been improved to the expected state. ${ }^{20}$ For instance, the death of a patient who died of rabies due to his/her doctor's delay in injecting Rabies Vaccine falls into the category of an iatrogenic injury in that the patient can be medically cured. However, if this harm cannot be avoided by any treatment, it should be better interpreted as a non-iatrogenic injury.

The opposite to an iatrogenic injury is a non-iatrogenic injury, which is the natural progression of the patient's pre-existing conditions. Because of lacking a causal link with medical interventions, non-iatrogenic injuries are particular risks that are considered to be the patient's own responsibility and that can be dealt with by the patient via the use of insurance, disease prevention or other measures. ${ }^{21}$ Given that quality uncertainty and risks are characteristic of the healthcare market, ${ }^{22}$ it is comprehensible that even a properly administered treatment may sometimes fail to cure the patient's illness due to the limits of modern medicine. Therefore, the "fact that the treatment did not achieve a desired result does not, of itself" constitute iatrogenic injury. ${ }^{23}$ As far as many critical diseases are concerned, failure to cure may be the highly foreseeable or ordinary consequences given the then available medical knowledge. These ordinary consequences of the treatment are non-iatrogenic injuries.

\subsubsection{Adverse Events}

A notion similar to or identical with the iatrogenic injury is the adverse event (hereinafter AE). ${ }^{24}$ The Harvard Study defined an adverse event as "an unintended injury caused by medical management rather than by the disease process" where the "injury is sufficiently serious to lead to prolongation of

Stauch 2008, p. 1

Vaughan \& Vaughan 2008, p. 6.

See generally Arrow 1963.

NZ-ACA 2001, Section 32(3).

Sometimes, scholars use other similar terms such as "medical adversity," see generally Havighurst \& Tancredi, 1973; Havighurst 1975, or "medical mal-occurrence," see generally Pollack 1987; 1988. 
hospitalisation or temporary or permanent impairment or disability in the patient." ${ }^{25}$ It seems that the Harvard Study intended to equate the "iatrogenic injury" with the $\mathrm{AE},{ }^{26}$ or at least the $\mathrm{AE}$ is a subset of the iatrogenic injury the serious iatrogenic injury. Note that an event usually denotes "a thing that happens or takes place," ${ }^{27}$ which has nearly the same meaning as an incident or accident. In contrast, an injury normally refers to "any harm or damage" done to a person in an accident. ${ }^{28}$ Hence, it sounds somewhat weird to treat the $\mathrm{AE}$ and the iatrogenic injury as synonymous. It may be more appropriate to redefine an $\mathrm{AE}$ as an accident where an iatrogenic injury was caused by medical treatment or procedures. ${ }^{29}$

\subsubsection{Iatrogenic Injuries, Errors, and Negligence}

Iatrogenic injuries may trigger legal interventions. Under traditional private law, only damage caused by medical malpractice (or clinical/medical negligence $)^{30}$ is compensable. Medical malpractice normally denotes a health care provider's failure to exercise the due care (proper medical interventions) which a reasonable provider would exercise in similar circumstances. ${ }^{31}$ However, it should be noted that not all iatrogenic injuries can be prevented by a properly given treatment. An iatrogenic injury can be caused by a properly preventable medical error or by a properly non-preventable medical mishap. ${ }^{32}$

Interestingly, a notion of "medical misadventure" was adopted in New Zealand before 2005. Medical misadventure consists of medical error and medical mishap. ${ }^{33}$ The medical error was defined as "the failure of a registered health professional to observe a standard of care and skill reasonably to be

25 Id.

26 Cascão and Hendrickx argued that the notion of an adverse event "coincides with the notion of iatrogenic injury.” Cascão \& Hendrickx 2007, p. 117, note 10.

27 Stevenson 2010

$28 \quad$ Garner 2014.

29 This definition is conceptually sound, since it makes a clear distinction between an accident (AE) and the consequence of the accident (iatrogenic injury). However, this distinction is trivial in terms of practical significance, because, by this definition, one $\mathrm{AE}$ precisely corresponds to one iatrogenic injury. Hence, these two terms are often used interchangeably throughout this thesis.

30 While "clinical/medical negligence" is often used under the UK tort law, "medical malpractice" is a particularly predominant terminology under the US tort law. Since these two terms are essentially synonymous, they will often be used interchangeably throughout this thesis.

Garner 2014.

Boccara 2009, p. 341.

NZ-IPRCAA 2001, Section 32(1). 
expected in the circumstances." ${ }^{{ }^{34}}$ In the light of liability law, a medical error is roughly equivalent to the notion of clinical negligence.

In contrast, medical mishap means a "severe" (at least suffering a temporary disability more than 28 days) and "rare" (less than 1\%) adverse consequence of treatment which is given properly. ${ }^{35} \mathrm{~A}$ medical mishap occurs so rarely that even the reasonably qualified medical expert cannot (but the most qualified expert can) anticipate or prevent it. Nevertheless, an injury resulting from a medical mishap is still iatrogenic in that it is associated with a treatment intervention rather than the pre-existing condition. Thus, a medical mishap is somewhere in between a medical error and a pre-existing condition.

Weiler et al. also defined a medical error resulting from an iatrogenic injury as a negligent $A E$, and thus a medical mishap as a non-negligent $A E^{36}$ It ought to be noted that a negligent $\mathrm{AE}$ is not equivalent to but only a limited subset of a medical error, since the "vast majority of errors do not result in injury to patients because the error was identified in time and mitigated; because the patient was resilient; or because of simple good luck." ${ }^{\prime 37}$ Medical errors that do not lead to iatrogenic injury are also called "near misses, close calls, potential adverse events or warning events." ${ }^{38}$

Likewise, we can divide iatrogenic injuries into negligent iatrogenic injuries and non-negligent iatrogenic injuries. Under the fault-based malpractice system, only negligent iatrogenic injuries are compensable. However, under no-fault plans, both negligent and non-negligent iatrogenic injuries may be recoverable. ${ }^{39}$

The relationship among all the preceding concepts is summarised in Figure 1.1 as follows.

Figure 1.1: The Relationship among Basic Concepts

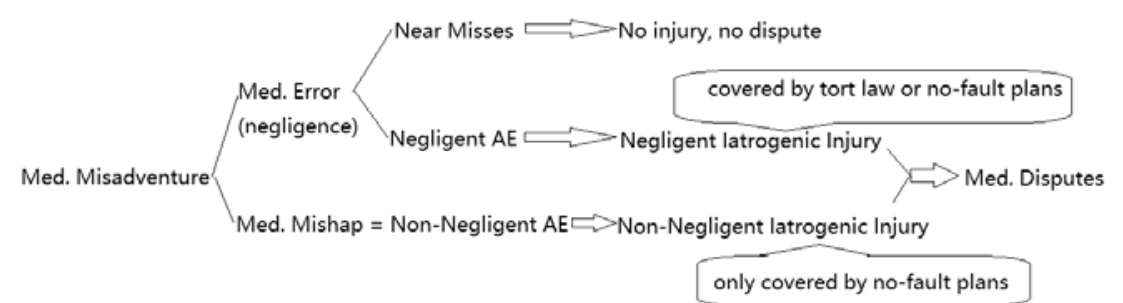

NZ-IPRCAA 2001, Section 33(1).

NZ-IPRCAA 2001, Section 34

Weiler et al. 1993, p. 35.

Grober \& Bohnen 2005, p. 41.

Id.

Weiler et al. 1993, pp. 19-25. See also infra Chapter 11. 
Introduction

\subsection{DOCTOR-PATIENT CONFLICTS IN CHINA}

\subsubsection{The Frequency of Medical Disputes and Iatrogenic Injuries}

Scattered empirical studies in the past decade suggest that medical disputes are prevalent and becoming more and more frequent in China.

First, there is an increasing trend nationwide. As early as in 2002, Zheng et al. conducted a questionnaire survey of 326 hospitals in several provinces and found that 321 (98.47\%) of all these hospitals had suffered from serious medical disputes..$^{40}$ In September 2002, the Chinese Hospital Association carried out a questionnaire survey of 200 hospitals and pointed out that the number of medical disputes occurring in Level 3 hospitals had risen by $17.98 \%$, in Level 2 hospitals by $34.71 \%$ and in Level 1 hospitals by $40 \%$ compared to the data in January $2002 .{ }^{41}$

Second, the same growing trend can be detected at the municipal level. For example, Yang et al. reported that the number of medical disputes had risen from 77 in 2003 to 110 in 2004 to 126 in 2005 in Huangshi City of Hubei Province. ${ }^{42}$

Third, this upward trend can also be identified by studying individual hospitals. For instance, Wang and Yang reported an increasing trend in a large hospital: from 89 medical disputes in 2004 to 111 in 2005, to 115 in $2006 .{ }^{43}$ Consistently, Liu and Feng (2013) pointed out that the number of medical disputes in 9 public hospitals in Chancheng District of Foshan City of Guangdong Province had gone up from 17 in 2008 to 33 in 2011.44

One may wonder whether this growing trend may also have been caused by a better registration of medical disputes rather than to actual rises in the number of medical disputes. However, this is unlikely to be the case, since there is often little incentive for hospitals to improve registration. As we will see later, some disputes that are resolved behind the scenes are seldom recorded or reported to the authorities by hospitals. ${ }^{45}$

A medical dispute arises from an identified AE. However, some unobservable AEs may never be detected and disputed by patients. That is to say, medical disputes are a subset of AEs. Hence, although data on the

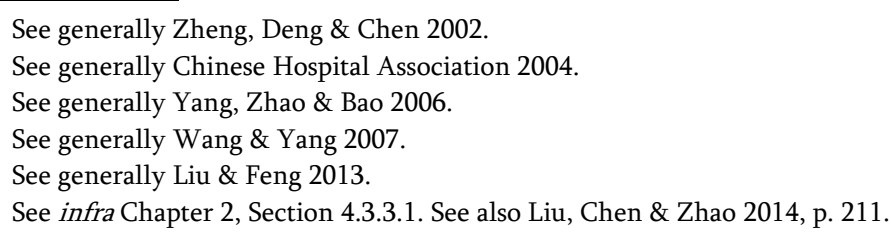


incidence of AEs are currently unavailable, a plausible inference is that AEs may be prevalent as well.

\subsubsection{Violence against Doctors}

In China, there are often "incidents of violence or protest arising from medical disputes." ${ }^{46}$ Parts of these incidents are "spontaneous outbursts of anger and frustration because of poor care, medical errors, or exorbitant costs," but in recent years a significant proportion of them are $\mathrm{Yi} \mathrm{NaO}$ incidents. ${ }^{47}$

“Yi Nao" (医闹) is an equivocal concept, which has not been defined by any law or regulation yet. On the one hand, it may denote a social phenomenon where a victimised patient, his/her family members or a mob of hired trouble makers attempt to claim damages from the healthcare provider involved for the injury the patient has suffered by various coercive measures. Some of these coercive measures are extremely violent, such as assault and battery, false imprisonment ${ }^{48}$ and vandalism. ${ }^{49}$ Less violent examples include burning joss paper of the nether world, ${ }^{50}$ setting up a mourning hall, laying funeral wreaths, displaying the dead body of the deceased patient, mobbing, ${ }^{51}$ picking a quarrel and making trouble ${ }^{52}$ in the medical institution concerned. Some measures without violence are also reported. For instance, a trouble maker may sit quietly as a form of protest in the hospital manager's office day after day. ${ }^{53}$ In this sense, $Y i$ Nao can be termed "hospital disturbance" or "Yi Nao incidents".

On the other hand, Yi Nao can also refer to a mob of people, namely the "professional hospital trouble makers" (职业医闹), who are hired by the victimised patient or his/her family members. These trouble makers pretend to be relatives of the patient and help to carry out the aforesaid coercive measures. Moreover, the patient or his/her family members promise to share the obtained "damages" with them. Normally, trouble makers can get as high as $40-50 \%$ of total "damages." ${ }^{54}$ In an exceptional case, the hospital paid

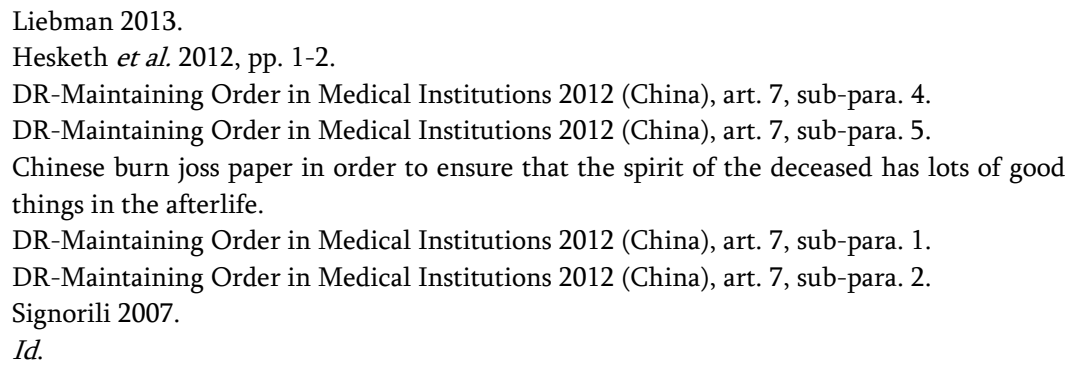


"damages" totalling 300,000 yuan, of which 270,000 yuan (90\%) was actually obtained by the trouble makers..$^{55}$

The basic information on professional $\mathrm{Yi} \mathrm{NaO}$ in China is summarised in Table 1.1.

Table 1.1: What Is Professional Yi Nao ${ }^{36}$

\begin{tabular}{ll}
\hline Definition & $\begin{array}{l}\text { Yi Nao means medical or hospital disturbance (it can also refer to the } \\
\text { gangs or individuals who create the disturbance) }\end{array}$ \\
\hline Purpose & $\begin{array}{l}\text { Use of } Y i \text { Nao to obtain compensation for perceived or actual medical } \\
\text { malpractice has developed in many parts of China over the past 5-10 } \\
\text { years }\end{array}$ \\
\hline Benefits & $Y i$ Nao receive a substantial cut of any compensation received \\
\hline Coercive & $\begin{array}{l}\text { Yi Nao gangs consist largely of unemployed people with a designated } \\
\text { leader. They threaten and assault hospital personnel, damage } \\
\text { facilities and equipment, and prevent the normal activities of the } \\
\text { hospital }\end{array}$ \\
\hline Initiation & $\begin{array}{l}\text { Although some people approach Yi Nao to deal with medical } \\
\text { disputes, Yi Nao also solicit business by wandering around hospitals, } \\
\text { looking for potential "malpractice" cases and encouraging individuals } \\
\text { to pursue them }\end{array}$ \\
\hline Consequences & $\begin{array}{l}Y i \text { Nao disturbances, many of which have been very serious with } \\
\text { fatal consequences, have been widely reported in the Chinese press }\end{array}$ \\
\hline
\end{tabular}

In the past decade, the surge in protests and violence pertaining to medical disputes has been widely reported in the media in China. In 2002, Zheng Xuqian et al. reported that of all the 326 hospitals, $73.5 \%$ had encountered patients who disturbed the order inside the hospital, $43.86 \%$ had experienced beating and smashing inside the hospital, $35.58 \%$ had suffered from facilities damage and 113 medical staff members in $34.66 \%$ of all the 326 hospitals had been injured. ${ }^{57}$ In 2006, Wang et al. reported that as high as $56.1 \%$ of all the staff members from 20 hospitals in Chengdu City of Sichuan Province said that they were physically threatened by patients..$^{58}$ In 2007, Zheng Xuqian et al. studied medical violence in 250 hospitals nationwide, reporting that 73.33\% hospitals experienced incidents where medical staff members had been violently beaten, threaten or abused by patients or their family members, and $61.48 \%$ hospitals experienced incidents where the deceased patient's family members laid wreaths or set up a mourning hall inside

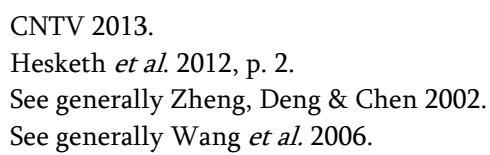


hospitals. ${ }^{59}$ Recently in 2014, Jia studied 316 hospitals nationwide and found that the proportion of hospitals that suffered from medical violence had risen from $90 \%$ in 2008 to $96 \%$ in 2012 , and the percentage of medical staff members who had been attacked and suffered from obvious injury had risen from $47.7 \%$ in 2008 to $63.7 \%$ in $2012 .{ }^{60}$

Besides reports in the Chinese media, violence against Chinese doctors has also made the headlines in English media such as the Economist, ${ }^{61}$ the BMJ (originally called the British Medical Journal), ${ }^{62}$ the National Public Radio (NPR), ${ }^{63}$ the $\mathrm{BBC},{ }^{64}$ the Lancet, ${ }^{65}$ the New Yorker, ${ }^{66}$ and the Washington Post. ${ }^{67}$

Violence against doctors is common in many other countries. ${ }^{68}$ However, in countries such as Turkey, Pakistan, and the US, violence against doctors is virtually always done by patients or their close relatives and serious injury and murder are relatively rare. ${ }^{69}$ Compared to these countries, China is unique on account of "the extreme nature of the violence and the use of $Y i$ Nao vigilante groups."70

\subsubsection{Provider Negligence and Medical Disputes}

Although there is no report on the incidence of adverse events, some empirical studies suggest that the rate of medical disputes due to provider negligence compared to all identified medical disputes is strikingly high. For example, Yang et al. found that $52.3 \%$ of the medical disputes could be attributed to the negligent healthcare provider in Huangshi of Hubei Province (2003-2005). ${ }^{71}$ Wang found that $59.36 \%$ of the medical disputes are associated with negligence in a hospital (2004-2006). ${ }^{72}$ Song even reported that as high as $93.83 \%$ of all medical disputes were caused by medical malpractice in Yueyang of Hunan Province (2007-2010). ${ }^{73}$

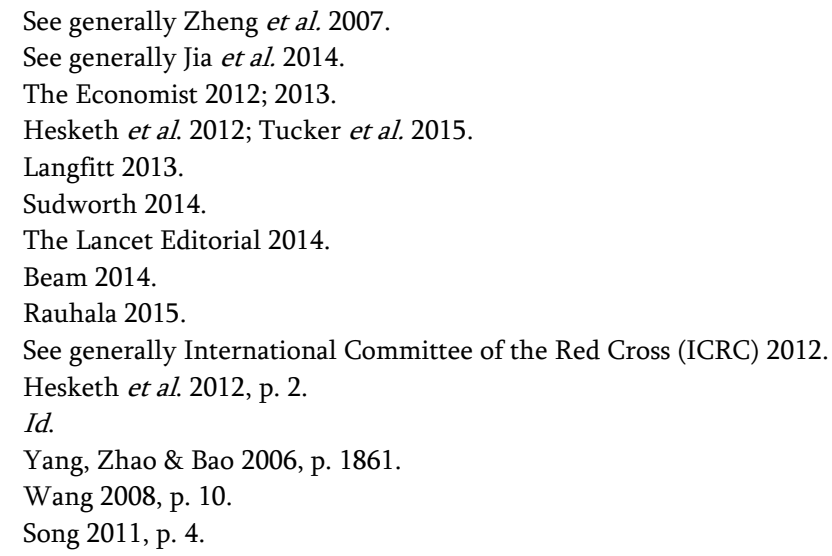


Moreover, Li provided a much more complete picture of the distribution of various factors. ${ }^{74} \mathrm{He}$ found that of the 260 medical disputes occurring in 4 hospitals in Dongguan of Guangdong Province (2007-2011), $145(55.77 \%)$ were attributable to the health care provider, $79(30.38 \%)$ to the patient $^{75}$ and $36(10.38 \%)$ to other social factors. Furthermore, Li specifically pointed out that of all the 145 disputes where providers were negligent, 74 $(51.03 \%)$ were caused by failure to live up to the then medical standard or lack of commitment, 24 (30.38\%) by failure to fulfil the duty of disclosure, 9 (11.39\%) by excessive medicine.

Hence, the above data suggest that more than half of all medical disputes can be attributed to physician negligence. However, evidence on the extent to which physician negligence contributes to all AEs is currently unavailable.

\section{RESEARCH QUESTIONS}

The previous Section shows that recently in China the frequency and severity of medical disputes (a subset of AEs) have been increasing substantially, which remains an issue of concern to the whole society. Although the root cause of many medical disputes may be deficiencies in the health care system, a substantial part of them can be attributed to sub-standard quality of care. One may thus wonder what legal remedies are available in China that are intended to maintain the quality of medical care and thus reduce the frequency and severity of AEs. Are these legal remedies effective and efficient?

On the other hand, in cases where an AE (especially a negligent one) occurs, one may also wonder how the Chinese legal system handles medical malpractice claims. Will victims of medical malpractice obtain adequate compensation quickly and cheaply? The prevalence of $Y i$ Nao incidents suggests that many victims of medical malpractice do not trust the formal legal system. Instead, they resort to the "weapons of the weak." Some argued that this is because the legal channels for handling medical disputes are ineffective, inefficient, and biased towards hospitals. ${ }^{76}$ Is this argument valid?

75 Of all the 79 patient-provoked disputes, 26 (32.91\%) were associated with the patient's lack of medical knowledge, $21(26.58 \%)$ with the patient's strategy of using violence to obtain compensation, and $18(22.78 \%)$ with the patient's extremely high expectation of curative effects. Id. 
In this thesis, it is taken for granted that if the Chinese legal remedies were effective and efficient at preventing medical malpractice (or quality assurance) and compensating victims of medical malpractice adequately, there would be a substantial reduction in the frequency and severity of medical malpractice (and ultimately in medical disputes, AEs, violence against doctors, and $\mathrm{Yi}$ Nao incidents). This assumption is in line with law and economics literature on the goals of accident law. ${ }^{77}$ Based on this prior assumption, answers to the following three interrelated main research questions will be provided in this thesis:

(1) Are the current legal remedies for medical malpractice in China sound from a legal perspective?

(2) Are these legal remedies also efficient when measured against economic benchmarks?

(3) If not, how can we improve these legal remedies?

If the answers to the first two questions are "Yes," there will be no need to answer the third one.

The first main question can be divided into two sub-questions. (1-a) What are the legal remedies currently available in China that are aimed at the prevention of medical malpractice and the compensation of victimised patients? (1-b) Are these remedies sound according to traditional legal doctrines that have been developed in China?

The second main question can be divided into two sub-questions as well. (2-a) How should the legal remedies be structured in order to prevent medical malpractice and compensate victims for iatrogenic injuries efficiently in theory and have these theoretical predictions been tested? (2-b) Are the legal remedies in China efficient in the light of economic benchmarks?

In the case where the answers to the first two main questions are not "Yes," the thesis will proceed to answer the third main question.

It should be noted that, in China, the primary legal remedy for medical malpractice is private law compensation under tort law (hereinafter the malpractice system), which is the central focus of this thesis. However, the malpractice system is not operating without the influence of other legal remedies such as regulation, private insurance, and social security. These alternative remedies to tort law and their interaction with the malpractice system, will also be addressed in this thesis, though in a less detailed way.

Specific questions call for particular methods. In this thesis, three methods are carefully chosen in order to answer the research questions - the

$77 \quad$ See generally infra Chapter 7. 
doctrinal approach, empirical legal research, and comparative law and economics, which will be addressed in the following section.

\section{METHODOLOGY}

\subsection{THE DOCTRINAL APPROACH}

Doctrine is often defined as "a synthesis of rules, principles, norms, interpretive guidelines and values" which "explains, makes coherent or justifies a segment of the law as part of a larger system of law."78 The doctrinal approach "lies at the heart of any lawyer's task because it is the research process used to identify, analyse and synthesise the content of the law." ${ }^{79}$ In order to answer Sub-question (1-a), it is important that the description of the legal remedies should reflect the true content of the law in the light of dominant doctrines in China, which lays the foundations of further discussions.

\subsection{EMPIRICAL LEGAL RESEARCH}

Empirical Legal Research (hereinafter ELR) is concerned with "the systematic collection of information ('data') and its analysis according to some generally accepted method." ${ }^{80}$ Data are just "facts about the world," ${ }^{81}$ which may come from "a wide range of sources including surveys, documents, reporting systems, observation, interviews, experiments, decisions, and events." ${ }^{82}$ ELR is primarily interested in law in action rather than the law in the book. ${ }^{83}$ Also, ELR is focused on the "functioning of organisations and institutions in the legal field" and "effects, consequences or impacts of legal arrangements on the behaviour of persons and organisations. " ${ }^{84}$ Empirical evidence can be either quantitative or qualitative. ${ }^{85}$ Due to limitations of time and financial resources, this $\mathrm{PhD}$ project will employ the qualitative approach.

\footnotetext{
Hutchinson 2013, p. 9.

Id.

Cane \& Kritzer 2010, pp. 4-5.

Epstein \& Martin 2014, p. 3.

Cane \& Kritzer 2010, pp. 4-5.

Leeuw \& Schmeets 2016, p. 2.

Leeuw \& Schmeets 2016, pp. 5-6.

Epstein \& Martin 2014, p. 3.
} 
Sub-question (1-b) will be answered by using empirical evidence the medical malpractice law in action, the functioning of the legal remedies pertaining to quality assurance and compensation, and their impact on actors in the health care sector. The main data are collected from court decisions and semi-structured interviews. As Epstein and Martin pointed out, "we could have extracted information from the text of court decisions" and the "data in this case would be words, not numbers, that could interpret, organise into categories, and use to identify patterns." ${ }^{86}$ In order to figure out how the malpractice law functions in practice, I have conducted an analysis of 592 court decisions from the Gulou District People's Court, located in Nanjing of the Jiangsu Province in China.

Semi-structured interviews are non-standardised interviews that are often used in qualitative analysis. ${ }^{87}$ A list of issues and questions are listed before the interview and additional questions that were not expected before the interview could be raised in the process. ${ }^{88}$ Semi-structured interviews allow for "probing of views and opinions" especially when it is important to "explore subjective meanings that respondents ascribe to concepts or events." ${ }^{99}$ For the purpose of finding out more information that cannot be drawn from court decisions, 21 semi-structured interviews were conducted with judges, attorneys, public health officials, physicians, etc. in Nanjing and elsewhere in China. Key findings of existing empirical studies will be summarised as supplementary evidence.

\subsection{COMPARATIVE LAW AND ECONOMICS}

\subsubsection{Why Law and Economics?}

The law and economics approach is adopted to answer Sub-question (2-a). A question that is often raised by lawyers is - Why should we be bothered about law and economics? This can be answered from two perspectives positive analysis and normative analysis.

Positive analysis is intended to "provide a system of generalisations that can be used to make correct predictions about the consequences of any change in circumstances." ${ }^{90}$ An essential assumption of economics is that rational maximisers respond to incentives - "that if a person's surroundings

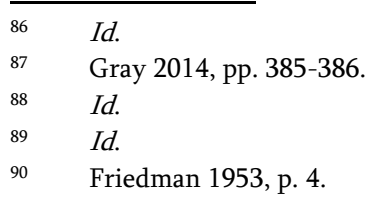


change in such a way that he/she could increase his satisfaction by altering his behaviour, he/she will do so." ${ }^{.1}$ Incentives are provided by prices in the market and by sanctions in the legal system. To economists, "sanctions look like prices, and presumably, people respond to these sanctions much as they respond to prices." ${ }^{.92}$ Specifically, tort sanctions can be viewed as "prices" that induce potential tortfeasors to take appropriate precautions in order to avoid being held liable for harm done. This deterrence function of tort law is also stressed by article 1 of the new Tort Law 2009 in China, which reads "this law has been formulated for the purposes of ... preventing ... tortious acts."

The legal system also assumes that individual actors are rational, which can be evidenced by many legal principles or standards such as "freedom of contract" 93 and the "reasonable person" standard ${ }^{94}$ Hence, the intersection of the basic assumptions of economics and law provides a strong case for using economic methods to analyse legal problems. Based on "mathematically precise theories (price theory and game theory)" 95 and "empirically sound methods (statistics and econometrics)," economics is perfectly fit for analysing how people respond to "implicit prices" of legal sanctions. ${ }^{96}$

In this thesis, it is important to first describe and predict how parties and stakeholders in a medical malpractice setting will behave in response to incentives provided by different legal rules. In this way, it is possible to observe the effects of different legal rules on the behaviour of people. This is what positive economics is about, which is already very interesting.

In contrast, normative analysis "incorporates value judgements about what the economy should be like or what particular policy action should be recommended to achieve a desirable goal." ${ }^{97}$ Besides "justice" and "fairness," efficiency is also integral to society. Efficiency is a legitimate goal that has

Posner 2011, p. 5.

Cooter \& Ulen 2012, p. 3.

Freedom of contract is the doctrine "that people have the right to enter into binding private agreements with others ... that people are able to fashion their relations by private agreements." Garner 2014. Therefore, the underlying assumption of freedom of contract is that people are rational so that they are able to pursue their interests through contracts.

94 A "reasonable man" is a "hypothetical person ... who exercises the degree of attention, knowledge, intelligence, and judgment ... The reasonable man acts sensibly, does things without serious delay, and takes proper but not excessive precaution." Id. It follows that a reasonable man in law is almost identical to a rational man in economics.

95 Readers who have not been trained in economists or mathematics should not be intimidated by the application of mathematics to legal analyses. As we will see in the following chapters, only a basic high school level mathematical knowledge is employed to demonstrate critical propositions when it is indeed necessary. Higher and Further Mathematics such as Calculus is avoided throughout this thesis.

$96 \quad$ Cooter \& Ulen 2012, p. 3.

$97 \quad$ McConnell, Brue \& Flynn 2009, p. 7. 
been recognised and treasured in China throughout the post-Mao era. ${ }^{98}$ Hence, the first main research question also asks about the efficiency of the legal remedies for medical quality assurance and victim compensation.

The pursuit of efficiency should be reflected in legislation and law and economics seems highly fit for this job. Based on the fundamental assumption that people are rational maximisers of their ends in life, economics offers a powerful tool to conduct cost-benefit analysis which is aimed at enhancing efficiency. ${ }^{99}$ In welfare economics, the basic notion of efficiency is Pareto efficiency, meaning a situation where "it is impossible to change it so as to make at least one person better off ... without making another person worse off." ${ }^{100}$ Dissatisfied with Pareto efficiency, contemporary economists relaxed the stringent requirement of Pareto efficiency and developed the notion of Kaldor-Hicks efficiency (or a potential Pareto improvement), which "allows changes in which there are both gainers and losers but requires that the gainers gain more than the losers lose." ${ }^{101}$

Therefore, after the positive analysis of legal remedies for medical malpractice is done, normative economics will lead to the formulation of some policy recommendations in line with the normative criterion of efficiency.

\subsubsection{The Use of Comparative Law}

In some chapters of this thesis, the systems of compensating victims of AEs in foreign jurisdictions (primarily the US, New Zealand, and several European countries) and relevant empirical evidence have been mentioned as a frame of reference for China. However, this has been done primarily from a functional approach. ${ }^{102}$ It will be done in a problem-oriented way. The focus will be on how a legal system deals with the problem of medical malpractice and on empirical evidence on whether it works in practice. The ultimate purpose is to ascertain what are the best practices in other legal systems. Hence, it

98 The relationship between efficiency and fairness is not only an economic and political issue, but also one of social development. Since the adoption of the reform and opening-up policy in 1978, the Communist Party and the Government of China have undergone a continual process of exploration into understanding the relation between efficiency and fairness, from "treating efficiency and fairness equally" to "giving priority to efficiency over fairness" and then to "properly balancing the relation between efficiency and fairness both in primary distribution and redistribution, and giving more consideration to fairness in redistribution." See generally Li \& Zhang 2013.

$99 \quad$ Posner 2011, pp. 4-5.

$100 \quad$ Cooter \& Ulen 2012, p. 14.

$101 \quad$ Cooter \& Ulen 2012, p. 42.

102 Siems 2014, pp. 26-27. 
should not be regarded as a fully-fledged application of traditional comparative law. ${ }^{103}$ Detailed descriptions and comparisons of medical liability or no-fault schemes among different jurisdictions around the world are currently available elsewhere, ${ }^{104}$ and will therefore not be repeated in this thesis.

Several legal jurisdictions have been chosen in the light of whether they can be interesting examples or can provide some useful lessons for China, which of course is a way of cherry picking. For empirical evidence, the main focus is on empirical studies in the US, because the deterrent function of tort law is strongly stressed there and relevant empirical literature on the deterrent effect of medical malpractice liability is voluminous. Since both the US and China primarily depend on fault-based tort liability to deal with medical malpractice issues, the US experience may provide China with useful lessons. Be that as it may, if other legal systems such as the Netherlands also provide some valuable empirical evidence or interesting legal solutions that may be relevant to China, they will be briefly addressed as well.

For alternative schemes to tort law, medical no-fault compensation schemes in New Zealand and Scandinavian countries will be analysed. The reason for this choice is that these are the only jurisdictions in the world where comprehensive no-fault compensation schemes that are alternative to tort law are well developed.

\section{STRUCTURE}

The remainder of the thesis is divided into three parts as follows:

Part I (Chapter 2 to Chapter 6) examines the legal remedies for medical quality assurance and victim compensation in China, which is intended to answer Sub-question (1-a) and Sub-question (1-b). Chapter 2 is concerned with the provision of health care and the regulation of the medical profession. It is primarily aimed at answering the question of how the regulatory system works in practice in terms of quality assurance (or the prevention of medical errors). Chapter 3 thoroughly describes the substantive system of medical

103 The traditional approach to comparative law often includes the following four steps: "First, a comparative analysis starts with preliminary considerations, deciding on the research question and the choice of legal systems. Second, the comparatist has to describe the laws of these countries. Third, she has to compare them, in particular exploring the reasons for unexpected similarities and differences. Fourth, she should critically evaluate her findings, possibly also making policy recommendations." Siems 2014, p. 13.

104 See e.g. Dute, Faure \& Koziol 2004; Stauch 2008; Hondius 2010c; Koch 2011; Oliphant \& Wright 2013; Taylor 2015. 
malpractice liability in China, which is now provided for by the new Tort Law 2009. Chapter 4 discusses the issues about medical disputes, iatrogenic injuries, malpractice litigation, and patient compensation in practice based on empirical evidence drawn from the analysis of court decisions and semistructured interviews that have been conducted on the one hand, and existing empirical studies on the other hand. Chapter 5 explores alternative regimes that may compensate victims of medical malpractice such as medical liability insurance, first-party insurance, and social security. Chapter 6 evaluates the legal remedies in China from the perspective of traditional legal doctrines and builds a bridge between the legal perspective in Part I and the law and economics approach in Part II.

Part II (Chapter 7 to Chapter 11) is primarily concerned with economic theories and relevant empirical evidence pertaining to medical malpractice or AEs. While Chapter 7, Chapter 8, and Chapter 9 focus on legal mechanisms in the light of the prevention of medical errors, Chapter 10 and Chapter 11 examine legal mechanisms from the perspective of victim compensation. Chapter 7 reviews theoretical studies on the classic fault-based model of medical malpractice liability. Chapter 8 examines empirical evidence pertaining to the deterrent effect of medical malpractice liability and updates the classic model in the light of new evidence. Chapter 9 addresses alternative legal remedies to tort law that are also aimed at quality assurance. Chapter 10 discusses the fault-based compensation mechanisms for iatrogenic injuries. Chapter 11 explores medical compensation schemes that are not based on the fault rule.

Part III (Chapter 12 and Chapter 13) evaluates the legal remedies for medical quality assurance and victim compensation in China from the perspective of law and economics (Chapter 12), and tries to make a few concluding remarks and to formulate some policy recommendations (Chapter 13). 

PART I

LEGAL REMEDIES FOR MEDICAL

MALPRACTICE IN CHINA 



\section{INTRODUCTORY NOTE}

This part is intended to answer the first main research question - Are the current legal remedies for medical malpractice in China sound from a legal perspective? For this purpose, firstly, it is necessary to know what are the legal remedies currently available in China that are aimed at the prevention of medical malpractice and the compensation of victimised patients (Subquestion (1-a)). In China, both public regulation (incl. criminal law) and tort law may be used to prevent medical malpractice. Victims of medical malpractice may obtain compensation via tort law, private insurance, or social security.

Regulation of the medical profession will be described in Chapter 2. In addition, Chapter 2 will also sketch the outline of the Chinese health care provision system intending to provide the context of medical malpractice in China.

The part of the tort system that deals with medical malpractice will be addressed in Chapters 3 and 4. Chapter 3 will describe the "law in the books" - substantive rules of medical malpractice liability and relevant rules of evidence. Chapter 4 will examine the "law in action" - empirical findings concerning the functioning and impact of the medical malpractice liability system.

Other compensation schemes that may provide victims of medical malpractice with some remedies will be briefly addressed in Chapter 5. In China, these schemes may include medical liability insurance, first-party private insurance, and social security (social insurance and administrative assistance).

After describing these legal remedies, they will be evaluated according to traditional legal doctrines (Sub-question (1-b)). In Chapter 6, traditional legal doctrines or benchmarks that prevail in China will be summarised. Then, the foregoing legal remedies will be evaluated in light of these traditional legal benchmarks. Thereafter, the weaknesses of the traditional approach will be pointed out and the need for a law and economics approach will be explained. 



\section{CHAPTER 2 HEALTH CARE PROVISION AND REGULATION}

\section{INTRODUCTION}

This chapter is intended to answer part of the first main research question. Specifically, it attempts to answer how the medical profession is regulated as far as the prevention of medical malpractice or quality assurance is concerned (Sub-question (1-a)). However, in order to answer this question better, it is helpful to draw the outline of how health care services are provided and financed in China in the first place. Hence, this Chapter is organised as follows. Section 2 will provide an overview of the current health care providers in the Chinese health care system. Then, Section 3 will address the financing of the health care provision, touching upon both public and private health insurance. Thereafter, Section 4 will describe the regulation of the quality of care, including currently applicable professional standards and regulatory enforcement mechanisms.

\section{THE MEDICAL PROFESSION}

\subsection{INTRODUCTION}

The government of China has a constitutional duty to develop a system to provide health care to Chinese citizens. This duty is provided in the current Chinese Constitution as follows:

The state develops medical and health services, promotes modern medicine and traditional Chinese medicine, encourages and supports the setting up of various medical and health facilities by the rural economic collectives, state enterprises and institutions and neighbourhood 
Part I. Legal Remedies for Medical Malpractice in China

organisations, and promotes health and sanitation activities of a mass character, all for the protection of the people's health. ${ }^{1}$

The task of directly providing health care to citizens is undertaken by various institutional and individual health care providers. Section 2.2 will give a brief account of the classification of medical and health institutions. Section 2.3 will outline the scope of individual providers.

\subsection{INSTITUTIONAL PROVIDERS}

In China, institutional providers are broadly described as medical and health institutions (医疗卫生机构), which generally refer to any licensed or registered undertakings that provide medical care, disease prevention or health inspection services or conduct medical research or on-the-job training. ${ }^{2}$

Regarding their functions, medical and health institutions can be divided into four groups: (1) hospitals, (2) health care institutions at the grassroot level, (3) specialised public health institutions, and (4) other medical and health institutions. ${ }^{3}$ City-based hospitals are primarily intended to provide secondary and tertiary care to all patients. ${ }^{4}$ Grass-root-level care institutions are developed only to provide primary care to rural or community-based patients. ${ }^{5}$ Specialised health institutions offer special care such as disease prevention and maternal and child care to certain groups of patients. ${ }^{6}$ Other institutions may include medical research agencies, medical on-the-job training centres, medical examination centres, and information statistics centres, most of which do not provide medical care directly. ${ }^{7}$ Up to the end of April 2014, China had a total of 25,860 hospitals, 917,335 health care institutions at the grass-root level, and 35,029 specialised public health institutions. ${ }^{8}$

More relevant to medical malpractice issues are medical institutions (医疗机构), which are the mainstream of medical and health institutions that specifically provide diagnosis and treatment services. ${ }^{9}$ All hospitals and health

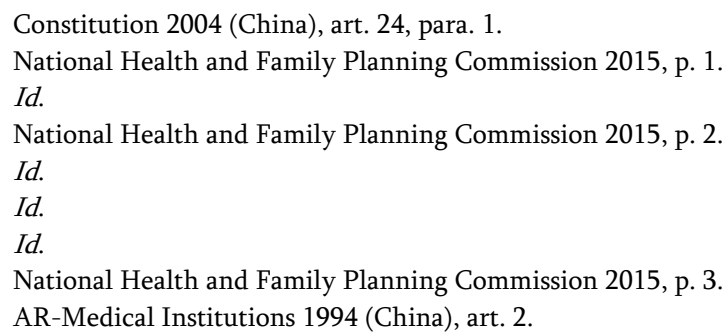


care institutions at the grass-root level and most of the specialised public health institutions fall within the scope of medical institutions. ${ }^{10}$ The majority of medical care services are provided by hospitals and health care institutions at the grass-root level. In 2014, there were about 2.97 billion hospital admissions and 4.36 billion grass-root-level health care institution admissions, whereas there were only 260.46 million specialised public health institution admissions and 5.38 million other institution admissions. ${ }^{11}$ In view of the service they provide, all medical institutions can be roughly called "hospitals" in a broader sense, no matter whether their names contain the word "hospital." ${ }^{12}$ Nonetheless, those medical institutions with a registered name of "hospital" are usually larger and have more medical resources, skilled health workers and better equipment than community/township health centres, village infirmaries or private clinics.

Judging by the ownership, medical institutions can be either public or non-public (or private). Public hospitals are registered as state-owned or collectively-owned medical institutions, ${ }^{13}$ depending on whether they are financed and owned by the government or by collective entities such as industrial and mining enterprises or village committees. Non-public hospitals are financed and owned by private entities or individuals. ${ }^{14}$ Foreign medical institutions, companies, enterprises or other economic organisations may also cooperate with a Chinese counterpart to establish non-public Sino-foreign equity joint or Sino-foreign cooperative joint medical institutions. ${ }^{15}$

Apart from financial investment and ownership, public and non-public hospitals may differ in several other aspects. First, they differ in the

$10 \quad$ According to DR-Detailed Rules-Medical Institutions 2006 (China), art. 3, there are 12 types of statutorily recognised medical institutions: (1) hospitals, (2) maternal and child health service centres, (3) community health service centres, (4) township health centres, (5) convalescent hospitals, (6) out-patient departments, (7) clinics, (8) village infirmaries, (9) first aid centres, (10) clinical laboratory centres, (11) specialised disease prevention and treatment institutions and (12) nursing homes.

$11 \quad$ National Health and Family Planning Commission 2015, p. 118.

12 As a matter of the fact, all these medical institutions are called "hospitals" in everyday life in China, irrespective of their officially registered names. For instance, township health centres are usually called "township hospitals", and occasionally even village clinics are called "village hospitals" by local people. Therefore, "medical institutions" and "hospitals" are used occasionally as interchangeable in this dissertation, if there is no need to make a strict distinction.

13 According to Constitution 2004 (China), art. 6, para. 1, public ownership means the ownership of the properties by the whole people or the collective ownership by the working people. In accordance with Property Law 2007 (China), art. 54, para. 2, the ownership of state-owned properties is exercised by the State Council (the central government) on behalf of the State.

14 See generally N-Private Medical Institutions 2010 (China).

15 DR-Sino-Foreign Medical Institutions 2000 (China), art. 2. 
employment relationship. Physicians of a private hospital enter into a labour contract (劳动合同) with the hospital and receive salaries entirely from the hospital. ${ }^{16}$ In contrast, physicians of a public hospital are quasi-public servants who are subject to an "employment contract" (聘用合同) and partially subsidised by the government. ${ }^{17}$ Second, they have different operational targets. Public hospitals are mostly run on a non-profit basis, while private hospitals are normally running for profits. Nonetheless, private hospitals may register as "non-profit medical institutions", if they are willing to adhere to government-set prices for medical care. ${ }^{18}$ Third, they charge different prices. Public hospitals must charge medical expenses at government-set prices, whereas private hospitals are normally not limited by such a cap, unless they choose to register as non-profit medical institutions. ${ }^{19}$ Fourth, they enjoy different tax treatment. Public hospitals and not-for-profit private hospitals are free from enterprise income tax, whereas other private hospitals are not. ${ }^{20}$

Public hospitals and not-for-profit private hospitals play a dominant role in the Chinese health care system. By the end of 2014, there were 542,616 public medical institutions and 438,816 non-public medical institutions in China. ${ }^{21}$ Although the number of public and private medical institutions are comparable (1.24:1), public hospital admissions (2.65 billion in 2014) are about 8 times as many as private hospital admissions (324.65 million in 2014). ${ }^{22}$ In the light of operational targets, the number of not-forprofit (public and private) hospitals (17,705 in 2014) is more than double that of for-profit private hospitals (8,155 in 2014). ${ }^{23}$ However, admissions to notfor-profit hospitals (2.81 billion in 2014) are roughly 17 times greater than those to for-profit private hospitals (165.91 million in 2014). ${ }^{24}$

All the aforesaid medical institutions combine to form the Chinese medical care service system. In rural areas, there is a "three-level medical service network" that is composed of county-level hospitals, township health centres and village clinics, where the county-level hospitals perform the leading role. In urban areas, there is a "new type of urban medical service system" that features division of work and collaboration among diverse types

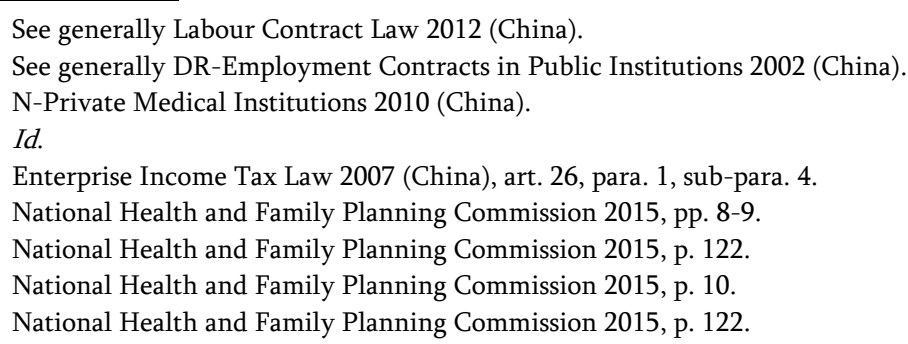


of hospitals above the sub-district level ${ }^{25}$ and community health service centres at the sub-district level. ${ }^{26}$ Currently, patients, no matter where they come from, are basically free to choose any type of hospitals at any level and any location, although they may have to pay out-of-pocket medical expenses if their chosen hospitals are not covered by their health insurance schemes. ${ }^{27}$ Patients tend to go to hospitals rather than clinics in the hope of getting a better quality of care, which is the reason why Chinese hospitals are often more crowded than clinics. ${ }^{28}$

Irrespective of types, the ownership, levels or locations, the relationship between all medical institutions and their patients are governed by the same set of civil statutes - Contract Law 1999 and Tort Law 2009. As far as disputes over medical malpractice are concerned, there is no separate forum for dispute resolution or procedural rules that are designed for public medical institutions exclusively.

\subsection{INDIVIDUAL PROVIDERS}

In China, health workers (卫生人员) are considered to comprise a range of persons employed in medical and health institutions, such as technical medical personnel, village doctors and assistants, other technical personnel, administrative personnel and logistics technical workers. ${ }^{29}$ Medical technical personnel usually work in hospitals or community/township health centres. ${ }^{30}$ They primarily include licensed (assistant) doctors, nurses, pharmacists, and medical laboratory scientists, etc. ${ }^{31}$ Licensed (assistant) doctors may also work at village clinics.32 Not all health workers are associated with medical malpractice issues. Only those who provide medical care service, namely medical technical personnel and village doctors and assistants, are medical practitioners who are likely to be involved in malpractice disputes, in which case they are universally termed "medical staff members" (医务人员). ${ }^{33}$ Although an intern has not obtained the necessary qualifications, it is

25 Hospitals in urban areas include ministry-level, provincial-level, prefecture-level and district-level hospitals.

26 The State Council Information Office 2012.

$27 \quad$ DR- Designated Medical Institutions 1999 (China), art. 12, para. 2.

28 This situation may be reversed when the general practitioner (GP) system is supposed to be established in China by the end of 2020. See generally AR-General Practitioners 2011 (China).

29 National Health and Family Planning Commission 2015, p. 23.

30 National Health and Family Planning Commission 2015, p. 24.

31 Id.

$32 \quad$ Id.

33 Tort Law 2009 (China), art. 54. 
generally accepted that he/she is regarded as a medical staff member if he/she practices in a teaching hospital under the guidance of a qualified practising physician. ${ }^{34}$

In China, all medical staff members must register and work at medical institutions, and also have to practice medicine under the name of their medical institutions. ${ }^{35}$ Even if there is only one doctor practising in his/her own clinic, he/she is still deemed to be the "medical staff member" of his/her medical institution. A great portion of medical staff members working at public medical institutions receive salaries and high-performance bonuses from their medical institutions, which are partly subsidised by the government. For instance, in public hospitals in Beijing, only about $10 \%$ of medical staff's salaries are subsidised by the government, the other $90 \%$ are paid by their hospitals in the name of bonuses. ${ }^{36}$ In contrast, all medical staff members at private medical institutions are paid by their institutions through labour contracts without government subsidies. This difference, however, does not affect the legal basis of the doctor-patient relationship (or more precisely the hospital-patient relationship) - normally a medical service contract concluded between medical institutions and their patients.

The relationships between doctors and hospitals are rather complicated in China. It depends on whether the hospital is public or private. Private hospitals are commercial companies. The relationship between the medical staff and private hospitals is based on the Labour Contract Law 2012. Private hospitals are basically free to hire or fire doctors without much governmental interference.

Public hospitals are quasi-state organs or public institutions, which are established and maintained by the government. Before the 2000s, it was true that most medical staff members were state functionaries, whose employment was directly managed by the government. However, in 2002, China initiated the reform of the employment of public-institution staff members. ${ }^{37}$ Since then, more and more public hospitals have begun to shift from the old administrative affiliation system (行政任用制), under which neither hospitals could fire doctors freely nor doctors could quit office easily, to a more open and free employment system (聘用制), under which hospitals are relatively free to hire and fire doctors and doctors are totally free to quit the job. ${ }^{38}$ Currently, some data show that the majority (more than 95\% in the Jiangsu

DR-Unregistered Interns 2004 (China), art. 3. See also Yang 2012, p. 20.

Doctors Law 1998 (China), arts. 13-14.

Li 2011.

See generally DR-Employment Contracts in Public Institutions 2002 (China).

Liu, Y. 2014, p. 44. 
and Zhejiang Provinces) of individual providers are employed by public hospitals rather than administratively affiliated. ${ }^{39}$

Under the employment contract, hospitals are permitted to conduct an annual assessment of the performance of each employed provider. ${ }^{40}$ Those providers who fail the assessment must take the necessary training or their positions will be changed accordingly. ${ }^{41}$ If they refuse to accept the change in positions, hospitals are entitled to terminate the employment contract unilaterally. ${ }^{42}$ In cases where employed providers cause medical accidents due to any breach of regulations or clinical protocols, hospitals may terminate the employment contract unilaterally at any time. ${ }^{43}$

\subsection{SUMMARY}

In China, health care is provided by various institutional and individual providers. City-based hospitals are the primary form of institutional providers. Urban areas and rural areas have different systems of medical institutions. Public hospitals and not-for-profit private hospitals serve a crucial role in the health care system, compared to for-profit private hospitals. Public hospitals are slightly subsidised by the government, while private hospitals operate without any subsidy. Not-for-profit hospitals are subject to governmental price regulations, whereas for-profit hospitals are free to charge market prices. Regarding the doctor-patient relationship and malpractice issues, there are no special rules or forums that are established for public or not-for-profit hospitals. Contract Law 1999 and Tort Law 2009 apply to all doctor-patient relationships and disputes over medical malpractice

Currently, in China, all individual providers are medical staff members in that they must register and practice at medical institutions (even a private clinic). The doctor-patient relationship is actually the hospital-patient relationship because it is the hospital and the patient that are parties to the medical service contract. Public hospitals now have the authority to hire and fire the majority of their employee-providers relatively freely.

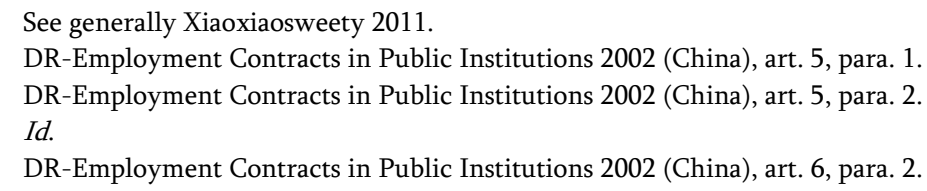




\section{FINANCING OF PUBLIC HEALTH CARE PROVISION}

\subsection{INTRODUCTION}

For more than six decades, China has been endeavouring constantly to establish, develop and maintain its health care system, despite periods of successes and failures. In general, the financing of China's health care system has undergone two eras, which are largely influenced by the economic structures before and after its economic reform initiated in 1978. During the Mao era (1949 to 1978), a closed, centralised and planned economy, which was copied from the former Soviet Union, was characteristic of China. ${ }^{44}$ Since the beginning of the post-Mao era (1978 onward), however, China has been on its way to an open, decentralised and market-driven economy. Correspondingly, China's health care system in the Mao era was largely based on socialisation (expenses mainly paid by the government, state enterprises, and rural communes), whereas more and more elements of privatisation (expenses mainly paid by individual patients out of their own pocket) are attached to the post-Mao era. ${ }^{45}$

In the next section, the health care reforms in China and financial impacts on individuals in Section 3.2 will be introduced. Then, attention will be given to the covered groups under the basic public health insurance systems and government subsidies in Section 3.3. After that, a summary will be made in Section 3.4 .

\subsection{HEALTH CARE REFORMS AND FINANCIAL BURDENS ON INDIVIDUALS}

In China, the total costs of health care (卫生总费用) are shared by the government, society, and individuals. ${ }^{46}$ The government provides subsidies to public hospitals, and to the Basic Medical Insurance Schemes (hereinafter BMIS) and the Urban-Rural Medical Assistance System (hereinafter URMAS), and covers administrative costs associated with health care provision. ${ }^{47}$ Society as a whole furnishes patients with health coverage through the BMIS,

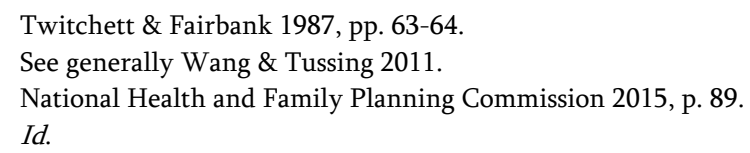


the URMA, and private health insurance. ${ }^{48}$ Besides, individuals (employees, unemployed urban residents, and rural residents) have to pay some out-ofpocket expenses in cash depending on the kind of medical services they receive. ${ }^{49}$

During the period 1949-1978 (Mao's era), China established and maintained a socialist welfare system. In urban areas, the GovernmentFunded Medical Care System (hereinafter GFMCS) and the Labour

Insurance System (hereinafter LIS) had been developed in the early 1950s. Only national public servants, employees of public institutions, and disabled veterans were eligible for cover under the GFMCS, ${ }^{50}$ and most medical expenses were financed almost entirely by the government..$^{51}$ All employees of the enterprise were covered under the LIS, ${ }^{52}$ and all LIS premiums were paid by the administration or capital of each enterprise..$^{53}$ In rural areas, people's communes adopted a Rural Cooperative Medical Care System (hereinafter RCMCS). By the end of 1976, about $90 \%$ of all communes in China implemented the RCMCS. ${ }^{54}$ Since the government set prices of medical services extremely low in order to show the superiority of socialism over capitalism, ${ }^{55}$ out-of-pocket expenses paid by patients in cash might be conceivably minimal.

Be that as it may, this socialist welfare system suffered from several problems. First, not all individuals enjoyed benefits under the LIS. ${ }^{56}$ Employees of many newly established collective enterprises in towns and self-employed workers were not covered by any insurance plan. ${ }^{57}$ Insurance benefits for rural residents under the RCMCS were very limited. Second, the heavy burden of financing the LIS reduced the enterprise's economic profits significantly, making the enterprise less productive. ${ }^{58}$ Third, it was inefficient to let each enterprise to manage its own insurance pool..$^{59}$ Enterprises are primarily intended for promoting production and operating businesses. ${ }^{60}$ Not every enterprise is good at administering an insurance scheme.

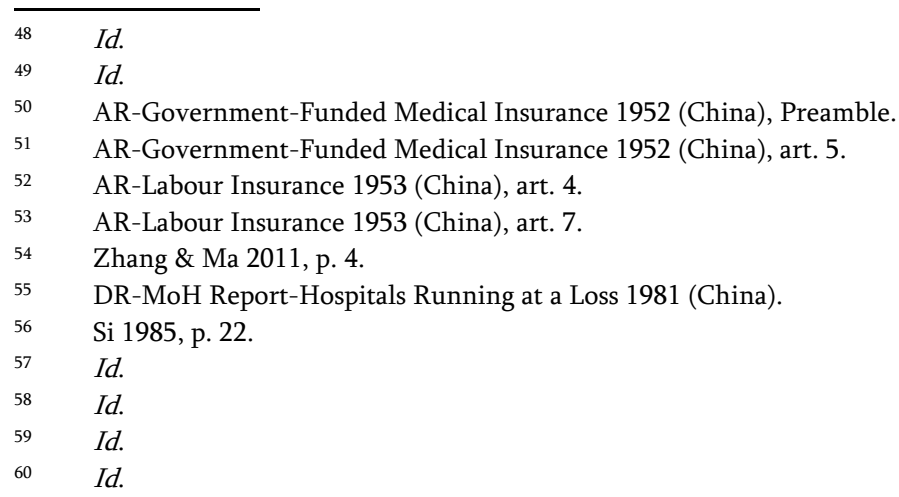


The current health care system in China was the outcome of three rounds of health reforms after 1978 when China decided to shift to a marketbased economy. Beginning in the early 1980s, the first round of health reform aimed at making hospitals rely more on their operating income rather than on public financial subsidies. ${ }^{61}$ More and more new forms of non-public enterprises began to emerge, while the old LIS was not prepared to provide cover for employees of these enterprises and self-employed workers. ${ }^{62}$ The dissolution of people's communes soon led to the collapse of the RCMCS, rendering rural residents uncovered by any insurance scheme. ${ }^{63}$ Consequently, medical care became unaffordable for many uninsured patients. ${ }^{64}$ Some of the uninsured patients who were able to pay would begin to live in extreme poverty after paying considerable expenses in cash. ${ }^{65}$

The second round, starting in 1998, was conducted to attach much more weight to social welfare than to economic benefits. ${ }^{66}$ The promulgation of the AR-BMI for Urban Employees 1998 was an important landmark in that it established the first nationwide public health insurance scheme- the Basic Medical Insurance for Employees (hereinafter BMIE) - in China, which is meant to replace the old LIS. Based on DR-Neo-Rural Cooperative 2003, the Neo-Rural Cooperative Medical Care (hereinafter NRCMC) began to develop in 2003, ending the history of a lack of health coverage for Chinese rural residents for about 20 years. Unemployed urban residents have also been covered under the Basic Medical Insurance for Urban Residents (hereinafter BMIUR) since 2007.

Although the BMIS was established during the second round of the health care reform, the affordability of health care had not been improved due to dramatically increasing health care costs. On the one hand, it is alleged that the costs of health care were increasing because hospitals overcharged customer-patients in various ways. First, many hospitals would induce patients to receive excessive or unnecessary examinations. ${ }^{67}$ Second, many hospitals would provide extra types of services that are not ex ante permitted by the authorities. ${ }^{68}$ Third, many hospitals would charge an additional fee for special equipment or material. ${ }^{69}$ Fourth, many hospitals would not strictly comply with regulations on prices and refuse to disclose the composition of

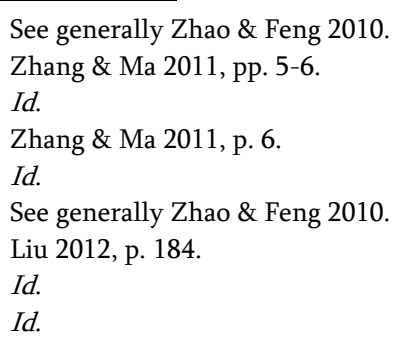


service prices to patients. ${ }^{70}$ As a result, the costs of health care rose from 367.87 billion yuan in 1998 to 1.45 trillion yuan in 2008, with an annual growth rate of $14.73 \% .^{71}$ On the other hand, the proportion of government subsidies to health care provision to total health care costs was relatively low. On average, during the period 1998-2008, only about $17 \%$ of all health care costs were paid by the government, and $30 \%$ by society, whereas almost $53 \%$ was paid by individuals. ${ }^{72}$ Hence, although the second round of the reform established the BMIS, individuals still faced heavy burdens of out-of-pocket expenses in that the government had not shared a greater portion of total health care costs.

The third round was initiated in 2009 , intending to reduce individual burdens for medical care. ${ }^{73}$ The "overall objectives" of the 2009 reform are to "establish and improve a basic medical and health care system covering both urban and rural residents, which provides safe, effective, convenient and affordable medical and healthcare services for the people" by the end of $2020 .^{74}$ The reform is still evolving. Therefore, it is too early to say whether the reform will achieve its goals at the end of the day. Recent data shows that the government began to increase its subsidies to public health care. For the period 2009-2014 on average, the government increased its share of total health care costs to about $25 \%$, and society's share rose to almost $36 \%{ }^{75}$ Hence, since the beginning of the third round of the reform, individuals seem to have shared roughly $40 \%$ of total health costs. ${ }^{76}$ Nevertheless, due to the dramatic increase in total health care costs, the reduction in individuals' share of the costs does not seem to suggest that individuals' financial burden is relieved. On average, whereas individuals had to pay 379.79 billion yuan in cash for the period 1998-2008, they had to pay more than one trillion yuan for the period 2009-2014. ${ }^{77}$

\subsection{CURRENTLY COVERED GROUPS AND GOVERNMENT SUBSIDIES}

In China, the BMIS are composed of three types of public health insurance the BMIE, the BMIUR, and the NRCMC. The BMIS are designed to provide

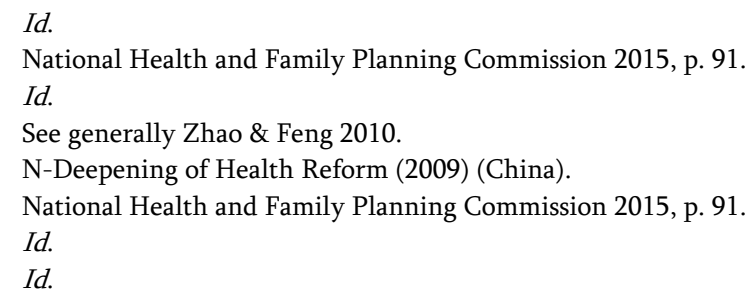


different groups of Chinese citizens, in the light of their professional status and location, with basic public health insurance coverage for medical expenses. The employed urban population and the self-employed are covered by the BMIE, ${ }^{78}$ the rural population by the $\mathrm{NRCMC},{ }^{79}$ and the unemployed urban population by the BMIUR. ${ }^{80}$ Whereas the BMIE is mandatory for employees, it is voluntary for the self-employed. ${ }^{81}$ Also, the BMIUR and the NRCMC are also voluntary. ${ }^{82}$ By the end of 2011, more than 1.3 billion Chinese citizens were covered by the BMIS, representing at least $95 \%$ of the whole population. ${ }^{83}$

As a rule, insured persons should finance the BMIS by their own contributions, especially when they are self-employed or freelance workers, and they have to pay the whole BMIE premium by themselves. ${ }^{84}$ In other cases, however, the premiums are shared by the employer or the government. First, if the insured is an employee, the BMIE premiums should be paid jointly by the employer (about $6 \%$ of the total amount of the employees' wages) and the employee ( $2 \%$ of his wages). ${ }^{85}$ Second, under the BMIUR, unemployed urban residents are heavily subsidised by the government. For instance, the required BMIUR premium for the year of 2016 is at least 570 yuan for each insured, of which 420 yuan $(73.68 \%$ ) are subsidised by the government. ${ }^{86}$ The relatively vulnerable group of unemployed urban residents - those who enjoy the minimum living safeguard, the disabled who have lost the ability to work, senior citizens aged 60 or more, and minors of lowincome families - are fully subsidised by the government. ${ }^{87}$ Third, rural residents are also partly subsidised by the villagers' committees and the government under the NRCMC. ${ }^{88}$ In 2014, the per capita cost of the NRCMC premium was 410 yuan, of which 90 yuan $(21.95 \%)$ were paid by the government. ${ }^{89}$

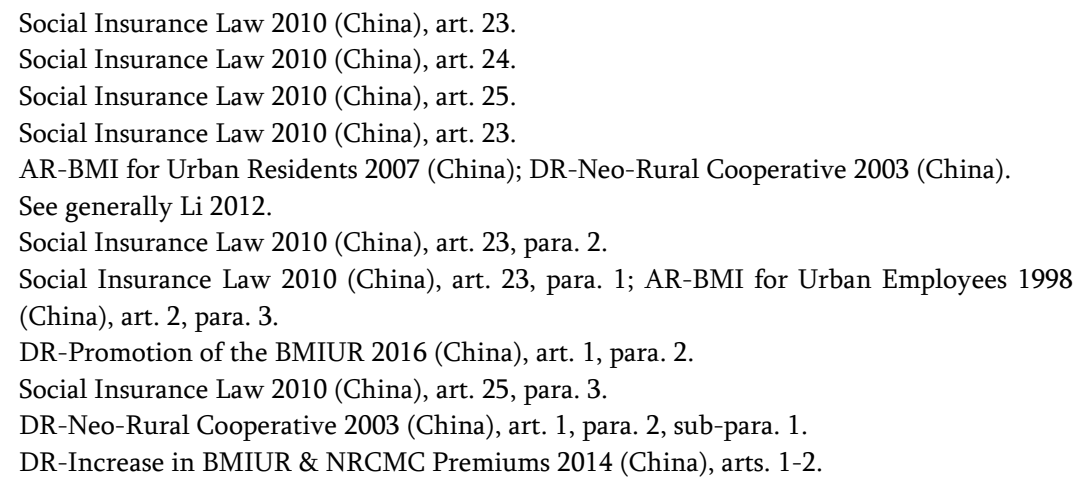


Health Care Provision and Regulation

\subsection{SUMMARY}

After three rounds of health care reforms since the Mao era, China's public health care provision has largely shifted from an enterprise-based labour insurance system to a society-based social insurance system, although the full impact of the reforms cannot yet be assessed. The new system covers the majority of both employed and unemployed, urban and rural residents. The Chinese government realised the limitations of the market-oriented health care reforms (the first two rounds) and has begun to increase government subsidies to public health care provision since the latest round of health care reform. Currently, about $40 \%$ of all health care costs are paid by individuals out of their own pocket. However, the rapidly growing health care costs imply that the financing burden on individuals has not been much relieved.

\section{REGULATION OF THE MEDICAL PROFESSION}

\subsection{INTRODUCTION}

In China, the power to direct and administer the affairs of public health is entrusted by the Constitution to the State Council (central government). .90 Specifically, it is now the National Health and Family Planning Commission (hereinafter the NHFPC) ${ }^{91}$ of the State Council that oversees public health affairs. Its duties include but are not limited to: drafting laws and regulations in relation to public health; planning the resource allocation of medical care, public health services; establishing a basic medicine system to standardise drug prices; and supervising and administering public health, medical care services. ${ }^{92}$

Correspondingly, there are local Health and Family Planning Commissions (hereinafter the HFPC) at the provincial, prefecture and county levels, which perform similar functions within their own jurisdictions. The NHFPC and each local HFPC, which can be described together as the public

\footnotetext{
90 Constitution 2004 (China), art. 89, para. 1, sub-para. 7. In China, the National People's Congress (hereinafter NPC) is the organ of supreme power, which is also the supreme legislative organ. The State Council is the executive organ of the NPC, which directs all levels of local governments.

91 The then Ministry of Health (hereinafter $\mathrm{MoH}$ ) and National Population and Family Planning Commission merged into the current National Health and Family Planning Commission in 2013.

$92 \quad$ National Health and Family Planning Commission 2014.
} 
health authorities, have the power to direct subordinate units or danwei, ${ }^{93}$ such as hospitals, health inspection and supervision organs, and medical associations.

In the following, the focus will be on how the medical profession is regulated in China as far as quality assurance is concerned. In general, the process of regulation is twofold - input controls and output controls. On the one hand, the government sets many prior criteria that should be met before any institutional or individual provider is allowed to operate or practice in the health care sector to guarantee a minimum level of competence (Section 4.2). On the other hand, the government continually supervises the behaviour of those providers who have been permitted to enter the medical profession intending to ensure the quality of care (Section 4.3). Then, in Section 4.4, the role of "self-regulation" in the Chinese health care system will be discussed. A summary will be given in Section 4.5.

\subsection{INPUT CONTROLS}

\subsubsection{Controls on the Entry of Institutional Providers}

To be qualified to operate, medical institutions must satisfy some statutory requirements. They must register with the public health authorities and apply to the same authorities for the Operating License for Medical Institutions (hereinafter OLMI). ${ }^{94}$ The basic criteria for establishing medical institutions must be enacted by the central public health authorities..$^{95}$ Accordingly, the then $\mathrm{MoH}$ promulgated the DR-Criteria for Medical Institutions 1994. Without a license, any institution or individual is not permitted to carry out diagnostic and therapeutic activities. ${ }^{96}$ Whoever contravenes this prohibition will be punished by the public health authorities above the county level. ${ }^{97}$ Those lawbreakers' activities may be restrained by injunction, and their illegal gains, pharmaceuticals, and equipment confiscated. ${ }^{98} \mathrm{~A}$ fine with a cap of 10,000 yuan may be imposed in the light of the seriousness of the violation. ${ }^{99}$ Moreover, individuals running a medical institution without the

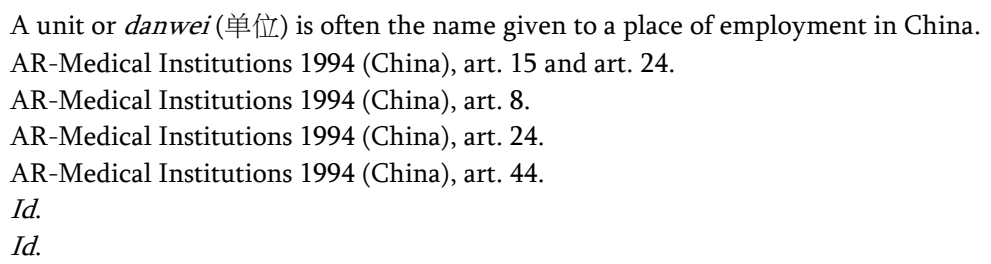


OLMI will be guilty of the Crime of Illegal Medical Practice (hereinafter CIMP), if the violation is serious. ${ }^{100}$

Empirical evidence on either administrative or criminal punishments imposed on institutional providers nationwide is currently unavailable. Nevertheless, some studies focusing on local jurisdictions show that a significant proportion of the hospitals that contravene codes of conduct are punished by the public health authorities because they practice without a license. A total of 1,309 (87.74\%) of all the 1,492 punishments were imposed on unlicensed hospitals in Haidian District (2010-2014).101 In Futian District (2010-2012), 25 (19.23\%) of all the 130 contraventions were practising without a license. ${ }^{102}$ Yudu County (2007-2009) punished 218 (21.90\%) cases of practising without a license in all the 917 cases. ${ }^{103}$

It is also reported that fines imposed on unlicensed hospitals are relatively modest. In Haidian District (2010-2014), the average of the fines imposed was 5,438 yuan. ${ }^{104}$ In Yudu County (2007-2009), the maximum of the fines imposed was 4,000 yuan, and the average was 1,477 yuan. Although this outcome is inconsistent with the cap of 10,000 yuan provided by the ARMedical Institutions 1994, article 44, after more than two decades the low level of fines is argued to be insufficient to deter law-breakers. ${ }^{105}$

The frequency of the charges of the CIMP is even rarer. After reviewing 100 randomly selected cases of illegal medical practice, Zhang and Zhang reported that for every 16 cases of administrative punishments, only nine would involve criminal charges. ${ }^{106}$

However, empirical data on the rate of identification of illegal practising without a license either by the public health authorities or by the public security authorities is unavailable.

The OLMI of medical institutions with less than 100 hospital beds must be verified (校验) once every year, and those with over 100 hospitals beds verified once every two years by the same public health authorities that grant the OLMI. ${ }^{107}$ If a medical institution refuses to be verified in the light of

\footnotetext{
$100 \quad$ Criminal Law 1997 (China), art. 336; JI-Criminal Filing Standards 2008 (China), art. 57, para. 2, sub-para. 2.

Kong et al. 2016.

Feng, Zhu \& Xie 2013, p. 37.

$\mathrm{Xu}$ et al. 2012, p. 213.

Kong et al. 2016, p. 43.

Kong et al. 2016, p. 44.

Zhang \& Zhang 2015, p. 48.

AR-Medical Institutions 1994 (China), art. 22.
} 
the preceding provision, its OLMI will be revoked. ${ }^{108}$ Currently, there is little evidence showing that many hospitals would be in violation of this rule.

\subsubsection{Controls on the Entry of Individual Providers}

To practise medicine, aspiring individual providers (doctors, nurses, pharmacists, etc.) should go through three phases successfully. First, they must obtain the required degrees or credentials after years of medical education and training. ${ }^{109}$ Second, they must pass the national exams for practising doctors, nurses, or pharmacists. ${ }^{110}$ If they pass the exam, they will receive the Certificate for Practising Doctors (hereinafter CPD), ${ }^{111}$ the Certificate for Practising Nurses (hereinafter CPN), ${ }^{112}$ or the Certificate for Practising Pharmacists (hereinafter CPP). ${ }^{113}$ Third, certified (assistant) doctors and nurses must apply to the public health authorities and certified pharmacists to the Drug Administration for a license to practise. ${ }^{114}$ If permitted, doctors will obtain the License to Practise as Doctors (hereinafter LPD), ${ }^{115}$ nurses the License to Practise as Nurses (hereinafter LPN), ${ }^{116}$ and pharmacists the License to Practise as Pharmacists (hereinafter LPP). ${ }^{117}$ Hence, in China, the government controls the entry of aspiring individual providers through education, certification, and licensing.

In 1993, China initiated the Regime of Standardised Training of Residents (hereinafter RSTR) in some local jurisdictions. Medical graduates who have just begun their job as residents will receive the training for a period of four to six years. ${ }^{118}$ The content of the training under the RSTR includes political ideology, professional ethics, clinical practice, theoretical knowledge and foreign language. ${ }^{119}$ After about two decades of local experiments, the central public health authorities decided to expand the

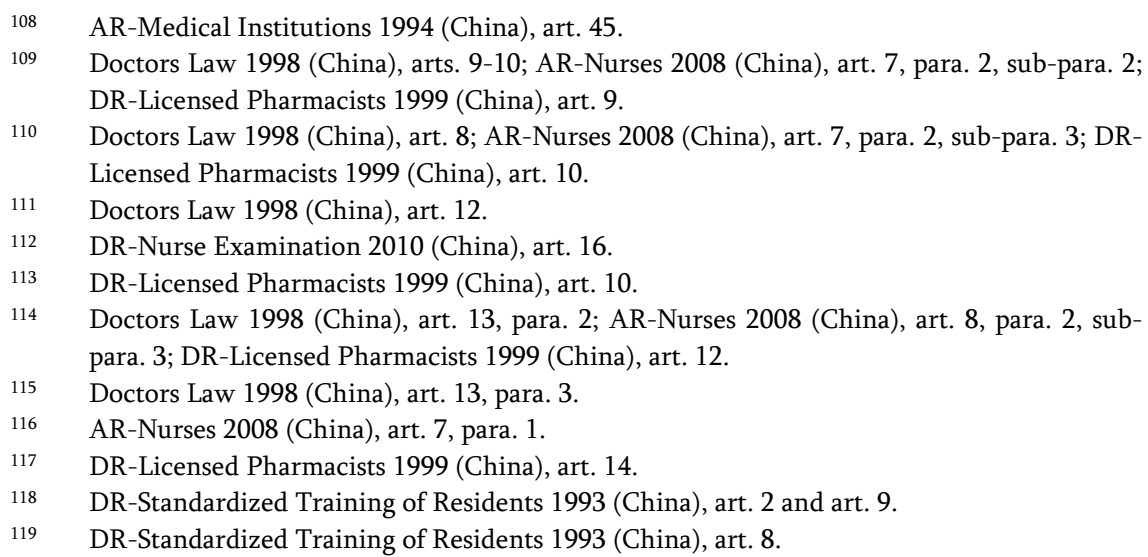


RSTR across the country. ${ }^{120}$ The current period of the training is reduced to three years, immediately after five years of medical school education. ${ }^{121}$ The content of training under the new RSTR focuses more on professional ethics, policies and regulations, the capability of clinical practice, theoretical knowledge, communication and inter-personal skills, etc. ${ }^{122}$ Some empirical evidence shows that the training is under-enforced in practice in that evaluations of residents after training primarily take the form of examinations which focus on theoretical knowledge. ${ }^{123}$ Residents may be induced to pay more attention to medical knowledge than to clinical techniques.

Without a license, individual providers are forbidden to practise medicine. ${ }^{124}$ Unlicensed doctors may face very severe sanctions. If unlicensed doctors are found to provide treatment services, their activities will be banned, their illegal gains, pharmaceuticals, and equipment will be confiscated, and they will be fined up to 100,000 yuan for the violation by the public health authorities. ${ }^{125}$ In addition to the foregoing administrative sanctions, those lawbreakers may also be subject to criminal penalties if the violation is so serious that it constitutes the CIMP. ${ }^{126}$ They can be sentenced to fixed-term imprisonment, criminal detention, or control, and/or a criminal fine in light of the seriousness of the consequence. ${ }^{127}$

In contrast, unlicensed nurses and pharmacists would face no or less severe sanctions. If unlicensed nurses are identified, it is their employerhospital rather than themselves that will be punished. The operation of the hospital involved will be suspended and hospital managers may be subject to administrative sanctions. ${ }^{128}$ If unqualified pharmacists are identified, they will be ordered to take intensified training within a fixed period. ${ }^{129}$ If they still fail the exam, they will be removed from their position. ${ }^{130}$

Since all the aforementioned individual providers may be prone to commit medical errors if they are significantly unfit for practice, it is unclear why the Chinese law treats them so differently as far as illegal practice is concerned.

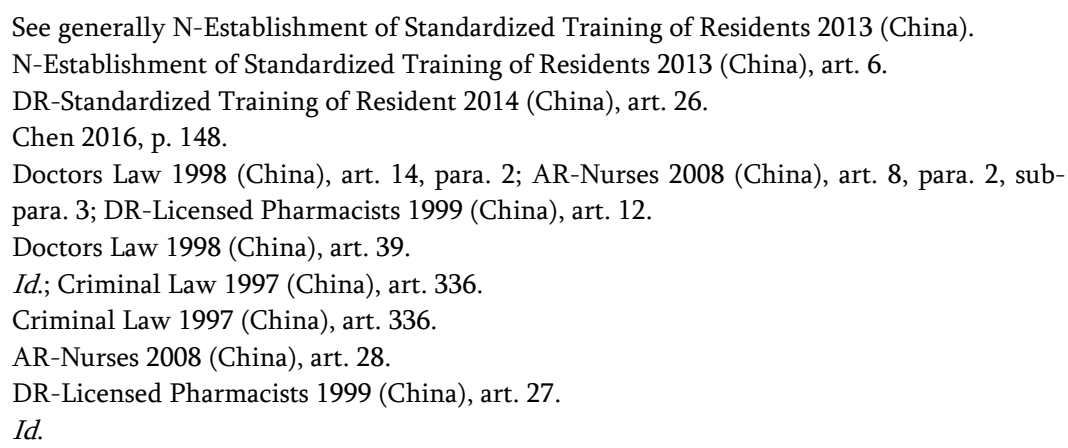


Empirical data on punishments imposed on individual providers for practising without a license are rare. Some evidence suggests that for every two punishments (either administrative or criminal) of institutional offenders, there would be three punishments of individual offenders. ${ }^{131}$ However, it is currently unknown how many individuals are practising medicine without a license and to what extent they will be identified.

Some anecdotal evidence implies that the black market where clinics and unqualified doctors practise without a license is remarkably persistent in China, especially in rural and suburban areas. ${ }^{132}$ The demand for black market health care in those areas is high because the majority of healthcare resources are invested in urban areas, leaving rural and suburban areas without a sufficient supply of health care services. ${ }^{133}$ Another reason is that government supervision may be ineffective. On the one hand, local public health supervision agencies have only limited manpower, funds for operation, and necessary instruments to obtain evidence. ${ }^{134}$ On the other hand, many illegally practising individuals are under the protection of local gangsters, and public health agents are sometimes reluctant to enforce law fully because they may be personally threatened by those gangsters. ${ }^{135}$ Hence, it seems that the problem is likely to persist until when more high-quality medical services are available in rural and suburban areas and government supervision and public security are enhanced at the same time.

\subsection{OUTPUT CONTROLS}

\subsubsection{Controls on the Performance of Institutional Providers}

\subsubsection{Codes of Conduct and Sanctions}

Hospitals must operate and practise in compliance with relevant laws, regulations, and medical-technical norms. ${ }^{136}$ The AR-Medical Institutions 1994 already provides several codes of conduct that hospitals must comply with. First, hospitals must disclose the OLMI, permitted specialties of practice, consultation hours, and fee scales to patients by displaying them in obvious places. ${ }^{137}$ Second, hospitals must provide treatment services within

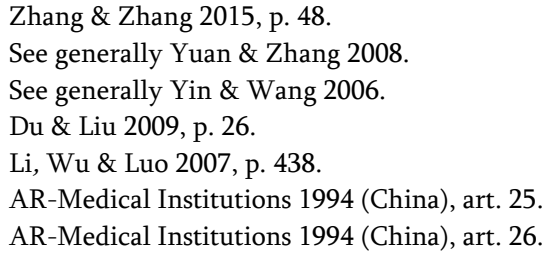


the permitted scope. ${ }^{138}$ Third, hospitals must not employ non-health workers to carry out medical-technical work. ${ }^{139}$ Fourth, hospitals must rescue critically ill patients without delay, or transfer those patients promptly if it is difficult to treat them due to limitations of equipment or technical conditions. ${ }^{140}$ Fifth, hospitals must obtain the patient's (or his/her family members' or stakeholder's) consent before conducting any surgery, special examination, or special treatment. ${ }^{141}$

Hospitals may be punished by the public health authorities if they contravene the foregoing codes of conduct. For example, if hospitals provide treatment services outside the permitted scope, they should be warned, ordered to rectify the wrongdoing, and fined not more than 3,000 yuan for that wrongdoing; if the contravention is severe, their OLMI will be revoked. ${ }^{142}$ If hospitals employ non-health workers to do medical-technical work, they will be ordered to rectify the wrongdoing within a fixed period, and fined not more than 5,000 yuan for that wrongdoing; if the contravention is severe, their OLMI will be revoked. ${ }^{143}$ However, the AR-Medical Institutions 1994 do not provide any sanction for non-compliance with the other codes of conduct. Hence, it is uncertain whether hospitals in practice would comply with those other norms concerned with informed consent and transfer.

In addition to the norms above, hospitals must abide by codes of conduct provided by other laws and regulations. According to the ARMedical Accidents 2002, hospitals (and also medical staff members) must practise as follows:

Medical institutions and the staff members thereof shall, in the medical treatment activities, rigidly follow the laws, regulations, ministerial rules concerning medical treatment and health and the standards and conventions of medical treatment and nursing, and scrupulously abide by the professional ethics of medical treatment. ${ }^{144}$

The preceding provision can be seen as an extension of the AR-Medical Institutions 1994 (China), article 25. The former broadly interprets "medicaltechnical norms" as "standards and conventions of medical treatment and nursing," which seems to have extended the scope of applicable professional

\footnotetext{
$138 \quad$ AR-Medical Institutions 1994 (China), art. 27.

139 AR-Medical Institutions 1994 (China), art. 28.

140 AR-Medical Institutions 1994 (China), art. 31.

141 AR-Medical Institutions 1994 (China), art. 33.

142 AR-Medical Institutions 1994 (China), art. 47.

143 AR-Medical Institutions 1994 (China), art. 48

144 AR-Medical Accidents 2002 (China), art. 5.
} 
norms. Conventions or customary practice can be regarded as professional standards even if they are not in a written form. If hospitals (or staff members thereof) contravene any of the foregoing norms negligently and cause personal injuries, i.e. when a medical accident occurs, ${ }^{145}$ hospitals will be warned by the public health authorities; where the contravention is serious, their activities will be suspended and they will be ordered to rectify the wrongdoing within a fixed period, or their OLMI will be revoked. ${ }^{146}$

The AR-Medical Accidents 2002 also provides several other written norms for hospitals. First, hospitals must provide staff members with educational and training programs to learn those codes of conduct and medical ethics. ${ }^{147}$ Second, hospitals must establish special departments to supervise the quality of medical care and handle complaints. ${ }^{148}$ Third, hospitals must record and properly keep case history materials and are prohibited to alter, fabricate, conceal, destroy, or steal case history materials. ${ }^{149}$ Fourth, hospitals must inform patients truthfully of the state of illness, measures of treatment, medical risks, etc. ${ }^{150}$ Fifth, hospitals must make preventive plans for avoiding and handling medical accidents so as to avoid the occurrence of medical accidents and mitigate the injuries caused by medical accidents. ${ }^{151}$ If hospitals are in breach of any of those norms, they will be ordered by the public health authorities to rectify the wrongdoing; if the breach is severe, the person-in-charge and other responsible persons will be given administrative punishments or disciplinary sanctions. ${ }^{152}$ Thus, in the light of the AR-Medical Accidents 2002, it is clear that failure to disclose relevant information to patients is punishable. However, the AR-Medical Accidents 2002 has not clarified whether failure to obtain the patient's consent, to rescue or make a timely referral is punishable.

Empirical data about the frequency of administrative punishments imposed on hospitals nationwide are rare. Nonetheless, there are several empirical studies of local jurisdictions. Some features of administrative punishments of hospitals are summarised and discussed as follows:

Most contraventions are identified by the public health authorities in the routine process of supervision and inspection and reported to the

\footnotetext{
145 AR-Medical Accidents 2002 (China), art. 2.

146 AR-Medical Accidents 2002 (China), art. 55, para. 1.

AR-Medical Accidents 2002 (China), art. 6.

AR-Medical Accidents 2002 (China), art. 7.

AR-Medical Accidents 2002 (China), arts. 8-9.

AR-Medical Accidents 2002 (China), art. 11.

AR-Medical Accidents 2002 (China), art. 12

AR-Medical Accidents 2002 (China), art. 56.
} 
authorities by patients. $52.80 \%$ of all violations in Shenzhen City (20102012) were recognised by the authorities and $39.2 \%$ were reported by patients. ${ }^{153} 63.14 \%$ of those cases were identified by the authorities in Anhui Province (2011-2012) and $17.77 \%$ were reported by patients. ${ }^{154}$ Reporting by hospitals is rare. ${ }^{155}$ However, this result does not necessarily mean that the public health authorities are incredibly effective at identifying wrong-doers. The rate of identification is currently unknown since no data on the total number of contraventions are available. What is more certain is that self-reporting is rather unreliable as a source of information.

- $\quad$ For-profit private clinics, private out-patient departments, village clinics are more likely to be punished than public hospitals. In urban areas, private clinics or out-patient departments were involved in 209 cases of all the 214 cases of administrative punishments in Longgang District (2005-2009), while no public hospitals were punished. ${ }^{156}$ Also, the ratio of the frequency of public hospitals punished $(n=4)$ to that of private hospitals punished $(\mathrm{n}=217)$ was about 1.84:100 in Shenzhen City (20102012 ), ${ }^{157}$ while the ratio of the number of public hospitals ( $\left.n=352\right)$ to that of private hospitals $(\mathrm{n}=1555)$ was about 23:100. ${ }^{158}$ In other words, private hospitals are roughly 12 times more likely to be punished than public hospitals. In rural areas, for example, of all the 699 hospitals punished in Yudu County (2007-2009), 472 were village clinics (51.50\%) and 213 were private clinics (23.20\%). ${ }^{159}$ This result implies that the quality of care provided by public hospitals may be considerably better than that provided by private clinics or village clinics, which is entirely understandable since more resources are invested in patient safety in not-for-profit public hospitals than in private for-profit clinics or small village clinics.

- Licensed Hospitals are most likely to be punished for practising outside the permitted scope and employing non-health workers to conduct medical-technical work while rarely for causing medical accidents. In Haidian District (2010-2014), a total of 115 punishments (51.34\%) were imposed for employing non-health workers, 70 (31.25\%) for practising outside the permitted scope, whereas only $3(1.34 \%)$ for medical

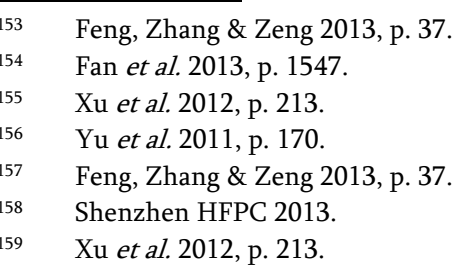


accidents. ${ }^{160}$ In Futian District (2010-2012), 28 (21.54\%) of all the 130 violations were involved with practising outside the permitted scope and $27(20.77 \%)$ were for employing non-health workers. ${ }^{161}$ Hospitals, mostly private ones, attempt to practise outside the permitted scope in order to gain more profits, and to employ unqualified non-health workers with a view to lowering labour costs. The temptation to obtain more profits by violating regulatory codes of conduct is highly likely to sacrifice the quality of care.

- Warnings and fines are frequently imposed while licensing sanctions are rarely used. In Haidian District (2010-2014), of all the 240 punishments imposed, $235(97.92 \%)$ were fines $(n=138)$ and warnings $(n=97)$ while only one was revocation of the license. ${ }^{162}$ In Anhui Province (20112012), 1,171 (90.78\%) of all the 1,290 punishments were fines $(\mathrm{n}=868)$ and warnings $(\mathrm{n}=303)$ whereas only 14 were revocation of the licence. ${ }^{163}$ In Longgang District (2005-2009), for all the 378 violations, a total of 188 warnings and 199 fines were imposed while only the licences of five hospitals were revoked. ${ }^{164}$

- Fines imposed on licensed hospitals who contravene codes of conduct are rather modest. In Haidian District (2010-2014), the average magnitude of fines was 2,489 yuan. ${ }^{165}$ In Yudu County (2007-2009), the average was 1,477 yuan. Of course, these results are consistent with the caps of 3,000 or 5,000 yuan mentioned above. However, those caps set in 1994 appear considerably low after more than two decades.

As far as the quality of care is concerned, the preceding evidence seems to support the following implications. First, routine supervision and inspection by the public authorities and reliance on patient reporting may be more effective ways of identifying wrong-doers than hospital self-reporting. Second, patients are likely to receive a better quality of care in not-for-profit public hospitals than in for-profit or small-scale clinics. Hence, the quality of care may be affected by the resources available and hospitals' financial incentives. Third, the public health authorities are very cautious about imposing licensing sanctions. Fourth, the caps of fines appear rather obsolete more than twenty years later. However, to what extent they should be increased needs to be answered very carefully. More research should be done

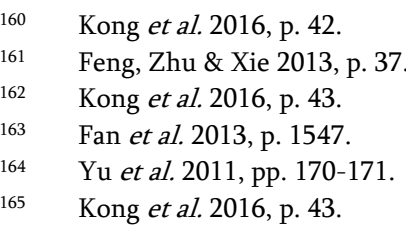


in order to find out the rate of identification of wrong-doers, the illegal gains of violations, administrative costs, etc.

\subsubsection{Hospital Accreditation}

In addition to the norm-sanction approach of output control, the practising activities and the quality of medical care services of licensed hospitals must be comprehensively appraised by external accreditation committees composed of experts. ${ }^{166}$ The objective of the accreditation is to administer medical institutions in line with their rankings, which are based extensively on their functions, tasks, facilities and equipment, advances in medical technology, quality of medical service and the scientific awareness of the management. ${ }^{167}$ It is currently considered as an effective way to promote improvement in medical quality and conduct vocational quality monitoring in China. ${ }^{168}$

The accreditation produces the rankings of hospitals. The ranking system of Chinese hospitals is composed of "Three Levels and Ten Grades" (三级十等). On the one hand, hospitals can be classified into three levels in the light of their functions and tasks as shown in Table 2.1.

\section{Table 2.1: Three Levels of Hospitals in China ${ }^{169}$}

\begin{tabular}{|l|l|}
\hline $\begin{array}{l}\text { Level One/Primary } \\
\text { Hospitals (一级医院) }\end{array}$ & $\begin{array}{l}\text { hospitals and health care centres at a grass-root level } \\
\text { which directly provide prevention, treatment, health care } \\
\text { and rehabilitation services to a community with a certain } \\
\text { population }\end{array}$ \\
\hline $\begin{array}{l}\text { Level Two/Secondary } \\
\text { Hospitals (二级医院) }\end{array}$ & $\begin{array}{l}\text { regional hospitals which provide comprehensive medical } \\
\text { and health care services to several communities and } \\
\text { undertake certain tasks of teaching and scientific research }\end{array}$ \\
\hline $\begin{array}{l}\text { Level Three/Tertiary } \\
\text { Hospitals (三级医院) }\end{array}$ & $\begin{array}{l}\text { hospitals above the regional level which provide a high } \\
\text { level of specialised medical and health care services to } \\
\text { several regions and assume the tasks of higher education } \\
\text { and scientific research }\end{array}$ \\
\hline
\end{tabular}

On the other hand, hospitals at each level can be sub-classified into three grades, scaling down from the most qualified Grade A (甲等), to modest qualified Grade B (乙等), then to the least qualified Grade C (丙等), according to their accreditation scores based on their levels of technology, quality and

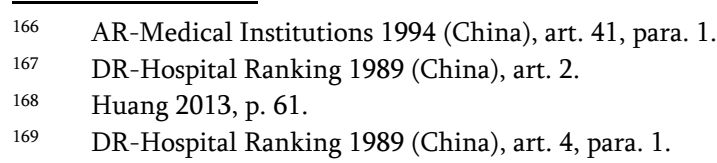


management. ${ }^{170}$ In addition, an exceptional “Top Grade” (特等) can be granted to an extremely well-qualified hospital. ${ }^{171}$

There are three levels of accreditation committees: ministry level, provincial level and prefecture level. ${ }^{172}$ All accreditation committees are organised by the public authorities at the same level. ${ }^{173}$ All primary hospitals will be accredited by prefecture-level committees, while all secondary and most tertiary hospitals by provincial-level committees. ${ }^{174}$ Only the Top Grade can be granted by the ministry-level committee to some tertiary hospitals. ${ }^{175}$

Hospital accreditation began to develop in China at the end of the 1980s. From then on, China witnessed a surge in the first round of accreditation from 1989 to 1998. It is reported that as many as 17,708 had been accredited, of which 558 were tertiary hospitals, 3,100 were secondary hospitals and 14,050 were primary hospitals, together representing $26.4 \%$ of all Chinese hospitals up to the end of 1998. ${ }^{176}$ The incentives behind this surge might be explained by at least two reasons. First, from the perspective of patients, higher rankings mean better quality of care. Thus, hospitals of higher level and grade may attract more patients. Second, medical charges are linked to the rankings of hospitals. ${ }^{177}$ The higher the rankings, the more hospitals can charge and the more profits they can earn. For instance, tertiary hospitals may charge medical expenses twice as much as that of secondary hospitals. ${ }^{178}$

Due to hospital accreditation, the quality of care and the management levels of Chinese hospitals were greatly improved compared to previous years. However, the incentives behind the surge were so strong that many "undesirable side effects" occurred in the first round of accreditation. First, many hospitals paid great attention to the development of hardware, such as adding hospital beds and constructing more buildings and purchasing heavy medical equipment, instead of quality of care and patient safety. ${ }^{179}$ Second, many hospitals had made concentrated efforts to maintain good quality of care and management before accreditation, while such efforts did not continue after the accreditation due to a lack of continuous external

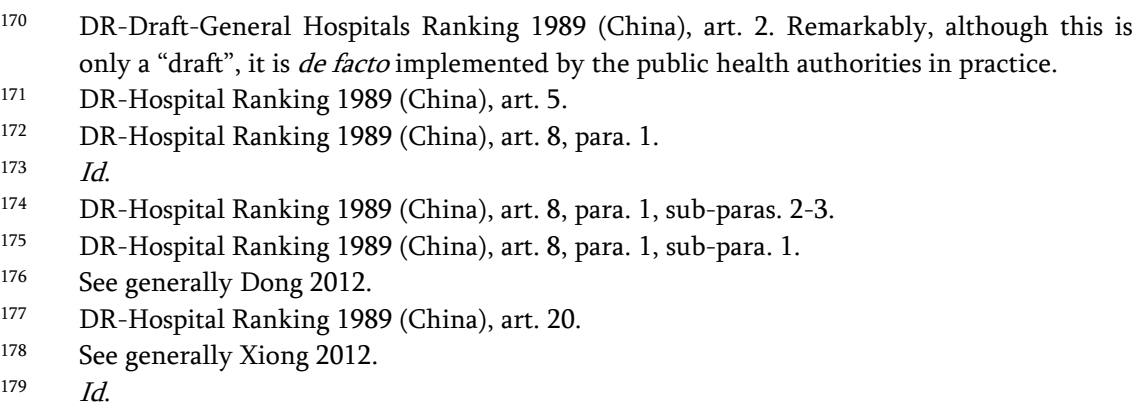


supervision. ${ }^{180}$ Third, many hospitals made their endeavours to engage in fraudulent behaviour, such as modifying medical history data or setting up a fake emergency room, in order to obtain high scores in accreditation. ${ }^{181}$ Fourth, some hospitals even paid bribes to accreditation committee members. ${ }^{182}$

Painfully aware of these "side effects", hospital accreditation had been suspended by the then $\mathrm{MoH}$ since $1998 .{ }^{183}$ Higher rankings mean higher benefits, which is a huge temptation. Therefore, many provinces continued to conduct hospital accreditation on their own even after 1998, showing their discontent with the MoH's 1998 decision. ${ }^{184}$

On consideration, the then $\mathrm{MoH}$ decided to restart hospital accreditation in 2011 and issued two new rules concerning accreditation DR-Hospital Accreditation 2011 and DR- Accreditation Expert Database 2011. The new criteria for accreditation attach considerable weight to the quality of care, patient safety, service, management, and performance, embodying the idea that patients' welfare should be the prime consideration. ${ }^{185}$ There are periodical (every four years) and non-periodical accreditations, which are designed to ensure continual supervision. ${ }^{186}$ More non-governmental organisations and individuals, such as medical associations, medical insurance agencies and representatives of the masses, are allowed to participate in the accreditation process, ${ }^{187}$ aiming to guarantee a scientific, impartial and fair hospital accreditation. ${ }^{188}$ The results of the new round of accreditation only include "Grade A," "Grade B," and "Being Unqualified” (不合格), eliminating Grade C. ${ }^{189}$ If a hospital is accredited as "Being Unqualified", the legal representative or the person chiefly in charge of the hospital should be subject to administrative or disciplinary sanctions rendered by the public health authorities. ${ }^{190}$

Hospital accreditation was suspended twice after 2011. In 2012, the then $\mathrm{MoH}$ suspended the process because a significant number of unqualified

\footnotetext{
$180 \quad$ See generally Dong 2012.

181 See generally Chai \& Jia 2013.

182 See generally Dong 2012.

183 See generally DR-Hospital Accreditation 1998 (China).

184 Most provinces defied the 1998 suspension order. It is remarkable that an official from the Department of Health of Sichuan Province even yelled "why suspend" at officials from the Ministry of Health at the conference table. Xiong 2012.

185 DR-Hospital Accreditation 2011 (China), art. 4.

186 DR-Hospital Accreditation 2011 (China), art. 6 and art. 15.

187 DR-Hospital Accreditation 2011 (China), art. 12.

188 DR-Accreditation Expert Database 2011 (China), art. 1.

189 DR-Hospital Accreditation 2011 (China), art. 34.

190 DR-Hospital Accreditation 2011 (China), art. 50.
} 
hospitals strived to obtain Grade A by fraud and revoked the Grade A qualification of 240 newly accredited hospitals. ${ }^{191}$ After 2012, the then $\mathrm{MoH}$ promulgated new standards for accreditation and began to review the qualification of hospitals that obtained Grade A in the 1990s. ${ }^{192}$ In 2014, it was reported that hospital accreditation was suspended again because some large hospitals objected to the new accreditation standards. ${ }^{193}$ Currently, it is unclear whether new rounds of hospital accreditation will be launched in the future.

Interestingly, many hospitals that are dissatisfied with the Chinese hospital accreditation system attempted to get accredited by international institutions. For instance, by the end of October, 2015, a total of 38 Chinese hospitals had passed the accreditation conducted by the Joint Commission International (JCI). ${ }^{194}$ It remains to be seen how this trend will develop and what implications there will be.

\subsubsection{Controls on the Performance of Individual Providers}

\subsubsection{Codes of Conduct and Sanctions}

Generally, individual providers (doctors, nurses, and pharmacists) must comply with regulatory standards provided by laws and regulations and professional codes of conduct. ${ }^{195}$ Some commonly seen obligations that individual providers should fulfil are summarised as follows:

- $\quad$ Doctors and pharmacists shall abide by professional ethics; ${ }^{196}$

- $\quad$ Doctors and nurses shall protect the patients' privacy; ${ }^{197}$

- Doctors and pharmacists shall strive to gain professional proficiency, update their knowledge, and raise the level of professional techniques; ${ }^{198}$

- $\quad$ Pharmacists shall take continued medical education regularly; $; 99$

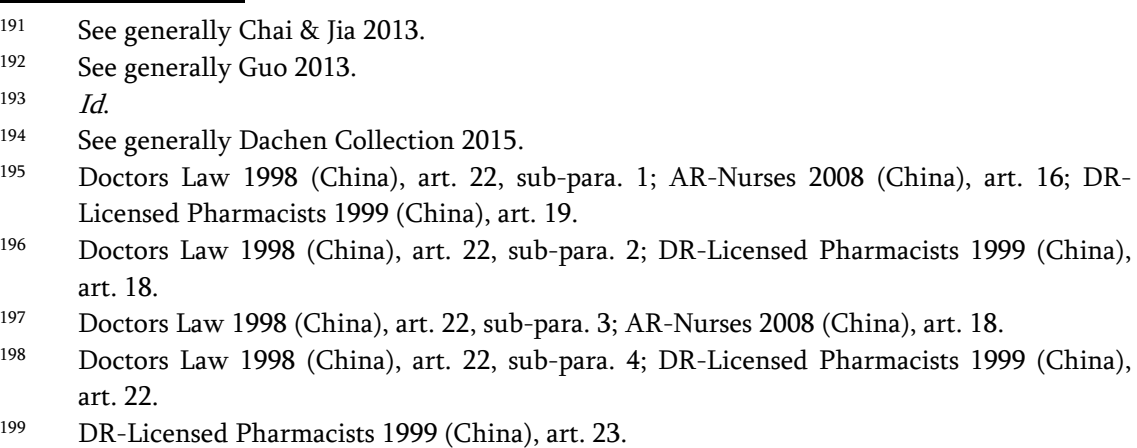


- Doctors shall not hide, forge, or destroy any medical documents and relevant materials;200

- In case of an emergency, doctors shall adopt emergency treatment measures and shall not refuse to give emergency treatment; ${ }^{201}$ if a nurse finds it first, he/she shall immediately inform the doctor and take some necessary rescue measures at once; 202

- Doctors shall use medicines, sterilising drugs, and medical equipment approved for use by the government; ${ }^{203}$

- Doctors shall disclose information truthfully and obtain consent before clinical experiments are conducted;

- Doctors shall not solicit or accept bribes from patients;204

- When a nurse finds that a doctor's order is in violation of regulations or codes of conduct, he/she shall timely inform the doctor, and report it hospital managers if necessary.

If individual providers contravene the preceding standards or codes of conduct, they will be subject to sanctions. Doctors or nurses will be warned or their licenses will be suspended by the public health authorities for at least six months but not more than one year; if the contravention is severe, their licenses will be revoked. ${ }^{205}$ Pharmacists will be sanctioned by the drug administration according to the seriousness of the consequences. ${ }^{206}$

Where tangible personal injuries are caused by negligence on the part of any medical staff member, by definition, a "medical accident" occurs. ${ }^{207}$ The negligent individual providers concerned will be subject to administrative or disciplinary sanctions (e.g. warnings), and their licenses will be suspended for a term of not less than six months but not more than a year; if the contravention is serious, their licenses will be revoked. ${ }^{208}$

Empirical evidence on the total number of medical accidents and all kinds of administrative punishments imposed nationwide is rare. One study on health care punishments in Shanghai (2003-2006) suggests that negligent providers who are responsible for medical accidents are considerably underpunished. ${ }^{209}$ For all the 565 suspected providers who were reported to the

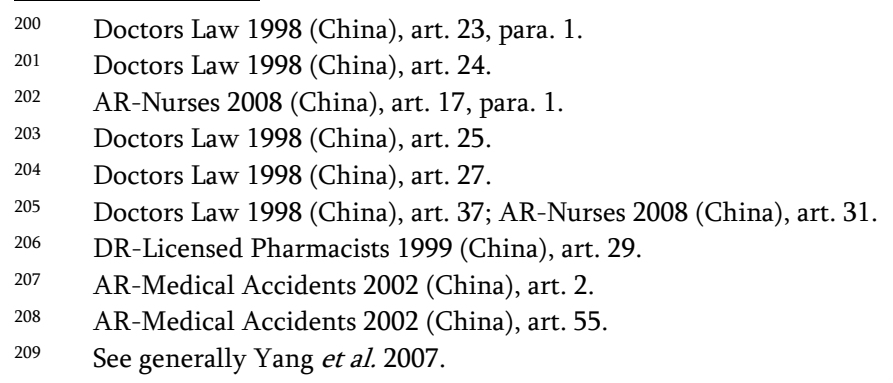


public health authorities, only 51 (9.03\%) were punished: 26 warnings, 24 license suspensions, and only one license revocation. ${ }^{210}$ A total of 514 (90.97\%) were not punished, of which 397 (77.23\%) were exempt from all charges because either the consequence of the medical accident was not serious or the hospital had already imposed disciplinary sanctions on the suspected provider. ${ }^{211}$ Remarkably, 106 (20.62\%) of the 514 non-punished providers were exempted from liability due to exceeding the statutes of limitations. ${ }^{212}$ Where an illegal act is not discovered within two years of its commission, administrative penalty will no longer be imposed. ${ }^{213}$ Whether a provider's behaviour is illegal (i.e. constituting a medical accident) will be determined by clinical expert witnesses first through the so-called process of Medical Accident Technical Ascertainment (hereinafter MATA). ${ }^{214}$ In practice, however, the MATA procedure is time-consuming, often exceeding two years, which explains why many providers who were responsible for medical accidents escaped punishments. ${ }^{215}$

Not only administrative punishments but criminal penalties may be imposed as well. If those licensed providers ${ }^{216}$ who caused medical accidents were "seriously irresponsible" (严重不负责任), and caused death or serious harm to the patients, they will be sentenced to not more than three years of fixed-term imprisonment or criminal detention on the charge of the Crime of Medical Accidents (hereinafter CMA). ${ }^{217}$ However, there is a lack of consensus on how to define being "seriously irresponsible." Some scholars explained that providers were seriously irresponsible when they contravened laws, regulations, and codes and conventions of diagnosis and treatment negligently. ${ }^{218}$ This interpretation is consistent with the definition of medical accidents provided in AR-Medical Accidents 2002, article 2. However, this opinion cannot explain why Criminal Law 1997, article 335 employs the wording "seriously irresponsible" whereas AR-Medical Accidents 2002, article 2 only mentions "negligence." Another interpretation from the

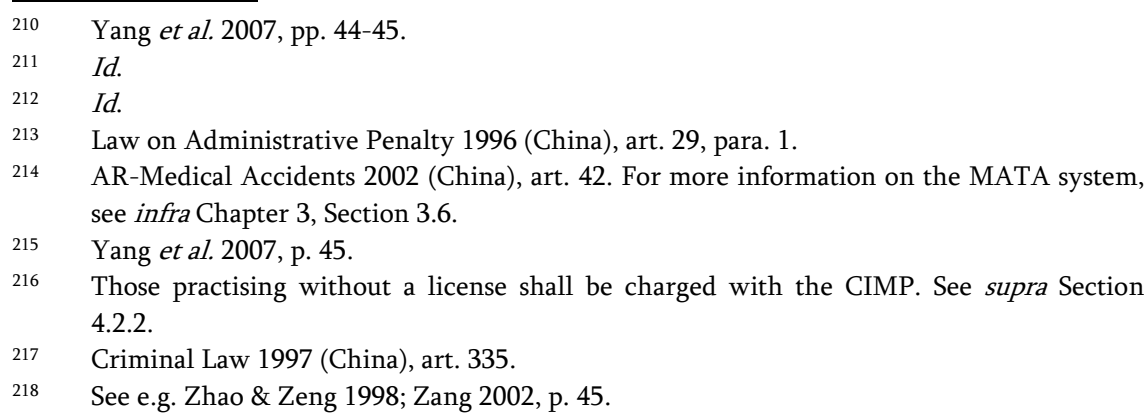


Supreme People's Procuratorate (hereinafter SPP) suggests that providers are seriously irresponsible if they conduct any of the following actions: ${ }^{219}$

(1) leaving his/her post without permission;

(2) refusing to provide necessary medical treatment for any patient in a critical condition without any justifiable reason;

(3) conducting experimental medical treatment without approval;

(4) seriously violating the checking or re-checking system;

(5) using any unapproved medicine, medical disinfectant or medical instrument;

(6) seriously violating any law or regulation of the state or any expressly prescribed codes or conventions of diagnosis and treatment; or

(7) any other case of being seriously irresponsible.

The SPP enumerates several commonly recognised cases of seriously irresponsible behaviour and emphasises the seriousness of the offence. However, the SPP does not provide a definition of "serious irresponsibility" directly neither.

In contrast, some scholars unambiguously maintain that serious irresponsibility is not merely ordinary negligence but gross negligence. ${ }^{220}$ In other words, a provider would be seriously irresponsible (grossly negligent) if an ordinary person (not a medical expert) could have reasonably foreseen the adverse consequence of the accident and could have reasonably avoided the accident. ${ }^{221}$ However, other scholars argued against the preceding interpretation because it would unduly restrict the scope of criminal liability for medical malpractice ${ }^{222}$ In their opinion, all violations of laws, regulations, and codes of medical conduct per se are serious. ${ }^{223}$ Hence, serious irresponsibility could simply be equated with negligence. ${ }^{224}$

Interestingly, some pointed out the fact that imposing a special CMA on providers is intended to protect licensed providers in that its penalties are relatively lenient in contrast to that of similar crimes.225 Five reasons can

219 JI-Criminal Filing Standards 2008 (China), art. 56, para. 1.

$220 \quad$ See e.g. Zhou 2005, p. 39; Tan 2007, pp. 123-125.

221 Tan 2007, p. 124.

222 Li \& Song 2012, p. 16.

223 Id.

$224 \quad I d$.

225 Zhao \& Zeng 1998, pp. 31-32. For example, an unlicensed provider guilty of the CIMP who caused serious injury (or death) to patients will be sentenced to not less than three years and not more than ten years (or more than ten years) of fixed-term imprisonment, and a fine, while a licensed provider guilty of the CMA would only be sentenced to not more than three years of fixed-term imprisonment without a fine. An ordinary individual 
explain this leniency. First, the major risk faced by patients is their underlying conditions rather than medical interventions. ${ }^{226}$ Second, medical services are humanitarian activities that should be distinguished from illegal activities. ${ }^{227}$ Third, each patient is unique, and each condition changes rapidly, which makes therapeutic effects highly uncertain. ${ }^{228}$ Fourth, medicine is advancing, and codes of medical-technical work are being updated continually. ${ }^{229}$ Fifth, therapeutic risks are often so high that a successful result cannot be guaranteed. ${ }^{230}$ However, if medical services are so unique that providers deserve leniency, one may wonder why fines are not used instead of imprisonment or criminal penalties on providers are eliminated given the fact that licensing sanctions are already available.

Individual providers are rarely charged with the CMA. Data from 6 district courts in Beijing City (2013-2014) show that about 665 medical malpractice civil cases were concluded, whereas no providers were charged with the CMA. ${ }^{231}$ The first charge with the CMA in Beijing was pursued at the end of 2014, and so far, has not been finished yet. ${ }^{232}$ Nationwide, the two largest commercial legal databases show that criminal charges with the CMA are few and far between. By June 26, 2016, the Chinalawinfo (CaseShare) Database ${ }^{233}$ had collected 2,532 CIMP cases, 3,332 CNM cases, but only 16 CMA cases. Similarly, the Lawyee Case Databases ${ }^{234}$ had gathered 4,082 CIMP cases, 5,842 CNM cases, but only 46 CMA cases. Recently, Zhang and Dai reviewed 16 CMA cases concluded between 1997 and 2014 and found that

guilty of the Crime of Negligent Manslaughter (hereinafter CNM) would be sentenced to more than three years and not more than seven years of fixed-term imprisonment, see Criminal Law 1997 (China), art. 233.

$226 \quad I d$.

227 Id.

228 Id.

$229 \quad I d$.

$230 \quad I d$.

$231 \quad$ See generally Zhang \& Dai 2016.

232 Without the guide of his chief physician, an uncertified intern failed to rescue a patient when the chief physician was somewhere else. The chief physician charged with the CMA denied in the court that he was seriously irresponsible. He argued that he had properly guided the intern by telephone while he was treating another urgent patient elsewhere. See e.g. Hong \& Wang 2014. Voices from the Chinese Medical Doctor Association generally support the defendant's argument - personally treating a more urgent patient while sending an intern to treat a less urgent patient is not irresponsible but responsible for all patients. Deng 2014.

233 The Chinalawinfo (CaseShare) Database (北大法宝大数据分享平台) is available at: $<\mathrm{http}: / /$ caseshare.cn/> (accessed on 26 June 2016).

234 The Lawyee Case Databases (北大法意中国裁判文书库) is available at: $<$ www.lawyee.org/Act/Act.asp > (accessed on 26 June 2016). 
most judges avoided interpreting what is "serious irresponsibility." 235 Nevertheless, the majority of the contraventions of standards and codes of medical conduct indicate that the defendant was grossly negligent. For instance, in almost half of the 16 cases the defendants forgot to conduct skin test before injecting or were absent during the intravenous injection. ${ }^{236}$

Hence, although the Criminal Law 1997, article 335 provides an unclear notion of "serious irresponsibility" which may blur the demarcation between civil liability for medical malpractice and the CMA, courts in practice are fairly cautious about imposing criminal penalties on providers.

\subsubsection{Periodical Doctor Assessment}

After obtaining the LPD, physicians are allowed to practice medicine in hospitals. However, they may lose their jobs if they fail to maintain or improve their professional expertise. All physicians should pass the Periodical Doctor Assessment (hereinafter PDA) to continue the practice. Institutions or organisations entrusted by the public health authorities must conduct regular assessment of the professional expertise, performance, and ethics of doctors according to professional standards ${ }^{237}$ every two years. ${ }^{238}$

The result of the PDA is divided into the qualified (合格) and the disqualified (不合格). ${ }^{239}$ A licensed doctor, who is primarily responsible for the occurrence of a medical accident, who practices outside the permitted hospital or beyond the registered category of services, who is found to be in breach of good professional ethics, or who has been given an administrative punishment, should be assessed as disqualified. ${ }^{240}$

Once a licensed doctor is evaluated as disqualified, he/she will face unfavourable licensing sanctions by the public health authorities. The doctor's license will be suspended for three to six months, and he/she will be obliged to receive training and CME. ${ }^{411}$ When the suspension expires, the doctor should be assessed again by the assessment agency. ${ }^{242}$ If he/she passes the assessment, he/she may continue medical practice; if he/she fails again, his/her license will be revoked. ${ }^{243}$

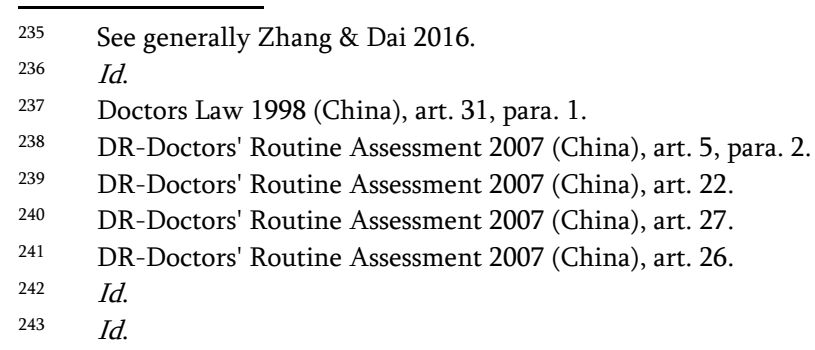


Some studies show that the PDA may promote the quality of care. First, some hospitals introduce the latest clinical guidelines and codes of conduct into training and CME. ${ }^{24}$ Second, some hospitals link the result of the assessment to rewards and punishments. ${ }^{245}$ Hence, physicians are induced to take the assessment seriously and invest in improving their expertise by updating their medical knowledge and skills continually..$^{246}$

However, other studies suggest that the current PDA system has its limitations. First, the primary form of the PDA in practice is a written examination which is mostly likely to test only the expertise of physicians. ${ }^{247}$ Most of the questions needing to be answered are associated with basic theories, basic knowledge, basic techniques, and some knowledge of health and medical law. ${ }^{248}$ Professional performance and ethics are rarely assessed. ${ }^{249}$ Second, in the case where a disqualified physician is identified, many hospitals are unwilling to invest too much in CME due to limited funding, and may temporarily change the disqualified doctor's position. ${ }^{250}$ Third, perhaps the most serious problem is that many large hospitals assess their own staff members. Agencies that are entrusted by the public health authorities to conduct the PDA are normally large-scale hospitals or associations that satisfy one of the following conditions: (1) having more than 100 beds; (2) having more than 50 doctors; or (3) academic organisations with complete structures. ${ }^{251}$ Thus, many large-scale hospitals would conduct "selfassessment" without external oversight. ${ }^{252}$ These hospitals might unduly lower the difficulty of the examination in order to make it easier for their staff members to pass the PDA. ${ }^{253}$ For instance, in XX hospital for the period 20112012, of all the 426 physicians who had taken the PDA, only one failed the assessment. ${ }^{254}$ After taking the resit exam, the disqualified easily passed the PDA. ${ }^{255}$

Weighing up the foregoing pros and cons, it is unlikely that the current PDA regime in China is very effective at enhancing physicians' professional expertise, performance, and ethics.

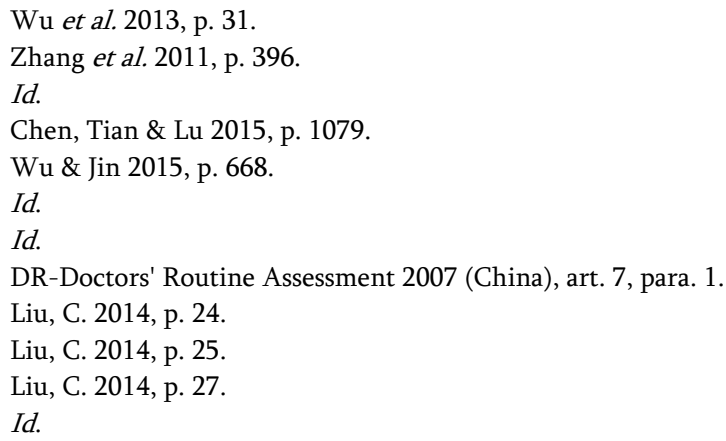




\subsubsection{Medical Quality and Safety Incident Management}

\subsubsection{Incident Reporting}

According to AR-Medical Accidents 2002, article 14, when any medical accident occurs, the medical institutions must report to the local administrative department of health. This obligation to report incidents is detailed by the DR-Incident Reporting 2011 in order to better implement the reporting system and enhance the quality of care continually. ${ }^{256}$

Under this reporting system, all Medical Quality-Safety Incidents (hereinafter MQSI) must be reported to the public health authorities. An MQSI denotes an incident with tangible personal damage such as death, disability or organ/tissue dysfunction that was attributable to medical fault on the part of a medical institution or its staff members, or any defect in pharmaceuticals or equipment. ${ }^{257}$ Specifically, MQSIs are classified into three grades in the light of the severity of the personal injury and the number of victimised patients. ${ }^{258}$ Different grades require a different time limit for incident reporting. ${ }^{259}$ The criteria for classification and respective time limit for reporting are presented in Table 2.2.

Table 2.2: Three Grades of Medical Quality-Safety Incidents

\begin{tabular}{llll}
\hline & Severity of Personal Injury & $\begin{array}{l}\text { Patient } \\
\text { Number }\end{array}$ & $\begin{array}{l}\text { Time } \\
\text { Limit }\end{array}$ \\
\hline Ordinary MQSIs & $\begin{array}{l}\text { mitigated disability, general organ/tissue } \\
\text { dysfunction or other personal injuries } \\
\text { death, mid-level disability, or serious } \\
\text { organ/tissue dysfunction } \\
\text { disability below mid-level, organ/tissue } \\
\text { dysfunction or other personal injuries }\end{array}$ & $\leq 3$ & 15 days \\
Gross MQSIs & death or serious disability & $\geq 3$ & 2 hours \\
$\begin{array}{l}\text { Especially Gross } \\
\text { MQSIs }\end{array}$ & & & 12 hours \\
\hline
\end{tabular}

The MQSI will be reported through the network and a unified national information system is established for the reporting. ${ }^{260}$ The performance of the incident reporting will be set as important criteria for hospital accreditation

\footnotetext{
256 DR-Incident Reporting 2011 (China), art. 1.

257 DR-Incident Reporting 2011 (China), art. 2

258 DR-Incident Reporting 2011 (China), art. 6.

259 DR-Incident Reporting 2011 (China), art. 8.

260 DR-Incident Reporting 2011 (China), art. 5.
} 
and evaluation. ${ }^{261}$ Any medical institution that fulfils the reporting obligation well and enhances the quality of medical care significantly may be praised and rewarded by the public health authorities. ${ }^{262}$ However, where any medical institution hides the truth in making reports or fails to handle the MQSI properly, resulting in severe consequences, the individual directly responsible for the violation will be "disciplined in conformity with legal provisions" (依法处理) and the results must be announced by the public health authorities. ${ }^{263}$

Nationwide data on the MQSI reporting is currently unavailable. One study reviewed 2,589 reported MQSIs in Jiangsu Province (2011-2014).264 The distribution of the reported MQSIs among the 13 municipal jurisdictions relative to the number of medical institutions and admissions is presented in Table 2.3.

Table 2.3: The Distribution of the Reported MQSIs in Jiangsu Province ${ }^{265}$

\begin{tabular}{lrlllll}
\hline Municipalities & \multicolumn{2}{l}{ Reported MQSIs } & \multicolumn{2}{l}{ Medical Institutions } & \multicolumn{2}{l}{ Hospital Admissions } \\
\cline { 2 - 7 } & No. & $\begin{array}{l}\text { Proportion } \\
\text { No) }\end{array}$ & No. & Proportion & No. & Proportion \\
Nanjing & 204 & $7.88 \%$ & 2,315 & $7.83 \%$ & 62.00 & $12.89 \%$ \\
Wuxi & 78 & $3.01 \%$ & 2,027 & $6.86 \%$ & 42.53 & $8.84 \%$ \\
Xuzhou & 24 & $0.93 \%$ & 4,454 & $15.07 \%$ & 55.43 & $11.52 \%$ \\
Changzhou & 107 & $4.13 \%$ & 1,123 & $3.80 \%$ & 25.02 & $5.20 \%$ \\
Suzhou & 283 & $10.93 \%$ & 3,007 & $10.17 \%$ & 79.73 & $16.57 \%$ \\
Nantong & 1,113 & $42.99 \%$ & 3,187 & $10.78 \%$ & 37.19 & $7.73 \%$ \\
Lianyungang & 42 & $1.62 \%$ & 2,612 & $8.84 \%$ & 27.57 & $5.73 \%$ \\
Huai'an & 203 & $7.84 \%$ & 710 & $2.40 \%$ & 26.69 & $5.55 \%$ \\
Yancheng & 35 & $1.35 \%$ & 3,067 & $10.38 \%$ & 39.56 & $8.22 \%$ \\
Yangzhou & 258 & $9.97 \%$ & 1,815 & $6.14 \%$ & 24.43 & $5.08 \%$ \\
Zhenjiang & 160 & $6.18 \%$ & 897 & $3.04 \%$ & 22.36 & $4.65 \%$ \\
Taizhou & 79 & $3.05 \%$ & 1,995 & $6.75 \%$ & 13.32 & $2.77 \%$ \\
Suqian & 3 & $0.12 \%$ & 2,345 & $7.93 \%$ & 25.23 & $5.24 \%$ \\
Mean & 199.15 & $7.69 \%$ & 2,273 & $7.69 \%$ & 37.00 & $7.69 \%$ \\
\hline
\end{tabular}

$261 \quad$ DR-Incident Reporting 2011 (China), art. 19.

262 DR-Incident Reporting 2011 (China), art. 21, para. 1.

263 DR-Incident Reporting 2011 (China), art. 21, para. 25.

264 See generally Xia \& Tian 2015.

265 Data on the number and proportion of the reported MQSIs (2011-2014) are based on Xia \& Tian 2015, p. 30, Table 1. Data about the number of medical institutions and hospital admissions in all 13 municipal jurisdictions of Jiangsu Province in 2013 are from Jiangsu Provincial Commission of Health and Family Planning 2014, pp. 210-351. 
According to Table 2.3, it is evident that MQSIs were unevenly reported by various municipal jurisdictions. For instance, Xuzhou had the largest number $(4,454)$ of medical institutions and the third largest number (79.73 million) of hospital admissions but reported almost the smallest number (24) of MQSIs. Nantong reported more $40 \%$ of all the MQSIs, although it only had an average number of hospital admissions. This result indicates that the MQSI reporting system meets with resistance in practice.

In addition, even though the MQSI reporting is mandatory, Liu et al. found that most of the MQSIs were not reported of the providers' own accord but were reported passively in cases where dissatisfied patients had already filed a lawsuit before the court, applied to the public authorities for a technical investigation, or applied for people's mediation. ${ }^{266}$ Many MQSIs identified by hospitals in the course of routine administration were not reported to the authorities. ${ }^{267}$

Several reasons may explain this low rate of reporting. First, hospitals hesitate over reporting in that they are very concerned with the result of hospital accreditation. ${ }^{268}$ Hospitals may fail the accreditation if they are responsible for medical accidents. Second, physicians are unwilling to report MQSIs for fear of losing reputation and chances of winning promotion and bonuses. ${ }^{269}$ Third, the mandatory obligation to report is not strictly enforced by the public health authorities and few providers are actually punished because of non-reporting. ${ }^{270}$

\subsubsection{Regulatory Threats}

In addition to the MQSI reporting system, the then $\mathrm{MoH}$ established the Medical Quality-Safety Dissuasion-Conversation System (hereinafter MQDS) in 2011. The MQDS is a form of regulatory threats (行政告诫), ${ }^{271}$ which is intended to improve the management of the quality of care and patient safety, and the prevention of MQSIs through soft measures such as dissuasion and conversation instead of punishments. In China, regulatory threats fall into the

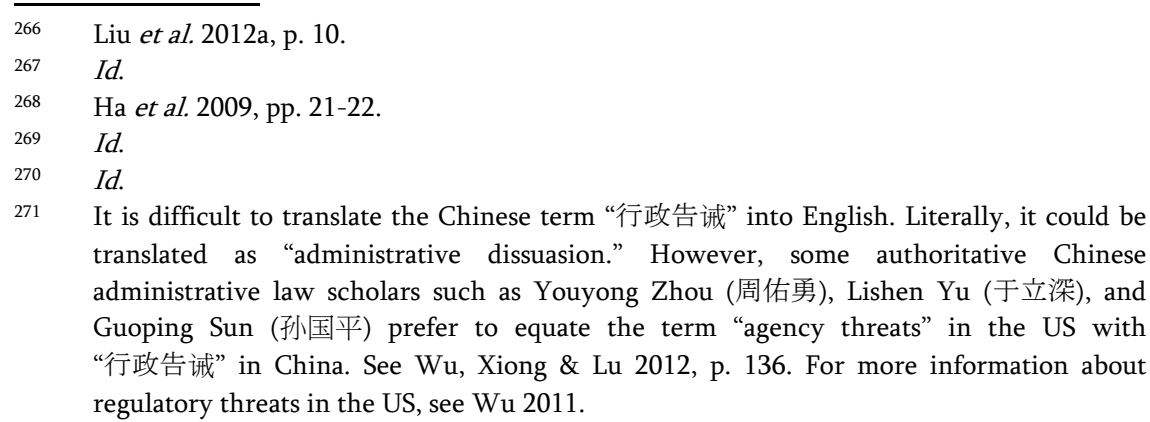


category of administrative guidance (行政指导), which is a non-coercive form of administrative action for a certain administrative purpose. ${ }^{272}$

The manager of a hospital which is directly involved in gross or especially gross MQSIs or has serious hidden dangers of MQSIs will be subjected to the MQDS. ${ }^{273}$ Once a gross or especially gross MQSI occurs or a serious MQSI hidden danger is identified, the public health authorities will organise and conduct the MQDS within 30 days. ${ }^{274}$ During the process, the public health authorities should point out the main problems and dangers faced by the hospital involved, and demand that the hospital rectifies any mistake within three months. ${ }^{275}$ If the manager refuses to undergo the MQDS process, the public health authorities should circulate a notice of criticism and must not accept any application for hospital accreditation or evaluation from the hospital involved. ${ }^{276}$ If the hospital involved fails to make rectifications in time or fails to carry out measures as required, the public health authorities will criticise and educate it and urge it to make corrections. ${ }^{277}$

Ideally, the fear of losing the eligibility for accreditation may induce hospitals involved in MQSIs to make corrections quickly and invest more in patient safety. Hence, the MQDS is potentially effective at preventing medical errors that are due to defects in hospital management, training, coordination among hospital departments, etc. For the time being, however, there is no empirical evidence that can prove the effectiveness of the MQDS. One may wonder whether soft measures such as criticism, education or persuasion would be as effective as punishments.

\subsection{THE ROLE OF SELF-REGULATION}

In addition to direct governmental regulation, several medical associations also play a role in the "self-regulation" of the medical profession in China. Three major associations are the Chinese Hospital Association (hereinafter CHA), the Chinese Medical Doctor Association (hereinafter CMDA) and the Chinese Medical Association (hereinafter CMA). Providers may decide to join these associations voluntarily, meaning that in China it is not an essential pre-

\footnotetext{
272 Ying 2011, p. 199. Other forms of administrative guidance may include, inter alia, proposals, negotiations, commendations, encouragement, mediation, guiding plans, and information disclosure. Id., p. 201.

273 DR-Administrative Dissuasion 2011 (China), art. 2.

274 DR-Administrative Dissuasion 2011 (China), art. 5.

275 DR-Administrative Dissuasion 2011 (China), art. 9.

276 DR-Administrative Dissuasion 2011 (China), art. 12

277 DR-Administrative Dissuasion 2011 (China), art. 13.
} 
condition for providers to be enrolled as members of these associations. Providers obtain licenses from, and register with, the public health authorities rather than with those associations.

Secondary and tertiary medical institutions are eligible to join the CHA. ${ }^{278}$ The key purposes of the CHA are to protect the legal rights and interests of the members, play an active role in trade instruction, limited selfregulation, coordination, and supervision, and try its best to improve the management level of member institutions. ${ }^{279}$ Notably, the CHA can be entrusted or authorised by the NHFPC to carry out such activities as supervising medical ethics, medical care quality and safety, assisting in drafting regulations on hospital management and criteria for assessing managers' performance, participating in hospital accreditation, etc. ${ }^{280}$ The members are required to adhere to the CHA's Statutes and decisions and maintain the legal rights and reputation of the CHA. ${ }^{281}$ Any member who has violated the CHA's Statutes severely will be removed from the CHA membership. ${ }^{282}$ However, the CHA does not have any competence in imposing disciplinary sanctions on its members, when they breach laws and regulations in the healthcare sector.

Licensed (assistant) doctors are qualified for joining the CMDA, 283 which aims to protect the doctor's legal rights and interests and promote the improvement of the doctor's medical standard and quality of service. ${ }^{284}$ Some significant tasks which the CMDA undertakes are to enhance the limited selfregulation of doctors, to assist in drafting professional standards of care and codes of conduct and to establish regimes of on-the-job training, routine assessment of the doctor's performance and review of the medical technology. ${ }^{285}$ It is demanded that members should abide by the CMDA's Statutes and decisions, medical ethics, professional standards and codes of conduct, and maintain the legal rights and interests and reputation of the membership. ${ }^{286}$ If it is authorised, the CMDA has the power to bestow awards to excellent doctors on the one hand and impose disciplinary sanctions on those members who breach medical professional standards and ethics on the other hand. ${ }^{287}$ However, the CMDA's Statutes do not specify what kinds of

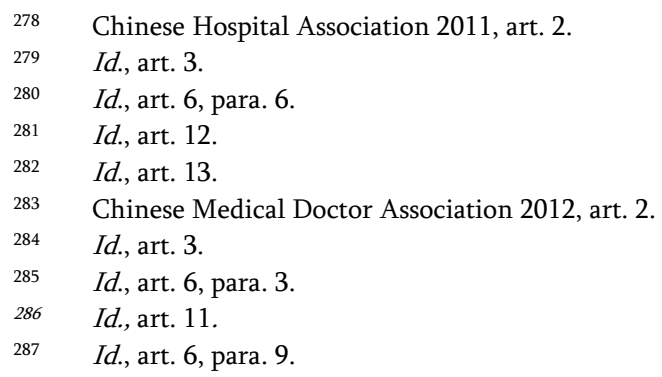


disciplinary sanctions shall be imposed, except that those members who severely violate the Statutes should be removed from the membership. .28

All medical institutions and medical staff members, medical colleges and medical enterprises can join the CMA. ${ }^{289}$ It is a national academic organisation, which is an important social force in the development of medical science and technology and a linkage between the government and the medical professionals. To promote academic communications in medicine, to publish medical journals and books and to carry out continuing medical education and on-the-job training and so on are among the CMA's basic functions. ${ }^{290}$ As far as medical malpractice and professional standards are concerned, the tasks entrusted by the government to conduct the MATA system and publish and update the Clinical Practice Guidelines (hereinafter CPG) and the Norms of Technical Operations in Clinical Practice (hereinafter NTOCP) are the most notable. ${ }^{291}$ Members have an obligation to abide by the CMA's Statues and decisions, accomplish the tasks entrusted to them, promote the development of the CMA and maintain the legal rights and interests of the CMA. ${ }^{292}$ Those members who severely violate the CMA's Statutes should be denied membership. ${ }^{293}$

To sum up, medical professional associations in China do play a role in the "self-regulation" of the medical profession. However, the degree of independence of these associations from the government is surprisingly low. Without the authorization and permission from the government, many functions of these associations are unable to be fulfilled. In this respect, they actually play the role of assistants to the public health authorities. Many substantial functions such as imposing administrative or disciplinary punishments, especially the suspension or revocation of a license, are still within the exclusive competence of the public health authorities. This may be explained by the fact that China lacks a liberal tradition of self-regulation ${ }^{294}$ and that the government may still be reluctant to allow any nongovernmental organisation to be too independent. ${ }^{295}$

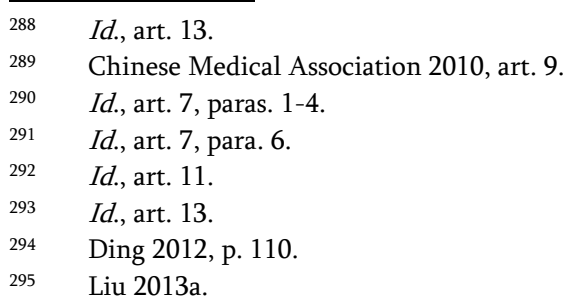


Health Care Provision and Regulation

\subsection{SUMMARY}

In China, the medical profession is directly regulated by the government. Specifically, the public health authorities (the new NHFPC and local HFPCs) administer the health care provision system within their respective jurisdictions. The authorities control both inputs (competence of health care providers) and outputs (service quality and patient safety).

As far as input controls are concerned, both institutional and individual providers should obtain a license from the authorities before they can practise medicine. If they practise without a license, they will be subject to administrative punishments and/or criminal penalties. Empirical evidence on the rate of identification of offenders is rare. Some available evidence suggests that practising without a license is not an uncommon phenomenon, especially in rural and suburban areas. It seems likely that the government control of inputs may not be so effective in these areas. Then, it is likely that some iatrogenic injuries may not be caused by negligence on the part of relatively competent providers but by the technical incompetence of unqualified people.

When it comes to output controls, the authorities basically employ the command-and-control method. Providers must comply with professional codes of conduct that are provided for by relevant laws, regulations, and medical-technical norms. If they contravene any code of conduct, institutional providers will be subject to administrative punishments, whereas individual providers may be sanctioned either administratively and/or criminally. Empirical data on the rate of identification of lawbreakers are currently unavailable. Some evidence shows that sanctions actually imposed on identified wrong-doers are fairly lenient - the size of fines is relatively modest and license revocation and criminal penalties are rarely imposed. One may question whether the current sanctioning system is sufficient to deter non-compliance.

In order to induce providers to maintain subsequent expertise and service quality, hospitals may choose to be accredited by external organisations and doctors are supposed to be assessed periodically. However, it seems that hospital accreditation meets with considerable resistance in practice and has been suspended several times. Some evidence also implies that the PDA system is not targeted at professional performance and ethics but only at medical knowledge and techniques and doctors assessed by their employer-hospitals rarely fail the exam. One may wonder whether the accreditation and the PDA system are effective at quality assurance. 
In cases where an MQSI (adverse incident) occurs, providers are supposed to report the MQSI to the authorities. However, empirical evidence suggests that the reporting system does not work well in that providers are unwilling to report MQSIs for fear of being punished or losing reputation, promotion, or bonuses and that the authorities do not enforce the reporting obligation strictly.

In addition to the command-and-control method, the authorities also adopt a non-coercive regime of regulatory threats, whereby the authorities criticise, educate, and urge hospital managers to make corrections. However, evidence on the efficacy of this regime is currently rare. Given that the command-and-control method is not so effective in practice, one may wonder whether the soft measure of regulatory threats will actually work.

Besides direct government regulation, several professional associations play an assistant role in the regulation of the medical profession. However, the role of these associations is rather limited because the Chinese government does not allow true self-regulation in the health care sector.

\section{CONCLUSIONS}

Chapter 2 examined the organisation, financing, and regulation of healthcare provision in China. Several conclusions can be drawn here. First, all individual providers are employed medical staff members of medical institutions (hospitals, health centres, and clinics). The medical service contractual relationship (doctor-patient relationship) is actually between medical institutions and patients rather than between doctors and patients. The law (contract law, tort law, etc.) applies to all doctor-patient relationships and medical malpractice disputes, irrespective of whether public or private, for-profit or not-for-profit hospitals are involved. Second, although the government recently started to increase investment in public health care provision, patients on average still have to pay about $40 \%$ of all medical expenses out of pocket. Hence, patients normally have a strong incentive to claim compensation once they suffer iatrogenic injuries. Third, although China has established a comprehensive system of public regulation of the medical profession, its effectiveness in quality assurance is open to suspicion on account of inadequate enforcement in practice. 


\section{CHAPTER 3 \\ COMPENSATION FOR IATROGENIC INJURIES UNDER TORT LAW}

\section{INTRODUCTION}

From an ex post facto perspective of a case where an iatrogenic injury suffered by a patient occurred, one may wonder what the potential legal consequences of iatrogenic injuries could be in China. As addressed in Chapter 2, a negligent provider who caused injuries to the patient (a "medical accident") may be subject to administrative punishments (license suspension/revocation) and/or criminal sanctions (imprisonment). ${ }^{1}$ Some consequential losses such as medical expenses may be covered by various insurance or social security schemes. ${ }^{2}$ This Chapter focuses on the system of private law compensation for iatrogenic injuries. Specifically, it will explore the issue of what legal rules or regimes victimised patients may rely on to obtain redress and how good they may appear according to the available literature in China (part of Sub-question (1-a)).

To begin with, Section 2 will briefly summarise the development of the Chinese medical malpractice liability system. Then, currently applicable rules concerning medical malpractice will be discussed in detail in Section 3.

\section{DEVELOPMENT}

Medical malpractice liability was first developed in the West hundreds of years ago. As a matter of history, medical malpractice liability can be traced back to the fourteenth century in England and the late eighteenth century in

See supra Chapter 2, Section 4.3.2.1.

See infra Chapter 5 . 
the US. ${ }^{3}$ In France, medical malpractice liability began to grow at the end of the eighteenth century. ${ }^{4}$ In China (PRC), however, medical malpractice liability had not been taken seriously until the late 1980's when China began to rebuild its civil law regime after the Cultural Revolution.

The evolution of medical malpractice liability in modern China is full of twists and turns. Before the 1980's, few medical malpractice claims were brought before the court when neither a substantive civil law regime nor a well-functioning civil litigation system was available in Mao's China. ${ }^{5}$ Most of the medical accidents were handled by the administrative authorities and some criminal penalties were imposed on negligent providers. ${ }^{6}$ Some evidence shows that although the victimised patient or his/her family members were not allowed to obtain compensation from hospitals concerned, they might get some limited financial aid from the government if they fell into financial dislocations due to the death or disability of the patient. ${ }^{7}$ Also, part of the medical expenses, lost earnings and/or loss of maintenance due to iatrogenic injuries might also be covered by then social security schemes for public officials and employees (the GFMCS and the LIS). ${ }^{8}$ However, empirical data on the extent and size of the aid or social insurance benefits are unavailable.

As of the beginning of the 1980's, China began to restore its civil justice system. ${ }^{9}$ Although the Principles 1986 (full title: General Principles of Civil Law $)^{10}$ contain a general fault-based tort clause ${ }^{11}$ which provides a potential legal basis for medical malpractice claims, this act does not provide specific and detailed rules concerning medical malpractice liability.

Danzon 1985a, p. 59.

Boccara 2009, p. 342.

Harris \& Wu 2005, pp. 459-460.

Li 1987, pp. 1-3; Liang 1998, pp. 24-29.

JI-No Compensation Shall Be Granted 1964 (China). See also Wang \& Oliphant 2012, pp. 26-27.

See supra Chapter 2, Section 3.2.

The NPC enacted two statutes which are the cornerstone of the civil litigation system the Civil Procedure Law 1982 (China) (and later the Civil Procedure Law 1991) and the Principles 1986 (China).

10 China has not enacted a civil code yet. The Principles 1986 is intended as a transitional form of civil law until China promulgates the unified civil code. Based on the Principles 1986, many single civil statutes have been enacted, such as Contract Law 1999 (China), Property Law 2007 (China), and Tort Law 2009 (China). In June 2016, the codification of Chinese civil law was initiated and the draft General Part of Civil Law (民法总则) was submitted to the NPC. It is expected that the Chinese Civil Code will be enacted around 2010. See generally Sun 2016

11 Principles 1986 (China), art. 106, para. 2 reads, "Citizens and legal persons who through their fault encroach upon state or collective property, or the property or person of other people shall bear civil liability." 
Merely a year later, an administrative regulation ${ }^{12}$ was issued in order to provide both substantive rules for compensating medical injuries and procedural rules for resolving medical disputes. On the one hand, this regulation adopted an extremely limited compensation regime. Victimised patients would only receive a fixed lump sum of modest payment from defendant hospitals, ${ }^{13}$ which could seldom make good the real losses. On the other hand, it pre-empted medical malpractice litigation by establishing an administrative adjudication (行政裁决) regime, under which the dispute would be resolved by the public health authorities rather than by the court. Victimised patients could not file a lawsuit before the court unless they were unwilling to accept the result of the administrative adjudication. ${ }^{14}$

With the deepening of the market economy in China, the deficiencies of the AR-Medical Accidents 1987 became more and more obvious. Harris and $\mathrm{Wu}$ summarised four deficiencies as follows: (1) narrowness in the definition of medical accidents (directly causing death, disability or tissueorgan functional impairment); (2) unfair limitations on compensation (a limited lump sum of modest payment);15 (3) weaknesses in the system for expert testimony (lack of neutrality and credibility); and (4) conflicts and lack of integration with other laws (contradicting the Principles 1986 and the Civil Procedure Law 1982, 1991).16 Dissatisfied with this regulation, the Supreme People's Court (SPC) stressed that the Principles 1986 and the ARMedical Accidents 1987 should be equally applicable, and some local courts applied the Principles 1986 in deciding medical malpractice cases, e.g. Liu v. Datong Clinic. ${ }^{17}$

In response to the above deficiencies, the SPC issued the JI-Rules of Evidence 2001, article 4 of which reversed the burden of proof as to both fault and causation in medical malpractice litigation. It provides that the defendant had to produce evidence to prove that either it was not at fault or

$12 \quad$ AR-Medical Accidents 1987 (China). In China, administrative regulations are statutes enacted by the State Council in order to perform its executive role. As far as legal authority is concerned, administrative regulations are inferior to national laws promulgated by the NPC or the SC-NPC but superior to rules or regulations issued by local congress or government.

$13 \quad$ AR-Medical Accidents 1987 (China), art. 18.

$14 \quad$ AR-Medical Accidents 1987 (China), art. 11.

15 In particular, the limited compensation appeared considerably inadequate during a period when more and more residents were not covered the LIS. See supra Chapter 2, Section 3.1. 16 Harris \& Wu, 2005, pp. 459-463.

17 In Liu v. Datong Clinic, although the injury (the sub-acute pelvic inflammatory disease) caused by poorly disinfected medical equipment could not be regarded as serious as a medical accident defined by the AR-Medical Accidents 1987 (China), the court nonetheless granted the plaintiff damages in accordance with the Principles 1986 (China). 
there was no causal link between negligence and injuries. ${ }^{18}$ The SPC justified the virtually full reversal of the burden of proof on the grounds that patients as medical laymen are unable to understand medical procedures and produce evidence due to severe information asymmetry. ${ }^{19}$

Moreover, the State Council amended the AR-Medical Accidents 1987 and replaced it with the AR-Medical Accidents 2002. The new regulation has expanded the definition of medical accidents, removed several unfair limitations on compensation, rebuilt a much more neutral expert ascertainment regime and replaced the old administrative adjudication regime with a new administrative mediation system..$^{20}$ In addition, parties to a medical dispute are encouraged to negotiate and settle the dispute in private before initiating the administrative mediation system or filing a lawsuit. ${ }^{21}$ Therefore, as of 2002, three means of resolving medical disputes are available: (1) behind-the-scenes negotiation, (2) administrative mediation by public health authorities and (3) formal civil litigation.

Although the AR-Medical Accidents 2002 has eased the conflicts with the Principles 1986 and the Civil Procedure Law 1991 by greatly expanding compensation and abolishing the administrative adjudication regime, it is still a relatively limited compensation regime in comparison to the then compensation system in tort law. The latter was based on article 106, para. 2 of Principles 1986, together with two judicial interpretations ${ }^{22}$ issued by the SPC - JI-Emotional Damage 2001 and JI-Personal Injury 2003. First, the ARMedical Accidents 2002 requires that injuries suffered by the patient must be "tangible" or "obvious." ${ }^{23}$ Second, it does not provide for compensation for death, ${ }^{24}$ the amount of which is often substantial in other personal injury cases involving death. Third, more caps are placed on some compensation items such as compensation for living expenses for the dependent and compensation for emotional distress..$^{25}$

None of the foregoing limitations can be found in the Principles 1986 and relevant judicial interpretations. For this reason, some courts were more willing to apply the Principles 1986 instead of the AR-Medical Accidents

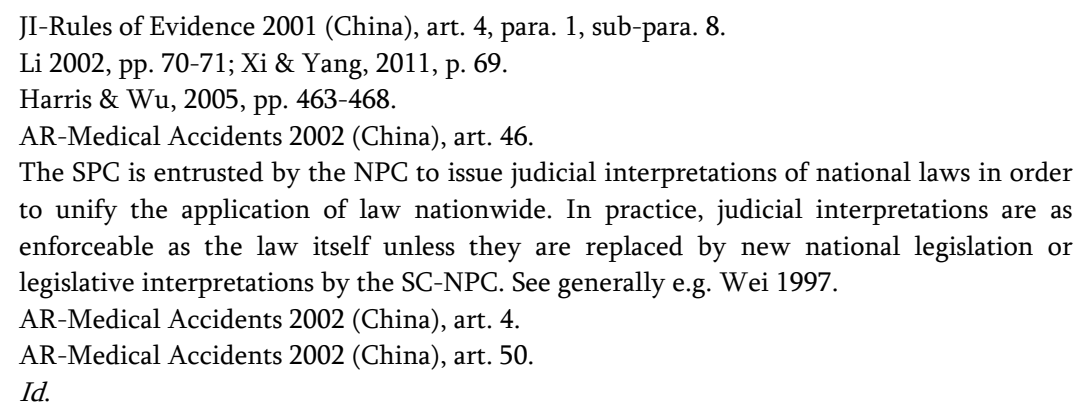


2002 for the sake of awarding fair and adequate compensation to victimised patients. Eventually, the SPC split medical malpractice claims into two types - medical accident claims and ordinary claims. ${ }^{26}$ The differences between these two types of medical malpractice claims are briefly summarised in Table 3.1.

Table 3.1: Medical Accident Claims versus Ordinary Claims

\begin{tabular}{|c|c|c|}
\hline & Medical Accident Claims & Ordinary Claims \\
\hline Definition & $\begin{array}{l}\text { - negligence on the part of providers }{ }^{27} \\
\text { - contravening laws, regulations, } \\
\text { rules, codes of conduct, or customary } \\
\text { practice }^{28} \\
\text { - "obvious" (明显的) personal } \\
\text { injuries }{ }^{29}\end{array}$ & $\begin{array}{l}\text { - fault (either intent or } \\
\text { negligence) on the part of } \\
\text { providers }^{30} \\
\text { - damage to person }\end{array}$ \\
\hline Rules & - AR-Medical Accidents 2002 & - Principles 1986 \\
\hline Damages $^{32}$ & $\begin{array}{l}\text { - More limited (more caps + no } \\
\text { compensation for death) }\end{array}$ & $\begin{array}{l}\text { - Less limited (less caps + } \\
\text { compensation for death) }\end{array}$ \\
\hline $\begin{array}{l}\text { Expert } \\
\text { witness }^{33}\end{array}$ & $\begin{array}{l}\text { - clinical physicians selected by local } \\
\text { medical associations from local } \\
\text { hospitals (MATA) }\end{array}$ & $\begin{array}{l}\text { - forensic pathologists } \\
\text { independent of the medical } \\
\text { profession }\end{array}$ \\
\hline
\end{tabular}

Then, an entirely illogical paradox emerged. Although, by definition, patients were injured more severely in medical accidents (obvious injuries) than in ordinary torts (less obvious injuries), they would, in theory, obtain less compensation under medical accident claims than under ordinary claims. In practice, however, it would not be possible for plaintiff-patients always to opt for compensation under ordinary claims freely. ${ }^{34}$ It was argued that the

\footnotetext{
26 JI-Notice on Referring to the RHMA 2003 (China).

27 AR-Medical Accidents 2002 (China), art. 2.

28 Id.

29 AR-Medical Accidents 2002 (China), art. 4, para. 1.

$30 \quad$ Principles 1986 (China), art. 106, para. 2.

$31 \quad$ Id.

32 For a detailed contrast between the two rules of damages, see e.g. Ding 2012, pp. 196-197; Wang \& Oliphant 2012, p. 38.

33 JI-Notice on Referring to the RHMA 2003 (China), art. 2.

34 In most cases, the court would normally first ask clinical experts to offer their testimony as to whether the adverse event could constitute a medical accident. If the clinical experts testified that there was no medical accident, the court may then ask forensic pathologists to testify whether there would be any ordinary fault. Hence, once clinical experts testified that the event was a medical accident, then plaintiff-patients would have no choice but to accept the potentially lower amount of damages determined in light of AR-Medical Accidents 2002 (China). See e.g. Xiamen Intermediate People's Court and Siming District People's Court 2008, p. 77.
} 
presence of this paradox would completely contradict the principle of fairness and equity ${ }^{35}$ and greatly undermine the unification of the application of law. ${ }^{36}$

To resolve this paradox, the Standing Committee of the National People's Congress (SC-NPC) provides for 11 articles on liability for iatrogenic injuries in Chapter VII of the new Tort Law 2009. The new rules are intended to unify the old double tracks of medical malpractice claims. ${ }^{37}$ Tort Law 2009 confirms the Principles 1986's approach to both liability rules and rules of damages. Scholars generally welcomed the unification of applicable medical malpractice liability rules. ${ }^{38}$ More strikingly, Tort Law 2009 has abandoned the rule of virtually full reversal of the burden of proof. However, some criticised the abandonment of the reversal of the burden of proof and regarded it a "backward" step in the road of victim protection..$^{39}$

In addition to tort law, contract law may play a limited role in medical malpractice claims. The current medical malpractice tort rules, together with some relevant reforms of the old rules, and the role of Contract Law 1999 will be examined in Section 3.

\section{THE SUBSTANTIVE SYSTEM OF PRIVATE LAW COMPENSATION}

\subsection{INTRODUCTION}

\subsubsection{The Relevance of Contract Law}

In China, it is generally accepted that the doctor-patient relationship is a medical service contract concluded between hospitals and patients. ${ }^{40}$ Under such a contract, hospitals provide specific medical care services to patients in

\footnotetext{
35 Xiamen Intermediate People's Court and Siming District People's Court 2008, pp. 87-88.

36 Ai \& Fang 2010

37 Recently, the JI-Notice on Referring to the RHMA 2003 (China) was repealed by the SPC on April 8, 2013.

$38 \quad$ See e.g. Xi \& Yang 2011, pp. 72-75.

39 Wang \& Oliphant 2012, pp. 50-51.

40 Liu \& Li 2002, p. 6; Qiang 2010, p. 19; Wang, C. 2011, p. 65. This viewpoint is also supported by the SPC. In the JI-Causes of Civil Action 2001 (China), the JI-Causes of Civil Action 2008 (China), and the JI-Causes of Civil Action 2011 (China), the SPC stipulates a cause of action called "Disputes over Medical Service Contracts" (医疗服务合同纠纷). Some scholars do not believe the doctor-patient relationship is of civil law. They argue that it is of administrative law or a hybrid of civil and administrative relationship. See e.g. Hu 2001, pp. 57-59; Zhang 2001.
} 
return for an agreed payment. ${ }^{41}$ Therefore, in theory, the Contract Law 1999 is applicable to the doctor-patient relationship. However, the Contract Law does not provide for any special rule for the standard of medical care or medical malpractice issues. Some contract law scholars argued that the primary contractual obligation that health care providers have to fulfil is to exercise due care in the course of treatment (an obligation of means), ${ }_{4}^{42}$ which is actually not different from the standard of care in tort law. Moreover, parties under the contract are not permitted to either waive tort liability for personal injuries ${ }^{43}$ or alter the statutory standard of care in tort law. ${ }^{44}$

In case an iatrogenic injury occurs, patients are allowed to choose either a contractual claim or a tort claim (the concurrence of contractual and tort liability). ${ }^{45}$ To patients, contractual claims may look superior to tort claims in that the former has longer statute of limitations ( 2 years $)^{46}$ than the latter (1 year). ${ }^{47}$ However, most patients in practice opt for tort claims for three reasons. First, medical malpractice liability and quantum rules under tort law are much more detailed than under contract law. ${ }^{48}$ Second, the expert witness regime is designed to serve medical malpractice claims under tort law rather than under contract law. ${ }^{49}$ Third, recovery for non-pecuniary losses is often denied under contract law..$^{50}$

Since the Chinese public health insurance system (BMIS) is still underfunded and under-developed, some residents (esp. unemployed, rural, or poor people) may not be covered by health insurance schemes and even those who are covered by the BMIS may have to pay a significant proportion $(40 \%$ on average) of medical bills out of their own pocket. ${ }^{51}$ Hence, some Chinese

\footnotetext{
$41 \quad$ Cheng 2007, p. 18.

$42 \quad$ Han 2005, pp. 95-96.

43 Contract Law 1999 (China), art. 53, para. 1, sub-para. 1.

44 Contract Law 1999 (China), art. 52, para. 1, sub-para. 5.

$45 \quad$ Contract Law 1999 (China), art. 122.

46 Principles 1986 (China), art. 135.

$47 \quad$ Principles 1986 (China), art. 136, para. 1.

48 For old medical malpractice rules in tort law, see supra Section 2. for the current medical malpractice rules in tort law, see infra Sections 3.2 to 3.6. However, Contract Law 1999 (China) does not specify any rule for medical malpractice.

49 In practice, the majority of expert evidence is produced by the MATA system, which is intended only for determining whether a medical accident occurs. By definition, a medical accident is a severe type of tort.

50 Contract Law 1999 (China), art. 113, para. 1 provides that only "economic losses" are compensable under contract law. See also Zheng \& Chen v. Jiangsu Hospital (China), where the court decided that changing the agreed treatment plan unilaterally without the consent of the patient constituted a breach of contract. In addition, the court denied the plaintiff's claim for non-pecuniary damages. This decision was appraised and published by the SPC on its official gazette.

$51 \quad$ See supra Chapter 2, Section 3.
} 
patients cannot afford treatment services, especially those that are expensive. ${ }^{52}$ One important question is whether hospitals can legitimately refuse to provide treatment services for patients who refuse to pay for medical bills. This question should be answered in the light of two scenarios.

Under the first scenario, the hospital finds that the patient cannot afford medical bills before admitting him/her to the hospital. Is the hospital legally allowed to refuse to enter into a contract with the patient? It all depends. In the case of emergencies where the patient is critically ill, the hospital and physicians should conduct emergency treatment measures immediately and should not refuse to give emergency treatment..$^{53}$ In case the hospital is not capable of rescuing the patient due to limited equipment or technology, it must refer the patient to another hospital promptly. ${ }^{54}$ Urgentcare centres and hospitals should not refuse to provide or delay emergency medical measures because of unpaid medical bills. ${ }^{55}$ If physicians breach their duty of rescuing and treating the critically ill patient in time and cause serious consequences, they will be subject to license sanctions (suspension or revocation) and/or criminal penalties. ${ }^{56}$ In addition, the victimised patient or his/her close relatives may file a lawsuit against the faulty hospital either under contract law or under tort law. ${ }^{57}$ However, in non-emergent cases, it is currently not compulsory for the hospital to admit the patient.

Due to this compulsory obligation to enter into the medical service contract in case of emergencies and the fact that many patients cannot afford treatment, a lot of Chinese hospitals are facing the problem of arrears of medical bills. This problem often occurs in public hospitals, since they are not-for-profit and are not allowed to increase service prices freely. According to one recent empirical study, three types of non-paying patients - those who are insolvent, who have no close relatives, or whose identity cannot be verified - accounted for about $16 \%$ of all the unpaid medical bills in the

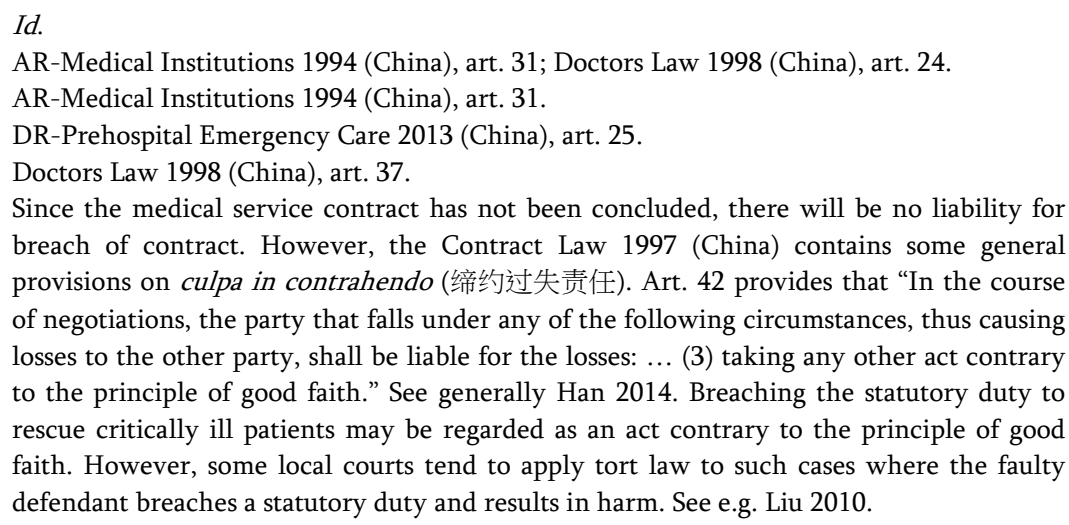
of negotiations, the party that falls under any of the following circumstances, thus causing losses to the other party, shall be liable for the losses: ... (3) taking any other act contrary to the principle of good faith." See generally Han 2014. Breaching the statutory duty to rescue critically ill patients may be regarded as an act contrary to the principle of good faith. However, some local courts tend to apply tort law to such cases where the faulty defendant breaches a statutory duty and results in harm. See e.g. Liu 2010. 
Shandong Province for the period 2008-2010.58 Nationwide, these non-paying patients incur about three to four trillion yuan medical expenses annually. ${ }^{59}$

In 2013, in order to help these non-paying patients and lessen the financial burden on public hospitals, China established the Regime of Assistance for Non-paying Emergencies (hereinafter RANE), which is intended to cover the medical bills incurred by those patients who are unable to pay or whose identity cannot be verified. ${ }^{00}$ Accordingly, the government established a special fund, which is partly subsidised by the government and partly relies on donations. ${ }^{61}$

Although some of the unpaid bills may be covered by the RANE, the lion's share of them are still borne by hospitals. ${ }^{62}$ For instance, for the period 2011-2013, the Third People's Hospital of the Chengdu City had admitted 286 non-paying patients, none of whom had been refused treatment or been driven out..$^{63}$ By the end of 2014, these patients had incurred costs of a total of 274,667 yuan, most of which were still covered by the hospital itself. ${ }^{64}$

Under the second scenario, the hospital finds that the patient cannot afford the treatment after admitting him/her. Is the hospital allowed to terminate treatment or cancel the medical service contract? According to article 94 of the Contract Law 1997, the hospital may terminate the contract if the patient "delayed performance of their main obligation after such performance has been demanded, and fails to perform within a reasonable period." Obviously, the main obligation that the patient has to fulfil is to pay the medical bills. Hence, it seems that the hospital is allowed to cancel the contract in the case where the patient is unable to pay.

In practice, however, Chinese courts seem to add two conditions for the termination of the contract: first, it must not contravene humanitarianism, i.e. the patient's health must not be adversely affected by the termination; and second, experts testify that the patient's condition meets the standards for being discharged from the hospital. ${ }^{65}$ Therefore, the hospital

\footnotetext{
58 The remaining $84 \%$ of the unpaid medical bills were due to non-paying health insurers or governmental institutions. Zhang et al. 2013, p. 47.

$59 \quad$ Li, H. 2014, p. 5.

60 N-Assistance for Non-Paying Emergencies 2013 (China).

$61 \quad$ Id.

$62 \quad$ Li 2014, pp. 7-8.

$63 \quad$ Li 2014, p. 7.

64 Id.

65 See e.g. Chongqing Children's Hospital v. Pang et al. (China), where a patient who was fully cured refused to pay medical expenses and refused to leave the ward in order to continue to enjoy the service. The court decided that it was justifiable for the plaintiffhospital to cancel the medical service contract, to claim back unpaid medical expenses, and to ask the defendant-patient to leave the ward. See also Chen \& Dai 2011, pp. 27-28.
} 
will not be allowed to cancel the contract freely and will be held liable for any harm done to the patient by physician inaction out of concerns for costs. Neither is the patient allowed to stay in the ward bed without paying anything when his/her conditions meet the standards for leaving hospital.

It seems that contract law is not totally irrelevant to the doctor-patient relationship. However, as far as medical malpractice is concerned, contract law is not that relevant in China. ${ }^{66}$

\subsubsection{The General Clause for Medical Malpractice Claims}

Hence, in China, tort law is the primary route for victimised patients (or their family members), especially those who only receive modest social insurance benefits in cases of permanent disability or death, to obtain compensation for iatrogenic injuries. Also, tort law is the only regime that provides victims with reparation for non-pecuniary losses (精神损害).

Before 2010, as we saw in Section 2, the legal basis for medical malpractice claims could be found in either administrative regulations (ARMedical Accidents 1987, 2002) or civil law (Principles 1986, JI-Emotional Damage 2001, and JI-Personal Injury 2003). Since 2010, the primary legal basis has become the Tort Law 2009, together with JI-Emotional Damage 2001, and JI-Personal Injury 2003.67

Chapter VII of the Tort Law 2009 provides for 11 articles (arts. 54-64) to handle liability issues concerning iatrogenic injuries. The general clause for medical malpractice liability is stipulated by article 54 , which reads as follows

Where a patient sustains any harm during diagnosis and treatment, if the medical institution or any of its medical staff is at fault, the medical institution shall assume compensatory liability.

When comparing article 54 to the old rules in the AR-Medical Accidents $2002,{ }^{68}$ we can easily identify three alterations. First, the requirement of

66 Some Chinese scholars have even begun to question the desirability of the theory of medical contractual liability. For instance, Ye took as an example the recent shift in French medical liability law from contractual liability to statutory tort liability to support his argument that China should learn from the French experience and abandon the theory of medical contractual liability which is already rarely applied in practice. See generally Ye 2012.

67 These two judicial interpretations are still applicable insofar as they do not contravene the new Tort Law 2009 (China).

68 AR-Medical Accidents 2002 (China), art. 2 defines "medical accidents" as "those that have caused personal injury to the patients negligently by the medical institutions or the staff members thereof in the activities of medical treatment by violating the laws, regulations, ministerial rules concerning medical treatment and health or the standards or conventions 
"negligence" has been changed to "fault," which, by definition, consists of both intent and negligence. Second, the requirement of "wrongfulness" or "unlawfulness" -contravening laws, regulations, rules, codes of conduct, or customary practice - has been cancelled. Third, the threshold of "obvious personal injury" has been abolished as well.

When reading article 54 and the old general tort clause in the Principles 1986 together, ${ }^{69}$ we can find that article 54 is more detailed in two respects. First, article 54 clarifies that either the hospital's fault or its employee-provider's fault suffices to establish liability. Second, article 54 reaffirms that the AR-Medical Accidents 2002's approach that the medical institution is the sole defendant that is liable for paying damages for iatrogenic injuries. Most scholars in China regard the hospital's liability in article 54 as "vicarious liability" (替代责任). ${ }^{70}$ However, this viewpoint seems somewhat ambiguous because vicarious liability is usually intended to make an employer liable for the actionable conduct of an employee, ${ }^{71}$ but is not meant to exonerate the employee's tort liability. ${ }^{72}$

Article 54 looks very like a "channelling of liability," where liability is allocated exclusively to one responsible tortfeasor. ${ }^{73}$ The Tort Law does not provide the hospital with the right of recourse against faulty medical staff members. Nevertheless, this does not affect the possibility that the hospital and its staff members may work out an agreement on this issue under the employment contract. ${ }^{74}$

Both feasance and nonfeasance are subsumed under the notion of "fault" in article 54. Hospitals will be held liable for harm due to inaction if they breach their affirmative duty of care owed to patients..$^{75}$

Most of the remaining articles in Chapter VII of the Tort Law can be subsumed under article 54. It is interesting, in the light of the nature of the duty of care, that the Law divides medical malpractice claims into two types -

of medical treatment and nursing." AR-Medical Accidents 2002 (China), art. 3, para. 1 sets the threshold of compensable damage as "obvious personal injury."

69 Principles 1986 (China), art. 106, para. 2 reads, "Citizens and legal persons who through their fault encroach upon state or collective property, or the property or person of other people shall bear civil liability."

$70 \quad$ Wang 2013, p. 185; Yang 2014, p. 323.

71 Garner 2014.

72 In Europe, the employer and the employee are jointly liable for the damage caused by the employee in the majority of the cases. See Van Dam 2013, p. 512.

73 See e.g. Faure 2016, pp. 621-629.

$74 \quad$ Wang 2013, p. 192.

75 See e.g. in He v. A Chongqing Hospital (China), the appellate court remarked that "the defendant-hospital shall be held liable because it is fully capable of conducting an emergency Caesarean ... but it had delayed the surgery for about four hours without any justification, which was in breach of their statutory duty to rescue the patient promptly." 
medical technical malpractice (hereinafter technical malpractice) claims and medical ethical malpractice (hereinafter ethical malpractice) claims. ${ }^{76}$ Technical malpractice refers to the breach of the duty of care required of providers as regards medical techniques - diagnosis, examination, the choice of therapies, surgeries, medication, monitoring, etc. ${ }^{77}$ In contrast, ethical malpractice denotes the breach of the duty of care regarding medical ethics informed consent, privacy, bona fides, etc. ${ }^{78}$ These two types of claims will be addressed respectively in Section 3.2 and Section 3.3.

In addition to the two types of malpractice claims mentioned above, Chinese hospitals, together with manufacturers, may also be held jointly and severally liable for defective medical products, including substandard blood, which will be examined in Section 3.4. Sometimes, courts even rely on "equitable liability" to resolve a dispute over medical malpractice in cases where neither the provider nor the patient is at fault (Section 3.5).

The Tort Law 2009 does not provide for new rules concerning expert evidence. Hence, the two-track expert testimony system - clinical physicians selected by medical associations from hospitals and forensic pathologists independent of the medical profession - still exist for the time being. Section 3.6 will give a brief introduction to the expert evidence system.

Although the Tort Law 2009 outlines the compensable heads for personal injuries cases, ${ }^{79}$ it does not specify detailed rules about how to calculate damages. Currently, Chinese courts still rely on the JI-Emotional Damage 2001 and the JI-Personal Injury 2003 to measure damages in all personal injury cases. The Chinese law of damages will be sketched in Section 3.7. A summary will be given in Section 3.8 .

\subsection{TECHNICAL MALPRACTICE}

\subsubsection{Introduction}

As mentioned earlier, fault is a requirement for establishing medical malpractice liability. Article 57 of the Tort Law 2009 defines the standard of care regarding medical techniques in China for the first time, which reads

\footnotetext{
76 This new division between technical malpractice claims and ethical malpractice claims should be distinguished from the old division between medical accident claims and ordinary claims. The new division is only intended to show the different types of the medical duty of care, whereas the old division was made because of different definitions and applicable rules. Yang 2009a, p. 48. 
Where any medical staff member fails to fulfil the duty of medical care corresponding to the then medical standard (当时的医疗水平) and causes any harm to a patient, the medical institution shall assume the compensatory liability. [italics added]

Hence, currently in China, technical malpractice should be assessed against the duty of care "corresponding to the then medical standard." According to lawmakers, article 57 is significantly important in that it explicitly introduces the notion of duty of care and standard of care into Chinese tort law, ${ }^{80}$ which are recognised in most countries. ${ }^{81}$ The wording "then" clearly excludes the possibility of applying retrospective liability to medical malpractice cases. All the medical standards against which the provider's behaviour is assessed should be prevailing at the time of treatment. Providers should not be held negligent merely because a medical standard is updated after the treatment.

Be that as it may, the Law still does not clarify how the "medical standard" itself should be determined. Ambiguities in such terms are left to courts and legal scholars.

The following section will first summarise scholarly opinions on the relationship between statutory standards, written treatment norms, and unwritten customary practice on the one hand, and the standard of care on the other in Section 3.2.2. Any relevant legal rule will also be examined. However, for technical malpractice liability to be established, the requirement of causation has to be satisfied too. Also, the establishment both of fault and of causation rely on proof rules, and so the causation and proof rules will be discussed in Sections 3.2.3 and Section 3.2.4 respectively. Causation and proof issues discussed in Section 3.2 are largely applicable to ethical malpractice claims and medical products liability. Hence, they will not be addressed again in Section 3.3 and Section 3.4.

\subsubsection{Statutory Standards, Written Treatment Norms, and Unwritten Customary Practices}

Unlike article 2 of the AR-Medical Accidents 2002, which requires that "a statutory standard provided for by laws, administrative regulations, or ministry rules, a treatment and care norm (诊疗护理规范) or a customary practice (常规)" must be contravened before a medical accident can be established, article 57 of the Tort Law 2009 only provides for an abstract

$80 \quad$ Wang 2013, p. 317.

81 For more information on the standard of care in the US tort law, see e.g. Keeton, Sargentich \& Keating 2004, pp. 369-440. For the standard of care in Europe, see e.g. Van Dam 2013, pp. 234-258. 
notion of the "then medical standard" and leaves it undefined. Nonetheless, one may immediately wonder how a breach of a statutory standard, a treatment norm or a customary practice should be treated in the light of the new Tort Law.

A statutory standard is a legal duty imposed on the medical profession by several state organs (the NPC or SC-NPC, the State Council, and various ministries). China has a long tradition of regulating the medical profession by the state. ${ }^{82}$ Thus, many professional standards are directly enacted by the state rather than by the profession itself. ${ }^{83}$

The distinction between a treatment norm and customary practice is difficult to make. It seems that neither the drafters of the AR-Medical Accident 2002 nor those of the Tort Law have ever attempted to make such a distinction. ${ }^{84}$ Some argued that treatment norms are written practice guidelines issued by various medical professions associations, while customary practices are unwritten conventions that need to be ascertained based on expert testimony. ${ }^{85}$ Others maintained that only those practice guidelines that at least have been endorsed by the NHFPC (then $\mathrm{MoH}$ ) could be regarded as treatment norms. ${ }^{86}$ It follows that, at a minimum, a treatment norm should be in a written form. Hence, an unwritten convention could only be regarded as a customary practice.

Since statutory standards and treatment norms are normally act-based rules in a written form, it is much easier for a plaintiff to prove whether a contravention of a rule has occurred. Given this fact, article 58 of the Tort Law provides for a special rule as follows,

Under any of the following circumstances, a medical institution shall be presumed to be at fault for any harm caused to a patient:

(1) violating a statutory standard provided for by laws, administrative regulations, or rules, or a treatment norm (诊疗规范);

(2) concealing or refusing to provide the medical history data related to a dispute; or

(3) forging, tampering or destroying any medical history data. [italics added]

Clearly, article 58 adopts the 'prima facie evidence of negligence doctrine', under which the presumption of fault may be rebutted by a showing of

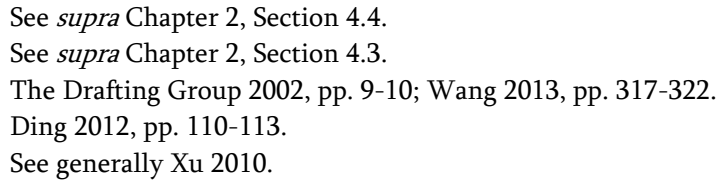


adequate counter evidence. ${ }^{87}$ The reason for this presumption is that violations of those standards or norms are very strong prima facie evidence that the medical institution was at fault. ${ }^{88}$ However, the presumption of fault could be rebutted in cases where e.g. a physician had exercised a reasonable level of care in rescuing an emergency although he/she violated some standards or norms. ${ }^{89}$

An interesting question is whether compliance with these standards and norms can exclude the possibility of being found liable. Lawmakers give a negative answer: statutory standards and treatment norms are often set at a minimum level and are more likely to be out of date, while the standard of medical care may require a higher level or other types of care and may keep up to date more easily. ${ }^{90}$ Hence, it is often argued that adherence to statutory standards or treatment norms has only evidentiary value and per se is not sufficient to disprove fault. ${ }^{91}$

The deletion of the wording "a customary practice" by article 58 , subpara. 1 suggests that the presumption rule does not apply to cases where a customary practice is contravened. However, this does not imply that a customary practice cannot be used as the standard of medical care. The court should decide this issue on a case-by-case basis. Although some scholars attempt to equate the standard of medical care with the customary practice, their argument is basically unfounded. ${ }^{92}$

It ought to be noted that taking an unwritten customary practice as the standard of care implies the use of the "locality rule," since a customary practice is often developed, recognised and adopted by the local medical community. The locality rule "defined the relevant group whose standard of practice would govern the local medical community in which the defendant doctor practised." ${ }^{93}$ However, the Tort Law is silent on this issue.

Once the locality rule had been contained in the draft Tort Law, which reads "when determining the standard of care required of the health care provider, due consideration shall be given to factors such as locations, qualifications of the medical institution and of the practitioner." ${ }^{94}$ However, due to complexities of this issue, lawmakers finally decided to leave this provision out. ${ }^{95} \mathrm{Be}$ that as it may, lawmakers recommended alternative

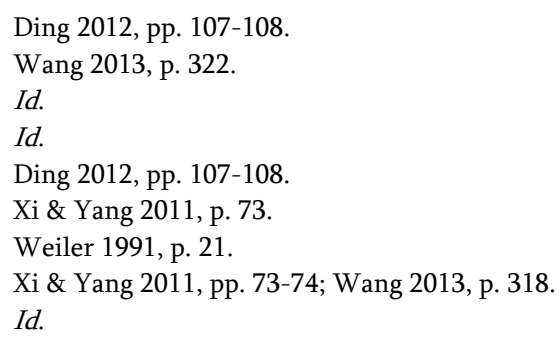


solutions: on the one hand, statutory standards and treatment norms are unified and detailed rules that should be complied with nationwide; on the other hand, the locality rule may apply to cases where no statutory standards or treatment norms are violated.96 In other words, the "then medical standard" may be interpreted as the "then medical standard there" if consideration of local factors is justified by specific circumstances. ${ }^{97}$

\subsubsection{Proof and Causation Issues}

\subsubsection{General Proof Rules}

The burden of proof in civil cases rests on the plaintiff as a matter of principle unless otherwise provided by the law. ${ }^{98}$ In medical malpractice cases, the issue of the burden of proof is complex and controversial. For the period of19862001, there was no special provision relating to the burden of proof in either the AR-Medical Accidents 1987 or the Principles 1986, and thus the general principle applied to medical cases.

The general allocation of the burden of proof was dramatically reversed for medical malpractice liability in the following decade (20012010). As of 2001, the defendant-hospital began to bear the burden of proving the absence of both fault and causation. ${ }^{99}$ This reversal rule was fiercely criticised for three reasons. First, it would encourage frivolous actions. ${ }^{100}$ Patients would be more willing to file malpractice claims if they bore little burden of proof. Second, it would induce providers to practice defensive medicine. ${ }^{101}$ Providers would take excessive precautions in response to the increased risk of losing a malpractice lawsuit due to failure to disprove causation and fault. Third, it violates the principle of "equality of arms."102 There should be a fair allocation of the risk of losing a lawsuit between the plaintiff and the defendant. ${ }^{103}$ The reversal rule imposes too much risk on the defendant, which is unfair. ${ }^{104}$

\footnotetext{
97 Id. In contrast, some strongly advocated the locality rule and believed that it could apply to all medical malpractice cases in China. See e.g. Wang \& Oliphant 2012, p. 45. However, this radical argument is largely unfounded.

98 JI-Rules of Evidence 2001 (China), art. 2.

$99 \quad$ JI-Rules of Evidence 2001 (China), art. 4, para. 1, sub-para. 8.

100 Shao 2013, p. 105.

$101 \quad$ Id.

$102 \quad$ Yang 2009b, p. 37.

103 Shen 2005, p. 29.

$104 \quad$ Yang 2009b, p. 37.
} 
Hence, article 54 of the new Tort Law 2009 has largely abandoned this quasi-total reversal rule. The only exception is article 58, under which the burden of proof regarding fault would be transferred to defendant-hospitals via presumption of fault in some rather limited circumstances. ${ }^{105}$ However, plaintiff-patients still should produce evidence to establish causation. Article 58 provides for a rule of presumption of fault rather than that of causation.

As far as the standard of proof is concerned, China had applied an "obviously more forceful" standard in civil cases for the period 2001-2014, which was provided by article 73, para. 1 of the JI-Rules of Evidence 2001 as follows

Where both parties concerned produce contradicting evidence to prove the same fact but neither has enough evidence to rebut the evidence of the other party, the People's court shall determine which evidence is obviously more forceful than the other evidence by taking the case into consideration, and shall affirm the evidence that is more forceful [italics added].

Some interpreted the "obviously more forceful" as a high probability nearly "nine times out of ten." 106 However, a case study found that many courts in practice simply equate "obviously more forceful" with the "preponderance of evidence" standard (more than 50\%) in the US law. ${ }^{107}$ Hence, during the period 2001-2014, the application of the standard of proof in civil cases is not always unified or consistent in China due to dividing interpretations of the "high probability" standard.

In response, in 2015, the SPC tried to clarify this issue by article 108, para. 1 of the newly enacted JI-Application of Civil Procedure Law 2015, which reads

For evidence provided by a party who bears the burden of proof, where a people's court finds out a high probability of the existence of the facts to be investigated upon examination in combination with relevant facts, it shall be deemed that the facts exist. [italics added]

Hence, the preponderance of evidence (more than 50\%) rule does not seem to be compatible with the high probability rule. According to the drafters, the high probability should be interpreted as about $75 \%{ }^{108}$

\footnotetext{
$105 \quad$ See supra Section 3.2.2.

$106 \quad$ Li 1999, p. 20.

107 See generally Wu, Z., 2013.

108 Shi \& Yan 2016, p. 660.
} 


\subsubsection{Defining Causation}

Despite the fact that causation plays an essential role in tort law, none of the provisions in the civil law statutes or any judicial interpretation has ever defined this term. The theory of causation in tort law has largely been developed by legal scholars and courts in China. Currently, it seems that the adequacy theory plays a significant role in tort cases. ${ }^{109}$

Interestingly, although the law and the SPC are silent on how to define the adequacy theory, some provincial courts have attempted to provide a clear definition of an "adequate cause." 110 For instance, the Shanghai High People's Court believes that the determination of causation shall be based on the adequacy theory:

... an adequate causation exists between a negligent treatment and an injury if the treatment is the conditio sine qua non of the injury and if the treatment substantially increases the objective probability of the occurrence of the injury. ${ }^{111}$

Similarly, the Jiangsu High People's Court defines the adequacy theory as follows:

The causation between an action and an injury would be established, if the injury would have not occurred but for the action, and it is reasonably likely that the presence of the action would have resulted in the injury; the causation would not be established, if although the injury would have not occurred but for the action, the injury would normally have not occurred even in the presence of the action. ${ }^{112}$

Combining the foregoing two guides, it is evident that the Chinese version of the adequacy theory also bases causation on two essential tests: (1) the "but for" or "conditio sine qua non" test, and (2) the "adequacy" - an increased

109 For more information on the development of the theory of causation in Chinese tort law, see e.g. Yu 2016.

110 See e.g. LJI-Shanghai Guide to Malpractice 2005 (China); LJI-Jiangsu Guide to Torts 2011 (China). Local judicial guides issued by high or intermediate courts are not judicial interpretations. They are by no means applicable rules and cannot be directly cited in decisions. In practice, nevertheless, these local guides are highly influential in local judges' application of law in the sense that cases of the first instance may be overruled by appellate courts if trial judges do not strictly follow relevant guides issued by the appellate courts. In other words, local judicial guides represent opinions of appellate courts.

111 LJI-Shanghai Guide to Malpractice 2005 (China), art. 13.

112 LJI-Jiangsu Guide to Torts 2011 (China), art. 5, para. 1. 
objective probability or reasonable likelihood. ${ }^{113}$ Interestingly, in China the first step is also referred to as "causation in fact/factual causation" (事实上的因果矢系) and the second one as "causation in law/legal causation" (法律上的因果关系). While factual causation is essential to the establishment of liability, legal causation is more concerned with the scope of compensation. Hence, issues of legal causation will be addressed in Section 3.7 where the law of damages in China is examined.

\subsubsection{Uncertainty over Factual Causation}

In particular, proof of causation is difficult in medical malpractice cases. Besides faulty treatments, injuries suffered by patients may result from two non-tortious factors: (1) the normal outcome of the patient's underlying or pre-existing medical condition, and (2) therapeutic risks inherent in treatment beyond physicians' control. ${ }^{114}$ It is often indeterminate whether, or which part of, the final injury is attributable to the negligent treatment. In practice, a significant proportion of medical cases involves scientific uncertainty and are quite difficult cases to resolve.

At least two factors may contribute to evidential uncertainty and dispute over causation ("causal uncertainty"). First, there is evident informational asymmetry between medical professionals and patients (and judges). ${ }^{115}$ Second, it is not infrequent in some medical cases that even medical experts are unsure whether or to what extent an injury was caused by the negligent treatment. ${ }^{116}$ In short, causal uncertainty may make proof of causation highly problematic.

Although the Tort Law 2009 provides for rules handling alternative causes, ${ }^{117}$ multiple sufficient causes, ${ }^{118}$ joint torts (no single defendant's conduct could cause full harm alone), ${ }^{119}$ and contributory negligence, ${ }^{120}$ it does not specify any rule concerning causal uncertainty in medical malpractice cases. For this reason, after reading the text of the Tort Law 2009,

113 This two-step approach is similar to that under German tort law. See e.g. Magnus 2000, pp. 64-65.

114 Khoury 2006, pp. 51-52; Stauch 2008, p. 76; Yang 2008, p. 38; Wang 2014, pp. 8-10.

$115 \quad$ Khoury 2006, p. 51.

$116 \quad$ Young, Faure \& Fenn 2004, p. 507.

117 Tort Law 2009 (China), art. 10 (liability in solidum unless the real tortfeasor could be identified).

118 Tort Law 2009 (China), art. 11 (liability in solidum).

119 Tort Law 2009 (China), art. 12 (several liability apportioned in light of relative responsibility).

120 Tort Law 2009 (China), art. 26 (apportioned in light of comparative negligence) and art. 27 (no liability in case the harm is caused intentionally by the victim). 
Oliphant concluded that, "by providing a general solution only to the problem of 'alternative' or 'indeterminate' defendants and restricting itself to an all-or-nothing approach, the new Chinese Tort Liability Law lags behind cutting-edge developments at national level" - proportional liability. ${ }^{121}$

\subsection{ETHICAL MALPRACTICE}

In China, not all medical ethics are recognised by law and thus become enforceable. According to the Tort Law 2009, only three types of medical ethics are legally protected - respecting the patient's autonomy, protecting the patient's privacy, and providing services with bona fides. Ethical malpractice on the part of providers could be established if they failed to disclose information or to obtain consent, if they infringed upon the patient's privacy, ${ }^{122}$ or if they conducted unnecessary examinations. ${ }^{123}$ Compared to the latter two, disclosure malpractice claims are the most important form of ethical malpractice claims in that they are often intertwined with technical malpractice claims and associated with the choice of treatment measures and iatrogenic injuries. Hence, only disclosure malpractice issues will be addressed in this section.

Before the advent of the Tort Law 2009, the patient's right to informed consent was stipulated dispersedly by some laws and regulations regarding health care provision. However, none of these laws and regulations had provided for compensatory liability for breach of the informed consent rule. ${ }^{124}$ Nevertheless, the "undergoing reform in China has germinated and fertilised patients' awareness of informed consent and their readiness to sue hospitals"125 and more and more local courts began to accept and hear medical

121 Oliphant 2012, p. 395. For more information about proportional liability from the perspective of comparative law, see generally Gilead, Green \& Koch 2013.

122 Tort Law 2009 (China), art. 62 reads, "A medical institution and its medical staff shall keep confidential the privacy of a patient. If any privacy data of a patient is divulged or any of the medical history data of a patient is open to the public without the consent of the patient, causing any harm to the patient, the medical institution shall assume the tort liability."

123 Tort Law 2009 (China), art. 63 reads, "A medical institution and its medical staff shall not conduct unnecessary examinations in violation of the procedures and standards for diagnosis and treatment."

124 In other words, a provider who is found in contravention of any of these rules pertaining to informed consent would be subject to administrative punishments. See supra Chapter 2, Section 4.3. However, victims could not claim compensation for any infringement of their rights to informed consent on the basis of these rules. For a detailed discussion on the evolution of the informed consent doctrine in China, see generally Zhao 2012. Dai 2003, p. 59. 
cases concerning disputes over informed consent even without a clear legal basis around 2000.126

One of the most impressive achievements of the new Tort Law is that it exposes a health care provider's "breach of the duty of disclosure to potential civil (tort) liability." 127 The Law creates the informed consent doctrine by article 55 , which reads

In the course of providing treatment services, medical staff members shall disclose the condition and relevant medical measures to patients. If any surgery, special examination or special treatment is needed, the medical staff shall disclose the medical risks, alternative treatment plans and other information to the patient in a timely manner, and obtain the written consent of the patient; or, when it is not advisable to disclose the information to the patient, disclose the information to the close relative of the patient, and obtain written consent from the close relative.

Where any medical staff member fails to fulfil the duties in the preceding paragraph and causes any harm to a patient, the medical institution shall assume the compensatory liability. [italics added]

In normal circumstances, providers only have to disclose information on the patient's condition and relevant medical measures to patients. However, in some special circumstances, providers are supposed to disclose "medical risks" and "alternative treatment plans" to patients and obtain their written consent. Whether all risks or alternative plans, or only those significant ones should be disclosed (the materiality test) is not specified by the Law.

Special circumstances refer to "surgery, special examination or special treatment." While the notion of "surgery" is clear and easy to understand, "special examination or special treatment" are rather ambiguous phrases. The Tort Law does not define these phrases. Nonetheless, they are defined elsewhere. ${ }^{128}$

The Tort Law treats the duty to inform and the duty to provide treatment as two different types of duty of medical care. Hence, the "then medical standard" (article 57) that is intended for technical malpractice claims

\footnotetext{
$126 \quad$ Jiang 2006, pp. 116-117.

127 Zhao 2012, p. 164

128 DR-Detailed Rules-Medical Institutions 2006 (China), art. 88 provides, "Special examination and treatment refer to any examination and treatment: (1) that entail some risks and may produce adverse consequences; (2) that may produce adverse consequences and risks due to the patient's idiosyncratic pre-dispositions or critical conditions; (3) that are of clinical experiments; or (4) that may impose a considerable financial burden on patients.
} 
does not seem to apply to disclosure malpractice claims. ${ }^{129}$ In theory, it follows that expert testimony may become unnecessary in disclosure malpractice cases in that information disclosure is "essentially a matter of practical and ethical consideration rather than one requiring exclusively medical judgement/technical skills." ${ }^{30}$ If article 57 does not apply to disclosure malpractice claims, one may wonder what standard providers have to comply with when disclosing information. However, the Law is silent on the standard of disclosure. Hence, it is still open to argument whether the doctor-oriented or the patient-oriented approach should be adopted in China.

According to para. 2 of article 55, in case the provider fails to disclose sufficient information and inflicts any harm on the patient's autonomy, the provider-hospital shall be held liable for paying non-pecuniary damages if the patient suffered severe emotional distress. ${ }^{131}$

\subsection{MEDICAL PRODUCTS LIABILITY}

To non-Chinese readers, it may be somewhat odd to mention medical products liability in the context of medical malpractice liability, since the provision of health care services and the sale of medical products are usually separated in most countries. However, in China, hospitals rely heavily on drug sales to "provide nearly $80 \%$ of their revenue"132 due to low service prices and government subsidies. Some reported that hospitals' markup could be $15 \% .{ }^{133}$ Hence, the Law treats medical institutions rather like sellers in products liability cases.

To begin with, it is necessary to see how Chinese law handles products liability in ordinary cases. In principle, strict liability (liability irrespective of fault) applies to manufacturers ${ }^{134}$ while fault liability applies to sellers. ${ }^{135}$ However, towards the victim, either the manufacturer or the seller of a

\footnotetext{
129 Zhao 2012, pp. 165-167.

130 Zhao 2012, p. 167

131 Tort Law 2009 (China), art. 22. See also infra Section 3.7.3.

132 Burkitt 2015.

133 Gu 2014, p. 160.

134 Tort Law 2009 (China), art. 41 provides, "Where a defective product causes any harm to another person, the manufacturer shall assume the tort liability." See also Product Quality Law 2000 (China), art. 41, para. 1.

135 Tort Law 2009 (China), art. 42, para. 1 provides: "Where a product with any defect due to the fault on the part of the seller causes any harm to another person, the seller shall assume the tort liability." In addition, according to art. 42, para. 2, the seller shall also be held liable if it "can neither specify the manufacturer of a defective product nor specify the supplier of the defective product." See also Product Quality Law 2000 (China), art. 42.
} 
defective product is strictly liable. ${ }^{136}$ In other words, the victim may claim damages from either the manufacturer or the seller provided that he/she could prove that the product was defective and caused the injury he/she suffered. The defect is defined as "an unreasonable danger" or a breach of safety standards. ${ }^{137}$ After paying the whole damages to the victim, the manufacturer and the seller have recourse against each other in accordance with who is ultimately liable for the defect. ${ }^{138}$ Punitive damages may be granted in case of intentional torts. ${ }^{139}$

Hence, towards the victim, both the manufacturers and the seller are held strictly liable in the first place, often termed "intermediate liability" (中间责任). ${ }^{140}$ Then, between the manufacturer and the seller, either the former is ultimately liable (based on strict liability) or the latter is ultimately liable (based on fault). ${ }^{141}$ Thus, the liability is not really joint and several liability (or liability in solidum), but is what most Chinese scholars term as “imperfect liability in solidum" (不真正连带责任). ${ }^{142}$ The legislative rationale behind this imperfect solidary liability is to "better protect victims by making it more convenient for them to file a lawsuit, by reducing the burden of proof

$136 \quad$ Tort Law 2009 (China), art. 43, para. 1 provides, "Where any harm is caused by a defective product, the victim may claim damages for his/her injury from either the manufacturer or seller." See also Product Quality Law 2000 (China), art. 43.

137 Product Quality Law 2000 (China), art. 46 provides, "The defect mentioned in the Law refers to an unreasonable danger existing in the products that threatens the safety of person or property, or a breach of national or industrial standards that are intended to protect the health, person, or property of citizens."

138 Tort Law 2009 (China), art. 43, para. 2 provides, "If the defect of the product is caused by the manufacturer and the seller has paid full damages to the victim, the seller shall have recourse against the manufacturer for the payment." Art. 43 , para. 3 provides: "if the defect of the product is caused by the fault on the part of the seller and the manufacturer has paid full damages to the victim, the manufacturer shall have recourse against the seller." See also Product Quality Law 2000 (China), art. 43.

139 Tort Law 2009 (China), art. 43, art. 47 provides, "Where a manufacturer or seller knowing any defect of a product continues to manufacture or sell the product and the defect causes a death or any serious damage to the health of another person, the victim shall be entitled to claim a proper amount of punitive damages." In China, products liability is the only type of tort cases where punitive damages may be imposed. All the other types of tort cases apply compensatory damages.

140 See generally Yang \& Yang 2013.

141 Id.

142 The basic features of the "imperfect liability in solidum" include: (1) that the victim is entitled to claim damages from each of the multiple defendants; (2) that liability is generated by several independent torts rather than a joint tort; (3) that each of the multiple defendants has to pay the same amount of damages for the same harm; and (4) that either each of the multiple defendants has no recourse against the others, or recourse is sought not because of contribution among joint-tortfeasors but because one or several of the multiple defendants are ultimately liable. See generally e.g. Kong 1994; Wu 2008; Wang 2009; Jiang 2010; Gao 2012. 
on them, and by imposing the risk of insolvency on all potentially liable parties." ${ }^{143}$ In practice, for the purpose of efficiency, most courts would list manufacturers and sellers as joint defendants and resolve all disputes in a single trial. ${ }^{144}$

It should be noted that products liability in China is strict liability, but it is not absolute liability. The manufacturer may legitimately raise three defences against both the victim and the seller, of which the development risk defence is the most remarkable one. ${ }^{145}$ However, the law is silent on whether the seller may raise any of these defences against the victim if the victim sues it first. Some argue that the seller should be allowed to raise these defences against victims; otherwise, the seller who was not at fault but nonetheless had paid full damages to the victim first would ultimately bear the losses alone if the manufacturer raised any of the defences. ${ }^{146}$

Before the inception of the Tort Law, it was highly debatable whether hospitals should be treated as sellers. For instance, in the famous Liang $v$. The Third Hospital et al. (or "Qi Er Yao" case), ${ }^{147}$ the trial court regarded the defendant-hospital as a seller. The reason was that the hospital "purchased the pharmaceutical in question at the price of 36.005 yuan from the defendant-company, and then sold it to the victimised patient at the price of 46.10 yuan, with a markup of $28 \%$, which is not different from a sale in the market." The hospital lodged an appeal and argued that hospitals are not sellers primarily on three grounds: first, the giving of medicine is a treatment activity for the purpose of curing diseases, which is by no means a sale in the market; second, most medicine is prescribed by physicians in the light of the patient's conditions rather than the patient's free choice; and third, the markup is not a profit but a permitted remedy for the government's underinvestment in public hospitals. ${ }^{148}$ However, the hospital's arguments were not accepted by the appellate court, and the hospital was still held liable as a seller.

\footnotetext{
$43 \quad$ Jiang 2010, p. 19.

$144 \quad$ Jiang 2010, p. 20.

145 Product Quality Law 2000 (China), art. 41, para. 2 provides, "Producers shall not be held liable if they can prove one of the following cases: (1) that the products have not been put into circulation; (2) that the defects are non-existent when the products are put into circulation; or (3) the defects cannot be found at the time of circulation due to scientific and technological limitations." Sub-paras. 1-2 are merely proof of the absence of causation. Only sub-para. 3 is the development risk defence.

146 Zhang 2013, p. 222; Dong 2015, pp. 188-190.

147 For a detailed description and comment on the "Qi Er Yao" case, see Zhao 2013, pp. 306309.

148 Liang v. The Third Hospital et al. (China).
} 
This dispute ends with the advent of the Tort Law. Article 59 confirms that hospitals are sellers of medical products, which reads

\begin{abstract}
Where any harm to a patient is caused by the defect of any pharmaceutical, medical disinfectant or medical instrument or by the transfusion of substandard blood, the patient may require compensation from the manufacturer or institution providing blood, or require a compensation from the medical institution. If the patient requires compensation from the medical institution, the medical institution that has paid the compensation shall be entitled to be reimbursed by the liable manufacturer or institution providing blood.
\end{abstract}

As far as pharmaceuticals, disinfectant, and medical instruments are concerned, article 59 is virtually a repetition of article 43 . Hence, the same definition of the defect applies to these medical products, and the same defences are available to manufacturers of medical products.

What is hotly debated is how to treat blood used for transfusion. Some argue that blood can be a product while others do not agree. ${ }^{149}$ Lawmakers believe that blood used for transfusion is "quasi-products," and hence they list "substandard blood" and other real medical products parallel to each other in article $59 .{ }^{150}$ The rationale is that "providers of blood are abler than patients at controlling, bearing, and spreading risks of transfusion infection." ${ }^{\prime 15}$ Therefore, strict liability applies to cases involving substandard blood.

However, the Law does not specify what "substandard" means. According to lawmakers, the wording "substandard" in article 59 is intended to describe the quality of blood itself rather than the behaviour of blood providers or hospitals. ${ }^{152}$ In practice, many statutory standards concerning the collection, testing, storage, transportation, and transfusion of blood are imposed on blood banks and hospitals. ${ }^{153}$ Once they contravene any of these standards and cause harm to patients, they may be found liable based on fault liability in that article 59 is not meant to apply to those cases where e.g. article 54 is applicable. Therefore, strict liability for substandard blood in article 59 is specifically intended to handle cases where neither the blood bank nor the hospital is at fault - the so-called "faultless blood transfusion" (无过错输血). ${ }^{154}$

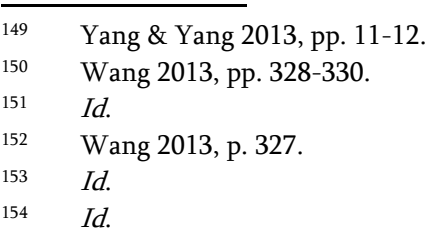


It follows that "substandard blood" in article 59 narrowly only refers to the blood contaminated by malignant bacteria or viruses either that cannot be reliably detected due to a window period ${ }^{155}$ or that are unknown to the medical community in the light of the then state of the art. ${ }^{156}$ Before the inception of the Tort Law, courts were divided on how to tackle this difficult issue: some courts applied strict liability to these cases and held the hospital liable irrespective of fault; in contrast, some courts insisted that fault liability should be applicable and denied the plaintiff's claims; and, more remarkably, some courts simply applied "equitable liability" (公平责任) ${ }^{157}$ to these cases and apportioned the damage between the plaintiff and the defendant in light of fairness. ${ }^{158}$ With the enactment of the Tort Law, it is now clear that strict liability applies to substandard blood cases.

This narrow interpretation of "substandard" also implies that liability for harm due to substandard blood is stricter (almost absolute) than ordinary products liability since the former excludes the possibility of raising a development risk defence. ${ }^{159}$ The rationale behind this difference is that lawmakers intend "to intensify patient protection and to induce hospitals and blood banks to take more precautionary measures to prevent iatrogenic injuries." "160 However, if the blood bank is not allowed to raise the development risk defence, why is such a defence available to the manufacturer of medical products?

When it comes to recourse, a notable difference between a sellerhospital and an ordinary seller is that recourse is sought unidirectionally. Hospitals who have paid full damages to victimised patients are allowed to claim the payment back from manufacturers or blood banks who are ultimately liable, while it is unclear whether the latter may have recourse against the former.

\footnotetext{
155 In medicine, a window period for a test designed to detect a specific disease (often infections) is the time between the first infection and when the test can reliably detect that infection. In blood transfusion, the window period is significant in that during the period, an infected person cannot be detected as infected but may still be able to infect others.

$156 \quad$ Yang \& Yang 2013, p. 12.

157 The relevance of "equitable liability" will be addressed in infra Section 3.5. It should be noted that “公平责任” is also translated by Chinese scholars as "equity liability" or "fairness liability" in English. See e.g. Koziol \& Zhu 2010; Zhang 2011. They all refer to the same Chinese legal concept.

$158 \quad$ Wang 2013, pp. 326-327.

159 Yang \& Yang 2013, p. 12.

$160 \quad$ Id.
} 


\subsection{EQUITABLE LIABILITY}

Equitable liability is a fairly elastic regime in Chinese tort law. Article 24 of the Tort Law provides, "Where neither the victim nor the actor is at fault for the occurrence of the damage, both of them may share the damage based on the actual situations." ${ }^{161}$ Thus, it is argued that equitable liability "manifests more the spirit of distributive justice than corrective justice"162 According to lawmakers, "actual situations" mean "the means and details of the action, the magnitude of the losses, the impacts of the losses and the financial positions of the two parties, etc." 163 In practice, particular attention is paid to the disparity in financial positions between the two parties and it is highly likely that the party with a deeper pocket would share a larger portion of the damage. ${ }^{164}$

One may question whether equitable liability is applicable to medical malpractice claims. The uncertainty here is generated by the fact that article 24 is located at the General Part of the Tort Law whereas liability for iatrogenic injuries (arts. 54-64 in Chapter VII) lies at the Special Part. Hence, it can be said that article 24 is a general principle that may apply to all types of special torts at the Special Part. However, it can be equally argued that because medical torts are a special type of torts, Chapter VII may exclude the possibility of applying article 24 to medical disputes. Regrettably, neither the Tort Law nor the SPC has ever specified this issue.

In practice, local courts are divided on this issue. On the one hand, many courts would like to apply equitable liability in the event that the victim suffered considerable harm and had to shoulder heavy financial burdens. ${ }^{165}$ On the other hand, some courts would object to the application of equitable liability to medical malpractice cases and hold that "it is groundless to apply equitable liability to medical malpractice cases where only fault liability applies."166

Unlike courts, scholars are generally opposed to the application of equitable liability to medical torts for two main reasons. First, it makes medical malpractice liability "stricter" and may stimulate defensive

\footnotetext{
161 See also Principles 1986, art. 132.

162 Wang, L. 2011, p. 225.

Wang 2013, p. 130.

Wang. L. 2011, pp. 254-255.

165 See e.g. Yang v. Ruijing Hospital (China); Liu v. Pingdingshan Hospital (China); Li v. Shaoyang Hospital (China); Xu v. Changge Hospital (China); Wang v. Nantong Affiliated Hospital(China); Shen v. A Hospital(China); Yang v. Shantou Affiliated Hospital(China). 166 Huang v. Chen (China).
} 
medicine. ${ }^{167}$ Second, a rich hospital relative to a poor patient may become less rich when compared with the whole population of its patients. ${ }^{168}$

This contradiction between prevailing court practice and main academic opinions gives rise to greater uncertainty as to the applicability of equitable liability to medical disputes.

\subsection{EXPERT EVIDENCE}

\subsubsection{Introduction}

In medical malpractice claims, expert evidence is critical since judges lack the necessary medical expertise to determine, inter alia, whether there is a breach of the standard of medical care and whether or to what extent the faulty treatment has contributed to the injury. ${ }^{169}$ The expert witness system is relevant to the topic of medical malpractice in that it may have significant implications for the substantive determination of medical liability and the apportionment of damages.

For the period 2002-2009, two parallel expert witness systems were available for medical malpractice claims - the Medical Accident Technical Ascertainment System (hereinafter MATAS) for medical accident claims, and the Judicial Ascertainment System (hereinafter JAS) other for ordinary claims. ${ }^{170}$ Section 3.6 .2 will briefly describe the basics of the two systems. Section 3.6.3 is intended to compare and contrast these two systems. Section 3.6.4 will discuss any changes concerning the two systems after the advent of the Tort Law 2009.

\subsubsection{The Basics}

\subsubsection{The MATAS}

The MATAS, dating back to the 1980 s, ${ }^{171}$ has been run by various levels of medical associations ${ }^{172}$ since $2002 .{ }^{173}$ By 2010, about 400 ascertainment

\footnotetext{
167 Shu 1998, p. 74; Deng, Li \& Chen 2007, p. 120.

168 Xu 2004, p. 21; Deng, Li \& Chen 2007, p. 121.

169 Zhang \& Chen 2013, p. 240.

170 For the differences between medical accident claims and ordinary claims, see supra Section 2.

171 The old MATAS (1987-2001) was established in accordance with arts. 12-17 of the ARMedical Accidents 1987 (China). Expert witnesses were directly administered by special ascertainment committees, which were in turn led by the public health authorities. However, this old MATAS was criticized for protectionism (both ascertainment
} 
institutions had been established by various levels of medical associations, with a total of 1,500 staff members. ${ }^{174}$

The most remarkable advantage of the MATAS is that each medical association has developed its own expert bank, ${ }^{175}$ from which several experts are randomly selected by both parties to a medical dispute to form an ad hoc Expert Ascertainment Group (hereinafter EAG) ${ }^{176}$ Both clinical providers and forensic pathologists with senior titles, within or outside the local jurisdiction, may be included in the expert bank. ${ }^{177}$ When being demanded, qualified clinical providers or forensic pathologists are obliged to be included in the expert bank and to undertake the duty of providing expert testimony. ${ }^{178}$ There must be an odd number of EAG's members and more than half of its members shall be experts in the major discipline involved. ${ }^{179}$ In case it is necessary to ascertain the cause of the death or the degree of disability, forensic pathologists should be selected randomly from the expert bank to join the EAG. ${ }^{180}$ Up to 2010, about 100,000 medical experts had been included in expert banks. ${ }^{181}$ The expert bank is sub-divided into 62 specialties in order to guarantee the scientific standard of ascertainment. ${ }^{182}$

The EAG shall provide testimony on the basis of a collegial system (simple majority votes) rather than individual opinions. ${ }^{183}$ Based on all evidence, statements, and answers from both disputants, the medical association that administers the EAG shall issue a letter of ascertainment

committees and public hospitals were subordinate to the same public health authorities), monopoly (experts not belonging to authentication committees were not permitted to testify in court), and lack of transparency (no signatures of experts and conducted in black boxes). Harris \& Wu 2005, pp. 461-462. For a more thorough discussion on medical expert expertise in China, see Ding 2012, pp. 143-186.

172 Local medical associations are branches of the Chinese Medical Association (CMA). For more information on the CMA, see supra Chapter 2, Section 4.4. It should be made clear that just as the CMA is subordinate to the NHFPC (MoH before 2013), a local medical association is subordinate to the HFPC at the same level within the same jurisdiction. Hence, no medical associations in China are self-regulated organisations.

173 The current MATAS was created on the basis of the AR-Medical Accidents 2002 (China), arts. 20-34.

$174 \quad$ See generally Zhang 2010.

175 AR-Medical Accidents 2002 (China), art. 23, para. 1.

176 AR-Medical Accidents 2002 (China), art. 24, paras. 1-2.

177 AR-Medical Accidents 2002 (China), art. 23, paras. 2-4.

178 AR-Medical Accidents 2002 (China), art. 24, para. 3.

179 AR-Medical Accidents 2002 (China), art. 25.

$180 \quad$ Id.

181 See generally Zhang 2010

$182 \quad$ Id.

183 Id.; AR-Medical Accidents 2002 (China), art. 31, para. 1. 
within 45 days. ${ }^{184}$ The letter of ascertainment shall include, inter alia, whether the provider has contravened any statutory standards, treatment norms, or customary practice, whether there is a causal link between the negligent treatment and the personal injury, to what extent the negligent treatment has contributed to the injury, and the degree of the accident. ${ }^{185}$

In case any of the disputants refuses to accept the conclusion of the first ascertainment, a second ascertainment conducted by medical associations of the higher level may be initiated. ${ }^{186}$ The final conclusion of ascertainment shall be treated as the basis for imposing administrative punishments and compensation for iatrogenic injuries. ${ }^{187} \mathrm{Up}$ to 2010, the rate of medical accidents that would be established had been between 35\% and 37\% in the first ascertainment, and between $51 \%$ and $53 \%$ in the second ascertainment. ${ }^{188}$ The conclusions of the first instance and the second instance had matched in $75 \%$ of all ascertainment. ${ }^{189}$ More than two-thirds of all ascertainment had been used in litigation. ${ }^{190}$ After the first ascertainment, litigants would only apply for a second ascertainment in less than one-quarter of the cases. ${ }^{191}$

Disputants should pay some fees for the ascertainment to medical associations. ${ }^{192}$ In case a medical accident is established, these fees will be paid by the hospital ultimately; if not, the fees will be paid by the disputant that applies for the ascertainment. ${ }^{193}$ The ascertainment fee is relatively low. In Jiangsu Province, for example, where there are 7 appointed experts or more, the fee is 2,200 yuan for the first ascertainment and 3,200 yuan for the second; if there are less than seven experts, the fee is 1,700 yuan for the first ascertainment and 2,200 yuan for the second. ${ }^{194}$

\subsubsection{The JAS}

The JAS is much older than the MATAS, which can be traced back to the 1930s. ${ }^{195}$ Forensic pathologists had played a significant role in ascertaining the

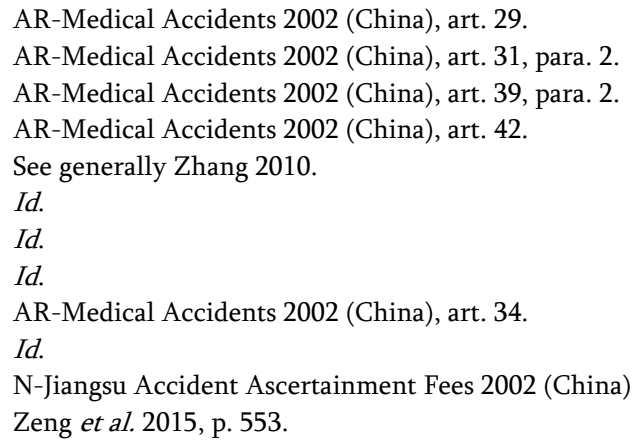


cause of the death of a patient between 1949 and $1986^{196}$ However, during the period 1987-2002, most expert evidence on medical malpractice was offered by experts under the MATAS. Since 2003, the JAS has begun to grow rapidly in that ordinary claims need to be resolved on the expert testimony offered by forensic pathologists. ${ }^{197}$ Unlike the MATAS which can be applied for outside litigation, the JAS is only intended to be used in litigation. ${ }^{198}$ While medical associations are administered by the public health authorities, forensic institutions and pathologists are administered by the judicial administrative authorities. ${ }^{199}$ Hence, the JAS is rather independent of the medical profession. By the end of 2011, there were a total of 2,284 forensic ascertainment institutions. ${ }^{200}$

The procedure of the JAS is much simpler than that of the MATAS. There is no expert bank, the EAP that primarily consists of clinical experts, the collegial system, a short time limit for providing a conclusion, or two instances of ascertainment under the JAS. Three qualified forensic pathologists with necessary equipment are allowed to engage in judicial ascertainment. ${ }^{201}$ There is no hierarchical relationship between ascertainment institutions. ${ }^{202}$ The court may appoint a forensic pathologist without any geographical restriction. ${ }^{203}$ The forensic pathologist must offer testimony individually and put his/her signature to the conclusion of ascertainment. ${ }^{204}$ If, in the process of litigation, any party concerned has any objection to the conclusion of ascertainment, the forensic pathologist will appear in court to bear witness. ${ }^{205}$ In practice, forensic pathologists normally provide testimony on whether there was any fault on the part of the provider, whether there was causation between the fault and the injury, to what extent the injury was caused by the faulty treatment, and the degree of disability. In 2011, forensic pathologists had provided about 8,000 pieces of expert evidence for medical malpractice cases. ${ }^{206}$

Ascertainment fees are often considered as part of litigation costs, which are in principle imposed on the losing party. ${ }^{207}$ In case neither of the

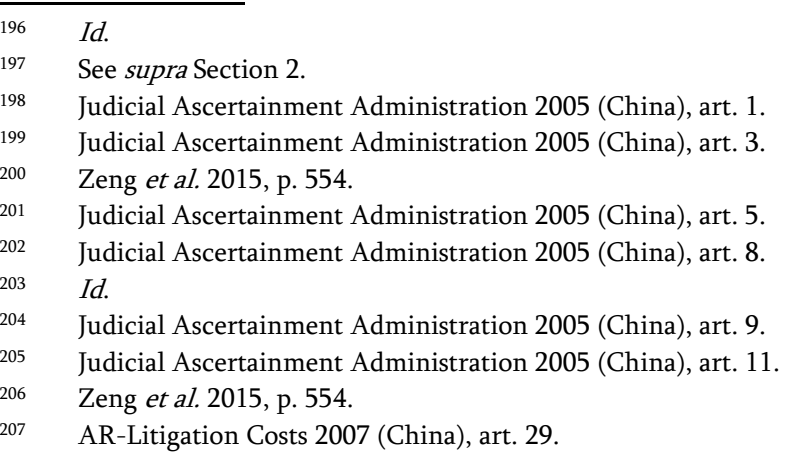


parties wins the lawsuit completely, they should share all litigation costs. ${ }^{208}$ Compared to fees under the MATAS, the fees under the JAS are relatively higher. It is reported that forensic ascertainment fees would often be between 4,300 and 10,000 yuan. ${ }^{209}$ Some even pointed out that in practice in most cases the fee would be around 10,000 yuan. ${ }^{210}$

\subsubsection{A Comparison and Contrast}

The main similarities and differences mentioned are summarised in Table 3.2 as follows:

Table 3.2: Similarities and Differences between the MATAS and the JAS

\begin{tabular}{|c|c|c|}
\hline & JAS & MATAS \\
\hline Nature & $\begin{array}{l}\text { litigation activities (basis } \\
\text { for compensation) }\end{array}$ & $\begin{array}{l}\text { administrative activities (basis for } \\
\text { administrative punishments and } \\
\text { compensation) }\end{array}$ \\
\hline $\begin{array}{l}\text { Targets of } \\
\text { ascertainment }\end{array}$ & $\begin{array}{l}\text { - fault } \\
\text { - causation } \\
\text { - causal potency } \\
\text { - degree of disability }\end{array}$ & $\begin{array}{l}\text { - unlawfulness (implying negligence) } \\
\text { - causation } \\
\text { - seriousness of liability (equivalent to } \\
\text { causal potency) } \\
\text { - degree of the accident (in light of } \\
\text { disability or death) }\end{array}$ \\
\hline Organiser & $\begin{array}{l}\text { judicial ascertainment } \\
\text { institutions }\end{array}$ & medical associations \\
\hline $\begin{array}{l}\text { Administration } \\
\text { concerned }\end{array}$ & $\begin{array}{l}\text { judicial administrative } \\
\text { authorities }\end{array}$ & public health authorities \\
\hline Appointed experts & $\begin{array}{l}\text { - forensic pathologists } \\
\text { - independent of the } \\
\text { medical profession }\end{array}$ & $\begin{array}{l}\text { - clinical providers (the majority, always } \\
\text { included) } \\
\text { - forensic pathologists (the minority, not } \\
\text { always included) } \\
\text { - less independent of the medical } \\
\text { profession }\end{array}$ \\
\hline Procedures & $\begin{array}{l}\text { - less strict } \\
\text { - an individual decision } \\
\text { - personal signature on } \\
\text { the conclusion } \\
\text { - experts obliged to appear } \\
\text { in court }\end{array}$ & $\begin{array}{l}\text { - stricter (quasi-litigation) } \\
\text { - a collective decision by a simple } \\
\text { majority vote } \\
\text { - no personal signature on the conclusion } \\
\text { - experts not obliged to appear in court }\end{array}$ \\
\hline $\begin{array}{l}\text { Competent } \\
\text { Authorities }\end{array}$ & $\begin{array}{l}\text { judicial administrative } \\
\text { authorities }\end{array}$ & public health authorities \\
\hline
\end{tabular}

\begin{tabular}{ll}
\hline 208 & Id. \\
209 & Guo 2015, p. 296. \\
210 & Liu, Y. 2014, p. 68.
\end{tabular}




\begin{tabular}{lll}
\hline & \multicolumn{1}{c}{ JAS } & \multicolumn{1}{c}{ MATAS } \\
\hline Levels & no limits to the level, location or number of times & $\begin{array}{l}\text { - first ascertainment } \\
\text { - second ascertainment at a } \\
\text { higher level }\end{array}$ \\
\hline Fees & $\begin{array}{l}\text { - the applicant or the hospital if a medical accident } \\
\text { is established has to bear } \\
\text { - lower fees }\end{array}$ & $\begin{array}{l}\text { - the losing party has to bear } \\
\text { - higher fees }\end{array}$ \\
\hline
\end{tabular}

After comparing and contrasting the two systems, it is clear that neither of them is necessarily superior to the other. On the one hand, the MATAS has three advantages over the JAS. First, the MATAS may ensure a better scientific level of ascertainment through peer review than the JAS. ${ }^{211}$ Clinical providers have better knowledge, expertise, and experience than forensic pathologists as far as the determination of negligence is concerned. ${ }^{212}$ The sub-division of the expert bank into 62 specialties is conducive to greater accuracy of the conclusion. Pathologists, who are better at ascertaining the cause of a death and the degree of disability, may also be included in the expert bank. Second, the MATAS may better promote due process than the JAS. The MATAS is conducted on the basis of a quasi-litigation, where appointed experts review both disputants' evidence and hear their statements and answers. In contrast, the JAS does not have such a strict procedure. Third, the MATAS is administratively less costly than the JAS. The ascertainment fee under the MATAS is relatively lower than that under the JAS.

On the other hand, the JAS appears superior to the MATAS in two aspects. First, the JAS may ensure better impartiality than the MATAS. Forensic institutions and pathologists are independent of the medical profession and the public health authorities. In practice, forensic ascertainment conclusions are more welcomed by patients and the court. ${ }^{213}$ Second, the JAS may better facilitate the fact-finding in court than the MATAS. In case the ascertainment conclusion is disputed, forensic pathologists will often attend the court and testify in person, whereas clinical experts will rarely do so. ${ }^{214}$

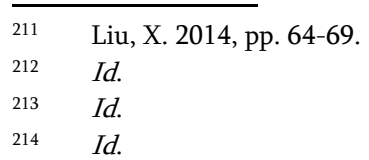




\subsubsection{The Two Systems after the Inception of the Tort Law}

The implementation of the new Tort Law 2009 has not changed the double tracks of expert witness systems substantially. The SPC simply issued an ambiguous statement that when deciding medical cases, the court may, upon the request of litigants or ex officio, organise forensic ascertainment or other ascertainment. ${ }^{215}$ Hence, the MATAS and the JAS are still running parallel to each other for the time being. The only change is that both of them are now called the Medical Injury Ascertainment System (hereinafter MIAS). However, the administration, organisation, and procedures of each system remain largely unchanged.

Local high people's courts interpret the preceding SPC's statement differently. For instance, both Jiangsu High Court ${ }^{216}$ and Beijing High Court ${ }^{217}$ issued new rules concerning ascertainment. Although they both allow the coexistence of the MATAS and the JAS, they take a very different attitude towards the choice of priority between them - while Jiangsu prefers the MATAS to the JAS, Beijing assigns a priority to the JAS. ${ }^{218}$

Currently, it is unclear whether the two parallel systems will merge in the future.

\subsection{THE LAW OF DAMAGES}

\subsubsection{Introduction}

For the period 1987-2001, only a rather limited lump sum of compensation has been available to victimised patients. ${ }^{219}$ Between 2002-2009, two parallel criteria for compensating iatrogenic injuries had existed - on ${ }^{220}$ for medical accident claims, and the other ${ }^{221}$ for ordinary claims (and for any other civil claims). Since the implementation of the Tort Law, the criteria for medical accident claims have not been applicable any longer. The current criteria for compensating iatrogenic injuries (also for any other type of personal injury)

\footnotetext{
215 JI-Application of Tort Law 2010 (China), art. 3.

216 LJI-Jiangsu Guide to Injury Ascertainment 2010 (China); LJI-Jiangsu Notice on Injury Ascertainment 2010 (China).

$217 \quad$ LJI-Beijing Guide to Malpractice 2010 (China).

218 For a detailed comparison between the Jiangsu model and the Beijing model, see generally Xiao 2011.

AR-Medical Accidents 1987 (China), art. 18.

AR-Medical Accidents 2002 (China), arts. 49-52.

Principles 1986 (China), art. 119, together with the JI-Emotional Damage 2001 (China) and JI-Personal Injury 2004 (China).
} 
are primarily provided for in article 16 and article 22, together with the JIEmotional Damage 2001 (for non-pecuniary losses) and the JI-Personal Injury 2003 (for pecuniary losses).

Since the criteria in the AR-Medical Accidents 2002 are not applicable anymore, the details of those criteria will not be described in this section. The general finding is that victims would obtain more damages by the criteria for ordinary claims than by the criteria for medical accident claims in that fewer caps had been imposed on the former, and the latter did not permit death compensation while the former did. ${ }^{222}$

In the remaining parts of this section, the current criteria for compensating personal injuries will be addressed. Section 3.7.2 will discuss compensation for pecuniary losses and Section 3.7.3 will touch upon compensation for non-pecuniary losses. Section 3.7.4 will examine the hotly debated issue of whether injury due to non-tortious causative factors such as the pre-existing condition should be compensable.

\subsubsection{Compensation for Pecuniary Losses}

\subsubsection{The Legal Basis}

Article 16 of the Tort Law defines the categories of compensation for pecuniary losses as a consequence of harm to health, bodily integrity, or loss of life, which reads as follows,

Where a tort causes any personal injury to another person, the tortfeasor shall compensate the victim for the reasonable costs and expenses for treatment and rehabilitation, such as medical expenses, nursing fees and travel expenses, as well as the lost earnings. If the victim suffers any disability, the tortfeasor shall also pay the costs of disability assistance equipment for the living of the victim and disability compensation (残疾赔偿金). If it causes the death of the victim, the tortfeasor shall also pay the funeral service fees and death compensation (死亡赔偿金).

Although the Tort Law has specified the scope of compensable injuries, it does not provide for detailed criteria for calculating each category of compensation. The court still has to refer to the JI-Personal Injury 2003, since new judicial interpretations on damages have not been enacted by the SPC yet. Based on arts. 17-29 of the JI-Personal Injury 2003, the criteria for measuring pecuniary losses in personal injury cases can be summarised in Table 3.3. 
Part I. Legal Remedies for Medical Malpractice in China

Table 3.3: Criteria for Measuring Pecuniary Losses in Personal Injury Claims

\begin{tabular}{|c|c|}
\hline Compensation Items & JI-Personal Injury 2003 \\
\hline medical expenses (art. 19) & $\begin{array}{l}\text { - medicine expenses and hospital expenses, etc. } \\
\text { - necessary expenses for recovering, appropriate } \\
\text { face-lifting expenses and other follow-up } \\
\text { treatment expenses }\end{array}$ \\
\hline $\begin{array}{l}\text { loss of earnings due to missed } \\
\text { working time (art. 20) }\end{array}$ & $\begin{array}{l}\text { - fixed income: the income actually reduced } \\
\text { - no fixed income: his average income during the } \\
\text { latest three years } \\
\text { - unable to prove his average income during the } \\
\text { latest three years: the average wages of the } \\
\text { employees in the same or similar industry at the } \\
\text { locality of the case-accepting court of the last } \\
\text { year }\end{array}$ \\
\hline nursing expenses (art. 21) & $\begin{array}{l}\text { - the nursing personnel has income: referring to } \\
\text { the loss of earnings due to missed working time } \\
\text { - have no income or any nurse is employed: } \\
\text { referring to the remuneration rates of the local } \\
\text { nurses engaging in the labour services of the same } \\
\text { class of nursing }\end{array}$ \\
\hline traffic expenses (art. 22) & $\begin{array}{l}\text { - the expenses that actually occurred to the } \\
\text { victim and his necessary accompanying carers } \\
\text { due to medical treatment or due to hospitalisation } \\
\text { in another hospital }\end{array}$ \\
\hline $\begin{array}{l}\text { accommodation expenses } \\
\text { (art. 23) }\end{array}$ & $\begin{array}{l}\text { - treated in another place and unable to be in } \\
\text { hospital due to objective reasons, the reasonable } \\
\text { proportion of the accommodation expenses that } \\
\text { actually occurred to the victim and his } \\
\text { accompanying carers }\end{array}$ \\
\hline $\begin{array}{l}\text { food allowances for } \\
\text { hospitalisation (art. 23) }\end{array}$ & $\begin{array}{l}\text { - referring to the standard of food allowances for } \\
\text { the business trip enjoyed by ordinary } \\
\text { functionaries of local state organs }\end{array}$ \\
\hline $\begin{array}{l}\text { expenses for nutrition (art. } \\
\text { 24) }\end{array}$ & $\begin{array}{l}\text { - referring to the opinions of the medical } \\
\text { institution }\end{array}$ \\
\hline $\begin{array}{l}\text { disability compensation (art. } \\
25 \text { ) }\end{array}$ & $\begin{array}{l}\text { - on the basis of the extent of the victim's } \\
\text { inability to work or the grade of injury or } \\
\text { disability and in the light of the per capita } \\
\text { disposable income of the urban residents or the } \\
\text { per capita net income of the rural residents at the } \\
\text { locality of the case-accepting court of the last }\end{array}$ \\
\hline
\end{tabular}

$222 \quad$ Ding 2012, pp. 190-191. 


\begin{tabular}{|c|c|}
\hline & $\begin{array}{l}\text { year, for a period of } 20 \text { years as of the day when } \\
\text { the disability is determined } \\
\text { - at the age of } 60 \text { or over, the period shall be } \\
\text { reduced by one year for each year of age added } \\
\text { - at the age of } 75 \text { or over: } 5 \text { years }\end{array}$ \\
\hline $\begin{array}{l}\text { expenses for disability aids } \\
\text { (art. 26) }\end{array}$ & $\begin{array}{l}\text { - in the light of reasonable expense standards of } \\
\text { common applicable devices }\end{array}$ \\
\hline funeral expenses (art. 27) & $\begin{array}{l}\text { - in light of the per capita monthly average wage } \\
\text { of the employees at the locality of the case- } \\
\text { accepting court of the last year, and at the total } \\
\text { amount of six months of such wage }\end{array}$ \\
\hline death compensation (art. 29) & $\begin{array}{l}\text { - shall be calculated for } 20 \text { years in the light of } \\
\text { the per capita disposable income of the urban } \\
\text { residents or the per capita net income of the rural } \\
\text { residents at the locality of the case-accepting } \\
\text { court of the last year } \\
\text { - at the age of } 60 \text { or over, the period shall be } \\
\text { reduced by one year for each year of age added } \\
\text { - at the age of } 75 \text { or over: } 5 \text { years }\end{array}$ \\
\hline $\begin{array}{l}\text { living expenses for the } \\
\text { dependent (art. 28) }\end{array}$ & $\begin{array}{l}\text { - on the basis of the extent of the victim's } \\
\text { inability to work, and in light of the per capita } \\
\text { consumption expenditures of the urban residents } \\
\text { or the per capita annual living consumption } \\
\text { expenditures of the rural residents at the locality } \\
\text { of the case-accepting court of the last year } \\
\text { - if the dependent is a minor, the period shall be } \\
\text { calculated up to the age of } 18 \\
\text { if the dependent has no ability to work or no } \\
\text { other source of income, the period shall be } \\
\text { calculated as } 20 \text { years } \\
\text { - at the age of } 60 \text { or over, the period shall be } \\
\text { reduced by one year for each year of age added } \\
\text { - at the age of } 75 \text { or over, the period shall be } \\
\text { calculated as } 5 \text { years }\end{array}$ \\
\hline
\end{tabular}

\subsubsection{The Abstract/Standardised Approach to Future Damage}

In ordinary cases where no disability or death is concerned, the "full compensation" rule is adopted - all reasonable once-and-for-all losses (damnum emergens), e.g. medical expenses, travel expenses, or lost earnings, that can be objectively measured will be fully compensable. ${ }^{223}$ In order to

$223 \quad$ Wang 2013, p. 94. 
achieve full compensation, the "difference hypothesis"224 should in principle apply.

However, the evaluation of future damage (lucrum cessans) in serious cases where disability or death is involved is a rather complicated matter. It has to take into account various personal factors such as "the nature of the injury, the age the victim will reach, his mental and physical strength, and the expected future development of the victim's position" and external factors like "inflation, the rise in wages, as well as changes in tax law and social security law."225 The SPC employs an abstract/standardised rather than a concrete/individualised approach to the calculation of future damage. ${ }^{226}$ The standardised method, however, may ignore an individual victim's actual financial positions or earning capability, which may deviate from the difference hypothesis and devalue the full compensation principle.

Disability compensation and death compensation are the two essential categories of compensation for future damage. It is, therefore, necessary to describe briefly how they are calculated. Disability compensation in China is based on the "doctrine of elimination of earning capacity" (劳动能力丧失说), complemented by the "doctrine of lost earnings" (收入丧失说). ${ }^{227}$ Article 25, para. 1 of the JI-Personal Injury 2003 provides that disability compensation must be calculated by multiplying the degree of the victim's loss of earning capacity and a standardised quantity. The latter is normally the product of a period of 20 years and the Per Capita Disposable Income (hereinafter PCI) ${ }^{228}$ for the previous year in the area of the court which is hearing the case or the victim's domicile or habitual residence, if the PCI there is higher in terms of the victim's Hukou ${ }^{229}$ registration. The PCI is further sorted into the Per Capita Disposable Income of the Urban Residents (hereinafter urban PCI) and the Per Capita Net Income of the Rural Residents (hereinafter rural PCI). The criteria for measuring disability compensation is abstract because the PCI is an objective and average index that applies to a certain local jurisdiction. Article 25, however, does not abandon the doctrine of lost earnings altogether. In its second paragraph, article 25 stipulates that if the disabled

224 According to this difference hypothesis, "damage or loss is the difference between the wealth of a person as it is at a given time, and the wealth as it would have been at the time if the damaging event had not occurred.” F. Mommsen, Beiträge zum Obligationenrecht, 2. Abteilung, Zur Lehre von dem Interessen, Braunschweig: Schwetschke 1855, p. 3, cited in Visscher 2015, p. 11.

Van Dam 2013, pp. 360-361

Huang 2004, p. 260.

Huang 2004, pp. 317-318.

The CPI is the average income a person has after paying taxes.

Hukou denotes to the system of registered permanent residence in China, which divides Chinese citizens into rural residents and urban residents based on their locality. 
victim's actual earnings are not reduced due to his/her disability, or the other way around his/her employment is dramatically affected by his/her minor disability, damages for disability may be adjusted accordingly.

When it comes to death compensation, the "doctrine of lost maintenance" (抚养丧失说) is the common currency in English, German and French tort law. ${ }^{230}$ The law provides "a right to compensation to the natural person whom the deceased maintained or would have maintained if death had not occurred." ${ }^{231}$ Therefore, if there is no such "natural person," the defendant will not have to pay any death compensation. In contrast, death compensation is calculated in light of the "doctrine of lost expected inheritance" (继承丧失说) in China. ${ }^{232}$ The death of the deceased not only means the loss of life but also implies the loss of future earnings that the deceased would have earned in the rest of his/her life if it were not for the fatal accident. ${ }^{233}$ The deceased's expected future earnings less his/her expected personal expenditure (roughly amount to $25 \%$ to $40 \%$ of his/her total income) are considered to be the expected inheritance of his/her family members or other legitimate heirs. ${ }^{234}$ The measure of the loss of expected future earnings of the deceased is also standardised in China. According to article 29 of the JIPersonal Injury 2003, death compensation is calculated by the product of a period of 20 years and the PCI at the seat of the case-accepting court (or the victim's domicile or habitual residence, if the PCI there is higher) of the last year.

Reading article 29 in conjunction with article 25, it seems that the SPC regards dead as full disability (100\%) in economic terms. The degree of loss of earning capacity is measured by the degree of disability, which is divided into ten levels ranging from Level 1 (full disability) to Level 10 (least severe disability). The compensation coefficients are summarised in Table 3.4.

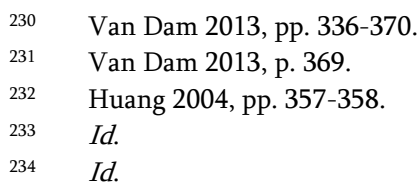


Part I. Legal Remedies for Medical Malpractice in China

Table 3.4: Compensation Coefficients in Light of the Degree of Disability ${ }^{235}$

\begin{tabular}{lc} 
Degree of Disability & Compensation Coefficients \\
\hline Level 1 (full disability: equivalent to death) & $100 \%$ \\
Level 2 & $90 \%$ \\
Level 3 & $80 \%$ \\
Level 4 & $70 \%$ \\
Level 5 & $60 \%$ \\
Level 6 & $50 \%$ \\
Level 7 & $40 \%$ \\
Level 8 & $30 \%$ \\
Level 9 & $20 \%$ \\
Level 10 (least severe disability) & $10 \%$
\end{tabular}

Hence, in most cases, both disability and death compensation can be expressed in the same formula $-20^{*} \mathrm{PCI}^{*}$ Coefficient - where the coefficient for the former ranges from $100 \%$ to $10 \%$ while the one for the latter is always $100 \%$.

Strikingly, before the inception of the Tort Law 2009, the SPC permitted an extra claim for living expenses for the dependent (secondary victims) in light of article 28 of the JI-Personal Injury 2003. This maintenance compensation is calculated by the product of the Per Capita Consumption Expenditures (hereinafter PCE), ${ }^{236}$ the coefficient for disability (death treated as full disability), and the years that the dependent would have been financially supported by the primary victim by law. The PCE is also divided into the PCE of urban residents (hereinafter urban PCE) and the PCE of rural residents (hereinafter rural PCE).

Since disability and death compensation are already intended to recover the victim's future pecuniary losses, one may wonder why a separate maintenance compensation is warranted. After all, if the victim were not injured, he/she would have to financially support his/her dependents out of his/her disposable income. It seems that the dependent would be able to obtain "double compensation." The SPC has not provided a satisfactory

235 N-Criteria for Ascertaining the Degree of Disability 2005 (China).

236 While the PCI is used to measure the average income a person can have after paying taxes annually, the PCE is intended to describe how much money is spent on average by a person on purchasing products and services annually. By definition, the PCE is smaller than the PCI. In 2014, the PCI nationwide was about 20,167 yuan while the PCE was about 14,491 yuan. In other words, roughly $70 \%$ of a person's disposable income had been spent on consumptions annually. National Bureau of Statistics of China 2015. 
explanation for this arrangement. ${ }^{237}$ Lawmakers have noted this conflicting arrangement and have abandoned compensation for maintenance fees in article 16 of the Tort Law 2009. However, if maintenance expenses were not compensable any longer, secondary victims after 2010 would be worse off than victims before 2010. To resolve this problem, the SPC simply orders that after 2010 "living expenses for the dependent should be counted into the compensation for disability or the compensation for death." ${ }^{238}$ However, there is still no explanation why both the PCI and the PCE are considered when measuring future damage.

\subsubsection{Caps on Pecuniary Damages}

According to the JI-Personal Injury 2003, a cap of a period of 20 years has been placed on several categories of compensation e.g. for the nursing expenses (article 21, para. 3), for disability (article 25, para. 1) and death (article 29). The 20-year period will be deducted by one year for each year of age added if the victim reaches 60 , and the 20 -year period will be reduced to 5 years if the victim reaches 75 .

Why should there be a cap of 20 years? The SPC provides four reasons to justify the cap. First, the cap of 20 years is consistent with previous laws ${ }^{239}$ and regulations. ${ }^{240}$ Second, because the interest or dividends that victims can earn by investing the damages over the period need not be deducted in China; there may not be a wide gap between the once-and-for-all award based on a period of 20 years and the counterpart method depending on life expectancy which is used in other countries. Third, since a much longer period entails a greater likelihood of uncertainty and may consequently lead to gross overcompensation, it is necessary to choose a moderate period of 20 years which is socially acceptable. Fourth, article 32 provides for a possibility of extending the period, which largely offsets the disadvantages of the cap. ${ }^{241}$

The first three of the reasons above are highly questionable. Regarding the SPC's first reason, it is rather weak to mention simply that some old legislation adopts the cap of 20 years without explaining why the old law chooses that cap. Also, the cap of 20 years is not in tune with all the previous legislation. For instance, the AR-Medical Accidents 2002 provides for a

\footnotetext{
$237 \quad$ Huang 2004, p. 351.

238 JI-Application of Tort Law 2010 (China), art. 4.

239 See e.g. State Compensation Law 1994 (China), art. 27.

240 See e.g. AR-Road Traffic Accidents 1991 (China), art. 37.

$241 \quad$ Huang 2004, pp. 325-326.
} 
longer period of 30 years for disability compensation. ${ }^{242}$ It appears that the choice of 20 years or 30 years is quite groundless.

The SPC's second reason lacks the support of empirical evidence and is theoretically unlikely to be true. The SPC's approach tends to result in undercompensation. On the one hand, victims under 55 would be undercompensated significantly. The average life expectancy is roughly 75 for both men and women in China. ${ }^{243}$ According to the 2010 census, about $80 \%$ of Chinese residents were under $55 .{ }^{244}$ These facts imply that $80 \%$ of Chinese are expected to live longer than 20 years. The younger the victim, the greater the under-compensation. On the other hand, victims older than 55 (about $20 \%$ of the population) would only be modestly over-compensated. Arts. 25-29 of the JI-Personal Injury 2003 provide that for victims older than 60, the period of 20 years shall be reduced by one year for each year older, and for victims older than 75 years, the period of 20 years shall be reduced to 5 years. Given the small proportion of victims older than 55 , it is expected that overcompensation for the aged would be modest compared to undercompensation for victims younger than 55 .

When it comes to the SPC's third reason, there is also no empirical evidence to support that the cap of 20 years is socially accepted. The fact that many close relatives of the deceased are frustrated or angry at inadequate death compensation may suggest otherwise. ${ }^{245}$

Pertaining to the SPC's fourth reason, the possibility of re-opening a case to extend the duration of payment by 5 to 10 years by article 32 is a welcome remedy to the inadequacy of compensation caused by the cap of 20 years. However, this corrective still seems insufficient. For one thing, the period of 20 years is extended in exceptional circumstances and is actually based on what victims "indeed need" rather than what they are likely to lose in the future. ${ }^{246}$ For another, article 32 applies to compensation for the nursing expenses, the expenses for aid for disability and disability compensation except death compensation. This may lead to unfair results because a full $(100 \%)$ disabled victim may obtain a payment of compensation for up to 30 years whereas the close relatives of a deceased victim could only receive a similar payment for up to 20 years. In terms of lost earning

\footnotetext{
242 Although it adopts a longer period, it based compensation on the PCE rather than the PCI. Hence, suppose the PCE is equal to $70 \%$ of the PCI, then, remarkably, the two methods of calculating disability compensation would yield similar amounts (70\%*30=21 versus $100 \% * 20=20$ )

243 World Health Organisation 2011, p. 46.

244 National Bureau of Statistics of China 2010

245 Ju \& Ma 2012, p. 100.

246 Ding 2012, p. 199.
} 
capabilities or future incomes, there should have been no difference between a $100 \%$ disabled victim and a deceased victim. The longer payment period may contribute to the wide disparity between death compensation and disability compensation, which seems particularly worrying in the context of traffic accidents. This disparity may even produce evil incentives for drivers to kill rather than injure the victim in order to avoid paying larger damages. ${ }^{247}$ Be that as it may, so far, there has been no evidence that doctors would do the same thing. ${ }^{248}$

\subsubsection{Compensation for Non-Pecuniary Losses}

\subsubsection{The Legal Basis}

Article 22 of the Tort Law 2009 provides for the basis for claiming damages for non-pecuniary losses, which reads as follows

Where any harm caused by a tort to a personal right or interest of another person inflicts a serious emotional distress on the victim of the tort, the victim of the tort may claim compensation for the infliction of the emotional distress.

In order for emotional distress to be compensable, it must be "serious." According to lawmakers, "occasional pain and unhappiness" should not be count as serious emotional distress. ${ }^{249}$ However, no further interpretation regarding the wording "serious" is provided. In its commentary on article 22, the SPC argued that "seriousness" is a stringent criterion, which requires that the defendant's behaviour is so "extreme and injurious" that it is "beyond the

247 Anecdotal evidence suggests that the saying "better to kill the pedestrian than to only disable him" becomes a latent practice among motorists. Behind this practice is the barefaced cost and benefit analysis: while many drivers may afford paying death compensation, few are capable of paying disability compensation. Although traffic liability insurance is available, not all the compensation will be paid by the insurer. Some $5 \%$ up to $20 \%$ of the damages may be deducted according to the degree of the driver's liability. Regarding criminal charges, it is usually difficult to prove a homicide in the case of "an accident." The criminal penalty for a negligent traffic accident, however, is normally from one to three years of imprisonment. Therefore, some drivers prefer to give up personal freedom for a few years in return for a huge reduction in compensation. See e.g. Sohu News 2010.

248 This can be explained by two reasons. First, doctors would not be personally liable for compensation although they might lose promotion or bonuses, or get fired if they caused a medical accident. Second, doctors would be easily detected and subject to licensing sanctions and criminal charges if they killed a patient deliberately. 
limits of tolerance when leading a normal life," that is "like nothing on earth," or that "absolutely cannot be tolerated by a civilized society." medical malpractice cases, pain and suffering due to physical injuries fall into the category of serious emotional distress when the injuries meet the criteria for disability (at least Level 10). ${ }^{251}$

Another ambiguous wording in article 22 is the "victim of the tort" (被侵权人). One may wonder whether it includes secondary victims (often close relatives) who suffer emotional distress because of the death of the primary victim. Regarding this, both lawmakers and the SPC maintained that emotional distress suffered by close relatives of the deceased should be regarded as serious enough. ${ }^{252}$ Article 18 of the Tort Law 2009 also provides that "where a tort causes the death to the victim, the close relative of the victim shall be entitled to require the tortfeasor to assume the tort liability." Arts. 18 does not exclude the close relative's right to claim non-pecuniary damages. There is no requirement that the close relative must have witnessed the death of the victim. ${ }^{253}$ The ties of kinship already suffice in most of the cases.

\subsubsection{The Measure of Non-Pecuniary Damages}

Six benchmarks that the court should consider when determining compensation for non-pecuniary losses is provided for by article 10 of the JIEmotional Damage 2001, which reads as follows

(1) the seriousness of the fault;

(2) means, occasion, and manner of the infringement;

(3) consequences of the infringement;

(4) earnings gained by the tortfeasor through the infringement;

(5) financial capacity for the tortfeasor to pay damages; and

(6) the average standard of living in the locality where the case-accepting court sits.

$250 \quad$ Xi \& The Supreme People’s Court 2010, p. 171.

251 Id.

252 Xi \& The Supreme People's Court 2010, p. 173; Wang 2013, p. 124.

253 Nonetheless, if the close relative witnessed the process of the victim's death, a higher amount of non-pecuniary damages may be granted. See e.g. Yan v. Zhu \& Beijing Bus Co. Ltd. (China), where an old professor witnessed the death of his young daughter who was only 14. The professor and his daughter quarrelled with the bus conductor Ms. Zhu over tickets when suddenly Ms. Zhu attacked his daughter and strangled her neck until the daughter was dead. Professor Yan sued Ms. Zhu and her company. The trial court granted 100,000 yuan as non-pecuniary damages. The appellate court increased it to 300,000 yuan since "the plaintiff had witnessed the whole process of his only daughter's death." 
In China, it is generally believed that compensation for non-pecuniary losses has three functions: compensation, satisfaction (抚慰), and punishment. ${ }^{254}$ The first three benchmarks of article 10 seem in tune with these functions. The first benchmark is intended to achieve the punishment function: intentionally inflicted emotional distress tends to be more severe than negligently inflicted emotional distress; emotional damages for gross negligence should be larger than that for ordinary negligence. The second and third benchmarks are closely associated with how much emotional distress or pain and suffering has been inflicted on victims or their close relatives to offer adequate compensation and satisfaction. The more unacceptable the means, occasion and manner of the infringement, the more severe the consequences are, and the more considerable the emotional distress may be.

The last three benchmarks, however, appear somehow questionable. The fourth benchmark concerns unjust enrichment and the plaintiff may claim for restitution of unjust profits in accordance with article 92 of the Principles 1986. Therefore, the fourth benchmark is only justifiable insofar as the court can establish that the tortfeasor's unjust enrichment affects the plaintiff's emotions. ${ }^{255}$ The fifth benchmark aims at connecting the tortfeasor's financial capacity to the measure of non-pecuniary loss. This is highly debatable, for compensation for non-pecuniary loss is a kind of civil liability rather than social relief or donation. ${ }^{256}$ Considering the tortfeasor's financial position would lead to unfair outcomes in the context of medical malpractice claims: patients suffering similar iatrogenic injuries would obtain higher non-pecuniary damages from large hospitals ("deep-pocket") than from small hospitals. The last benchmark involving the average standard of living seems rather odd since non-pecuniary damages are intended to compensate non-pecuniary loss which has nothing to do with the standard of living.

Although there is no statutory cap on non-pecuniary damages, lawmakers reported that high courts in some provinces impose a cap of 50,000 yuan while in other provinces they adopt a cap of 100,000 yuan. ${ }^{257}$ However, it is unclear why these caps are imposed.

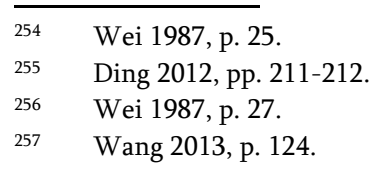


Part I. Legal Remedies for Medical Malpractice in China

\subsubsection{Uncertainty over Legal Causation}

In cases where factual causation is already established but it is indeterminate which part is caused by the faulty treatment and the patient's pre-existing condition, it is debatable whether the defendant should be held liable for any harm due to the non-tortious factor. The new Tort Law 2009 does not provide for any clear rule concerning how to deal with such non-tortious factors. Note, however, that the legal basis for handling non-tortious factors in medical malpractice cases once existed. For the period 2002-2009, article 49, para. 1 of the AR-Medical Accidents 2002 provided such a basis, which reads as follows:

The following elements shall be taken into consideration in the determination of the specific sum of compensation for a medical accident:

(1) The grade of the medical accident;

(2) The degree of liability (责任程度) of the negligent medical act in the consequences of the injury caused by the medical accident;

(3) The relationship between the injury caused by the medical accident and the state of the pre-existing illness.

Sub-para. (2) and sub-para. (3) together provide a basis for apportioning damages between the negligent health care provider and the patient whose pre-existing medical condition also contributed to the occurrence or expansion of the final injury. It is also evident that the patient's pre-existing condition cannot be regarded as contributory negligence on the part of the patient. Hence, the relationship between the negligent treatment and the preexisting condition can only be understood by comparing the influence of the two causative factors.

The extent to which the tortfeasor's negligent treatment contributed to the occurrence or expansion of the injuries suffered by the victim is defined as the "degree of liability" by article 49 . Also, widely termed "causal potency" or "causal significance," it denotes the degree of the causal connection between negligent treatment and harmful consequences in terms of factual causation. In practice, the degree of liability is recommended by expert witnesses in the first place and determined by the court in the end. According to article 36 of the DR-Accident Ascertainment 2002 and Liu, ${ }^{258}$ the degree of liability can be broken down into six categories as shown in Table 3.5.

$258 \quad$ Liu, X. 2014, p. 245. 
Table 3.5: Degrees of Liability

\begin{tabular}{ccc}
\hline Code & Degree of Liability & Range of Causal Significance (\%) \\
\hline A & No responsibility & 0 \\
B & Minor responsibility & $1^{\sim} 20$ \\
C & Secondary responsibility & $21^{\sim} 40$ \\
D & Equal responsibility & $41^{\sim} 70$ \\
E & Major responsibility & $71^{\sim} 90$ \\
F & Full responsibility & $91^{\sim} 100$ \\
\hline
\end{tabular}

The AR-Medical Accidents' approach to non-tortious factors was argued to be applicable to other tort cases by analogy. In practice, before 2014, this approach was de facto widely adopted in the trial of traffic accident cases. The publication of Guiding Case No. $24^{259}$ by the Supreme People's Court, however, marked a turning point in the application of article 49 para. 1 to other tort cases by analogy. In Rong v. Wang \& Yongcheng Insurance Ltd., the appellate court clarified that the ratio decidendi is that

[i]f the victim of a traffic accident was not at fault, the influence of his/her pre-existing or underline vulnerabilities or pre-dispositions on his/her final harm does not fall within any statutory ground of justification that can mitigate the tortfeasor's compensatory liability.

Accordingly, the appellate court held the defendant fully liable for all harm suffered by the victim. This is similar to the eggshell skull rule ("a tortfeasor takes his victim as he finds him") in the common law. ${ }^{260}$ The Guiding Cases are highly authoritative because the selected cases' selection and publication clearly indicate that the SPC shares the same opinion as the appellate court. ${ }^{261}$ As a matter of fact, currently many local courts tend to refuse to adopt article 49's approach in traffic accident cases. ${ }^{262}$ Therefore, article 49 is no longer applicable to traffic accident cases by analogy.

Theoretically, the Tort Law 2009 has replaced the AR-Medical Accidents 2002 as far as medical malpractice claims are concerned. Since the Tort Law does not provide for any provision that is equivalent to article 49 of

259 Rong v. Wang \& Yongcheng Insurance Ltd. (China). See The Supreme People's Court 2015, pp. 77-80.

260 Guiding Case Office of the Supreme People's Court 2015, p. 11. The defendant has to be responsible for all of the adverse outcomes of the victim's own vulnerabilities or predispositions such as an eggshell skull or a weak heart. For more information on the eggshell skull rule, see Van Dam 2013, p. 344.

261 For more information on the newly developed regime of Guiding Cases in China, see e.g. Deng 2015.

262 See e.g. Yin \& Li v. Xue \& PICC (China); Sun et al. v. Ansheng Tianping Ltd. (China). 
the AR-Medical Accidents, it is questionable whether it is still justifiable to continue to apply article 49 to medical malpractice claims after 2010.

\subsection{SUMMARY}

All patients injured after 2010 should base their claims against defendanthospitals on the new Tort Law 2009, which has unified the double tracks of compensation systems for iatrogenic injuries during the period 2002-2009. The current medical liability rules are precisely located in Chapter VII of the Tort Law, with article 54 as the fault-based general clause for medical malpractice claims. Similar to the doctrine of "channelling of liability," article 54 imposes liability on hospitals exclusively without granting a right of recourse against negligent medical staff members. Medical malpractice claims are divided into technical malpractice claims, and ethical malpractice claims.

Under technical malpractice claims, the standard of care required of providers is the "then medical standard." Defendant-hospitals will be presumed to be at fault if providers contravene statutory standards or written treatment norms. Whether a breach of a customary standard necessarily establishes negligence should be determined by the court on a case-by-case basis. Compliance with statutory standards, written treatment norms, and customary practices does not imply the absence of negligence. It is unclear whether the locality rule applies to medical malpractice cases. Causation is undefined in China, and local courts seem to apply the adequacy theory first developed in German law. In principle, the plaintiff-patient should bear the burden of proving fault, causation, and injury in order to establish medical liability. In cases where the provider violates a statutory standard or a treatment norm, the burden of proof regarding fault will be shifted to the defendant-hospital - it has to bear the burden of proving the absence of fault. The Tort Law is silent on how to deal with uncertainty over causation, especially in cases where a non-tortious factor (i.e. the patient's pre-existing condition) is involved.

Ethical malpractice consists of disclosure malpractice and other forms of malpractice (e.g. a breach of confidence, unnecessary examinations), with disclosure malpractice being the most significant form. The Tort Law imposes the duty of disclosure (and the duty to obtain a written consent when surgery, special examination, or special treatment is concerned) on providers. Medical risks and alternative treatment plans should be disclosed in cases where surgery, special examination, or special treatment is needed. For the first time, article 55 provides a legal basis for claiming civil damages for the violation of the patient's right to informed consent. However, the Law does not specify the criteria for information disclosure. 
Besides medical malpractice claims, article 59 of Chapter VII provides a basis for medical products liability, which is based on strict liability. Towards victims, either the court or the manufacturer/blood bank is strictly liable. After paying full damages, the hospital may have recourse against the manufacturer/blood bank. It is unclear whether the development risk defence can be raised by defendants.

In cases where neither the defendant nor the plaintiff was at fault, article 24 of the Tort Law apportions the damage between the two parties under the doctrine of equitable liability. It is unclear whether article 24 should be applicable to medical malpractice claims.

The expert evidence systems play an essential role in the establishment of medical liability. The two competing systems - the MATAS and the JAS are still running parallel to each other today. There are many pros and cons of these two systems. The Tort Law does not touch upon this issue. It is unclear whether these two parallel systems will merge in the future.

After 2010, the general civil law of damages situated at Chapter II of the Tort Law applies to all medical malpractice and product liability claims. However, the detailed criteria for calculating compensation are still provided for in the JI-Personal Injury 2003 and the JI-Emotional Damage 2001. Regarding pecuniary damages, an abstract/standardised method applies to the measure of disability/death compensation. A cap of 20 years is also imposed in most of the cases. This approach is likely to lead to under-compensation. When it comes to non-pecuniary damages, several benchmarks are stipulated against which damages should be measured. However, many of these benchmarks do not appear relevant to emotional distress. In cases where nontortious causative factors are involved, the AR-Medical Accidents 2002 once allowed proportional apportionment between tortious and non-tortious factors but the current Tort Law does not specify this rule. It is also unclear whether local courts will apply the Guiding Case No. 24 to medical malpractice claims widely in the future.

\section{CONCLUSIONS}

Chapter 3 has described the substantive medical malpractice system in China. After almost a decade of "trial and error," China began to unify its private law system of compensation for iatrogenic injuries with the Tort Law 2009, departing from a chaotic system of double tracks of compensation criteria the one provided for by the AR-Medical Accidents 2002 and the one by the Principles 1986 (including the JI-Emotional Damage 2001 and the JI-Personal Injury 2003). At present, only the Tort Law, together with the preceding two judicial interpretations, applies to medical malpractice and medical products 
liability claims. Hence, in all disputes over medical liability, victimised patients are theoretically better off now for the following three reasons: (1) a broader notion of medical fault is defined, (2) more patient rights (e.g. those to informed consent, privacy, and professional services with bona fides) are defined and protected by tort liability; and (3) a relatively higher amount of compensation is available.

However, the achievements of the Tort Law 2009 are still theoretically limited. First, some critical terms or criteria are ambiguous or undefined. The notion of the "then medical standard" should be further defined. The criteria for information disclosure and the concept of causation need to be defined. Whether equitable liability is applicable to medical malpractice or medical products liability claims should be clarified. Second, the quasi-full reversal of the burden of proof (regarding fault and causation) has been abandoned by the Tort Law; however, the problem of information asymmetry is still prevalent in the health care sector. The Tort Law is silent on how to reduce the difficulties faced by plaintiff-patients in producing evidence. Third, the Tort Law has not touched upon the issue of expert witnesses. The double tracks of expert ascertainment still exist today. The unnecessary competition between the two parallel systems may lead to multiple times of ascertainment in a single case which may increase litigation costs significantly. Fourth, the Tort Law has not corrected the unjustifiable limitations or caps imposed by the JI-Personal Injury 2003. Fifth, the Tort Law is silent on whether the ARMedical Accidents 2002's approach to non-tortious factors is still applicable, which may lead to chaotic legal application in practice. 


\section{CHAPTER 4 MEDICAL DISPUTES, IATROGENIC INJURY, MALPRACTICE LITIGATION, AND PATIENT COMPENSATION: EMPIRICAL EVIDENCE}

\section{INTRODUCTION}

After describing the substantive and evidence rules pertaining to medical malpractice claims in China in the previous chapter, this chapter will explore the question of how the Chinese malpractice system actually works in practice (part of Sub-question (1-a)). Specifically, the aim is to figure out the features of medical dispute resolution, the major causes of negligent iatrogenic injuries, the role played by expert witnesses in litigation, the way the court actually handles hard cases, the rate and degree to which victimised patients in fact obtain compensation, the barriers to quick and fair compensation, and finally the actual impact of the law on medical dispute resolution and the behaviour of providers.

To answer the preceding sub-questions, empirical data are indispensable. Although a comprehensive empirical study on the measure of malpractice like the famous Harvard Study in the US ${ }^{1}$ has not yet been conducted in China, some scattered empirical studies concerning these issues are currently available.

Several legal scholars and local courts have conducted empirical studies on malpractice litigation ${ }^{2}$ and the implications of the expert witness

$1 \quad$ See generally Harvard Medical Practices Study 1990; Burris et al. 1991; Leape et al. 1991; Localio et al. 1991; Weiler et al. 1993.

$2 \quad$ See e.g. Weng, Fan \& Sun 2005; Beijing High People's Court First Civil Chamber, 2006; Wang et al. 2006; Beijing Haidian District People's Court, 2008; Xiamen Intermediate People's Court and Siming District People's Court, 2008; Wang 2010; Zhejiang High People's Court, First Civil Chamber, 2010; 2011; Tang et al. 2012; Liebman 2013; Jiangsu Nantong Intermediate People's Court, First Civil Chamber, 2013; Liu \& Song 2013; Wei et 
Part I. Legal Remedies for Medical Malpractice in China

systems for judges and litigants. ${ }^{3}$ Although these studies are fairly informative, they are often subject to two limitations. On the one hand, many of them are based on data collected from online case databases. In practice, however, most courts tend to publish only a minority of high-quality decisions online and mediated or withdrawn cases are never reported online. ${ }^{4}$ It is thus impossible to see the whole picture of malpractice litigation by merely examining decisions at random published online, no matter how large the number is. On the other hand, many studies carried out by local courts are primarily qualitative, focusing on the application of legal rules rather than on the frequency and size of claims and their potential impact on the prevention of medical errors, and a quarter of these studies were done before 2009. In order to overcome these limitations, in July 2014 I paid a visit to a trial court in China - the Gulou District People's Court (hereinafter the Gulou Court) - and collected a total of 592 decisions concerning medical disputes accepted between 2002 and 2013. All the main findings are presented in Section 2 and their implications, together with that of prior studies, are discussed in Section 3. However, the appellate court of the Gulou Court was not willing to provide appellate decisions. Instead, some interviews with judges, ${ }^{5}$ which were intended to ascertain any further information on the matter, will be presented in Sections 3.1-3.6 as a complement to the data on court decisions.

In addition, a group of scholars, mostly in the field of public health, have paid particular attention to the ways of medical dispute resolution. ${ }^{6}$ These quantitative studies are often based on samples collected from the whole country, a local jurisdiction, several hospitals or a single hospital. Data are mostly collected by surveys or retrospective reviews of hospital documents, which are sufficient for answering part of the sub-questions in this Chapter. Some findings of these studies are summarised in Section 3.7. In order to clarify some unreported issues, several semi-structured interviews

al. 2013; Zhejiang Ningbo Intermediate People's Court, First Civil Chamber, 2013; Li et al. 2014; Sun et al. 2014; Zhejiang Hangzhou Intermediate People's Court, 2015; Bai \& Pei 2016; Hu \& Shi 2016.

3 See e.g. Wang \& Su 2009; Liao et al. 2010; Xu et al. 2010; Zhang 2010; Chengdu Jingjiang District People's Court, First Civil Chamber, 2011; Fang \& Yang 2011; Liu et al. 2012a; Liu et al. 2012b; Xiao 2014.

Liu, Wang \& Zhang 2014.

See infra Appendix 3: Abbreviations of Semi-Structured Interviews.

See e.g. Zheng, Deng \& Chen 2002; Chinese Hospital Association, 2004; Yang, Zhao \& Bao 2006; Zheng et al. 2006; Zheng et al. 2007; Shu 2008; Wang 2008; Xu \& Lu 2008; Xie 2009; Song 2011; Zheng et al. 2012; Li 2013; Liu \& Feng 2013. 
with physicians, public health officials, and malpractice lawyers were conducted, ${ }^{7}$ the results of which will also be summarised in Section 3.7.

Finally, some empirical studies touch upon the issue of "defensive medicine." Most of these studies are surveys conducted into the attitudes of physicians towards medical disputes and malpractice risks. A summary of some of them is in Section 3.8 together with a discussion of the extent to which "defensive medicine" may be explained by the malpractice system. Some of the interview results are summarised in Section 3.8 as well.

\section{RESULTS OF THE COURT DECISIONS FROM THE GULOU COURT}

\subsection{FREQUENCY AND OUTCOMES OF CLAIMS}

A total of 592 cases were collected by the year of acceptance, which ranges between 2002 and 2013. Table 4.1 presents the breakdown of cases accepted, the size of the population of the Gulou District, ${ }^{8}$ and the cases accepted per million residents by year.

Table 4.1: Cases Accepted by the Gulou Court by Year

\begin{tabular}{|l|c|c|c|}
\hline Year & Cases (No.) & $\begin{array}{l}\text { No. of Population } \\
\text { (Thousand) }\end{array}$ & $\begin{array}{l}\text { Cases per million } \\
\text { residents (No.) }\end{array}$ \\
\hline 02 & 22 & 607 & 36.24 \\
\hline 03 & 25 & 638 & 39.18 \\
\hline 04 & 27 & 656 & 41.16 \\
\hline 05 & 57 & 684 & 83.33 \\
\hline 06 & 57 & 696 & 81.90 \\
\hline 07 & 55 & 695 & 79.14 \\
\hline 08 & 50 & 687 & 72.78 \\
\hline 09 & 27 & 673 & 40.12 \\
\hline 10 & 44 & 659 & 66.77 \\
\hline 11 & 41 & 646 & 63.47 \\
\hline 12 & 50 & 635 & 78.74 \\
\hline 13 & 137 & 1,030 & 133.01 \\
\hline
\end{tabular}

\footnotetext{
$7 \quad$ See infra Appendix 3: Abbreviations of Semi-Structured Interviews.

8 For data on the population of the Gulou District, see Nanjing Gulou District Bureau of Statistics 2015.
} 
In general, the number of cases accepted was on the increase in recent years even when it was adjusted for population growth, with a sudden surge in 2013. There was a growth trend in the number of cases accepted, though it was not steady. For example, it increased from 36.24 cases per million residents in 2002 to 83.22 in 2005, decreased to 72.78 in 2009 and increased again to 66.77 in 2010 and 133.01 in 2013. Taking data in 2002 as the base number, the number of cases accepted per year more than doubled in 2005 and there was an almost fourfold increase in 2013. Remarkably, the rapid increases from 2004 to 2005 and from 2009 to 2010 coincided with the implementation of the JI-Personal Injury 2003 and the Tort Law 2009 respectively.

However, there was no new legislation concerning medical malpractice claims between 2010 and 2013. The abnormal surge in 2013 may be explained by the fact that two districts of Nanjing City - the then Gulou District and the then Xiaguan District - merged into the current Gulou District in 2013. ${ }^{9}$ The two former districts might have had a different frequency of cases accepted before 2013.

If we ignore the temporary decrease in 2009 and the abnormal increase in 2013, we will find that the number of cases accepted adjusted for population growth was relatively stable, and it will be hard to say whether the new Tort Law had any impact on the frequency of claims.

Nearly half of the cases were still settled by final judgements, although in-court mediation ${ }^{10}$ began to play a more substantial role as time went on. Of all the 592 cases, $47 \%(\mathrm{n}=280)$ were closed by judgements, 38\% $(\mathrm{n}=224)$ by consent judgements upon mediation in court, whereas only $15 \%(\mathrm{n}=88)$ by rulings granting withdrawal of an action, ${ }^{11}$ as presented in Figure 4.1. As time went on, the proportion of mediated court cases tended to overtake that of judged cases from 2011 onwards. Figure 4.1 shows the breakdown of the proportion of each kind of cases closed each year to all cases closed each year from 2003 to 2013.

See generally Shen 2013.

Judges in China are actively encouraged to mediate in a dispute and to nudge litigants to reach a settlement, especially in difficult cases like medical malpractice. Once such a settlement is reached, the court will prepare a consent judgment stating the claims, facts of the case and results of mediation. Civil Procedure Law 1991 (2012 Amendment) (China), art. 97.

11 Unlike a judgment, a ruling in China only applies to procedural issues such as refusing to accept a case, objection to jurisdiction or dismissing a case. Civil Procedure Law 1991 (2012 Amendment) (China), art. 154. 
Figure 4.1: Cases Closed in Different Ways during the Period 2003-2013

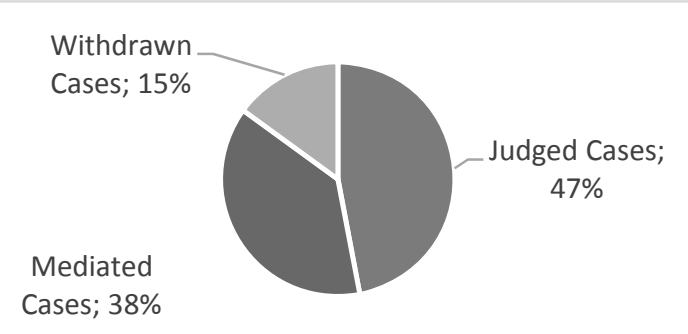

Figure 4.2: Cases Resolved in Different Ways by Year of Decision

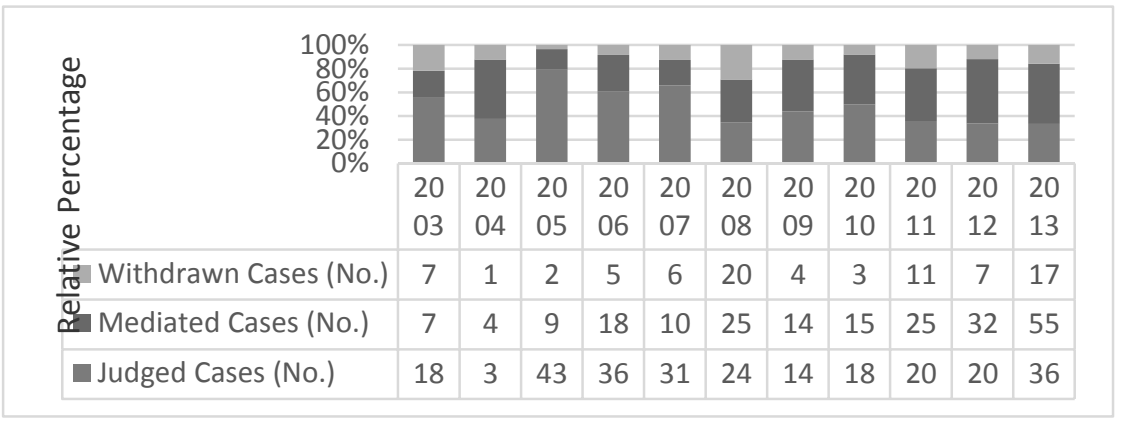

Plaintiffs would win in roughly three quarters of all cases. ${ }^{12}$ In the majority $(67.86 \% ; n=190)$ of all the 280 judgements judges granted awards, while in the remaining 90 judgements the claims were dismissed. Hence, as far as cases closed with judgements are concerned, the rate of winning was $67.86 \%$. All in-court-mediated cases closed with consent judgements $(n=224)$ granted awards whereas no damages were awarded where a case was withdrawn $(\mathrm{n}=88)$. Taking into account only judgements and consent judgements, the rate of winning rose to $82 \%[(190+224) /(280+224)]$. When all cases are considered, the rate of winning cases was still as high as $70 \%(414 / 592)$.

12 "Winning a case" refers to the outcome of a case where the plaintiff is awarded damages either in full or partially. The "rate of winning cases," "success rate" or "chances of success" denotes the percentage of the number of cases where the plaintiff won over the number of all the cases studied. 
However, the degree of winning ${ }^{13}$ was relatively low. The degree of winning a case can only be measured by cases closed by judgements, for data on the value in dispute were seldom reported either in consent judgements or rulings. Of all the 190 judgements with some awards, the degree of winning ranged widely from $0.08 \%$ to $112 \%$, with a relatively low mean of $27 \%$. In the majority (68\%; $n=130)$ of all the 190 cases, the plaintiffs received less than $30 \%$ of their claims. The plaintiffs obtained more than $50 \%$ of their claims in only $17 \%(n=32)$ of all the 190 cases, with only one complete winning case ${ }^{14}$ where the plaintiff received $112 \%$ of his claims (the defendant was willing to pay extra money through liability insurance for blood transfusion).

\subsection{REPRESENTATIVES AND DEFENDANTS}

In the majority of cases patients were themselves plaintiffs and were represented by lawyers. On the one hand, 496 of all the 592 cases recorded the relationship between the plaintiff and the patient. In $63 \%$ of all these 496 cases, the patient himself/herself was the plaintiff ( $\mathrm{n}=313$ ) and in $37 \%$ his/her legal representatives or close relatives $(=183)$ were the plaintiffs. On the other hand, 461 of all the 592 cases included data on legal counsel. Of all these 461 cases, almost $60 \%$ were represented by lawyers ( $\mathrm{n}=351)$, 2 by legal aid lawyers without charge, $4 \%$ by legal workers who have a basic level of legal knowledge and can only work at grass-root level legal service firms $(n=26)$ and $14 \%$ by close relatives or friends $(\mathrm{n}=82)$.

Most of the defendants were large public hospitals and no physicians were sued. In all the 592 cases, a total of 54 defendants were sued and the overwhelming majority of the defendants were medical institutions (93\%; $\mathrm{n}=50$ ), except one pharmaceuticals producer, one blood products producer and two blood centres. Of all the 50 medical institutions, $86 \%$ were hospitals $(\mathrm{n}=43)$, the remaining were health centres $(\mathrm{n}=2)$, out-patient clinics $(\mathrm{n}=3)$ and private clinics $(n=2) ; 80 \%$ were public institutions $(n=40)$, while $20 \%$ private ones $(n=20) ; 38 \%$ were tertiary Grade A hospitals $(n=19), 22 \%$ secondary hospitals $(n=11), 4 \%$ primary hospitals and $16 \%$ unaccredited hospitals. The 50 medical institutions were sued 601 times altogether, of which 22 hospitals were sued more than twice. Two of the largest tertiary Grade A hospitals in the Gulou District appeared in court as defendants 324 times, creating more than $50 \%$ of the caseload.

\footnotetext{
13 The "degree of winning a case" is defined as the percentage of the final awards of a case over the case's value in dispute (damages initially claimed by the plaintiff).

14 Gu v. Drum Tower Hosp. \& Shanghai RAAS Co., Ltd. (China).
} 
To non-Chinese readers, it may be unbelievable that no individual provider was sued. However, as stated in previous chapters, all individual providers practice as staff members of medical institutions (even as small as a clinic $)^{15}$ and the "channelling of liability" seems applicable to medical malpractice cases. ${ }^{16}$ Hence, medical institutions are the sole defendant in malpractice lawsuits and joint and several liability is not applicable here.

\subsection{LENGTH OF TRIALS ${ }^{17}$}

Exceeding the statutory time limits for trial was fairly common. On average, it took 289 days for the court to close a case with a judgement, 149 days with a consent judgement and 194 days with a ruling granting the withdrawal of an action. The maximum duration of trial was 1766 days (almost five years). All the average trial days exceeded the time limits for trial in civil litigation three months for a summary procedure and six months for a formal procedure. In the vast majority $(76 \% ; n=157)$ of the 216 cases following a formal procedure 157 cases exceeded the time limits, while only 166 (44\%) of the 376 cases following a summary procedure did so. Therefore, judges found it difficult to adjudicate within the time limits in more than half $(55 \%$; $=323)$ of all the 592 cases.

\subsection{CAUSES OF ACTION ${ }^{18}$ AND LEGAL STANDARDS}

\section{APPLIED}

Accident claims were surprisingly rare whereas ordinary claims were the major cause of action. Of all the 592 cases, 73\% (n=430) were brought under

15 See supra Chapter 2, Section 2.3

$16 \quad$ See supra Chapter 3, Section 3.1.

17 According to the Civil Procedure Law 1991 (2012 Amendment) (China), a civil case can be tried following either a "formal procedure" or a "summary procedure." Where a case is simple with "clear facts, unambiguous rights and obligations and minor disputes," a summary procedure shall apply. Id., art. 157. Different time limits are imposed on trials. Under a formal procedure, a case should be closed within six months after the case is docketed. Id., art.149. Under a summary procedure, however, a case should be closed within three months after it is docketed. Id., art. 161.

18 As discussed in Chapter 3, Section 3.1, victimised patients are allowed to file a claim against the defendant's hospitals either under contract law or tort law. Hence, there is a separate cause of action based on contract law - Disputes over Medical Service Contract (hereinafter contract claims). When it comes to tort law, before 2010, two parallel causes of action - accident claims and ordinary claims - existed, as described in supra Chapter 3, Section 2. After 2010, the only cause of action under the Tort Law 2009 is Disputes over Liability for Iatrogenic Injury (hereinafter injury claims). 
ordinary claims, while only $19 \%(\mathrm{n}=111)$ under injury claims, $7 \%(\mathrm{n}=44)$ under accident claims, and $1 \%(n=7)$ under contract claims. The fact that injury claims occurred less frequently than ordinary claims was not surprising, for the Tort Law had only entered into force in 2010.

Similarly, the AR-Medical Accident 2002 was seldom used, and the majority of cases were disposed of in accordance with the Principles 1986. Only the 280 cases closed with judgements reported information about legal standards applied. 234 cases were accepted before 2010 and applied legal rules before the Tort Law 2009, and 46 after 2010 and applied the Tort Law. As far as liability rules prior to the Tort Law are concerned, almost $96.15 \%(n=225)$ of all the 234 judgements were decided pursuant to the Principles 1986 (article 5, article 106, para. $2 \&$ article 132), whereas only about $2.56 \%(\mathrm{n}=6)$ the AR-Medical Accident 2002 (article 2), 1.28\% (n=3) the Contract Law 1999 (article 60), less than $1 \%(\mathrm{n}=2)$ the Product Quality Law 2000 (article 26 \& article 41) combined with the Principles 1986. In one case (Zheng \& Chen v. Jiangsu Hospital), the plaintiff argued that the defendants should be subject to strict service liability on the basis of the Consumer Law 1993. The court ruled against this argument on the grounds that the defendant was a not-for-profit public hospital and was by no means a "business operator" which is required by article 3 of the Consumer Law. Table 4.2 gives the distribution of the application of liability rules. and about $16 \%(n=46)$ the Tort Law (arts. 54-57)

Table 4.2: Liability Rules Applied to Medical malpractice Cases

\begin{tabular}{|c|c|c|c|c|}
\hline period & Liability Rules Contained in & $\begin{array}{c}\text { Cases Applied } \\
\text { (No.) }\end{array}$ & \multicolumn{2}{|c|}{ Percentage } \\
\hline \multirow{4}{*}{$\begin{array}{l}2002- \\
2009\end{array}$} & Principles 1986 & 223 & $96.15 \%$ & \multirow[t]{4}{*}{$100 \%$} \\
\hline & AR-Medical Accidents 2002 & 6 & $2.56 \%$ & \\
\hline & Contract Law 1999 & 3 & $1.28 \%$ & \\
\hline & $\begin{array}{c}\text { Principles } 1986 \text { \& Product Quality } \\
\text { Law } 2000\end{array}$ & 2 & $0.85 \%$ & \\
\hline $\begin{array}{l}2010- \\
2013\end{array}$ & Tort Law 2009 & 46 & \multicolumn{2}{|c|}{$100 \%$} \\
\hline
\end{tabular}

Surprisingly, both the "bonus pater familias" and the "medical customary practice" were cited most frequently as the standard of care for technical malpractice, followed by the duty of information disclosure for ethical malpractice. ${ }^{19} 246$ of the cases above, which were closed with judgements,

19 For the distinction between technical malpractice and ethical malpractice and the standard of care applicable to medical malpractice claims in China, see supra Chapter 3, Sections 3.2-3.3. 
involved only a single treatment measure whereas the remaining cases involved two or more treatment measures. It turned out that the court had to determine negligent behaviour 297 times in total in these 280 cases. The court seemed most likely to hold the defendant liable in three scenarios: (a) where the defendant breached the "due care," the "due diligence," the "high degree of diligence," or the "maximum duty of care" (40\%; $n=119)$; (b) where the defendant violated treatment norms, or customary practices $(26 \% ; n=77)$; and (c) where the defendant failed to adhere to the duty of disclosing information and obtaining the patient's informed consent (19\%; $\mathrm{n}=56$ ).

Cases involving direct contravention of statutory standards defined by laws and regulations were rare; so were cases of applying the reversal of the burden of proof rule. The court established liability in a few instances of the foregoing 297 potentially negligent treatment measures: (a) where the defendant violated laws, regulations and departmental rules on medical provision (5\%; $\mathrm{n}=16$ ); (b) where the reversal of the burden of proof applied (4\%; $\mathrm{n}=13)$; (c) where the defendant breached contractual obligations of proper medical care $(4 \% ; n=11)$; (d) where the rule of res ipsa loquitur applied $(1 \% ; n=4)$; and (e) where the defendant was presumed to be negligent because the authenticity of medical records could not be determined due to the defendant's negligence $(\mathrm{n}=1)$.

The court often confirmed causation without giving much explanation. Of all the 280 cases, 246 mentioned causation issues or reported how cause was established. However, in about $38 \%(n=94)$ of the 246 cases, the court simply applied the conditio sine qua non rule by stating that there were no injuries but for the medical negligence without giving any argument without further elaboration. This often occurred in cases where a direct infringement was involved.

The court was most likely to apply a "proportional liability" to many cases where there was severe uncertainty over factual causation. In almost $38 \%(\mathrm{n}=95)$ of the aforementioned 246 cases, the court identified that, where there was a certain degree of causality (even with a probability of less than $50 \%$ ) between the negligence and the damage, such causality could not be excluded or there was indirect causality. The degree of causal connection would then be transferred into the degree of liability, against which the final awards are measured.

When confronted with causal uncertainty, the court also switched the causal link to other kinds of injuries in some cases. If there were no tangible personal injuries, the court might establish that there was a causal connection between the negligence and the loss of expectations/chances of being cured, survival or a longer life $(3.6 \% ; n=9)$, pure emotional distress caused by the provider's failure to disclose information sufficiently and to obtain consent $(8 \% ; n=21)$, or pure added medical costs $(2 \% ; n=4)$. 
In some rare cases, the court would grant damages even though the defendant was not at fault. In four of all the 280 judgements, the court granted compensation to the plaintiff in cases where it was already established that the defendant had not been at fault. One judgement was based on equitable liability. ${ }^{20}$ The other three judgements had no legal basis. Strikingly, the court nonetheless granted damages in that the non-negligent defendants "were willing to pay some ex gratia money out of humanitarianism." 21

Quantum/damages rules22 under the AR-Medical Accidents were seldom applied while those under the JI-Personal Injury 2003 and the JIEmotional Damage were frequently used both in accident claims and in ordinary/injury claims. Only the 190 judgements with some awards reported data on the applicable quantum rules. Whereas 156 applied rules prior to the Tort Law 2009, 34 applied the Tort Law. Note that the preceding two judicial interpretations are still applicable. Of all the foregoing 156 accepted before 2010, roughly $90.38 \%(\mathrm{n}=141)$ applied the Principles 1986, together with the aforesaid two judicial interpretations, while only 7.05\% ( $\mathrm{n}=11)$ exclusively applied the AR-Medical Accident 2002 (arts. 49 \& 50), about 3.85\% (n=6) applied the AR-Medical Accident and the Principles 1986/judicial interpretations jointly, and 1 applied Contract Law 1999 (article 107). After 2010, all the 34 cases applied the Tort Law and the two judicial interpretations jointly. Table 4.3 presents the distribution of the application of quantum rules.

Table 4.3: Quantum Rules Applied to Medical Malpractice Claims

\begin{tabular}{|c|c|c|c|c|}
\hline Period & Quantum Rules Contained in & Cases (No.) & \multicolumn{2}{|c|}{ Percentage } \\
\hline \multirow[t]{4}{*}{ 2002-2009 } & Principles 1986 \& Interpretations & 141 & $90.38 \%$ & \multirow[t]{4}{*}{$100 \%$} \\
\hline & Regulation & 11 & $7.05 \%$ & \\
\hline & $\begin{array}{l}\text { Regulation \& Principles } \\
\text { 1986/Interpretations }\end{array}$ & 6 & $3.85 \%$ & \\
\hline & Contract Law & 1 & $0.64 \%$ & \\
\hline 2010-2013 & Tort Law \& Interpretations & 34 & \multicolumn{2}{|c|}{$100 \%$} \\
\hline
\end{tabular}

Plaintiffs seemed to enjoy a higher rate of winning and degree of winning and more damages on average in cases where the Tort Law rather than the

20 Wang v. Brain Hospital (China). For more information on equitable liability, see supra Chapter 3, Section 3.5.

21 Xiong v. Drum Tower Hospital (China); Qian v. Zhongda Hospital (China); Zhou \& Jin v. Children's Hospital (China).

22 For more information about the law of damages in China, see supra Chapter 3, Section 3.7. 
Principles 1986 applied, even after being adjusted for the CPI. 66\% ( $\mathrm{n}=149)$ of all the 225 cases where the Principles 1986 applied were closed with an average award of 87,248 yuan, only representing $20 \%$ of the value in dispute. In contrast, $72 \%(\mathrm{n}=33)$ of all the 46 cases decided under the Tort Law were resolved with an average award of 130,746 yuan, which represented $33 \%$ of the value in dispute. This finding was striking because actually uniform quantum rules - the JI-Emotional Damage 2001 and the JI-Personal Injury 2004 - apply to both kinds of cases even after the advent of the Tort Law. Table 4.4 presents the different outcomes in cases where the Principles 1986 and the Tort Law applied.

Table 4.4: Outcomes under the Principles 1986 and the Tort Law 2009

\begin{tabular}{|l|r|l|l|l|l|l|l|}
\hline $\begin{array}{l}\text { Liability } \\
\text { Rules }\end{array}$ & Total & $\begin{array}{l}\text { Cases } \\
\text { with } \\
\text { Awards }\end{array}$ & $\begin{array}{l}\text { Rate of } \\
\text { Winning }\end{array}$ & $\begin{array}{l}\text { Degree } \\
\text { of } \\
\text { Winning }\end{array}$ & $\begin{array}{l}\text { Mean } \\
\text { Damages } \\
(¥)\end{array}$ & CPI** $^{* *}$ & $\begin{array}{l}\text { Mean } \\
\text { Damages } \\
\text { Adjusted } \\
\text { for CPI } \\
(¥)^{* * *}\end{array}$ \\
\hline $\begin{array}{l}\text { Principles } \\
1986^{*}\end{array}$ & 225 & 149 & $66 \%$ & $20 \%$ & 87,248 & $\begin{array}{r}474.49 \\
(2002-\end{array}$ & 87,248 \\
& & & & & & $2009)$ & \\
\hline Tort Law & 46 & 33 & $72 \%$ & $33 \%$ & 130,746 & $\begin{array}{r}569.90 \\
(2010-\end{array}$ & 108,857 \\
& & & & & & $2013)$ & \\
\hline
\end{tabular}

${ }^{*}$ Equitable liability and product liability were also included in this category.

** The Consumer Price Index (CPI) ${ }^{23}$ is often used to adjust data for inflation. Data in 1978 is taken as the base number (100).

${ }^{* * *}$ The mean damages granted under the Principles 1986 for the period 2002-2009 were taken as the base number.

\subsection{THE IMPACT OF EXPERT TESTIMONY ${ }^{24}$ ON THE}

\section{TRIAL}

Expert evidence was frequently used by the court and clinical experts from the municipal medical association provided the majority of expert testimonies. Data on the use of expert opinions were not recorded in withdrawn case documents. With the focus on the 504 cases closed by either judgements or consent judgements, it appears that information about expert opinions was recorded in $60 \%$ ( $\mathrm{n}=293$ ) of the 504 cases. In all these 293 cases, a total of 420 expert testimonies were produced, $85.71 \%(n=360)$ of which

$23 \quad$ For data on the CPI in China from 1978 to 2013, see e.g. China Economic Net 2014.
$24 \quad$ For more information on expert evidence in China, see supra Chapter 3, Section 3.6. 
were given by clinical experts from the medical association while $14.29 \%$ $(\mathrm{n}=60)$ via forensic pathologists. Of all the 360 testimonies offered by clinical experts, 286 were provided by the Nanjing Municipal Medical Association, 73 by the Jiangsu Provincial Medical Association, and only one by the Chinese Medical Association. Moreover, of all these 293 cases, almost 58\% ( $\mathrm{n}=169)$ involved only one expert testimony, $40 \%(\mathrm{n}=116)$ involved two expert testimonies, and about $3 \%(n=8)$ involved three expert testimonies. Sources of expert evidence are presented in Table 4.5.

Table 4.5: Sources of Expert Evidence

\begin{tabular}{|l|c|c|c|}
\hline \multicolumn{2}{|c|}{ Expert witnesses } & $\begin{array}{c}\text { Testimonies } \\
(\text { No.) }\end{array}$ & Percentage \\
\hline $\begin{array}{l}\text { Clinical experts } \\
\text { from medical } \\
\text { associations }\end{array}$ & $\begin{array}{c}\text { Nanjing Municipal Medical } \\
\text { Association }\end{array}$ & 286 & $68.10 \%$ \\
\cline { 2 - 4 } & $\begin{array}{c}\text { Jiangsu Provincial Medical } \\
\text { Association }\end{array}$ & 73 & $17.38 \%$ \\
\cline { 2 - 4 } & Chinese Medical Association & 1 & $0.24 \%$ \\
\hline $\begin{array}{l}\text { Forensic patho- } \\
\text { logists }\end{array}$ & $\begin{array}{c}\text { Various forensic ascertainment } \\
\text { institutions }\end{array}$ & 60 & $14.29 \%$ \\
\hline & Total & 420 & $100 \%$ \\
\hline
\end{tabular}

For plaintiffs, the MATAS was least favourable, the JAS most favourable, whereas the newly developed MIAS was somewhere in between. As far as accident claims are concerned, only a minority $(11 \%$; $=27)$ of all the 243 testimonies testified for the plaintiffs (i.e. medical accidents were established). Insofar as injury claims are involved, a simple majority $(55 \% ; n=28)$ of all the 51 testimonies testified in favour of the plaintiffs (i.e. liability for medical injuries was established). When it comes to ordinary claims, a significant majority $(80 \% ; \mathrm{n}=45)$ of all the 56 testimonies testified in favour of the plaintiffs (i.e. medical fault could be established). In total, only about $30 \%$ $(\mathrm{n}=100)$ of all the 350 testimonies testified for the plaintiff. Moreover, experts were unable to give opinions in five cases, either because it was impossible to distinguish whether evidence materials were genuine or fake or because the patients refused to accept tests or examinations again.

Full responsibility was rare and more cases were testified as below equal responsibility than above it. ${ }^{25} 82$ of the 100 expert testimonies testifying for the plaintiffs reported the degree of liability, of which almost 33\% ( $n=27)$ suggested major responsibility, $30 \%(\mathrm{n}=24)$ secondary responsibility, $23 \%$

25 For more information about the degree of liability, see supra Chapter 3, Section 3.7.4. 
$(\mathrm{n}=19)$ minor responsibility, $13 \%(\mathrm{n}=11)$ equal responsibility and only about $1 \%(\mathrm{n}=1)$ full responsibility.

Medical experts were most likely to testify against the plaintiff on the grounds of lack of causation. A total of 250 (71.43\%) of the 350 cases with some data on expert evidence testified against the plaintiffs. Of all the 250 testimonies, 236 reported the reason why the experts found no liability. In almost $44 \%$ ( $n=103$ ) of all the 236 cases, experts testified that although there were some deficiencies in diagnoses and treatment, there were no (direct) causal links between the treatment and the damage; in $25 \%$ of the cases, neither a violation of customary practices nor (direct) causation could be established; in about $22 \%(\mathrm{n}=52)$ of the cases, no contravention of statutory standards, treatment norms, or customary practices could be found; in about $5 \%(\mathrm{n}=11)$ of the cases, although there were some deficiencies in treatment, there was no tangible damage.

Plaintiffs were more dissatisfied than defendants with expert testimonies provided by medical associations under the MATAS. In all the 350 cases recording expert testimonies, the plaintiff challenged accident testimonies (under MATAS) 108 times and both accident and forensic testimonies (under JAS) 31 times. In contrast, the defendant only challenged accident testimonies 24 times, forensic testimonies twice and both types once.

Expert witnesses, especially those clinical experts under the MATAS, rarely appeared in court to give opinions. Pathologists under the JAS appeared in court in eight cases, whereas clinical experts from expert groups organised by the medical association appeared in court only in three cases. Instead of appearing in court, the medical association offered a written reply in 27 cases while forensic pathologists did so in only 5 cases.

The court relied heavily on expert opinions, especially those provided by forensic pathologists, and found it hard to challenge the opinions completely. Of all the aforesaid 350 cases, almost $65 \%(n=227)$ reported how judges dealt with expert testimonies. Judges completely adopted expert testimonies in almost $57 \%(n=129)$ of the 227 cases, partly adopted in about $39 \%(\mathrm{n}=88)$ and refused to adopt in only 10 cases. There were 103 cases with more than two types of expert opinions. In about $51 \%(n=38)$ of the 103 cases, the court adopted forensic testimonies under the JAS; in almost $23 \%(\mathrm{n}=17)$, the court adopted accident testimonies under the MATAS; and, in 24\% $(n=18)$ where both types of testimonies gave largely the same conclusions, the court adopted both testimonies completely or partly. 
Figure 4.3: Admissibility of Expert Testimonies

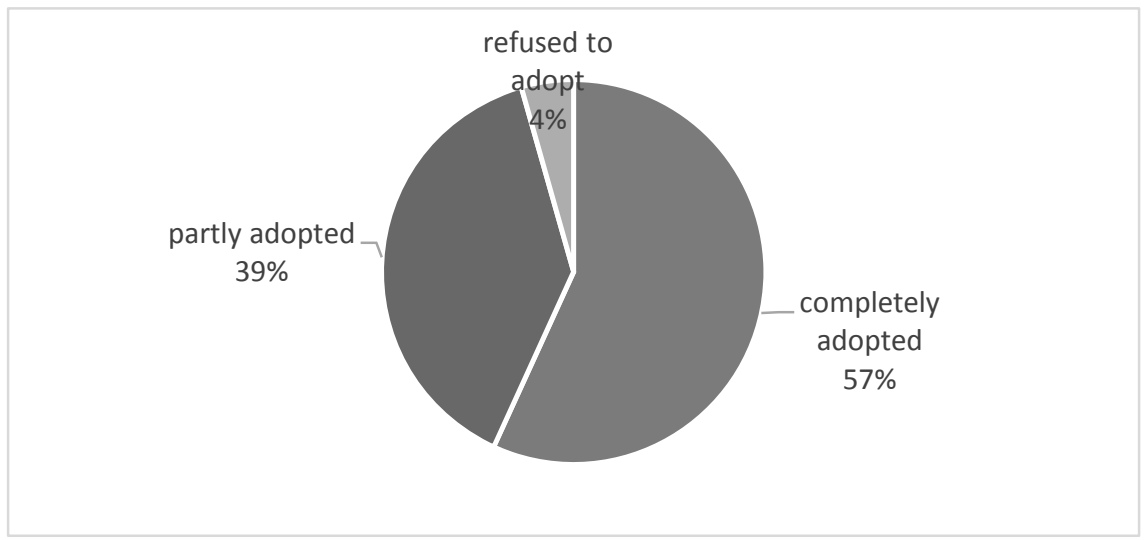

The court was most likely to reject a testimony on the grounds that some medical errors other than medical accidents could satisfy the requirements of negligence or a slight degree of causal link could suffice in the case of causal uncertainty. The court partly or completely rejected expert testimonies in $43 \%(\mathrm{n}=98)$ of the aforesaid 227 cases. A total of 138 testimonies were reported in these 98 cases. The courts were ready to reject an expert testimony in five cases: (1) where there were some other types of malpractice that the experts had ignored $(37 \% ; n=51)$, (2) where although a medical accident could not be established, some identified deficiencies were sufficient for establishing ordinary medical negligence $(33 \% ; n=45)$, (3) where there was some causal link between the negligent treatment and the injuries although this link might not be so "direct" $(14 \% ; n=20)$, (4) where experts made mistakes in deciding the degree of liability (5\%; $n=7)$ and (5) where experts made mistakes in identifying the damage, and there were other intangible injuries such as loss of opportunities $(5 \% ; n=7)$

\subsection{PRE-EXISTING CONDITIONS AND SPECIALITIES INVOLVED}

Pre-existing conditions. A total of 343 judgements or consent judgements reported the primary disease that brought the patient to the defendant. Primary diseases such as neoplasms $(15.45 \% ; n=53)$ and diseases of the musculo-skeletal system and connective tissue $(10.20 \%$; $n=35)$ were most frequently associated with medical disputes, followed by diseases of the nervous system $(9.62 \% ; \mathrm{n}=33)$, the circulatory system $(9.33 \% ; \mathrm{n}=32)$, the genito-urinary system $(9.04 \% ; n=31)$, the digestive system $(8.45 \% ; n=29)$, the respiratory system $(5.54 \% ; \mathrm{n}=19)$ and so on. 
Specialities Involved. The same group of the 343 cases as mentioned above reported disciplines involved. Largely corresponding to primary diseases, medical disciplines like oncology $(15.74 \% ; n=54)$ and bone surgery $(10.79 \% ; n=37)$ were most frequently confronted with malpractice claims, followed by neurology $(8.16 \% ; n=28)$, cardiology $(7.00 \% ; n=24)$, urinary surgery $(6.12 \% ; n=21)$, gastro-enterology $(5.54 \% ; n=19)$, general surgery $(5.25 \% ; \mathrm{n}=18)$, etc. The frequency of the top ten of these specialities is presented in Figure 4.4 .

Figure 4.4: Frequency of the Top-Ten Specialities Related to Adverse Events $(A E)$

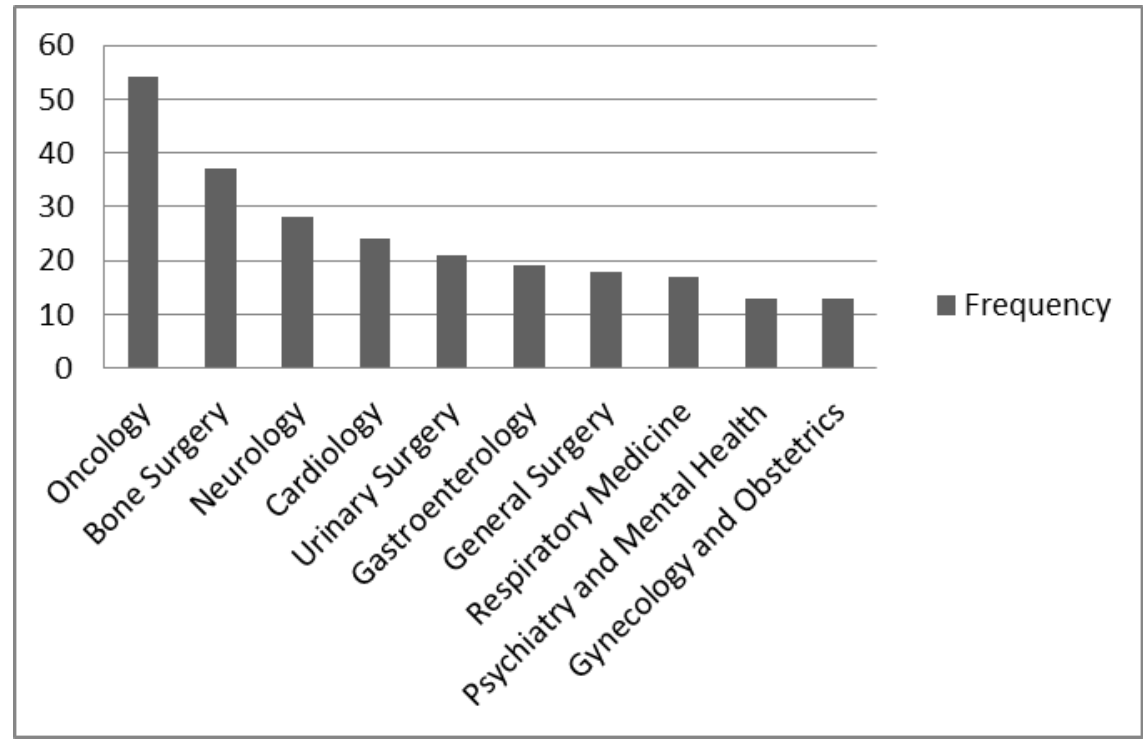




\subsection{SERIOUSNESS ${ }^{26}$ AND CAUSES ${ }^{27}$ OF IATROGENIC INJURIES ${ }^{28}$}

Both death and minor injuries were fairly frequent consequences of medical errors or defective medical products. The extent of iatrogenic injuries was reported in the 190 judgements with some awards. It turned out that almost $40 \%(n=74)$ of all the 190 cases involved minor injuries, and in about $36 \%$ $(\mathrm{n}=68)$ malpractice resulted in death. Less frequent injuries were emotional distress only in about $14 \%(n=27)$ of the cases, serious injuries in nearly $9 \%$ $(\mathrm{n}=17)$ and pure economic losses in only four. This result is summarised in Table 4.6.

Table 4.6: Seriousness of Iatrogenic Injuries

\begin{tabular}{|lrccccc|}
\hline Extent & Death & $\begin{array}{c}\text { Serious } \\
\text { Injuries }\end{array}$ & $\begin{array}{c}\text { Minor } \\
\text { Injuries }\end{array}$ & $\begin{array}{c}\text { Emotional } \\
\text { Distress Only }\end{array}$ & $\begin{array}{c}\text { Pure } \\
\text { Economic } \\
\text { Loss }\end{array}$ & Total \\
\hline $\begin{array}{l}\text { Frequen- } \\
\text { cy (No.) }\end{array}$ & 68 & 17 & 74 & 27 & 4 & 190 \\
$\begin{array}{l}\text { Percen- } \\
\text { tage }\end{array}$ & $35.79 \%$ & $8.95 \%$ & $38.95 \%$ & $14.21 \%$ & $2.11 \%$ & $100.00 \%$ \\
\hline
\end{tabular}

The largest category of the causes of iatrogenic injuries was technical malpractice mostly related to errors in diagnoses, surgery, nursing and monitoring and medication, followed by ethical malpractice primarily

26 Seriousness of medical injuries is divided into five categories: (1) "minor injuries" (injuries below the sixth level of disability or medical accidents below Grade A, Level Three; moderate, minor or trivial organ dysfunction), (2) "serious injuries" (disability from the first level to the sixth level or medical accidents from Grade B, Level One to Grade D, Level Two; relatively severe, severe or complete organ dysfunction), (3) "death," and (4) "emotional distress alone." In some rare cases, no personal injury had been caused by negligent treatment but some added financial costs were incurred because of the negligent treatment. The patient may claim these added costs back from the defendant-hospital either under contract law or under tort law.

27 In the light of the Tort Law 2009, causes of iatrogenic injuries can be divided into three categories: (1) technical malpractice, (2) ethical malpractice, and (3) defective medical products. See supra Chapter 3, Sections 3.2-3.4.

28 Of course, iatrogenic injuries include both negligent and non-negligent ones. See supra Chapter 1, Section 1.1. In the context of Chinese law, the primary type of iatrogenic injuries is the negligent one due to medical malpractice However, in a minority of the cases where a patient suffers injury from a defective medical product or substandard blood, the injury falls within the category of the non-negligent one, which is based on strict liability under tort law. See supra Chapter 3, Section 3.4. But note, this non-negligent iatrogenic injury due to defective products should not be confused with non-negligent iatrogenic injuries coverable under no-fault insurance schemes. 
concerning informed consent. Many cases involved more than a single type of malpractice and many injuries were caused jointly by several medical errors. The aforesaid 190 judgements reported a total of 230 adverse events $(\mathrm{AE})^{29}$ which could be classified into three groups and twelve categories as shown in Table 4.7. In general, technical malpractice accounted for $72 \%(n=166)$ of all the 230 AEs, ethical malpractice represented $27 \%(n=61)$, while defective products explained only about $1 \%(\mathrm{n}=3)$. As far as technical malpractice is concerned, diagnosis $(23 \% ; n=53)$, surgery $(22 \% ; n=50)$ and nursing and monitoring $(15 \% ; n=35)$ related errors were the most frequent ones. When it comes to ethical malpractice, the overwhelming majority $(23 \% ; n=53)$ type of malpractice was a breach of the duty to inform or duty to obtain consent, in contrast to management related errors $(3 \% ; n=6)$ and organizsation related errors (less than $1 \%$; $=2$ ).

Table 4.7: Causes of Iatrogenic Injuries

\begin{tabular}{|lcc|}
\hline Type of Adverse Events (AE) & $\begin{array}{c}\text { Frequency } \\
\text { (No.) }\end{array}$ & Percentage \\
\hline (1) Medical Technical Malpractice & 166 & $72.17 \%$ \\
Diagnosis-related & 53 & $23.04 \%$ \\
Surgery-related & 50 & $21.74 \%$ \\
Nursing and monitoring-related & 35 & $15.22 \%$ \\
Medication-related & 18 & $7.83 \%$ \\
Other treatment errors & 7 & $3.04 \%$ \\
Anaesthesia-related & 2 & $0.87 \%$ \\
Infection-related & 1 & $0.43 \%$ \\
(2) Medical Ethical Malpractice & 61 & $26.52 \%$ \\
Disclosure or self-determination-related & 53 & $23.04 \%$ \\
(Informed consent) & & \\
Management-related & 6 & $2.61 \%$ \\
Organisation-related & 2 & $0.87 \%$ \\
(3) Defective Medical Products & 3 & $1.30 \%$ \\
Blood and blood products-related & 2 & $0.87 \%$ \\
Drug-related & 1 & $0.43 \%$ \\
\hline \multicolumn{1}{c}{ Total } & 230 & $100.00 \%$ \\
\hline
\end{tabular}

$29 \quad$ Adverse events here only refer to negligent AEs and medical product accidents. But note, non-negligent AEs include, but are not limited to, medical product accidents. 


\subsection{DAMAGES AWARDS}

Remarkably, plaintiffs were on average awarded more damages in mediated cases than in judged ones. 190 cases closed by judgements and all the 224 cases closed by consent judgements upon in-court mediation were rendered with some awards. A total of almost fifty million yuan was paid as compensation in the 414 cases, with an average amount of about 121,000 yuan for each winning case. On average, plaintiffs received a higher amount of compensation in cases closed by in-court mediation (about 142,000 yuan) than in cases closed by judgements (about 96,000 yuan). The largest award in judgements (about 889,000 yuan) was far less than the largest award in consent judgements (as high as 3.84 million yuan). Table 4.8 shows the mean, median and the largest damage awards in general. Both medians are far lower than the means, indicating the substantial influence of extremely large awards on the means.

Table 4.8: Mean, Median, and Maximum Damages

\begin{tabular}{|lcccc|}
\hline & $\begin{array}{l}\text { Cases } \\
(\text { No. })\end{array}$ & Mean $(¥)$ & Median (¥) & $\begin{array}{c}\text { Maximum } \\
(¥)\end{array}$ \\
\hline $\begin{array}{l}\text { Judgements with } \\
\begin{array}{l}\text { Awards } \\
\text { Consent } \\
\text { Judgements }\end{array}\end{array}$ & 190 & 95,906 & 45,382 & 889,027 \\
\hline
\end{tabular}

As time went on, awards in each year were largely on the increase, especially from 2004 to 2010 and from 2011 to 2013, even after being adjusted for the CPI. Table 13 compares and contrasts the damage awards respectively in (consent) judgements each year from 2003 to 2013. In order to show the trend of the average size of damages awards more clearly, data on the mean, median, and maximum of the awards for the period 2003-2013 is presented in Table 4.9 .

Table 4.9: Awards in (Consent) Judgements by Year of Decision*

\begin{tabular}{|lccccc|}
\hline Year & $\begin{array}{c}\text { Total Number of } \\
\text { (Consent) Judgements }\end{array}$ & $\begin{array}{c}\text { Mean (¥) } \\
\text { Awards }\end{array}$ & $\begin{array}{c}\text { Median (¥) } \\
\text { Awards }\end{array}$ & $\begin{array}{c}\text { Maximum (¥) } \\
\text { Awards }\end{array}$ & $\begin{array}{c}\text { Judgements } \\
\text { without } \\
\text { Awards (No.) }\end{array}$ \\
\hline 2003 & 25 & 25,454 & 19,959 & 103,906 & 10 \\
2004 & 7 & 23,967 & 15,772 & 58,188 & 1 \\
2005 & 52 & 77,882 & 36,814 & 595,530 & 10 \\
2006 & 54 & 75,127 & 36,100 & 521,597 & 15 \\
2007 & 41 & 81,561 & 27,593 & 790,146 & 15 \\
2008 & 49 & 89,800 & 47,271 & 467,804 & 11 \\
132 & & & & Intersentia
\end{tabular}




\begin{tabular}{|cccccc|}
\hline Year & $\begin{array}{c}\text { Total Number of } \\
\text { (Consent) Judgements }\end{array}$ & $\begin{array}{c}\text { Mean (¥) } \\
\text { Awards }\end{array}$ & $\begin{array}{c}\text { Median (¥) } \\
\text { Awards }\end{array}$ & $\begin{array}{c}\text { Maximum (¥) } \\
\text { Awards }\end{array}$ & $\begin{array}{c}\text { Judgements } \\
\text { without } \\
\text { Awards (No.) }\end{array}$ \\
\hline 2009 & 28 & 90,728 & 50,487 & 490,262 & 2 \\
2010 & 33 & 122,163 & 56,790 & 924,699 & 3 \\
2011 & 45 & 79,711 & 33,303 & 362,607 & 5 \\
2012 & 52 & 122,090 & 73,921 & $1,876,791$ & 7 \\
2013 & 91 & 144,508 & 60,188 & $2,832,226$ & 10 \\
\hline
\end{tabular}

* In order to exclude the influence of inflation, all data on damages are adjusted for the CPI. ${ }^{30}$ Data in 2003 is taken as the base number.

Figure 4.5: The Trend of Awards in (Consent) Judgements by Year of Decision

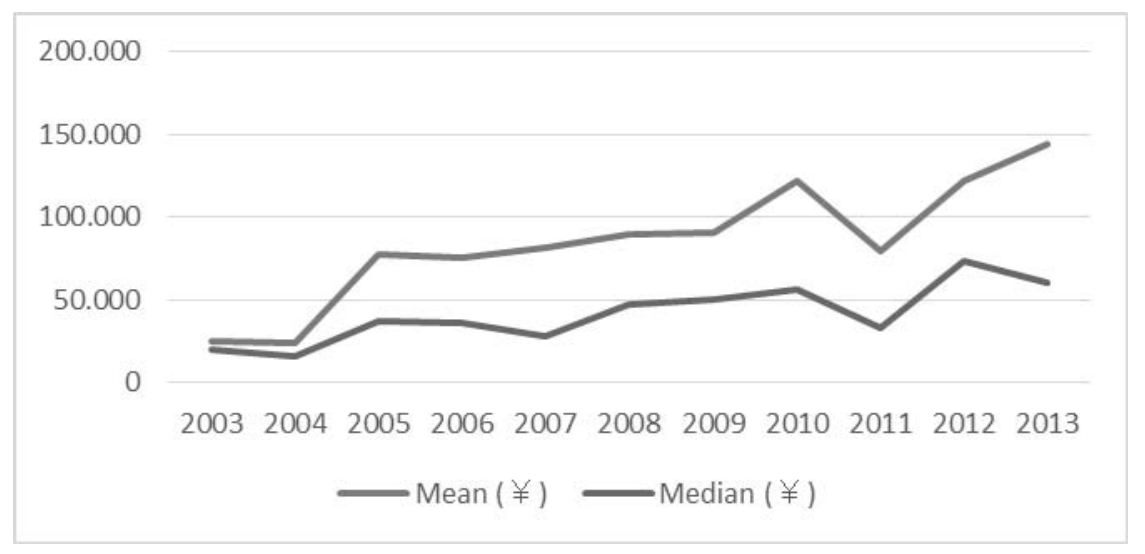

The court tended to increase the degree of liability testified by expert witnesses. A total of 163 judged cases reported the degree of liability the court finally determined. Both the mean and the median degrees of liability of all the 163 judged cases was roughly $50 \%$, falling within the category of equal responsibility. The most frequently decided degrees were equal responsibility $(26 \% ; n=42)$, secondary responsibility $(25 \% ; n=41)$ and minor responsibility (23\%; $\mathrm{n}=38)$, followed by full responsibility $(17 \%$; $\mathrm{n}=27)$ and major responsibility (9\%; $\mathrm{n}=15)$. Compared with degrees testified by expert witnesses, the court found a higher proportion of cases as not less serious than equal responsibility (52\% compared with $47 \%$ ) or as full responsibility $(17 \%$ compared with only $1 \%$ ). Table 4.10 presents the degrees of liability given by both expert witnesses and the court.

$30 \quad$ For data on the CPI in China from 1978 to 2013, see e.g. China Economic Net 2014. 
Part I. Legal Remedies for Medical Malpractice in China

Table 4.10: Degrees of Liability in Comparison

\begin{tabular}{lcc}
\hline Degree of Liability & Expert Opinions & Court Decisions* \\
\hline Full & $1 \%(\mathrm{n}=1)$ & $17 \%(\mathrm{n}=27)$ \\
Major & $33 \%(\mathrm{n}=27)$ & $9 \%(\mathrm{n}=15)$ \\
Equal & $13 \%(\mathrm{n}=11)$ & $26 \%(\mathrm{n}=42)$ \\
Secondary & $30 \%(\mathrm{n}=24)$ & $25 \%(\mathrm{n}=41)$ \\
Minor & $23 \%(\mathrm{n}=19)$ & $23 \%(\mathrm{n}=38)$ \\
\hline
\end{tabular}

${ }^{*}$ Mean Degree $=51 \%$; Median Degree $=50 \%$; Maximum Degree $=100 \%$

The degree of liability was mostly determined by comparing the causal potency or significance of the faulty treatment, on the one hand, and the causal potency of the patient's pre-existing conditions, on the other hand, to the occurrence or expansion of the final injuries. A total of 188 of all the 190 judgements closed with awards reported the causes contributing to the occurrence or expansion of the patient's injuries. In $72 \%(n=135)$ of the 188 cases, the patient's injuries were caused by multiple factors, while the patient's injuries were wholly caused by negligence on the part of a single hospital in $28 \%$ ( $n=53$ ) of the cases. As far as cases where multiple causative factors are involved, the most frequent $(\mathrm{n}=127)$ concurrent cause of injuries in all these 135 cases was the patient's pre-existing conditions. Less frequent causes included comparative negligence ${ }^{31}$ on the part of the patient in seven cases and joint torts in three cases. The distribution of the single and multiple causative factors are presented in Figure 4.5.

$31 \quad$ Comparative negligence on the part of the plaintiff was applied in the following cases: (1) Zhu v. Children's Hospital \& Jiangsu Hospital (China) (where the plaintiff failed to reexamine his heart as required by the doctor's advice); (2) Fu v. Jiangsu Hospital (China) (where the plaintiff was determined to have left hospital before his surgery wound completely healed); (3) Jia et al. v. Zhongda Hospital (China) (where the close relatives of the deceased patient refused to give consent to final rescue medical attempts in case of emergency); (4) Zhang v. Zhongda Hospital (China) (where the patients were uncooperative in the operation); (5) Zhang \& Wang v. Zhenjiang First Hospital \& Children's Hospital (China) (where the parents delayed to refer their child to another hospital); (6) Wang et al. v. Jiangsu Hospital (China) (where the plaintiff failed to pay enough attention to medical history and showed it to the doctor in time); and (7) Yuan \& Zheng v. Brain Hospital (China) (where the patient, in spite of his old age and severe illnesses, took the liberty to go to another ward and used the sports equipment without the guidance of any medical staff member). 
Figure 4.6: Distribution of Causative Factors
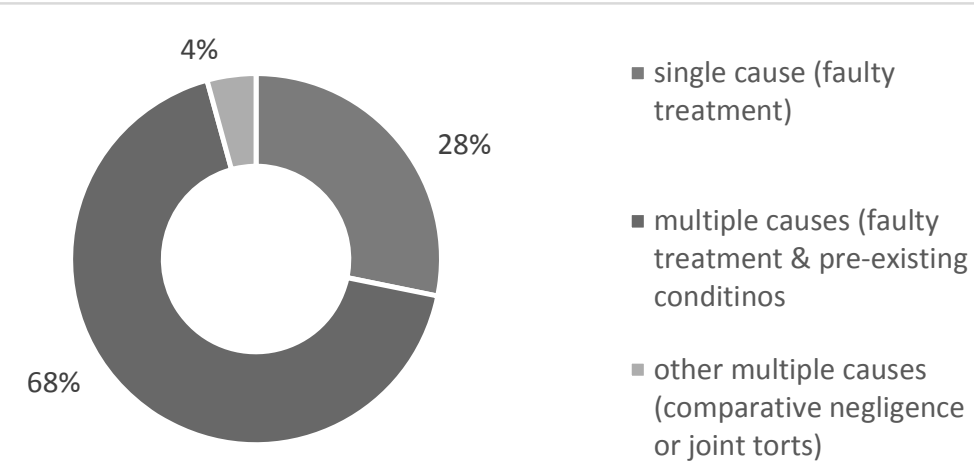

The size of final damages was influenced by the degree of liability and collateral benefits set-offs. Final damage awards were basically calculated on the basis of the sum of the consequential pecuniary losses (medical bills, nursing costs, loss of earnings, etc.), with collateral benefits subtracted (compensation lucre cum damno), and non-pecuniary losses (numerical assessment of emotional distress). The pecuniary losses were lessened in proportion to the degree of liability. This process can be described by Expression 4.1 as follows:

\section{awards $=$ \\ (pecunlary losses - collateral benefits) $\times$ degree of liabllity + emotional losses (Expression 4.1)}

The final damage awards were limited more by the degree of liability than by the collateral benefits set-offs. As noted before, damage awards in the majority of the 190 judged cases closed with awards $(72 \%$; $n=136)$ were reduced by taking into account the degree of liability. In contrast, only about $7 \%(n=14)$ judged cases reported that social insurance benefits were deducted from the full pecuniary losses. So did two judged cases where even private health insurance benefits were subtracted.

Although generally available in most cases, compensation for nonpecuniary losses was largely moderate and normally limited by a nonstatutory cap of 50,000 yuan. 163 (86\%) of the aforementioned 190 judgements awarded compensation for emotional distress or pain and suffering. The damage awards for non-pecuniary losses ranged from 1,000 yuan to 60,000 yuan, with a mean of about 14,853 yuan and a median of 
10,000 yuan. Although damage awards for non-pecuniary losses exceeded 50,000 yuan in two old cases ${ }^{32}$ they were the exception rather than the rule.

The court seldom gave more explanation for awarding non-pecuniary damages than simply stating that the "plaintiff had suffered serious emotional distress," though it explained more when refusing to award such damages. In all the 163 judgements with emotional damage awards, the court explained why claims for emotional damages had been denied in 17 cases. The court argued that claims for emotional damages in the following cases should be denied: (a) where no serious personal injury or disability was caused $(n=5) ;(b)$ where the degree of the defendant's negligence was minor $(\mathrm{n}=4)$; (c) where the presiding judge held that compensation for death should be regarded as compensation for emotional distress ( $\mathrm{n}=2)$; (c) where the presiding judge held that claims for emotional distress could never be based on contract law $(\mathrm{n}=1)$; (d) where although the patient's right to informed consent was encroached upon, there was no causal link between the emotional distress and the personal injuries $(\mathrm{n}=1)$; (e) where pain and suffering was caused by postoperative complications rather than negligence on the part of the defendant $(\mathrm{n}=1)$; (f) where the patient or his close relatives were also negligent $(\mathrm{n}=1) ;(\mathrm{g})$ where negligence on the part of the defendant was not a major cause for the occurrence or expansion of the damage $(n=1)$ or $(h)$ where the victimised patient was so young that he/she was unable to feel pain and suffering $(\mathrm{n}=1)$.

Plaintiffs were awarded fewer damages in cases where patients died than in cases where patients were received serious injuries. A total of 190 cases with the extent of injuries identified reported the damages awarded. All the mean, median and maximum amounts of damages were summarised in Table 11 in terms of different categories of the extent of injuries. On average, plaintiffs obtained the largest damages (289,446 yuan) in cases where patients suffered serious injuries and the second largest damages (129,150 yuan) where patients died. Only an average amount of damages of 54,437 yuan was awarded in cases involving minor injuries and 14,498 yuan in cases where only emotional distress was caused. Table 4.11 shows the association between damages and extent of injuries. Smaller medians indicate the substantial influence of large damage awards on the means.

32 Wu v. Drum Tower Hospital (China); Li \& Cheng v. Jiangsu Hospital(China). 
Table 4.11: Damages and Extent of Injuries

\begin{tabular}{lcccc}
\hline Extent of Injuries & \multicolumn{3}{c}{ Damages (¥) } & Total Number \\
\cline { 2 - 4 } & Mean & Median & Maximum & \\
Death & 129,150 & 71,606 & 584,340 & 69 \\
Serious Injuries & 289,446 & 250,256 & 889,027 & 18 \\
Minor Injuries & 54,437 & 30,441 & 224,147 & 75 \\
Emotional Distress & 14,498 & 10,000 & 50,000 & 28 \\
Only & & & & \\
\hline
\end{tabular}

\subsection{LITIGATION COSTS 33}

Costs of the action were relatively high, especially for rural plaintiffs. 502 of all the 592 cases in the study reported data on litigation costs. The initial case acceptance fees ranged from 50 yuan to 19,834 yuan, with a mean of 1,662 yuan and a median of 900 yuan. The initial case acceptance fees advance to the court were halved in value in the final stage of litigation in almost $30 \%$ $(\mathrm{n}=142)$ of the 502 cases. Therefore, the final case acceptance fees paid to the court ranged from 25 yuan to 19,834 yuan, with a reduced mean of 1,469 yuan and a new median of 702 yuan. The average expert ascertainment fees paid to the municipal medical association were 2,180 yuan, to the provincial medical association were 3,197 yuan, to the Chinese Medical Association were 8,500 yuan and to the medico-legal authentication institutions were 6,606 yuan. Before the trial, litigants on average had to advance a total of 4,395 yuan as litigation costs in general, 5,938 yuan as litigation costs in cases closed by judgements and 2,479 yuan in cases closed by in-court mediation. At the end of the trial, the final mean litigation costs, in general, were slightly reduced to 4,200 yuan.

Plaintiffs did have to share a large proportion of costs of the action. Before the trial, plaintiffs were required to advance an average litigation cost of about 3,261 yuan, representing almost $72 \%$ of the mean initial costs of the action. At the end of the trial, plaintiffs were ordered to pay a reduced average litigation cost of 2,277 yuan, still representing nearly $60 \%$ of the final mean litigation costs.

Plaintiffs had to advance higher litigation costs before the trial in cases where the new Tort Law applied, although they actually paid less at the end of the case. A total of 234 cases reported both the advance of litigation costs and the application of law, consisting of 44 new tort law cases and 190 old cases. Plaintiffs on average had to advance 4,293 yuan in the former cases,

33 Litigation costs include court acceptance fees and medical ascertainment fees but do not include attorney fees. 
whereas only 3,696 yuan in the latter case. In contrast, 44 new tort law cases and 195 old cases recorded data on the final burden of litigation costs. Plaintiffs only had to pay 2,206 yuan for litigation costs in the new tort law cases while 2,868 yuan in the old cases. Nevertheless, high advance payments already build barriers to access to justice to many victimised patients. These increased advance payments may be explained by the fact that the reversal of the burden of proof rule has been abolished by the new Tort Law. As a result, plaintiffs have to advance expert ascertainment fees before the trial, which were usually advanced by the defendant prior to the advent of the Tort Law.

\section{DISCUSSIONS (SUPPLEMENTED WITH INTERVIEW RESULTS)}

\subsection{HIGH-RISK HOSPITALS, SPECIALITIES AND MEDICAL DISPUTES}

Data on court decisions from the Gulou Court (hereinafter Gulou Data) show that most medical malpractice claims $(60 \%)$ are associated with general hospitals (Level 2 or Level 3), which are consistent with Li et al.'s study (66\%, nationwide $)^{34}$ and Liu et al.'s study $\left(95.58 \%\right.$, Beijing). ${ }^{35}$ However, this finding does not necessarily suggest that the quality of care provided by high-level hospitals is worse than that provided by low-level health centres or clinics. The high rate of medical disputes associated with high-level hospitals may be explained by two factors other than service quality. First, a high proportion of all patients are actually treated by high-level hospitals. ${ }^{36}$ The more hospital admissions, the higher the frequency of medical disputes. Second, these hospitals are intended by the government to treat more serious, dangerous, or complex diseases. ${ }^{37}$ The riskier the disease, the higher the chances of resulting in treatment failure and medical disputes.

According to the Gulou Data, oncology (15.74\%), bone surgery $(10.79 \%)$, and neurology $(8.16 \%)$ are the top three specialities related to medical disputes. This finding contradicts Li et al.'s finding that obstetrics and gynaecology (19\%), plastic surgery (19\%), and general surgery (15\%) are the top three, ${ }^{38}$ but is partly consistent with Liu et al.'s finding that obstetric and

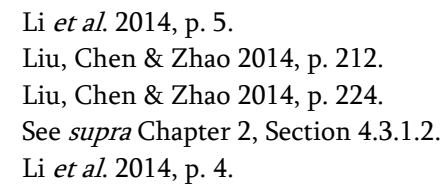


gynaecology (23\%), bone surgery (21\%), and general surgery (13\%) are most frequently involved. ${ }^{39}$ The differences among these findings may be attributed to the heterogeneity of service quality among different localities in China. Be that as it may, all these most frequently involved specialties fall within the category of surgery where operative manual and instrumental techniques are used on a patient. Modern surgical technology becomes more and more intrusive, which increases therapeutic risks significantly. ${ }^{40}$ At least, these data indicate that there may be a positive correlation between the complexity and intrusiveness of medical interventions and the frequency of medical disputes.

\subsection{THE ROLE OF EXPERT WITNESSES}

Based on the Gulou Data, we can find that the court relies heavily on expert evidence to resolve medical malpractice claims, which is widely confirmed by other studies. ${ }^{41}$ About $60 \%$ of the 504 judged or mediated cases involved medical ascertainment and a total of 420 expert testimonies were produced (1.43 testimonies per case), $95 \%$ of which were completely or partly adopted by the Gulou Court whereas only 5\% were rejected. In Ezhou of the Hubei Province (2002-2008), more than $70 \%$ of the 145 cases underwent medical ascertainment, and a total of 251 expert testimonies were given (1.73 testimonies per case), most of which were adopted by the court. ${ }^{42}$ Hence, medical ascertainment has almost become a must in malpractice litigation, which may in effect dwarf the importance of the issue of burden of proof. ${ }^{43}$ In other words, since either the proof or the lack of proof of liability is given by the expert, then the burden of proof is relevant insofar as who should pay ascertainment fees in advance (usually the party who bears the burden of proof). ${ }^{44}$

Three factors may explain why judges retreat in the face of the determination of malpractice liability. First, modern medicine is highly technical and professional which is by no means readily intelligible to lay people. ${ }^{45}$ Even when a judge is a medical graduate, in an era when medicine

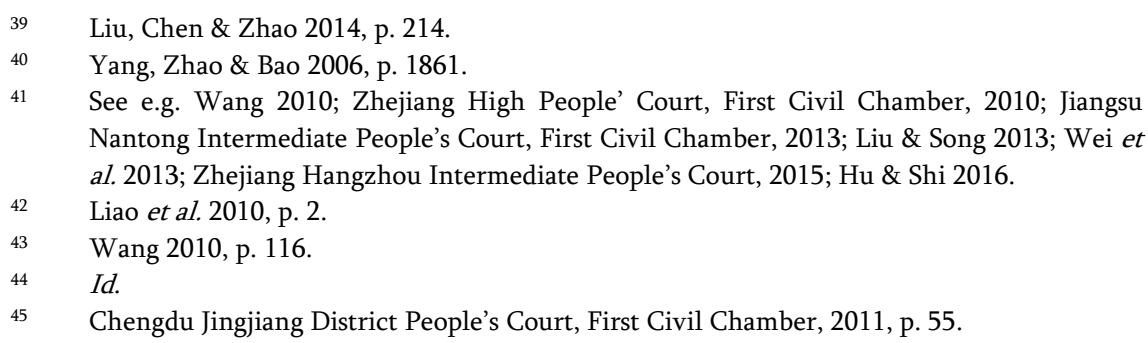


advances rapidly, he/she will soon fall behind his/her colleagues who are practising clinical medicine. ${ }^{46}$ Thus, a judge, be he/she a medical graduate or not, may feel or be regarded as unqualified to determine medical malpractice issues. ${ }^{47}$ Second, placing heavy reliance on medical expert evidence may help courts and judges to protect them from challenge by litigants since litigants' attention will be distracted from court decisions to conclusions of medical ascertainment. ${ }^{48}$ Third, to trial judges, basing court decisions on expert testimonies may help reduce the chances that their cases will be remanded by appellate courts for a new trial since it is also difficult for appellate judges to challenge an expert testimony (unless a new medical ascertainment is conducted at the request of the appellate court). ${ }^{49} \mathrm{~A}$ trial judge whose cases are often remanded by the appellate court for new trial will adversely affect his/her promotion prospects. ${ }^{50}$

The Gulou Data also tell us that the court sometimes prefers forensic testimonies to accident testimonies, although it is often believed that clinical experts are more qualified than forensic pathologists for peer review. A judge from the appellate court explained,

\begin{abstract}
Expert testimonies provided by medical associations are often rather vague and only give a very brief demonstration of the conclusion. For instance, the letter of conclusion may simply state that "no treatment norm has been contravened," but it does not specify how the experts have come to this conclusion. Being presented with such a short testimony, we would feel at sea if patients somehow pointed out the defendant's fault according to some medical textbooks. In contrast, the letter of conclusion offered by pathologists is more detailed with a thorough demonstration of how they came to the conclusion ... We, as judges who lack medical knowledge and experience, really hope that experts would present us with a detailed answer to the issues of fault and causation. ${ }^{51}$
\end{abstract}

It seems that judges prefer forensic testimonies to accident testimonies in that this helps make their work less burdensome and their decisions more convincing. To medical lay people, a detailed and well-argued ascertainment conclusion appears more acceptable than a brief and vague conclusion, irrespective of the expertise of the experts who produce the testimony. The

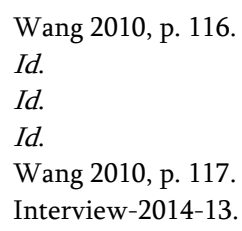


briefness and vagueness of the accident testimony may also explain why patients challenge accident testimonies more frequently than forensic ones.

In addition, the Gulou Data disclose that clinical experts rarely signed the conclusion letter and appeared in court to testify, although pathologists always signed the conclusion letter and sometimes appeared in court, which is consistent with most previous studies. ${ }^{52}$ Article 73 of the Civil Procedure Law 1991 (2012 Amendment) provides that a witness shall testify in court in principle; nonetheless, if the witness is unable to appear in court, due to health reasons, remote residence and travel difficulty, a force majeure or any other justifiable reason, he/she may testify by written testimony or any other means as permitted by the court. Mr. Hu, an official from the public health authorities in Nanjing, said that most experts invent excuses such as falling ill for their refusal to appear in court. ${ }^{53}$ Without being present in court, experts are not subject to cross-examination, which may go against the fact-finding process. $^{54}$

Two factors may help explain why clinical experts are unwilling to sign the conclusion letter and appear in court. First, these experts are worried that they might face revenge by angry patients or their family members if they testified against the plaintiff. ${ }^{55}$ For this very reason, even the experts' personal signatures on the conclusion letter are usually not disclosed to the patients or their family members in e.g. Nanjing. ${ }^{56}$ Second, since accident ascertainment by definition should be conducted by a group of experts, it is difficult in practice to summon all members of the expert group, most of whom are high-ranking doctors and are very busy with their work, to appear in court at the same time. ${ }^{57}$

In addition, one judge even questioned the usefulness of making experts appear in court by arguing that

[c]linical experts do not seem to know how to play the role of a witness for they always quarrel with plaintiff-patients, give irrelevant answers, or simply admit that they are unable to answer some of the questions, which does not assist the trial but creates greater uncertainty. All of these will

\footnotetext{
$52 \quad$ See e.g. Liao et al. 2010; Chengdu Jingjiang District People's Court, First Civil Chamber, 2011; Zhejiang Ningbo Intermediate People’s Court, First Civil Chamber, 2013.

53 Interview-2013-1.

54 Liao et al. 2010, p. 2.

55 Interview-2013-1.

56 Id.

57 Interview-2014-13.
} 
make it more difficult for us to render a clear and convincing judgement ... Thus, we prefer a written testimony to testifying in court. ${ }^{58}$

Again, judges' preference for written evidence rather than cross-examination could be explained by their lack of medical expertise. If judges do not understand what experts say in court, how will they be able to conduct a cross-examination? A well-argued written testimony would facilitate the trial significantly and judges could simply include the ascertainment conclusion in their decisions. That judges retreat from determining malpractice liability on their own may further reinforce the current essential role played by expert witnesses in medical malpractice lawsuits.

Interestingly, although the Gulou Court would initiate the medical ascertainment procedure in the vast majority of the cases, it still emphasises that in cases where the doctrine of “res ipsa loquitur" (事实自证) could apply, it would be unnecessary to commence the ascertainment process. ${ }^{59}$ The mere fact of the occurrence of an accident, prima facie, will raise an inference of fault and causation if the following conditions are met:

(1) the instrumentalities were exclusively controlled by the hospital;

(2) the accident does not ordinarily occur in the absence of the hospital's fault, and

(3) other possible causes have been reasonably excluded. ${ }^{60}$

In Lü v. Drum Tower Hospital, the Gulou Court argued:

Because the surgery was performed "behind the scenes" (密室性), the entire surgical procedure was only open to medical practitioners who participated in the surgery, and the medical records were written by these practitioners, it would be very difficult for the patient to produce evidence to establish negligence on the part of the defendant. In such a special case, one can infer from the occurrence of the complications suffered by the patient and some circumstantial evidence that the defendant might be at fault.

However, this rule is rarely used in practice. In all the 592 cases studied, the preceding case was the only one that applied this rule.

\footnotetext{
$58 \quad$ Id.

59 Jiangsu Nanjing Gulou District People's Court, First Civil Chamber, 2014.

$60 \quad$ Id.
} 


\subsection{LOCUS OF LIABILITY AND STANDARD OF CARE}

\subsubsection{Locus of Liability}

Risks of compensation facing medical institutions and medical staff members are different, because article 54 of the Tort Law 2009 provides that all compensation for medical injury shall be paid by medical institutions solely and entirely. This is absolutely true when the medical institution is at fault itself in e.g. management or organisation which leads to the occurrence of medical injury in the course of diagnoses and treatment.

But what if the injury is solely or primarily caused by malpractice on the part of medical staff members? Although medical staff members cannot be sued directly by the victimised patient, their medical institutions can impose internal punishments such as "fines" on the wrongdoers. ${ }^{61} \mathrm{~A}$ hospital is composed of many different departments. Not only the wrongdoer but also the whole department to which he/she belongs may have to be fined by the hospital. That is to say, the total compensation paid by the hospital to the victimised patient is sometimes de facto shared among the hospital, the department and the individual wrongdoer.

Due to the lack of law that governs this issue, the actual proportion of corresponding liability varies from hospital to hospital and even from case to case. One doctor interviewed said that a doctor who commits medical malpractice is usually fined no more than $10 \%$ of the total compensation. ${ }^{62}$ Sometimes, even this $10 \%$ fine is not actually imposed, making the internal punishment a mere formality. ${ }^{63}$ Another doctor interviewed offered a specific example. Suppose the total compensation is 500,000 yuan, a doctor who commits a tort has to pay $10,000^{\sim} 20,000$ yuan $\left(2^{\sim} 4 \%\right)$, and the remaining compensation is divided between the department $\left(16^{\sim} 18 \%\right)$ and the hospital $(80 \%){ }^{64}$ In some exceptional cases where the department does not want the dispute to be heard by the hospital, the dispute can even be settled between the department and the patient without the involvement of the hospital. ${ }^{65}$

61 Interview-2014-1; Interview-2014-2; Interview-2014-4; Interview-2014-5; Interview2014-6; Interview-2014-7.

62 Interview-2014-1.

63 Interview-2014-1.

64 Interview-2014-5.

65 Some rich departments have established "compensation funds" on their own, which are actually a form of self-insurance. Doctors in these departments contribute some of their performance bonuses awarded by the hospital to the "compensation funds." See Interview2014-4. 
As a matter of interest, it seems that doctors are more worried about other types of internal sanctions than fines imposed by their employerhospitals. If it is ordinary malpractice rather than medical accidents, the doctor concerned will not be subject to administrative punishments or criminal penalties imposed by the state. Nevertheless, one doctor interviewed mentioned that, in addition to fines imposed by the hospital, the wrongdoer also faces reduced chances of promotion and low scores of performance evaluation. ${ }^{66}$ Sometimes, his/her professional title may be degraded, e.g. from an "attending doctor" to a "resident doctor." ${ }^{\text {"7 }}$ Furthermore, his/her right to prescribe may also be limited accordingly. ${ }^{68}$

\subsubsection{Technical Malpractice}

In accordance with the Gulou Data, the court was very flexible in applying the standard of care for medical malpractice and did make a clear distinction between the "bonus pater familias/due care" or the "medical customary practice." Judges often used terms such as "due care," "due diligence," "high degree of diligence," or "maximum duty of care" without defining them.

Previous studies found a similar chaotic application of the standard of care. For instance, Tang et al. analysed 243 malpractice lawsuits collected from on-line databases for the period 2005-2010 and reported that the “treatment norm” test (诊疗规范标准) was employed in $44.03 \%(\mathrm{n}=107)$ of all the cases, the "medical standard" test (医疗水平标准) in $29.63 \%(\mathrm{n}=72)$, and the "reasonable doctor" test (理性医生标准) in $26.34 \%$ ( $\mathrm{n}=64) .{ }^{69}$ Tang et al. defined the three tests as follows: ${ }^{70}$

- The treatment norm test: rules or customary practices that all medical professionals should comply with when providing specific treatment.

- The medical standard test: the standards that should be followed by clinical physicians, which require that the efficacy and safety of the treatment measure have been confirmed and that the treatment measure is ready to be implemented in clinical practice in accordance with available medical equipment, technology, personnel, etc.

- The reasonable doctor test: the same level of expertise and care as a reasonable doctor would exercise under the same or similar circumstances.

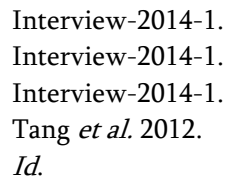


Tang et al.'s preceding definition of the "medical standard" test might be influenced by Korean or Japanese law. ${ }^{71}$ However, the fact that some Chinese judges mentioned this term in their decisions does not necessarily imply that they bear the same definition in their mind. At least, neither the lawmakers nor the SPC has ever defined the "then medical standard" in the same way as Japanese or Korean law. ${ }^{72}$

Interviews with judges provide a better insight into how judges understand and apply the standard of care required of physicians in practice. Ms. Justice A (alias) from the appellate court of the Gulou Court - the Nanjing Intermediate People's Court (hereinafter Nanjing Court) - confirmed that a reasonable doctor test (合理医师标准) is adopted in China (at least in Nanjing).$^{73}$ However, whether a treatment measure is reasonable or not is tested against the so-called "then medical standard" as currently required by article 57 of the Tort Law 2009.

However, again, how should the "medical standard" be interpreted? Mr. Justice Li from the Gulou Court explained that the "medical standard" could be classified into four categories as presented in Table 4.12.74

$71 \quad$ For more information on the "medical standard" test which is widely adopted in South Korea (perhaps also in Japan) and which seems to have influenced art. 57 of the Tort Law 2009 (China), see generally Suk 2007; Xia 2007, pp. 105-139.

72 For the commentaries provided by the law makers and the SPC on the Tort Law 2009, see generally Xi \& The Supreme People's Court 2010; Wang 2013.

73 Interview-2014-13.

74 Interview-2014-10. Mr. Justice Li also kindly provided an internal document that summarises the opinions of the Gulou Court, see Jiangsu Nanjing Gulou District People's Court, First Civil Chamber, 2014. 
Part I. Legal Remedies for Medical Malpractice in China

Table 4.12: Four Categories of the "Medical Standard" Applied by the Gulou Court

\begin{tabular}{|c|c|c|c|}
\hline Categories & Name & Definitions & Explanations \\
\hline Class One & $\begin{array}{l}\text { Minimum standards } \\
\text { (最低水平) }\end{array}$ & $\begin{array}{l}\text { - Non-technical } \\
\text { requirements provided for } \\
\text { by laws and regulations }\end{array}$ & $\begin{array}{l}\text { - standards developed after the } \\
\text { treatment should not be applied } \\
\text { retrospectively (art. 57, Tort }\end{array}$ \\
\hline Class Two & $\begin{array}{l}\text { Basic medical } \\
\text { standards } \\
\text { (基本医疗水平) }\end{array}$ & $\begin{array}{l}\text { - Standardised written } \\
\text { treatment norms }\end{array}$ & $\begin{array}{l}\text { Law) } \\
\text { - the locality rule } 75 \text { should not } \\
\text { apply to Class One and Class }\end{array}$ \\
\hline $\begin{array}{l}\text { Class } \\
\text { Three }\end{array}$ & $\begin{array}{l}\text { Ordinary medical } \\
\text { standards }\end{array}$ & $\begin{array}{l}\text { - Customary practices that } \\
\text { cannot be standardised in a }\end{array}$ & $\begin{array}{l}\text { Two, but could apply to Class } \\
\text { Three }\end{array}$ \\
\hline & (通常医疗水平) & written form & $\begin{array}{l}\text { - When applying Class Four } \\
\text { specific factors such as the trust }\end{array}$ \\
\hline Class Four & $\begin{array}{l}\text { Medical standards } \\
\text { based on trust } \\
\text { (信赖医疗水平) }\end{array}$ & $\begin{array}{l}\text { - Medical standards based on } \\
\text { trust between doctors and } \\
\text { patients that are higher than } \\
\text { ordinary medical standards }\end{array}$ & $\begin{array}{l}\text { between doctors and patients } \\
\text { should also be taken into } \\
\text { account }^{76}\end{array}$ \\
\hline
\end{tabular}

"Treatment norms" may refer to a variety of written documents such as clinical guidelines published by the Chinese Medical Association (CMA) and medical textbooks. ${ }^{77}$ However, treatment norms are often outdated quickly. Hence, the court often regards customary practices "prevailing in LevelThree-Grade-A hospitals in several provinces" as the standard of medical care, but rejects the "cutting-edge standard developed by some experts through a large number of human trials." ${ }^{\prime 7}$ International clinical guidelines are rarely considered. ${ }^{79}$

As far as the standard for diagnosis, the Gulou Court clarified that the "reasonable duty of medical care" should not be interpreted as the "golden standard" for diagnosis. ${ }^{80}$ The "golden standard" refers to the diagnostic measure that is widely recognised by the clinical and medical community as the most reliable method, such as biopsy, microbiological culture, special examination and imaging diagnosis, and long-term follow-up. ${ }^{81}$

75 The locality rule denotes that differences in localities, levels of hospitals, and qualifications of physicians should be taken into account when determining the standard of care.

76 For instance, if a hospital boasts in the advertisement that it can cure some diseases with certainty, or that it has the most advanced equipment or the best qualified physicians, and if a patient goes to the hospital because s/he trusts what the hospital says, then the court shall apply the high level of standard as advertised by the defendant-hospital. Chen 2011.

77 Interview-2014-10.

$78 \quad$ Id.

79 Id.

$80 \quad$ Jiangsu Nanjing Gulou District People’s Court, First Civil Chamber 2014.

$81 \quad$ Id. 
The Nanjing Court does not seem to classify the medical standard in such a detailed way, although it does confirm that the locality rule should apply when necessary. ${ }^{82}$

Several interviewees pointed out the problems of determining fault in the medical ascertainment procedure. ${ }^{83}$ The then medical standard test suggests that a physician's conduct should be assessed against a reasonable doctor's behaviour in similar circumstances, which entails the use of the locality rule and peer review. In practice, clinical experts selected for the purpose of providing expert evidence are high-ranking physicians who are better qualified and more experienced than the average level. ${ }^{84}$ Two problems may arise. First, experts from Level-Three hospitals may be more likely to find that a physician from a Level-One health centre acted below the "then medical standard." $\$ 55$ Second, experts from a locality with higher levels of quality of care may tend to confirm that a physician from a locality with lower levels of quality of care does not comply with the "then medical standard." "86 Hence, the current regime of expert witnesses may appear unfair and biased against hospitals of low levels or hospitals located in localities where medical resources are rather limited.

Given that judges often rely on expert testimony to decide fault, the defects in the medical ascertainment system may reduce the accuracy of court decisions. Since experts from high-level hospitals and localities with more medical resources are often included in the expert bank, it is reasonable to estimate that the likelihood of false positives (i.e. finding a non-negligent doctor at fault erroneously) may exceed that of false negatives (i.e. exonerating a negligent doctor erroneously).

\subsubsection{Ethical Malpractice}

It is found, on the basis of the Gulou Data, that disclosure malpractice accounted for about 23\% of iatrogenic injuries and the Gulou Court confirmed the patient's right to know and to self-determination as early as around 2004. In Chen v. Stomatological Hospital, the court made clear that "physicians are not supposed to disclose any information to patients but only

\footnotetext{
82 Interview-2014-13. Ms. Justice A (alias) also provided an internal document that summarizes the opinions of the Nanjing Court, see Jiangsu Nanjing Intermediate People's Court, First Civil Chamber 2014.

83 Interview-2013-1; Interview-2014-10; Interview-2014-14.

84 For information on the selection of clinical experts, see supra Chapter 3, Section 3.6.

85 Id.

$86 \quad$ Id.
} 
the risk of commonly seen complications that cannot be prevented by a properly given treatment."

In Wang v. Drum Tower Hospital, the court defined the doctrine of informed consent for the first time as follows:

Treatment is administered with the consent of the patient rather than out of a professional privilege naturally owned by physicians. The law requires physicians to respect patient autonomy in order to protect individual dignity during the course of treatment. Patients not only have the right to be informed of their conditions, treatment measures, the risks associated with treatment, alternative treatment plans, and the prognosis, but also are entitled to give consent to or turn down the physician's decision. In particular, the consent should in principle be given by patients themselves in case the treatment measure would have a significant impact on their life, health, and safety. [italics added]

In the same case, the court also defined the standard of information disclosure:

Patients rely heavily on the information provided by physicians to grant or refuse consent. Therefore, the information disclosed by physicians should be readily intelligible to patients. The effective discharge of the duty of information disclosure is an essential guarantee that an "informed consent" could be given. Physicians are supposed to disclose information to such an extent that patients can fully understand and make true decisions accordingly. [italics added]

Remarkably, the Gulou Court had already adopted a clear scope and standard of disclosure even more detailed than article 55 of the Tort Law before 2009. ${ }^{87}$ The scope of disclosure is more or less identical with that of article 55 .

The duty to disclose alternative treatment plans is highly contentious. It is very difficult to determine the scope of alternative plans. For instance, providing that a disease can be cured either by a short surgery or by a method of internal medicine lasting several months, it is unclear whether these two plans are alternative to each other..$^{88}$ For another instance, suppose that there is only one treatment plan for a disease in Nanjing, but there may be multiple plans in Shanghai or Beijing which entail high medical expenses, it is questionable whether these treatment plans in different localities are alternative to one another. ${ }^{89}$ The Gulou Court seems to regard treatment

\footnotetext{
87 For more information about disclosure malpractice in China, see Chapter 3, Section 3.3.

88 Interview-2014-10.

$89 \quad$ Id.
} 
plans provided by different specialties within the same hospital as alternatives to one another. ${ }^{90}$ However, it is silent on how to cope with treatment plans in different hospitals or localities. ${ }^{91}$

As far as the standard of disclosure is concerned, article 55 is silent while the Gulou Court employed the patient-oriented approach before 2009. However, the court did not clarify whether a specific/subjective patient or a reasonable/objective patient should be set as the benchmark.

Recently, the Gulou Court seems to have adopted the "double-test doctrine" (二重标准说), which is a combination of a reasonable/objective physician test and a reasonable or a specific patient test. ${ }^{92}$ The objective tests are given priority in most of the cases, whereas the subjective patient test will be taken into account only when it is too unfair to ignore a specific patient's requirements. ${ }^{93}$ With the rapid development of medicine, it is unrealistic to reject the subjective patient test completely, since patients are heterogeneous and have different requirements. ${ }^{94}$

\subsection{CAUSAL UNCERTAINTY AND PROPORTIONAL LIABILITY ${ }^{95}$}

\subsubsection{Uncertainty over Factual Causation}

Remarkably, the Gulou Data tell us that the court was most likely to apply a "proportional liability" to many cases where there was causal uncertainty (the majority); in addition, the court also switched the causal link to other kinds of injuries in some cases (the minority). Hence, the "high probability" standard of proof ${ }^{96}$ in China is almost totally circumvented by the court in malpractice lawsuits. On the one hand, it is found that the court frequently adopted a "proportional liability" in many malpractice cases where there was causal uncertainty. In the court's opinion, a certain degree of causal link $\mathrm{P}^{*}$ between medical malpractice and harm done - even when the $\mathrm{P}^{*}$ is as low as $10 \%-$ suffices to establish causation. Then the court would normally calculate

\footnotetext{
Jiangsu Nanjing Gulou District People’s Court, First Civil Chamber, 2014. 
pecuniary damages based on the product of the $\mathrm{P}^{*}$ and the amount of pecuniary losses suffered by plaintiff-patients.

On the other hand, in some cases of wrong diagnosis or breach of the duty of information disclosure, if the $\mathrm{P}^{*}$ is relatively low, the court might also switch the causal link between malpractice and physical harm to the causal connection between malpractice and the loss of chances of recovery, survival or longer life, or the infliction of pure emotional distress.

There is additional evidence showing that this relaxation, or more appropriately, "abandonment" of the "high probability" standard of proof in medical malpractice cases is not unique to the Gulou Court, but rather has become a common practice nationwide. ${ }^{97}$

Ms. Justice A (alias) explained the rationale behind this deviation as follows:

\begin{abstract}
Sometimes, expert testimony on causation is highly ambiguous, using wording such as "there is a certain degree of causation" or "the possibility of the causal link cannot be excluded." We, as judges, often feel confused by this wording and then we decide to use our discretion to interpret the testimony. If the defendant grossly breaches the duty of medical care and this breach of duty may sufficiently lead to iatrogenic injuries, we will find that the causation is established. The word "sufficiently" implies a standard of proof relatively lower than the "high probability" standard. Otherwise, it would be unfair on plaintiff-patients and their right to life and health could not be protected well. [italics added] ${ }^{98}$
\end{abstract}

It thus seems that the deviation is caused by both the ambiguity of expert testimony and by judges' natural partiality to the weaker party - patients.

Perhaps the most striking aspect of the Chinese approach to uncertainty over factual causation is that Chinese courts are so flexible that they may apply either proportional liability or the lost chance doctrine to medical cases at their discretion. By reading cases from the Gulou Court, two patterns can be detected. First, the court would apply proportional liability mostly likely to (direct infringement) cases where errors in treatment procedures are involved and expert witnesses provide a statistical causal probability or merely testify that the "causation cannot be eliminated (不排除因果关系).” Second, the court would apply the lost chance doctrine mostly likely to (indirect infringement) cases where wrong diagnoses or failure to disclose critical medical information is concerned and expert witnesses normally disprove the existence of factual causation. In either of 
the two foregoing patterns, the plaintiff would be compensated for at least a small proportion of his/her full harm.

Three factors may help explain why the court chooses a two-pattern approach to medical malpractice cases.

First, expert witnesses themselves systematically employ the proportional approach to factual and legal causation together. ${ }^{99}$ The defendant's compensatory liability should be proportional to the "causal potency (原因力)" of the faulty treatment to the occurrence of the patient's final injury, which is ultimately based on the probability of the factual causation. ${ }^{100}$ Therefore, if expert witnesses already provide the court with a statistical causal probability (although it might be lower than 50\%), it would become very convenient for the court to apply proportional liability in the light of equity and victim protection. ${ }^{101}$

Second, in cases where expert witnesses disproved any causal connection, the court would find it difficult to estimate the statistical probability. ${ }^{102}$ If the physical injury or death did occur, the court would roughly establish causation between malpractice and lost chances of survival or living a longer life. ${ }^{103}$ If the risk did not materialise, the court would grant some compensation for non-pecuniary losses to the plaintiff. ${ }^{104}$

Third, both proportional liability and the lost chance doctrine are theoretically compatible with the Tort Law. On the one hand, the Tort Law's silence on the definition of causation leaves it open to a broader and more flexible interpretation. Neither the traditional all-or-nothing approach nor proportional liability is evidently excluded by the Tort Law. On the other hand, article 2 of the Tort Law defines the scope of protection so broadly as "civil rights and interests," which does not seem to exclude chances of survival and living a longer life as well. ${ }^{105}$ Hence, lost chances of survival or living a longer life may well fall into the category of compensable damage.

\footnotetext{
99 In practice, expert witnesses usually make a rough estimate of the causal probability based on several levels: 100\% (full liability 全部责任), 75\% (primary liability 主要责任), 50\% (equal liability 同等责任), 25\% (secondary liability 次要责任), 10\% (minor liability 轻微责任) and $0 \%$ (no liability 无责任). The factual and legal causation are not clearly distinguished and are actually determined together. Interview-2014-14. See also supra Chapter 3, Section 3.7.4.

100 Interview-2014-14.

101 Interview-2014-10.

$102 \quad I d$.

103 Shan v. Third Hospital (China); Feng \& Xue v. Drum Tower Hospital (China); Zeng et al. v. Drum Tower Hospital (China); Wang et al. v. Jiangsu Hospital (China); Qi \& Qi v. Stomatological Hospital (China).

104 Yan v. Drum Tower Hospital(China); Zhu v. Children's Hospital(China).

105 Interview-2014-10.
} 
Part I. Legal Remedies for Medical Malpractice in China

\subsubsection{Uncertainty over Legal Causation ${ }^{106}$}

On the basis of the Gulou Data, we can find that the court would apportion damages where it is established that, besides the defendant's faulty treatment, the patient's pre-existing condition also contributed to his/her final injuries. The defendant's share of the damages would be in proportion to the causative potency or significance of the faulty treatment on the injuries. This rule was once provided for by article 49 of the AR-Medical Accidents 2002 and even applied to traffic accidents by analogy. Because of Guiding Case No. 24, article 49 is currently not applicable to traffic accidents. However, the Gulou Data prove that the article 49's approach is still applicable even when the Tort Law has nullified the AR-Medical Accidents as far as medical malpractice is concerned.

This practice is not unique to the Gulou District. At the provincial level, at least high courts in Beijing, ${ }^{107}$ Zhejiang, ${ }^{108}$ Xinjiang, ${ }^{109}$ and Anhui ${ }^{110}$ have expressly pronounced that they will continue to apportion damages between the faulty hospital and the patient whose pre-existing conditions contributed to the damage after 2010.

In an interview, Mr. Justice Dai explained why applying Guiding Case No. 24 to medical cases involving non-tortious factors is undesirable. ${ }^{111}$ Unlike drivers and pedestrians who are strangers to each other before the accident, patients at large receive benefits from medical care under a contractual relationship with health care providers. Therefore, it may be an unfair burden on health care providers to make them pay for the portion of the injury that is caused by risks within the patient's own sphere. ${ }^{112}$

\subsection{DEFECTIVE MEDICAL PRODUCTS AND SUBSTANDARD BLOOD}

Data from Gulou show that defective medical products and substandard blood accounted for less than $2 \%$ of all the iatrogenic injuries. There is little dispute over the fact that pharmaceutical and medical equipment are products where

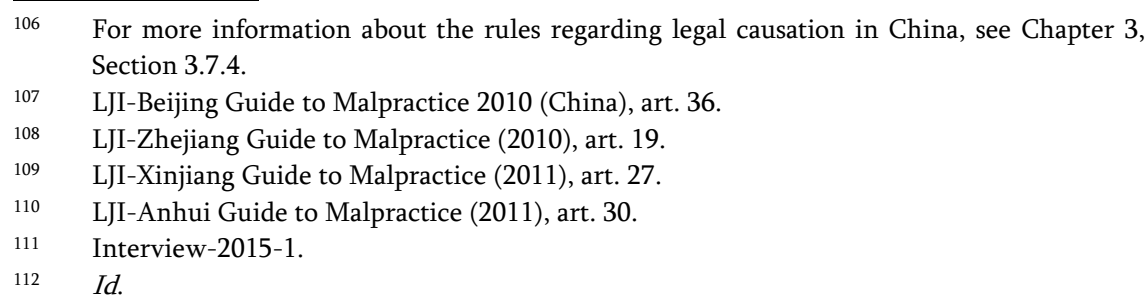


strict product liability in principle applies. However, it is highly debated whether blood could be regarded as a product in China. ${ }^{113}$ The dominant view is that no matter whether blood could be considered as a product, article 59 of the Tort Law expressly imposes strict liability on hospitals and blood banks in cases where an injury is caused by substandard blood and the defence of development risks is not applicable here. ${ }^{114}$

Remarkably, the Nanjing Court refuses to accept the foregoing dominant view. Ms. Justice A (alias) stressed that it is fault liability that applies to cases involving substandard blood in that blood is by no means a product. ${ }^{115}$ Since the problem of a "window period" - even the most advanced technology cannot guarantee that blood intended for transfusion does not contain any infectious virus - always exists, it is unjustified to impose these risks on hospitals and blood banks, most of which are not-for-profit organisations. ${ }^{116}$ However, if it is established that neither the hospital nor the blood bank was at fault, we would nonetheless grant some modest damages to the patient based on equitable liability (article 24, Tort Law). ${ }^{117}$ The rationale behind this arrangement is that, in order to maintain social stability, hospitals and blood banks, as enterprises, can play a role as "insurance companies" by spreading risks through purchasing blood transfusion accident insurance (输血事故保险). ${ }^{118}$

The difference between the dominant view and Nanjing's approach lies primarily in the fact that full compensation still applies under strict liability whereas it often does not apply under equitable liability. It seems that courts in Nanjing are very cautious about imposing blood infection risks on hospitals and blood banks.

\subsection{PAYMENT OF MEDICAL MALPRACTICE CLAIMS}

It is shown by the Gulou Data that patients normally have a high chance of winning a case (70\%), which is highly inconsistent with previous studies by Li et al. $(67 \%)^{119}$ and Liu et al. (71.21\%). ${ }^{120}$ Since about $11 \%$ of the 243 accident testimonies testified for the plaintiff whereas almost $80 \%$ of the 56 forensic testimonies testified in favour of the plaintiff, the high rate (70\%) of

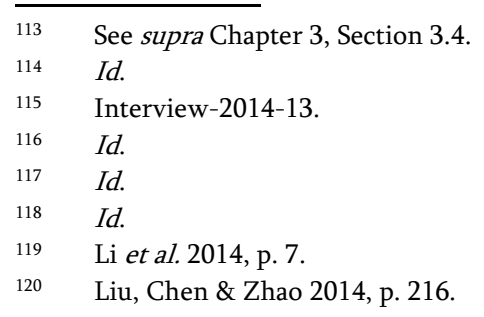


winning a case suggests that the court may deviate from accident testimonies wholly or partly, and is thus partial towards victim protection in many, if not most, cases. The Gulou Data also show that the court would reject (part of) the accident testimony by finding that some less obvious medical errors other than a medical accident could be established or a slight degree of causal link would suffice because of causal uncertainty. ${ }^{121}$ In this way, the court increased the plaintiffs likelihood of winning a case greatly.

However, the court is not extremely biased in favour of victimised patients. It attempts to keep a balance between the interests of patients and that of hospitals, especially public hospitals that provide the lion's share of all medical services to society. ${ }^{122}$ The Gulou Data show that full compensation would be granted in less than $20 \%$ of all the cases where the plaintiff won. In the remainder of these cases, damages would not be full, either because there was uncertainty over factual causation, or the court applied proportional liability or the lost chance doctrine, or because the patient's pre-existing condition also contributed to the injury, the court would apportion damages between the plaintiff and the defendant. ${ }^{123}$ Hence, although plaintiff-patients enjoyed a high likelihood of winning a case, the degree of such a win was relatively low as the Gulou Data prove: on average, only less than $30 \%$ of their original claims would be met.

One important implication of this finding of the low degree of winning is that plaintiff-patients may feel entirely dissatisfied or even frustrated with damages awards when it turned out that $70 \%$ of their original claims, which they may see as perfectly legitimate, would be rejected by the court. Patients may not be aware of the honest endeavours made by the court to increase their chances of winning the case, which they may take for granted. Ironically, patients may feel a major disappointment with the reduced damages, and thus may develop a deep distrust of the entire malpractice litigation system. ${ }^{124}$

Another striking finding based on the Gulou Data is that although the law treats $100 \%$ disability as equivalent to death in terms of future pecuniary damage, the average damages for death (129,150 yuan) were less than half of that for serious injuries $(289,446$ yuan), which is consistent with Li et al.'s finding. ${ }^{125}$ This may be explained by the fact that a disabled victim is likely to incur more medical expenses even after the accident whereas the deceased victim will surely not after death. Li et al. argued that this result implies that

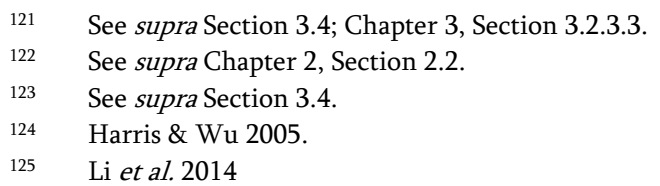


the "loss of life" is less substantial than the "loss of health," which goes against our sense of just and fairness. ${ }^{126}$ Some anecdotal evidence also reports that in a traffic accident scenario where it is very difficult to distinguish between an intentional tort and negligence, some drivers might take the risk of being charged with homicide and kill the wounded victim in order to avoid paying greater damages. ${ }^{127}$ This may be less worrying in the health care sector since physicians are not personally held liable for paying damages, ${ }^{128}$ although they might suffer some non-monetary losses or sanctions. ${ }^{129}$

\subsection{THE TIME AND MONEY SPENT ON MALPRACTICE LITIGATION}

\subsubsection{The Burden of Time}

The Gulou Data report that on average it took about 173 days to close a malpractice case, and more than half exceeded the time limits for trial. Previous studies even reported a higher number. Liu et al. reported 309.2 days in Beijing ${ }^{130}$ and Li et al. reported 999 days nationwide. ${ }^{131} \mathrm{Li}$ et al.'s data may be somewhat exaggerated since they based their research on on-line case databases where hard cases needing a longer period to trial are more likely to be published than simple ones. Hu and Shi reported that in Zibo of Shandong Province, the average time needed to try malpractice cases is three to five times longer than other types of civil cases. ${ }^{132}$

One explanation for this long length of trial time is that medical ascertainment procedures are initiated more often than not, and many, if not most, cases involved ascertainment more than once, which prolonged the trial significantly. In Gulou, medical ascertainment was initiated in more than $60 \%$ of all the 592 cases, which is consistent with data in Beijing $(57.8 \%),{ }^{133}$ in Zibo of Shandong (88.46\%), ${ }^{134}$ in Ningbo of Zhejiang (51.85\%). ${ }^{135}$ The proportion of cases involving two or three times of ascertainment was $20.95 \%$

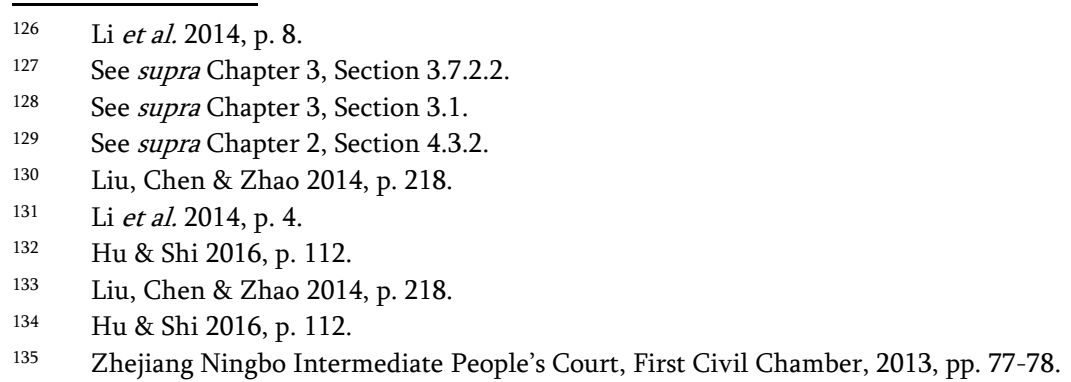


in Gulou, $19.03 \%$ in Beijing, ${ }^{136}$ and $15.38 \%$ in Ningbo of Zhejiang. ${ }^{137}$ This finding supports the claim that many litigants challenge the conclusion of ascertainment provided by expert witnesses and applied for another ascertainment, which delayed the litigation process considerably. The existence of the two parallel regimes of expert witnesses - the MATAS and the JAS - may intensify the prolongation of malpractice litigation. ${ }^{138}$

Another explanation is that, compared to ordinary civil cases, medical malpractice claims are highly technical and complicated, which entails longer time to make professional opinions both for expert witnesses and for judges. ${ }^{139}$

Although the burden of time on plaintiff-patients is heavy, it is less burdensome for physicians. Since hospitals are the sole defendant in malpractice litigation, physicians involved are still allowed to work in hospitals normally ${ }^{140}$ and hospitals will send their own lawyers and experts, who are employed specifically for the purpose of defence, to appear in court to defend the case.

\subsubsection{The Burden of Financial Costs}

According to the Gulou Data, on average the plaintiff would obtain a total of 121,000 yuan as damages and incur 4,200-yuan litigation costs (court acceptance fees and ascertainment fees) at the same time. In other words, for every 28.81-yuan damages, 1 yuan would be spent on litigation procedures. In this regard, it seems that the burden of litigation costs on litigants in China is relatively modest.

The above conclusion would be weakened if we took into account legal fees and average incomes of Chinese residents. As far as medical malpractice claims are concerned, contingency fees are strictly forbidden in the Jiangsu Province. ${ }^{141}$ Hence, plaintiff-patients have to pay legal fees if they are going to hire a legal representative. Legal fees for non-property civil disputes in Nanjing range from 2,500 yuan to 10,000 yuan. ${ }^{142}$ From 2002 to 2012 in Jiangsu Province, the average per capita consumption expenditure (PCE) of urban households was about 11,100 yuan and of rural households was only 5,021 yuan. ${ }^{143}$ Before trial, plaintiff-patients would have to advance

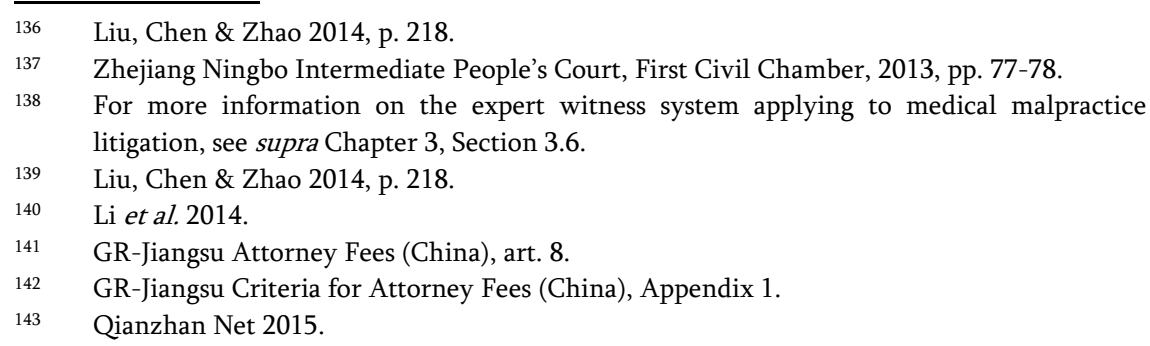


4,395 yuan as litigation costs, together with paying legal fees (at least 2,500 yuan). That is to say, because of the ban on contingency fees, the initial financial burden on plaintiff-patients would at least amount to 6,985 yuan, which was about $62 \%$ of the urban PCE and almost $137 \%$ of the rural PCE.

Is there any legal aid available for victims of medical malpractice? At least in the Jiangsu Province, there has been legal aid available for poor victims since $2001^{144}$ or poor victims who "suffered severe bodily injuries" since 2005. ${ }^{145}$ Law firms that participate in legal aid schemes should provide legal services free of charge. ${ }^{146}$ However, the Gulou Data show that plaintiffpatients were represented by attorneys in only $60 \%$ of the cases and legal aid attorneys helped plaintiffs in only two of the 496 cases in the recorded information on the identity of counsels. This finding implies that many attorneys may not be willing to provide free legal aid services in view of the fact that medical malpractice claims are rather complicated and it could take them quite a long time and a lot of energy to handle even a single case.

The fact that about $40 \%$ of plaintiff-patients filed medical malpractice claims before the court without any assistance of attorneys suggests that many, if not most, victimised patients would be in an unfavourable position in litigation given that most of them are both medical and legal laymen. Furthermore, when confronted with such considerable costs of litigation and the lack of readily available legal aid, many patients may never file any claim before the court due to poverty.

\subsection{THE IMPACT OF THE TORT LAW 2009 AND THE ROLE OF CHINESE COURTS}

In some aspects, the Tort Law has made advances. First and foremost, it has unified the substantive rules regarding medical malpractice by abandoning the distinction between accident claims and ordinary claims. In so doing, compensation for all iatrogenic injuries is based on the JI-Personal Injuries 2003 rather than the AR-Medical Accidents 2002. ${ }^{147}$ To some extent, this may explain why damages for iatrogenic injuries grew faster after 2011.

$144 \quad$ LR-Jiangsu Legal Aid 2001 (China), art. 13.

145 LR-Jiangsu Legal Aid 2001 (2005 Amendment, China), art. 10, sub-para. 6.

146 LR-Jiangsu Legal Aid 2001 (China), art. 2; LR-Jiangsu Legal Aid 2001 (2005 Amendment, China), art. 2.

147 Theoretically, plaintiffs may obtain more compensation under the JI-Personal Injuries than under the AR-Medical Accidents in that the former allows death compensation and imposes fewer caps on compensation. See supra Chapter 3, Section 3.7.2. 
Second, since the AR-Medical Accidents 2002 does not apply to malpractice lawsuits any longer, clinical experts from the medical association now should make judgements in light of the Tort Law 2009. After 2010, the name of medical ascertainment provided by medical associations was changed from the MATAS to the MIAS, although the organisation and the expert bank largely remain unchanged. Nevertheless, the change in applicable rules did have some impact - while under the MATAS clinical experts testified for the plaintiff in only $11 \%$ of the cases, under the MIAS clinical experts did so in almost $55 \%$ of the cases, although the rate was still lower than that under the JAS (80\%).

However, in other aspects, the Tort Law's achievements may be somewhat exaggerated. For instance, many applaud the Tort Law because it has abolished the reversal of the burden of proof rule regarding fault and causation in order to reduce defensive medicine. However, there is no empirical evidence showing that "defensive medicine" in China was caused by the reversal rule and that "defensive medicine" declines after 2010. As mentioned before, ${ }^{148}$ since Chinese courts rely heavily on medical ascertainment to determine fault and causation in hard cases, and expert witnesses are obliged to give a definite answer, the only case where the burden of proof matters is that the party which bears the burden of proof will have to pay advance ascertainment fees. In this regard, the Tort Law's reform in the burden of proof may be unfavourable to plaintiff-patients, especially those who find it hard to afford the ascertainment fee.

A second achievement of the Tort Law is that it provides a legal basis for claiming damages for disclosure of malpractice for the first time. However, as discussed before, we should not ignore the fact that the Gulou Court developed a fully-fledged doctrine of informed consent several years before the inception of the Tort law. ${ }^{149}$

In addition to its achievements, the Tort Law has its limitations. On the one hand, it has not touched upon the issue of medical ascertainment which still struggles along the two conflicting and competing regimes of expert witnesses. The duplicate systems of expert evidence may reduce the litigant's trust in the credibility of the malpractice system. Also, conducting multiple ascertainment tests increases litigation costs. However, this problem should be resolved by other legislation than the Tort Law.

On the other hand, the Tort Law is silent on both the definition of causation and the rules regarding uncertainty over factual and legal causation where a non-tortious causative factor (e.g. the patient's pre-existing

$48 \quad$ See supra Section 3.2.

$149 \quad$ See supra Section 3.3.2. 
condition) is involved. However, this problem is lessened by the flexibility and creativity of local courts. The Gulou Data suggest that local courts may apply either "proportional liability" or the doctrine of lost chances to hard medical malpractice cases. Although the Tort Law is somewhat vague about these issues, the same vagueness allows a broader interpretation by local courts when applying the Tort Law.

\subsection{MEDICAL DISPUTE RESOLUTION AND VIOLENCE}

\subsubsection{Negotiation, Administrative Mediation, and Litigation}

So far, this study has focused solely on the implications of court decisions. In practice, however, not all medical disputes are resolved through the litigation system. As far as medical dispute resolution is concerned, article 46 of the AR-Medical Accidents 2002 provides for three ways - behind-the-scenes negotiation, administrative mediation by the public health authorities (hereinafter AM), and civil litigation.

Existing empirical evidence shows that a large proportion of medical disputes are resolved through negotiation. As early as in 2004, the Chinese Hospital Association reported that of all the surveyed medical disputes occurring in 200 hospitals nationwide, as high as $83.31 \%$ were resolved through negotiation, whereas only $10.48 \%$ through litigation and $6.2 \%$ through administrative mediation. ${ }^{150}$ A later study done by Zheng et al. found that of all the surveyed 53 medical disputes that involved compensation, 44 $(83.02 \%)$ were resolved through negotiation, while only $6(11.32 \%)$ through litigation and $3(5.66 \%)$ through administrative mediation. ${ }^{151}$ Recently in 2013, Li found that of all the surveyed 260 medical disputes, as high as 232 (89.23\%) were resolved through negotiation, while only 20 (7.69\%) through litigation and $8(3.08 \%)$ through administrative mediation. ${ }^{152}$ After studying medical disputes in 9 public hospitals in the same year, Liu and Feng concluded that as high as $59(77.64 \%)$ medical disputes were resolved through negotiation, whereas merely $12(16.22 \%)$ through litigation and $3(4.05 \%)$ through administrative mediation. ${ }^{153}$ Hence, about $7.69 \%$ to $16.22 \%$ of all medical disputes are resolved through formal litigation, and about $4.05 \%$ to $6.2 \%$ through AM.

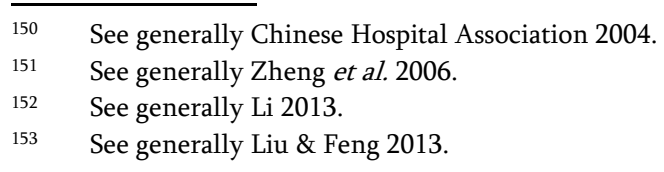


The low rate of application for AM seems to support that view that patients generally do not believe that the public health authorities can play a neutral and impartial role in mediation (i.e. they are the "boss" of public hospitals). The relatively low rate of filing claims before the court may be due to the heavy burden of both time and financial costs on plaintiff-patients.

\subsubsection{Yi-Nao Incidents}

When confronted with the choice of the way to resolve medical disputes, victimised patients may, on the one hand, fear that their claims would not be met fully, and may not be able to afford the time and money spent on litigation, and, on the other hand, do not believe that the public health authorities are unbiased and impartial. This may become a constant source of worry to them, and they might be more willing to settle the dispute through negotiation in private. This may be the most plausible reason for the "malpractice crisis" in China - it is not (allegedly) frivolous litigation or (allegedly) ever-increasing malpractice insurance premiums but "the lack of a credible system to deal with medical accidents and related problems in quality of care."154

In 2008, $\mathrm{Xu}$ and Lu conducted an extensive review of $557 \mathrm{Yi} \mathrm{NaO}$ or violent incidents which occurred in hospitals for the period 2000-2006. ${ }^{155}$ Surprisingly, they found that not all violent incidents which happened in hospitals were for the purpose of claiming damages through coercive measures. ${ }^{156}$ About $69 \%$ of the violent incidents were simply due to patients or their family members losing control of their emotions. ${ }^{157}$ They were irritated because of mistrust of doctors, because their expectations of a cure were frustrated, because serious bodily injuries or death occurred, because of high medical expenses, etc. ${ }^{158}$ Nonetheless, they still found that about $18 \%$ of these events were true $\mathrm{Yi} \mathrm{NaO}$ incidents, where violent or non-violent trouble-making measures were used as the means to compel hospitals to pay damages irrespective of whether provider negligence could be established or not. ${ }^{159}$

According to $\mathrm{Xu}$ and $\mathrm{Lu}$, one of the deep-rooted reasons for victimised patients to resort to these "weapons of the weak" is that they do not trust the

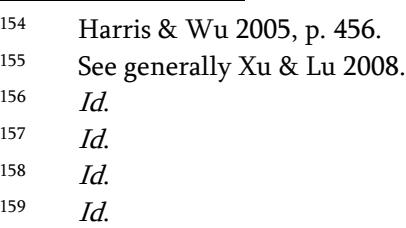


current medical dispute resolution system. ${ }^{160}$ They do not trust accident ascertainment because clinical experts more often than not would testify against them. ${ }^{161}$ They do not trust litigation because they cannot afford the burden of time and financial costs imposed by litigation. ${ }^{162}$ They do not trust AM because the public health authorities may be biased towards hospitals. ${ }^{163}$

The "weapons of the weak" ( $Y i \mathrm{NaO}$ ) appear rather effective in practice. For instance, in the first half of 2006, a total of $200 \mathrm{Yi}$-Nao incidents occurred. Hospitals paid damages in $64.5 \%(\mathrm{n}=129)$ of the 152 "resolved" medical disputes under the threat of the Yi Nao incidents. ${ }^{164}$ It is highly likely that in many, if not most, of the cases hospitals would pay compensation in order to avoid greater damage due to $\mathrm{Yi}$ Nao incidents even if no negligence could be established. In such cases, the "weapons of the weak" de facto turned fault-based medical malpractice liability into strict liability or even absolute liability.

Many doctors interviewed admitted that being involved in $\mathrm{Yi} \mathrm{NaO}$ incidents is a nightmare for most of Chinese hospitals and doctors. ${ }^{165}$ Not only is violence threatening, but consistent trouble-making behaviour is annoying as well. In order to settle the dispute as quickly as possible, many hospitals compromise with patients on claims of compensation, even if the hospitals have to pay a higher amount of compensation than what could have been granted by the court. ${ }^{166}$ However, some doctors interviewed who were also in charge of management were not willing to disclose any detailed data pertaining to the actual payment of compensation, which seems to have left deep scars in their hearts. ${ }^{167}$ In some cases, even though there is no malpractice, hospitals are still forced to pay some "buchang in terms of humanitarianism" (人道主义补偿). ${ }^{168}$ Although it is de facto blackmail, which can be punished administratively ${ }^{169}$ or criminally, ${ }^{170}$ reports of actual

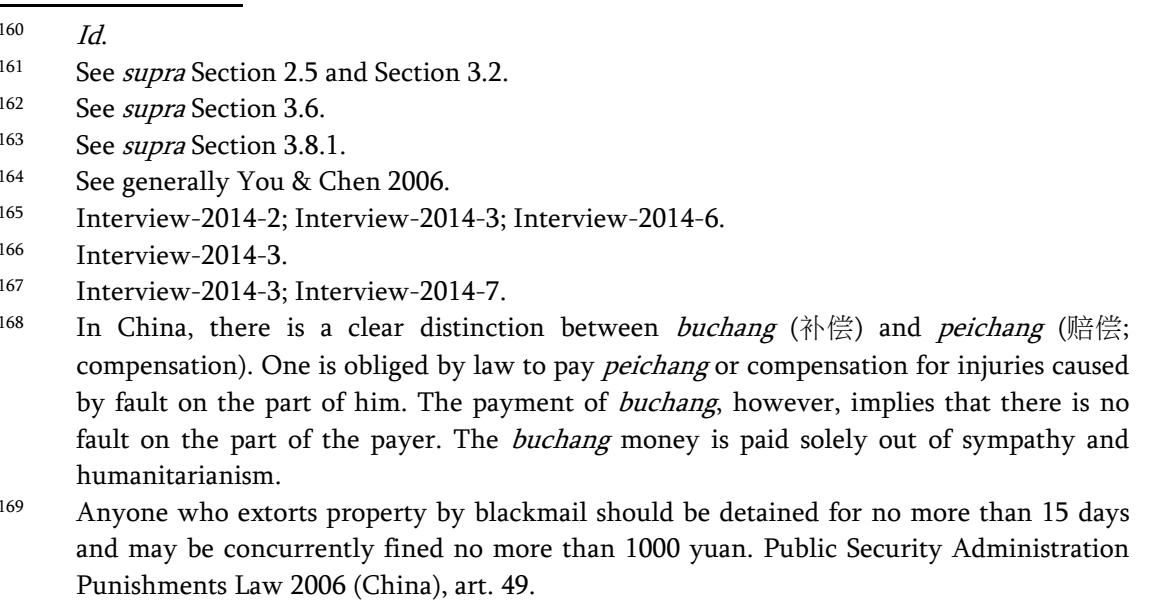


punishments are rare. It appears that lots of these illegal acts of blackmail are covered in the name of the settlement of medical disputes.

The police once often hesitated to intervene in $\mathrm{Yi} \mathrm{NaO}$ incidents because it is difficult to distinguish between an ordinary medical dispute and illegal act. ${ }^{171}$ The police would try their best to avoid transforming the conflict between hospitals and patients into a conflict between the government and patients. ${ }^{172}$ In some extreme cases, the government might even order the hospital involved to pay compensation and the government would subsidise the payment out of general taxes. ${ }^{173}$ The rationale behind the government's seemingly "irrational" behaviour is that social instability created by medical disputes would adversely affect the promotion prospects of the local head of government. ${ }^{174}$ This is exactly what Liebman called "state over-responsiveness to individual grievance." ${ }^{175}$

Although the government has announced several rounds of a crackdown on Yi Nao incidents and even criminalized coercive measures employed in Yi Nao incidents in the ninth amendment of the Criminal Law 1997 (imprisonment up to 7 years), some reported that the crackdown was ineffective and only very rarely have $\mathrm{Yi} N \mathrm{NaO}$ mobs been charged and punished so far. ${ }^{176}$ Three reasons may explain why criminal charges against patients or their family members are hard to pursue or enforce: first, it is hard to make a clear distinction between a civil dispute and a Yi Nao incident; second, the police are not willing to intervene in medical disputes; and last but not least, the general public may feel sympathy for victimised patients who would lose both damages and personal freedom due to the criminalization of Yi Nao incidents. ${ }^{177}$

\subsubsection{People's Mediation}

Recently, a new type of Medical Dispute People's Mediation (hereinafter MDPM) was developed in many local jurisdictions. People's mediation refers to "a process that a People's Mediation Commission (hereinafter PMC)

\footnotetext{
170 Whoever extorts property by blackmail, and the amount involved is quite large, is to be sentenced to not more than three years of fixed-termed imprisonment, criminal detention, or control; when the amount is large, the sentence is to be not less than three years but not more than 10 years of fixed-term imprisonment. Criminal Law 1997 (China), art. 274. Interview-2014-12. See generally Ge 2016; Interview-2014-12. Id. Id. 
persuades the parties concerned in a dispute to reach a mediation agreement on the basis of equal negotiation and free will and thus solve the dispute between them." 178 The difference between AM and MDPM mainly lies in the fact that they have different mediators. ${ }^{179}$ By May 2014, a total of 3,396 PMCs for medical disputes had been established, $55 \%$ of which were financed by the government. ${ }^{180}$

In two interviews, ${ }^{181}$ officials of justice maintained that MDPM has some advantages over the traditional three means of medical dispute resolution. First, the mediation by a persuasive third party may reduce the antagonism between the two disputants. More often than not, medical disputes resolved through MDPM are those with claims for a high amount of damages or with strong antagonism between the two disputants. Second, PMCs are "mass-based organisations" (群众性组织), ${ }^{182}$ which are nongovernmental organisations under the joint guidance of administrative departments of justice and courts at the grass-roots level ${ }^{183}$ and are independent of the public health authorities, hospitals or medical liability insurers. As far as neutrality is concerned, MDPM seems superior to AM. Third, no fee will be charged for $\mathrm{MDPM}^{184}$ and no process of medical ascertainment is required for the resolution of medical disputes. Thus, it is usually less costly and more time-saving to apply for MDPM than to file a lawsuit. Moreover, although no medical ascertainment is required in MDPM, the process of consulting clinical experts from the medical association may guarantee a minimum of necessary expertise. Some scholars also argue that the neutral position and considerable professional experience of meditation may contribute to the PMC' success in resolving medical disputes. ${ }^{185}$

There is a rising trend that the means of negotiation has been being gradually replaced with people's mediation. In Beijing, for instance, the space for negotiation in private has been narrowed considerably by MDPM. The Beijing government orders that medical malpractice claims against public hospitals that exceed 10,000 yuan shall be resolved through people's mediation or civil litigation, and, unsurprisingly, most malpractice claims in practice go beyond this cap. ${ }^{186}$ In Jiangsu, recent data show that of all the

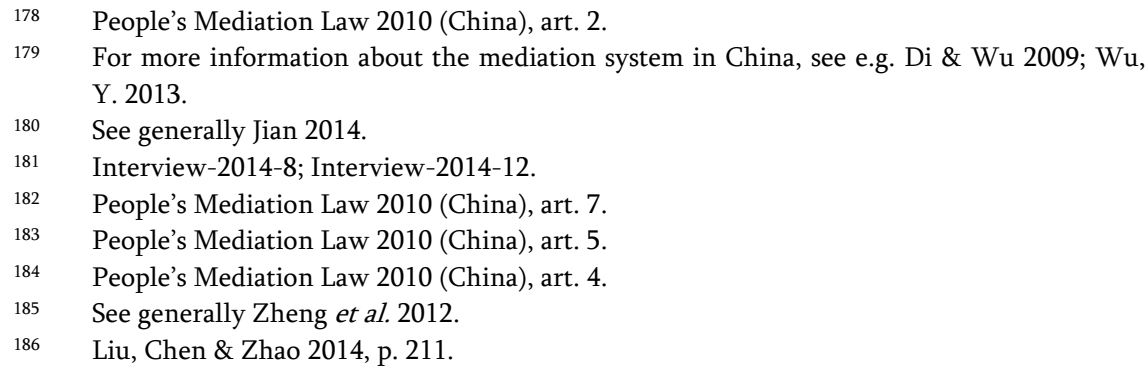


1,377 resolved MQSIs that had been reported to the authorities for the period 2011-2014, a total of 1,250 (90.78\%) were settled out of court (863 through bilateral negotiation, 346 through MDPM, 41 through AM) whereas only 127 through litigation. ${ }^{187}$

The success rate of MDPM is rather high. Data from the Nanjing Justice Bureau suggest that MDPM is highly successful in resolving medical disputes. In Nanjing of Jiangsu, about 800 medical disputes are handled by the Nanjing Medical Dispute PMC, of which $85 \%$ are mediated successfully. ${ }^{188}$ On average, hospitals in Nanjing would pay 30,000 yuan to patients in these medical disputes. ${ }^{189}$ Data from the Shanxi Province show that $90 \%$ of medical disputes accepted by the Shanxi Provincial PMC are resolved successfully, and $98.1 \%$ of the patients involved are satisfied with the mediation result. ${ }^{190}$ Nationwide, about $88 \%$ of medical disputes handled by PMCs are resolved. ${ }^{191}$

However, some argued that the higher success rate is achieved at the expense of legal standards for liability and compensation. ${ }^{192}$ Unlike AM that is based on the conclusion of accident ascertainment, MDPM does not rely on any medical ascertainment. Instead, people's mediators (usually retired doctors or lawyers) would consult clinical experts from the medical association about some difficult issues if necessary. ${ }^{193}$ However, this procedure is rather informal and not always initiated. ${ }^{194}$ It seems that the primary purpose of MDPM is to resolve the dispute rather than make a clear distinction between right and wrong, which is heavily criticised by liability insurers. ${ }^{195}$ To this end, the PMC would try to decrease the patient's expectations of high damages and persuade the hospital to pay a modest amount of damages irrespective of whether liability could be established. ${ }^{196}$

187 Id. For more information on the Chinese medical dispute resolution system, see generally infra Chapter 4.

Interview-2014-12.

Id.

Ren 2015.

Id.

See generally Yi 2014

Interview-2014-12.

Id.

Id.

Id. Mr. Shen told me a typical case, "A patient from other localities went to a hospital in Nanjing and suffered actual injuries amounting to 100,000 yuan. He initially claimed 200,000 yuan as damages. But eventually we managed to persuade him to accept 50,000 yuan as final damages. Why? Because it would take him lots of money and time to file a lawsuit against the hospital in Nanjing. The patient would prefer to obtain 50,000 yuan immediately and go home instead of gaining 100,000 yuan or more one year later. The hospital would also be willing to pay such a modest amount of damages even if it was not at fault. Why? Because all conflicts or $\mathrm{Yi}$-Nao incidents would be removed out of the hospital. Some rich hospitals even told us in private that they have enough money, and if 
The mediation agreement would be concluded in a written form. Typically, the agreement would state that "the hospital was not at fault, but agreed to pay some compensation out of humanitarianism."197 Why is it important to stress the absence of fault? This is because hospitals do not want to report the event as an MSQI to the authorities in order to avoid being punished or getting a low score in hospital accreditation. ${ }^{198}$ Patients normally do not object to this wording in the agreement as long as they obtain compensation. ${ }^{199}$

To sum up, although patients would obtain quick compensation under MDPM, they would be likely to be under-compensated in some cases and overcompensated in other cases. Although hospitals might be less worried about $\mathrm{Yi}-\mathrm{NaO}$ incidents, they would have to pay some modest compensation in the vast majority of the cases. The overall effect is currently unknown. What is certain in the Gulou District is that although the success rate to patients under MDPM (85\%) is higher than that under litigation (70\%), the average damages under the former (30,000 yuan) is about one quarter of that under the latter (121,000 yuan).

\subsection{DEFENSIVE MEDICINE}

\subsubsection{Does Defensive Medicine Exist in China?}

In China, defensive medicine (防御性医疗) is normally defined as any defensive measures conducted by physicians for the purpose of avoiding medical risks, medical disputes and malpractice lawsuits rather than medical treatment. ${ }^{200}$ There are positive defensive medicine (hereinafter PDM) and negative defensive medicine (hereinafter NDM). PDM usually refers to excessive examinations, tests, consultations, referrals, etc., whereas NDM denotes refusal to admit patients who are critically ill, avoiding highly risky therapies, etc. ${ }^{201}$

Although defensive medicine has been extensively studied in the West, Chinese scholars began to pay attention to this issue just a decade ago.

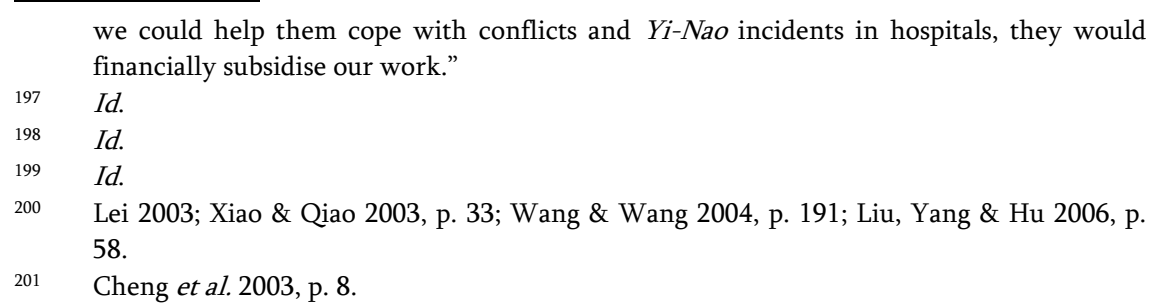


However, most of these studies are qualitative or theoretical discussions, ${ }^{202}$ although empirical studies began to grow recently. ${ }^{203}$

The vast majority of these empirical studies were based on questionnaire surveys of doctors from one or a number of hospitals in one local jurisdiction. ${ }^{204}$ Although nationwide studies are currently unavailable, these scattered studies in different locations indicate that defensive medicine does exist in China. Cheng et al. found that of all the 512 physicians surveyed from 9 hospitals in Beijing, 407 (79.49\%) had practised defensive medicine at a high level. ${ }^{205}$ Han et al. surveyed 380 doctors from a hospital in Chengde of the Hebei Province and found that more than half (59\%) of them admitted that they had practised defensive medicine and doctors who had experienced medical disputes were more likely than those who had not to practice defensive medicine. ${ }^{206}$ Li surveyed doctors from four hospitals in Dongguan of the Guangdong Province and reported that $74 \%$ of them had tried to keep medical records more complete, $68 \%$ had expanded examination items or treatment procedures, $57 \%$ had increased the frequency of subsequent visits, $60 \%$ had increased time for treatment, $80 \%$ had refused to accept difficult cases. ${ }^{207} \mathrm{Cao}$ and Chen found that $82.9 \%$ of all the 375 doctors surveyed from a hospital in Hebei Province complained that medical disputes adversely affected their work and the personal experience of a medical dispute intensified defensive medicine. ${ }^{208}$ Zhang et al. surveyed 428 doctors and nurses in Weifang of the Shandong Province and found that medical disputes significantly contributed to defensive medicine, PDM was prevalent in all specialties, and low-ranking young providers were more likely than highranking senior providers to practice NDM. ${ }^{209}$ Based on a survey of 392 doctors in Shenzhen of Guangdong Province, Peng and Huang reported that 76.53\% of the doctors often conducted defensive medicine. ${ }^{210}$ Last year, Ma et al., surveyed 476 doctors in a hospital in Hebei Province and found that the

202 See e.g. Lei 2003; Xiao \& Qiao 2003; Chen, Wang \& Liu 2004; Liang, Zheng \& He 2004; Wang \& Wang 2004; Gu \& Zhuang 2008; Wang \& Xu 2008; Wei \& Shen 2009; Chen, Shen \& Wei 2010; Fei 2010; Ren \& Bai 2011; Tan 2011; Xiao 2012; Wang, Huang \& Li 2013; Cao \& Wu 2014a; Cao \& Wu 2014b; Xu 2016.

203 See e.g. Cheng et al. 2003; Wang 2012; Han et al. 2013; Hu \& Zhao 2013; Li 2013; Cao \& Chen 2014; He 2014; Cao \& Wu 2014c; Ma et al. 2015; Peng \& Huang 2015; Zhang et al. 2015.

204 Cheng et al. 2003; Wang 2012; Han et al. 2013; Hu \& Zhao 2013; Li 2013; Cao \& Chen 2014; He 2014; Ma et al. 2015; Peng \& Huang 2015; Zhang et al. 2015.

Cheng et al. 2003, p. 9.

Han et al. 2013, p. 575.

Li 2013, pp. 207-208.

Cao \& Chen 2014, p. 9.

Zhang et al. 2015, p. 295.

Peng \& Huang 2015, p. 385. 
frequently practised defensive medicine included more detailed records of medical conditions (91.2\%), more information disclosure and informed consent (84.3\%), more consultations and referrals (82.9\%), excessive examinations $(63.5 \%)$, avoiding highly risky treatment plans or operations (57.6\%), refusing to admit patients who are critically ill (51.7\%), etc. ${ }^{211}$

All the preceding studies were based on the method of direct questionnaire surveys of providers. The problems with this method are that sometimes doctors cannot tell the difference between defensive medicine and behaviour for other purposes, and that, due to various considerations, providers may either over-report or under-report their frequencies of defensive medicine. ${ }^{212}$ In response to the deficiencies of the questionnaire method, Cao and $\mathrm{Wu}$ conducted a retrospective review of 110 medical records, in a combination of 20 interviews with doctors. ${ }^{213}$ Similarly, they found that various kinds of defensive medicine were conducted by physicians, and defensive medicine accounted for $24.6 \%$ of all expenses for examinations in internal medicine procedures and $21.1 \%$ of that in surgical procedures. ${ }^{214}$

Moreover, several other doctors interviewed also confirmed the prevalence of defensive medicine in China. ${ }^{215}$ Both $\mathrm{PDM}^{216}$ and $\mathrm{NDM}^{217}$ were reported.

The mentality of defensive medicine had even taken root in the heads of medical students - the aspiring physicians. Wang reported that of all the medical students surveyed, $68 \%$ had acquainted themselves with or were aware of the phenomenon of defensive medicine, $48 \%$ had been in favour of the practice of defensive medicine, $34 \%$ had doubted their initial decision to study medicine ( $5 \%$ even expressed their regret about studying medicine and said that they would find other jobs instead of clinical medicine), $49 \%$ had

$211 \quad$ Ma et al. 2015, p. 98.

$212 \quad$ Cao \& Wu 2014c, p. 12.

$213 \quad I d$

214 Cao \& Wu 2014c, p. 14.

215 Interview-2014-1; Interview-2014-2; Interview-2014-4; Interview-2014-5; Interview2014-6.

216 An example of PDM provided by one interviewee is as follows: It is usually not necessary for old people their eighties or nineties to take an HIV test before a blood transfusion, for they have a very low chance of being infected with HIV. However, in order to protect themselves against adverse outcomes, doctors would prefer to order the HIV test, which necessarily increases medical expenses. Interview-2014-1.

217 An instance of NDM provided by one interviewee is as follows: After an incident of violence against doctors in Ruijing Hospital in Shanghai, the chief physician of one department of the hospital declared that emergency cases would not be admitted. Ruijing Hospital is one of the few top hospitals in China. "Where would patients go if Ruijing Hospital refused to admit them?" said Gu. Interview-2014-2. 
been unable to judge whether defensive medicine is ethical or not (all they expressed was that they had no other options), and 58\% had preferred to choose "an old technique which is widely practiced and accepted rather than a new technique with more risks, although the new one may improve the curative effects and advance medical science." ${ }^{218}$

\subsubsection{The Causes of Defensive Medicine}

All the preceding studies confirmed that medical disputes are the main cause of defensive medicine. However, given the fact that hospitals are always the sole defendant in medical malpractice litigation in China, ${ }^{219}$ why should individual providers have a feeling of fear of medical disputes? The individual providers' fear may be explained by two reasons as follows.

On the one hand, although negligent individual providers are not liable for paying damages to victims, they may be subject to other forms of sanctions. First, if they contravene statutory standards of care and cause severe iatrogenic injuries (medical accidents), they may be subject to administrative punishments (license suspension/revocation) or even criminal penalties (imprisonment).220

Second, even if the negligent iatrogenic injuries are not severe enough to trigger administrative punishments or criminal penalties, negligent providers may nonetheless be punished by their employer-hospitals. In addition to fines imposed by the hospital, the wrongdoer also faces fewer chances of promotion and low scores of performance evaluation. ${ }^{221}$ Sometimes, his/her professional title may be degraded, e.g. from an "attending doctor" to a "resident doctor."222 Furthermore, his/her right to prescribe may also be limited accordingly.223 However, it is also remarkable to find that most of the other doctors interviewed seem not to be very familiar with or not so care about the details of internal punishments imposed by their own hospitals. ${ }^{224}$ This suggests that hospitals may be reluctant to impose other kinds of internal punishments if fines suffice.

On the other hand, it is also possible that individual providers practise defensive medicine because they fear violent Yi-Nao incidents which

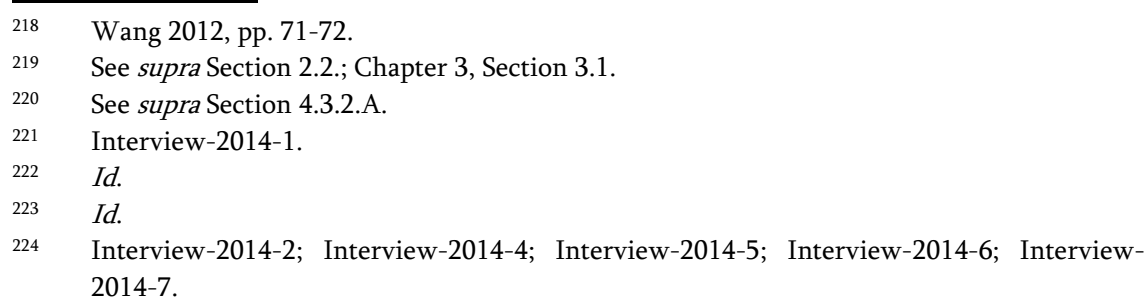


frequently occur with medical disputes. Jia found that of all the 316 hospitals surveyed, $100 \%$ held that violence against doctors had an adverse impact upon hospitals, as high as $96.9 \%$ expressed that the impact had been considerable. ${ }^{225}$ About $60 \%$ of all the staff members from these hospitals were of the opinion that the current working environment was bad, nearly $40 \%$ were considering changing their jobs and 16\% expressed that "we would never allow our children to study medicine."226 In other words, compared to malpractice litigation, hospitals, and individual providers may feel that $\mathrm{Yi}^{-}$ Nao incidents are much more difficult to tackle. Thus, they may practise defensive medicine with a view to preventing medical disputes from occurring in the first place.

It should be noted, however, that excessive examinations (过度检查) or over-prescription (大处方) are induced by the pursuit of economic profits rather than for defensive purposes. A respondent found that "low-income and the perceived imbalance between efforts and rewards indeed contribute to physicians' motivation" of excessive medicine (过度医疗). ${ }^{227}$ When many examinations are conducted, or pharmaceuticals are prescribed not for reducing the probability of AEs but primarily for gaining more profit, then the physician's behaviour is excessive medicine, which has nothing to do with the risks of medical malpractice liability. ${ }^{228}$ To pursue more profit is a natural tendency of private medical institutions, where excessive tests and examinations are more commonly seen.229 Public medical institutions are non-profit organisations. In practice, however, due to increasingly low financial input from the government and more caps on the prices that they can charge, they may increase the frequency of tests and examinations in order to earn extra income on condition that it will not increase the risks they are facing. ${ }^{230}$ Nevertheless, economic incentives do not seem comparable to the threats of liability or $\mathrm{Yi}$-Nao incidents. ${ }^{231}$

\section{CONCLUSIONS}

Chapter 4 has presented and discussed empirical evidence on medical disputes, iatrogenic injuries, malpractice litigation, and patient compensation.

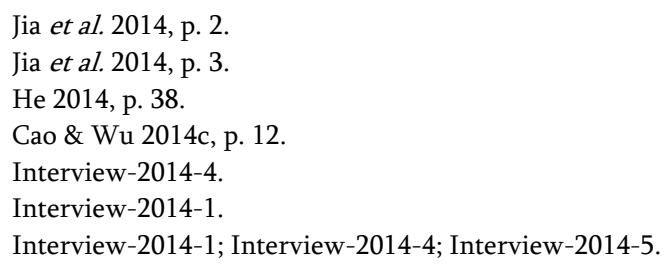


The data have been drawn from a self-conducted analysis of court decisions and semi-structured interviews, supplemented with existing empirical literature. Several conclusions have been reached.

First, medical disputes frequently occur in secondary and tertiary hospitals and are frequently related to surgical procedures, not because the quality of care of these hospitals or specialties is low but because these hospitals are often overcrowded, and diseases treated by these hospitals and specialities are usually highly risky.

Second, in most cases, judges rely heavily on expert witnesses to determine important medical malpractice issues such as fault and causation and they normally prefer a detailed written testimony submitted by the medical association or a forensic pathologist to an expert appearing in court as a witness and conducting cross-examination.

Third, in practice, judges usually interpret the "then medical standard" as written standards prescribed by lawmakers and the government or customary practices if there are no such written standards. Whether the doctor complies with customary practices will be determined through the expert ascertainment (peer review) process. The current MATAS may be biased against doctors from low-level hospitals or localities with a low-level quality of care due to limited resources.

Fourth, as far as disclosure malpractice is concerned, there is still uncertainty as to how to interpret the "alternative treatment plan" and how to define the standard of disclosure. The so-called "double-test doctrine" is very complicated to understand and apply in practice.

Fifth, Chinese courts are so flexible and active that they systematically apply proportional liability to malpractice cases where it is not clear whether the faulty treatment or a non-tortious factor contributed to the patient's injury in the absence of any legal basis.

Sixth, although the Tort Law 2009 imposes strict product liability on hospitals and blood banks, courts in the Jiangsu Province are very cautious about enforcing this rule. Instead, they apply equitable liability to cases where neither the patient nor the hospital/blood bank is at fault and grant some modest damages to the patient.

Seventh, although plaintiff-patients have a high chance of winning a case (about 70\%), only a modest proportion (less than 30\%) of their original claims will be satisfied. Severely disabled victims of medical malpractice may receive more damages than close relatives of deceased victims.

Eighth, plaintiff-patients are often confronted with heavy burdens of time and money when they intend to obtain compensation through the litigation system. The proceedings are often delayed by medical ascertainment, which is hardly affordable to relatively poor plaintiff-patients. 
The legal aid system seems under-developed, and contingency fees are strictly banned.

Ninth, the biggest achievement of the Tort Law 2009 is that it has unified substantive medical malpractice liability and quantum rules. However, it is still limited in that it has not abolished the often conflicting parallel regimes of expert ascertainment - MATAS and JAS.

Tenth, heavy burdens of the malpractice litigation system and distrust of administrative mediation often drive victimised patients to resort to "weapons of the weak" - Yi Nao incidents, which disturbs social stability and leads to considerable social costs. The newly developed people's mediation for medical disputes may help in mediation between hospitals and patients. However, patients may obtain less compensation than they would otherwise receive in court.

Eleventh, defensive medicine is prevalent in China, which may be accounted for both by the threat of medical malpractice litigation and by the violent nature of medical disputes ( $Y i \mathrm{NaO}$ ) per se. The pursuit of economic profits may explain some unethical practices such as over-prescription and excessive examinations that have little to do with treating the patient's condition. 



\section{CHAPTER 5 OTHER COMPENSATION SCHEMES}

\section{INTRODUCTION}

Chapter 5 attempts to examine alternative regimes of compensation in China that may cover at least part of the losses suffered by a victim of medical malpractice, which is an attempt to answer part of Sub-question (1-a). The most relevant mechanism is medical liability insurance (hereinafter MLI), often covering a large proportion of tort damages (Section 2). Some compensation schemes other than MLI will be examined in Section 3.

\section{MEDICAL LIABILITY INSURANCE (MLI)}

\subsection{INTRODUCTION}

In this Section, an attempt will be made to answer three sub-questions concerning MLI in China: first, what the legal basis is (Section 2.2); second, what the existing state of affairs of MLI is in China (Section 2.3); and third, what problems MLI in China is facing (Section 2.4).

\subsection{LEGAL BASIS}

In China, the legal basis for liability insurance, in general, is currently provided for in article 65 and article 66 of the Insurance Law 2009, ${ }^{1}$ which read as follows:

They were originally provided for in art. 49 and art. 50 of Insurance Law 1995 (China). 
Part I. Legal Remedies for Medical Malpractice in China

Art. 65: For the damage caused to a third party by the insured to a liability insurance contract, the insurer may directly pay insurance benefits to the third party according to law or the insurance contract.

Where the insured to the liability insurance contract causes any damage to a third party and the insured's liability for compensating the third party has been determined, at the request of the insured, the insurer shall directly pay insurance benefits to the third party. If the insured delays making a request, the third party shall have the right to directly request the insurer to pay the insurance benefits for the damage which the third party shall be compensated for.

Where the insured to the liability insurance contract causes any damage to a third party and the insured has not compensated the third party for the damage, the insurer shall not pay insurance benefits to the insured.

Liability insurance means a type of insurance which takes the insured's legal liability for compensation to a third party as the subject matter insured.

Art. 66: Where an arbitration or litigation is instituted against the insured to a liability insurance contract for an insured accident which causes damage to a third party, the arbitration or litigation costs and other necessary and reasonable expenses paid by the insured shall be covered by the insurer, unless it is otherwise provided for by the insurance contract.

Art. 65 defines liability insurance and the basic rights and obligations of the parties involved - the insurer, the insured, and the third party. Paragraph 1 grants the insurer a right of choice - it may pay insurance benefits to either the insured or the third-party victim if the law or the contract permits, which is inconsistent with the ultimate goal of liability insurance. ${ }^{2}$ Where the law or the contracts do not specify this issue, in the light of paragraph 2 , the insurer must directly pay insurance benefits to the third-party victim at the request of the insured, given that "liability for compensating the third party has been determined." According to lawmakers, "liability ... determined" usually refers to either of the following cases: first, damages have been determined by court judgements or arbitration awards; or second, damages have been determined by a settlement agreement between the insured and the third-party victim, which is accepted by the insurer. ${ }^{3}$ Of course, if the size of damages as it has been determined above exceeds the insured amount, the excess must be paid by the insured itself. ${ }^{4}$ In practice, however, the insured may sometimes fail to make such a request in time. In that case, paragraph 2 grants the third-party victim a direct right to claim insurance benefits from the insurer. In order to

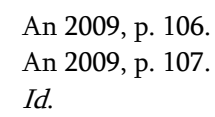


avoid the case where the insured refuses to compensate the third-party victim after receiving insurance benefits, ${ }^{5}$ paragraph 3 provides that the insurer should not pay insurance benefits to the insured before the insured compensates the victim. In accordance with article 66, all necessary and reasonable costs of litigation or arbitration shall be covered by the insurer as well.

That being said, there are no special legal rules regarding medical liability insurance (hereinafter MLI). Hence, arts. 66-67 and other relevant provisions of the Insurance Law 2009 apply to MLI. In light of article 66, para. 4, MLI is often defined as a contract, under which the insurance company provides coverage against the insured medical institution's liability for iatrogenic injury suffered by the patient for the duration of insurance coverage. ${ }^{6}$ Since arts. $66-67$ are very short, detailed rights and obligations are stipulated in MLI contracts in practice.

Also, it ought to be noted that it is generally not compulsory for any party to purchase insurance in China unless other national laws or administrative regulations provide otherwise. ${ }^{7}$ To this day, no other national laws or administrative regulations have yet provided for a compulsory obligation to purchase MLI.

\subsection{THE EVOLUTION OF MLI IN CHINA: LOCAL EXPERIMENTS}

\subsubsection{Introduction}

Although malpractice litigation was established in the second half of the 1980s, China had not developed MLI until the beginning of the 2000s. Since then, some provinces and large municipalities such as the Yunnan Province, Shanghai City, Beijing City, etc. have initiated their own MLI schemes. Currently, there is no unified MLI scheme that applies to the entire country as a whole. All MLI initiatives are local experiments. Hence, this Section will give a short introduction to several representative local MLI schemes (Sections 2.3.2 to 2.3.7) and summarise their similarities and differences (Section 2.3.8).

\section{Id.}

Chen 2013, p. 9.

Insurance Law 2009 (China), art. 184, para. 2 provides, "For compulsory insurance, where laws and administrative regulations provide otherwise, such provisions shall apply." 
Part I. Legal Remedies for Medical Malpractice in China

\subsubsection{The Yunnan MLI Scheme}

The Yunnan Province was the first local jurisdiction in China that initiated the MLI scheme. In 1998, the Yunnan provincial government enacted the LGR-Yunnan Iatrogenic Injury Incidents 1998, article 16 reads as follows,

Medical institutions and their medical staff members shall purchase medical professional liability insurance.

When a medical accident or error occurs in the insured medical institution, the insurance company shall, in the light of expert ascertainment conclusions and statutory criteria for compensation, pay a lump sum of compensatory damages to the patient or his/her family members, and pay necessary expenses for continued treatment or unpaid treatment expenses to the medical institution.

The Yunnan MLI scheme was intended as compulsory liability insurance. The Yunnan public health authorities made it clear that the Operating License for Medical Institutions (OLMI) of a medical institution that failed to purchase medical liability insurance would be revoked. ${ }^{8}$

The Yunnan government established the "Joint Office of Medical Professional Liability Insurance of the Yunnan Province" that serves as the insurance broker. The insured are medical institutions and medical staff members. Two commercial insurance companies - PICC Yunnan Branch and CPIC Kunming Branch - provide coverage jointly.

The premiums that medical institutions should pay are determined on the basis of the number of ward beds (e.g. 300,000 yuan for a hospital with 1505 to 2000 beds). ${ }^{9}$ The premiums for staff members are determined in accordance with their specialities and positions, ranging from 1 to 20 yuan per month. ${ }^{10}$

According to article 16 of the LGR-Yunnan Iatrogenic Injury Incidents 1998, iatrogenic injuries due to medical accidents (severe negligent AEs) and medical errors (less severe negligent AEs) are covered by the MLI scheme while those due to medical mishaps (non-negligent AEs) are not. Various caps are imposed on insurance benefits depending on the types of hospitals and seriousness of the incident. A deduction of 5\% (but not exceeding 5,000 yuan) is imposed for every MLI claim.

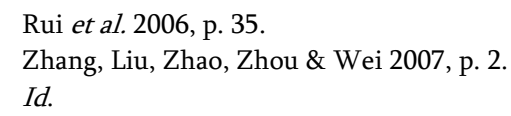


Zhang et al. conducted a retrospective review of MLI in the Yunnan Province for the period $1999-2003 .{ }^{11}$ During these five years, a total of 5,750 policies had been taken out, and 54-million-yuan premiums had been paid ( $63.41 \%$ by medical institutions and $36.59 \%$ by individual providers). ${ }^{12}$ By the end of August 2004, a total of 277 claims had been settled, paying about 16.45 million yuan as insurance benefits (roughly 59,000 yuan per claim). ${ }^{13}$

Strikingly, Zhang et al. reported that there had been a rapid contraction of the MLI market during the five years as shown in Table 5.1.

Table 5.1: The Loss Ratio and the Insured Medical Institutions in Yunnan Province ${ }^{14}$

\begin{tabular}{|c|c|c|c|c|c|c|}
\hline Year & $\begin{array}{l}\text { Claims } \\
\text { (No.) }\end{array}$ & $\begin{array}{l}\text { Payouts } \\
\text { ( } ¥)\end{array}$ & $\begin{array}{l}\text { Loss Ratio* } \\
\text { (\%) }\end{array}$ & $\begin{array}{l}\text { Insured } \\
\text { Med. Inst. } \\
\text { (No.) }\end{array}$ & $\begin{array}{l}\text { The ratio } \\
\text { Insured } \\
\text { Inst. to all } \\
\text { Inst. (\%) }\end{array}$ & $\begin{array}{l}\text { of } \\
\text { Med. } \\
\text { Med. }\end{array}$ \\
\hline 1999 & 80 & $6,692,961$ & 36.8 & 2,068 & & 17.0 \\
\hline 2000 & 75 & $4,696,501$ & 42.7 & 1,265 & & 9.0 \\
\hline 2001 & 60 & $2,951,344$ & 33.5 & 888 & & 7.0 \\
\hline 2002 & 53 & $1,984,130$ & 20.1 & 904 & & 10.0 \\
\hline 2003 & 7 & 109,668 & 17.3 & 625 & & 3.0 \\
\hline
\end{tabular}

More recent empirical data on the MLI market in Yunnan are currently unavailable.

\subsubsection{The Shanghai MLI Scheme}

With the implementation of the AR-Medical Accidents 2002, the Shanghai Municipal Government, by enacting the N-Shanghai Medical Liability Insurance 2002 and the N-Shanghai Medical Liability Insurance Implementation Schemes 2002, initiated an MLI scheme and encouraged all public hospitals to purchase MLI policies. ${ }^{15}$

The Shanghai MLI scheme consists of insurance schemes covering liability for medical accidents and "liability for medical mishaps" (医疗意外责任). ${ }^{16}$ The MLI scheme for medical accidents was initiated on

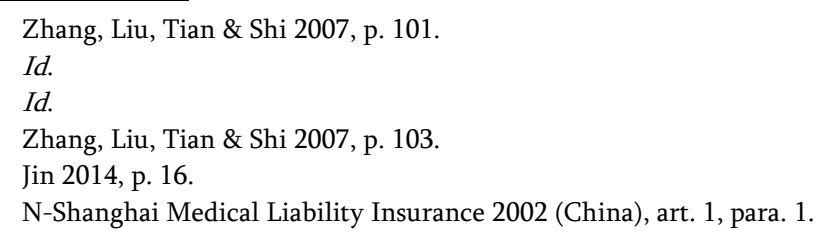


Sep. 1, 2002; the scheme for medical mishaps would be initiated after more research. ${ }^{17}$ PICC Shanghai Branch underwrote the MIL contract in 2002. ${ }^{18}$

The purchase of MLI policies is voluntary. The medical institution is the sole policyholder and the insured. ${ }^{19}$ However, both the medical institution and its staff members are required to bear part of the MIL premium. ${ }^{20}$ The whole premium is paid by the medical institution to the insurer annually. ${ }^{21}$ The premium that the medical institution has to bear is determined by the types of institutions, the number of ward beds, and the choice of caps (either 100,000 yuan or 200,000 yuan). ${ }^{22}$ Individual providers have to bear premiums annually in accordance with the types of their workplaces and jobs. ${ }^{23}$

It appears that premiums of the next year are modified in light of the loss experience of the prior year. The detailed rates adjusted according to loss ratios are presented in Table 5.2.

Table 5.2: Premiums Adjustments under the Shanghai MLI Scheme

\begin{tabular}{|llllllll|}
\hline $\begin{array}{l}\text { Loss ratio of } \\
\text { the prior year }\end{array}$ & $0-10 \%$ & $\begin{array}{l}10- \\
20 \%\end{array}$ & $\begin{array}{l}20- \\
30 \%\end{array}$ & $\begin{array}{l}30- \\
50 \%\end{array}$ & $\begin{array}{l}50- \\
70 \%\end{array}$ & $\begin{array}{l}70- \\
100 \%\end{array}$ & $\begin{array}{l}100 \% \\
\text { plus }\end{array}$ \\
\hline $\begin{array}{l}\text { Multiplicands } \\
\text { for the basis } \\
\text { premiums }\end{array}$ & 0.8 & 0.85 & 0.9 & 0.95 & 1 & 1.1 & 1.3 \\
\hline
\end{tabular}

The Shanghai MLI scheme employs claims-made coverage, with a certain extended reporting period (ERP) or "tail coverage."24 The ERP is two years, which applies to the first year of the MLI contract as well. ${ }^{25}$ However, the policy excludes claims that have already been made to the insured before the commencement date of the policy even when the accident occurred within the ERP. ${ }^{26}$

The Shanghai MLI scheme for medical accidents covers the following costs: (1) economic compensation for personal injury due to a medical accident; (2) the costs of reducing the consequences of a medical accident;

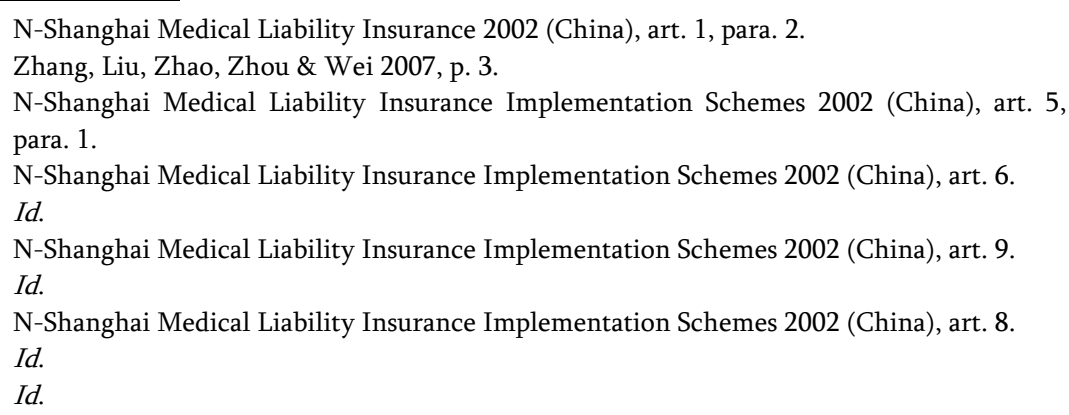


and (3) litigation costs, attorney fees, expert ascertainment fees, etc., which should not exceed $10 \%$ of the cap that is placed on damages per capita per accident. $^{27}$

PICC Shanghai Branch and the Shanghai International Medical Centre (SIMC) jointly established the PICC Shanghai Medical Accident Liability Insurance Handling Centre (hereinafter PICC Shanghai MLI Centre) in October 2002, which has employed about 20 lawyers and 35 medical experts. ${ }^{28}$ The Centre is primarily intended to investigate medical accident disputes, settle MLI claims, and help the insured hospital in preventing AEs. ${ }^{29}$

When informed of any medical dispute, the Centre will first try to encourage disputants to settle in private. ${ }^{30}$ If the disputants fail to settle, they may apply for MATA, administrative mediation (AM) or file a lawsuit. ${ }^{31}$ The insured medical institution shall be represented by the Centre in all legal proceedings. ${ }^{32}$

The insurer must pay insurance benefits in accordance with court judgements, mediation agreements through the AM, or settlement agreements accepted by the insurer. ${ }^{33}$

By the end of 2012, a total of 435 medical institutions in Shanghai had purchased MLI policies. ${ }^{34}$ During the period 2002-2012, the Centre had settled 10,830 claims, with an insurance payout of 277 million yuan (roughly 25,577 yuan per claim). ${ }^{35}$

That being said, a slight contraction of the MLI market was also reported. The number of insured medical institutions decreased from 486 in 2002 to 435 in 2012, representing less than 90\% of all medical institutions in Shanghai. ${ }^{36}$

Remarkably, a large proportion of compensatory damages is still paid by medical institutions to patients even when MLI is available. Reportedly, only about $30 \%$ of all damages are covered by MLI policies in Shanghai. ${ }^{37}$

N-Shanghai Medical Liability Insurance Implementation Schemes 2002 (China), art. 7. Zhang, Liu, Zhao, Zhou \& Wei 2007, p. 3.

N-Shanghai Medical Liability Insurance Implementation Schemes 2002 (China), art. 10.

N-Shanghai Medical Liability Insurance Implementation Schemes 2002 (China), art. 12, para. 1.

31 N-Shanghai Medical Liability Insurance Implementation Schemes 2002 (China), art. 12, para. 2.

32 N-Shanghai Medical Liability Insurance Implementation Schemes 2002 (China), art. 12, para. 3.

$33 \quad$ N-Shanghai Medical Liability Insurance Implementation Schemes 2002 (China), art. 13.

$34 \quad$ Jin 2014, p. 17.

35 Id.

$36 \quad$ Id.

37 Id. 
Another surprising fact is that the MLI insurer in Shanghai has remained in deficit for a long time. For the period 2003-2011 in the Putuo District of Shanghai, the annual insurance payout was 1.79 million yuan while the annual premium was 1.73 million yuan. ${ }^{38}$ For the period 2002-2010 in Shanghai, a total of 268 million yuan had been collected as premiums whereas 238 million yuan had been paid as insurance benefits. ${ }^{39}$

\subsubsection{The Beijing MLI Scheme}

At the end of 2004, the Beijing Health Bureau enacted the N-Beijing Medical Liability Insurance 2004, and the Beijing MLI scheme was initiated in 2005. The Bureau is responsible for organising MLI, designing detailed insurance plans, and choosing the MLI insurer through public bidding..$^{40}$ PICC Beijing Branch and CPIC Beijing Branch jointly underwrite the MLI policies. ${ }^{41}$

The Beijing MLI scheme is compulsory for all state-owned not-forprofit medical institutions. ${ }^{42}$ Both the medical institution and its staff members have to contribute to the premium, which is paid annually by the institution to the insurer ${ }^{43}$ The medical institution is not allowed to increase service prices on account of paying the premium. ${ }^{44}$

The MLI premium for medical institutions is determined with regard to types of the institution and the number of ward beds. ${ }^{45}$ The premium for individual providers is calculated on the basis of the types of their hospitals, specialties, and jobs. ${ }^{46}$

The Beijing MLI scheme covers liability for harm due to clinical negligence, ${ }^{47}$ which is broader than liability for medical accidents with obvious negligent iatrogenic injuries. ${ }^{48}$ A cap of 200,000 yuan is imposed on the coverage.$^{49}$ Non-pecuniary damages and litigation costs are covered by the scheme as well. ${ }^{50}$

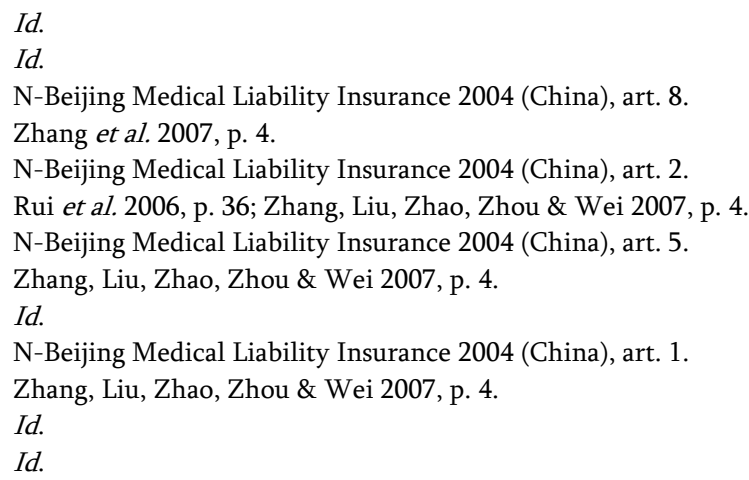


A supporting system was developed to facilitate the resolution of medical disputes and injury prevention..$^{51}$ Accordingly, the insurer established two mediation organisations - the Beijing Health Law Research Committee Medical Dispute Mediation Centre and the Beijing Medical Education Association Medical Dispute Mediation Centre. ${ }^{52}$

Although the Beijing government intended the MLI scheme as a compulsory insurance system, the number of the insured hospitals has been decreasing. There are about 729 medical institutions in Beijing, of which 445 purchased MLI policies in 2005, 387 did so in 2006, and 341 did so in 2007, representing about $46 \%$ of all the medical institutions. ${ }^{53}$ Reportedly, only less than $10 \%$ of hospitals purchased MLI policies in 2013. ${ }^{54}$

\subsubsection{The Shenzhen Medical Professional Risk Insurance Scheme}

The Shenzhen Health Bureau initiated the Shenzhen MLI scheme in 2004 by enacting the N-Shenzhen Medical Professional Risk Insurance 2004. The MLI scheme was compulsory for all state-owned not-for-profit medical institutions and their staff members.

The MLI premium consists of fixed premiums for the medical institution and individual risk savings (个人风险储金) for medical staff members..$^{55}$ The fixed premiums must be paid by medical institutions and will not be returned. ${ }^{56}$ Individual risk savings will be paid by medical institutions $(80 \%)$ and staff members (20\%) jointly, and any money not required for claims will be treated as savings and returned to individual providers when they cease practising medicine. ${ }^{57}$

Fixed premiums for medical institutions are determined by the types of institutions and the output of medical services (ascending from the tenth risk level to the first; ranging from 10,000 yuan to 350,000 yuan annually). ${ }^{58}$ Individual risk savings are determined on the basis of specialities (ascending from the tenth risk level to the first; ranging from 140 yuan to 500 yuan per month)..$^{59}$

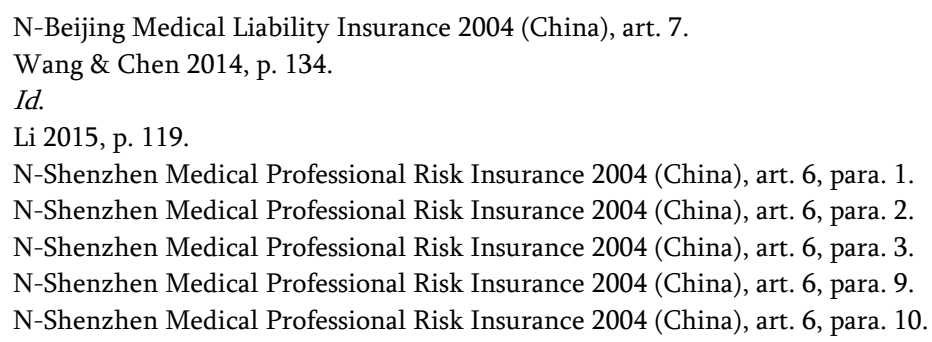


The Shenzhen scheme covers liability for medical accidents, liability for medical errors, and liability for medical mishaps. ${ }^{60}$ If an injury was caused by a medical staff member's negligence, the damages should be apportioned between the staff member and the insurer (co-insurance). The detailed rules of the co-insurance are presented in Table 5.3.

Table 5.3: Co-insurance between Individual Providers and the Insurer

\begin{tabular}{|lccc|}
\hline \multicolumn{2}{|l}{ Types of Liability } & Individual providers (\%) & The insurer (\%) \\
\hline Medical & Grade One & $40 \%$ & $60 \%$ \\
accidents & Grade Two & $30 \%$ & $70 \%$ \\
(obvious & Grade Three & $20 \%$ & $80 \%$ \\
injury) & Grade Four & $10 \%$ & $90 \%$ \\
\hline $\begin{array}{l}\text { Medical errors (less } \\
\text { obvious injury) }\end{array}$ & $5 \%$ & $95 \%$ \\
\hline $\begin{array}{l}\text { Medical mishaps (non- } \\
\text { negligent) }\end{array}$ & 0 & $100 \%$ (less than 20,000 \\
\hline
\end{tabular}

Remarkably, there was no cap placed on compensatory damages for the first few years. ${ }^{61}$ Insurance benefits are paid according to court judgements, administrative mediation agreements, and settlements recognised by the insurer. ${ }^{62}$ However, the absence of caps led to a surge in premiums and hospitals were not willing to pay high premiums. Hence, the insurer later placed a cap of 500,000 yuan per accident and 5 million yuan per year on damages. $^{63}$

\subsubsection{The Ningbo MLI Scheme}

In 2008, Ningbo City established a compulsory MLI scheme for all public medical institutions. Private hospitals are also encouraged to participate in the scheme. By April 2010, a total of 220 medical institutions purchased MLI policies, including four private hospitals. ${ }^{64}$

Four insurance companies in Ningbo jointly underwrite MLI policies. ${ }^{65}$ The insurer also established a Medical Dispute Compensation and Handling Centre for investigating, evaluating, and settling claims. ${ }^{66}$ The Centre must

N-Shenzhen Medical Professional Risk Insurance 2004 (China), art. 3.

Zhang, Liu, Zhao, Zhou \& Wei 2007, p. 4.

N-Shenzhen Medical Professional Risk Insurance 2004 (China), art. 19.

Zhang, Liu, Zhao, Zhou \& Wei 2007, p. 4.

Chen \& Yuan 2011, p. 61.

Chen \& Yuan 2011, p. 60.

Id. See also LGR-Ningbo Medical Dispute Resolution 2007 (China), art. 23. 
intervene in the negotiations between hospitals and patients in cases where the value of a claim exceeds 10,000 yuan. ${ }^{67}$

The Ningbo scheme covers not only liability for medical accidents, but also liability for medical mishaps (humanitarian damages). ${ }^{68}$

It was claimed that the Ningbo MLI Scheme was successful. During the period 2008-2010, the Centre had accepted 1,102 claims, of which $75.8 \%$ $(\mathrm{n}=1,102)$ claims had been settled. ${ }^{69}$ It was found that the frequency of Yi-Nao incidents was on the decrease. The number of Yi-Nao incidents had been reduced by $30 \%$ from 2007 to $2008 .{ }^{70}$

\subsubsection{The Nanjing Scheme}

The Nanjing Municipal Government initiated the MLI scheme in 2009 and required all state-owned medical institutions at or above Level Two participate in the scheme. ${ }^{71}$ Through bidding, six insurance companies were chosen to provide MLI coverage in Nanjing jointly. ${ }^{72}$ By the end of 2013, all of these medical institutions ( $\mathrm{n}=186)$ had purchased MLI policies. ${ }^{73}$

The Nanjing MLI scheme is composed of primary insurance (covering liability for medical accidents, liability for medical errors, and liability for medical mishaps) and additional insurance (covering liability for injuries suffered by medical staff members due to violence, and liability for infectious disease).$^{74}$ While the purchase of the primary insurance is compulsory, that of the additional insurance is voluntary. ${ }^{75}$

Both the medical institution and the staff member have to contribute to the MLI premium. The premium for the medical institution is determined according to the number of ward beds. ${ }^{76}$ The premium for individual providers is determined in the light of their specialities, ranging from 60 yuan to 270 yuan annually. ${ }^{77}$

It seems that the MLI premium is experience rated. The PICC Nanjing Branch adjusts premiums in the light of loss ratios of the previous year(s). The method of adjusting premiums for the year of 2009 is presented in Table 5.4.

\footnotetext{
LGR-Ningbo Medical Dispute Resolution 2007 (China), art. 24.

Chen \& Yuan 2011, p. 61.

Chen \& Yuan 2011, p. 60.

Id.

Lin et al. 2016, p. 68.

Id.

Id.

Id.

Id.

Id.

Id.
} 
Part I. Legal Remedies for Medical Malpractice in China

Table 5.4: MLI Premium Adjustments Used by the PICC Nanjing Branch (2009)8

\begin{tabular}{|lcccccc|}
\hline $\begin{array}{l}\text { Loss ratio of } \\
\text { the pre- } \\
\text { vious year }\end{array}$ & $\mathbf{0 \% - 1 0 \%}$ & $\mathbf{1 0} \%-30 \%$ & $\mathbf{3 0 \% - 5 0 \%}$ & $\mathbf{5 0 \% - 7 0 \%}$ & $\begin{array}{l}70 \%- \\
100 \%\end{array}$ & $100 \%$ plus \\
\hline $\begin{array}{l}\text { Coefficient } \\
\text { for the base } \\
\text { premium }\end{array}$ & 0.80 & 0.85 & 0.9 & 1.0 & 1.1 & 1.3 \\
\hline
\end{tabular}

A special system of medical dispute people's mediation has been established to mediate between hospitals and patients. ${ }^{79}$ This people's mediation was also argued to be successful. By the end of 2012, a total of 3,173 medical disputes were accepted, of which $98 \%$ were settled $(n=3,173){ }^{80}$ People's Mediation is independent of the MLI insurer. The insurer does not intervene in mediation. ${ }^{81}$

Regarding medical accidents, the insurer must pay benefits on the basis of MATA conclusions..$^{82}$ As far as medical errors are concerned, damages will be determined in the light of mediation agreements through people's mediation or court judgements. ${ }^{83}$

A cap of 100,000 yuan to 1 million yuan is placed on damages per capita per accident and a cap of 100,000 yuan to 6 million yuan is imposed on damages per year. ${ }^{84}$

\subsubsection{A Comparison and Contrast}

The similarities and differences of the foregoing six local MLI schemes are summarised in Table 5.5 as follows.

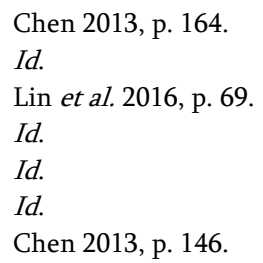


Other Compensation Schemes

Table 5.5: Six Representative Local MLI Schemes in China

\begin{tabular}{|c|c|c|c|c|c|c|}
\hline & $\begin{array}{l}\text { Yunnan } \\
\text { Province }\end{array}$ & $\begin{array}{l}\text { Shanghai } \\
\text { City }\end{array}$ & Beijing City & $\begin{array}{l}\text { Shenzhen } \\
\text { City }\end{array}$ & $\begin{array}{l}\text { Ningbo } \\
\text { City }\end{array}$ & $\begin{array}{l}\text { Nanjing } \\
\text { City }\end{array}$ \\
\hline $\begin{array}{l}\text { Year of } \\
\text { Commen- } \\
\text { cement }\end{array}$ & 1998 & 2002 & 2004 & 2004 & 2008 & 2009 \\
\hline MLI Mode & $\begin{array}{l}\text { - govern- } \\
\text { ment } \\
\text { initiated } \\
\text { - commer- } \\
\text { cial MLI } \\
\text { - compul- } \\
\text { sory } \\
\text { - occurrence } \\
\text { coverage }\end{array}$ & $\begin{array}{l}\text { - govern- } \\
\text { ment } \\
\text { initiated } \\
\text { - commer- } \\
\text { cial MLI } \\
\text { - voluntary } \\
\text { - claims- } \\
\text { made with } \\
\text { an ERP of } 2 \\
\text { years }\end{array}$ & $\begin{array}{l}\text { - govern- } \\
\text { ment } \\
\text { initiated } \\
\text { - commer- } \\
\text { cial MLI } \\
\text { - compul- } \\
\text { sory for all } \\
\text { public } \\
\text { medical } \\
\text { institutions } \\
\text { - claims- } \\
\text { made with } \\
\text { an ERP }\end{array}$ & $\begin{array}{l}\text { - govern- } \\
\text { ment } \\
\text { initiated } \\
\text { - commer- } \\
\text { cial MLI } \\
\text { - compul- } \\
\text { sory for all } \\
\text { public } \\
\text { medical } \\
\text { institutions } \\
\text { - claims- } \\
\text { made with } \\
\text { an ERP }\end{array}$ & $\begin{array}{l}\text { - govern- } \\
\text { ment } \\
\text { initiated } \\
\text { - commer- } \\
\text { cial MLI } \\
\text { - compul- } \\
\text { sory for all } \\
\text { public } \\
\text { medical } \\
\text { institutions } \\
\text { - claims- } \\
\text { made with } \\
\text { an ERP }\end{array}$ & $\begin{array}{l}\text { - govern- } \\
\text { ment } \\
\text { initiated } \\
\text { - commer- } \\
\text { cial MLI } \\
\text { - compul- } \\
\text { sory for all } \\
\text { Level Two } \\
\text { or Three } \\
\text { public } \\
\text { medical } \\
\text { institutions } \\
\text { - claims- } \\
\text { made with } \\
\text { an ERP }\end{array}$ \\
\hline The Insured & $\begin{array}{l}\text { - medical } \\
\text { institutions }\end{array}$ & $\begin{array}{l}\text { - medical } \\
\text { institutions }\end{array}$ & $\begin{array}{l}\text { - medical } \\
\text { institutions }\end{array}$ & $\begin{array}{l}\text { - medical } \\
\text { institutions }\end{array}$ & $\begin{array}{l}\text { - medical } \\
\text { institutions }\end{array}$ & $\begin{array}{l}\text { - medical } \\
\text { institutions }\end{array}$ \\
\hline $\begin{array}{l}\text { Premium } \\
\text { Payers }\end{array}$ & $\begin{array}{l}\text { - medical } \\
\text { institutions } \\
\text { - medical } \\
\text { staff } \\
\text { members }\end{array}$ & $\begin{array}{l}\text { - medical } \\
\text { institutions } \\
\text { - medical } \\
\text { staff } \\
\text { members }\end{array}$ & $\begin{array}{l}\text { - medical } \\
\text { institutions } \\
\text { - medical } \\
\text { staff } \\
\text { members }\end{array}$ & $\begin{array}{l}\text { - medical } \\
\text { institutions } \\
\text { - medical } \\
\text { staff } \\
\text { members } \\
\text { (risk } \\
\text { savings) }\end{array}$ & $\begin{array}{l}\text { - medical } \\
\text { institutions } \\
\text { - medical } \\
\text { staff } \\
\text { members }\end{array}$ & $\begin{array}{l}\text { - medical } \\
\text { institutions } \\
\text { - medical } \\
\text { staff } \\
\text { members }\end{array}$ \\
\hline $\begin{array}{l}\text { Criteria for } \\
\text { Calculating } \\
\text { Premiums } \\
\text { for } \\
\text { Institutions }\end{array}$ & $\begin{array}{l}\text { - number of } \\
\text { ward beds }\end{array}$ & $\begin{array}{l}\text { - number of } \\
\text { ward beds } \\
\text { - types of } \\
\text { institutions } \\
\text { - choice of } \\
\text { caps }\end{array}$ & $\begin{array}{l}\text { - number of } \\
\text { ward beds } \\
\text { - types of } \\
\text { institutions }\end{array}$ & $\begin{array}{l}\text { - output of } \\
\text { medical } \\
\text { services } \\
\text { - types of } \\
\text { institutions }\end{array}$ & - unknown & $\begin{array}{l}\text { - number of } \\
\text { ward beds }\end{array}$ \\
\hline $\begin{array}{l}\text { Criteria for } \\
\text { Calculating } \\
\text { Premiums } \\
\text { for Staff }\end{array}$ & $\begin{array}{l}\text { - specialities } \\
\text { - positions }\end{array}$ & $\begin{array}{l}\text { - jobs } \\
\text { - types of } \\
\text { institutions }\end{array}$ & $\begin{array}{l}\text { - specialities } \\
\text { - jobs } \\
\text { - types of } \\
\text { institutions }\end{array}$ & - specialities & - unknown & - specialities \\
\hline $\begin{array}{l}\text { Experience } \\
\text { Rating }\end{array}$ & - no & $\begin{array}{l}\text { - adjusted in } \\
\text { light of the } \\
\text { loss ratio of } \\
\text { the previous } \\
\text { year }\end{array}$ & - unknown & - no & - unknown & - yes \\
\hline
\end{tabular}


Part I. Legal Remedies for Medical Malpractice in China

\begin{tabular}{|c|c|c|c|c|c|c|}
\hline $\begin{array}{l}\text { Scope of } \\
\text { Coverage }\end{array}$ & $\begin{array}{l}\text { - medical } \\
\text { accidents } \\
\text { - medical } \\
\text { errors* }\end{array}$ & $\begin{array}{l}\text { - medical } \\
\text { accidents } \\
\text { - non- } \\
\text { pecuniary } \\
\text { damages } \\
\text { excluded } \\
\text { - costs of } \\
\text { reducing } \\
\text { the } \\
\text { consequenc } \\
\text { es of an } \\
\text { accident } \\
\text { - litigation } \\
\text { costs, } \\
\text { attorney } \\
\text { fees }\end{array}$ & $\begin{array}{l}\text { - clinical } \\
\text { negligence } \\
\text { (medical } \\
\text { accidents + } \\
\text { errors) } \\
\text { - non- } \\
\text { pecuniary } \\
\text { damages } \\
\text { included } \\
\text { - litigation } \\
\text { costs }\end{array}$ & $\begin{array}{l}\text { - medical } \\
\text { accidents } \\
\text { - medical } \\
\text { errors } \\
\text { - medical } \\
\text { mishaps }\end{array}$ & $\begin{array}{l}\text { - medical } \\
\text { accidents } \\
\text { - medical } \\
\text { mishaps }\end{array}$ & $\begin{array}{l}\text { - medical } \\
\text { accidents } \\
\text { - medical } \\
\text { errors } \\
\text { - medical } \\
\text { mishaps }\end{array}$ \\
\hline Deductibles & $\begin{array}{l}-5 \% \text { (with } \\
\text { a cap of } \\
5,000 \text { yuan) }\end{array}$ & - no & - unknown & - no & $\begin{array}{l}-10,000 \\
\text { yuan }\end{array}$ & - no \\
\hline Co-Insurance & - no & - no & - no & - yes & - no & - no \\
\hline $\begin{array}{l}\text { Caps on } \\
\text { Insurance } \\
\text { Benefits }\end{array}$ & - yes & - yes & - yes & $\begin{array}{l}\text { - no } \\
\text { - yes } \\
\text { (several } \\
\text { years later) }\end{array}$ & - yes & - yes \\
\hline $\begin{array}{l}\text { Dispute } \\
\text { Resolution** }\end{array}$ & $\begin{array}{l}\text { - no special } \\
\text { mechanism }\end{array}$ & $\begin{array}{l}\text { - PICC } \\
\text { Shanghai } \\
\text { MLI Centre }\end{array}$ & $\begin{array}{l}\text { - two } \\
\text { Mediation } \\
\text { Centres }\end{array}$ & $\begin{array}{l}\text { - no special } \\
\text { mechanism }\end{array}$ & $\begin{array}{l}\text { - people's } \\
\text { mediation } \\
\text { - a claims } \\
\text { handling } \\
\text { centre }\end{array}$ & $\begin{array}{l}\text { - people's } \\
\text { mediation }\end{array}$ \\
\hline
\end{tabular}

These six schemes share certain similarities. First, all of them were initiated by the government and are underwritten by commercial insurance companies. Second, the sole insured under the MLI contract is the medical institution, although medical staff members should contribute to part of the premium. Third, all of them cover liability for medical accidents - clinical negligence with an obvious personal injury. Fourth, all of them (at least ultimately) place caps on insurance benefits.

Be that as it may, they differ in several aspects. First, not all of them are claims-made coverage. While most of them are claims-made with an ERP, the Yunnan scheme seems to be occurrence coverage. Second, not all of them are compulsory. Whereas most of them are compulsory insurance schemes (at 
least for part of public hospitals), the Shanghai scheme adopts the voluntary approach. Third, not all of them employ the same criteria for determining premiums. As far as premiums for hospitals are concerned, although most of the schemes are based on the number of ward beds, the Shenzhen scheme takes the output of medical services as one of the criteria. Regarding premiums for individual providers, while most of the schemes take into account specialities, some also consider the types of hospitals. Fourth, not all of them have adopted experience ratings. Only the Shanghai and Nanjing schemes have expressly employed experience ratings. Fifth, not all of the schemes cover "liability for medical mishaps." Whereas the Shenzhen, Ningbo, and Nanjing schemes provide cover for medical mishaps (nonnegligent AEs), the other schemes restrict cover to negligent AEs (medical accidents, medical errors, or clinical negligence). Sixth, not all of the schemes impose deductibles. Only the Yunnan and Ningbo schemes seem to adopt a deductible. Seventh, most of them do not employ co-insurance. Only the Shenzhen scheme splits damages between negligent providers and the insurer. Eighth, not all of them have established a special mechanism for medical dispute resolution. Only in Shanghai, Beijing, Ningbo, and Nanjing, there are some claims mediation and handling centres or people's mediation commissions that may facilitate dispute resolution.

Some of the other local jurisdictions than these six have implemented similar MLI schemes since 2007. ${ }^{5}$ Overall, however, MLI is rather underdeveloped in China. Some empirical data show that by the end of 2013, only 30,000 medical institutions had purchased MLI policies, representing less than $10 \%$ of all medical institutions in China. ${ }^{86}$ As mentioned above, there seems to be a contraction of the MLI market in Yunnan, Shanghai, and Beijing, although both the Yunnan and the Beijing schemes are claimed to be compulsory. In some other localities, no single MLI policy had ever been sold for almost a decade. ${ }^{87}$

\subsection{DISCUSSION}

After examining some local MLI schemes in China, one may wonder why it is still so underdeveloped in China and what solutions are already discussed.

\footnotetext{
85 In 2007, the then $\mathrm{MoH}$ of China, together with the China Insurance Regulatory Commission (CIRC) and the State Administration of Traditional Chinese Medicine, enacted the DR-Promotion of MLI 2007 (China) and encouraged local experiments of MLI nationwide.

$86 \quad$ Dong 2014, p. 17.

87 Id.
} 
This Section will try to explain the barriers that may prevent Chinese MLI schemes from developing well as follows:

Although many local MLI schemes require that at least public hospitals must purchase MLI policies, it is difficult to enforce this obligation. According to art. 184, para. of the Insurance Law 2009, compulsory insurance must be provided for by national laws or administrative regulations. In China, however, no national law or administrative regulation has ever provided that MLI shall be compulsory insurance. Currently, all local MLI schemes are based on local government orders, most of which do not specify any sanction. One exception is the Yunnan scheme, under which hospitals that fail to purchase MLI policies shall be subject to license revocation. However, this sanction has not been imposed in practice. ${ }^{88}$ In effect, if hospitals refuse to purchase MLI policies, the public health authorities currently cannot force hospitals to fulfil the obligation. ${ }^{89}$

- $\quad$ Large hospitals are not willing to purchase MLI policies. First, large hospitals often have to pay considerable premiums, which may exceed the insurance benefits. For instance, one Level Three hospital in Beijing paid 1.9 million yuan as the premium while the insurer only paid about 600,000 yuan as insurance benefits in that year, ${ }^{90}$ representing only $31.58 \%$ of the premium. Hence, large hospitals may prefer selfinsurance rather than MLI. Second, not all insurance companies are willing or able to provide mediation services. One important motive for hospitals to purchase MLI is that they want to free themselves from handling medical disputes. ${ }^{91}$ In practice, however, many insurance companies do not provide such a service. One hospital manager even said, "If we still have to face conflicts between doctors and patients or Yi-Nao incidents after we have already purchased MLI policies, why do we need insurance companies?"'92

- Some hospitals want to conceal medical accidents. As addressed before, hospitals and individual providers may be subject to administrative punishments or even criminal penalties in cases where a severe medical accident occurs. ${ }^{93}$ These sanctions may adversely affect hospital accreditation, promotion, and reputation of physicians. Hence, hospitals

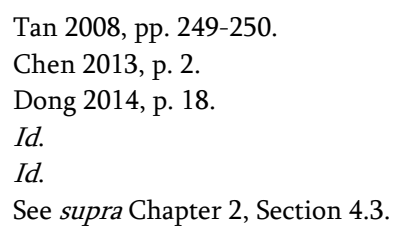


and physicians are induced to conceal medical accidents and try to settle the dispute in private even when they are not at fault. ${ }^{94}$ However, these behind-the-scenes settlements are often excluded from MLI coverage. ${ }^{95}$ Therefore, these hospitals would opt for self-insurance rather than MLI.

- Many insurance companies are not willing to sell MLI policies because of considerable uncertainty over legal standards. As described before, for the period 2002-2009, two parallel regimes of medical malpractice liability had existed. ${ }^{96}$ After the implementation of the new Tort Law 2009, there are still two parallel expert ascertainment systems that may result in different outcomes. Hence, insurance companies often find it difficult to determine the frequency and severity of malpractice claims, which makes the calculation of premiums very arbitrary. ${ }^{97}$ Due to a lack of data on true claims history, they can only base premiums on some rough indicators such as the number of ward beds, types of hospitals, or specialities.

The under-development of MLI market in China suggests that in a significant proportion of the cases, victimised patients still obtain compensation directly from hospitals.

\section{OTHER COMPENSATION SCHEMES}

\subsection{INTRODUCTION}

In many European legal systems, social security plays a primary role regarding compensation for victims of medical malpractice ${ }^{98}$ In some jurisdictions such as New Zealand and Nordic countries, a no-fault insurance scheme provides extensive cover for iatrogenic injuries. ${ }^{99}$ One may wonder, besides the fault-based medical malpractice liability and MLI, whether there are any alternative regimes that may cover at least part of a victimised patient's losses.

In China, losses suffered by victimised patients may be covered by some private insurance schemes and social security schemes. I will address

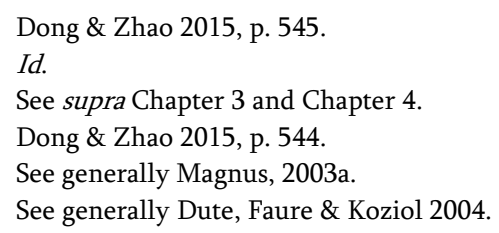


the role of private health insurance and social security schemes that are relevant to victimised patients in Section 3.2 and Section 3.3 respectively. Section 3.4. will discuss the relationship between social security and tort law in China.

\subsection{PRIVATE INSURANCE}

\subsubsection{Private Health Insurance}

In China, private/commercial health insurance is a voluntary regime, which is a necessary supplement to social medical insurance (BMIS). ${ }^{100}$ Although the BMIS covers a large part of the population, the coverage for the expenses of some high-priced services may be rather limited. With the progressive increase in medical expenses ${ }^{101}$ and demand for diverse medical care, the BMIS is obviously unable to satisfy people's needs. Thus, commercial health insurance has begun to grow very fast recently in China. Private health insurance aims to provide benefits that are not covered by the BMIS. Private health insurance is governed by the Insurance Law 2009 rather than the Social Insurance Law 2010.

Currently, the role played by private health insurance in the Chinese health care system is quite limited. In 2012, a total of 86.3 billion commercial health insurance premiums was earned, with a year-on-year growth of $25 \%$, which was faster than any other kind of personal insurance. ${ }^{102}$ By the end of 2012, more than 50 million people had been covered by commercial health insurance in China. ${ }^{103}$ However, private health insurance only covered a small proportion (3.57\%) of the whole population (almost 1.4 billion ${ }^{104}$ ). Hence, most Chinese patients primarily rely on the BMIS to cover their medical expenses.

\subsubsection{Medical Mishap Insurance}

Potential victims may also purchase private insurance against loss through accidental bodily injury or death. In the context of treatment, patients may purchase the so-called “medical mishap insurance" (医疗意外险). In practice,

\footnotetext{
100 For a basic description of the financing of the BMIS, see supra Chapter 2, Section 3.

101 See infra Section 3.5.

102 Wang, P. 2014, p. 9.

103 Yuan 2013, p. 118.

104 According to the National Bureau of Statistics of China 2016, by the end of 2012, the total population in China had reached 1,354,040,000.
} 
some hospitals tried to persuade patients to buy "surgical mishap insurance" (手术意外险) with a view to covering losses that are not caused by fault on the part of hospitals. ${ }^{105}$ However, many patients refuse to purchase this insurance and thus the market for surgical mishap insurance is rather underdeveloped. ${ }^{106}$

As mentioned before, ${ }^{107}$ in some Chinese cities (e.g. Shenzhen, Ningbo, and Nanjing), hospitals began to purchase medical mishap insurance for the benefit of patients. Why are these hospitals so benevolent toward their patients? Because hospitals want to resolve medical disputes as quickly as possible and safeguard themselves against $Y i$ Nao incidents by paying injured patients a sum of compensation irrespective of whether they are at fault or not. Compared to disturbances caused by $Y i$ Nao incidents, hospitals may well find it worthwhile to pay premiums for medical mishap insurance. Hence, it is striking to find that although Chinese tort law adopts the fault-based medical malpractice liability, meaning that hospitals cannot be held liable for non-negligent iatrogenic injuries, some hospitals in practice are "coerced" into purchasing medical mishap insurance for the benefit of patients in order to avoid Yi Nao incidents.

\subsection{SOCIAL SECURITY SCHEMES}

\subsubsection{Introduction}

In China, the two most significant social security schemes are social insurance ${ }^{108}$ and social assistance. ${ }^{109}$ The Chinese social insurance system consists of basic pension insurance, basic medical insurance (BMIS), workrelated injury insurance, unemployment insurance, and maternity insurance, ensuring the rights of citizens to receive material assistance in old age, sickness, work-related injury, unemployment, and maternity from the State and society. ${ }^{110}$ The social assistance system is intended to guarantee the basic livelihood of citizens when they are relatively or extremely poor, when they suffer from natural disasters, when they cannot afford medical care, education, housing, etc. ${ }^{111}$

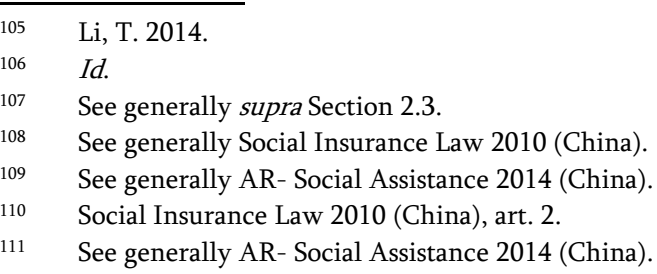


Not all of these schemes are relevant to victims of medical malpractice so only social security schemes that may cover medical expenses and lost future earnings will be addressed in Section 3.3.2 and Section 3.3.3 respectively. Section 3.3.4 will give a summary and evaluation of these social security schemes in the light of compensation for damage caused by medical malpractice

\subsubsection{Social Security Schemes Covering Medical Expenses}

\subsubsection{The Basic Medical Insurance Schemes}

The benefits under the BMIS are limited: only those expenses that are covered by the BMIS Drug Catalogue (基本医疗保险药品目录), the BMIS Treatment Items (基本医疗保险诊疗项目), and BMIS Medical Service Facilities (基本医疗保险医疗服务设施), and expenses for emergency treatment or rescue are compensable. ${ }^{112}$ The expenses payable under the BMIS are directly paid by the Social Insurance Agencies (hereinafter SIA) from the Basic Medical Insurance Funds (hereinafter BMIF) to the Designated Medical Institutions (hereinafter DMI). ${ }^{13}$ If patients intend to receive medical services that are outside the cover under the BMIS, they have to pay in cash for the expenses of these services or purchase private health insurance to cover these expenses. Even within the cover under the BMIS, insurance benefits may not make up for the whole medical expenses in that there are various deductibles and caps applicable to different categories of the insured, different levels of hospitals, different types of treatment, and different localities. For instance, on average only about $75 \%$ of the expenses of medical services that are covered by the BMIS are compensable in Shaanxi Province in 2015. ${ }^{114}$

Currently, nationwide, about $40 \%$ of all medical expenses are paid by patients out of pocket on average. ${ }^{115}$ The direct implication of the fact that patients in China currently have to pay out-of-pocket medical expenses which are equal to about $40 \%$ of the total cost of medical services is that they still have a strong incentive to file a tort claim against hospitals for increased treatment costs due to medical malpractice. The higher the price, the stronger the incentive.

\footnotetext{
$112 \quad$ Social Insurance Law 2010 (China), art. 28.

113 Social Insurance Law 2010 (China), art. 29.

114 Chinese Government Network 2016.

115 See infra Section 3.5.
} 


\subsubsection{The Urban-Rural Medical Assistance System}

There are still some extremely vulnerable groups, i.e. urban or rural residents where the average income of family members living together is lower than the local standard for guaranteeing minimum subsistence (城乡低保家庭成员), ${ }^{116}$ rural dependents who are aged, disabled or under the age of 16 (农村五保户) ${ }^{117}$ and other family members who are in financial difficulties (其他经济困难家庭人员). ${ }^{118}$ In addition to the BMIS, those groups should be covered by the Urban-Rural Medical Assistance System (hereinafter URMAS), which is an important type of social assistance. ${ }^{119}$

There are several ways of medical assistance. Premiums under the BMIUR and the NRCMC may be fully paid by the government directly. ${ }^{20}$ The out-of-pocket expenses of basic medical care that are not covered by the BMIUR or NRCMC and are unaffordable for the vulnerable groups may also be partly subsidised by the Urban-Rural Medical Assistance Funds (hereinafter URMAF). ${ }^{121}$ Finance for the URMAF comes from channels such as public finance and budgeting, public welfare funds from lottery and donation. ${ }^{122}$ A large population of poor patients benefit from the URMAF. In 2014, a total of 17.02 million patients received full government subsidies on BMIUR premiums (95.18 yuan per capita), 50.22 million patients obtained full subsidies on NRCMC premiums (64.32 yuan per capita), and 239,53 million patients were granted partial subsidies on the out-of-pocket expenses by the URMAF (80.21 yuan per capita). ${ }^{123}$

116 AR-Minimum Subsistence for Urban Residents 1999 (China), art. 2, para. 1; AR-Minimum Subsistence for Rural Residents 2007 (China), art. 3, para. 2.

117 AR-Five Guarantees 2006 (China), art. 6. To be specific, "five guarantees" means providing those vulnerable rural villagers with "care and material support in their daily lives in terms of food, clothing, housing, medical care and burial expenses.”

118 According to DR-Medical Assistance System 2009 (China), art. 2, para. 1, these other family members specifically refer to seriously ill patients living in a low-income family and other members who are suffering special hardships defined by the local government.

$120 \quad$ AR-Social Assistance 2014 (China), art. 29, para. 1.

121 DR-Medical Assistance System 2009 (China), art. 2, para. 2; AR-Social Assistance 2014 (China), art. 29, para. 2.

122 DR-Medical Assistance Funds 2013 (China), art. 2.

123 National Health and Family Planning Commission 2015, p. 336. 


\subsubsection{Social Security Schemes Covering Other Losses}

\subsubsection{Basic Pension Insurance}

In China, all employees must participate in the basic pension insurance scheme (hereinafter BPIS), the premium of which is jointly paid by employers and employees. ${ }^{124}$ Individuals under the BPIS, who have paid premiums for over fifteen cumulative years when reaching the statutory retirement age, receive a monthly basic pension. ${ }^{125}$ A victim of medical malpractice who is also retired is certainly eligible for receiving an old-age pension. By the end of 2014 , about $80 \%$ of the population has been covered under the BPIS. ${ }^{126}$

For individuals participating in the BPIS pass away due to illness or non-work-related reasons such as medical malpractice, their dependents can receive funeral subsidies (about 4,000 yuan) and survivor's pensions (about ten months of the deceased's salaries). ${ }^{127}$

If these individuals under the BPIS lose their earning capacity completely due to illness or non-work-related reasons such as medical malpractice before reaching the statutory retirement age, they can receive incapacity benefits (病残津贴). ${ }^{128}$ Incapacity benefits are a new regime which was unavailable before 2010. So far, it has been unclear how much benefits the incapacitated could receive. However, at least one thing is clear: rural residents and unemployed urban residents may not be eligible for incapacity benefits.

3.3.3.2. Minimum Subsistence Guarantee and Support of the Especially Poor

In case a household's per capita income is lower than the local minimum subsistence standard, the State will grant the household some benefits to maintain the local minimum subsistence standard. ${ }^{129}$ In Nanjing, for instance, the guaranteed minimum subsistence standard was 660 yuan per month for both urban and rural residents in 2015. ${ }^{130}$

Also, the state grants benefits to individuals if they are especially poor due to incapacity, young or old age and there is no person who is under a

Social Insurance Law 2010 (China), art. 10, para. 1.

Social Insurance Law 2010 (China), art. 16, para. 1.

Bai 2015.

Social Insurance Law 2010 (China), art. 17.

Id.

AR-Social Assistance 2014 (China), art. 9.

Civil Affairs Bureau of Jiangning District of Nanjing Municipal 2015. 
statutory obligation to maintain them. ${ }^{131}$ The support of the especially poor includes (1) providing basic living conditions, (2) looking after those who cannot take care of themselves, (3) providing disease treatment, and (4) handling funeral matters. ${ }^{132}$

In a case where a patient becomes poor because of medical malpractice, he/she will be eligible for the foregoing social assistance if all the conditions are satisfied.

\subsubsection{Summary and Evaluation}

Medical expenses and foregone future earnings due to incapacity or death normally represent the lion's share of pecuniary losses suffered by a victim of an accident. In China, several social security schemes may provide a minimum level of coverage for these pecuniary losses, no matter whether they are caused by accidents, diseases, or poverty. As far as treatment costs are concerned, the BMIS provides patients with cover against medical expenses, and those patients who are extremely financially vulnerable are covered under the URMAS. When it comes to foregone future earnings, the BPIS provides the dependents of a deceased employee with funeral subsidies and survivor's pensions, and those employees who are completely incapacitated may receive incapacity benefits. Poor patients may also receive social assistance from the State.

That being said, there is one essential difference between the tort system and social security - while the former is intended to make a victim whole again (full compensation), the latter will only provide a minimum level of compensation for the purpose of maintaining a minimum livelihood. For instance, on average not all but only about $60 \%$ of medical expenses are covered under the BMIS. Poor citizens will be maintained by the State at the minimum subsistence level rather than a higher level of livelihood. Also, not all citizens are covered by social security schemes equally. Rural residents and unemployed urban residents usually receive less social insurance benefits than those who are employed. Furthermore, compensation for non-pecuniary losses is only possible under tort law.

Overall, we may conclude that many victims of medical malpractice in China do benefit from the development of various social security schemes in that they may receive compensation for part of their pecuniary losses much more quickly. Those patients who are eligible for social security benefits do not have to file a lawsuit which may be costly and time-consuming in order

$131 \quad$ AR-Social Assistance 2014 (China), art. 14.

$132 \quad$ AR-Social Assistance 2014 (China), art. 15, para. 1. 
to receive compensation. However, these social security benefits may be fairly modest when compared to full compensation under tort law, and many rural or unemployed victims may not be eligible for these benefits. Hence, unlike victims in many European countries, victims of medical malpractice in China may still rely heavily on tort law to obtain compensation for iatrogenic injuries.

\subsection{RELATIONSHIP WITH TORT LAW}

In China, private insurance and most social security schemes described above are parallel to the tort system, meaning benefits paid to victims under these schemes will not be deducted from medical malpractice claims. In other words, the collateral-source rule ${ }^{133}$ in principle applies to cases where both social security benefits and tort damages are available.

However, there is one exception - medical expenses that should be compensated by a third-party (e.g. a tortfeasor) will not be covered by the BMIS. ${ }^{134}$ Where the medical expenses are assumed by a third party but the third party fails to pay, the medical expenses should be prepaid from the basic medical insurance funds (BMIF), who in turn should be entitled to be reimbursed by the third party after prepayment (subrogation). ${ }^{135}$

\section{CONCLUSIONS}

Chapter 5 addressed several compensation mechanisms that may be alternatives to tort law in China. On closer examination, it was found that none of these mechanisms are true alternatives. MLI is directly built on top of the tort system. The eligibility for and the amount of MLI benefits is often determined in light of medical malpractice liability and quantum rules. As far as social security schemes are concerned, they only provide some groups of victims with a minimum level of compensation rather than with full compensation. Therefore, we may conclude that the tort system is still indispensable to victims of medical malpractice in China.

\footnotetext{
133 The collateral-source rule, also termed collateral-benefit rule, denotes the "doctrine that if an injured party receives compensation for the injuries from a source independent of the tortfeasor, the payment should not be deducted from the damages that the tortfeasor must pay" and insurance proceeds are "the most common collateral source." Garner 2014.

134 Social Insurance Law 2010 (China), art. 30, para. 1.

135 Social Insurance Law 2010 (China), art. 30, para. 2.
} 


\section{CHAPTER 6}

\section{A DOCTRINAL EVALUATION AND TENTATIVE CONCLUSIONS}

\section{INTRODUCTION}

After describing all the Chinese legal remedies related to medical quality assurance and victim compensation, one may wonder how these systems perform. However, before conducting any meaningful evaluation, one needs to make clear the benchmarks against which the legal remedies will be evaluated.

There are at least three doctrinal benchmarks that are widely used in China - legal certainty, effectiveness, and fairness, which are defined as follows:

- Legal certainty. Legal certainty is essential to the principle "treat like cases alike" and legal effectiveness. To guarantee legal certainty, at least two conditions must be met: (1) legal concepts and rules must be as unequivocal and as clear as possible, and different legal rules must not conflict with or contradict one another; ${ }^{1}$ and (2) the procedures and criteria for fact finding must be clear and consistent. ${ }^{2}$

- Effectiveness. Each legal rule may have its own functions to fulfil. Lawmakers enact certain statutes because they intend to achieve some goals. A certain legal rule is said to be effective if it achieves its legislative goals in practice. ${ }^{3} \mathrm{~A}$ legal rule is de facto if not de jure invalid if it is ineffective at fulfilling its functions.

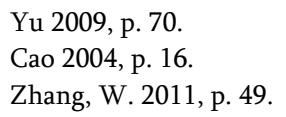


Part I. Legal Remedies for Medical Malpractice in China

- $\quad$ Fairness or justice. As the saying goes, "Ius est ars boni et aequi," i.e. the "law is the art of good order and justice."4 In China, legal scholars also generally recognised that the most important value of the law is to achieve justice. ${ }^{5}$ As far as tort law is concerned, most Chinese tort scholars maintain that the basic rationale behind tort law is corrective justice, i.e. tortfeasors ought to restore victims to their pre-accident situations through compensation. ${ }^{6}$ In order words, tort law is intended to provide victims with fair and adequate compensation. ${ }^{7}$ This goal is also stressed by art. 1 of the Tort Law 2009 as victim protection - "to protect the legitimate rights and interests of parties in civil law relationships." Therefore, the compensation function of tort law in China is generally considered to be a means to an end - corrective justice. ${ }^{8}$ In order for tort law to achieve corrective justice, two general requirements must be met: first, "legal doctrine (inputs) must embody basic principles of corrective justice;" and second, "the operation of the liability regime (outputs) must in practice provide for the initiation and proper disposition of legitimate claims and for the payment of appropriate damages to successful plaintiffs by wrongful defendants."

In the next section, we will see how legal remedies in China work from the above traditional legal perspective.

\section{DOCTRINAL EVALUATION}

\subsection{THE REGULATORY QUALITY ASSURANCE SYSTEM}

China has enacted strict licensing rules for both medical institutions and individual providers..$^{10}$ These rules are largely clear and certain, and they are

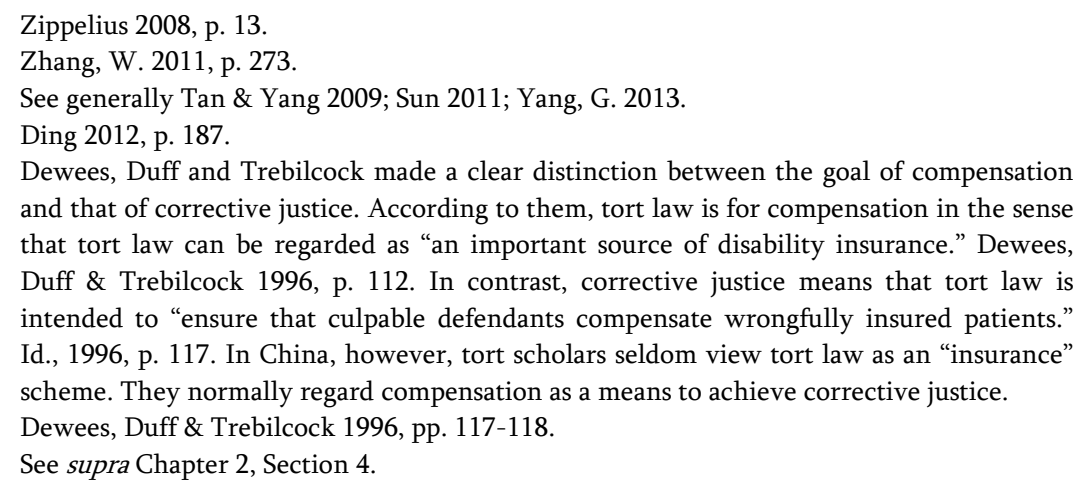


enforced directly by the government. One exception is the ambiguous concept of "serious irresponsibility," which is one of the requirements of imposing the Crime of Medical Accidents (CMA) on culpable providers. ${ }^{11}$

There is generally no concern about justice or fairness, except for input controls on the entry of different individual providers. The law imposes criminal penalties on unlicensed doctors while it shows leniency towards unlicensed nurses and pharmacists. ${ }^{12}$ If unlicensed nurses or pharmacists may equally pose a threat to patient safety, why should they not be punished as severely as unlicensed doctors?

Perhaps the greatest worry for the regulatory quality assurance system is under-enforcement, which may significantly impede the goal of effective quality assurance. First, some evidence shows that the black market where clinics and unqualified doctors practise without a license is persistent in China, especially in rural and suburban areas. ${ }^{13}$ This suggests that at least in some areas, the licensing law for medical practice may be substantially underenforced. Second, the hospital accreditation system has been suspended several times, ${ }^{14}$ which challenges the soundness and effectiveness of hospital accreditation. Third, the Periodical Doctor Assessment (PDA) is primarily a written examination that tests knowledge rather than professional performance and ethics, ${ }^{15}$ which may not be effective in assuring the quality of care. Fourth, Medical Quality-Safety Incidents (MQSI) are considerably under-reported, ${ }^{16}$ which may account for many instances of underenforcement. Fifth, to hospitals that do not care about accreditation, the newly developed regime of regulatory threats does not seem to be effective. ${ }^{17}$

\subsection{THE VICTIM COMPENSATION SYSTEM: INPUT} ANALYSIS

\subsubsection{Liability Rules}

As far as the law in books is concerned, there is great uncertainty over many legal concepts and rules. For example, the standard of care applying to

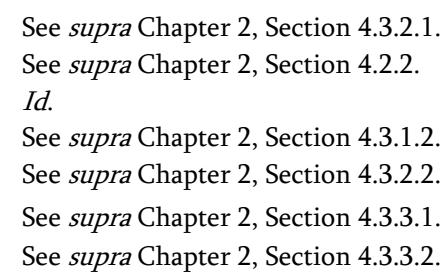


technical malpractice ("then medical standard"), ${ }^{18}$ the one applying to disclosure malpractice, ${ }^{19}$ and causation ${ }^{20}$ have not been defined by the Tort Law 2009, and whether equitable liability will be applicable to medical disputes is uncertain. However, when we turn our gaze from law in books to law in action, we will find that Chinese courts have developed their own approaches to resolving these problems. They interpret the "then medical standard" as a combination of statutory written norms and unwritten customary practices. ${ }^{21}$ They apply the "double-test doctrine" as the standard for information disclosure. ${ }^{22}$ They even apply both proportional liability and the lost chance doctrine to cases where factual causation is highly indeterminate. ${ }^{23}$ They do not widely apply equitable liability to medical dispute cases but seem to restrict it to cases where patients are injured due to substandard blood, but neither the plaintiff nor the defendant is at fault. ${ }^{24}$

Most of the preceding fault-based rules of medical malpractice liability are compatible with principles of corrective justice, except for equitable liability and the "channelling of liability." 25 From the perspective of corrective justice, it is difficult to explain why the defendant-hospital may be held liable in some cases where neither the defendant nor the plaintiff is at fault, and why individual medical staff members should not be held liable jointly and severally even when they are negligent.

\subsubsection{Quantum Rules}

Legal uncertainty over quantum rules that was once considerable has been eliminated by the Tort Law 2009. ${ }^{26}$ Now, article 16 (recoverable heads of pecuniary damages) and article 22 (criteria for non-pecuniary damages) of the Tort Law, together with the JI-Personal Injury 2003 (detailed methods of measuring pecuniary damages) and the JI-Emotional Damage 2001 (detailed criteria for non-pecuniary damages), apply to all kinds of tortious medical cases (and all other personal injury cases) equally.

That being said, quantum rules in China may not be regarded as fair enough for corrective justice. First, compensation for wrongful disability and death is systematically capped by an arbitrary period of 20 years, which is

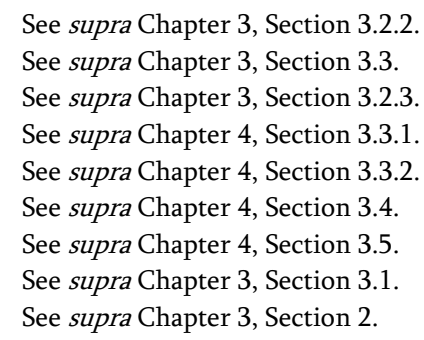


significantly unfair on young victims. ${ }^{27}$ Second, the assessment of nonpecuniary losses should take into account several factors that have nothing to do with emotional distress suffered by victims ${ }^{28}$ and an arbitrary cap of 50,000 yuan has been imposed by the court in practice, ${ }^{29}$ both of which are unfair to victims. Third, a severely disabled patient often receives much more damages than close relatives of a deceased patient. ${ }^{30}$ This may imply that the value of life is lower than the value of health, which may go against many people's feeling of justice. Fourth, the law sets different compensation criteria for rural and urban residents. ${ }^{31}$ This means that even when several victims are injured or killed in the same accident, urban victims may receive higher compensation than rural victims, which may indicate that the value of life or health of urban residents is higher than that of rural residents. ${ }^{32}$

\subsection{THE VICTIM COMPENSATION SYSTEM: OUTPUT ANALYSIS}

\subsubsection{Claims Initiation}

Currently in China, data on the ratio of the number of medical malpractice claims initiated to the total number of negligent AEs are unavailable. Neither could such data be generated from the analysis of court decisions or semistructured interviews. Hence, any discussion on medical malpractice claims initiation in China is highly speculative. What we now know is that only a small proportion (less than 20\%) of medical malpractice claims are resolved through litigation and a large proportion of claims are settled through behind-the-scenes negotiation or people's mediation. ${ }^{33}$ Many of these medical disputes resolved out of court are associated with violent Yi Nao incidents. ${ }^{34}$ It seems that whenever a patient suffers severe injury after treatment, the patient or his/her close relatives will attempt to negotiate with the hospital in

\footnotetext{
$27 \quad$ See supra Chapter 3, Section 3.7.2.3.

28 See supra Chapter 3, Section 3.7.3.2.

29 See supra Chapter 4, Section 3.6.

$30 \quad$ Id.

$31 \quad$ See supra Chapter 3, Section 3.7.2.2.

32 Interestingly art. 17 of the Tort Law 2009 provides that "where the same tort causes the death of several persons, a uniform amount of death compensation may be determined." However, the Tort Law has not specified whether the rural criteria or the urban criteria shall apply. Moreover, art. 17 does not seem useful for victims of medical malpractice, since there is often only one victim involved in a medical malpractice case.

33 See supra Chapter 4, Section 3.8.1.

$34 \quad$ See supra Chapter 1, Section 1.2.2; Chapter 4, Section 3.8.2.
} 
order to obtain some compensation. Hence, in case a medical error is severe or easily identifiable, the rate of claims initiation should not be low.

That being said, many factors may prevent victims of medical malpractice from initiating claims. First, there is the problem of "claims consciousness," because it is sometimes difficult for victimised patients to identify that their injuries are due to medical errors or that they have suffered iatrogenic injuries. ${ }^{35}$ Second, due to the high transaction costs (litigation costs, legal fees, ascertainment fees, or the risks of being punished because of adopting the Yi Nao approach), many victimised patients do not think it worthwhile to initiate claims. Third, part of the victim's losses may well be covered by other collateral sources such as health insurance, pension benefits, and social assistance. ${ }^{36}$

\subsubsection{Claims Disposition}

In general, Chinese courts rely heavily on expert testimony to decide essential issues such as fault, causation, and the scope of liability, since judges as medical laymen cannot conduct peer review and handle scientific issues. The well-organised expert witness system in China may help in guaranteeing the accuracy of the settlement of claims. ${ }^{37}$ However, detailed empirical evidence on the accuracy of claims disposition is currently unavailable.

Nonetheless, several factors may reduce the accuracy of claims disposition and generate more legal uncertainty in China. First, the double tracks of the expert witness system - the MATAS and the JAS ${ }^{38}$ - often lead to inconsistency and contradictions with respect to both fact finding and legal application. Second, since clinical expert witnesses are often high-ranking physicians from high-level hospitals, they may be likely, more often than not, to establish fault when they are reviewing the behaviour of low-ranking physicians or those from low-level hospitals. ${ }^{39}$ Third, more than $80 \%$ of claims are settled out of court, which "are almost certain to contain a significant margin of error." ${ }^{40}$ It is often reported that, when facing $\mathrm{Yi} \mathrm{NaO}$ incidents, hospitals give in and pay some damages not because they are at fault but because they want to restore hospital order as quickly as possible. ${ }^{41}$

Dewees, Duff \& Trebilcock 1996, p. 120.

See generally Chapter 5 .

See supra Chapter 3, Section 3.6.

Id.

See supra Chapter 4, Section 3.2.

Dewees, Duff \& Trebilcock 1996, p. 120.

See supra Chapter 1, Section 1.2.2; Chapter 4, Section 3.8.2. 
Victimised patients normally obtain only one quarter of what they would otherwise obtain in court. ${ }^{42}$

The heavy burden of time on victims is considerable. It normally takes a longer time for victims of medical malpractice than other types of victims to obtain compensation through litigation. ${ }^{43}$ This is unfair on victims of medical malpractice, since "compensation long after the occurrence of the injury is undoubtedly inadequate in terms of making the plaintiff whole again." ${ }^{\prime 4}$ If they want to obtain compensation more quickly, they may choose alternative dispute resolution (ADR). However, they will face another type of unfairness - their claims will be considerably reduced compared to statutory quantum rules.

\subsubsection{Liability Insurance}

Liability insurance may attenuate the "moral significance of the damage award as a vehicle for corrective justice," 45 since liability insurers may represent the defendant throughout the process of dispute resolution and directly pay damages to the patient. Be that as it may, there should be little worry about this issue in China, since medical liability insurance (MLI) is rather under-developed (covering less than 10\% of all hospitals) for the time being. ${ }^{46}$

\section{TENTATIVE CONCLUSIONS AND DISCUSSION}

\subsection{A SUMMARY OF THE DOCTRINAL EVALUATIONS}

From traditional legal perspectives, the current Chinese legal remedies have been evaluated for medical quality assurance and victim compensation. As far as the regulatory medical quality assurance system is concerned, although regulatory standards are largely clear and certain, they may be underenforced for many reasons and unfair to some actors in the medical profession in some cases. When it comes to the input system of victim compensation, although liability rules are largely consistent with principles of corrective

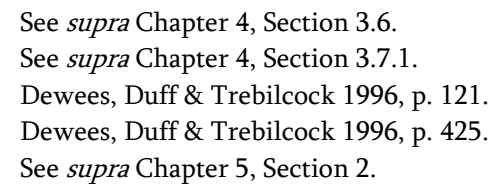


justice, ${ }^{47}$ quantum rules are relatively unfair for several reasons. ${ }^{48}$ Regarding the output of the victim compensation system, liability insurance in China does not seem to attenuate the moral significance of corrective justice. ${ }^{49}$ However, a speculated low rate of claims initiation, ${ }^{50}$ and the actual delays in malpractice litigation ${ }^{51}$ suggest that there may be a wide gap between conceptual purity of corrective justice and actual victim protection in practice.

The preceding doctrinal approach to the analysis of the legal remedies is legitimate insofar as it can help to maintain legal certainty, legal effectiveness, and fairness of legal provisions (esp. fair compensation). The prevalence and popularity of the doctrinal approach in China, however, does not necessarily mean that it is flawless.

This approach suffers from at least two major drawbacks. First, it pays full attention to the values of "fairness" or "justice" while it ignores "efficiency." Of course, the law is closely associated with morality and should reflect socially accepted values. However, the definition of fairness or justice is ambiguous, and it is not the only value that law intends to realise. On the one hand, it is hard to define and compare different types of fairness or justice. To take the damage calculation method as an example: while it is claimed that the concrete method achieves corrective justice, it is also claimed that the standardised method attains social justice or distributive justice. Why is one type of justice more important than another? That the Supreme People's Court prefers social justice to corrective justice when calculating compensation is an unconvincing reason. On the other hand, many other values such as efficiency are also socially desirable. Law is more and more considered to be an instrument that serves to achieve important social goals.

Second, the application scope of the "Legal Methods" is rather limited. The so-called "Legal Methods" are actually the methods of understanding and interpreting legal provisions. They serve more the purpose of maintaining and fixing the existing legal system than innovating new concepts, rules, and institutions. Armed with legal methods, judges may feel more confident in applying the law and deciding cases correctly. However, a scholar may find it difficult to analyse or explain the impact of law on actors' behaviour solely with the help of legal methods. Therefore, an inter-disciplinary approach may

\footnotetext{
$47 \quad$ Equitable liability and the "channelling of liability" contradicts the idea of corrective justice. See supra Section 2.2.1.

$48 \quad$ See supra Section 2.2.2.

$49 \quad$ See supra Section 2.3.3.

$50 \quad$ See supra Section 2.3.1.

$51 \quad$ See supra Section 2.3.2.
} 
be advisable in the sense that it helps lawyers to better understand the interaction between law and society.

\subsection{A CALL FOR LAW AND ECONOMICS}

Medical malpractice incurs heavy costs. Empirical evidence shows that medical disputes are prevalent and have become more and more frequent in China, and more than half of these disputes concern harm caused by medical errors. National data on the costs of medical errors and the costs of prevention are rare.

Nonetheless, we can catch a glimpse of the picture by examining the data from the Gulou District of Nanjing. For all the 416 medical cases with damage awards accepted from 2002 to 2013, the mean award is about 112,000 yuan; the mean court fees for both parties are roughly 4,000 yuan, and attorneys usually charge each side more than 2,500 yuan. Thus, the cost of medical errors in the Gulou District is about 112,000 yuan per case, with an administrative cost of at least 9,000 yuan ${ }^{52}$ per case. These numbers are not low, given that the urban average per capita consumption expenditure in Jiangsu Province from 2002 to 2012 was about 11,000 yuan, and the rural one was only 5,000 yuan. This suggests that the money saved by the avoidance of an adverse event caused by medical malpractice can support a jobless urban resident or two unemployed rural residents for an entire year.

Efficiency entails avoidance or reduction of the costs of medical errors. Tort law aims at protecting victims' rights and interests by means of compensation. Be that as it may, there is no denying that "the best way of victim protection is to avoid victimisation in the first place." 53 This requires a new understanding of the functions of tort law. While many Chinese tort law scholars do mention the deterrent or preventive aspect of tort law, they usually treat deterrence as a by-product and rarely apply an economic analysis. While lawyers give great weight to the compensation function of tort law, economists place more value on the deterrence function. ${ }^{54}$ Interestingly, the deterrence function is already highlighted by article 1 of the Tort Law (2009), which reads "this law has been formulated for the purposes of ... preventing ... tortious acts."

The remainder of the thesis will summarise the economic theories and empirical evidence concerning the prevention of medical errors and victim

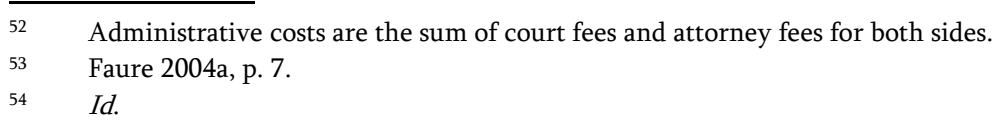


Part I. Legal Remedies for Medical Malpractice in China

compensation and evaluate the Chinese legal remedies from the perspective of law and economics. 
PART II

ECONOMIC THEORIES AND

EMPIRICAL EVIDENCE 



\section{INTRODUCTORY NOTE}

In Part I, it was explained that China has developed various legal remedies for medical malpractice, such as regulation, the medical malpractice liability system, liability insurance, first-party insurance, and social security. However, these legal remedies are far from perfect and many problems such as under-enforcement, under-compensation, and $\mathrm{Yi} \mathrm{NaO}$ incidents arise in practice. The primary goal of this thesis is to conduct an efficiency analysis of the Chinese legal remedies for medical malpractice. In order to be able to answer the second main research question, economic literature will now be examined.

Specifically, Part II will deal with part of the second main question Sub-question (2-a) - How should the legal remedies be structured in order to prevent medical malpractice and compensate victims for iatrogenic injuries efficiently in theory and have these theoretical predictions been tested? This question is approached in the light of Calabresi's analytical framework for the analysis of accident law. According to Calabresi, the primary goal of accident law is to reduce the sum of expected accident costs and the costs of care (primary cost avoidance). The secondary goal is to reduce the social and economic dislocation suffered by victims when the accident nonetheless occurs (secondary cost avoidance). The tertiary goal is to reduce the costs incurred by the legal procedures for resolving disputes (tertiary cost avoidance). In addition to theoretical models, available empirical evidence that is used to test these models is also incorporated.

The primary goal corresponds to the preventive or deterrent function of accident law. Chapter 7 is aimed at explaining how the medical malpractice system could be designed in order to generate ex ante incentives for health care providers to take optimal precautions. Based on empirical evidence from the US, Chapter 8 will answer the question whether the malpractice system can be cost-effective in practice as far as deterrence is concerned. Chapter 9 will explore the desirability of alternative solutions the contractual approach and regulation - in the light of optimal deterrence. In these chapters, the main economic benchmarks are primary cost avoidance and tertiary cost avoidance. Issues of secondary cost avoidance are addressed separately in the following chapters.

The secondary goal corresponds with the compensation function of accident law. Chapter 10 will address the fault-based compensation mechanisms, mainly including tort law and liability insurance. Chapter 11 will discuss the desirability of medical compensation mechanisms not based 
Part II. Economic Theories and Empirical Evidence

on fault liability which consist of first-party insurance, no-fault compensation funds, and social security. When evaluating these compensation mechanisms, not only secondary cost avoidance but also primary and tertiary cost avoidance will be taken into account. 


\section{CHAPTER 7}

\section{PREVENTING MEDICAL ERRORS THROUGH TORT LAW - THEORETICAL MODELS}

\section{INTRODUCTION}

This Chapter is intended to answer the question how to prevent medical errors efficiently through tort law (part of Sub-question (2-a)). Calabresi divided the goal of accident law into three sub-goals: "primary cost avoidance" or prevention (to reduce the frequency and severity of accidents and the costs of precautions); "secondary cost avoidance" or compensation (to reduce the economic dislocation suffered by victims when an accident nonetheless happens; and "tertiary cost avoidance" (to reduce the costs of administering the systems that are intended to reduce primary or secondary costs). ${ }^{1}$ As far as error prevention is concerned, efficiency requires that Calabresi's primary costs should be reduced without incurring too high tertiary costs. ${ }^{2}$ It should also be noted that this chapter will answer the research question from a theoretical point of view. ${ }^{3}$

This Chapter will begin with a brief introduction to the economic model of tort law (Section 2). Since China adopts fault-based tort liability to deal with medical malpractice issues, particular attention will be paid to the economic model under negligence. In Section 3, the basic economic model of the negligence rule will be applied to medical malpractice issues, discussing how the malpractice system (incl. the standard of care, causation, rules of

1 Calabresi 1970, pp. 26-31. For critical reviews of Calabresi's theoretical framework, see e.g. Posner 1970; 2005.

2 For issues of secondary cost avoidance (compensation) through liability insurance and nofault compensation schemes their impact on tort liability, see infra Chapter 10 and Chapter 11 respectively.

3 For empirical evidence concerning whether tort law is effective at reducing medical errors efficiently, see infra Chapter 8. For alternative regimes aimed at error prevention, see infra Chapter 9. 
evidence, the law of damages, and dispute resolution) should be designed so that both primary and tertiary accident costs could be minimised. The final Section 4 concludes.

\section{THE CLASSIC MODEL OF TORT LAW ${ }^{4}$}

\subsection{INTRODUCTION}

The classic accident models of tort law attempt to explain how to minimise Calabresi's primary accident costs. ${ }^{5}$ Calabresi took it "as axiomatic that the principal function of accident law is to reduce the sum of the costs of accidents and the costs of avoiding accidents." ${ }^{\prime \prime}$ Later, Brown developed a unified economic model of liability which takes into account the care taking of the injurer and the victim simultaneously. ${ }^{7}$ In contrast, Shavell made a clear distinction between unilateral accidents (where only the injurer can affect accident risk) and bilateral accidents (where both the injurer and the victim can contribute to the occurrence of an accident) and analyses them separately. ${ }^{8}$ Moreover, Shavell took into account two kinds of decisions that may affect accident risk - care levels and activity levels. Injurers and victims have to decide not only "the degree of care to exercise when engaging in an activity" (care levels) but also "whether, or how much, to engage in a particular activity" (activity levels). ${ }^{9}$

For the sake of simplicity, this begins with the simplest model where the injurer and the victim did not know each other before the accident (accidents between strangers) ${ }^{10}$ and only the injurer can affect the accident risk (unilateral accidents). ${ }^{11}$ Also, it is further assumed that parties are risk

\footnotetext{
I have already described the classic model of tort law elsewhere, see generally Yu 2016

Faure 2004a, pp. 7-8.

Calabresi 1970, p. 24.

See generally Brown 1973.

See generally Shavell 1980. See also Shavell 1987a, pp. 4-46.

Id.

Although there is a contractual relationship between health care providers and patients before any adverse event occurs, parties in practice are not allowed to either waive tort liability or change the content of tort liability by mutual agreements. Also, the prevalence of considerable information asymmetry between health care providers and patients often renders regulating medical malpractice through contractual liability undesirable. See generally e.g. Calabresi 1978; Arlen 2006; Baker \& Lytton 2010.

11 In the literature, medical errors are normally treated as unilateral accidents for it is assumed that only health care providers can affect medical malpractice risks. See generally e.g. Shavell 1978; Boccara 2009; Van Velthoven \& Van Wijck 2012. Of course, there are
} 
neutral, ${ }^{12}$ that there is a lack of regulation and insurance, that injurers are solvent enough to pay full compensation, and that there are no litigation costs..$^{13}$ Moreover, because in practice medical malpractice liability in China is primarily fault-based, only the model of the negligence rule in Section 2.2. will be presented. Nevertheless, the main theoretical findings concerning strict liability will be briefly mentioned where it is necessary. In Section 2.3, the tertiary goal of accident cost avoidance will be addressed. ${ }^{14}$

some exceptions to this assumption. For example, if the patient did not take medication as her doctor advised and suffered an injury as a result, her own carelessness obviously contributed to her injury. However, these are relatively rare cases in practice relevant to medical errors committed by physicians. Hence, the unilateral-accident assumption is valid in most of the cases.

12 Risk-neutral as well as risk-averse and risk-loving are the three categories of risk attitudes. However, before explaining risk attitudes, it is essential to introduce the notions of a random variable and the expected value in the first place. A random variable is "a numerical measurement of the outcome of a random phenomenon." Agresti \& Franklin 2013, p. 265. For example, the harm of an accident is a random with two possible values: either $\mathrm{H}$ (if the accident does occur) or 0 (if no accident occurs). Suppose also that the probability of the accident is $\mathrm{P}$, and thus the probability of no accident is $(1-\mathrm{P})$. Then, the expected value of the harm of the accident (hereinafter the expected accident harm) is defined as the weighted average of the harm in the long run, i.e. $\mathrm{P}^{*} \mathrm{H}+(1-\mathrm{P})^{*} 0$, which is simply $P^{*}$ H. Agresti \& Franklin 2013, p. 269. Then, let us define risk-neutral by making reference to risk-averse and risk-loving. An individual is risk-averse if $s /$ he prefers a certain harm $M$ to a risky prospect of an uncertain harm $M$ (expected value $=P^{*} H=M$ ) with a high magnitude $(\mathrm{H})$ and a low probability $(\mathrm{P})$, where $\mathrm{H}$ will far exceed $\mathrm{M}$ if $\mathrm{P}$ is extremely low. In contrast, $\mathrm{s} / \mathrm{he}$ is risk-loving if $\mathrm{s} / \mathrm{he}$ prefers the risky prospect of an uncertain harm $\mathrm{M}$ (expected value $=\mathrm{P}^{*} \mathrm{H}=\mathrm{M}$ ) to a certain harm $\mathrm{M}$. A risk-neutral individual is indifferent between a risky prospect of an uncertain harm $\mathrm{M}$ and a certain harm. Black, Hashimzade \& Myles 2012, pp. 366-367. Therefore, the significance of the risk-neutral assumption is that it allows us to determine the prospect of accident costs in terms of expected values before any accident occurs.

13 Cooter \& Ulen 2012, p. 230. These assumptions, of course, may not be all valid in practice: Health care providers may be risk averse; the health care system may be heavily regulated by the state; a well-functioning medical malpractice insurance may have already been developed; individual physicians, especially young ones, may not have enough personal assets to pay damages; and patients may be discouraged from filing malpractice claims because of prohibitive litigation costs. The effects of relaxing these assumptions are already thoroughly examined by economists as well. See generally e.g. Schäfer \& Müller-Langer, 2009. The relaxation of these assumptions will be addressed in the remaining Sections in this Chapter and later Chapters.

14 As mentioned before, secondary cost avoidance (compensation) and its impact on primary cost avoidance (prevention), together with tertiary cost avoidance, will be discussed in Chapter 10 and Chapter 11. 
Part II. Economic Theories and Empirical Evidence

\subsection{THE MODEL OF PRIMARY ACCIDENT COST}

\section{AVOIDANCE}

As mentioned above, the first goal of tort law is to minimise total primary accident costs, which amount to the sum of the cost of care and the expected accident losses. The levels of activity are assumed to be constant. Then, the (expected) total accident costs can be mathematically presented as follows:

$\mathrm{T}(\mathrm{x})=\mathrm{C}(\mathrm{x})+\mathrm{p}(\mathrm{x}) \mathrm{H}($ Expression 1$)$,

where " $\mathrm{x}$ " denotes the level of care - how much time and effort spent; " $\mathrm{C}(\mathrm{x})$ " the cost of care - monetary value of the time and effort spent - when the injurer chooses to take $\mathrm{x}$ units of care, which is an increasing function; " $\mathrm{p}(\mathrm{x})$ " the probability of the accident when the injurer chooses to take $\mathrm{x}$ units of care, which is a decreasing function because more care will reduce the probability of the accident; " $\mathrm{H}$ " the magnitude of harm; " $\mathrm{p}(\mathrm{x}) \mathrm{H}$ " the expected accident cost; and " $\mathrm{T}(\mathrm{x})$ " the (expected) total primary accident costs before any accident occurs. $\mathrm{T}(\mathrm{x})$ can be illustrated in Figure 7.1.

Figure 7.1: The Optimal Level of Care ${ }^{15}$

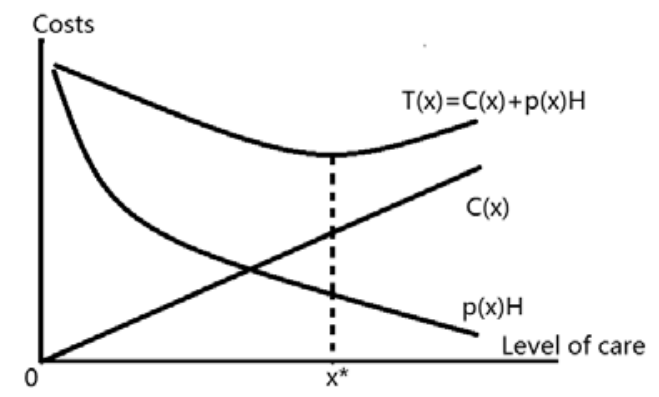

Intuitively, the curve of $\mathrm{T}(\mathrm{x})$ is $\mathrm{U}$-shaped, suggesting there is a minimum at the bottom of the U. ${ }^{16}$ The level of care that corresponds to this minimum is denoted as $\mathrm{x}^{*}$. This $\mathrm{x}^{*}$ is frequently referred to as the socially efficient level of precaution or the optimal level of care. ${ }^{17} \mathrm{~A}$ level of care higher or lower than $\mathrm{x}^{*}$ is socially undesirable. On the one hand, if the injurer took too little care (below $\mathrm{x}^{*}$ ), too many accidents would be caused and scarce social resources

Figure 7.1 is modelled on Cooter \& Ulen 2012, p. 200, Figure 6.3.

Cooter \& Ulen 2012, p. 200.

Shavell 1987a, p. 34; Cooter \& Ulen 2012, p. 201. 
would be wasted. On the other hand, the highest level of care (well past $x^{*}$ ) could surely prevent an accident from happening; however, more scarce resources would be spoiled, since taking one more unit of care will incur greater costs than the reduced expected accident costs. ${ }^{18}$

Under the model of the negligence rule, given that causation can be easily established in the absence of causal uncertainty, injurers will be held liable only when they fail to exercise due care $(\tilde{x})$. Under the assumption that the court correctly sets due care equal to the socially optimal level of care $\left(\tilde{x}=\mathrm{x}^{*}\right),{ }^{19}$ and also that the court sets the magnitude of compensatory liability (L) equal to the actual harm $(\mathrm{H})$, then the total primary accident costs faced by a potential injurer is a piecewise function expressed as follows:

$$
T(x)=\left\{\begin{array}{c}
C(x)+p(x) L, \text { if } x<\tilde{x} \\
C(x), \text { if } x \geq \tilde{x}
\end{array}, \text { where } \tilde{x}=x^{*} \text { and } L=H \text { (Expression } 2\right)
$$

Graphically, $\mathrm{T}(\mathrm{x})$ can be expressed in Figure 7.2 as follows:

Figure 7.2: The Total Primary Accident Costs Faced by Injurers under Negligence ${ }^{20}$

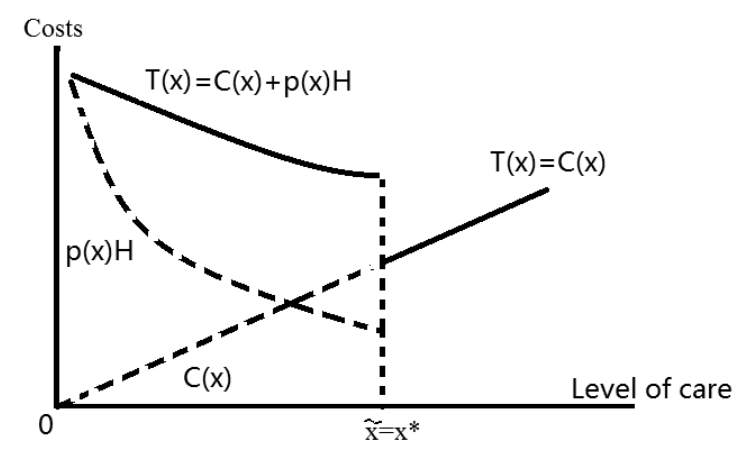

The solid line in Figure 7.2 suggests that the minimum of the total primary accident costs faced by the injurer occurs exactly where the injurer exercises due care, no more and no less! Consequently, the negligence rule is efficient, because it is able to induce the potential injurer to exercise just the optimal

$18 \quad$ Faure 2004a, p. 8.

19 Due care, also termed reasonable care, ordinary care, adequate care or proper care, as a test for negligence, is "the degree of care that a prudent and competent person engaged in the same line of business or endeavour would exercise under similar circumstances." Garner 2014. The legal notion of due care is not necessarily identical with the economic notion of the optimal level of care $\mathrm{x}^{*}$. However, it would be social desirable if the court set due care equal to $\mathrm{x}^{*}$ in order to economise on the total accident costs.

$20 \quad$ Figure 7.2 is modelled on Van Velthoven \& Van Wijck 2012, p. 32, Figure 2. 
level of care ex ante. Strict liability is as efficient as the negligence rule as far as care levels are concerned. Under strict liability injurers will be induced to choose the socially optimal level of care as well, since total primary accident costs will become their own costs once causation is established. ${ }^{21}$

Be that as it may, the negligence rule has its limitations when it comes to activity levels. Under negligence, injurers will not bear accident costs if they exercise due care. Hence, they will continually engage in their activity until they cannot obtain any extra utility,,$^{22}$ which would not be socially desirable if their activity were so inherently risky that they might generate considerable negative externalities. Strict liability is still efficient even if activity levels are taken into account, because injurers are obliged to internalise all total accident costs. ${ }^{23}$ Hence, they will attempt to minimise total primary accident costs by choosing an appropriate level of activities. ${ }^{24}$

\subsection{TERTIARY COST AVOIDANCE}

Tertiary costs, also termed administrative costs, are "costs of administering our treatment of accidents." ${ }^{25}$ Specifically, administrative costs include "the time and effort spent by injurers, victims, and their legal counsel and insurers in coming to settlements and in litigation, as well as the publicly incurred operating expenses of the courts." ${ }^{26}$ One of the unique features of Calabresi's analytical framework is the idea that accidents should not be avoided without giving any thought to tertiary costs. Hence, the goal of tertiary cost avoidance serves as "a kind of general balance wheel to the cost reduction goal." ${ }^{\text {27 }}$

Shavell 1987a, p. 8.

Shavell 1987a, pp. 22-25.

Shavell 1987a, p. 23.

Id.

Calabresi 1970, p. 28.

Shavell 1987a, p. 262

Calabresi 1970, p. 28. 


\section{APPLYING THE CLASSIC MODEL TO MEDICAL MALPRACTICE}

\subsection{INTRODUCTION}

The traditional economic analysis of medical malpractice is largely based on the foregoing classic accident model of the negligence rule..$^{28}$ This theoretical choice is consistent with judicial practice in most of the legal systems, including China, the US, Germany, France, the UK, etc. ${ }^{29}$ According to the model, iatrogenic injuries are caused by health care providers' treatment unilaterally. It is important to provide health care providers with incentives to conduct the optimal treatment that minimises total primary accident costs - the costs of care and expected accident losses. Leaving aside liability, health care providers only bear the costs of care but do not bear expected accident losses. In an attempt to maximise their own expected welfare, providers will exercise too little care and engage too much in their activities.

Tort liability, ${ }^{30}$ especially the negligence rule as applied in many legal systems, may be needed to induce providers to take into account expected accident losses and exercise the optimal treatment. In a well-functioning medical malpractice system, providers will only be held liable for negligent iatrogenic injuries if they fail to exercise due care that is assumed to be equal to the optimal level of care. Providers are presumed to bear the costs of treatment and know the costs and benefits of care and always comply with due care. ${ }^{31}$ Legal standards and quantum rules are optimally set and tertiary costs are negligible. ${ }^{32}$ Hence, under the classic model, the malpractice system can eliminate negligence and prevent all negligent iatrogenic injuries because fully informed providers will always choose to exercise due care (optimal treatment). ${ }^{33}$ Under the US law, for instance, if a provider deviates from the

$28 \quad$ See generally Arlen 2013; 2014. For a more detailed normative comparison and contrast between negligence and strict liability, see generally e.g. Faure 2004a; Sher 2007; Schäfer \& Müller-Langer 2009.

$29 \quad$ See generally Oliphant \& Wright 2013.

30 In some legal systems such as Germany and the Netherlands, malpractice liability is mainly based on contract law. However, this contract-based malpractice liability does not seem to differ significantly from tort-based malpractice liability. Hence, the economic model of tort law also applies to contract-based malpractice liability. See e.g. Hondius 2010a, pp. 134-144; Stauch 2013, p. 184.

31 See generally Shavell 1980.

32 Id.

$33 \quad$ Arlen 2013, p. 34. 
optimal treatment, he/she must do so "deliberately," which may trigger punitive damages. ${ }^{34}$

The presence of medical malpractice lawsuits in practice suggests that the ideal negligence-based malpractice model must be fraught with difficulties and frustration in practice. It should be noted that the model is based on a set of assumptions, including, inter alia, perfect information on safety and quality assurance, properly assessed damages, and the absence of insurance, regulation and tertiary costs. ${ }^{35}$ Many unique features of health care services may also detail the model or challenge the underlying assumptions of the model. ${ }^{36}$

In the remaining part of this Chapter (and subsequent Chapters), we will see how the health care provider's incentives are affected when these assumptions are relaxed. Section 3.2 will point out three distinguishing features of health care services. These features may not only affect the classic model of the negligence rule (discussed in this Chapter), but also may have implications for alternative regimes such as contractual waiver or variation of the statutory standard of care, safety regulation, liability insurance, etc. (discussed in subsequent Chapters). Section 3.3 to Section 3.7 will address how malpractice sub-rules (standard of care, causation, proof issues, ${ }^{37}$ and damages rules) and dispute resolution procedures should be designed in order to minimise primary and tertiary costs.

34 In the US common law, punitive damages refer to those "awarded in addition to actual damages when the defendant acted with recklessness, malice, or deceit." Garner 2014. It seems that punitive damages are applicable to a broad category of tort cases in the US. In China, however, punitive damages are only applicable to some product liability cases in light of art. 47 of the Tort Law 2009 (China). Medical malpractice claims do not apply punitive damages.

35 See Van Velthoven \& Van Wijck 2012, pp. 28-29.

$36 \quad$ Id

37 Although proof rules or rules of evidence lie beyond the scope of tort law, they play a significant role in the establishment of the elements of malpractice liability in court. As demonstrated later, not only substantive elements but also evidentiary issues can affect the primary goal of injury prevention. 


\subsection{FEATURES OF HEALTH CARE SERVICES AND THE CHOICE BETWEEN NEGLIGENCE AND STRICT LIABILITY}

\subsubsection{Product Uncertainty}

Health care services are provided to patients in order to cure their illnesses or injuries. However, the efficacy of a drug or a treatment is highly uncertain in many cases. "Recovery from disease is as unpredictable as is its incidence." 38 One physician gave an example as follows:

If I give penicillin to a patient with a strep throat, one or more of several things may occur: The patient may improve, which we all want to happen; the patient may develop an allergic reaction to penicillin; diarrhoea may occur after a few days; or nothing at all may change with the pharyngitis persisting. ${ }^{39}$

It is often hard to foretell because the pathogenesis of a disease can sometimes be fairly complicated, and in severe cases physicians may be extremely inexperienced in making appropriate diagnoses or treatment decisions. ${ }^{40}$ The possibility of "learning from one's own experience or that of others" in the medical profession is faint due to a lack of "an adequate number of trials." The same treatment measure may in some cases result in diverse effects owing to the idiosyncrasies of different patients. Thus, to physicians, "medical uncertainty is part of daily practice." ${ }^{42}$

On account of considerable uncertainty over therapeutic effects, the quality of medical care is normally measured by the performance rather than the result. That is to say, the contractual obligation that physicians owe to patients is an obligation of means instead of an obligation of results unless it is otherwise specified in the medical service contract. Whether this obligation of means is fulfilled or not should be assessed against the same due care standard under tort law (assuming the court sets due care equal to the efficient level of care) unless otherwise indicated.

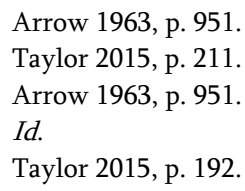




\subsubsection{Information Asymmetry}

An evident characteristic of the physician-patient relationship is sharp differences between professionals and laymen in medical knowledge. While health care providers are medical professionals who have received years of medical education and training, most patients are laymen in medicine. Patients normally do not know the actual quality of medical care before going to hospital. In respect of this feature, medical services fall into the category of "experience goods" rather than "search goods." ${ }^{43}$ In general, the quality of experience goods can only be known after the purchase.

However, medical services are so special that even after being treated patients may still do not know whether they have received the appropriate quality of care. In practice, it is sometimes seen that well-administered treatment cannot prevent the deterioration of the patient's serious disease whereas poorly-performed treatment does not lead to any adverse events. For this reason, the quality of medical care is usually assessed in the light of highly technical standards, ${ }^{44}$ which is beyond the capacity of most patients. Hence, medical customers generally have no information in relation to accident risks. ${ }^{45}$

The imperfect information problem may be relieved by wellperformed regulation on information disclosure. ${ }^{46}$ However, medical knowledge is so complicated and the quality of care is so uncertain that most patients often do not know how to appreciate the safety of medical care or malpractice risks even when they are fully informed. Put another way, the imperfect information problem is caused by huge differences between physicians and patients in medical knowledge and aggravated by considerable uncertainty over the quality of medical care. Consequently, patients have to purchase medical services on the basis of their confidence placed in medical professionals rather than their self-assessment of the quality of care. This explains why medical services can also be regarded as a type of "confidence goods." ${ }^{47}$

\subsubsection{Externalities}

The classic accident model assumes that the injurer's activity only generates negative externalities to victims. Negative externalities, also termed external

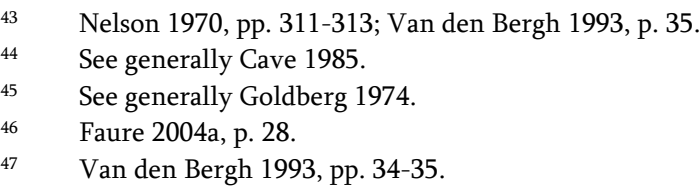


costs, are the costs of the exchange imposed on third parties involuntarily. ${ }^{48}$ In the health care sector, negative externalities normally include: ${ }^{49}$

- infectious disease: untreated infectious disease will lead to higher population vulnerability to that disease on account of increased exposure;

- environmental degradation: health care generates a great deal of chemical waste and emissions (ambulances, etc.), and, more critically, alters the natural ecological environment of bacteria;

- $\quad$ antibiotic resistance: growing resistance to antibiotics of bacteria will reduce medical solutions available to others.

When taking these negative externalities into account, strict liability seems more efficient than the negligence rule, since the lower the activity levels, the fewer the external costs.

However, it is not surprising that many activities do not only generate negative externalities, but produce positive externalities as well..$^{50}$ Positive externalities, also called external benefits, are the benefits of an exchange that spill over onto third parties. ${ }^{51}$ Apart from creating negligent externalities, the health care market generates huge positive externalities to society in general, such as: ${ }^{2}$

- increasing wealth: providing healthier and more productive workers who create positive economic gains;

- technology and information: increasing medical knowledge and the technological capacity of society;

- vaccinations: herd immunity reducing the likelihood of contracting certain infectious diseases

Both negative and positive externalities should be internalised to prevent a market failure. $^{53}$

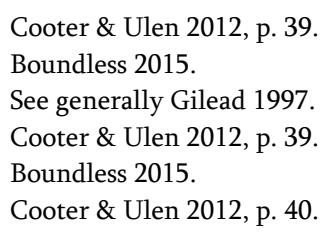


Part II. Economic Theories and Empirical Evidence

\subsubsection{Negligence versus Strict Liability}

When only the care level is taken into account, the classic model of tort law predicts that both negligence and strict liability are efficient. However, when it comes to both the care level and the activity level, strict liability appears more efficient than negligence since only the former will induce potential tortfeasors to engage in their activities at the socially optimal level. ${ }^{54}$ Information asymmetry between health care providers and patients (and judges) may also constitute an argument in favour of strict liability. ${ }^{55}$ In practice, customary practices and regulatory standards may be relied on to relieve the problem of information asymmetry. ${ }^{56}$

Also, there are several arguments against strict liability. First, insolvent tortfeasors will be under-deterred under strict liability whereas they will still be deterred under negligence because they will have to pay if they do not take optimal care and the cost of care taking is often lower than their total assets. ${ }^{57}$ Second, since the health care industry generates huge positive externalities, we should be very cautious about limiting activity levels by imposing strict liability on health care providers. ${ }^{58}$ Third, strict liability will impose on health care providers some costs of non-negligent iatrogenic injuries or even non-iatrogenic injuries due to considerable uncertainty over causation..$^{59}$ This is "over-internalisation" rather than "full internalization." Physicians may respond to this expansion of the scope of liability by practising negative defensive medicine - reducing activity levels (e.g. refusing to admit patients with potentially severe conditions or refraining from conducting experimental or innovative treatment measures).$^{60}$ Fourth, some

\footnotetext{
$54 \quad$ See supra Section 2.

Faure 2004a, p. 15.

See supra Section 3.3.3.

Faure 2004a, pp. 15-16.

See supra Section 3.2.3; Faure 2004a, pp. 16-17.

Yang, J. 2013, pp. 52-53.

See supra Section 3.3.3, infra Section 3.6.4. See also Wang 2006, p. 132. However, Weiler et al. held an opposite view and argued only strict liability is able to promote patientsafety investments. They maintained that the above argument against strict liability is a "fallacy" because of its "static perspective" on the malpractice issue. Their central reasoning is that medical knowledge and techniques are evolving so rapidly that many iatrogenic injuries "that were considered unavoidable but acceptable risks at one time become readily avoidable and unacceptable just a few years later." Therefore, imposing strict liability on providers would give them continual incentives to "invest in research and innovation in safer medical techniques." Weiler et al. 1993, pp. 148-149. Be that as it may, the fault-based enterprise medical liability (EML) may also be able to induce providers to invest in patient safety continually. See infra Chapter 8, Section 3.2.2. The standard of care is also improving because of advances in medical science and technology.
} 
even argued that negligence is abler than strict liability to convey the required information to the market, because it induces both parties to seek and gather relevant information in order to win the case. ${ }^{61}$ Such information is invaluable to the market in that it will focus on "disclosing the hidden actions and qualities" of health care providers. ${ }^{62}$

After weighing up all these pros and cons of the two types of liability rules, it is highly likely that the negligence rule is fitter than strict liability for quality assurance in the health care sector.

\subsection{THE STANDARD OF CARE}

\subsubsection{The Learned Hand Rule}

With respect to the standard of care, the traditional criterion for determining negligence in the US, i.e. the Learned Hand Rule ${ }^{63}$ can be used to induce health care providers to make cost-justified investments in the avoidance of iatrogenic injuries. ${ }^{64}$ According to Judge Learned Hand, an injurer would be found negligent if the product of the probability of an accident $(\mathrm{P})$ and the gravity of the accident (L) were larger than the burden of adequate precaution (B), i.e. $\mathrm{B}<\mathrm{PL}$. Brown compared costs and benefits at the margin and derived from Judge Hand's formulation the Incremental Standard, ${ }^{65}$ which is exactly equivalent to the social cost minimization solution as demonstrated in Section 2.2. Therefore, applying the Learned Hand Rule to the determination of due care in a malpractice setting should in theory generate efficient outcomes in terms of deterrence.

In accordance with the Learned Hand Rule, the standard of due care varies with the capability of each injurer. The lower the costs of taking care which injurers bear, the higher the socially optimal level of care they have to live up to. ${ }^{66}$ Therefore, "blindness, lameness, or infirmity" may lower the standard of care while "strength, size, special knowledge, or professional skill" may increase it. ${ }^{67}$ If it is not difficult for courts to determine the varying costs of care taking among parties of the same group, i.e. tertiary costs are minimal,

If providers do not fear to conduct experimental or innovative treatment measures, they may make more rapid progress in developing safer medical techniques.

61 See generally Sher 2007.

62 Id.

63 U.S. v. Carroll Towing Co., 159 F. 2d 169, 173 (2d Cir. 1947).

64 See Schwartz \& Komesar 1978, pp. 1282-1283.

65 See generally Brown 1973.

66 Shavell 1987a, pp. 73-74.

67 Shavell 1987a, pp. 75-76. 
courts should set up the standard of due care individually. ${ }^{68}$ As far as medical malpractice is concerned, the costs of differentiating medical professionals who have superior knowledge from laymen are minimal. Hence, the benefits of classification in this case may greatly exceed the costs of classification. ${ }^{69} \mathrm{It}$ is socially optimal to impose a higher level of due care on health care providers than on ordinary citizens. By the same token, in case of an emergency, the standard of due care should be lowered accordingly, due to increased costs of care.

The other way around, if differentiation of the standard of care is very costly, i.e. tertiary costs are prohibitive, courts should employ a uniform level of due care as the standard for establishing negligence on the part of the parties of the same group. ${ }^{70}$ In many legal systems, a bonus pater familias or reasonable man criterion for the determination of negligence is adopted. ${ }^{71}$ The optimal uniform level of due care is argued to be the "individually optimal level of care for some 'representative' individual" within the parties of the same group. ${ }^{72}$ This reasonable-person standard may be able to reduce administrative costs significantly and deter the inept from engaging in activities. $^{73}$

\subsubsection{Prior Precautions and Competence}

Another relevant topic is prior precautions. Many prior precautions, such as obtaining information about risk, investing in the expertise needed to properly conduct treatment and maintaining medical equipment, affect health care providers' ability to take care when they are treating specific patients later. If the costs of prior precaution are sufficiently low, and if the reduction in total accident costs, because of the prior precaution, is sufficiently high, it will be socially optimal to employ a prior precaution..$^{74}$ In the event that the standard of due medical care also entails that health care providers should take optimal prior precautions, providers will be induced both to take optimal prior precautions and to exercise optimal care when engaging in their activity. ${ }^{75}$ Otherwise, they will find it extremely costly or impossible to exercise optimal care without taking prior precautions. ${ }^{76}$

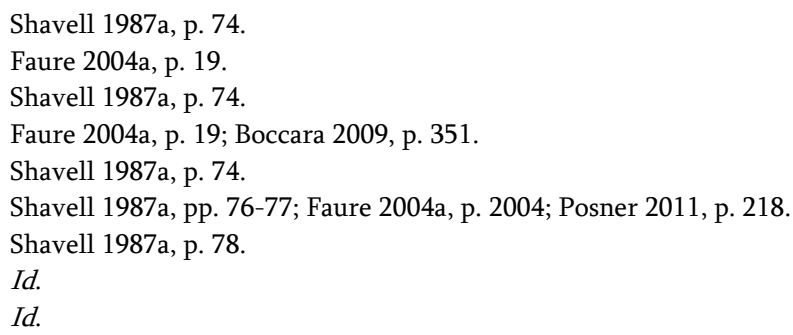


One significant dimension of prior precautions is investment in professional competence. In the health care sector, competence denotes "the skill and knowledge of a physician, reflecting both his training and his native ability," whereas care only refers to "the effort and time" spent by a physician of given competence providing treatment. ${ }^{77}$ It is generally presumed that a qualified physician has sufficient competence to provide appropriate treatment. If a physician under-invests considerably in medical expertise, he/she will be considered a "bad apple" who does not care about patient welfare. ${ }^{78}$

Both regulation and liability can be used to eliminate these "bad apples." On the one hand, educational standards and tests for licensing are crucial measures to screen "bad apples" out. ${ }^{79}$ However, to update skills and knowledge regularly is critical to the maintenance and improvement of competence. This underscores the importance of regulation via a continuous re-appraisal of expertise. "Bad apples" should be identified and forbidden from engaging in certain or all activities. ${ }^{80}$ On the other hand, incentives generated by liability affect not only care but competence as well. Since "bad apples" are prone to commit medical errors, malpractice liability tends to improve competence in two ways: (a) physicians, if possible, may be highly motivated to acquire new skills and knowledge in order to decrease the likelihood of committing medical errors; or (b) they may choose to withdraw from practising certain fields of medicine altogether, if they are dubious about their capability. ${ }^{81}$

The choice between regulation and liability ${ }^{82}$ should be based on the actual causes of medical errors. If most errors are committed by sufficiently competent but careless physicians, stricter incentives via liability rather than regulation are clearly more warranted. If, the other way around, the majority of errors are due to the incompetence of a small group of "bad apples," stricter regulation (e.g. licensing) may be more desirable than liability.

\subsubsection{Uncertainty over the Standard of Care}

The deterrent effect of malpractice liability can be influenced by uncertainty over the standard of care. Setting due care equal to the efficient level of care

Shavell 1978, p. 44.

See generally Berwick 1989a.

Shavell 1978, p. 44.

Arlen 2014, p. 19.

Shavell 1978, p. 45.

For a more detailed comparison and contrast between liability and regulation, see infra Chapter 9. 
in practice is easier said than done. Due to a lack of perfect information concerning the costs and benefits of injury prevention, ${ }^{83}$ it is very difficult for courts, even for medical experts, to determine the optimal level of care with certainty ${ }^{84}$ If due care falls short of the efficient level of care, the problem of too many or too severe iatrogenic injuries will occur (under-deterrence). Conversely, if it is higher than the efficient level, the outcome is inefficient as well for more care is taken and scarce resources are wasted (over-deterrence). However, if due care is set so high that it is akin to strict liability, providers will simply choose the optimal level of care as it would be under strict liability.

Moreover, even if there were no error in setting the due care, there could be a related error that courts might assess health care providers' true levels of care wrongly due to imperfect information. First, in cases where courts systematically err in finding a party's negligence when in fact he/she has exercised due care, he/she will take socially excessive levels of care in order to reduce his chance of being found negligent by mistake. ${ }^{85}$ Second, if courts systematically err in exonerating a party from liability when in fact he/she has not exercised due care, he/she may take less care than the optimal level. ${ }^{86}$ Third, even where the likelihood of courts' overestimating care is the same with that of courts' underestimating care, i.e. the uncertainty is normally distributed about the efficient level of care, parties may still be induced to take more care than the optimal level of due care. This is because "raising the level of care reduces the chances of being found negligent by mistake." ${ }^{\prime 87}$ Fourth, since health care providers are not legal experts, they normally do not know with certainty what standard of care will be applied by courts in a single case. ${ }^{88}$ Neither can they anticipate the distribution of this uncertainty. Hence, it's more than likely that health care providers will react to the uncertainty by over-complying. ${ }^{89}$ As a result, the problem of defensive medicine will arise. ${ }^{90}$

This problem of legal uncertainty is largely caused by the fact that courts usually do not have perfect information in relation to medical malpractice risks. Since this kind of information is normally assumed to be possessed by medical professionals, this may constitute an argument in favour

See supra Section 3.2.2.

Van Velthoven \& Van Wijck 2012, pp. 32-33.

Craswell \& Calfee 1986, p. 280; Shavell 1987a, pp. 79-80.

Id.

Shavell 1987a, pp. 80-81.

Van Velthoven \& Van Wijck 2012, p. 33.

Van Velthoven \& Van Wijck 2012, p. 34.

See infra Chapter 8 . For the economics of defensive behaviour in the context of liability of public bodies, see generally De Mot \& Faure 2016. 
of strict liability for medical malpractice ${ }^{91}$ In the US, the traditional way to overcome this problem is by deferring to medical customary practice. ${ }^{92}$ Specifically, a physician's duty of care owed to his patients "requires him only to comply with customary standards of the medical profession in the area and speciality in which the doctor is practising." ${ }^{93}$ Posner argued that recognising compliance with custom as a defence to malpractice is efficient, since patients are the physicians' customers who are willing to pay higher prices for optimal treatment. ${ }^{94}$ Dewees, Duff and Trebilcock refuted Posner's argument on two grounds: ${ }^{95}$ on the one hand, some customary standards might fall beneath the optimum level due to severe information asymmetry between health care providers and patients; on the other hand, widespread health insurance coverage might induce inefficiently excessive treatment. ${ }^{96}$ Overall, this may make some customary standards exceedingly higher than the optimum. Hence, they argued that compliance with customary standards may not necessarily lead to efficient outcomes. Empirical evidence shows that in recent years most legal systems, even including many states in the US, tend to adopt the reasonable-person standard of care instead of medical custom. ${ }^{97}$

\subsubsection{The Impact of Regulation}

The classic model assumes that liability rules are sufficient to induce optimal incentives to prevent accidents and that other regulatory measures are not needed. However, it is well-known that professional standards in the health care sector are often defined by safety regulations in the form of "rules."98 These "rules" are usually set by the public health authorities (public regulation) or by professional organisations (private regulation). These regulators are assumed to have an information advantage over the court they have better information regarding patient safety and the quality of care than does the court. If the court can derive enough information regarding the optimal level of care from public or professional regulations and set due care properly, then court decisions on the basis of this information will "find their way into precedents and commentaries." ${ }^{\text {"9 }}$ Eventually, these decisions on

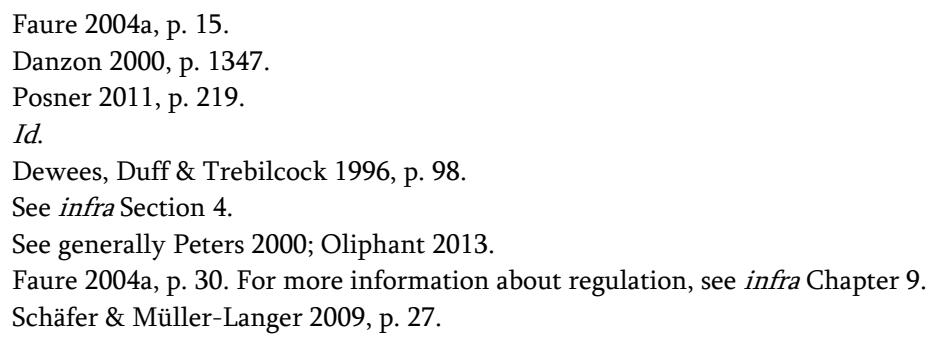


optimal medical safety technology will become public information that is also available to health care providers with inferior information.

Then, a big question which needs to be answered is what the relationship between safety regulations and due medical care should be for the sake of efficiency. ${ }^{100}$ Specifically, there are two sub-questions: Should a violation of the regulatory standard automatically result in a finding of negligence? Moreover, should compliance with the regulatory standard automatically exclude a finding of negligence?

Shavell gave a negative answer to the first question. ${ }^{101} \mathrm{He}$ argues that if failure to meet a regulatory standard automatically established negligence, then some injurers, who incur higher than usual costs of care or pose lower risks than usual, would be forced to comply with the standard even if it is inefficient for them to do so. ${ }^{102}$ However, Faure refused to apply this argument to medical malpractice without qualifications. ${ }^{103}$ After drawing an analogy between the regulatory standard and the bonus pater familias standard of care, Faure concludes that a single regulatory standard can be justified because it is extremely expensive for regulators to identify atypical injurers who must incur higher than normal costs of care. ${ }^{104}$ It is vital to note that medical professional standards, be it set by the public health authorities or professional organisations, are based on, or heavily influenced by, practices and opinions common to the medical profession. Therefore, these regulatory standards will "in most cases only be minimum levels of care." 105 Hence, as a rule, a violation of the regulatory standard should automatically establish negligence. The only exception to this rule can be made when it is not too costly for judges to identify an atypical injurer who will incur higher than normal costs to comply with a regulatory standard. ${ }^{106}$ For instance, in a lifethreatening emergent case, the standard of care required of a doctor may be reasonably lowered relative to a normal situation.

In relation to the second question, the opposite is not true: as a general rule, compliance with the regulatory standard should not automatically exclude a finding of negligence. If injurers could escape liability by simply complying with a single unitary regulatory standard (a complete "compliance defence"), then some injurers, who incur less than usual costs of care or pose

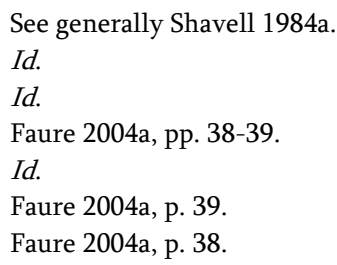


higher risks than usual, would be induced to under-invest in care. ${ }^{107}$ As mentioned above, since the regulatory standards, especially when they are set or greatly influenced by the medical profession, will only reflect the minimum levels of care in most cases, exposure to liability is truly needed to induce injurers to take efficient precautions. ${ }^{108}$ Moreover, liability can be intended as a "stopgap" measure for cases where no regulatory standard is enacted, ${ }^{109}$ or as an additional deterrent when the regulatory standard is set too low. ${ }^{110}$ Hence, as a general rule, compliance with the regulatory standard should not constitute a full defence to negligence. Nonetheless, if it were clear that the regulator had taken into account all costs and benefits of iatrogenic injury prevention and set the regulatory standard as efficiently as an informed court could have done, then a judge should not second-guess the efficient regulatory decisions. ${ }^{111}$ However, this is only the exception rather than the rule.

\subsection{CAUSATION}

\subsubsection{Causation in Fact}

Regarding causation, economists use positive tools from decision theory and statistics to define causation in fact on the one hand and normatively treat causation in law (proximate cause or scope of liability) as a tool to expand or restrict the scope of liability for the sake of optimal deterrence on the other. ${ }^{12}$ The test generally used in determining causation in fact is the "but for' or "sine qua non" test that eliminates all non-necessary causes from consideration..$^{13}$ As to causation in law, injurers should be held liable only for harm the likelihood of which would have been increased had they failed to take due care. ${ }^{114}$

Since causation in law is more concerned with the scope of liability rather than the establishment of liability, it will be addressed in Section 3.6.3.

\footnotetext{
107 See generally Shavell 1984a; Burrows 1999.

$108 \quad$ Faure 2004a, p. 39.

109 Rose-Ackerman 1992, p. 128.

$110 \quad$ Faure 2004a, p. 39.

$111 \quad$ Faure 2004a, p. 40.

112 Ben-Shahar 2009, pp. 83-84.

113 Shavell 1987a, p. 106

114 Shavell 1987a, pp. 106-107.
} 


\subsubsection{Uncertainty over Causation in Fact ${ }^{15}$}

\subsubsection{The Potential Inefficiency of the Threshold Approach}

Because of imperfect evidentiary information, it is not rare that there is considerable uncertainty about whether an injury suffered by the patient was caused by the provider's faulty treatment (a negligent iatrogenic injury), a therapeutic risk that cannot be avoided by a properly given treatment but could be prevented by the best treatment (a non-negligent iatrogenic injury), ${ }^{116}$ or the patient's pre-existing conditions (a non-iatrogenic injury). ${ }^{117}$ There are two main approaches to the determination of causation: the threshold probability criterion and the proportional probability criterion.

Under the threshold probability criterion (the "all-or-nothing" principle), injurers will not be held liable for harm done unless the probability of the causation between their actions and the accidents exceeds a given threshold. ${ }^{118}$ No matter how high the threshold is set, two types of problems may arise. On the one hand, if the actual likelihood of causation were systematically below the threshold, then injurers would never be held liable for harm done, i.e. they will face "a diminished burden of liability." 119 This would lead to under-deterrence under negligence, since potential injurers would have no incentive to take care at all. ${ }^{120}$ On the other hand, if the actual likelihood of causation were systematically above the threshold, then causation would always be easily established. Under negligence, there would be a potential danger of over-deterrence. This could be explained by two reasons. First, since causation could be easily established, it would be much easier to hold injurers liable under negligence. Second, due to considerable information asymmetry in the health care sector, courts may set due care either higher or lower than the socially optimal level of care. In

115 Section 3.4.2 is mainly based on Yu 2016.

116 For example, a patient may die of an immune reaction even when the nurse had conducted the skin test and waited for a reasonably long time, e.g. 15 minutes, before injecting penicillin. Yang, J. 2013, p. 72. But this is still an iatrogenic injury since if the nurse had waited a long time, e.g. 5 hours, after the skin test, the immune reaction could have been avoided.

117 An injury could not be avoided by the then best treatment available, and it would often be regarded as the natural progression of the patient's pre-existing or underlying conditions.

118 Shavell 1987a, p. 115; Schäfer \& Ott 2004, p. 209.

119 Shavell 1985a, p. 588.

$120 \quad$ Id. 
order to avoid being held liable erroneously, potential injurers may react to the uncertainty over the standard of care by over-complying. ${ }^{121}$

\subsubsection{The Efficiency of the Proportional Approach}

If information were perfect, i.e. the court set due care and applied the law correctly and injurers always complied with due care standards, then there would be no liability at all. However, quality uncertainty and information asymmetry are characteristics of the health care market. ${ }^{122}$ Hence, courts may sometimes err in setting due care and assessing the true levels of care and medical professionals may often commit errors inadvertently. ${ }^{123}$ In this subsection, we will examine the impact of causal uncertainty on accident prevention, given that negligence is already established.

Under the proportional probability criterion, however, parties will always be held liable for harm done unless the probability of causation is almost zero; and the damages will amount to the victim's losses multiplied by the probability of causation. ${ }^{124}$ Suppose the victim's harm was either caused by the injurer's negligence with a probability of $\mathrm{p}(\mathrm{x})$, which is the dependent variable of the level of care $\mathrm{x}$, or by a natural causative factor ${ }^{125}$ with a fixed probability of $\mathrm{q}$, which is not affected by the level of care $\mathrm{x}$. Suppose, also the cost of care is $\mathrm{C}(\mathrm{x})$ and the magnitude of liability is $\mathrm{L}$. If there were no causal uncertainty, we would assume $\mathrm{L}$ is equal to full harm $(\mathrm{H})$. Hence, if injurers attempted to exercise care less than due care, the total accident costs faced by them in the absence of causal uncertainty are exactly described by the first part of Expression 2: $\mathrm{T}(\mathrm{x})=\mathrm{C}(\mathrm{x})+\mathrm{p}(\mathrm{x}) \mathrm{H} \cdot{ }^{126}$ In the case of causal uncertainty, total accident costs faced by the injurers would be as follows:

$$
\mathrm{T}(\mathrm{x})=\mathrm{C}(\mathrm{x})+(\mathrm{p}(\mathrm{x})+\mathrm{q}) \mathrm{L}(\text { Expression } 3) \cdot{ }^{127}
$$

\footnotetext{
$121 \quad$ Van Velthoven \& Van Wijck 2012, pp. 33-34.

122 See supra Section 3.2.

123 Shavell 1987a, p. 82

124 Shavell 1987a, p. 115; Schäfer \& Ott 2004, p. 209.

125 Under the negligence rule, this natural causative factor refers to either therapeutic risks that cannot be avoided by a properly given treatment or the natural progression of the pre-existing or underlying conditions. In short, a natural causative factor is beyond the influence of the optimal treatment.

126 See supra Section 2.2.

127 Because of the presence of natural causative factors such as pre-existing conditions, the probability that the accident will happen or that the injurer will be held liable is $\mathrm{p}(\mathrm{x})+\mathrm{q}$. Hence, the expected liability faced by the injurer is $[\mathrm{p}(\mathrm{x})+\mathrm{q}]^{*} \mathrm{~L}$.
} 
It is important to note that the probability of causation in case of causal uncertainty precisely denotes the conditional probability ${ }^{128}$ that the injurer's negligence had caused the harm, given that the accident was already caused either by the injurer's negligence or by a natural factor. Hence, the probability of causation under causal uncertainty can be expressed as:

$\frac{\mathrm{p}(\mathrm{x})}{\mathrm{p}(\mathrm{x})+\mathrm{q}}($ Expresston 4$)$.

In case of causal uncertainty, if we adopted the proportional approach, we would set $\mathrm{L}$ not equal to $\mathrm{H}$ but identical with the product of the probability of causation as shown in Expression 4 and harm $\mathrm{H}$, which is shown as follows:

$\mathrm{L}=\frac{\mathrm{p}(\mathrm{x}) * \mathrm{H}}{\mathrm{p}(\mathrm{x})+\mathrm{q}}($ Expresston $\mathrm{5})$.

By substituting L in Expression 5 for L in Expression 3, we will get precisely:

$\mathrm{T}(\mathrm{x})=\mathrm{C}(\mathrm{x})+\mathrm{p}(\mathrm{x}) \mathrm{H}($ Expression 6$)$.

It turns out Expression 6 is identical with Expression 1, which indicates that if the court set the magnitude of liability equal to the product of the (conditional) probability of causation and the full harm in the case of causal uncertainty, the total accident costs faced by potential injurers would be identical with those accident costs in cases where there is no causal uncertainty, and "injurers will behave as they would in the absence of uncertainty over causation." 129

To summarise, it is maintained that proportional liability should be applied where there is considerable uncertainty over causation. ${ }^{130}$ It would appear that, since causal uncertainty is prevalent and significant in medical malpractice cases, it may be socially efficient to apply the proportional probability criterion to medical malpractice liability.

\footnotetext{
128 In statistics, conditional probability is normally defined as follows: "For events $\mathrm{A}$ and $\mathrm{B}$, the conditional probability of event $A$, given that event $B$ has occurred, is $P(A \mid B)=(P(A$ and B)) / (P(B)).” Agresti \& Franklin 2013, p. 231.

129 Shavell 1987a, p. 82.

130 Id.
} 


\subsection{PROOF RULES}

The classic model assumes that courts have sufficient information regarding the factual and legal issues of a dispute and can render a judgement without errors. However, tertiary costs due to searching and gathering evidence are not negligible in malpractice lawsuits. Therefore, errors in findings are committed from time to time. From the law and economics perspective, rules of evidence ${ }^{131}$ are needed in order to minimise tertiary costs of gathering evidence and of adjudicative errors. ${ }^{132}$ The efficient amount of evidence will be found where the marginal cost of searching evidence equals the marginal benefit of reduction in erroneous findings. ${ }^{133}$ Moreover, saving this kind of tertiary costs should also be weighed against the primary goal of injury reduction.

What and how much evidence is needed in order for a claim to be established is governed by procedural rules of evidence, which may introduce "special incentives, risks, and strategic behaviours among litigants and other stakeholders." 134 Two of the most important aspects of rules of evidence are the burden of proof and the standard of proof. The burden of proof, also called onus probandi, refers to a litigant's obligation to prove a disputed assertion on the basis of evidence. ${ }^{135}$ The standard of proof denotes the degree or level of proof that can convince the fact-finder of the litigant's assertion. ${ }^{136}$

In the light of the goal of tertiary cost avoidance, the allocation of the burden of proof should follow the "least-cost avoider" rule taught by Shavell ${ }^{137}$ by analogy - the burden of proof should be allocated to the type of parties who can give evidence at a lower cost. ${ }^{138}$. In principle, plaintiffs have to bear the burden of proving their main claims because they are assumed to be able to acquire sufficient evidence more cheaply.

In medical malpractice claims, however, it is widely assumed that plaintiff-patients encounter considerable difficulty in producing evidence on either negligence or causation for two reasons. First, a great deal of relevant

131 The discussion of rules of evidence in this Section is based on the adversarial nature of the US civil procedure law. Although China is primarily a civil law country, the procedures of civil litigation in China have moved from the inquisitive tradition toward the adversarial direction. Hence, most of the analysis here can apply to China.

132 Posner 2014, § 23.1.

133 Id.

134 Talley 2013, p. 305.

135 Garner 2014.

136 Id.

$137 \quad$ Shavell 1987a, p. 17

138 For more advanced economic models of the burden of proof, see e.g. Hay 1997; Kaplow 2012; Talley 2013. 
evidence such as medical records is in the hands of health care providers. Plaintiff-patients may find it difficult to acquire these evidentiary documents or may obtain falsified evidence. Second, plaintiff-patients generally lack medical knowledge. Even if they acquired these documents, they would probably be unable to evaluate negligence and causation on their own. Since health care providers are trained medical experts and are in charge of relevant evidential documents, it seems that it is less costly for them to bear the burden of proof regarding negligence and causation.

The above analysis appears to provide a prima facie case for the reversal of the burden of proof in medical malpractice cases. However, the reversal rule would become undesirable if we took into account more features of health care services. Due to imperfect information about the nature of diseases and the limits of modern medical technology, sometimes even trained medical experts may not be able to disprove either negligence or causation. ${ }^{139}$ Health care providers will risk bearing the costs of some potentially non-iatrogenic injuries or non-negligent iatrogenic injuries that cannot be currently prevented by making optimal investments in care. In effect, the reversal of the burden of proof as regards negligence will be akin to strict liability and that as regards causation will expand the scope of liability significantly. ${ }^{140}$ According to the classic accident model, under negligence, although an unrestricted scope of liability will not affect the care level, it will over-deter health care providers from engaging in their activity. ${ }^{141}$

The reversal of the burden of proof may be more socially undesirable when positive externalities ${ }^{142}$ are considered. Since the provision of medical care is a public welfare undertaking in many countries, and the availability of medical service benefits the general public tremendously, we should be very cautious about imposing strict liability upon health care providers, ${ }^{143}$ let alone expanding the scope of liability unjustifiably. On balance, taking positive externalities into account, it is not optimal to adopt the reversal of the burden of proof as regards negligence or causation in malpractice cases.

When it comes to the standard of proof, Posner favours the "preponderance of evidence" rule which can minimise error costs, because the costs of Type I errors ${ }^{144}$ and Type II errors ${ }^{145}$ will set off each other. ${ }^{146}$

Yang, J. 2013, p. 149.

See generally Young, Faure \& Fenn 2004.

See infra Section 3.6.3.

For a list of positive externalities generated by the health care sector, see supra Section 3.2.3.

$143 \quad$ Faure 2004a, p. 17.

144 Type I errors denote "false positives," meaning finding the defendant liable erroneously.

145 Type II errors denote "false negatives," meaning denying a meritorious claim.

146 Posner 2014, § 23.1. 
As addressed before, however, when applying the threshold probability criterion to the determination of causation, problems of either overdeterrence or under-deterrence may arise. Since the ex ante perspective of accident reduction may be preferable to the ex post perspective of mere error cost reduction, ${ }^{147}$ it may be socially more efficient to adopt the proportional probability criterion than the threshold one in the case of causal uncertainty.

\subsection{THE LAW OF DAMAGES}

\subsubsection{Introduction}

Tort law is normally composed of two parts - liability rules and quantum rules (or the law of damages). While liability rules are primarily concerned with prescribing the requirements for claiming damages, quantum rules are employed to assess the magnitude of damage. From the perspective of deterrence, the former "determines which party in which circumstances will receive a behavioural incentive from the legal system," while the latter "determines how large that incentive will be." 148

This Section will examine how quantum rules should be constructed in order to induce potential injurers to take optimal precautions. To begin with, the significance of the principle of full compensation for optimal deterrence in Section 3.6.2. will be discussed. Then, detailed approaches to the measure of damage, especially non-pecuniary losses, will be addressed in the light of full compensation in Section 3.6.3. After that, Section 3.6.4 will introduce the offsetting benefits rule or the restated negligence rule into the classic model with a view to properly limit the scope of compensation, especially in medical malpractice cases. Finally, it will examine the impact of uncertainty over the size of harm on preventive incentives in Section 3.6.5.

\subsubsection{Full Compensation}

According to the classic accident model, injurers should be held liable for the whole magnitude of actual harm $(\mathrm{H})$ done to victims. ${ }^{149}$ Otherwise, the negative externalities generated by injurers' activity cannot be fully internalised. This assumption corresponds to the traditional tort principle of

\footnotetext{
147 See generally Ben-Shahar 2009.

148 Visscher 2015, p. 16.

149 Shavell 1987a, pp. 127-128.
} 
"full," "fair" or "perfect" compensation. ${ }^{150}$ In the common law, a well-known expression of full compensation given by Lord Blackburn is as follows: ${ }^{151}$

... [the damage would be] that sum of money which will put the party who has been injured, or who has suffered, in the same position as he/she would have been if he/she had not sustained the wrong for which he/she is now getting compensation or reparation.

Also, almost all of Britain's continental neighbours follow the principle of restitutio ad integrum - "the wrongdoer has to make good the entire damage he/she caused ... as fully as possible." 152 In light of Mommsen's "difference hypothesis," damage is specifically measured by "the difference between the wealth of a person as it is at a given time, and the wealth as it would have been at that time if the damaging event had not occurred." 153

In economic terms, to "make the victim whole" requires that the damages should be so full that the victim is indifferent between having an accident with damages on the one hand and having no accident on the other ${ }^{154}$ which can be depicted by indifference curves in Figure 7.2. In this figure, we regard utility as a function of two independent variables - wealth and health. ${ }^{155} \mathrm{U}_{0}, \mathrm{U}_{1}$ and $\mathrm{U}_{2}$ are three indifference curves that represent three different levels of utility - utility before suffering a medical condition, utility before receiving treatment but after suffering a condition, and utility after suffering a negligent iatrogenic injury - respectively. Specifically, the impact of negligence on the patient's utility can be described by a downward shift from $U_{1}$ to $U_{2}$ in the patient's indifference map. Hence, full compensation requires that the patient's utility should be enhanced from $\mathrm{U}_{2}$ to $\mathrm{U}_{1}{ }^{156}$ Reparation can be paid in two forms: either (a) reparation in kind (restoring the status quo ante via e.g. repair or treatment) or (b) an equivalent amount of monetary compensation. ${ }^{157}$ Suppose the patient's health remains at $\mathrm{H}^{*}$

\footnotetext{
$150 \quad$ Friedman 1982, p. 81; Van Wijck \& Winters 2001, p. 319; Cooter \& Ulen 2012, p. 191.

151 Livingstone v. Rawyards Coal Co. (1880) 5 App Cas 25.

152 Magnus 2001a, p. 188

153 Mommsen 1855, p. 3, cited in Visscher 2015, p. 11.

154 Cooter \& Ulen 2012, p. 253.

155 Cooter \& Ulen 2012, p. 190. However, they did not provide a clear definition of health. For the purpose of full compensation, we accept WHO's definition of health: "Health is a state of complete physical, mental and social well-being and not merely the absence of disease or infirmity." World Health Organisation 2006, p. 1. Hence, full compensation entails that non-pecuniary losses such as pain and suffering or emotional distress should be compensable as well.

156 It will be explained that it is wrong to interpret full compensation as a shift from $U_{2}$ to $U_{0}$ in the ensuing sub-section.

$157 \quad$ Van Dam 2013, p. 348.
} 
$\left(H_{2} \leq H^{*} \leq H_{1}\right.$ ) after the remedial treatment, the defendant still needs to pay an additional amount of monetary damages $\left(\mathrm{W}^{* *}-\mathrm{W}^{*}\right)$ in order to make the patient whole.

Figure 7.3: Iatrogenic Injuries and Damages

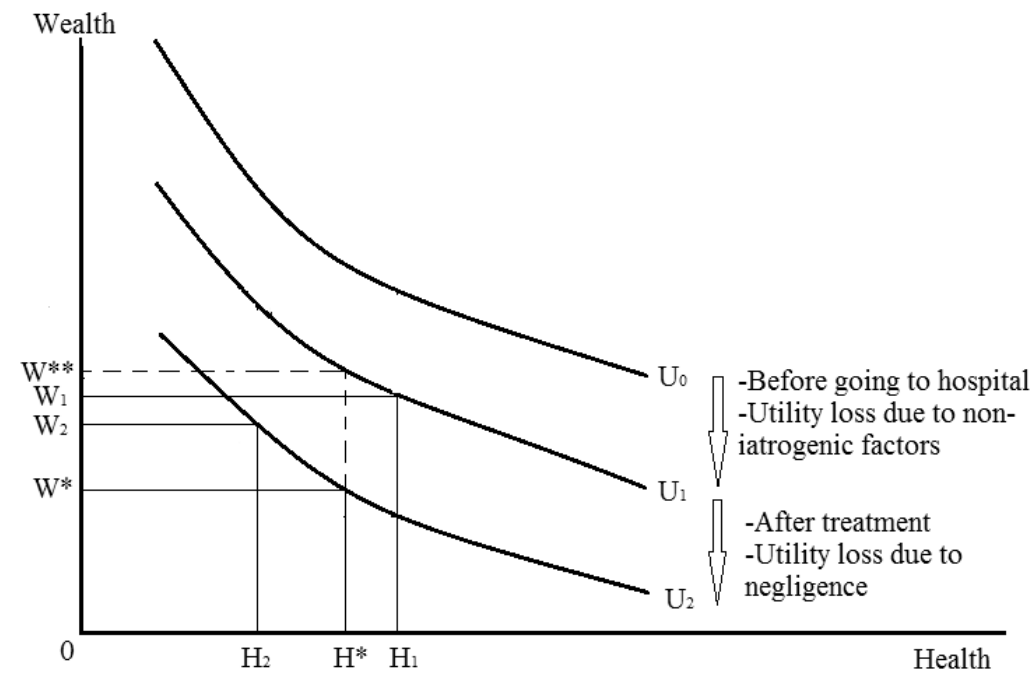

The whole magnitude of harm consists of both pecuniary losses and nonpecuniary losses. Whereas a pecuniary loss refers to a loss of the replaceable good, a non-pecuniary loss denotes a loss of irreplaceable good. ${ }^{158}$ An iatrogenic injury reduces the patient's state of health and may cause consequential losses both pecuniary such as the costs of health care and loss of income and non-pecuniary such as pain and suffering and loss of amenities. ${ }^{159}$ The indifference curves presented above are perfectly fit for analysing compensation for pecuniary losses. However, it is rather difficult to employ them to analyse non-pecuniary losses that are hard to be

$158 \quad$ Shavell 1987a, pp. 133-134.

159 In most European legal systems, the loss of life and severe disability themselves are not regarded as within the category of the notion of non-pecuniary losses, because it is normally considered unethical to monetize the value of life or health. Therefore, compensation for death or bodily injury is actually consequential pecuniary losses (e.g. treatment costs, lost earnings) and/or non-pecuniary losses (e.g. pain and suffering). Magnus 2001b, p. 194; Van Dam 2013, p. 346. However, if we treated death or serious bodily injury as harm directly, they would be "non-economic losses" as well, for they are "irreplaceable at any price." Hence, they are sometimes termed as "incompensable harms." Cooter \& De Pianto 2013, p. 439. 
monetized. ${ }^{160}$ Nevertheless, the principle of full compensation requires that the magnitude of liability should amount to the sum of pecuniary and nonpecuniary losses which corresponds to losses in social welfare, so that parties will be induced to take the optimal care. ${ }^{161}$ The incentives for parties to take care may be undesirably reduced particularly in the event that liability does not sufficiently reflect non-pecuniary losses. ${ }^{162}$

Since pecuniary losses amount either to actual monetary losses or to the costs of replacing goods, they are relatively easy to assess. ${ }^{163}$ In marked contrast to pecuniary losses, non-pecuniary losses are normally difficult to measure in that they cannot be observed directly, ${ }^{164}$ and they have no ready market substitute. ${ }^{165}$ Therefore, in order to save tertiary costs, non-pecuniary losses would be better ignored if they are fairly trivial. ${ }^{166}$ The other way around, if non-pecuniary losses tend to be relatively large when pecuniary losses are small, courts should make their best endeavours to assess such losses in order to prevent under-deterrence. ${ }^{167}$

\subsubsection{Assessment of Damages}

\subsubsection{Objective versus Subjective Methods}

Either an objective/abstract or subjective/concrete method can be used to assess the losses. ${ }^{168}$ In terms of saving tertiary costs, the former approach is obviously superior to the latter. ${ }^{169}$ Moreover, the latter method is not necessarily more efficient than the former as far as saving primary costs is concerned. If injurers were unable to anticipate the size of harm they might cause when making decisions, an accurate subjective/concrete assessment $e_{X}$ post would not affect their behaviour ex ante, which would be of no social value of deterrence. ${ }^{170}$ In such a case, only if damages were based on the average level of harm would injurers' behaviour be the same as if harm were assessed precisely. ${ }^{171}$

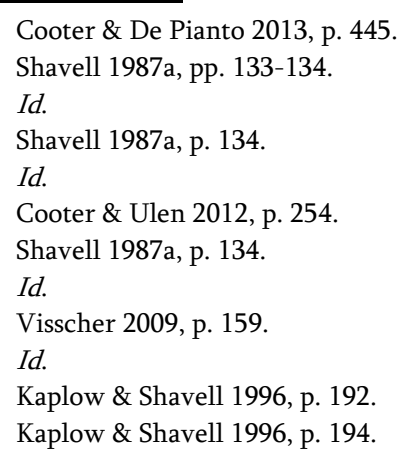


In the health care sector, it is normally difficult for health care providers to assess how much harm they will cause due to uncertainty over treatment. This fact suggests that if the average damages could be properly assessed, it would be more efficient to apply the objective than the subjective method to malpractice cases.

\subsubsection{Compensation for Wrongful Death}

Adverse events can be fatal, where a death is caused by negligence on the part of the provider. It is highly debated whether or how to provide a right of recovery for wrongful death. The most controversial issue is how to make a deceased patient who has died due to wrongful treatment, whole via compensatory damages.

The traditional approach widely used in practice is to avoid compensating wrongful death directly but to compensate secondary victims (usually close relatives) the consequential pecuniary and non-pecuniary losses that they themselves suffer. In most European countries and the US, for example, the loss of life in itself is not compensable. ${ }^{172}$ The court cannot base damages on a human being's market value, because markets for human beings are illegal and it is "repugnant" that a sum of money can be found so that e.g. "the parents are indifferent between having a dead child and the money, or having a living child and no money."173 In addition, most people have religious, ethical or philosophical objections to comparing death to money. ${ }^{174}$ Instead, close relatives of the deceased will be compensated as secondary victims for costs of funeral, loss of maintenance and non-pecuniary losses. ${ }^{175}$ In the case of the death of young children, compensation for the loss of maintenance is normally non-existent, because there are no dependents who relied on the deceased for support. ${ }^{176}$

This traditional approach to damages for fatal accidents was criticised as inefficient, for it leads to under-deterrence. ${ }^{177}$ Under-deterrence is due to under-compensation, because current tort law damages for wrongful death "do not include the welfare loss to the decedent." 178 For personal injuries concerning "the loss of a child or a limb, compensation simply cannot be

Rogers 2001a; Posner 2014, § 6.12.

Cooter 2003, p. 1098.

Cooter \& De Pianto 2013, pp. 444-445.

Van Dam 2013, p. 366.

Shavell 1987a, p. 134; Johnson \& Gunn 2009, p. 202; Van Dam 2013, pp. 367-370.

See generally Arlen 1985.

Posner \& Sunstein 2005, p. 598. 
perfect." 179 However, the loss of life is a real accident cost that should be internalised by negligent injurers. Otherwise, potential injurers will not be induced to take enough precautions against wrongful death.

In response, economists developed the notion of the "value of a statistical life" (VSL) in order to monetize risks of death. ${ }^{180}$ The central idea is that risks of fatal accidents are part of life and can be reduced by spending additional costs of prevention. ${ }^{181}$ Hence, "what actually is involved is determining the value that people place on avoiding small risks of death" rather than assessing the value of life itself. ${ }^{182}$ When balancing the costs and benefits of prevention, the product of the VSL and the marginal reduction in the probability of a fatal accident $(\Delta \mathrm{p})$ should be equal to the marginal cost of care $(\Delta C)$ - the reasonable person's willingness to pay (WTP). ${ }^{183}$ Hence, the value of being alive can be estimated by the following formulation: VSL = $\Delta \mathrm{C} / \Delta \mathrm{p}$, which is referred to as Hand rule damages by Cooter and Ulen. ${ }^{184}$ It is further argued that Hand rule damages are fuller than court awards under the traditional approach, they can reduce variation in damages among similar cases and they would provide better incentives for injury prevention. ${ }^{185}$

Implicit in the definition of the VSL is that all people should have the same value of being alive. Hence, the VSL does not make a distinction between old people and young people. However, Moore and Viscusi pointed out that "lives are extended, not permanently saved" and thus the more accurate assessment of the value of life should take into account "the duration of life involved." 186 Sunstein also maintained that a "program that saves younger people is better ... than an otherwise identical program that saves older people." 187 Therefore, they argued that the "value of a statistical life year" (VSLY) that bases the calculation on the age of potential victims is better than the VSL. Some objected to the notion of the VSLY on account of concerns for age discrimination, for this approach implies that the life of the young is more valuable than that of the old. ${ }^{188}$ However, Sunstein argued that this criticism of the VSLY is misconceived for two reasons. First, "every old

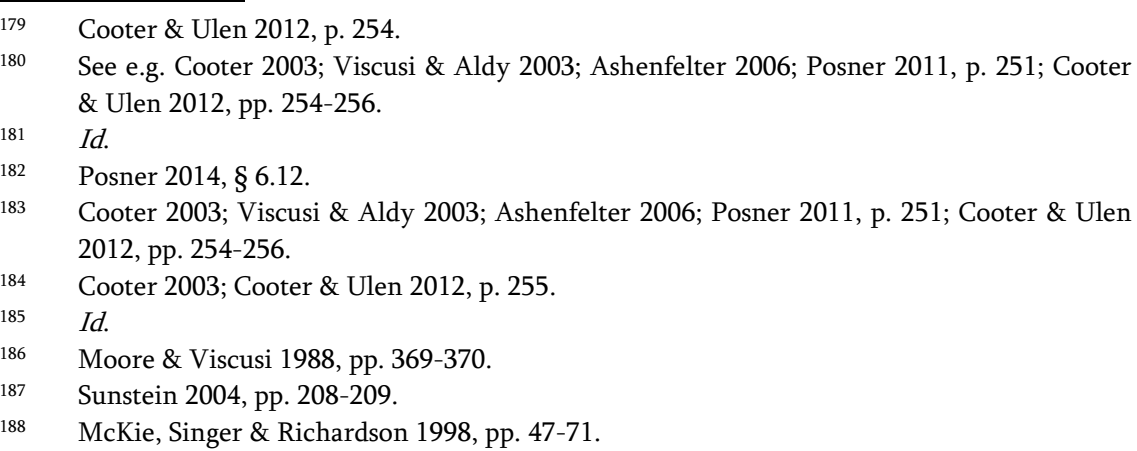


man was once young," and "the very people who lose when older also gained when younger." 189 Thus, there is no discrimination against the elderly. Second, younger people are more willing to pay more to reduce fatal risks than older people. ${ }^{190}$ Therefore, larger WTP should lead to higher VSL. In this regards, it is worth more to save a young life in terms of life years saved rather than the value of life itself. ${ }^{191}$

Although the VSLY does take into account of the duration of expected life, it does not treat the health conditions of the decedent before a fatal accident as a determinant. Instead, some economists advocated the notion of "quality adjusted life years" (QALYs), which can be used to assess compensation for both wrongful death and pain and suffering. ${ }^{192}$ A QALY is "a measure of the value of living one year in a certain health condition," which is "used as a proxy for quality of life during the year." 193 While VSLY years are employed to provide benchmarks against which the value of lost life years is assessed, QALYs specifically measure how much quality of life is lost. QALYs measure the value of living one year with a health indicator: " 0.00 " means death and "1.00" perfect condition. ${ }^{194}$ The health indicator "ranges from negatively valued aspects of life, including death, to the more positively valued aspects such as role function or happiness." ${ }^{195}$ Suppose a QALY were quantified by $Q$ dollars per year, a deceased victim's pre-accident health indicator was $\mathrm{H}(0.00<\mathrm{H} \leq 1.00)$ and his/her remaining life expectancy were $\mathrm{Y}$ years. Then, damages for the loss of life would be equal to $(\mathrm{Q} * \mathrm{Y} * \mathrm{H}-\mathrm{O})$ dollars.

In the context of medical malpractice, recovery for wrongful death in the light of QALYs are much more efficient than through the traditional "incompensable" approach, and even more appropriate than via the VSL and VSLYs. On the one hand, the traditional approach ignores direct compensation for the loss of life, which will lead to under-compensation and eventually under-deterrence. For the protection of patient safety, it is always of critical importance to reduce the number and severity of adverse events in the first place. Therefore, it is essential to compensate the decedent for his/her loss of life directly in order to generate behaviour incentives to take optimal precautions. Damages awards would then be left to close relatives of the decedent as his/her estate. If the decedent has no close relatives or heirs,

Sunstein 2004, pp. 209-210.

Sunstein 2004, p. 210.

Id.

See e.g. Weinstein 2005; Bagenstos \& Schlanger 2007; Adler \& Posner 2008.

Karapanou \& Visscher 2010, p. 59.

Visscher 2009, p. 162; Karapanou \& Visscher 2010, p. 59.

Guyatt, Feeny \& Patrick 1993, p. 622. 
it might be appropriate for the state to collect the damages as "fines" for the purpose of deterrence. On the other hand, QALYs seem better than the VSL and VSLYs, because the former take more determinants into account than the latter two. Specifically, young patients may be more willing to pay to avoid fatal risks than old patients. Hence, the VSL may be less desirable than VSLYs or QALYs. Since non-iatrogenic injuries due to patients' pre-existing conditions should be excluded from the scope of liability, QALYs may be superior to VSLYs in that the former take into consideration pre-existing health conditions.

\subsubsection{Compensation for Non-pecuniary Losses in Non-Fatal Accidents}

It has already been demonstrated that full recovery for non-pecuniary losses is essential for the purpose of optimal deterrence. Non-pecuniary losses are harm which cannot be compensated and which does not have market prices. Loss of life is indeed the most severe form of non-pecuniary loss. Economists developed several methods to measure the value of the loss of life, which has been addressed in the previous sub-section. In non-fatal accidents, victims may suffer various types of non-pecuniary losses, such as "pain and suffering, anxiety, fear, emotional strain, physical and psychological reduction of health and loss of enjoyment of life." 196 Karapanou and Visscher described these non-pecuniary losses together as some reduction in victims' quality of life. ${ }^{197}$

In practice, most legal systems do recognise the necessity to provide recovery for non-pecuniary losses. For instance, it is known as immaterieller Schaden (immaterial damage) in German, dommage moral (moral damage) in France, ${ }^{198}$ "hedonic" damages and damages for "loss of consortium" in the US. ${ }^{199}$ It is generally accepted that the measure of non-pecuniary losses should be based on the severity and duration of the pain and suffering. ${ }^{200}$ In case a patient suffers an iatrogenic injury which affects him for the rest of his life (continuing damage), it is mainly his future loss of earnings due to damaged earning capacity plus pain and suffering that will be compensable by a lump sum or by a periodical payment. ${ }^{201}$

In principle, damages for similar pain and suffering should not vary significantly at least within the same legal system. Otherwise, potential injurers facing similar accident costs may take different levels of precautions

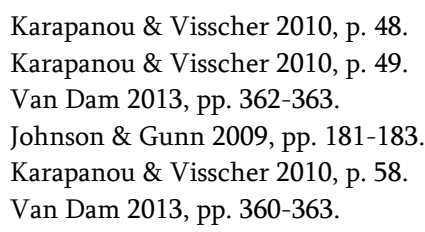


against these similar risks. However, Karapanou and Visscher found that the amount of damages for similar non-pecuniary losses differs greatly both between and within most European countries. ${ }^{202}$ Hence, they criticised these legal frameworks as "inadequate to effect the proper assessment of pain and suffering damages." ${ }^{203}$ Reliance on tables and schedules that summarise earlier case law or prescribe invalidity points may promote "equal treatment" from case to case. ${ }^{204}$ However, it does not mean that these tables and schedules will produce socially optimal amounts of non-pecuniary damages.

Similar to compensation for wrongful death, recovery of nonpecuniary losses in non-fatal accidents can also be justified. From the perspective of primary cost reduction, Faure maintained that "in case of unilateral accidents there is a reason to compensate non-pecuniary losses."205 However, the question as to how to provide recovery for non-pecuniary losses perfectly and consistently still needs to be answered. By analogy with the WTP approach to assessing the value of life, some economists advocated the application of an average ex ante WTP to the measure of non-pecuniary losses. ${ }^{206} E_{X}$ ante damages are superior to ex post damages, because the former "compensates the victim exactly for the amount he would have been willing to pay himself," while the latter will result in over-deterrence. ${ }^{207}$ Schäfer and Ott held that recovery for pain and suffering due to non-fatal injuries should be some fraction of the value calculated in light of the WTP to prevent death. ${ }^{208}$ After reviewing empirical studies, they concluded that, for the sake of optimal deterrence, at least a doubling of the current awards for pain and suffering for severe injuries is required in Germany, and even a fourfold or sixfold increase in the amounts currently paid would still be well compatible with the predictions based on these studies. ${ }^{209}$ This finding suggests that the current legal framework for assessing non-pecuniary losses may systematically lead to under-deterrence. However, they did not clarify how the fraction should be properly set in the light of the VSL.

Visscher and Karapanou filled in this gap by arguing that QALYs can be employed to assess pain and suffering properly.210 QALYs are fit for assessing non-pecuniary losses due to non-fatal injuries because "it has regard

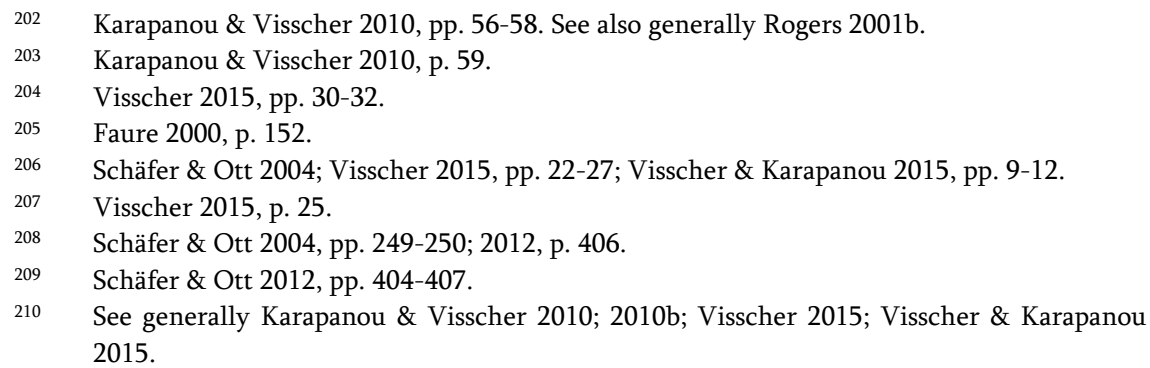


to quality of life."211 Suppose a QALY were quantified by Q dollars per year, a seriously injured victim's health indicator before the accident was $\mathrm{H}_{0}$ and after the accident was $H_{1}\left(0.00<H_{1}<\mathrm{H}_{0} \leq 1.00\right)$ and his/her remaining life expectancy was $Y$ years. Then, damages for non-pecuniary would be equal to $\left(\mathrm{Q} * \mathrm{Y} * \mathrm{H}_{\mathrm{Q}}-\mathrm{Q} * \mathrm{Y} * \mathrm{H}_{1}\right)$ dollars. After discussing several concrete cases, Visscher and Karapanou found that the traditional method of calculating non-pecuniary damages will normally result in under-deterrence. ${ }^{212}$ Hence, the adoption of QALYs would enhance the efficiency of the current system of non-pecuniary damages. Visscher and Karapanou concluded that this can be done in at least two ways: first, lawyers representing the plaintiff could assess the amount of non-pecuniary damages in the light of studies on QALYs; and second, courts could substitute QALY-based non-pecuniary damages for the currently used tables and schedules. ${ }^{213}$

Since the law of damages is applicable to medical malpractice cases in general, there is no special reason why QALYs cannot be applied to the evaluation of pain and suffering due to non-fatal iatrogenic injuries. Hence, for the purpose of optimal deterrence, health care providers should be induced to take appropriate precautions against fatal and non-fatal iatrogenic injuries. QALYs are socially desirable for they would be able to prevent under-deterrence.

\subsubsection{Collateral Benefits}

Traditional tort theories hold that tort law is intended to achieve restitutio in integrum but not to make victims more than whole. ${ }^{214}$ Hence, damages awards should be restricted by the principle of compensatio lucri cum damno (i.e. set-off of profit and loss). ${ }^{215}$ This rule (hereinafter the collateral-source set-off rule) is well known as Vorteilsausgleichung in Germany and réglementation du cumul d'indemnité in France. ${ }^{216}$ This doctrine requires that benefits which the victim receives because of the accident should be set off against losses that the victim suffers. ${ }^{217}$ Put another way, "insofar as the damage is reduced, the claimant does not have a claim." ${ }^{218}$ In contrast, the opposite rule (the collateral-source rule) has been developed in the US since

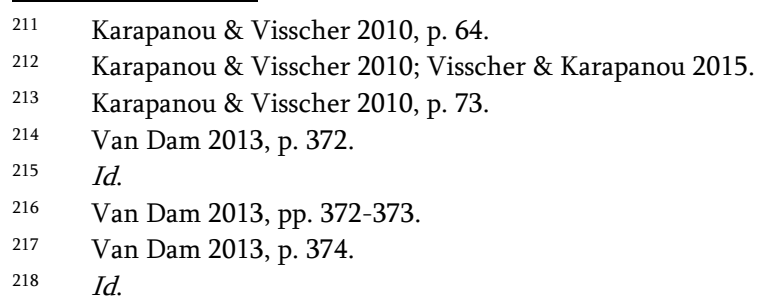


the 19th century, ${ }^{219}$ although several US States abolished it by statute in medical malpractice cases in the 1970s and later in all tort claims in the 1980 s. ${ }^{220}$ Nonetheless, many states "have not changed the traditional rule and some that have changed it have had the statute overturned by state supreme courts." ${ }^{221}$ The collateral-source rule is defined in the Re-statement (Second) of Torts as follows: "Payments made to or benefits conferred on the injured party from other sources are not credited against the tortfeasor's liability although they cover all or a part of the harm for which the tortfeasor is liable." ${ }^{222}$

From the perspective of law and economics, Posner argued that the collateral-source (or collateral benefits) rule is normally more efficient than the collateral-source set-off rule. ${ }^{223}$ First, let us suppose the victim did not assign his/her right to tort claims to the insurer (subrogation). If the defendant-injurer were permitted to set up the victim's insurance policy as a defence against the plaintiff-victim's claim, there would be underdeterrence. ${ }^{224}$ A "double recovery" is not "a windfall" to the victim, since he/she purchased the insurance policy at a premium amounting to the expected cost of his/her injury plus the overhead cost. ${ }^{225}$ Then, let us suppose the victim did assign his/her tort right to the insurer (subrogation). It is evident that the victim would not receive a "double recovery" at all, in view of the fact that he/she had already assigned his/her tort right to the insurer with a view to receiving a lower premium. ${ }^{226}$ The collateral-source set-off rule would not be applicable since the victim would not sue. There would be no under-deterrence either, because the insurer would file a claim against the defendant-injurer for the victim's loss. ${ }^{227}$ Hence, the collateral-source rule is normally efficient. Nevertheless, to the extent that insurance is financed by the government (social insurance) rather than purchased by the victim (private insurance), the social insurance benefits should be deducted from the award of damages and then the government is entitled to file a claim against the defendant-injurer to recover them. ${ }^{228}$

When it comes to medical malpractice cases, it seems that collateral benefits should be treated differently according to the type of the source. It is

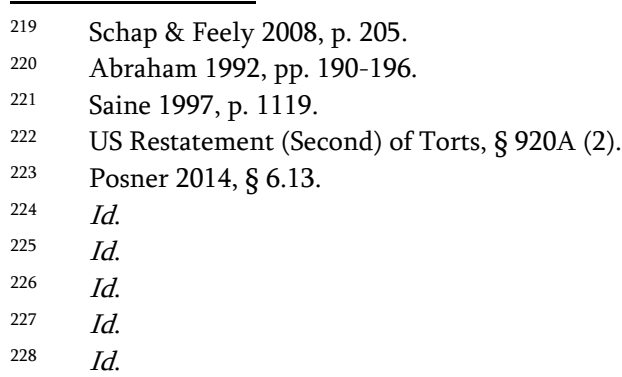


likely to be socially desirable to apply the collateral-source rule if (health, unemployment, disability, etc.) insurance is purchased privately by the victim, and to apply the collateral-source set-off rule in the case of social insurance.

\subsubsection{The Off-setting Benefits Rule/Re-stated Negligence Rule (Scope of Liability)}

Due to the complexity of the pathogenesis of a disease and the uncertainty over treatment, there is a real possibility that the shift from $U_{1}$ to $U_{2}$ is caused by non-iatrogenic injuries, non-negligent iatrogenic injuries and negligent iatrogenic injuries simultaneously in the real world. Under traditional medical malpractice liability, only negligent iatrogenic injuries are compensable. The other two types of injury are within the scope of the patient's own responsibility and should be deducted from the magnitude of liability that the provider involved has to pay.

In the classic models, however, concerns for causation are usually left out and it is normally assumed that the injurer should be held liable for all the harm done once liability is established. ${ }^{229}$ This neglect of causation in the models was strongly criticised by Kahan. ${ }^{230}$ According to Kahan, injurers under negligence should only be held liable for accidents "that would have happened even if they had employed due care."231 Porat referred to this rule as the off-setting benefits rule. Suppose that when the optimal (due) treatment is given, the patient still faces a therapeutic risk, i.e. $\mathrm{p}\left(\mathrm{x}^{*}\right) \mathrm{H}$. If the provider exercises care $(\mathrm{x})$ less than the optimal (due) care level $\left(\mathrm{x}^{*}=\tilde{x}\right)$, the patient will face an increased risk of $\mathrm{p}(\mathrm{x}) \mathrm{H}$. The provider should only be held liable for the increased risk when negligent, i.e. he/she should be ex ante exposed to the increased accident cost:

$$
\mathrm{p}(\mathrm{x}) \mathrm{L}=\mathrm{p}(\mathrm{x}) \mathrm{H}-\mathrm{p}(\mathrm{x} *) \mathrm{H}(\text { Expression } 7)
$$

Then, the negligent provider's magnitude of liability (L) could be expressed as follows: ${ }^{232}$

\footnotetext{
$229 \quad$ Be that as it may, Shavell does have considered issues of causation and scope of liability separately. See generally Shavell 1987a, pp. 105-126. 
$\mathrm{L}=\mathrm{H} \frac{\mathrm{p}(\mathrm{x})-\mathrm{p}\left(\mathrm{x}^{\mathrm{*}}\right)}{\mathrm{p}(\mathrm{x})}($ Expresston $\mathrm{B})$

After deducting from the scope of liability the expected accident cost when the optimal level of care is taken, Kahan had demonstrated that the classic model is inferior to his causation-based negligence rule. His reason is that in cases where due care is set higher than optimal care the former will lead to over-deterrence (taking due care instead of optimal care) while the latter will still induce injurers to take optimal care (as under strict liability). ${ }^{233}$ The essential implication of this advantage is that the court can set due care relatively higher in order to "counteract uncertainty about the level of due care" and hence avoid under-deterrence. ${ }^{234}$ In the context of medical malpractice, Porat argued that this rule is conducive to the lessening of the problem of defensive medicine, because it reflects the true accident risks that are caused by provider negligence. ${ }^{235}$

A model that resembles Kahan's model was developed by Van Wijck and Winters, and it was termed by them as the re-stated negligence rule. ${ }^{236}$ They agreed with Kahan on the opinion that injurers should not be held liable for harm that victims would have suffered if injurers had taken due care. ${ }^{237}$ One subtle difference between the two models is that while Kahan assumed that it is the probability rather than the magnitude of the harm which can be affected by care, Van Wijck and Winters believed that both the probability and the magnitude of the harm are affected by care. ${ }^{238}$ It seems that the latter assumption better reflects the reality than the former, especially in the context of medical malpractice. Although there are some rare cases where harm follows an "all-or-nothing" pattern, ${ }^{239}$ in most of the cases the extent of harm is likely to be strongly influenced by the level of care

239 For instance, if a nurse is only responsible for injecting two types of liquid medicine (A and $B$ ) into exactly two types of patients $\left(A^{*}\right.$ and $\left.B^{*}\right)$, where $A$ is only beneficial to $A^{*}$ but harmful to $B^{*}$ and $B$ is only beneficial to $B^{*}$ but harmful to $A^{*}$. In such a case, the only error that can be committed is injecting the wrong medicine - either injecting $A$ to $B^{*}$ or injecting $\mathrm{B}$ to $\mathrm{A}^{*}$. The time and effort spent in choosing the correct medicine will only affect the probability that $\mathrm{s} / \mathrm{he}$ makes an error, but has no continuous implications for the extent of the harm. There will be either no harm, if due care is taken (i.e. choosing the correct medicine), or full harm due to a wrong injection.
} 
excised. ${ }^{240}$ Be that as it may, the re-stated negligence rule does not alter the basic conclusion of Kahan's model. Van Wijck and Winters also concluded that although both the standard negligence rule described by the classic models and the re-stated negligence rule lead to under-deterrence if due care is set lower than optimal care; the former will lead to over-deterrence whereas the latter will always induce injurers to take optimal care if due care is set higher than optimal care. ${ }^{241}$

In addition, Van Wijck and Winters also took into account the impact of the re-stated negligence rule on activity levels. They demonstrated that the level of activity under the re-stated negligence rule will be much higher than the one under the standard negligence rule. ${ }^{242}$ The essential implication of this finding is that "the re-stated negligence rule gives better incentives for care, whereas the standard negligence rule gives better incentives for the activity level." ${ }^{243}$

In the context of medical malpractice, it seems that the re-stated negligence rule is superior to the standard negligence rule in terms of both care and activity levels. On the one hand, due to severe information asymmetry, the court may err and set due care either lower or higher than optimal care. Facing this uncertainty, health care providers are likely to respond by over-complying under the standard negligence rule ${ }^{244}$ than under the restated negligence rule. On the other hand, health care services generate considerable positive externalities to society at large. ${ }^{245}$ The level of health care activities should be encouraged rather than discouraged. Overall, if expected losses due to non-iatrogenic injuries and non-negligent iatrogenic

240 In practice, however, the example mentioned in supra note 48 is only the exception rather than the rule. Empirical evidence shows that most adverse events are associated with surgical procedures and medications, and some are due to highly preventable diagnostic errors. See infra Chapter 8, Section 2.1.1. First, as far as surgeries are concerned, it is not difficult to imagine that a careful surgeon will control his/her surgical knife better than a careless one, thus $\mathrm{s} / \mathrm{he}$ is less likely to make an unnecessary cut on the patient's brain, organs or limbs. Second, when it comes to medication, many physicians may be entitled to prescribe and many nurses may be responsible for injecting multiple types of medicine. The lower the care level, the more likely that more types of medicine will be erroneously prescribed or administered, hence the more likely that higher magnitude of harm may be done. Third, with regard to diagnosis, it is highly likely that greater care will reduce the extent of harm, because more accurate diagnoses may be made and more effective therapies may be provided.

241 Van Wijck \& Winters 2001, p. 330.

$242 \quad I d$.

243 Van Wijck \& Winters 2001, p. 326.

244 Widespread empirical evidence about positive defensive medicine is consistent with this theoretical prediction. For a detailed summary of empirical studies on defensive medicine, see infra Chapter 8, Section 1.5.1.

245 See supra Sub-Section 7.2.2.7. 
injuries are not deducted from the scope of liability, it is highly likely that the health care provider will be over-deterred. ${ }^{246}$

The preceding analyses of the offsetting benefits rule or the re-stated negligence rule are also consistent with Shavell's discussions on the scope of liability. Shavell demonstrated that an unrestricted scope of liability does not affect the level of care that parties would choose, because taking greater care would not reduce their liability for harm that would occur in any case. ${ }^{247}$ Nevertheless, such restrictions are still necessary for two reasons stated as follows. First, an unrestricted scope of liability may over-deter injurers from engaging in their activity, since due to uncertainties and errors in the determination of due care, health care providers might be found negligent even if they had taken efficient care. ${ }^{248}$ Second, the causal restriction of the scope of liability tends to decrease tertiary administrative costs, since the volume of cases may be reduced and fewer issues of causation remain to be decided by courts. ${ }^{249}$ The other way around, if the scope of liability is too restricted, it suggests that not all the states of the world - where the care of health care providers could have reduced the probability of harm - have been taken into account. ${ }^{250}$ Then, the problem of under-deterrence will arise.

To sum up, as far as the scope of liability is concerned, negligent providers should only be held liable for damages that are based on the increased risks of an accident arising from their negligence. Therapeutic risks that cannot be avoided by a properly given treatment or the natural progression of the patient's pre-existing or underlying conditions should be within the scope of the patient's own responsibility. Otherwise, the patient may be induced to practise defensive medicine and more tertiary costs may be incurred.

\subsubsection{Uncertainty over the Magnitude of Liability}

The above analysis of the re-stated negligence rule and different approaches to the assessment of compensation for iatrogenic injuries reveal the considerable complexity of disposing of medical malpractice claims. The measure of damages also suffers from imperfect information. On the one hand, courts may often find it difficult to distinguish iatrogenic and noniatrogenic injuries, leading to either expansion or contraction of liability

\footnotetext{
246 When applying Shavell's model of causation concerning unrestricted scope of liability, we can also come to the same conclusion. See supra Section 7.3.3.

Shavell 1987a, pp. 107-108.

Shavell 1987a, pp. 108-109.

Id.

Id.
} 
scope. On the other hand, it can be intellectually and technically challenging and administratively costly for courts to calculate future losses or the value of life or health precisely and fully. ${ }^{251}$ Hence, uncertainty over the magnitude of liability is almost impossible to eliminate in practice. If estimates were correct on average, however, courts would not have to determine the actual losses in fact. ${ }^{252}$ Since estimating uncertain elements may raise administrative costs, if excluding some uncertain elements do not reduce incentives for injurers to take great care, it may be socially desirable for courts to do so. ${ }^{253}$ If courts systematically under-estimate losses, there will not be adequate incentives for parties to take due care; the other way around, parties will take a socially excessive level of care..$^{254}$

\subsection{DISPUTE RESOLUTION AND TERTIARY COSTS}

The classic model assumes that health care providers will pay damages immediately they are found liable. However, the compensation process will not be initiated until victimised patients take some action. It is obvious that litigation costs cannot be zero in practice. The patients have to decide whether it is worthwhile to file a claim or whether to settle the case out of court in order to avoid litigation costs. ${ }^{255}$

In order for a claim to be filed, a victim's private expected benefits from making such a claim - the product of the subjective probability of winning a case and the payoff of the claim - must exceed his costs of making such a claim. ${ }^{256}$ The filing costs normally include the costs of retaining an attorney and paying the filing fee assessed by the court. ${ }^{257}$ A claim may never be filed if the filing costs are considerable relative to the expected value of the claim. Hence, claims with relatively minimal expected values, especially those cases where only trivial iatrogenic injuries are involved, may be systematically dropped in practice.

Parties will go to trial only when the difference in the expected judgement of the two parties (relative optimism) exceeds the difference in costs between litigating and settling (the cooperative surplus). ${ }^{258}$ There will be relative optimism if the sum of the two parties' subjective probabilities of

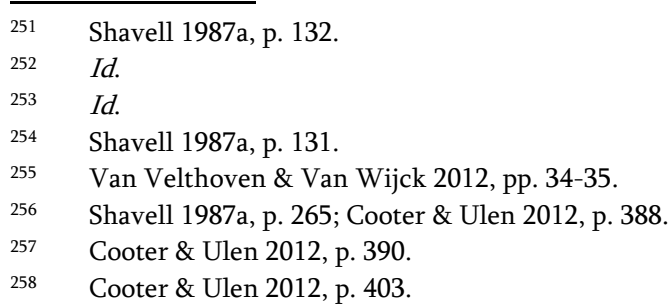


winning the case exceeds $100 \% .^{259}$ Thus, even though a claim is filed, the parties may choose to settle out of court, since the relative optimism is low. Theoretically, since bargaining takes place "in the shadow of the law," a settlement could reach the same outcome as a trial, and thus litigation costs would be saved. ${ }^{260}$ Indeed, a settlement that can mirror the expected court judgement can enhance social welfare. ${ }^{261}$ In practice, however, the settlement payment will normally be less than damages awards that would otherwise have been granted by the court. ${ }^{262}$

Overall, if many valid claims were not filed or were settled at sums considerably lower than damages awards that otherwise would have been granted by the court, health care providers would be under-deterred due to some reduction in the average magnitude of liability. This outcome would be inefficient, since too many or too severe iatrogenic injuries would be caused.

\section{CONCLUSIONS}

Chapter 7 has examined the desirability of applying the fault-based model of tort law to medical malpractice liability. This model is analysed with the intention of answering the question how Calabresi's primary and tertiary accident costs could be minimised in terms of medical error through tort law, especially the working of the negligence rule and its sub-rules (the standard of care, causation, proof rules, quantum rules, and dispute resolution). In the ideal world, the negligence rule is socially optimal. However, when some of the prior assumptions of the model are relaxed and more features of health care services are taken into consideration, the fault-based model has to be modified.

As far as the standard of care is concerned, it is socially optimal to impose a higher level of due care on providers than on ordinary citizens. To economise on tertiary costs, a uniform level of due care should be adopted for the same or similar group of providers. When the costs of prior precautions are relatively low, it is socially desirable to bring prior precautions into the dimension of due care. Uncertainty over the standard of care is likely to result in defensive medicine. One way to reduce this uncertainty is to rely on customary practices which are developed by the medical profession. However, this approach has been challenged by many legal systems. As a

\footnotetext{
$259 \quad$ Cooter \& Ulen 2012, p. 402.

260 Cooter \& Ulen 2012, p. 400.

261 Cooter \& Ulen 2012, p. 401

262 Dewees, Duff \& Trebilcock 1996, p. 100; Van Velthoven \& Van Wijck 2012, pp. 34-35.
} 
rule, a contravention of regulatory standards automatically establishes negligence, whereas compliance with regulatory standards may not automatically exclude a finding of negligence.

When it comes to causation, in cases where it is uncertain whether the provider's faulty treatment or other non-tortious factors (therapeutic risks or pre-existing conditions) have caused the patient's injury, proportional liability is more efficient than the traditional threshold approach.

Regarding proof rules, a reversal of the burden of proof is akin to strict liability, which is socially undesirable when taking into account the considerable positive externalities generated by health care activities. As regards the standard of proof, the preponderance of evidence is efficient at minimising error costs; however, it should not be applied to cases where uncertainty over causation in fact is considerable, for a proportional approach is better.

Full compensation is essential to the deterrent effect of tort liability. In order to save tertiary costs, damages should be assessed objectively rather than subjectively. With a view to better assessing the value of the loss of life, many innovative methods such as the value of a statistical life (VSL), the value of a statistical life year (VSLY), and quality adjusted life years (QALYs) are proposed, which appear more efficient than the traditional "incompensable" approach. New methods such as ex ante Willingness to Pay (WTP) and QALYs can also be employed to assess non-pecuniary losses. While the collateral-source set-off rule should be applied to cases where part of damages is paid under social insurance, the collateral-source rule should be applied to cases where part of the damages are paid under private health insurance. In light of the off-setting benefits rule, non-negligence iatrogenic injuries and non-iatrogenic injuries should be excluded from the scope of liability, which may lessen the problem of defensive medicine. Providers' incentives to take care could be affected by severe uncertainty over the size of liability.

Finally, a settlement that could mirror a court decision is socially desirable in that it saves tertiary costs. In practice, however, patients may receive significantly lower amounts of compensation in settlements than in court, which may lead to under-deterrence.

All the foregoing conclusions are drawn on the basis of law and economics theories. Whether the fault-based model of malpractice liability actually works efficiently is also an empirical question, which will be answered in the next Chapter. 


\section{CHAPTER 8}

\section{PREVENTING MEDICAL ERRORS THROUGH TORT LAW - EMPIRICAL EVIDENCE AND UPDATED MODELS}

\section{INTRODUCTION}

Chapter 8 is aimed at answering the questions whether the fault-based medical malpractice liability is efficient at deterring medical errors in practice and what implications there will be for the economic model of malpractice liability after reviewing relevant empirical evidence (part of Sub-question (2a)). Hence, in order to answer this question, it is essential to examine available empirical studies pertaining to medical malpractice issues.

The majority of the studies reviewed in this Chapter are primarily USbased. Several rounds of the "malpractice crisis" and tort reforms in the US have encouraged many scholars to research into medical malpractice issues. Hence, the largest category of the economic literature on malpractice is of empirical nature, which has developed considerably in the past two decades. ${ }^{1}$ Since the malpractice system in both China and the US is a fault-based tort system, these empirical findings may have high referential meaning for China. Nonetheless, empirical studies in other legal systems may also be included in the analysis if relevant.

The remainder of this Chapter is organised as follows. Section 2 will review empirical studies concerning the performance of the medical malpractice system. Section 3 will examine empirical evidence on the causes of iatrogenic injuries and point out its implications for the economic model of medical malpractice liability. The final Section 4 concludes.

Garcia 2011, pp. 2-3. 
Part II. Economic Theories and Empirical Evidence

\section{EMPIRICAL EVIDENCE: IATROGENIC INJURY, MALPRACTICE LITIGATION, AND DETERRENT EFFECT}

\subsection{INTRODUCTION}

The question with regard to the performance of medical malpractice liability can be divided into three sub-questions. First, whether the input system (liability and quantum rules) is effective as a fact, i.e. whether all meritorious claims are filed (Section 2.3) and whether the court system is effective at sorting out meritorious claims from non-meritorious claims (Section 2.4). Second, whether behavioural changes do exist and whether it is attributed to the threat of medical malpractice liability (Section 2.5). Third, whether the deterrence benefits generated by the medical malpractice system justifies the costs of the system (Section 2.6). Before that, Section 2.2 will describe the epidemiology of iatrogenic injuries in order to provide a context for subsequent discussions.

\subsection{INCIDENCE, SEVERITY, AND COSTS OF IATROGENIC INJURIES}

\subsubsection{Introduction}

Empirical evidence shows that iatrogenic or medical injuries are not rare events and many injuries result from substandard care in the US and elsewhere. Basically, empirical studies on the incidence and prevalence of iatrogenic injuries fall into two categories: first, general studies of patients suffering adverse events; second, studies of patients suffering medicationrelated or other special errors. ${ }^{2}$ For the sake of illustrating the overall picture of the epidemiology of iatrogenic injuries, I will pay particular attention will be paid to major general studies. In the light of data collection methods, the vast majority of these studies are retrospective (based on data gathered by reviewing medical records) and a small minority are prospective studies (based on data gathered by direct observation during hospital stay). The advantage of direct observation over a review of records is that the former

Kohn, Corrigan \& Donaldson 2000, p. 29. 
may capture more adverse events (AEs) that would not be recorded in a written form for various reasons. Hence, the validity of data directly observed may be higher than that of data based on record reviewing. The aggregate costs of medical errors and adverse events were also reported by some studies. Section 2.2.2 and Section 2.2.3 will summarise retrospective and prospective studies respectively. Section 2.2.4 will address studies on the costs of AEs and medical errors.

\subsubsection{Retrospective Studies}

Currently available retrospective studies are summarised in Table 8.1 as follows:

Table 8.1: Retrospective Studies on AEs in the US and Other Western Countries

\begin{tabular}{|c|c|c|c|c|c|c|c|}
\hline \multirow{2}{*}{ Studies by Year } & \multirow{2}{*}{ Sample } & \multirow{2}{*}{ Country } & \multicolumn{2}{|c|}{ Incidence } & \multicolumn{3}{|c|}{ Severity } \\
\hline & & & AEs & Neg.*/AEs & Minor & Permanent & Death \\
\hline Schimmel, 1964 & $\begin{array}{l}1,000 \text { plus } \\
\text { patients, } \\
\text { Yale } \\
\text { University } \\
\text { Medical } \\
\text { Service }\end{array}$ & US & $20 \%$ & 0 & $45.83 \%$ & $47.50 \%$ & $6.67 \%$ \\
\hline $\begin{array}{l}\text { Pocincki, Dogger } \\
\text { and Schwartz, } \\
1973\end{array}$ & $\begin{array}{l}800 \text { medical } \\
\text { records, two } \\
\text { hospitals }\end{array}$ & US & $\begin{array}{l}\text { at least } \\
7.50 \%\end{array}$ & $29.00 \%$ & $98.45 \%$ & - & $1.55 \%$ \\
\hline $\begin{array}{l}\text { Mills, } 1978 \\
\text { (California } \\
\text { Study) }\end{array}$ & $\begin{array}{l}20,864 \text { in } \\
\text { hospital } \\
\text { patient } \\
\text { charts from } \\
23 \\
\text { California } \\
\text { hospitals }\end{array}$ & US & $4.65 \%$ & $17.00 \%$ & $86.50 \%$ & \multicolumn{2}{|c|}{$13.50 \%$} \\
\hline Steel et al., 1981 & $\begin{array}{l}815 \text { patients } \\
\text { admitted to } \\
\text { a hospital }\end{array}$ & US & $36.00 \%$ & & $75.00 \%$ & $14.66 \%$ & $10.34 \%$ \\
\hline $\begin{array}{l}\text { Harvard Medical } \\
\text { Practices Study, } \\
1990 \text { (Harvard } \\
\text { Study) }\end{array}$ & $\begin{array}{l}\text { medical } \\
\text { records of } \\
30,121 \\
\text { patients } \\
\text { from } 51 \\
\text { hospitals in } \\
\text { New York }\end{array}$ & US & $3.70 \%$ & $27.60 \%$ & $71.00 \%$ & $7.00 \%$ & $14.00 \%$ \\
\hline $\begin{array}{l}\text { Wilson et al., } \\
1995\end{array}$ & $\begin{array}{l}14,179 \\
\text { admissions } \\
\text { to } 28 \\
\text { hospitals }\end{array}$ & Australia & $16.60 \%$ & $51.00 \%$ & $77.10 \%$ & $18.60 \%$ & $4.90 \%$ \\
\hline $\begin{array}{l}\text { Thomas et al., } \\
\text { 2000a }\end{array}$ & $\begin{array}{l}15,000 \\
\text { discharges } \\
\text { in Utah and } \\
\text { Colorado }\end{array}$ & US & $2.90 \%$ & $\begin{array}{c}33.00 \% \\
\text { (Utah) } \\
27.00 \% \\
\text { (Colorado) }\end{array}$ & & $.00 \%$ & $7.00 \%$ \\
\hline
\end{tabular}


Part II. Economic Theories and Empirical Evidence

\begin{tabular}{|c|c|c|c|c|c|c|c|}
\hline $\begin{array}{l}\text { Neale, } \\
\text { Woloshynowych } \\
\text { and Vincent, } \\
\text { 2001; Vincent, } \\
\text { Neale and } \\
\text { Woloshynowych, } \\
2001\end{array}$ & $\begin{array}{l}1014 \\
\text { records } \\
\text { from two } \\
\text { acute } \\
\text { hospitals }\end{array}$ & UK & $11.70 \%$ & $48.00 \%$ & $66.00 \%$ & $25.00 \%$ & $8.00 \%$ \\
\hline $\begin{array}{l}\text { Schiøler et al., } \\
2001\end{array}$ & $\begin{array}{l}1,097 \text { acute } \\
\text { care } \\
\text { admissions }\end{array}$ & Denmark & $9.00 \%$ & $40.40 \%$ & - & - & - \\
\hline $\begin{array}{l}\text { Davis et al., } \\
\text { 2002a; 2002b }\end{array}$ & $\begin{array}{l}6,579 \\
\text { records in } \\
13 \text { hospitals }\end{array}$ & $\begin{array}{c}\text { New } \\
\text { Zealand }\end{array}$ & $11.20 \%$ & $37.00 \%$ & $85.00 \%$ & $10.30 \%$ & $4.70 \%$ \\
\hline Baker et al., 2004 & $\begin{array}{l}3,745 \text { charts } \\
\text { from } 20 \\
\text { hospitals }\end{array}$ & Canada & $7.50 \%$ & $36.90 \%$ & $64.40 \%$ & $5.20 \%$ & $15.90 \%$ \\
\hline $\begin{array}{l}\text { Aranaz-Andres et } \\
\text { al., } 2008\end{array}$ & $\begin{array}{l}5,908 \\
\text { patients }\end{array}$ & Spain & $8.40 \%$ & $42.90 \%$ & - & - & - \\
\hline $\begin{array}{l}\text { Zegers et al., } \\
2009\end{array}$ & $\begin{array}{l}8,032 \\
\text { records }\end{array}$ & $\begin{array}{l}\text { The } \\
\text { Netherlands }\end{array}$ & $5.70 \%$ & $39.60 \%$ & $87.20 \%$ & $5.00 \%$ & $7.80 \%$ \\
\hline Soop et al., 2009 & $\begin{array}{l}1,967 \\
\text { admissions } \\
\text { from } 28 \\
\text { hospitals }\end{array}$ & Sweden & $12.30 \%$ & $70.00 \%$ & $88.00 \%$ & $9.00 \%$ & $3.00 \%$ \\
\hline Levinson, 2010 & $\begin{array}{l}\text { a nationally } \\
\text { random } \\
\text { sample of } \\
780 \\
\text { Medicare } \\
\text { beneficiaries }\end{array}$ & US & $13.5 \%$ & $44 \%$ & - & - & - \\
\hline $\begin{array}{l}\text { Landrigan et al., } \\
2010\end{array}$ & $\begin{array}{l}2341 \\
\text { admissions } \\
\text { from } 10 \\
\text { hospitals in } \\
\text { North } \\
\text { Carolina }\end{array}$ & US & $25.1 \%$ & $63.1 \%$ & $84.40 \%$ & $13.20 \%$ & $2.40 \%$ \\
\hline $\begin{array}{l}\text { Classen et al., } \\
2011\end{array}$ & $\begin{array}{l}795 \text { records, } \\
\text { three large } \\
\text { US tertiary } \\
\text { care centres }\end{array}$ & US & $33.2 \%$ & - & - & - & - \\
\hline $\begin{array}{l}\text { Sommella et al., } \\
2014\end{array}$ & $\begin{array}{l}1,103 \\
\text { records } \\
\text { from } 2008 \\
\text { discharges }\end{array}$ & Italy & $3.30 \%$ & - & - & - & - \\
\hline Sousa et al., 2014 & $\begin{array}{l}1,669 \\
\text { records } \\
\text { from three } \\
\text { hospitals }\end{array}$ & Portugal & $11.10 \%$ & $53.20 \%$ & $61.00 \%$ & $5.40 \%$ & $10.80 \%$ \\
\hline
\end{tabular}

${ }^{*}$ In these studies, negligent AEs are normally defined as preventable AEs.

The foregoing retrospective studies generally reported a relatively high incidence of AEs (2.90\% to $36.00 \%$ ) and the percentage of negligent AEs over all AEs (17.00\% to $70.00 \%)$. The variances in the incidence of AEs may be explained by the differences in the size of the samples. While studies based on small samples (less than 1,000 charts) such as Steel et al. (1981) and 
Classen et al. (2011) reported $36.00 \%$ and $33.2 \%$ respectively, those based on large samples (more than 20,000 charts) such as Mills (1978) and Harvard Medical Practices Study (1990) reported $4.65 \%$ and 3.70\% respectively. The variances in the proportion of negligent AEs to all AEs may reflect different levels of service quality in different regions, but they may also be caused by the differences in the size of samples. Be that as it may, these studies are sufficient to show that both AEs and negligent AEs are relatively wide-spread in the US and other Western countries.

Data on the seriousness of iatrogenic injuries did not vary too significantly and reported similar results: the majority (45.83\% to $98.45 \%)$ of AEs resulted in minor impairment whereas some $(5.00 \%$ to $47.50 \%)$ led to permanent disability, and only a few (2.40\% to $15.90 \%)$ ended in death.

Combining two large-scale studies in the US (California \& Harvard Study), it seems that adverse events occurred in about $4 \%$ of all hospitalisations and $25 \%$ of all adverse events suffered by hospitalised patients were due to substandard care. When extrapolating the adverseevent-related death total to the U.S. population, it was estimated that there were over 150,000 iatrogenic fatalities annually, more than half of which are due to negligence. Then, iatrogenic injury "accounts for more deaths than all other types of accidents combined, and dwarfs the mortality rates associated with motor vehicle accidents (50,000 deaths per year) and occupation-related mishaps (6,000 deaths per year). ${ }^{\prime 3}$ There were also more than 30,000 victims who suffered severe non-fatal iatrogenic injuries nationally, which was at least larger than the number of job-related disabilities. ${ }^{4}$

Recently, Landrigan et al. conducted a multi-variate analysis and did not find significant changes in either the overall rate of harm or the rate of preventable harm, indicating that "harm remains common, with little evidence of widespread improvement."

\subsubsection{Prospective Studies}

Compared to an abundance of after-the-fact retrospective studies, prospective studies based on the method of direct observation are relatively rare.

Andrews et al. conducted a prospective, observational study on the appropriateness of the care received by 1,047 patients admitted to a large, urban teaching hospital from around $1990 .{ }^{6}$ They argued that the retrospective approach primarily developed by the Harvard Study

Weiler et al. 1993, p. 55.

Id.

Landrigan et al. 2010, p. 2124.

See generally Andrews et al. 1997. 
underestimates the error rate for three main reasons. First, only errors that led to iatrogenic injuries were considered. Second, only errors that were documented in medical records were included. Third, while only one expert witness is needed to testify before the court in the US, the two-physician standard of the Harvard Study might be more stringent than what is actually required in the court. Based on their prospective method, they reported that $45.80 \%(\mathrm{n}=480)$ of all the 1,047 patients had experienced at least one AE. $17.70 \%$ of all the patients and $21.20 \%$ of all the AEs were associated with serious injuries. Although their incidence rate $(45.80 \%)$ was much higher than that reported by the Harvard Study (3.7\%), Andrews et al. still emphasised that their estimate was also an under-estimate. On the one hand, the seriousness of some cases was not mentioned by physicians discussing them. On the other, they might have missed some meetings that were not strictly scheduled.

Outside the US, Michel et al. also carried out a study concerning the care received by 778 patients admitted to 7 hospitals in southwestern France. ${ }^{7}$ They used both prospective and retrospective methods to collect data, which identified similar rates of iatrogenic injuries $(70 \%$ and $66 \%$, respectively). However, the prospective approach identified more preventable adverse events than the retrospective one ( $64 \%$ and $40 \%$, respectively). Hence, they concluded that the prospective approach of data collection may be superior to the other approach in terms of disclosing the epidemiology of negligent iatrogenic injuries.

Differences in the incidence of adverse events can be partly explained by various characteristics at hospital levels, different policies at national levels and the subtleties of variant approaches to the methodology. ${ }^{8}$ In spite of these variations in the incidence, the existing studies collectively demonstrate that the relatively high incidence and severity of adverse events, those preventable in particular, pose substantial risk to patient safety globally and considerable costs will be incurred. Tough preventive measures should be introduced and taken to reduce adverse events as much as possible.

\subsubsection{Costs of Medical Errors/AEs}

Some studies in the US reported the costs of medical errors or AEs, which are considerably high. The first large-scale study, the Harvard Study, estimated that the undiscounted cost of both initial illness and iatrogenic injury for the New York population to be $\$ 21.4$ billion, consisting of $\$ 2.6$ billion in lost

See generally Michel et al. 2004.

Runciman et al. 2000; Thomas et al. 2000b; Zegers et al. 2009. 
wages, $\$ 3.4$ billion in lost household production, and $\$ 15.4$ billion in medical care expenditures. ${ }^{9}$ Overall, iatrogenic injuries accounted for $\$ 3.8$ billion of the $\$ 20.3$ billion medical costs incurred by adults. ${ }^{10}$ Extrapolating to the US population, the costs of medical injuries totaled about $\$ 50$ billion nationally in 1984. ${ }^{11}$ The second large-scale study, the Utah and Colorado Study, reported that preventable medical errors accounted for $\$ 308$ million of the $\$ 662$ total injury costs. ${ }^{12}$ Extrapolated nationally, that would be roughly $\$ 37.6$ billion for adverse events and $\$ 17$ billion for preventable errors. ${ }^{13}$ In 1999 , the total national costs of preventable adverse events, including lost income, lost household production, disability and health care costs, were estimated by the US Institute of Medicine in its landmark report, To Err Is Human, to be between $\$ 17$ and $\$ 29$ billion per year..$^{14}$ Recently, Milliman reported that the costs of medical errors were estimated to be $\$ 19.5$ billion during the year 2008 in the US..$^{15}$

\subsection{MALPRACTICE CLAIMS FILED}

\subsubsection{The Initiation of Malpractice Claims}

\subsubsection{Theoretical Predictions}

The fundamental assumption underlying the classic model of malpractice liability is that tort law is a very effective deterrent for medical errors, which entails a correct initiation of claims - "that all negligently injured patients detect and file claims and that no non-negligently injured patients file claims." ${ }^{16}$ When a claim has a valid factual basis, meaning the plaintiff-patient was indeed injured by negligence on the part of the provider, the claim is said to be meritorious. ${ }^{17}$ By definition, a negligent $\mathrm{AE}$ should correspond to a meritorious claim. If the vast majority of meritorious claims are initiated and most non-meritorious are not initiated, deterrence will come close to the optimum. A malpractice claim is defined more broadly than a legal suit filed,

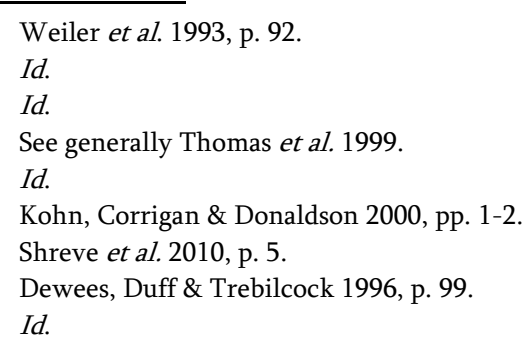


since many (perhaps more than 90\%) malpractice disputes are settled out of the court. ${ }^{18}$

In practice, however, physicians have long complained that many malpractice claims against them are frivolous, ${ }^{19}$ and one lawyer even criticised the malpractice system as "a capricious and unsatisfactory method of compensating ... the distribution of losses ... depend on a series of chance factors" 20 more than four decades ago. At the other end of the spectrum, patients may often fail to initiate a meritorious claim either because they have not realised that there were medical errors or on account of considerable litigation costs even if their claims are meritorious. Hence, the realities of the malpractice system may deviate from optimal deterrence. It follows that empirical evidence is essential to the clarification of this debate.

\subsubsection{Empirical Findings}

There is a considerable deficit in the initiation of meritorious claims. In general, there is an epidemic of medical errors (medical malpractice), ${ }^{21}$ but there is no epidemic of malpractice lawsuits. ${ }^{22}$ Numerous empirical studies in the US show that most victimised patients with meritorious claims do not sue. The main findings of some retrospective studies are summarised in Table 8.2.

Table 8.2: Medical Malpractice Claims Initiated

\begin{tabular}{|l|l|c|c|}
\hline Studies by Year & Location & $\begin{array}{l}\text { Claims Initiated } \\
\text { (No.): Neg. AEs } \\
\text { (No.) }\end{array}$ & $\begin{array}{l}\text { The Rate of } \\
\text { Nonmeritorious Claims } \\
\text { over the Claims Initiated }\end{array}$ \\
\hline Danzon, 1985a & California & $1: 10$ & $60 \%$ \\
\hline Danzon, 1988 & California* & $1: 5$ & - \\
\hline $\begin{array}{l}\text { Localio et al., 1991; Weiler } \\
\text { et al., 1993 }\end{array}$ & New York & $1: 7.6$ & 82.98\% \\
\hline $\begin{array}{l}\text { Studdert, Brennan and } \\
\text { Thomas, 2000 }\end{array}$ & Utah & $1: 5.1$ & - \\
\hline $\begin{array}{l}\text { Studdert } \text { et al., 2006 } \\
\text { Colorado }\end{array}$ & $\begin{array}{l}\text { four regions } \\
\text { of the US }\end{array}$ & $1: 6.7$ & - \\
\hline $\begin{array}{l}\text { Florida Centre for Health } \\
\text { Information and Policy } \\
\text { Analysis, 2012; 2013; 2014 }\end{array}$ & Florida & $1: 3.3$ & - \\
\hline
\end{tabular}

Danzon 1985a, p. 23; Weiler et al. 1993, p. 66.

Crane 2014

Ison 1967, pp. 28-29.

See supra Section 2.2.

Baker 2005a, p. 37.

Cited in Weiler et al. 1993, p. 62. 
* Observing a more than double increase in claim rate per doctor from the mid-1970s to the mid-1980s, Danzon adjusted the rate of claim made.

According to these retrospective studies, about 3.3 to 10 negligent AEs would lead to one initiated medical malpractice claim. Data from California and recent data from Florida may suggest that more claims are initiated compared to all AEs. However, the number of negligent AEs still considerably outnumber the claims actually made.

A prospective study after the mid-1990s also confirmed this conclusion, reporting that although more than $17 \%$ of patients suffered serious adverse events leading to longer hospital stays and more costs, only 13 of the 1047 total patients (1.2\%) made claims. ${ }^{24}$ Therefore, it is strongly contended that "the malpractice system is too inaccessible, rather than too accessible, to the victims of negligent medical treatment." 25

Not all the claims initiated are meritorious. As a matter of fact, there is a large excess of non-meritorious claims initiated. According to the available evidence, between $39 \%$ and $82.98 \%$ of the claims initiated were nonmeritorious. Patients with non-meritorious causes of action nonetheless initiated claims either induced by short limitation periods or intending to investigate facts through formal procedures. ${ }^{26}$ Other evidence suggests that an excess of lawyers may make lawyers "accept more readily from the pool of potential medical malpractice cases." 27

An excess of non-meritorious claims filed further provides the evidence that the real tort crisis may be that too few meritorious claims are actually made. ${ }^{28}$

\subsubsection{Trends in Medical Malpractice Claims Filed}

Some of the aforementioned data were from decades ago, and many readers may wonder whether more meritorious claims have been initiated relative to potentially negligent iatrogenic injuries in recent years. In this subsection, major studies on the trends in malpractice claims in the US are summarised.

Medical malpractice litigation first appeared in the US in the late $18^{\text {th }}$ century. ${ }^{29}$ However, malpractice claims were infrequent until the second half of last century. The 1960's had witnessed a dramatic increase in both the

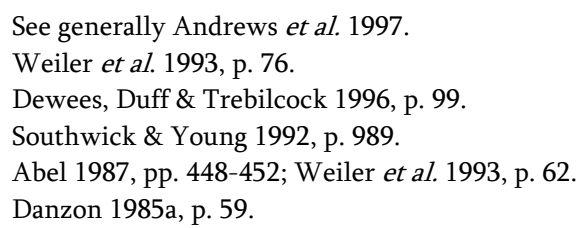


frequency and severity ${ }^{30}$ of medical malpractice claims and there had been growing concern about a malpractice insurance "crisis" in the mid-1970's. ${ }^{31}$ According to the American Medical Association, about 1.6 claims were filed per 100 physicians during the period between 1956 and 1963, whereas this frequency rose to roughly 2.7 claims per 100 physicians by $1968 .^{32}$ In California, there had been a rapid growth in both claim frequency and claim severity at an annual rate of roughly $10 \%$ since the 1960 's, which accelerated towards the end of the decade and into the 1970's. ${ }^{33}$ The average growth rate was 20\% in California during the whole period between 1969 and 1974; by 1975, about 33 claims per 100 physicians were initiated. ${ }^{34}$ This surge in claim frequency and severity around 1970 immediately preceded the malpractice insurance crisis of $1975,{ }^{35}$ with premium increases of up to $500 \%$ in some states. ${ }^{36}$ Malpractice claim frequency stabilised or even decreased in many states during the period from 1975 to 1978, although this rate began to rise steadily after 1978 . The St. Paul Company reported a 55\% surge in claim frequency from 10.5 claims per 100 physicians in 1980 to 16.3 claims in $1984,{ }^{37}$ and reached 17 claims in 1986, and then stabilised at an annual rate of roughly 15 claims thereafter. ${ }^{38}$ Empirical evidence confirms that the surge in claim frequency in the 1960's and early 1970's was significantly associated with wider use of surgical interventions and pro-plaintiff shifts in legal doctrines such as the abolition of the locality rule, the permission for expert witnesses from other states, the extension of hospital liability based on respondeat superior, and the reasonable patient standard under informed consent. ${ }^{39}$

Later data show that claim frequency and severity in the US stabilised or even decreased. In order to deal with the medical malpractice crisis of the mid-1970's and the 1980's, the majority of states initiated tort reforms to restrict malpractice claim costs. ${ }^{40}$ Reform measures such as caps on awards or collateral source offset were adopted by 18 states before 1985 and by 23 states

Danzon defined "severity" as "average dollar indemnity, per paid claim, including court awards and payments in out-of-court settlement." Danzon 1984a, p. 115.

See generally Danzon 1986; Olsen 1996.

American Medical Association 1969, cited in Boccara 2009, p. 343.

See generally Munch 1978.

Danzon 1985a, p. 60.

See generally Danzon 1986.

Danzon 1985a, p. 97.

Danzon 1986, p. 57.

Bovbjerg 1995, cited in Danzon, 2000, p. 1355.

Danzon 2000, p. 1355.

See generally Danzon 1987; 1994a; Ottenwess et al. 2011. 
from 1985 to $1990 .{ }^{41}$ By the end of June 2015, of all the 50 states and Washington D.C., 24 had modified or abolished the collateral source rule and 23 had adopted caps on awarding non-economic damages. ${ }^{42}$ Empirical evidence shows that claim severity was reduced by $19 \%$ to $39 \%$ due to caps and by $11 \%$ to $50 \%$ due to collateral source offset respectively. ${ }^{43}$ Claim frequency was reduced by $8 \%$ due to one year off the statute of limitations and by $14 \%$ due to the adoption of the collateral source off-set rule respectively. ${ }^{4}$

Recent data from Michigan, Texas, Florida and Missouri also confirm this stable or even downward trend in claim frequency, although claim severity appears to grow steadily. For the period from 2000 to 2007, claims filed in Michigan decreased considerably by $77 \%$, resulting in a modest drop in insurance premiums. ${ }^{45}$ In Texas, claim frequency declined from 6.4 claims per 100 physicians annually during the period 1990-1992 to 4.6 per 100 physicians annually during 2000-2002. ${ }^{46}$ Although claim severity rose during that period, the whole increase was argued to be the result of medical inflation and an increase in the number of "large" paid claims (at least $\$ 25,000$ in 1988 dollars). ${ }^{47}$ In Florida, although the absolute frequency of paid claims rose from 1990 to 2003, per capita claim frequency during 2000-2003 roughly amounted to that during $1990-1993 .{ }^{48}$ The average annual payouts increased during that period, largely due to rising medical costs or inflation. ${ }^{49}$ One striking finding was that the frequency of serious-injury claims jumped more than 5\% in 2002-2003 over previous years..$^{50}$ From 1990 to 2013 in Missouri, the number of newly-opened claims (except for an anomalous surge in 2005) and of closed claims (except for a surge in 2007) was roughly decreasing. ${ }^{51}$ However, median indemnity per claimant was generally on the increase during the same period, with an annual growth rate of $7.25 \% .52$ This increase in the size of claims was also claimed to be due to rising inflation and injury severity. ${ }^{53}$

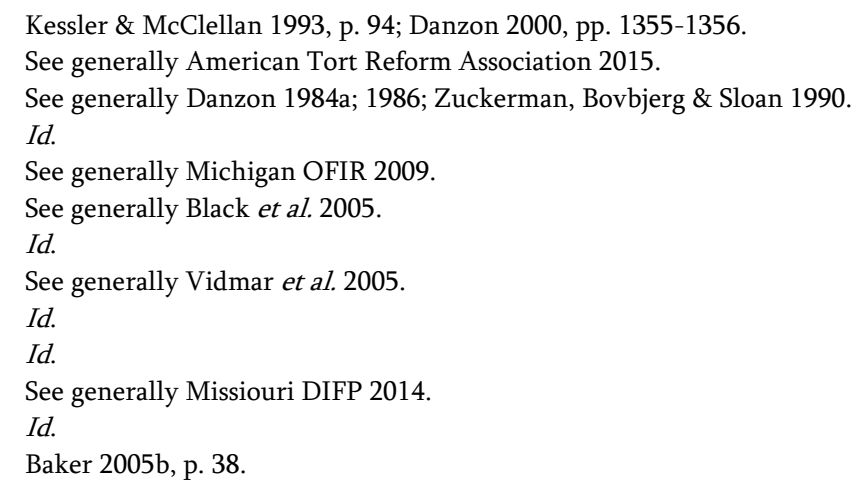


All the data summarised in this and the previous sub-section demonstrate that there is no epidemic of medical malpractice liability in the US. The ratio of claims initiated to potentially meritorious claims is still low and claim frequency has been stable since the 1980's. The increase in claim severity merely reflects rising inflation and a shift toward serious-injury claims. The real malpractice "crisis," if any, may still be that too few meritorious claims are actually made. ${ }^{54}$

\subsection{ACCURACY OF CLAIMS RESOLUTION}

\subsubsection{Defining Claim Accuracy}

The classic model of malpractice presupposes that the court has perfect information concerning legal standards and facts of a claim. Thus, the court is assumed to be able to adjudicate medical disputes without errors, which entails that all claims result in either "true positives" (patients with meritorious claims receiving payments) or "true negatives" (denying a nonmeritorious claim). However, many critics of the malpractice system contend that the outcome of the malpractice system is like the purchase of a "forensic lottery" which only benefits attorneys. ${ }^{55}$ Hence, there might be "false positives" (patients receiving payments when their claims are nonmeritorious) and "false negatives" (denying a meritorious claim) in practice. The relationship among different claim outcomes can be depicted in Table 8.3 .

Table 8.3: Defining Claim Accuracy

\begin{tabular}{|l|l|l|}
\hline \multicolumn{1}{|c|}{ Claims Merit } & \multicolumn{1}{|c|}{ Payment } & \multicolumn{1}{c|}{ No Payment } \\
\hline $\begin{array}{l}\text { Meritorious } \\
\text { (substandard care) }\end{array}$ & True positives & $\begin{array}{l}\text { False negatives (Type II } \\
\text { Errors) }\end{array}$ \\
\hline $\begin{array}{l}\text { Nonmeritorious } \\
\text { (due care) }\end{array}$ & $\begin{array}{l}\text { False positives (Type I } \\
\text { Errors) }\end{array}$ & True negatives \\
\hline
\end{tabular}

Therefore, the accuracy of meritorious claims can be measured by the percentage of the number of true positives relative to that of all meritorious claims (hereinafter TP\%): the higher the percentage, the more accurate the outcome of meritorious claims. The other way around, the accuracy of nonmeritorious claims depends upon the ratio of the number of false positives to that of all non-meritorious claims (hereinafter FP\%): the lower the ratio, the

See supra Section 2.3.1.2.

See generally Ison 1967; Brody 2004. 
more precise the outcome of non-meritorious claims. It is also possible to measure whether there is under- or over-deterrence by comparing the FP\% and the ratio of the number of false negatives to that of meritorious claims (hereinafter FN\%).

\subsubsection{Empirical Findings}

Then, it is imperative to know, in actuality, whether the civil liability system resolves medical malpractice claims accurately or not. Although it is wellknown that a complete absence of adjudicative errors in malpractice cases is not possible in the real world, several empirical studies show that most malpractice claims resolved by the court are reasonable in that there is a strong correlation between "the likelihood of receiving payment and the merits of malpractice claims." ${ }^{56}$ The main findings of these studies are summarised in Table 8.4.

Table 8.4: Percentage of True Positives versus Percentage of False Positives

\begin{tabular}{|l|l|l|l|l|l|}
\hline $\begin{array}{l}\text { Studies by } \\
\text { Year }\end{array}$ & \multicolumn{1}{|c|}{ Samples } & TP\%* & FP\%* & FN\%* & Ratio* \\
\hline $\begin{array}{l}\text { Ogburn et al., } \\
1988\end{array}$ & $\begin{array}{l}\text { 153 closed claims involving } \\
\text { perinatal injury filed from 1980 } \\
\text { to } 1982 \text { with the St. Paul } \\
\text { Company }\end{array}$ & $91 \%$ & $55 \%$ & $9 \%$ & 1.65 \\
\hline $\begin{array}{l}\text { Cheney et al., } \\
1989\end{array}$ & $\begin{array}{l}1,004 \text { closed malpractice claims } \\
\text { for anaesthesia-related injuries } \\
\text { from 17 insurance organisations } \\
\text { throughout the US in 1988 }\end{array}$ & $82 \%$ & $42 \%$ & $18 \%$ & 1.95 \\
\hline $\begin{array}{l}\text { Rosenblatt } \\
\text { and Hurst, } \\
1989\end{array}$ & $\begin{array}{l}\text { 54 claims involving obstetric } \\
\text { injury closed by an insurance } \\
\text { company during the } 6.5-y e a r \\
\text { from } 1982\end{array}$ & $95 \%$ & $0 \%$ & $5 \%$ & - \\
\hline $\begin{array}{l}\text { Farber and } \\
\text { White, 1991; } \\
1994\end{array}$ & $\begin{array}{l}\text { 258 closed claims initiated from } \\
1977 \text { to } 1989 \text { against a single } \\
\text { large hospital }\end{array}$ & $89 \%$ & $25 \%$ & $11 \%$ & 3.56 \\
\hline $\begin{array}{l}\text { Taragin } \text { et al., } \\
1992\end{array}$ & $\begin{array}{l}\text { 8,231 closed malpractice cases } \\
\text { from the New Jersey Medical } \\
\text { Inter-Insurance Exchange } \\
\text { between 1977 and 1992 }\end{array}$ & $91 \%$ & $21 \%$ & $9 \%$ & 4.33 \\
\hline $\begin{array}{l}\text { Peeples, } \\
\text { Harris and } \\
\text { Metzloff, } 2002\end{array}$ & $\begin{array}{l}\text { Carolina between 1991 and } \\
1995\end{array}$ & $93 \%$ & $15 \%$ & $7 \%$ & 6.20 \\
\hline
\end{tabular}

Boccara 2009, p. 353. 
Part II. Economic Theories and Empirical Evidence

\begin{tabular}{|c|c|c|c|c|c|}
\hline $\begin{array}{l}\text { Cranberg, } \\
\text { Glick and } \\
\text { Sato, } 2007\end{array}$ & $\begin{array}{l}42 \text { closed malpractice claims } \\
\text { against neurologists since } 1986\end{array}$ & $32 \%$ & $4 \%$ & $68 \%$ & 8.00 \\
\hline $\begin{array}{l}\text { Studdert et al., } \\
2006\end{array}$ & $\begin{array}{l}1,452 \text { closed claims from five } \\
\text { liability insurers }\end{array}$ & $73 \%$ & $27 \%$ & $27 \%$ & 2.70 \\
\hline $\begin{array}{l}\text { Harris, } \\
\text { Peeples and } \\
\text { Metzloff, } 2008\end{array}$ & $\begin{array}{l}348 \text { medical malpractice } \\
\text { lawsuits filed in North Carolina } \\
\text { between } 1992 \text { and } 1995\end{array}$ & $78 \%$ & $33 \%$ & $22 \%$ & 2.36 \\
\hline
\end{tabular}

The above studies generally conclude that the malpractice system functions effectively, since, except for one study, patients did receive payments in the vast majority ( $73 \%$ to $95 \%$ ) of meritorious claims. Put another way, a plaintiff was roughly 2 to 8 times more likely to obtain compensation if the defendant had provided substandard care than if the defendant had not, which "should provide a significant deterrent effect, despite the high overall error rate in claiming." 57

Moreover, some evidence shows that the law of damages also works well. There is a relatively strong correlation between claim disposition and injury severity: higher-injury claims are significantly more likely to be settled rather than denied. ${ }^{58}$ Based on two surveys of insurance company claims closed in 1974 and 1976, Danzon and Lillard reported that the mean award was over $\$ 100,000$ while the median was under $\$ 50,000$, indicating the underlying distribution of injury severity: while the vast majority of injuries were modest, a few were extremely severe ${ }^{59}$ Large awards would probably be mitigated either by the judge after trial or on appeal. ${ }^{60}$ The existence of false positives and false negatives, however small they are, does suggest that the malpractice system is not perfect. However, the system is by no means a random lottery. ${ }^{61}$

In 6 of all the above 9 studies, the percentage of false positives to nonmeritorious claims was larger than that of false negatives to meritorious claims. This finding suggests, other things being equal, that there might be considerable over-deterrence, since the court is more likely to commit Type I errors (false positives) than Type II errors (false negatives). ${ }^{62}$ However,

Danzon 2000, p. 1358.

See generally Farber \& White 1991; Taragin et al. 1992.

See generally Danzon \& Lillard 1983.

See generally Shanley \& Peterson 1987.

Van Velthoven \& Van Wijck 2012, p. 38

Dewees, Duff \& Trebilcock 1996, p. 100; Posner 2014, § 23.1. 
this over-deterrent effect may be totally reversed when taking into account the relatively low claim frequency ${ }^{63}$ and settlement out of court.

Many studies on malpractice claims reported that whereas only about $10 \%$ of all claims filed are tried to verdict, roughly $90 \%$ are settled out of court. ${ }^{64}$ Since the vast majority of malpractice claims are settled out of court, bargaining seems more important than trials for the resolution of malpractice disputes. Bargaining is argued to occur "in the shadow of the law," meaning "expectations about trials determine the outcomes of bargains." 65 If settlements were able to replicate trials, then the deterrent effect of the malpractice system would remain relatively unchanged. However, the fact that patients often receive lower payments in settlement of their claims than the amount of compensation that would otherwise have been payable at the trial renders the deterrence of the malpractice system doubtful. ${ }^{66}$ Danzon and Lillard reported that while the average award at verdict was $\$ 102,000$, the one at settlement was merely $\$ 26,000 .{ }^{67}$ Studdert et al. found that average jury awards $(\$ 799,000)$ were almost twice the size of the average out-of-court settlement $(\$ 462,000){ }^{68}$ This "under-compensation" due to out-of-court settlements may reduce the deterrent effect of the malpractice system. ${ }^{69}$

To conclude, the major problems plaguing the malpractice system are not that there are too many frivolous lawsuits or the system is an unpredictable "lottery," but that too few patients file claims and there are both "false positives" and "false negatives." Instead, the malpractice system is generally able to eliminate invalid claims. The efficiency of the malpractice system will be improved if these problems can be tackled.

\subsection{DOES MEDICAL MALPRACTICE LIABILITY HAVE A DETERRENT EFFECT?}

\subsubsection{Introduction}

The empirical evidence adduced in Section 2.4 generally confirms that the malpractice system is not a random lottery in that it is reasonably effective at

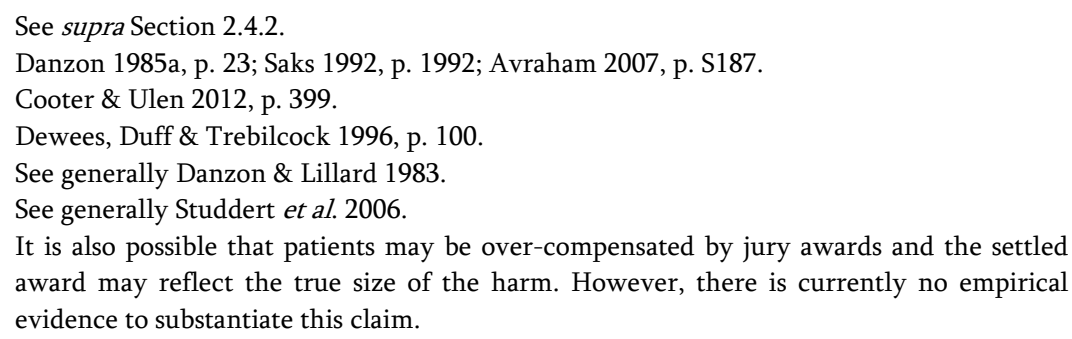


eliminating invalid claims. With regard to the impact of malpractice liability on medical practice, the aforementioned empirical findings are mixed, however. Whereas the fact that the likelihood of committing "false positives" is higher than that of committing "false negatives" suggests over-deterrence, health care providers may also be induced to under-invest in precautions when too few patients sue or when under-compensation is characteristic of settlement out of court through which roughly $90 \%$ of all claims are resolved.

By contrast, the classic model provides definite predictions. Due to imperfect information, ${ }^{70}$ it is highly likely that the resolution of malpractice disputes cannot be immune to "the use of inaccurate information, the inconsistent application of standards, and difficulties in determining correct standards." ${ }^{\prime 71}$ Hence, according to the classic model of malpractice, it's more than likely that health care providers will react to the uncertainty by overcomplying - "defensive medicine."

Even in a legal system where the customary practice standard for the determination of medical negligence is still prevailing, there are at least four factors associated with malpractice risks that can explain why physicians may deviate from professionally sanctioned practices..$^{72}$ First, although the opinion of a "respectable minority" falls within the category of customary practices, it may nevertheless be rejected by the court as unreasonable. ${ }^{73}$ Hence, physicians may prefer the majority opinion to the minority approach with a view to minimising malpractice risk. Second, physicians tend to respond to the risk of adjudicative errors by ordering more tests or procedures to satisfy adjudicators' expectations for highly technological treatment. ${ }^{74}$ Third, physicians may over-comply due to their unfamiliarity with applicable legal standards. ${ }^{75}$ Fourth, facing the financial and non-financial consequences of malpractice suits, physicians may become so risk averse that they adopt excessive precautions. ${ }^{76}$

Moreover, not only an increased malpractice threat but also a lack of cost constraints may contribute to excessive treatment. Under the traditional fee-for-service health insurance, ${ }^{77}$ there may be excessive treatment due to

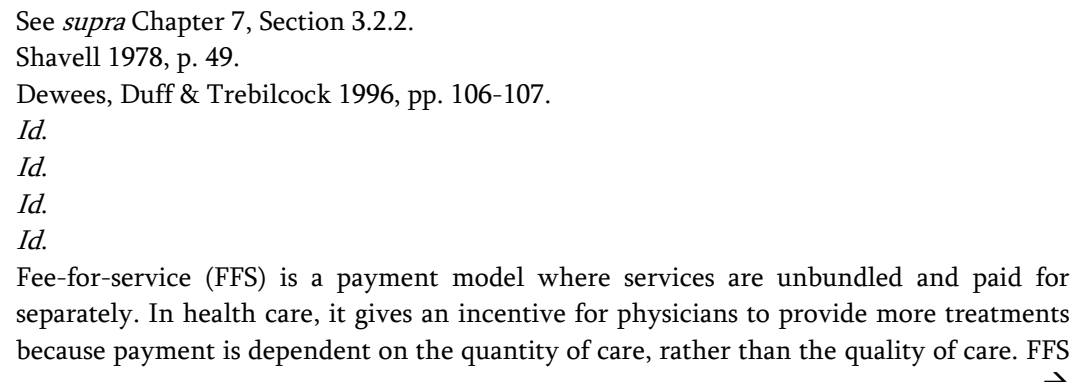
separately. In health care, it gives an incentive for physicians to provide more treatments because payment is dependent on the quantity of care, rather than the quality of care. FFS 
moral hazard, that is, physicians are induced to "provide the best care without regard to cost." ${ }^{.78}$

It is really an empirical question whether health care providers supply excessive treatment care by practising defensive medicine. Specifically speaking, it is important to know: (a) How is defensive medicine defined? (Section 2.5.2) (b) How extensive is defensive medicine? (Section 2.5.3) (c) What is the impact of tort reform on defensive medicine? (Section 2.5.4)

\subsubsection{Defining Defensive Medicine}

\subsubsection{Defining Defensive Medicine}

Defensive medicine is a vague concept that is hard to pin down. In practice, many empirical studies do not define "defensive medicine" from an economic angle. The most commonly cited definition of defensive medicine is proposed by the US Office of Technology Assessment (OTA): "Defensive medicine occurs when doctors order tests, procedures, or visits, or avoid high-risk patients or procedures, primarily (but not necessarily solely) to reduce their exposure to malpractice liability." 79 OTA's definition of defensive medicine differs from other versions in three aspects as follows: ${ }^{80}$

- OTA's definition does not exclude the case where physicians are not consciously incentivized by a threat of liability, but adhere to customary practice which was originally shaped by defensive purposes.

- OTA's definition does not exclude other motivations - such as to enhance effectiveness, or to reduce uncertainty over therapeutic effects or financial incentives - that eventually lead to defensive behaviour. A more stringent version that limits the purpose of defensive medicine solely to protect against future malpractice suits is not workable in practice, for it is extremely difficult to discriminate with confidence the fear of malpractice suits from other motivations.

- OTA's definition does not exclude those defensive practices that may be medically justified and appropriate. By contrast, the US Department of Health, Education, and Welfare (DHEW) limited defensive medicine to tests or procedures that are "not medically justified." ${ }^{1}$ OTA resisted this

is the dominant physician payment method in the US, and it is becoming the major payment method in China as well.

78 Project 1971, p. 946.

79 US Office of the Technology Assessment (OTA) 1994, p. 13.

80 US Office of the Technology Assessment (OTA) 1994, pp. 21-23.

81 US Department of Health, Education, and Welfare 1971, p. 14. 
limitation mainly on the grounds that it is impracticable to assess the appropriateness of all medical practices given the current state of medical knowledge. It is sometimes incredibly difficult to "draw a clear line between where good medical care ends and the purely selfish interests of the physician begin." 82

From the perspective of law and economics, "defensive medicine" is usually defined as "over-deterrence" - the situation where the expected costs of care exceed expected benefits in injury reduction..$^{83}$ In response to overdeterrence, health care providers may order tests or procedures excessively, or refrain from practising some highly risky procedures or even leave for locations with lower chances of malpractice suits. ${ }^{84}$ From this perspective, OTA's definition should be read with some reservations.

Although OTA's definition is workable, it can only be regarded as a rough measure of the extent of over-deterrence. First, OTA's definition is too broad. It includes some "medically justified" practices, which may be costjustified as well. Then, these practices actually reflect the socially optimal level of care rather than over-complying. It even includes "insurance-induced waste" that may increase physicians' income under fee-for-service insurance. ${ }^{85}$ Hence, the overall effect may be that OTA's definition is likely to exaggerate the extent of over-deterrence. Second, OTA's definition is not developed on the basis of efficient care. It only measures medically unjustified practices against the due care norm, which may be set either higher or lower than the optimal level of care. Therefore, even if empirical studies do find evidence of defensive medicine, that level of care might still fall short of the social optimum. ${ }^{86}$

\subsubsection{Positive versus Negative Defensive Medicine}

In the light of alterations in behaviour patterns, OTA also classifies defensive medicine into two categories: positive defensive medicine (hereinafter PDM) and negative defensive medicine (hereinafter NDM). PDM occurs when physicians "do extra tests or procedures primarily to reduce malpractice liability," while NDM happens when they "avoid certain patients or procedures," ${ }^{87}$ which was also referred to as "bias in patient selection." ${ }^{88}$ It

Bernzweig 1973, p. 39.

See generally Shavell 1978; Sloan \& Shadle 2009.

Sloan \& Chepke 2008, p. 11.

Danzon 2000, p. 1368.

See generally Sloan \& Shadle 2009; Van Velthoven \& Van Wijck 2012.

US Office of the Technology Assessment (OTA) 1994, p. 13. 
should be noted that OTA's definition of PDM excludes those behavioural changes that do not affect the rate of use of medical services, such as "spending more time with patients, giving more attention to careful documentation of the medical record, or making greater efforts to communicate or obtain informed consent." 89 However, from the law and economics perspective, some of these behavioural changes still entail greater costs of care, which nonetheless reflect over-complying. In this respect, OTA's definition of PDM tends to understate the extent of over-deterrence. However, since OTA's definition is so broad in many other aspects mentioned in the prior Section, the overall effect may still be an exaggeration of the actual extent of over-deterrence.

\subsubsection{The Extent of Defensive Medicine}

\subsubsection{Different Approaches}

To measure the extent of defensive medicine, even the one defined as broadly as OTA's version, can be exceedingly difficult. Nonetheless, numerous scholarly efforts have been made to assess defensive medicine in the past four decades. In terms of research methods, the available major literature on defensive medicine can be roughly grouped into two categories: (a) survey studies and (b) statistical studies..$^{90}$

Survey studies may be either direct physician surveys or clinical scenario surveys. Whereas the former attempted to measure the extent of defensive medicine by directly asking physicians how they altered their practice patterns in response to the threat of malpractice suits, the latter did so by asking physicians how they will respond to simulated clinical scenarios..$^{91}$ The main problem with the former method is that physicians may not always disclose what they actually do honestly, while that with the latter is that their results are associated only with the specific, simulated scenarios and may not be generalised..$^{92}$

By contrast, statistical studies, also called multi-variate analyses, are aimed at examining the correlation between the utilisation of a test or procedure and the threat of malpractice suits. ${ }^{93}$ One advantage of statistical studies is that they rely on "more objective data, the potential for large sample

Shavell 1978, p. 48.

US Office of the Technology Assessment (OTA) 1994, p. 22.

Manner 2007.

US Office of the Technology Assessment (OTA) 1994, p. 41.

US Office of the Technology Assessment (OTA) 1994, pp. 41-42.

US Office of the Technology Assessment (OTA) 1994, p. 42. 
sizes, and the ability to control for many different influences on physician behaviour." ${ }^{\prime 94}$ Although having their limitations, multi-variate studies produce crucial evidence as regards the "incremental impact of differences in malpractice liability risk on physicians' use of procedures." ${ }^{.95}$

Direct physician surveys and clinical scenario surveys are summarised in the remaining part of Section 2.5.3, while statistical studies on PDM and NDM will be addressed in Section 2.5.4 and Section 2.5.5 respectively.

\subsubsection{Direct Physician Surveys}

OTA (1994) reviewed 32 direct physician surveys conducted between 1983 and 1992. Of all the 32 surveys, whereas only half reported on PDM, 30 addressed NDM. ${ }^{96}$ Of the 16 surveys into PDM, on average about half of all physicians reported that they had ordered extra tests or procedures due to concerns about malpractice suits. ${ }^{97}$ By contrast, on average about $30 \%$ of physicians of the 30 surveys indicated that they imposed restrictions on their practices (NDM) in order to avoid malpractice suits. ${ }^{98}$ In relation to the reasons for excessive tests or procedures, most physicians only deemed the threat of malpractice suits as a relatively minor influential factor in comparison with other considerations such as inexperience, habit, pressure from colleagues, preference for laboratory tests instead of clinical judgement. ${ }^{99}$

Several direct survey studies after 1992 reported similar results. Weiler et al. administered a survey of 739 physicians and asked about changes in their pattern of practice. ${ }^{100}$ Most physicians indicated that the malpractice threat affected their pattern of practice - they would order more tests or procedures, or reduce the number of patients seen; but these changes did not have greater influence than hospital quality assurance programs on maintaining or improving the actual quality of care. ${ }^{101}$ Later, a mail survey of 824 physicians was conducted in Pennsylvania in 2003. ${ }^{102}$ Almost all (93\%) of the physicians reported defensive practices, $92 \%$ of which belong to "assurance behaviour" - ordering extra tests or procedures, or referring

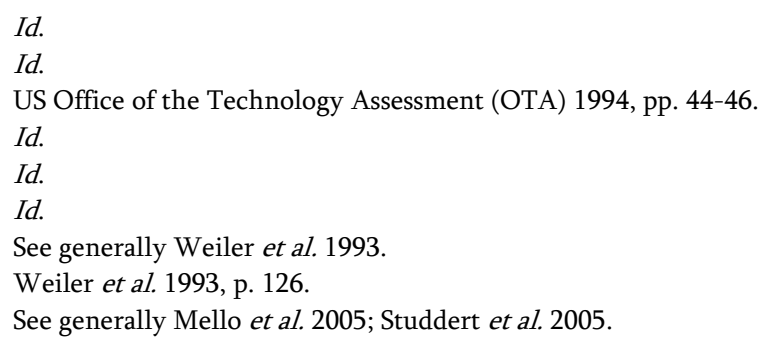


patients for consultation. ${ }^{103}$ In addition, $42 \%$ of the physicians indicated that they had taken steps to restrict their practice by avoiding complication-prone procedures or patients in the previous 3 years. ${ }^{104}$ Recently, Carrier et al. undertook a nationally representative mail survey of US physicians. ${ }^{105} \mathrm{~A}$ vast majority $(60 \% \sim 78 \%)$ of the physicians, even those who practice in relatively low-risk environments, expressed concern about malpractice suits. ${ }^{106}$ Emergency physicians and obstetrician-gynaecologists indicated deeper concern than psychiatrists or general paediatricians. ${ }^{107}$

Although, overall, these studies disclose the prevalence of defensive medicine their results may be exaggerated due to two reasons. First, the physicians' subjective perception of malpractice risk may not be accurate. Empirical evidence shows that physicians tend to over-estimate malpractice risks and some physicians in lower-risk specialties or regions even have greater concern for malpractice suits. ${ }^{108}$ Second, the data collection method of direct physician surveys may skew the results. As criticised by OTA, direct physician surveys "invariably prompt responding physicians to consider malpractice liability as a factor in their practice choices." ${ }^{109}$ As a matter of fact, several studies that intended to assess the impact of court decisions on the practice patterns found only a minimal or desirable deterrent effect rather than over-deterrence. ${ }^{110}$

\subsubsection{Survey Studies using Clinical Scenarios}

The Duke Law Journal Project was perhaps the first comprehensive study into defensive medicine in the US. ${ }^{111}$ The Project sent questionnaires asking about the use of procedures in simulated clinical scenarios to 827 randomly selected physicians in California and North Carolina. ${ }^{12}$ The Project concluded that "positive defensive medicine is not extensively practised and does not have as significant an impact as previously alleged." 113 In 8 out of 11 hypothetical scenarios, about $20 \%$ of physicians indicated that they would

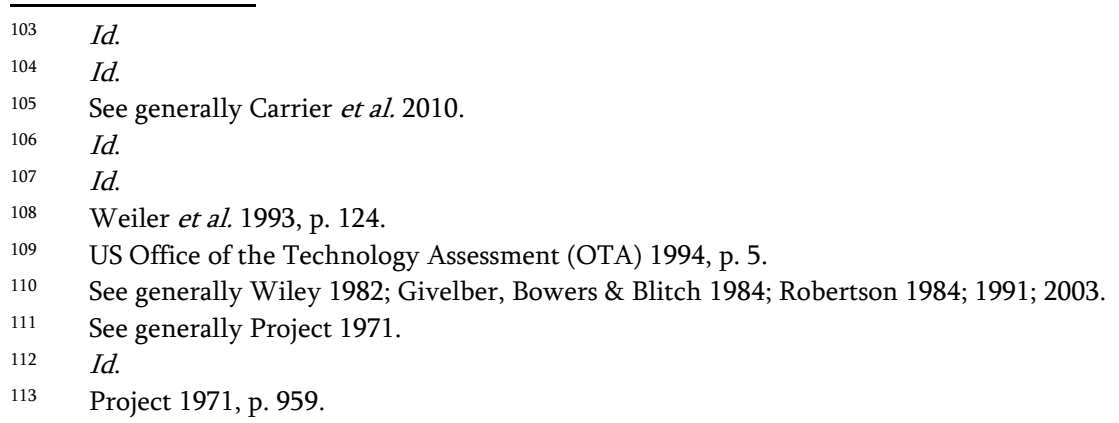


sometimes practice PDM. ${ }^{114}$ But only about $20 \%$ of physicians in half of these 8 scenarios reported that they would practice PDM more than half of the time. ${ }^{115}$

Following the Project's approach, OTA conducted a series of comprehensive studies using hypothetical clinical scenarios. ${ }^{116}$ In all the 9 selected scenarios, $5 \%$ to $29 \%$ of all physicians indicated they would choose the malpractice threat as one motivation for defensive clinical actions. ${ }^{117}$ However, in 6 out of the 9 scenarios, less than 10\% of all physicians regarded the malpractice threat as the primary reason for defensive clinical actions. ${ }^{118}$ Since the selected scenarios were deliberately designed to reflect defensive medicine, it is reasonable to deduce that only a minority of diagnostic procedures (less than 8\%) may be the result of concern about malpractice suits. ${ }^{119}$ Many physicians, motivated by medical indications rather than by the malpractice threat, would choose to provide excessive treatment. ${ }^{120}$

Since surveys using clinical scenarios overcome the methodological shortcoming of direct physician surveys, their results may be more reliable than those reported by direct surveys. As a result, it is reasonable to infer that defensive medicine is not practised so prevalently as many direct surveys or anecdotal evidence suggest. Nonetheless, clinical scenario surveys are still methodologically limited in that they are based on self-reports rather than on data on actual use of procedures.

\subsubsection{Statistical Evidence on the Extent of PDM}

\subsubsection{Introduction}

Statistical studies into PDM attempt to confirm or falsify the hypothesis that physicians with greater exposure to the malpractice risk will practice more PDM than those with lower exposure. There are mainly two groups of these studies: one group tested the hypothesis in a specific clinical setting of obstetrics, while the other in a general ailment setting. Obstetrics was chosen because it is among the specialties with the highest levels of exposure to the malpractice threat and Caesarian sections may minimise malpractice risks. ${ }^{21}$

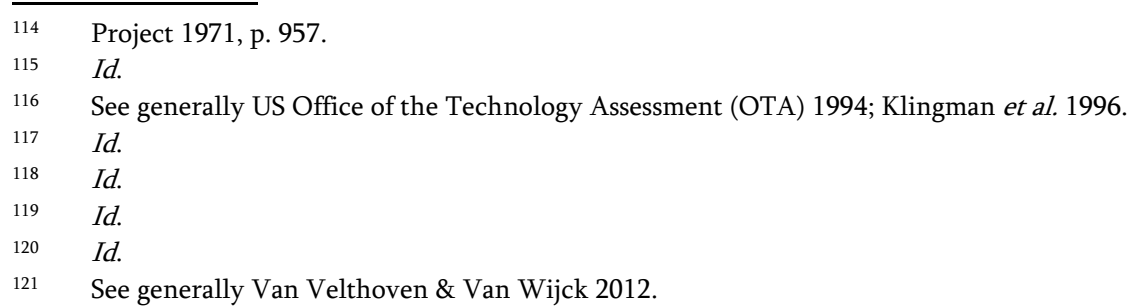


In the next, I will summarise statistical studies on PDM in the context of obstetrics in Section 2.5.4.2 and those in a general or other contexts in Section 2.5.4.3.

2.5.4.2. Statistical Studies on PDM in the Speciality of Obstetrics

The major statistical studies on PDM, as far as obstetrics is concerned, are summarised in Table 8.5.

Table 8.5: Statistical Studies on PDM in the Speciality of Obstetrics ${ }^{122}$

\begin{tabular}{|c|c|c|c|c|c|}
\hline $\begin{array}{l}\text { Studies by } \\
\text { Year }\end{array}$ & Data & $\begin{array}{c}\text { Cause } \\
\text { (Independent } \\
\text { Variable) }\end{array}$ & $\begin{array}{c}\text { Effect } \\
\text { (Dependent } \\
\text { Variable) }\end{array}$ & \multicolumn{2}{|c|}{ Results } \\
\hline $\begin{array}{l}\text { Goyert et } \\
\text { al., } 1989\end{array}$ & $\begin{array}{l}1,533 \text { affluent } \\
\text { women at low } \\
\text { risk of } \\
\text { obstetrical } \\
\text { complications in } \\
\text { a community } \\
\text { hospital }\end{array}$ & claims history & $\begin{array}{l}\text { caesarian- } \\
\text { section rate }\end{array}$ & \multicolumn{2}{|c|}{ no effect } \\
\hline $\begin{array}{l}\text { Tussing and } \\
\text { Wojtowycz, } \\
1992\end{array}$ & $\begin{array}{l}\text { a } 1986 \text { data set } \\
\text { concerning } \\
68,847 \text { obstetric } \\
\text { deliveries in } \\
\text { New York State } \\
\text { excluding New } \\
\text { York City }\end{array}$ & claims history & $\begin{array}{l}\text { caesarian- } \\
\text { section rate }\end{array}$ & \multicolumn{2}{|c|}{$\begin{array}{l}\text { negative: a negative } \\
\text { relationship between fear } \\
\text { of malpractice and } \\
\text { Caesarian section use* }^{*}\end{array}$} \\
\hline \multirow{3}{*}{$\begin{array}{l}\text { Localio et } \\
\text { al., } 1993\end{array}$} & \multirow{3}{*}{$\begin{array}{l}60,490 \text { deliveries } \\
\text { at } 31 \text { hospitals in } \\
\text { New York State } \\
\text { in } 1984\end{array}$} & $\begin{array}{l}\text { malpractice } \\
\text { premiums }\end{array}$ & \multirow{3}{*}{$\begin{array}{l}\text { caesarian- } \\
\text { section rate }\end{array}$} & \multirow{3}{*}{ positive } & $\begin{array}{l}\text { positively } \\
\text { associated } \\
\left(\mathrm{OR}^{* *}, 3.00\right)\end{array}$ \\
\hline & & $\begin{array}{l}\text { physician- } \\
\text { perceived risk }\end{array}$ & & & $\begin{array}{l}\text { positively } \\
\text { associated } \\
(\mathrm{OR}, 1.96)\end{array}$ \\
\hline & & claims history & & & $\begin{array}{l}\text { positively but } \\
\text { not } \\
\text { significantly } \\
\text { associated } \\
(\mathrm{OR}, 1.15)\end{array}$ \\
\hline $\begin{array}{l}\text { Baldwin et } \\
\text { al., } 1995\end{array}$ & $\begin{array}{l}\text { the use of } \\
\text { services in low- } \\
\text { risk prenatal } \\
\text { cases in } \\
\text { Washington in } \\
1989\end{array}$ & claims history & $\begin{array}{l}\text { caesarian- } \\
\text { section rate }\end{array}$ & \multicolumn{2}{|c|}{ no effect } \\
\hline
\end{tabular}

122 This table is modelled on Van Dijck 2015, pp. 290-292, Table 1. 
Part II. Economic Theories and Empirical Evidence

\begin{tabular}{|c|c|c|c|c|}
\hline $\begin{array}{l}\text { Sloan et al., } \\
1997\end{array}$ & $\begin{array}{l}\text { a survey of } 963 \\
\text { women who had } \\
\text { given birth in } 1987 \\
\text { in } 31 \text { counties in } \\
\text { Florida }\end{array}$ & $\begin{array}{l}\text { malpractice } \\
\text { lawsuit rate }\end{array}$ & $\begin{array}{l}\text { caesarian- } \\
\text { section } \\
\text { rate }\end{array}$ & no effect \\
\hline $\begin{array}{l}\text { Tussing and } \\
\text { Wojtowycz, } \\
1997\end{array}$ & $\begin{array}{l}\text { 58,441 obstetric } \\
\text { deliveries in New } \\
\text { York State outside } \\
\text { New York City for } \\
1975 \text { through } 1986\end{array}$ & $\begin{array}{l}\text { fear of } \\
\text { malpractice } \\
\text { (claims } \\
\text { history) }\end{array}$ & $\begin{array}{l}\text { caesarian- } \\
\text { section } \\
\text { rate }\end{array}$ & $\begin{array}{l}\text { positive: large effect: } \\
\text { caesarean-section rate } \\
\text { increased by } 33 \%\end{array}$ \\
\hline $\begin{array}{l}\text { Dubay, } \\
\text { Kaestner } \\
\text { and } \\
\text { Waidmann, } \\
1999\end{array}$ & $\begin{array}{l}\text { national birth } \\
\text { certificate data } \\
\text { from } 1990 \text { through } \\
1992\end{array}$ & $\begin{array}{l}\text { malpractice } \\
\text { premiums }\end{array}$ & $\begin{array}{l}\text { caesarian- } \\
\text { section } \\
\text { rate }\end{array}$ & positive: small effect \\
\hline $\begin{array}{l}\text { Grant and } \\
\text { McInnes, } \\
2004\end{array}$ & $\begin{array}{l}\text { data on the practice } \\
\text { behaviour of a } \\
\text { panel of } \\
\text { obstetricians in } \\
\text { Florida during the } \\
\text { period 1992-1995 }\end{array}$ & $\begin{array}{l}\text { claims } \\
\text { history }\end{array}$ & $\begin{array}{l}\text { caesarian- } \\
\text { section } \\
\text { rate }\end{array}$ & $\begin{array}{l}\text { positive: small effect: } \\
\text { Caesarean rates increased } \\
\text { by about } 1 \%\end{array}$ \\
\hline Kim, 2007 & $\begin{array}{l}\text { a national data set } \\
\text { of malpractice } \\
\text { claims resolved for } \\
\text { the period 1990- } \\
2005\end{array}$ & $\begin{array}{l}\text { claims } \\
\text { history }\end{array}$ & $\begin{array}{l}\text { caesarian- } \\
\text { section } \\
\text { rate }\end{array}$ & no effect \\
\hline $\begin{array}{l}\text { Murthy et } \\
\text { al., } 2007\end{array}$ & $\begin{array}{l}\text { data on singleton } \\
\text { births in Illinois for } \\
\text { the period 1998- } \\
2003 \text { from the } \\
\text { National Centre for } \\
\text { Health Statistics }\end{array}$ & $\begin{array}{l}\text { malpractice } \\
\text { premiums }\end{array}$ & $\begin{array}{l}\text { caesarian- } \\
\text { section } \\
\text { rate }\end{array}$ & $\begin{array}{l}\text { positive: an annual } \\
\$ 10,000 \text { premium } \\
\text { increase was associated } \\
\text { with an increase in } \\
\text { Caesarean rate by } 15,7 \\
\text { per } 1,000 \text { for nulliparous } \\
\text { women and by } 4.7 \% \text { per } \\
1,000 \text { for multiparous } \\
\text { women }\end{array}$ \\
\hline $\begin{array}{l}\text { Currie and } \\
\text { MacLeod, } \\
2008\end{array}$ & $\begin{array}{l}\text { data from national } \\
\text { vital statistics } \\
\text { natality files on } \\
\text { births for the } \\
\text { period 1989-2001 }\end{array}$ & $\begin{array}{l}\text { caps on non- } \\
\text { pecuniary } \\
\text { damages }\end{array}$ & $\begin{array}{l}\text { caesarian- } \\
\text { section } \\
\text { rate }\end{array}$ & $\begin{array}{l}\text { negative: imposing caps } \\
\text { associated with more use } \\
\text { of Caesarean sections }\end{array}$ \\
\hline
\end{tabular}




\begin{tabular}{|c|c|c|c|c|c|}
\hline \multirow[t]{2}{*}{$\begin{array}{l}\text { Yang et al., } \\
2009\end{array}$} & \multirow{2}{*}{$\begin{array}{l}\text { data on births } \\
\text { from the } \\
\text { Natality Detail } \\
\text { File in the US } \\
\text { for the period } \\
\text { 1991-2003 }\end{array}$} & $\begin{array}{l}\text { malpractice } \\
\text { premiums }\end{array}$ & \multirow[t]{2}{*}{$\begin{array}{l}\text { caesarian- } \\
\text { section } \\
\text { rate }\end{array}$} & \multirow[t]{2}{*}{ positive } & $\begin{array}{l}\text { a } \$ 10,000 \\
\text { decrease in } \\
\text { premiums was } \\
\text { associated with a } \\
\text { decrease of } 0.15 \\
\text { percentage } \\
\text { points in } \\
\text { Caesarian rate }\end{array}$ \\
\hline & & $\begin{array}{l}\text { Caps on non- } \\
\text { pecuniary } \\
\text { damages and } \\
\text { screening } \\
\text { panels } \\
\end{array}$ & & & $\begin{array}{l}\text { slightly } \\
\text { correlated }\end{array}$ \\
\hline $\begin{array}{l}\text { Dranove } \\
\text { and } \\
\text { Watanabe, } \\
2009\end{array}$ & $\begin{array}{l}\text { patient } \\
\text { discharge data } \\
\text { from } 1994 \\
\text { through } 2000 \\
\text { with physician } \\
\text { claims data for } \\
\text { the period } \\
\text { 1979-2003 from } \\
\text { Florida }\end{array}$ & claims history & $\begin{array}{l}\text { caesarian- } \\
\text { section } \\
\text { rate }\end{array}$ & $\begin{array}{l}\text { complicat } \\
\text { than simp } \\
\text { negative }\end{array}$ & $\begin{array}{l}\text { ed results rather } \\
\text { ly positive or }\end{array}$ \\
\hline
\end{tabular}

Overall, the results concerning the impact of the risk of malpractice on Caesarian rates provided by the above studies are mixed. Many studies confirmed that physicians respond to greater malpractice risk by performing more Caesarian sections. ${ }^{123}$ However, a few studies on obstetrics reported no significant association between the Caesarian rate and exposure to malpractice risk. ${ }^{124}$ More strikingly, a small minority of studies even reported a negative association between malpractice risk and Caesarian rates. ${ }^{125}$

Nevertheless, most of the studies did find a positive association, be it statistically significant or not. Results of a negative association are comparatively rare. Interestingly, there was a study reporting complex results rather than simply saying "yes or no." Dranove and Watanabe (2009) concluded that personal and local experiences of malpractice suits had only a "small and short-lived" implication for Caesarian rates and were limited to obstetricians with no previous claim experience. ${ }^{126}$ This finding indicates that

\footnotetext{
$123 \quad$ See generally Localio et al. 1993; Tussing \& Wojtowycz 1997; Dubay, Kaestner \& Waidmann 1999; Grant \& McInnes 2004; Manner 2007; Yang et al. 2009.

$124 \quad$ See generally Goyert et al. 1989; Baldwin et al. 1995; Sloan et al. 1997; Kim 2007.

125 See generally Tussing \& Wojtowycz 1992; Currie \& MacLeod 2008.

126 See generally Dranove \& Watanabe 2009.
} 
obstetricians over-responded to their first experience, and they "rapidly discover that the litigation process is neither costly nor particularly painful." ${ }^{127}$ Therefore, according to Dranove and Watanabe, at least obstetricians who have never experienced malpractice claims will perform more Caesaiean sections due to fear of malpractice claims. Whatever the results of the foregoing studies were, they only apply to obstetrics and cannot be generalised to the whole medical practices.

\subsubsection{Statistical Studies on PDM in the General Ailment Setting or Other}

\section{Specialities than Obstetrics}

Many studies on PDM did not pay particular attention to a single speciality such as obstetrics. In general, they attempted to measure the extent of PDM by examining the relationship between malpractice risk with costs of practice changes. The underlying hypothesis is that greater malpractice risk leads to higher health care costs. The major studies are summarised in Table 8.6.

Table 8.6: Statistical Studies on PDM in a General Ailment Setting or NonObstetrics Specialties

\begin{tabular}{|c|c|c|c|c|}
\hline $\begin{array}{l}\text { Studies by } \\
\text { Year }\end{array}$ & Data & $\begin{array}{c}\text { Cause } \\
\text { (Independent } \\
\text { Variable) }\end{array}$ & $\begin{array}{c}\text { Effect } \\
\text { (Dependent } \\
\text { Variable) }\end{array}$ & Results \\
\hline $\begin{array}{l}\text { Greenwald } \\
\text { and Mueller, } \\
1978\end{array}$ & $\begin{array}{l}\text { cross-sectional } \\
\text { data by state from } \\
1970\end{array}$ & $\begin{array}{l}\text { malpractice } \\
\text { premiums }\end{array}$ & $\begin{array}{l}\text { costs or use } \\
\text { of medical } \\
\text { care }\end{array}$ & $\begin{array}{l}\text { positive: a } 100 \% \\
\text { growth in physicians' } \\
\text { premiums was } \\
\text { associated with a } \\
2.3 \% \text { increase in } \\
\text { physicians' fees and } \\
\text { an } 8 \% \text { increase in use } \\
\text { of physician service, } \\
\text { and an } 4.1 \% \text { increase } \\
\text { in hospital prices }\end{array}$ \\
\hline $\begin{array}{l}\text { Reynolds, } \\
\text { Rizzo and } \\
\text { Gonzalez, } \\
1987\end{array}$ & $\begin{array}{l}\text { data from the } \\
\text { American Medical } \\
\text { Association's } \\
\text { Socioeconomic } \\
\text { Monitoring } \\
\text { System }\end{array}$ & $\begin{array}{l}\text { costs of } \\
\text { malpractice } \\
\text { liability and } \\
\text { practice changes }\end{array}$ & $\begin{array}{l}\text { costs of } \\
\text { medical } \\
\text { care }\end{array}$ & $\begin{array}{l}\text { positive: costs of } \\
\text { liability and practice } \\
\text { changes accounted } \\
\text { for } 57 \% \text { to } 63 \% \text { of } \\
\text { the growth in } \\
\text { physician fees }\end{array}$ \\
\hline $\begin{array}{l}\text { US Office of } \\
\text { the } \\
\text { Technology } \\
\text { Assessment } \\
\text { (OTA), } 1994\end{array}$ & $\begin{array}{l}1,540 \text { physicians } \\
\text { in New Jersey for } \\
\text { the period 1977- } \\
1992\end{array}$ & claims history & $\begin{array}{l}\text { physicians' } \\
\text { use of } \\
\text { resources }\end{array}$ & no_effect \\
\hline
\end{tabular}

127 Dranove \& Watanabe 2009, p. 92 
Preventing Medical Errors through Tort Law - Empirical Evidence and Updated Models

\begin{tabular}{|c|c|c|c|c|}
\hline $\begin{array}{l}\text { Kessler and } \\
\text { McClellan, } \\
\text { 1996; 2002a; } \\
\text { 2002b }\end{array}$ & $\begin{array}{l}\text { data on all elderly } \\
\text { Medicare } \\
\text { beneficiaries with } \\
\text { serious heart } \\
\text { disease }\end{array}$ & $\begin{array}{l}\text { tort reforms } \\
\text { aiming at } \\
\text { reducing the } \\
\text { level of } \\
\text { compensation }\end{array}$ & $\begin{array}{l}\text { costs of } \\
\text { medical } \\
\text { care }\end{array}$ & $\begin{array}{l}\text { positive: tort reforms } \\
\text { reduced medical } \\
\text { expenditures without } \\
\text { significant } \\
\text { implications for } \\
\text { patient health } \\
\text { outcomes }\end{array}$ \\
\hline $\begin{array}{l}\text { Baicker and } \\
\text { Chandra, } \\
\text { 2005a }\end{array}$ & $\begin{array}{l}\text { data sets from } \\
\text { several sources }\end{array}$ & $\begin{array}{l}\text { state-level } \\
\text { increases in } \\
\text { malpractice } \\
\text { costs }\end{array}$ & $\begin{array}{l}\text { the use of } \\
\text { procedures }\end{array}$ & no effect \\
\hline $\begin{array}{l}\text { Hellinger } \\
\text { and } \\
\text { Encinosa, } \\
2006\end{array}$ & $\begin{array}{l}\text { relatively recent } \\
\text { data from several } \\
\text { sources }\end{array}$ & $\begin{array}{l}\text { caps on } \\
\text { payments }\end{array}$ & $\begin{array}{l}\text { costs of } \\
\text { medical } \\
\text { care }\end{array}$ & $\begin{array}{l}\text { positive: statutes } \\
\text { imposing caps on } \\
\text { payments reduced } \\
\text { health care } \\
\text { expenditures by } 3 \text { to } \\
4 \text { percentage points }\end{array}$ \\
\hline $\begin{array}{l}\text { Baicker, } \\
\text { Fisher and } \\
\text { Chandra, } \\
2007\end{array}$ & $\begin{array}{l}\text { data from } \\
\text { Medicare for the } \\
\text { period 2000-2003 }\end{array}$ & $\begin{array}{l}\text { malpractice } \\
\text { premiums }\end{array}$ & $\begin{array}{l}\text { costs of } \\
\text { medical } \\
\text { care }\end{array}$ & $\begin{array}{l}\text { positive: an } 60 \% \\
\text { growth in premiums } \\
\text { resulted in an } \\
\text { increase of more than } \\
\$ 15 \text { billion in total } \\
\text { Medicare } \\
\text { expenditure }\end{array}$ \\
\hline $\begin{array}{l}\text { Sloan and } \\
\text { Shadle, } 2009\end{array}$ & $\begin{array}{l}\text { US longitudinal } \\
\text { data from the } \\
\text { National Long- } \\
\text { Term Care Survey } \\
\text { combined with } \\
\text { Medicare claims } \\
\text { for the period } \\
\text { 1985-2000 }\end{array}$ & $\begin{array}{l}\text { tort reforms } \\
\text { (caps on } \\
\text { damages, } \\
\text { abolition of } \\
\text { punitive } \\
\text { damages, and } \\
\text { collateral source } \\
\text { set-off) }\end{array}$ & $\begin{array}{l}\text { costs of } \\
\text { medical } \\
\text { care }\end{array}$ & no effect \\
\hline $\begin{array}{l}\text { Thomas, } \\
\text { Ziller and } \\
\text { Thayer, } 2010\end{array}$ & $\begin{array}{l}\text { thirty-five clinical } \\
\text { specialities }\end{array}$ & $\begin{array}{l}\text { malpractice } \\
\text { premiums }\end{array}$ & $\begin{array}{l}\text { costs of } \\
\text { medical } \\
\text { care }\end{array}$ & $\begin{array}{l}\text { positive: a } 10 \% \text { drop } \\
\text { in premiums led to } \\
\text { less than } 1 \% \text { decrease } \\
\text { in total medical care } \\
\text { costs, small impact }\end{array}$ \\
\hline $\begin{array}{l}\text { Smith- } \\
\text { Bindman et } \\
\text { al., } 2011\end{array}$ & $\begin{array}{l}\text { a national sample } \\
\text { of } 8,588 \text { women } \\
\text { patients in } 10 \text { US } \\
\text { states between } \\
1992 \text { and } 2001\end{array}$ & $\begin{array}{l}\text { tort reforms } \\
\text { (periodic } \\
\text { payments or } \\
\text { collateral source } \\
\text { off-set) }\end{array}$ & $\begin{array}{l}\text { neurologic } \\
\text { imaging } \\
\text { rates }\end{array}$ & $\begin{array}{l}\text { positive: mandated } \\
\text { periodic award } \\
\text { payments or specified } \\
\text { collateral source } \\
\text { offset rules had a } \\
\text { roughly } 40 \% \text { lower } \\
\text { likelihood of imaging } \\
\text { relative to states } \\
\text { without tort reforms; } \\
\text { the total number of } \\
\text { reform laws was } \\
\text { significantly } \\
\text { associated with the } \\
\text { odds of imaging }\end{array}$ \\
\hline
\end{tabular}


As shown in Table 8.6, the foregoing results generated by studies on settings other than obstetrics are mixed as well. Many studies reported a positive association. ${ }^{128}$ In contrast, a few studies reported results contradictory to the foregoing positive results. ${ }^{129}$ However, the number of studies reporting positive results is relatively larger than that of studies with no significant effect. More importantly, in contrast to studies into obstetrics, studies addressed under this sub-heading had not reported negative associations.

\subsubsection{Summary}

Existing empirical evidence on the extent of PDM, either in the speciality of obstetrics or in the general setting or other settings, is mixed. However, the number of studies reporting positive results $(\mathrm{n}=13)$ is slightly larger than that of studies reporting no effect $(n=7)$ or even negative effect $(n=2)$. Of course, we could not confirm the existence of PDM by simply counting and comparing the number of studies. But it is also inadvisable to ignore the many studies with positive results and deny the prevalence of PDM.

\subsubsection{Statistical Evidence on the Extent of NDM}

\subsubsection{Statistical Studies on NDM in the Specialty of Obstetrics}

Statistical studies on the extent of NDM in the context of obstetrics are often measured by changes in activity levels. Four studies are summarized in Table 8.7.

$128 \quad$ See generally Greenwald \& Mueller 1978; Reynolds, Rizzo \& Gonzalez 1987; Kessler \& McClellan 1996; 2002a; 2002b; Baicker \& Chandra 2005a; Hellinger \& Encinosa 2006; Baicker, Fisher \& Chandra 2007; Thomas, Ziller \& Thayer 2010; Smith-Bindman et al. 2011.

129 See generally US Office of the Technology Assessment (OTA) 1994; Baicker \& Chandra 2005a; Sloan \& Shadle 2009. 
Preventing Medical Errors through Tort Law - Empirical Evidence and Updated Models

Table 8.7: Statistical Studies on NDM in the Specialty of Obstetrics

\begin{tabular}{|c|c|c|c|c|}
\hline $\begin{array}{l}\text { Studies by } \\
\text { Year }\end{array}$ & Data & $\begin{array}{c}\text { Cause } \\
\text { (Independent } \\
\text { Variable) }\end{array}$ & $\begin{array}{c}\text { Effect } \\
\text { (Dependent } \\
\text { Variable) }\end{array}$ & Results \\
\hline $\begin{array}{l}\text { Rosenblatt } \\
\text { and } \\
\text { Wright, } \\
1987\end{array}$ & $\begin{array}{l}685 \text { members of } \\
\text { the Washington } \\
\text { Academy of } \\
\text { Family Practice } \\
\text { in } 1985\end{array}$ & $\begin{array}{l}\text { malpractice } \\
\text { premiums }\end{array}$ & $\begin{array}{l}\text { obstetric } \\
\text { practice }\end{array}$ & $\begin{array}{l}\text { positive: of the } 266 \\
\text { respondents not } \\
\text { currently practising } \\
\text { obstetrics, } 38.5 \% \text { had } \\
\text { discontinued } \\
\text { obstetric practice } \\
\text { within the past five } \\
\text { years due to } \\
\text { malpractice risk }\end{array}$ \\
\hline $\begin{array}{l}\text { US Office } \\
\text { of the } \\
\text { Technology } \\
\text { Assessment } \\
\text { (OTA), } \\
1994\end{array}$ & $\begin{array}{l}\text { self-reported } \\
\text { data from a } 1987 \\
\text { national survey } \\
\text { of member of } \\
\text { ACOG, state- } \\
\text { level data on } \\
\text { premiums and } \\
\text { other kinds of } \\
\text { data }\end{array}$ & claims history & $\begin{array}{l}\text { obstetric } \\
\text { practice }\end{array}$ & $\begin{array}{l}\text { positive: OB/GYNs in } \\
\text { states with greater } \\
\text { malpractice threat } \\
\text { and who reported } \\
\text { higher personal } \\
\text { malpractice claims } \\
\text { exposure were more } \\
\text { likely to be practising } \\
\text { obstetrics and had } \\
\text { higher volumes of } \\
\text { obstetric care* }\end{array}$ \\
\hline $\begin{array}{l}\text { Dranove } \\
\text { and Gron, } \\
2005\end{array}$ & $\begin{array}{l}\text { hospital in- } \\
\text { patient use data } \\
\text { provided by the } \\
\text { Florida State } \\
\text { Centre for } \\
\text { Health Statistics }\end{array}$ & $\begin{array}{l}\text { malpractice } \\
\text { premiums }\end{array}$ & $\begin{array}{l}\text { obstetric } \\
\text { practice }\end{array}$ & $\begin{array}{l}\text { no effect: a surge in } \\
\text { premiums did not } \\
\text { increase travel times } \\
\text { of women undergoing } \\
\text { high-risk deliveries** }\end{array}$ \\
\hline $\begin{array}{l}\text { Yang et al., } \\
2008\end{array}$ & $\begin{array}{l}\text { AMA Physician } \\
\text { Masterfile for } \\
\text { 1994-2004 }\end{array}$ & $\begin{array}{l}\text { malpractice } \\
\text { premiums/tort } \\
\text { reforms }\end{array}$ & $\begin{array}{l}\text { supply of } \\
\text { obstetrician- } \\
\text { gynecologists }\end{array}$ & $\begin{array}{l}\text { no effect: the supply } \\
\text { of OB/GYNs was not } \\
\text { significantly } \\
\text { associated with } \\
\text { premiums or tort } \\
\text { reforms }\end{array}$ \\
\hline
\end{tabular}

${ }^{*}$ It is assumed that the worse the liability climate, the less other providers of obstetric are (e.g. family practice physicians and nurse-midwives).

${ }^{* *}$ It is assumed that the higher travel times, the more obstetric care services.

The above results regarding the extent of NDM pertaining to obstetrics are mixed. Hence, it is hard to say whether the malpractice risk truly affects obstetric practice.

\subsubsection{Statistical Studies on NDM in the General Ailment Setting}

In contrast to the mixed results of statistical studies on NDM in the specialty of obstetrics, the vast majority ( 5 out of 7 ) of studies into NDM in a general setting or other specialties than obstetrics confirmed the hypothesis that 
greater malpractice risk is associated with less supply of care. These studies are summarised in Table 8.8.

Table 8.8: Statistical Studies on NDM in the General Setting

\begin{tabular}{|c|c|c|c|c|}
\hline $\begin{array}{c}\text { Studies by } \\
\text { Year }\end{array}$ & Data & $\begin{array}{c}\text { Cause } \\
\text { (Independent } \\
\text { Variable) }\end{array}$ & $\begin{array}{c}\text { Effect } \\
\text { (Dependent } \\
\text { Variable) }\end{array}$ & Results \\
\hline Gius, 2000 & $\begin{array}{l}\text { data from the } \\
\text { 1990's }\end{array}$ & $\begin{array}{l}\text { malpractice } \\
\text { premiums }\end{array}$ & $\begin{array}{l}\text { state-level } \\
\text { physician } \\
\text { supply }\end{array}$ & $\begin{array}{l}\text { positive: higher premiums } \\
\text { were correlated with } \\
\text { lower physician supply at } \\
\text { the state level }\end{array}$ \\
\hline $\begin{array}{l}\text { Kessler, } \\
\text { Sage and } \\
\text { Becker, } \\
2005\end{array}$ & $\begin{array}{l}\text { data on the } \\
\text { supply of } \\
\text { physician } \\
\text { services in the } \\
\text { US for the } \\
\text { period 1985- } \\
2001\end{array}$ & $\begin{array}{l}\text { direct tort } \\
\text { reforms }\end{array}$ & $\begin{array}{l}\text { physician } \\
\text { supply }\end{array}$ & $\begin{array}{l}\text { positive: physician supply } \\
\text { was increased by } 3.3 \% \\
\text { three years after } \\
\text { implementing direct tort } \\
\text { reforms }\end{array}$ \\
\hline $\begin{array}{l}\text { Encinosa } \\
\text { and } \\
\text { Hellinger, } \\
2005\end{array}$ & $\begin{array}{l}\text { county-level } \\
\text { data from all } \\
\text { fifty states for } \\
\text { the period } \\
1985-2000\end{array}$ & $\begin{array}{l}\text { caps on } \\
\text { damages }\end{array}$ & $\begin{array}{l}\text { physician } \\
\text { supply }\end{array}$ & $\begin{array}{l}\text { positive: a cap on damages } \\
\text { had } 2.2 \% \text { more physicians } \\
\text { per capita and rural } \\
\text { counties had } 3.2 \% \text { more } \\
\text { relative to their } \\
\text { counterparts in other } \\
\text { states }\end{array}$ \\
\hline $\begin{array}{l}\text { Baicker } \\
\text { and } \\
\text { Chandra, } \\
2005 b\end{array}$ & $\begin{array}{l}\text { data from } \\
\text { several } \\
\text { different } \\
\text { sources }\end{array}$ & $\begin{array}{l}\text { malpractice } \\
\text { premiums }\end{array}$ & $\begin{array}{l}\text { physician } \\
\text { supply }\end{array}$ & $\begin{array}{l}\text { no effect: increases in } \\
\text { premiums do not seem to } \\
\text { have an effect on the total } \\
\text { number of physicians in } \\
\text { each state }\end{array}$ \\
\hline $\begin{array}{l}\text { Klick and } \\
\text { Stratmann, } \\
2007\end{array}$ & $\begin{array}{l}\text { AMA data on } \\
\text { the number of } \\
\text { doctors } \\
\text { nationally for } \\
\text { the period } \\
1980-2001\end{array}$ & tort reforms & $\begin{array}{l}\text { physician } \\
\text { supply }\end{array}$ & $\begin{array}{l}\text { positive: only caps on } \\
\text { non-economic damages } \\
\text { were significantly } \\
\text { correlated with the per } \\
\text { capita number of } \\
\text { physicians; this effect was } \\
\text { more powerful on those } \\
\text { specialities facing the } \\
\text { greatest exposure to } \\
\text { malpractice suits }\end{array}$ \\
\hline $\begin{array}{l}\text { Matsa, } \\
2007\end{array}$ & $\begin{array}{l}\text { a data set on } \\
\text { county-level, } \\
\text { specialty- } \\
\text { specific annual } \\
\text { accounts of } \\
\text { physicians for } \\
\text { the period } \\
1970-2000\end{array}$ & $\begin{array}{l}\text { caps on } \\
\text { damages }\end{array}$ & $\begin{array}{l}\text { physician } \\
\text { supply }\end{array}$ & $\begin{array}{l}\text { mixed: although caps on } \\
\text { damages resulted in a } 10 \% \\
\text { to } 12 \% \text { increase in the } \\
\text { supply of frontier rural } \\
\text { specialist physicians, caps } \\
\text { had no implications for } \\
\text { physician supply for the } \\
\text { average resident }\end{array}$ \\
\hline
\end{tabular}




\begin{tabular}{|c|c|c|c|c|}
\hline $\begin{array}{l}\text { Helland } \\
\text { and } \\
\text { Showalter, } \\
2009\end{array}$ & $\begin{array}{l}\text { data from the } \\
\text { Physician } \\
\text { Practice Costs } \\
\text { and Income } \\
\text { Survey for the } \\
\text { period 1983- } \\
1988\end{array}$ & $\begin{array}{l}\text { claims } \\
\text { history/tort } \\
\text { reforms }\end{array}$ & $\begin{array}{l}\text { working } \\
\text { hours }\end{array}$ & $\begin{array}{l}\text { positive: an estimated } \\
\text { elasticity of hours worked to } \\
\text { exposure to malpractice } \\
\text { liability of }-.285 \text { for all } \\
\text { physicians and of }-1.224 \text { for } \\
\text { physicians } 55 \text { or older, } \\
\text { suggesting that greater } \\
\text { malpractice risk resulted in } \\
\text { fewer hours worked }\end{array}$ \\
\hline
\end{tabular}

\subsubsection{Summary}

Although existing evidence on NDM in the speciality of obstetrics is mixed, most empirical studies on NDM in the general ailment setting reported positive results. Overall, it is highly likely that greater malpractice risks decrease the supply of physician services.

\subsubsection{Summary and Evaluation}

After summarising the extensive body of empirical findings concerning defensive medicine from Section 2.5.3 to Section 2.5.5, it can be concluded that existing evidence on the association between malpractice risk and practice changes is not definitive. Statistical results of studies on PDM with regard to either obstetrics or general ailments and on NDM as regards obstetrics were somewhat mixed. Nevertheless, the vast majority of survey studies on defensive medicine and statistical studies on NDM in the general ailment setting suggest that defensive medicine may be prevalent and greater malpractice risks are highly likely attributable to more defensive medicine, though the association may be modest. Hence, it is more than likely that the deterrent effect of malpractice liability does exist, at least in some ailment settings. Overall, there may be some degree of over-deterrence and malpractice liability reforms in the US may help reduce defensive medicine and save health care costs. ${ }^{130}$

130 However, Van Dijck had a different view about these results. He questioned the validity of several measures such as "malpractice insurance premiums (not necessarily related to malpractice claims and malpractice payments), physician supply (extreme result, possible database accuracy issues), research that lacks a comparison group (causality concerns), and studies that rely on self-reporting (measurement concerns)." Accordingly, he argued that "defensive medicine merely or predominantly exists in the minds of people." Van Dijck 2015, pp. 302-303. In this regard, more well-designed future studies are expected. 
Part II. Economic Theories and Empirical Evidence

\subsection{IS THE MEDICAL MALPRACTICE SYSTEM COST- EFFECTIVE?}

\subsubsection{Costs of the Medical Malpractice System}

The economic rationale behind the classic model of malpractice liability is that optimal deterrence entails savings due to injury reduction that exceed the primary costs of injury prevention at the margin. Tertiary costs should also be added to the cost side of the scales. In general, the costs of the malpractice system are composed of direct costs (insurance premiums, insurance overheads and litigation costs) and indirect costs (mainly defensive medicine). ${ }^{131}$ Under this sub-heading, several studies attempting to measure the costs of the malpractice liability system are summarised. The weighing of deterrence benefits against costs will be addressed in Section 2.6.2.

Several studies have reported direct costs of the malpractice system. Using data from the AMA's Socio-economic Monitoring System, Reynolds, Rizzo and Gonzalez (1987) estimated that the cost of medical liability was between $\$ 12.1$ and $\$ 13.7$ billion, roughly $15 \%$ of the total health care expenditure in 1984. ${ }^{132}$ Rubin estimated that malpractice insurance premiums constitute less than $1 \%$ of total health care expenditure. ${ }^{133}$ By contrast, the absolute amount of the premiums - roughly $\$ 10$ billion - were by no means minimal. ${ }^{134}$ Recently, Hyman and Silver (2013) reported that the direct costs of malpractice liability reached $\$ 20$ to $\$ 30$ billion per year in the US.

Regarding the proportion of litigation costs to malpractice premiums, Danzon reported that of each one-dollar malpractice insurance premium, roughly 40 cents will be received by plaintiff-patients as compensation, about 40 cents will be spent on litigation costs and the remaining 20 cents are insurance overheads. ${ }^{135}$ Hence, the loading charge for compensation through the malpractice system is about $\$ 1.5$ per one-dollar compensation, which substantially exceeds that for large group first party insurance - less than 10 cents per one-dollar compensation. ${ }^{136}$ If the sole purpose of the malpractice system were compensation, then it would be exceedingly inefficient relevant to alternative compensation mechanisms such as first party insurance. ${ }^{137}$ The

Hyman \& Silver 2013, p. 503.

See generally Reynolds, Rizzo \& Gonzalez 1987.

Rubin \& Mendelson 1993, as cited in Danzon 2000, p. 1369.

Id.

Danzon 1985a, p. 31.

Danzon 2000, p. 1369.

Id. 
comparatively high loading charge can only be justified if deterrence benefits are much higher. ${ }^{138}$

In addition to malpractice premiums and the costs of litigating and defending malpractice claims, there are some other direct administrative "transaction costs." Based on the data collected by Zuckerman ${ }^{139}$ and the US General Accounting Office (GAO), ${ }^{140}$ Dewees, Duff and Trebilcock estimated that the foregone income of physicians was due to lost working days (2.7 days on average) and spending on defence (about $\$ 70$ million in the US in 1984). ${ }^{141}$ Given the then best available estimates, ${ }^{142}$ Dewees, Duff and Trebilcock also roughly calculated the public costs of providing court, judges and juries to resolve malpractice disputes: about $\$ 3.7$ million per year in the US. ${ }^{143}$ Besides direct monetary costs, some concomitant psychological burden such as anxiety and loss of reputation was not negligible. ${ }^{144}$

The second group of studies was focused on indirect costs attributable to defensive medicine. ${ }^{145}$ The results of the available evidence are mixed. Several early studies found considerably high costs of defensive medicine. Based on cross-sectional data by state from 1970, Greenwald and Mueller estimated that the $400 \%$ growth in malpractice premiums from 1970 to 1975 ultimately resulted in a total of $\$ 2.3$ billion increase in health care expenditures in the US. ${ }^{146}$ Using data from the Socio-economic Monitoring System survey in 1984, Reynolds, Rizzo and Gonzalez claimed additional costs of between $\$ 8.4$ and $\$ 12.1$ billion were incurred due to increased malpractice risk in the US for that year. ${ }^{147}$ By extrapolating their data to all ailments in the US, Kessler and McClellan estimated that "direct reforms could lead to expenditure reductions of well over $\$ 50$ billion per year without serious adverse consequences for health outcomes." ${ }^{148}$ Based on Kessler and McClellan's study, the Department of Health \& Human Services reported that tort reform "would save $\$ 70-\$ 126$ billion in health care costs per year." ${ }^{\prime 19}$ Mello et al. estimated that the overall annual medical liability system costs

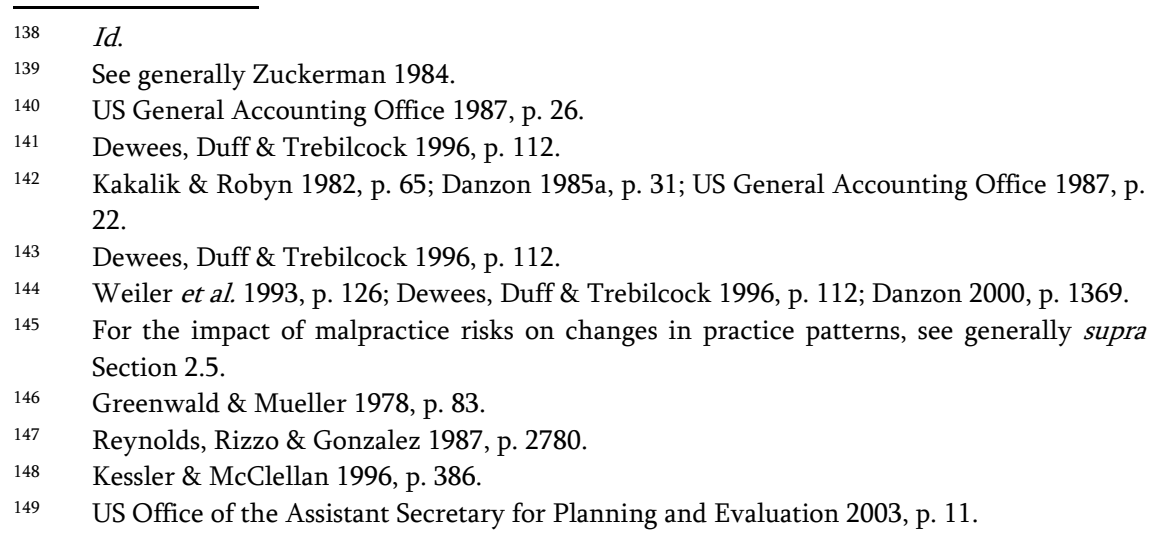


Part II. Economic Theories and Empirical Evidence

were $\$ 55.6$ billion in 2008 dollars (2.4\% of total health care expenditures), while $\$ 45,6$ billion were costs of defensive medicine. ${ }^{150}$

Remarkably, several recent studies reported insignificant results or low costs associated with defensive medicine. ${ }^{151}$ Nevertheless, the extensive evidence of prevalent defensive medicine as summarised in Section 2.5 does suggest that the costs added by defensive practice patterns should not be negligible. Taken together, the direct and indirect costs of the malpractice system tend to be considerable. Tort reforms aiming at limiting compensation may be conducive to the reduction in the costs of defensive medicine.

\subsubsection{Deterrence Benefits Compared to the Costs}

It has been demonstrated that malpractice liability can generate (often excessive) deterrent effects on practice patterns of physicians. ${ }^{152}$ However, it remains to be seen whether these deterrent effects eventually lead to a reduction in iatrogenic injuries. The deterrence benefits of malpractice liability crucially depend on to what extent these practice pattern changes improve the quality of medical care. ${ }^{153}$ However, empirical evidence on the benefits of malpractice deterrence is rare.

One credible study using econometric analysis was conducted by Weiler et al., ${ }^{154}$ which estimated the correlation between the negligent injury rate and claims per negligent injury across 49 hospitals in New York state. They used a standard econometric technique to resolve the problems of measurement errors and instrumental variables. ${ }^{155}$ After controlling for many other variables such as age, race, insurance status, hospital status and per capita income, Weiler et al. reported that more malpractice suits led to a lower number of negligent iatrogenic injuries, although this effect was not statistically significant. ${ }^{156}$ Based on these data, Weiler et al. estimated that the then malpractice system in New York could have reduced the negligent iatrogenic injury rate by $29 \%$ (from 1.25 without liability to 0.89 with liability) and the overall iatrogenic injury rate by $11 \%$ (from 3.7 without liability to 3.3 with liability). ${ }^{157}$

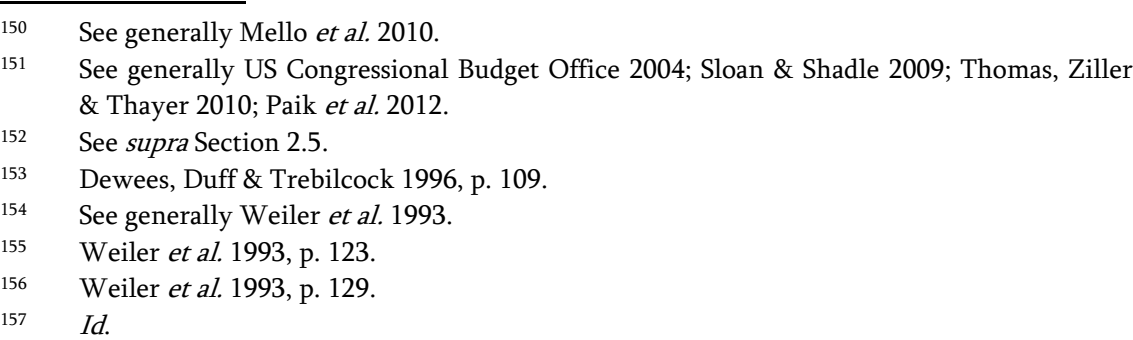


Several other studies attempted to assess deterrence benefits in a specific speciality setting or the impact of tort reforms on defensive medicine and ultimately on injury rates. They generally reported minimal or no effect on the quality of care. Sloan et al. attempted to examine the effect of changes in malpractice risk on birth outcomes and found that only decreases in foetal deaths were associated with greater malpractice risk in one of the many data sets. ${ }^{158}$ Hence, they concluded that, overall, there was no systematic improvement in birth outcomes when malpractice risk was increased. Using data on all elderly Medicare beneficiaries with serious heart disease, Kessler and McClellan consistently found that direct tort reforms aiming at reducing the level of compensation reduced medical expenditure without significant implications for patient health outcomes. ${ }^{159}$ Although Dubay, Kaestner and Waidmann found that malpractice liability pressures may lead to defensive medicine, they failed to find any evidence that PDM would produce better outcomes or that NDM would adversely affect infant health. ${ }^{160}$ Yang et al. (2012) used a longitudinal research design to examine millions of individual births in the US for the period 1991-2002 and reported that adverse birth outcome rates were not correlated with premium level or tort reform measures. ${ }^{161}$ Therefore, the implementation of liability-limiting reforms would only eliminate defensive medicine without damaging the desirable deterrent effect of malpractice liability. ${ }^{162}$ One study even reported mixed results. Currie and MacLeod (2008) found that not all tort reform measures resulted in the same outcome: while the reform of the Joint and Several Liability rule (setting a $50 \%$ faulty contribution threshold for $100 \%$ liability) reduced complications associated with a delivery, caps on non-economic damages increased them. ${ }^{163}$

However, it ought to be noted that the fact that liability-limiting tort reforms have no significant effect on injury rate does not necessarily mean that the malpractice system has no deterrence benefits. The foregoing evidence points at the possibility that reduced malpractice risk via tort reforms successfully eliminates defensive medicine without harming the desirable deterrent effect of malpractice liability. Put another way, the increased health care costs due to PDM such as additional tests and procedures are socially wasteful and do not enhance the quality of medical care. Changes in the supply of services do not affect patients' health adversely

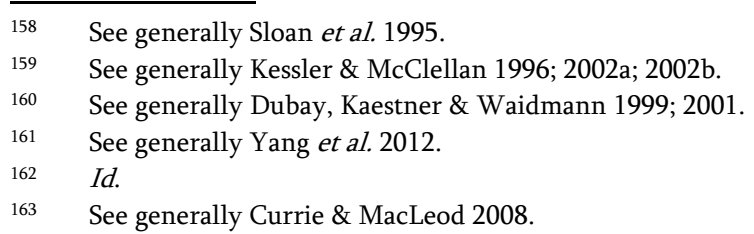


either, indicating that physicians withdraw from a particular practice or location due to incompetency. Therefore, the results of these studies can better be used to offer support for traditional tort reforms aiming at limiting liability rather than to negate the deterrence benefits of malpractice liability. Moreover, taking into account the extensive evidence on defensive medicine, ${ }^{164}$ and the fact that the elderly or uninsured patients, who suffered a higher proportion of negligent injuries, are exactly those "whose liability to sue is likely to pose the lowest threat to their providers," ${ }^{165}$ it is reasonable to conclude that at the margin the malpractice system does have a deterrent effect on injury prevention that is socially beneficial, ${ }^{166}$ though the effect may be modest and still remains to be studied.

Deterrence benefits should be weighed against the costs of the malpractice system. As Danzon argued, "if the tort system deters at least one injury of comparable severity for every injury currently compensated, the deterrence benefits outweigh the additional costs of the liability system."167 Taking the data generated by the Harvard Study as an example, patients obtained compensation in roughly 2.24 claims per 100 negligent AEs. ${ }^{168}$ According to Danzon, only a 2.24 percent reduction in the rate of negligent AEs is sufficient to justify the costs of the tort system as far as litigation costs are concerned. ${ }^{169}$ When taking other costs such as "defensive medicine, public costs of operating the courts, time and psychological costs of litigation to patients and providers" into account, Danzon estimated that the malpractice system would generate positive net benefits if it could reduce negligent iatrogenic injury rates by at least $20 \%{ }^{170}$ The results of the Harvard Study reported by Weiler et al. - 29\% - clearly met Danzon's 20\% threshold. Although tertiary costs of the malpractice system are considerable, ${ }^{171}$ this estimation of positive net benefits is plausible given the empirical finding that only a small minority of patients that suffered negligent iatrogenic injuries initiate claims. ${ }^{172}$ Total administrative costs are measured by the product of the number of claims and the costs per claim. ${ }^{173}$ Only when a claim is filed are tertiary costs incurred. Therefore, "a modest percentage reduction in injury rates is sufficient to offset reasonable estimates of overheads and defensive

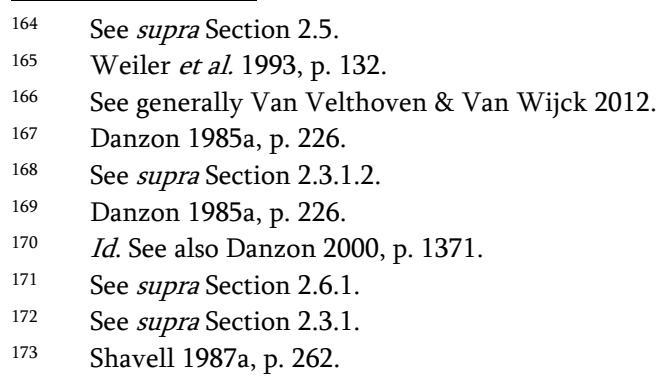


medicine costs." ${ }^{174}$ Combining all the foregoing evidence together, it is more than likely that the marginal benefits of the current malpractice system outweigh the costs. Nonetheless, many agree that the search for marginal improvements or more cost-effective alternatives regimes still remains open. ${ }^{175}$

\section{A NEW EMPIRICALLY-GROUNDED MODEL OF MEDICAL MALPRACTICE LIABILITY}

\subsection{INTRODUCTION}

An economic model is a "simplified system used to simulate some aspects of the real economy." ${ }^{176}$ The classic model of the fault-based medical malpractice liability is intended to predict the complex relationship between the negligence rule and health care providers' behaviour. The more features of health care services are included in the model, the higher the predicative power of the model. When economists such as Shavell and Posner who developed the classic model of medical malpractice liability around the 1980s, empirical evidence on medical malpractice was either unavailable or unsophisticated. Today, we have a wealth of empirical evidence. When new empirical evidence discloses new features regarding medical malpractice, the classic model needs to be updated accordingly in order to better reflect the real world.

Section 3 will introduce readers to a new empirically-grounded model of medical malpractice liability which was mainly developed by Arlen and MacLeod. ${ }^{177}$ In Section 3.2, some new evidence on the causes of iatrogenic injuries is presented. After that it will describe how the classic model was updated by Arlen and MacLeod for the purpose of achieving a better deterrent effect of medical malpractice liability.

\footnotetext{
$174 \quad$ Danzon 2000, p. 1371.

175 See generally Danzon, 2000; Sloan \& Chepke 2008; Van Velthoven \& Van Wijck 2012.

176 Black, Hashimzade \& Myles 2012, pp. 275-276.

177 See generally Arlen \& MacLeod 2003; Arlen \& MacLeod 2005; Arlen 2006; Arlen 2010; Arlen 2013; Arlen 2014.
} 
Part II. Economic Theories and Empirical Evidence

\subsection{EMPIRICAL EVIDENCE ON THE CAUSES OF IATROGENIC INJURIES}

\subsubsection{Risk Factors}

In an attempt to find out the causes of iatrogenic injuries, researchers considered a wide range of risk factors in relation to patients, providers and treatment characteristics. As far as patient characteristics are concerned, patients age, lower payment status and income levels were said to be associated with a higher incidence rate of iatrogenic injuries. ${ }^{178}$ This result implies that patients in a weaker position of health or wealth may receive lower quality of care than other groups of patients. Since elderly, uninsured or poor patients are less likely to be able to file meaningful malpractice claims, the fact that they suffer disproportionately large numbers of iatrogenic injuries is "suggestive of the preventive value of malpractice litigation." "179

Regarding provider characteristics, both the injury rate $(0.2 \%$ to $7.9 \%)$ and the negligent injury rate (1\% to $60 \%)$ varied dramatically from one hospital to another. ${ }^{180}$ This suggests that the quality of care is not evenly distributed through the community. Although university teaching hospitals had a higher rate $(4.1 \%)$ of adverse events than did voluntary non-teaching hospitals (2.3\%), only $10.7 \%$ of adverse events at university hospitals were due to substandard care which was lower than that (26.9\%) at non-teaching hospitals. ${ }^{181}$ In-patients were more likely to be said to commit errors than attending doctors. ${ }^{182}$

When it comes to treatment characteristics, most adverse events were relevant to surgical procedures (31.6\% to $48 \%$ ) and medications (19\% to 27.6\%). ${ }^{183}$ One striking fact is that although diagnostic errors or mishaps accounted for only a small portion of all adverse events (6.9\% to $8 \%$ ), a high percentage of them (75\% to $93.8 \%$ ) were considered to be preventable or negligent. ${ }^{184}$

Although the ideal goal of quality assurance is to prevent all iatrogenic injuries, many non-negligent iatrogenic injuries are unavoidable given the

Weiler et al. 1993, pp. 45-47. See also generally Mills 1978; Classen et al. 2011.

Weiler et al. 1993, p. 58.

Weiler et al. 1993, p. 47.

Weiler et al. 1993, p. 50.

See generally Andrews 2005.

See generally Weiler et al. 1993; Thomas et al. 2000a; Landrigan et al. 2010. Id. 
current state of medical knowledge. ${ }^{185}$ As far as the classic model of malpractice is concerned, it is not adequate to simply list risk factors that may contribute to iatrogenic injuries in general. Instead, the causes of negligent iatrogenic injuries - medical errors - should be carefully examined in order to optimise the deterrent effect of malpractice liability.

\subsubsection{Deliberate or Accidental Negligence?}

The classic model of malpractice pre-supposes that providers are fully informed of the costs and benefits of care and the optimal level of care (due care). If providers choose to be negligent, they will do so either by underinvesting in care knowingly in order to reduce patient-specific costs or they are "bad apples" who do not care about patient welfare or who know they are too incompetent to provide due care. Put another way, their deviation from due care is "deliberate." 186 This approach to the understanding of medical negligence has its roots in the Theory of Bad Apples - health care quality can be best assured by identifying "bad apples" and removing them from the medical profession. ${ }^{187}$ This theory predicts that sub-optimal care is attributable to poor intentions by bad apple physicians - "their venality, incompetence, or insufficient caution." 188 According to this theory, quality will be improved if deterrence can be precisely targeted at these small groups of bad apples. ${ }^{189}$

Health care providers, who are trained to provide careful treatment competently, are perhaps among the most conscientious professionals in society. ${ }^{190}$ They are normally expected to be infallible and function without error. ${ }^{191}$ However, empirical evidence shows that preventable adverse events occur frequently and often lead to severe personal injuries. ${ }^{192}$

One significant reason why providers nevertheless err is not because they are "bad apples" but because it is exceedingly difficult for them to handle human error when it does occur. ${ }^{193}$ Health care providers are simply unable to bring all aspects of patient care under control. ${ }^{194}$ Although professional

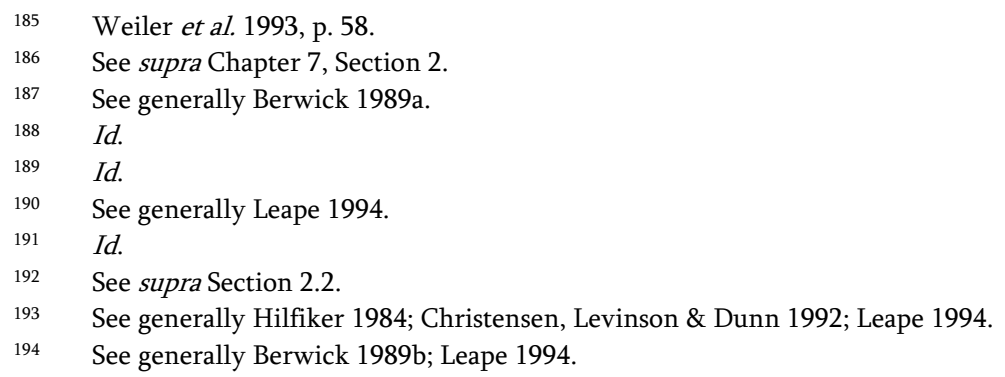


standards dictate error-free patient care, it is widely admitted in the health care sector that inadvertent mistakes are inevitable. ${ }^{195}$

Empirical evidence also shows that many, if not most, medical errors are committed accidentally by relatively competent physicians. ${ }^{196}$ First, momentary slips or lapses cannot be eliminated. ${ }^{197}$ Fatigue and sleep loss due to overwork or other forms of stress may divert providers' attention and lead to momentary slips or lapses during the largely automatic, routine performance. ${ }^{198}$ Second, many preventable adverse events are due to diagnostic errors. ${ }^{199}$ Providers may also confront novel situations for which they have no pre-packed solutions and the trial and error method is inevitable. ${ }^{200}$ If they fail to update their expertise regularly, they may lack sufficient information to make correct diagnoses. Moreover, many human errors are precipitated, activated, or amplified by system failures. ${ }^{201}$ Therefore, many medical errors are indeed accidental rather than deliberate. Providers often err when they do not know that they are providing suboptimal treatment. ${ }^{202}$

\subsubsection{Human Errors and System Failures}

One major feature of modern health care is that providers usually practise within complex institutional settings and collaborations among providers and between providers and hospitals are essential. Providers' behaviour is shaped by what task they undertake and where they work. ${ }^{203}$ Either human errors or system failures may contribute to medical errors. Andrews et al. found that while $37.8 \%$ adverse events were caused by an individual (e.g. by poor technical performance, poor judgement, or failure to act on or to obtain information), $25.4 \%$ were due to either interactive factors (e.g. the failure of a consultant team to communicate adequately with the requesting team) or administrative factors (e.g. defective or unavailable equipment or inadequate staffing). ${ }^{204}$

In many cases, system failures may play a leading role in inducing medical errors. Leape et al. studied 264 preventable adverse drug events

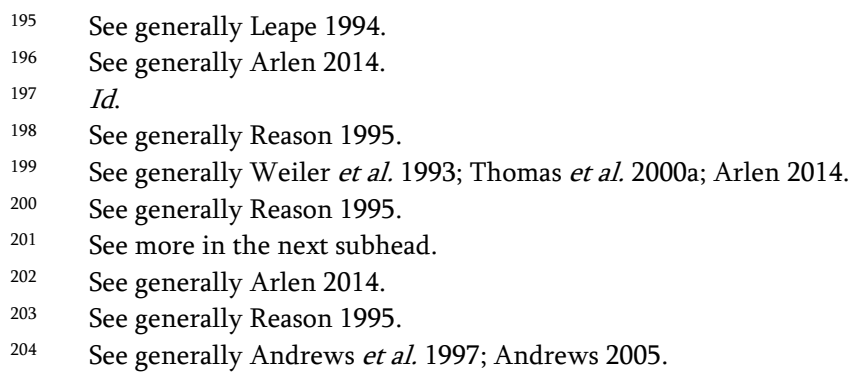


(ADEs) and reported that the major systems failure in the dissemination of drug knowledge accounted for $29 \%$ of all 334 errors and the deficiency in the availability of patient information (e.g. lab tests results) led to $18 \%$ of errors. ${ }^{205}$ In total, systems failures accounted for $78 \%$ of the errors. ${ }^{206}$ Gawande et al. conducted interviews with 45 surgeons from three teaching hospitals between 2000 and $2001 .^{207}$ They found that the vast majority of errors involved contributions from more than one clinician and failures in judgement or vigilance occurred in more than half of the adverse events. ${ }^{208}$ They also reported that systems factors contributed in $84 \%$ of these events. ${ }^{209}$ For example, errors in judgement were closely associated with inadequate supervision. $^{210}$ Due to more chances of inexperience, communication breakdown, lack of supervision, heavy workloads and fatigue, adverse events happened more frequently in emergency rooms than in other wards. ${ }^{211}$

More often than not, medical errors are caused by human errors and system failures jointly. Mello and Studdert found that individual factors often appeared in concurrence with system factors. Individual factors were fairly widespread, leading to injuries in $96 \%$ of the 889 cases with error. Judgement errors were the most frequent $(70 \%)$ among all individual factors. ${ }^{212}$ System factors were less prevalent, but still accounted for injuries in $56 \%$ of the cases. ${ }^{213}$ The most prevalent ones among all system factors were teamwork problems and other communication breakdowns (40\%). ${ }^{214}$ On average, an injury was caused by three different contributing factors, and more than a third of all injuries resulted from four or more contributing factors. ${ }^{215}$ The majority $(60 \%)$ of injuries were associated with two or more clinicians, and a quarter involved three or more. ${ }^{216}$ Their data confirmed the assertion that "when large systems fail, it is due to multiple faults that occur together in an un-anticipated interaction, creating a chain of events in which the faults grow and evolve." ${ }^{217}$

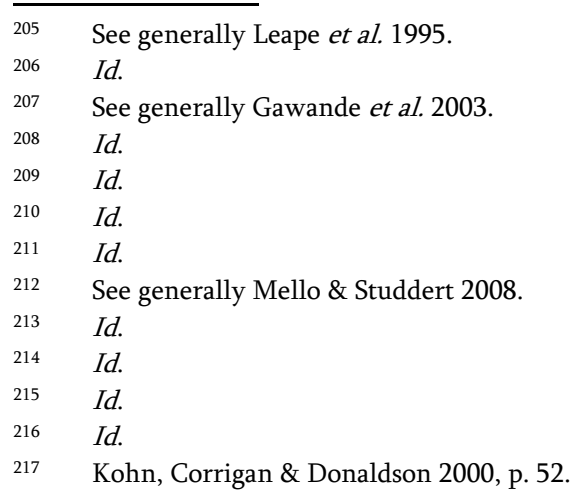


Furthermore, Mello and Studdert concluded that it is a mosaic "causal web" rather than a linear "causal chain" that leads to medical injury, i.e. multiple individual and system factors, while interacting with one another, independently contribute to medical injuries. ${ }^{218}$ They further found that individual failures appear to be a necessary but not sufficient condition for iatrogenic injuries to happen - in most of the cases, individual failures are "precipitated, activated, or amplified by system failures." 219 Individual factors alone accounted for only $30 \%$ of iatrogenic injuries, whereas both individual and systemic factors contributed to almost $70 \% .220$

Finally, there were "amplification effects," meaning the occurrence of system failures aggravates an injury due to individual failures. This can be evidenced by the fact that cases involving both system and individual factors led to more severe injuries and were thus associated with larger damages than those involving only individual factors. ${ }^{221}$ System failures such as lack of supervision, hand-over problems and excessive workload might have precipitating effects, meaning that they create "an environment in which inexperienced trainees are set up to do damage." 222

\subsection{UPDATING THE CLASSIC MODEL OF MALPRACTICE LIABILITY}

\subsubsection{Patient Safety Investments}

The traditional view of "deliberate" medical negligence has been fiercely attacked by Arlen and MacLeod. ${ }^{223}$ Extensive empirical evidence summarised in the previous Section has demonstrated that medical negligence is normally accidental and system failures often play a leading role in contributing to medical errors. Mcclanahan, Goodwin and Perlin even put forward a "formula" for medical errors: "Good People + Bad Systems."224 Adverse events are more often the result of error-prone situations and error-prone activities instead of error-prone providers. ${ }^{225}$ Therefore, the classic model of malpractice cannot be relied upon to design sound policies to prevent medical

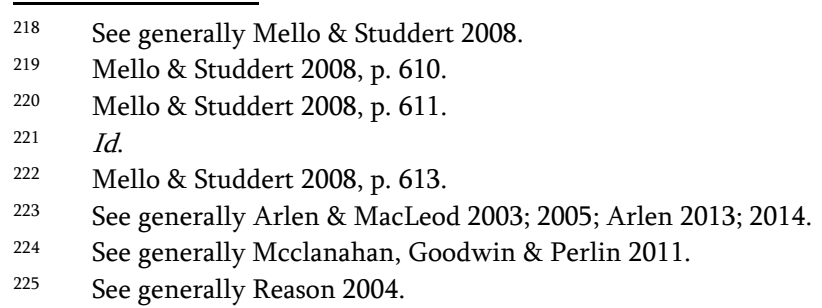


errors, because "it fails to capture the leading cause of medical error. ${ }^{226}$ Relatively competent providers often commit errors inadvertently because they fail to update their expertise regularly or lack proper supervision so that they sometimes fail to make correct diagnoses and provide optimal treatment. ${ }^{227}$ System failures also increase the likelihood of human errors or fail to prevent providers from erring accidentally. ${ }^{228}$

Accidental medical errors can be reduced by continuously investing in updating expertise or competence that is essential especially for proper diagnoses and treatment choice and perfecting system fail-safe designs at the institutional level - organisational leadership, centralised planning, and the mobilisation of resources. ${ }^{229}$ The management of competence can be regarded as a system issue as well, since "training, selection, continuing development, and life-long competency checking" are often conducted at the hospital level. ${ }^{230}$ These investments are referred to as "patient safety investments," which are different from patient-specific investment in care - effort, caution and time taken by a physician in a single case. ${ }^{231}$ Patient safety investments are regarded as "collective care" because they benefit all patients by increasing the likelihood that providers will make correct diagnoses and treatment choices and provide optimal treatment. ${ }^{232}$

Following this line of reasoning, a new empirically-grounded model of malpractice liability is proposed. ${ }^{233}$ Under this new model, malpractice liability should be used not only to induce informed providers to choose optimal treatment but also to incentivize providers to invest optimally in patient safety so as to ensure that the information needed to make optimal treatment choice is available. ${ }^{234}$ It does not matter whether the court incorporates patient safety investments within the standard of medical care. Even if the standard of care is entirely based on treatment choice, providers will nonetheless be induced to invest optimally in patient safety in order to reduce the probability of accidental negligence. ${ }^{235}$ Malpractice liability will incentivize the provider to make optimal investment in patient safety so long as the provider's expected damages for accidental negligence amount to the full expected cost to the patient of being given erroneous rather than the

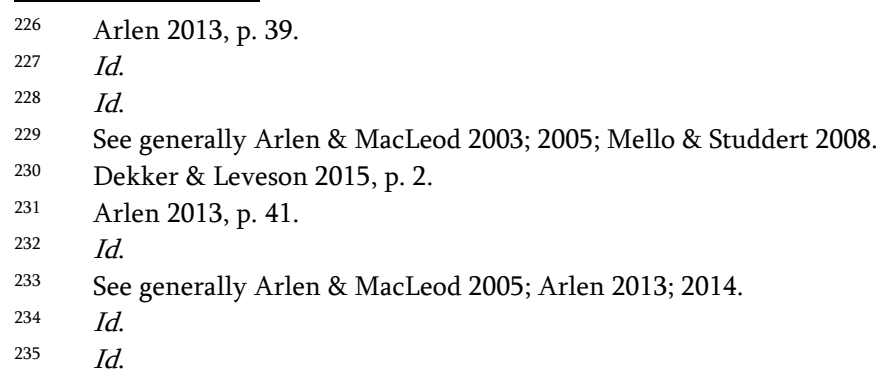


optimal treatment. ${ }^{236}$ The optimal amount of damages for accidental negligence should be less than the actual magnitude of harm done to the patient ex post; otherwise, providers will over-invest in patient safety due to excessive incentives to prevent accidental errors. ${ }^{237}$

\subsubsection{Enterprise (Hospital) Liability}

\subsubsection{Direct Hospital Liability and Vicarious Liability}

The classic model of malpractice liability mainly places the locus of liability on individual health care providers (typically doctors and nurses), because they provide the vast majority of treatment services and they are assumed to be in the best position to prevent medical errors. ${ }^{238}$ In the US, for instance, malpractice liability is mainly imposed upon the individual physician. ${ }^{239}$ Nevertheless, the classic model does not exclude the possibility that an institutional health care provider (typically a hospital) can be involved in the problems of malpractice. ${ }^{240}$

In most legal systems, hospitals are usually held liable for iatrogenic injuries in two scenarios - direct hospital liability or vicarious liability. On the one hand, patients may suffer iatrogenic injuries from pure system failures such as unhygienic conditions, poorly maintained or defective equipment and inadequate personnel or equipment. Even when physicians do not commit any medical error, hospitals should be held liable for iatrogenic injuries resulting from their own failures alone in many European countries based on either contractual liability or tort liability. ${ }^{241}$

On the other hand, hospitals may be held liable for injuries caused by negligence on the part of individual health care providers who practice under the auspices of the hospitals. If individual providers are hospital employees, hospitals will be subject to vicarious liability in most legal systems. ${ }^{242}$ The hospital may also be held liable for the physician's malpractice even when the physician is not an employee, based on either agency liability or corporate liability in the US ${ }^{243}$ or on Article 7:462 of the Dutch Civil Code (making the

\footnotetext{
$236 \quad$ Id.

237 Id.

238 Shavell 1978, p. 35.

239 See generally Abraham \& Weiler 1994.

$240 \quad$ Shavell 1978, p. 35; Faure 2004a, p. 5.

241 Baczyk-Rozwadowska 2013, p. 333; G'Sell-Macrez 2013, pp. 143-144; Koch 2013, pp. 12 13; Stauch 2013, p. 185.

$242 \quad$ Abraham \& Weiler 1994, p. 387; Koch \& Koziol 2004, p. 421; Oliphant 2013, p. 537.

243 See generally Abraham \& Weiler 1994.
} 
hospital jointly liable for any failure of treatment performed in the hospital) in the Netherlands. ${ }^{24}$ The negligence on the part of individual providers is normally a prerequisite to the imposition of vicarious liability. Even in the case where it is difficult to identify the specific physician whose negligence was the cause of the patient's iatrogenic injuries, vicarious liability may apply regarding "anonymous fault." 245 Once the physician's negligence is established, the physician and the hospital are normally subject to joint and several liability.

The fundamental, economic analysis of vicarious liability is largely based on principal-agent models. ${ }^{246}$ The basic intention to impose vicarious liability on the principal is to deal with the problem of judgement-proof agents, who may have insufficient personal assets to pay compensation to third party victims. ${ }^{247}$ If the agent's assets are limited, his incentive to take care will be diluted. ${ }^{248}$ Imposition of vicarious liability will incentivize the principal to urge the agent to take due care supposing that it is possible for the principal to observe and control the actor's behaviour. ${ }^{249}$ If the principal can monitor the agent's care-taking better than the court, vicarious liability will induce greater care levels than a regime of purely personal liability under which only the agent is held liable. ${ }^{250}$ In the absence of vicarious liability, the principal would have almost no incentive to urge the agent to exercise greater care, ${ }^{251}$ and the problem of too little care or too much activity would arise. The other way around, the principal will be induced to urge the agent to exercise optimal care if vicarious liability is imposed.

From the perspective of law and economics, vicarious liability imposed upon institutional health care providers can be justified on three grounds:252

First, an individual provider's assets are so limited that the problem of under-deterrence may arise due to insolvency. ${ }^{253}$ Insolvency is less of a problem under negligence since the provider will still take due care as long as the cost of taking care is less than his/her total assets. ${ }^{254}$ However, if a physician's assets are considerably limited, under-deterrence will still arise even under negligence. Modern hospitals are normally public or private

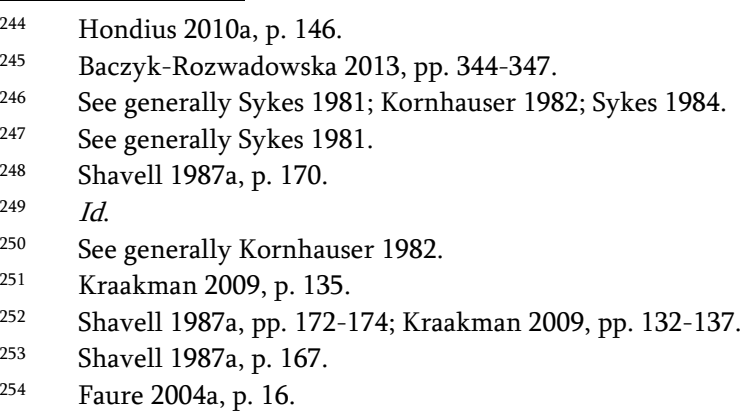


enterprises with sufficient capital assets. Hence, imposing vicarious liability on hospitals will not lead to under-deterrence resulting from insolvency. By contrast, the physician's incentives to take optimal care will be maintained by internal monitoring and disciplinary sanctions rather than by external malpractice litigations, since it is generally believed that hospitals are better able than the court to control the agent-physician's care-taking. The principal-hospital is assumed to have more information concerning the malpractice risk and safety standards and is better suited to the job of preventing medical errors and identifying and disciplining error-prone physicians.

Second, when the problem of "multiple agents" arises, ${ }^{255}$ i.e. when the victimised patient cannot identify which of the hospital's physicians has deviated from the standard of care even when one of them is clearly negligent, the principal-hospital is the easier target of liability. The principalhospital is presumed to be able to identify the specific negligent physician or at least to reduce the likelihood of medical errors via training programs or screening measures. ${ }^{256}$

Third, the principal-hospital may be better informed than the agentphysician concerning accident risks or preventive measures. Based on empirical evidence, Mello and Studdert point out that preventive interventions should be implemented at the organisational level rather than the individual level - "organisational leadership, centralised planning, and the mobilisation of resources" are essential to prevent system failures. ${ }^{257}$ On the one hand, the organisational approach recognises the presence of system failures that significantly contribute to iatrogenic injuries. On the other, even in cases where individual factors contribute substantially, the optimal intervention may still lie in organisational measures. Hence, "tort deterrence is best targeted at the institutional, not individual, level in medical malpractice law."258 Although individual physicians de facto cause many iatrogenic injuries, they are not the party who can prevent injuries at least cost.

In practice, one notable example of vicarious liability imposed on hospitals can be found in the first paragraph of Article 7:462 of the Dutch BW (Civil Code), which reads as follows:

If, in the implementation (performance) of the medical treatment agreement, activities are performed in a hospital which is not a party to

\footnotetext{
$255 \quad$ Kornhauser 1982, pp. 1370-1371.

256 Kraakman 2009, p. 136.

$257 \quad$ Mello \& Studdert 2008, p. 617.

$258 \quad$ Mello \& Studdert 2008, p. 618.
} 
that agreement, the hospital shall bear joint liability for any failure to comply with the medical treatment agreement as if it was a party to that agreement itself.

Hence, once a medical services contract is executed in a hospital, the hospital is nonetheless jointly and severally liable for any non-performance even if it is not a party to the contract. This is referred to as "central liability," the rationale behind which is "to identify the defendant to enable the patient to claim damages." ${ }^{259}$ If a victimised patient only files a claim against the hospital, the latter, after paying damages, may have recourse against liable doctors. ${ }^{260}$

\subsubsection{Enterprise Medical Liability}

Recently, a radical regime of enterprise liability for medical malpractice or enterprise medical liability (hereinafter EML) was proposed in the 1990s in the US. ${ }^{261}$ Under this regime, the individual physician will be entirely immune from malpractice litigation - the locus of liability will be completely transferred from the individual physician to an enterprise such as a hospital, $\mathrm{HMO}$ or health plan. ${ }^{262}$ This rule is rather similar to channelling of liability, under which liability is exclusively imposed on one responsible tortfeasor. ${ }^{263}$ Those proponents of EML argue that it would improve deterrence via better system fail-safe designs and reduce litigation costs through holding the hospital as the sole defendant. ${ }^{264}$

However, the advantage of EML over vicarious liability may not be so considerable as those proponents contended. First, holding the principalhospital vicariously liable for the agent-physician's negligence already improves deterrence relative to agent liability. ${ }^{265}$

Second, the savings in litigation costs could be small, since individual providers would still be required to testify as the primary witness in court and they may still feel "burdened by the prospect of having to defend their actions in court." ${ }^{266}$ Third, there are still some dimensions of medical errors

\footnotetext{
$259 \quad$ Giesen \& Engelhard 2011, p. 384.

$260 \quad$ Giesen \& Engelhard 2011, p. 385.

261 See generally Abraham \& Weiler 1994; Sage, Hastings \& Berenson 1994; Dewees, Duff \& Trebilcock 1996; Sage 1997; Arlen 2013. 
that are due to pure human errors and sometimes both individual factors and system factors play a role in causing iatrogenic injuries. The exclusive model of enterprise liability may lead to separate liability insurance arrangements, fragmented incentives and inefficiency in defending claims. ${ }^{267}$ In contrast, an arrangement of channelling is promising, under which hospitals take full responsibility for the purchase of malpractice insurance to cover their physicians, hence insulating them from malpractice liability financially, if not legally. ${ }^{268}$

That being said, EML is particularly desirable when taking into account patient safety investments, many of which can only be made at the institutional level such as investments in supervision, procedures for transferring responsibility for patients, staffing, sanitation procedures, medical technology and rules regulating the working hours of providers. ${ }^{269}$ Under vicarious liability, if system failures account for an iatrogenic injury, hospitals may be able to escape liability providing that individual providers comply with due care under the circumstances. As a result, hospitals may under-invest in patient safety systems without liability, although they are largely responsible for the injuries. ${ }^{270}$ For this reason, it is important to impose liability directly on medical entities in order to effectively induce sufficient investments in patient safety systems.

Of course, this may be achieved by the combined use of vicarious liability and direct hospital liability as is adopted in many legal systems today. However, it is often difficult for the court to draw a clear line between the cases where vicarious liability should apply and where direct hospital liability should apply in practice, which may send confusing signals to health care providers. Unifying vicarious liability with direct hospital liability may save tertiary costs considerably by sending clear deterrent signals.

Also, it is of vital importance to encourage patient safety investments, especially those at the institutional level, in order to respond to the everincreasing complexity of modern health care systems and risk of iatrogenic injuries. Hence, a systematic arrangement of placing the locus of liability on hospitals appears more efficient in terms of injury prevention. Individual providers' incentives to take care will not necessarily be diluted, given that either they will be regularly monitored and disciplined by hospitals where

See generally Mello \& Studdert 2008.

See generally Steves 1976; Abraham 1977; Abraham \& Weiler 1994.

See generally Mello \& Studdert 2008; Arlen 2013.

Arlen 2013, p. 58. 
they practice, or hospitals are granted a right of recourse against negligent practitioners. ${ }^{271}$

\section{CONCLUSIONS}

The Chapter has reviewed empirical evidence concerning the deterrent effect of the fault-based medical malpractice liability and discussed the modification of the classic model of medical malpractice liability in the light of new evidence pertaining to the causes of iatrogenic injuries.

Empirical evidence shows that the real crisis is not that there are too many frivolous claims but that patients with meritorious claims often do not sue or are denied compensation. Tort liability is not a "random lottery," because it is relatively effective at eliminating non-meritorious claims. ${ }^{272}$ The deterrent effect of tort liability does seem to exist. The prevalence of defensive medicine may suggest over-deterrence. Although the costs of the malpractice system are very high, the huge deterrence benefits of reduced iatrogenic injuries are highly likely to pay for the expenses incurred by the malpractice system. Be that as it may, this conclusion does not exclude the possibility that the current malpractice system can be further enhanced or that alternative plans may be more desirable.

New empirical evidence supports the view that medical negligence is mostly accidental rather than deliberate and most medical errors can be better prevented at the institutional level instead of the individual level. The updated and empirically-grounded model of malpractice liability requires that health care providers should be induced to invest in both care and patient safety and the locus of liability should be placed on institutional providers alone.

It should be noted that the vast majority of empirical evidence on medical malpractice in this Chapter has its origins in the US. One may wonder whether the findings of these empirical studies are directly applicable to China. The transferability of these empirical findings to China will be addressed later. ${ }^{273}$

\footnotetext{
$271 \quad$ Faure 2016, pp. 627-628.

272 This statement is valid only as far as deterrence is concerned. When taking into account the fact that many victims with meritorious claims never file a claim and obtain compensation, it would be unfair to say that tort law is not a random lottery.

273 See infra Chapter 12, Section 2.3.
} 



\section{CHAPTER 9 \\ PREVENTING MEDICAL ERRORS THROUGH ALTERNATIVE REGIMES}

\section{INTRODUCTION}

Although the fault-based malpractice system appears to be cost-effective at preventing medical errors (i.e. its deterrence benefits slightly exceed its costs as the American data show), ${ }^{1}$ the existence of considerable costs of defensive medicine and administrative costs lead us to the question whether there is any alternative regime to the tort system that will achieve greater efficiency (part of Sub-question (2-a)). In the literature, two alternative regimes are often discussed - the contractual approach ${ }^{2}$ and regulation.

At one extreme, proponents of the contractual approach emphasise that informed patients will only purchase the desired level of care (or risk of medical malpractice) in their best interests, and social welfare will be maximised in a free health market. The contractual approach is relevant for China in that a small part of the Chinese health care system is based on the free market - services provided by for-profit private hospitals. ${ }^{3}$ However, this approach does not seem fit for the part of the health care sector where services are provided by not-for-profit hospitals and prices are normally regulated.

At the other extreme, proponents of regulation do not believe individuals can make informed decisions in their best interest, and some

\footnotetext{
$1 \quad$ See supra Chapter 8, Section 2.6.

2 It should be noted that the notion of the "contractual approach" as used in this dissertation does not simply mean the doctor-patient relationship is based on a service contract. Instead, it specifically means contractual waivers of malpractice liability or contractual variations in the standard of care, irrespective of whether malpractice liability is contractual liability as adopted in the Netherlands and Germany or tort liability as employed in the common law systems.

3 For more information on private hospitals, see supra Chapter 2, Section 2.2.
} 
government interventions seem theoretically justified. This approach is highly relevant for China, since China has a deep-rooted tradition of strict governmental regulation and a regime of regulating health care provision has been developing in China for decades. ${ }^{4}$

This Chapter will review arguments for and against the contractual approach (Section 2) and quality regulation (Sections 3-6), and conduct a critical evaluation of them against Calabresi's goals of accident cost avoidance. Section 3 will provide a general overview of the regulation of the medical profession. Licensing and quality/safety regulation will be examined separately in Section 4 and Section 5. The pros and cons of public regulation and self-regulation will be addressed in Section 6. The final Section 7 concludes.

\section{THE CONTRACTUAL APPROACH: A DESIRABLE ALTERNATIVE?}

\subsection{INTRODUCTION}

The contractual approach was proposed against a background of the medical malpractice crisis in the US. In view of the deficiencies of the fault-based malpractice system, some scholars turned their gaze to contracts. Basically, there are two types of contractual approaches to medical malpractice liability. One group of scholars maintained that contracting out of or over malpractice liability ${ }^{5}$ between individual patients and health care providers may enhance social welfare. ${ }^{6}$ The other group of scholars paid more attention to enterprise liability and managed care, proposing that contracting with entities rather than individual providers is more desirable. ${ }^{7}$ Since managed care - the currently dominant form of health care provision in the US - is somewhat alien to China, and there is no sign that China will adopt this form of health care system in the near future, the second type of contractual approach will not be discussed here.

\footnotetext{
4 For more information on the regulation of health care in China, see supra Chapter 2, Section 4.

5 Here, "malpractice liability" may be either contractual liability or tortious liability.

$6 \quad$ See e.g. Epstein 1976; 1977; 1978; Havighurst 1983; Epstein 1986; Havighurst 1986; Robinson 1986; Epstein \& Sykes 2001; Thaler \& Sunstein 2008; Epstein 2013.

$7 \quad$ See e.g. Weiler et al. 1993; Abraham \& Weiler 1994; Sage, Hastings \& Berenson 1994; Danzon 2000.
} 


\subsection{THE CASE FOR THE CONTRACTUAL APPROACH}

Professor Richard Epstein strongly advocated a libertarian approach to medical malpractice issues. ${ }^{8}$ In his groundbreaking article "Medical Malpractice: The Case for Contract," Epstein criticised the traditional medical malpractice system, legislative innovations aiming to limit malpractice awards and medical no-fault insurance. ${ }^{9}$ Instead, Epstein pointed out that courts overlook "the possibility, indeed the desirability, of having the rules that they have laid down varied by the agreements between the parties." 10 Hence, Epstein proposed a contractual approach to medical malpractice issues - social welfare will be enhanced if patients and health care providers are permitted to negotiate ex ante on the level of care to be exercised and the price to be paid without government intervention. ${ }^{11}$

The rationale behind the contractual approach is that the best rules should be those that approximate to what "the parties themselves would choose to govern their own relationship." ${ }^{2}$ Under contract law, the parties should be encouraged to stipulate a set of individuated clauses in response to their practical needs. ${ }^{13}$ From the perspective of externalities, there is "no systematic external loss to offset the joint gains" by providers and patients. ${ }^{14}$ Accordingly, Epstein proposed two basic types of contracts: first, parties may agree on no protection - waiver of liability claims; ${ }^{15}$ and second, parties may agree on some but not full contractual liability protection. ${ }^{16}$ Since the statutory standard of care required of physicians - due care level - is removed or reduced, patients will receive a quid pro quo reduction in the prices of

$8 \quad$ Epstein 1976. Epstein has been vigorously defending his liberalist approach for decades since 1976. See Epstein 1977; 1978; 1984; 1986; 1988; 1995; Epstein \& Sykes 2001; Epstein 2013. This contractual approach is also advocated by Havighurst 1986; Robinson 1986 and recently by Thaler \& Sunstein 2008.

Epstein 1976, pp. 95-96.

Epstein 1976, pp. 94-95.

See generally Epstein 1976.

Epstein 1976, p. 95.

Id.

Epstein 1986, p. 202.

Epstein 1978, p. 256. It should be noted that waiver of tort liability is in effect equivalent to caveat emptor (no liability) under Shavell's market-based accident model. According to Shavell, caveat emptor is efficient only if customers have perfect knowledge of accident risks. See supra Chapter 6, Section 7.1.3.

16 Id. Parties may agree that providers are liable only for wilful infliction of harm or gross negligence, that the use of the doctrine of informed consent or res ipsa loquitur is restricted, or that medical customary practices, even one respectable school of thought, should be taken as standards of care. 
medical services. ${ }^{17}$ Put another way, the needy may benefit more from a combination of lower-cost treatment and lower prices for care than from that of higher-cost treatment and higher prices for care. ${ }^{18}$ For those who benefit more from the standard malpractice liability, they can simply replicate it by contract with a higher price for care. ${ }^{19}$

Recently, Thaler and Sunstein, in their well-known behavioural economics book "Nudge: Improving Decisions About Health, Wealth, and Happiness," put forward an even more radical proposal - "patients should be presumed to be permitted to sue only for intentional or reckless wrongdoing - and not for mere negligence." ${ }^{20}$ According to their approach, waivers of the right to sue for mere negligence would be the default option and patients would have to pay higher prices for more protection..$^{21}$ They predicted that if patients were fully informed, some of them would purchase more protection in the form of the right to sue for negligence, while most of them would be willing to "take their chances." 22 The rationale behind this prediction is that the costs of the malpractice system are too high and the whole system is a "lottery", and is a poor fit between malpractice claims and negligent iatrogenic injuries and highly erratic injury awards. ${ }^{23}$ Hence, many patients may not be willing to buy such "high-level" protection, which is a form of compulsory insurance via tort law, from which they do not believe they can benefit very much. ${ }^{24}$ The utility of those patients who do believe they can benefit from tort liability would not be affected since they could easily choose to purchase the statutory protection by paying more. ${ }^{25}$

In many jurisdictions, however, contracting out of or over malpractice liability may be blocked by the doctrines of unequal bargaining power, contracts of adhesion, economic duress, and unconscionability. ${ }^{26}$ Also, under the Dutch Civil Code, a waiver of malpractice liability is "plainly invalid." ${ }^{27}$ Epstein objected to this judicial restriction for three reasons: first, this judicial attitude directly violates the principle of freedom of contract; second, it

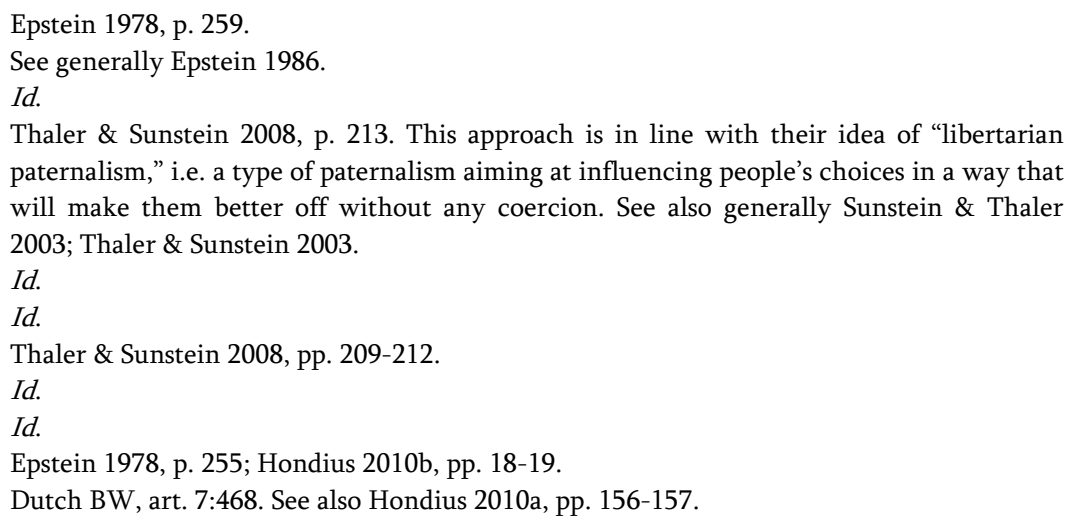


shares the same shortcoming with public regulation, namely that regulators often find that they make wrong estimations about what private parties actually need and the complexities of legal rules; and third, while errors made in private contracts can be corrected by alternative agreements, erroneous public orders cannot be corrected by private agreements. ${ }^{28}$ Thaler and Sunstein also pointed out that this judicial restriction is unacceptable to libertarians, because it denies providers and patients "the freedom to make contracts as they see fit." ${ }^{29}$

\subsection{ARGUMENTS AGAINST THE CONTRACTUAL APPROACH}

\subsubsection{Information Problems}

Opponents of the contractual approach maintained that patients are usually not fully informed of or unable to assess malpractice risks and thus it is virtually impossible for them to negotiate directly with physicians on liability in their own best interests. ${ }^{30}$ Product uncertainty and information asymmetry are characteristic of the health care market. ${ }^{31}$ Due to this information problem, if the contractual approach were allowed, many patients would opt out of malpractice liability even when they could be better off if they opted for liability. ${ }^{32}$ If consumers misunderstand the odds of product failure, sellers will produce the wrong products in the absence of government interventions..$^{33}$

Consumers are often not well-informed because they do not have sufficient expertise and resources to examine the quality of products, especially those infrequently purchased ones. ${ }^{34}$ Hence, consumers may be systematically optimistic about accident risks as a result of their inability to process data rather than due to insufficient data. ${ }^{35}$ Empirical evidence also shows that people who are relatively healthy tend to be unrealistically optimistic about accident risks - they believe their own odds of suffering injury are lower than that of others. ${ }^{36}$

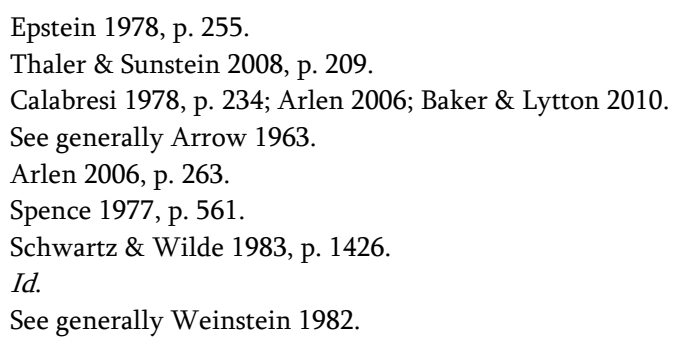


It is also argued that many patients under-state malpractice risks because they place great trust in their physicians and believe physicians will deliver the best care possible irrespective of regulation or liability. ${ }^{37}$ They may fail to recognise the important role of liability in quality assurance.

In addition, people may have the self-control problem of immediate gratification, which is that we often cannot resist the temptation to experience pleasure without delay which in the long run we do not appreciate. ${ }^{38}$ This cognitive bias might lead patients to overvalue the immediate gains of price reduction, which they would avoid were they fully informed. ${ }^{39}$

It follows from the preceding explanations that without government intervention, it is highly likely that many, if not most, patients would get hurt if they opted out of tort liability, because they tend to under-estimate malpractice risks, under-state the deterrent benefits of imposing liability on providers, and over-value the choice of opting out of tort liability.

\subsubsection{Other Arguments against Waivers of Statutory Liability}

Even if the information problem could be perfectly resolved by e.g. regulation on information disclosure, the contractual approach would not necessarily be superior to tort liability. Typically, Arlen maintained that many patients would get fewer benefits, at greater costs, from the contractual approach than from statutorily defined malpractice liability, even if they were fully informed..$^{40}$ The primary reason is that contractual arrangements for liability cannot replicate the same deterrent effects generated by statutory liability. ${ }^{41}$

Specifically, Arlen discovered three problems additional to imperfect information that would render contractual waivers of liability inferior to state-enforced liability: ${ }^{42}$

The Free-Rider Problem. Malpractice liability is needed to incentivize providers not only to invest time and effort in treating a single patient, but also to make patient safety investment in expertise, staffing, technology, equipment, clinical protocols, and administration for all

Arlen 2006, p. 264.

See generally O'Donoghue \& Rabin 2000.

Baker \& Lytton 2010, p. 234.

See generally Arlen 2006; 2010.

Id.

Arlen 2006, pp. 257-262; 2010. 
their patients. ${ }^{43}$ Since patient safety investment benefits all patients non-rivalrously, it can be regarded as a public good. The incentive to make collective patient safety investment cannot be induced by individual contracts, ${ }^{44}$ because a patient to a contract would only purchase the amount of safety that benefits him/her alone. In the health care sector, the contractual approach is inefficient in that it would create the free-rider problem that patients are induced to opt out of malpractice liability all together, decreasing their well-being collectively.

- Failure to Induce Optimal Pre-contractual Care. Malpractice liability can induce providers to make patient safety investment before, during and after any treatment continuously, because providers expect that this investment affects the safety of each treatment in the future. Therefore, under malpractice law patients usually do not have to worry about whether providers take sufficient prior precautions before they enter into a medical service contract. Proponents of the contractual approach argue that patients could receive more benefits if they were allowed to choose their desired level of safety. However, it is difficult in practice for high-quality providers to signal their pre-contractual quality level to patients through an offer to bear liability at a higher price for two reasons. First, malpractice liability is not experience-rated and it is difficult for patients to evaluate the quality of care of different providers before treatment. Second, it should be noted that what prior precautions have been made is already fixed before parties enter into a contract. This implies that waiving malpractice liability by means of the contract would not affect pre-contractual care.

- Adverse Selection. Patients are heterogeneous in terms of their willingness to purchase high-quality care. Patients with more complicate pre-existing or underlying conditions or litigious patients are expected to value malpractice liability most and are most likely to opt for more protection. Since providers do not have perfect information about patients' pre-conditions or litigiousness, they would surcharge all those who opt for tort liability an average price. Consequently, the problem of adverse selection would arise - lower-cost patients would waive malpractice liability and the average price would rise eventually. Those patients who value liability would have to choose either (a) to pay higher prices than they would pay under state-enforced liability to

43 See also supra Chapter 8, Section 2.2.1.

44 Be that as it may, it is possible that a group of patients who are in need of the same level of service quality may induce providers to invest in patient safety on the basis of a collective contract (e.g. via health insurance). 
obtain that protection or (b) to opt out of liability and obtain lowerquality care than what they would like to purchase. Either way, those patients would be worse off.

Furthermore, Danzon pointed out patients would have little incentive to opt for no liability if a significant part of their medical expenses had been already covered by health insurance and the reduction in out-of-pocket fee would be trivial. ${ }^{45}$ In the US, exactly as Danzon estimated in the 1980s, a waiver of malpractice coverage of a medical service costing $\$ 100$ would only reduce the out-of-pocket fee from $\$ 20$ to $\$ 19 .{ }^{46}$ Hence, in legal systems where social security is well developed, the contractual approach will become less attractive to patients.

\subsubsection{Other Arguments against Contractual Variation in the Standard of \\ Care}

In addition to waivers of malpractice liability, proponents of the contractual approach also maintained that allowing parties to negotiate on the standard of care that meets their needs best would be socially more desirable than tort liability since it would result in the optimal degree of variation in the standard of care. ${ }^{47}$ Arlen refuted the foregoing argument and maintained that allowing parties to negotiate on the standard of care would lead to "more variation in the standard of care than is socially optimal," because a patient in an individual contract would not take into account the benefits of standardised care to providers and other patients. ${ }^{48}$

Arlen held that health care providers can obtain learning and network benefits when they adhere to commonly recognised and practised standard of care..$^{49}$ Learning benefits in the health care sector include: (a) that providers will deliver health care more quickly and appropriately if they can rely on what they have learned from their past school education and training and clinical protocols; (b) that uncertainty over the standard of care will be greatly reduced if they follow commonly accepted professional standards; (c) that medical professionals will collaborate more closely and better coordinate their practices if they have the same understanding of the standard of care;

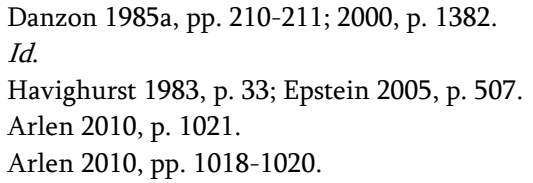


and (d) that best medical practices can be developed by researchers if they share the same "desired goal of medical treatment."

Network benefits result from the expectation that all other providers are using or new entrants will use the same standard of care contemporaneously. ${ }^{51}$ Their expertise will be enhanced through singleminded dedication to a common goal. ${ }^{52}$ It is evident that the cost of care is greatly reduced when providers observe the same standard of care rather than individualised standards of care. ${ }^{53}$ As mentioned before, improved collective care is a public good. Therefore, standardization also confers positive externalities upon all patients at large. ${ }^{54}$

The "switching costs" would be prohibitive if providers had to deliver different standards of care tailored to each individual patient's needs, because these learning benefits and network benefits to providers and the resulting positive externalities to all patients would be eliminated altogether..$^{55}$ Hence, Arlen concluded that an individual patient would seek more variation in the standard of care through private contracts than is socially optimal, because he/she would only be willing to purchase the level of safety to his/her own best interests and would externalise switching costs to providers and other patients. ${ }^{56}$

It follows from the foregoing analyses that the standardisation of care under the state-enforced malpractice liability is more efficient than variation in the standard of care by private contracts.

\subsection{SUMMARY AND EVALUATION}

Proponents of the contractual approach criticised the traditional fault-based malpractice liability as an expensive "lottery" that has little deterrent benefit. Instead, they maintained that fully informed parties should be allowed to negotiate on the extent of liability by private contracts, for they know better than others what is best for themselves. However, their fundamental assumption that parties have perfect information concerning malpractice risks is directly challenged by many opponents because serious quality uncertainty and information asymmetry is characteristic of the health care sector.

\begin{tabular}{ll}
\hline 50 & Id. \\
51 & Id. \\
52 & Id. \\
53 & Id. \\
54 & Id. \\
55 & Id. \\
56 & Id.
\end{tabular}


Moreover, opponents also raise objections to the contractual approach even when parties were fully informed. Patients would be systematically worse off if they opted out of statutory liability or varied the statutory standard of care. This is because a patient would only care about his/her own best interests in a private contract, neglecting the benefits of collective care to other patients, and learning and network benefits to providers and the resulting positive externalities to other parties. The availability of extensive social welfare provision in some legal systems may render the contractual approach less attractive.

As far as primary cost avoidance is concerned, ${ }^{57}$ although under the contractual approach the cost of care for a given treatment might be lowered, collective investments in patient safety would become very difficult. The contractual approach might greatly increase primary accident costs in two ways. First, it would increase the cost of collective care since it would become more difficult to make patient safety investments. Second, there would be more medical errors since both the level of care and patient safety investments would be reduced.

Regarding tertiary cost avoidance, indeed, the contractual approach would save many costs because the expensive malpractice litigation could be avoided. However, it would achieve this goal at the expense of primary and secondary cost avoidance.

After weighing up the pros and cons of the contractual approach, it is hard to believe that it would be necessarily more efficient than malpractice liability even in a free health care market. Needless to say, the contractual approach is indeed unfit for a health care system where service prices are heavily regulated by the government since providers are not allowed to charge different prices.

57 This Chapter is primarily concerned with prevention; hence, compensation is not touched upon. From the perspective of secondary cost avoidance, the contractual approach is barely efficient. If many patients opted for less protection in order to reduce expenses because they could not afford high medical expenses, then eventually those poor patients would be more likely to suffer more severe injuries due to physicians' lower level of care. Then, secondary costs would be more considerable, because more patients who are needy and risk-averse would be left uncompensated. 


\section{REGULATION: A GENERAL OVERVIEW}

\subsection{INTRODUCTION}

"Regulation" is an ambiguous term that can be used in different senses. ${ }^{58}$ In its loose sense, regulation is the "act or process of controlling by rule or restriction." 59 This control can be exercised by either the government or private entities. Accordingly, there is public regulation (or direct government regulation, meta-regulation or command-and-control regulation) as well as private regulation (or self-regulation).$^{60} \mathrm{~A}$ classic definition of public regulation is "sustained and focused control exercised by a public agency over activities that are valued by a community." 61 In contrast, self-regulation can be described as "regulation by organisations or associations in a field of society," 62 which specifically refers to "an organisation's or industry's control, oversight, or direction of itself according to rules and standards that it establishes." 63

From the perspective of law and economics, the goal of regulation is to induce actors to comply with regulatory standards in order to generate the optimal level of quality and safety against certain risks where the marginal costs of improving quality and safety amount to the marginal benefits of risk reduction. ${ }^{64}$ This goal is in line with Calabresi's primary accident cost reduction. Since regulation has no compensatory function, the secondary cost reduction goal will not be addressed in this section. Nonetheless, tertiary cost reduction ought to be considered since a regulatory regime cannot be efficient if it incurs too high administrative costs.

The delivery of health care is heavily regulated in most legal systems. Although both public regulation and self-regulation are jointly employed widely, each country gives its own preference to direct government regulation or indirect professional regulation. While countries such as the US

58 For instance, regulation at present may be understood as: (a) a specific set of commands (promulgating and enforcing regulatory rules); (b) deliberate state influence, including both command-based regimes and other modes of influence such as taxes or subsidies, contractual powers, tort law etc.; (c) all forms of social or economic influence, consisting of both state-based and non-state-based mechanisms (e.g. markets, self-regulation). See e.g. Baldwin, Cave \& Lodge 2013, p. 3.

Garner 2014, p. 1398.

See generally Coglianese \& Mendelson 2010.

Selznick 1985, p. 363.

Eijlander 2005, p. 2.

Garner 2014, p. 1398

Ogus 2007, p. 378. 
and the UK rely more on self-regulation but less on state structures to regulate the medical profession ${ }^{65}$ continental countries such as Germany and France have central health care authorities responsible for the regulation of the medical profession and embed self-regulatory professional institutions deeply in the state legal structure. ${ }^{66}$

In the health care sector, regulatory interventions can be classified as output controls and input controls. ${ }^{67}$ Output controls refer to quality regulation, under which the public agency will exercise the control over goods/services quality directly through setting and enforcing "regulations"68 or regulatory standards governing the safety and quality of these activities. ${ }^{69}$ Since it is often difficult for regulatory authorities to set a minimum quality standard due to imperfect information, ${ }^{70}$ the authorities also will tend to control input variables that are claimed to affect quality levels. Input controls are defined as the regulation of input variables that are believed to produce high-quality physicians. ${ }^{71}$ Three options are normally available for controlling input variables: (1) to set minimum education standards for entrants, (2) to outlaw behaviour deemed to be unprofessional, ${ }^{72}$ and (3) registration, certification and/or licensing. ${ }^{73}$

This Section will first answer the question why the health care industry needs to be regulated in Section 3.2. Then, I will summarise the pros and cons of input controls and output controls and make a critical evaluation respectively in Section 3.3. and Section 3.4. After that, public regulation will be compared with self-regulation in Section 3.5. A summary and an overall evaluation will be made in Section 3.6.

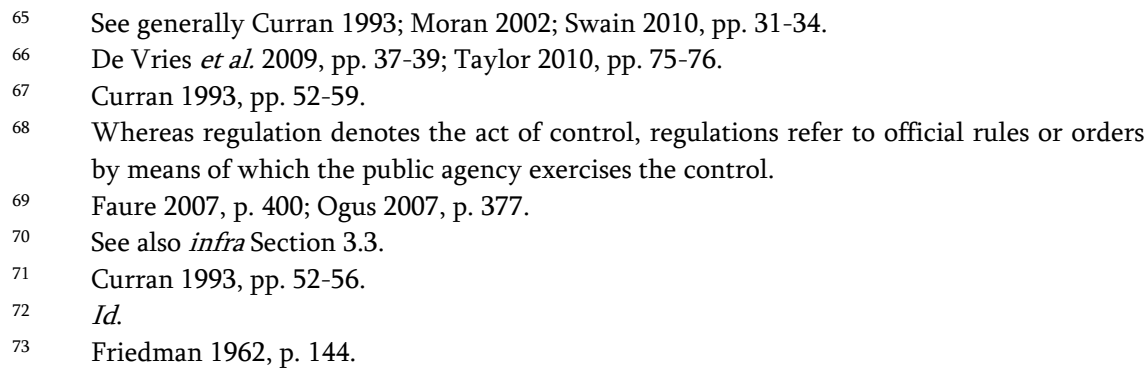




\subsection{ARGUMENTS FOR REGULATING HEALTH CARE PROVISION}

\subsubsection{Introduction}

Economists are not unanimous in how to theorise regulation. There are basically three major types of economic theories of regulation: the public interest theory, the "capture" theory and the public choice theory. ${ }^{74}$ The latter two are often described together as the private interest approach. ${ }^{75}$ The "public interest" theory suggests that regulation is instituted to correct market failure mainly for the protection and benefit of the public or some large subclass of the public. ${ }^{76}$ In contrast, according to the capture theory, the regulatory process is "captured" by the profession and is used to restrict entry and to increase the incumbent providers' earnings. ${ }^{77}$ Proponents of the public choice theory often recognise the fact that both consumer groups and the medical profession have implications for the existence and form of medical professional licensing. ${ }^{78}$ Empirical evidence in the US generally seems to support the public choice theory. ${ }^{79}$

Be that as it may, this section will only pay attention to the public interest theory and ignore the complications introduced by the private interest approach in this Section for two reasons. ${ }^{80}$ First, the basic analytical framework adopted in this Chapter is Calabresi's primary and tertiary costs, which is incompatible with the private interest approach. Second, these private interest theories of regulation developed in a highly democratic society like the US does not seem to fit in with the Chinese political reality. ${ }^{81}$

Den Hertog 2000; Olsen 2000, pp. 1021-1022.

See generally Den Hertog 1993; Philipsen 2003, pp. 9-27.

Stigler 1971, p. 3; Posner 1974; Dewees, Mathewson \& Trebilcock 1983.

See generally Friedman 1962.

See generally Stigler 1971; Peltzman 1976; Becker 1983.

Olsen 2000, p. 1027. See also generally Leffler 1978; Graddy 1991.

This stance is consistent with Shavell 1984a, p. 358.

Public hospitals, which play a dominant role in the Chinese health care system, are owned by the state, and most individual providers are employees of public hospitals. In other words, almost the entire medical profession is directly controlled by the state (and ultimately by the Chinese Communist Party (CCP)). It is thus odd to believe that either the medical profession or patient groups (virtually non-existent in China) would be able to "capture" or greatly influence the National People's Congress (NPC) or the CCP. It is de facto the CCP that makes final decisions for both the medical profession and patients. Nonetheless, it is possible that the medical profession may try to bribe high-ranking officials of the CCP to enact policies that are intended to benefit the medical profession only. In other areas, for example, Shen's study show that some local public officials impose 
Hence, in this Section, only the public interest theory will be employed to justify the regulation of the medical profession.

By and large, there are four sources of market failure that may justify regulation: informational asymmetries, externalities, public goods, and market power. ${ }^{82} \mathrm{We}$ will examine the applicability of these arguments to the health care market in Section 3.2.2.

\subsubsection{Public Interest Arguments for Health Care Regulation}

\subsubsection{Asymmetric Information}

Health care services are typical "confidence goods," for due to severe asymmetric information consumers place confidence in physicians rather than do quality assessment on their own. Where confidence goods are concerned, regulation is argued to be superior to market competition, for regulation can lower search costs, improve service quality and enhance social welfare by reducing risks faced by risk-averse consumers. ${ }^{83}$

Health care providers and their clients establish a relationship of trust. $^{84}$ If providers could be trusted, then the problems of asymmetric information (adverse selection and moral hazard) would be resolved. ${ }^{85}$ As Akerlof demonstrated, adverse selection would lead to the deterioration of product/service quality. ${ }^{86} \mathrm{In}$ addition, asymmetric information might result in a moral hazard that professionals would provide more services than consumers would have purchased if fully informed (demand generation). ${ }^{87}$ Moreover, consumers may "lack the education level, or even the intelligence,

stringent requirements on the cross-border establishment of companies in order to make it easier to take bribes. See Shen 2016, pp. 230-231. However, there is currently no empirical evidence that either the NPC delegates or high officials of the CCP decided to implement the licensing system for doctors because of rent-seeking. And in China, the medical profession is not self-regulatory, which reduces the possibility of pursuing the private interest of the profession through licensing. However, if the Chinese medical profession were allowed to self-regulate itself in the future, then the private interest approach would become relevant. See supra Section 6.

82 Cooter \& Ulen 2012, pp. 38-42. Of course, regulation is not the only form that can remedy market failures. For example, in cases where there is the problem of negative externalities, other forms of remedies may include individual bargaining based on the Coase Theorem, liability rules and lawsuits, corrective taxes on producers, and a market for externality rights. See e.g. McConnell, Brue \& Flynn 2009, pp. 341-346.

$83 \quad$ Van den Bergh 1993, p. 35.

$84 \quad$ Van den Bergh 1993, p. 36.

$85 \quad$ Id.

86 See generally Akerlof 1970

$87 \quad$ Philipsen 2003, p. 16. 
to process all available information on products and services in a correct way" due to bounded rationality. ${ }^{88}$

Devices such as trademarks economise on transaction costs so long as providers do not "abuse the confidence" given by their clients through strategic behaviour which may damage their clients' interests. ${ }^{89}$ In a free market of health care, trademarks are signals of service quality. It would be easier for patients to find a good provider if they could place a trust in the "trademarks" of hospitals/physicians (if there were trademarks) than if they would have to figure out the quality of care of each provider on their own (if there were no trademarks). Disclosure of information on the quality of care through advertising does not seem to apply to experience goods. In the health care sector, licensing, whereby low-quality providers are eliminated at the outset, could also alleviate the problem of information asymmetry if quality levels were truly raised by input controls. ${ }^{90}$ However, licensing alone may not be able to prevent licensed providers from abusing the confidence. Hence, output controls through setting and enforcing safety regulations may be indispensable.

Therefore, some government intervention in the health care sector is justifiable and necessary because preventing the quality of care from deteriorating and ultimately reducing primary accident costs is in the interest of the public.

\subsubsection{Negative Externalities}

Another reason in support of medical safety regulation is in response to the presence of negative externalities. Economists normally describe damage outside private contracts as an external cost, or simply an externality. ${ }^{91}$ The general public will be adversely affected by the injuries attributable to lowquality professional services (e.g. spreading diseases through unclean equipment). ${ }^{92}$ Given external costs, if potential injurers only take into account their own private marginal cost rather than the marginal social costs, there will be inefficient oversupply and more injuries will be created, leading to a deadweight loss. ${ }^{93}$

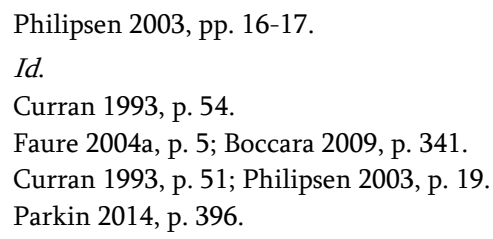


As an important source of market failure, externalities must be internalised ${ }^{94}$ An externality is said to be internalised when potential injurers take external costs into account before engaging in activities..$^{95}$ In theory, these externalities may be internalised through private contracts, if the costs of contracting were adequately small. ${ }^{96}$ However, if there is an outbreak of an infectious disease, potential patients may be so dispersed or numerous that the costs of individual contracting over liability would be prohibitive. ${ }^{97}$ There would be no private contracting possible and the market might nonetheless fail. ${ }^{98}$

Hence, regulation can be justified in that it may induce health care providers to internalise those external costs by enforcing them to comply with regulatory standards, with a view to reducing iatrogenic injuries and eliminating the deadweight loss. ${ }^{99}$ In so doing, the interest of the general public is protected.

\subsubsection{Public Goods}

Public goods (e.g. national defence) generally refer to a commodity, which is both non-rivalrous (consumption by one does not reduce availability to others) and non-excludable (non-paying consumers cannot be prevented from using it). ${ }^{100}$ The private supplier of public goods faces the problem of free riders, who use the public goods without paying for the costs. ${ }^{101}$ The government may remedy this problem by either subsidising the private provider or undertaking the provision of the public good directly. ${ }^{102}$ However, although medical services have a public goal of promoting public health, and may generate positive externalities, the problem of free riders "does not seem to occur in the market for professional services"103 since patients usually have to pay to receive treatment services. Hence, this third source of market failure does not appear relevant to the medical profession.

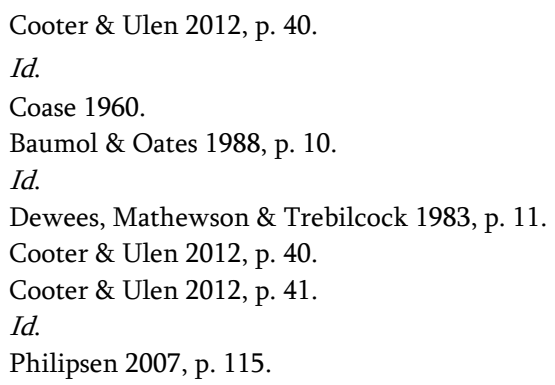




\subsubsection{Market Power}

Market power results from monopoly or cartel-like behaviour. ${ }^{104}$ Where there is a monopoly, the price will be too high, and the quantity will be too low in light of efficiency. ${ }^{105}$ As far as the health care market is concerned, competition law should be employed to fight against any "cartel-like behaviour and abuse of dominant positions by ... professional associations." 106 Natural monopolies such as public utilities may not be a problem, but the government should regulate their prices. ${ }^{107}$

\subsection{SUMMARY}

In the light of the public interest theory, regulation can be a legitimate instrument for the promotion of public interest. Regulation may be able to remedy the four sources of market failure: asymmetric information, externalities, public goods, and market power. While asymmetric information, externalities, and market power are relevant for the health care market, public goods do not seem to be a valid argument for regulating the medical profession. As far as quality assurance is concerned, asymmetric information and externalities seem more relevant than market power. Both asymmetric information and externalities may result in a lower quality of care, whereas market power is more likely to only affect the price and quantity of medical services. Both input and output regulation of the medical profession have the potential to be an alternative mechanism (or a nice complement) to medical malpractice liability.

Be that as it may, the question of whether these forms of regulation are likely to, or do actually, induce medical professionals to invest optimally in patient safety generally and in care specifically, will be addressed in Sections $4-5$. Section 6 is concerned with the question of who is the best regulator of the medical profession. ${ }^{108}$ Since regulation is not intended to compensate victims, only goals of primary and tertiary cost avoidance will be adopted to evaluate regulation.

\footnotetext{
$104 \quad$ Cooter \& Ulen 2012, p. 38.

105 Id.

$106 \quad$ Philipsen 2007, p. 116.

107 Cooter \& Ulen 2012, p. 39.

108 Although the medical profession is regulated directly by the government, it is still interesting to examine the pros and cons of self-regulation in the sense that China may alter its approach to the regulation of the medical profession in the future. Hence, the discussion on self-regulation may be helpful in the sense of a recommendation.
} 


\section{INPUT CONTROLS: IS LICENSING A DESIRABLE ALTERNATIVE?}

\subsection{INTRODUCTION}

Friedman defined three levels of input control: registration, certification and licensing. ${ }^{109}$ Under registration, physicians are only required to inform the government of their intent to practice and no restrictions are placed on entry, ${ }^{110}$ though it ought to be noted that the term "registration" in Europe may be used differently from the one used in the US. ${ }^{111}$ Under certification, the government (or sometimes a private organisation) allows a member of an occupation to use a title if he/she meets certain standards (e.g. a combination of education, on-the-job experience, and passing an examination), but does not exclude other uncertified members from practising. ${ }^{112}$ In contrast, licensing should be carefully distinguished from registration and certification. Under licensing, no one is allowed to enter the medical profession unless he/she has a license, and whoever is practising without a license may be subject to a fine or a jail sentence. ${ }^{113}$ The primary assumption for licensing is that the control of input variables (prior patient safety investments in professional competence) will raise the quality level of output services (patient-specific care). ${ }^{114}$

In practice, the most prevalent form of input controls in the health care sector is licensing. In the US, the regulatory power of initial medical licensure is delegated to the medical board in each State and the entry requirements vary markedly from one State to another. ${ }^{115}$ In Europe, while health authorization offices (e.g. Ministry of Health) are responsible for registration and licensing in some countries such as the Netherlands, Finland

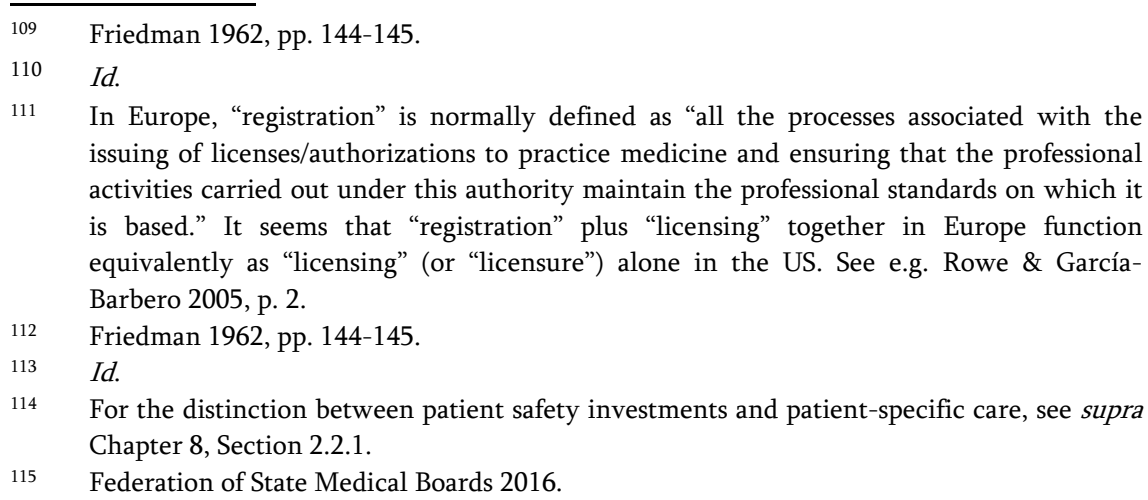


and Denmark, medical chambers are in charge of this task in e.g. the UK, Austria and Spain. ${ }^{116}$ In addition, in Belgium, Germany and Italy, health authorization offices and medical chambers work together to complete the whole process of registration and licensing. ${ }^{17}$ Licensing authorities or medical boards normally not only have the power to set prior requirements for obtaining a license, but also have the authority to demand remedial actions if an incompetent practitioner is identified.

In the next section, there will be a brief review of theoretical arguments for licensing in Section 4.2. Thereafter, there will be consideration of some arguments against licensing in Section 4.3. A summary and evaluation of licensing will be made in Section 4.4.

\subsection{ARGUMENTS FOR LICENSING}

To begin with, licensing is able to relieve the problem of asymmetric information. Licensing helps consumers to minimise their uncertainty over service quality and hence it will increase consumers' demand for that service. ${ }^{118}$ Licensing reduces consumers' costs of information in that a central information agency gathers information on aspiring practitioners by virtue of economies of scale. ${ }^{119}$

Secondly, licensing induces practitioners to invest in professionspecific human capital before they begin their careers. Licensed providers can recoup the whole returns to their investment given the fact that no lowquality substitutes for their services are allowed to be provided by unlicensed competitors. ${ }^{120}$ In this way, licensing may reduce the risk of imposing external costs to third parties.

Thirdly, licensing may reduce the marginal cost of providing care. Shapiro demonstrated the proposition that "human capital and quality are complements," i.e. "higher levels of training (human capital investment) reduce the marginal cost of providing quality." ${ }^{\prime 21}$ The likelihood of under-

\footnotetext{
$116 \quad$ Kovacs et al. 2014.

117 Id.

118 Arrow 1963, p. 966; 1971, pp. 208-210.

119 Trebilcock 1983, p. 95.

$120 \quad$ Shapiro 1986 , p. 850.

121 Shapiro 1986, p. 844. Shapiro believed this assumption is in tune with both common sense and the characteristics of professional services, since "a well-trained professional knows more easily what to do, finds it easier to keep up-to-date with changing technology and knowledge, and can do a good job with less effort than his less well-trained colleague." Id. p. 846.
} 
investment in precautions is decreased because it is less costly for welltrained physicians to provide high-quality care..$^{122}$

\subsection{ARGUMENTS AGAINST LICENSING}

\subsubsection{Is Licensing an Optimal Way to Provide Information?}

Many opponents of licensing dispute the foregoing points for licensing. To begin with, licensing is not the only way to provide consumers with information. Besides licensing, some other ways of obtaining information may include direct observation of providers' behaviour, providers' reputations that are tested and re-tested by consumers, and advice and direction from others such as referring physicians, friends and family members, along with speciality board certification. ${ }^{123}$ Direct observation may be highly impractical in the health care sector since patients obviously lack relevant expertise to evaluate physicians' performance. ${ }^{124}$ Reputation would not be successful in providing information in cases where there are numerous providers (esp. in large cities), because search costs for consumers would be considerable. ${ }^{25}$ Nonetheless, certification may be an acceptable alternative to licensing. Under certification, consumers have the freedom to purchase low-quality goods or services given their limited income or special taste, while at the same time they can obtain as much information under certification as under licensing. ${ }^{126}$ The "identification of qualified personnel" is not a sufficient justification for licensing, since this can be achieved via certification. ${ }^{127}$

In contrast, although both licensing and certification can provide consumers with information, licensing generates more social costs than certification. By restricting medical practice to high-quality physicians only, licensing may increase the quality of care received by customer-patients, but it may also decrease the overall quality of care in other ways. On the one hand, service prices will rise with the reduction in the number of providers due to licensing (monopoly), which will tend to reduce the average service quality received by consumers. ${ }^{128}$ The choices for consumers will also be

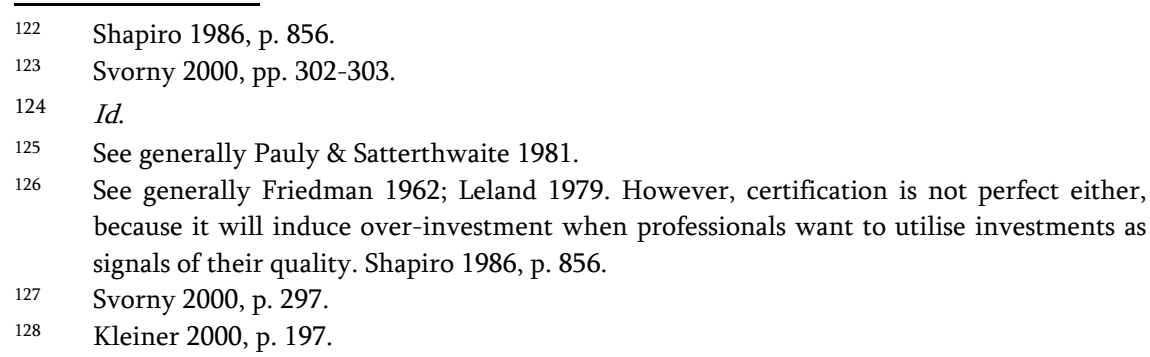


reduced due to this monopoly effect. On the other hand, the overall quality of medical care received by all consumers may be decreasing even though the average quality of care provided by professionals is increasing. ${ }^{129}$ This can be explained by the substitution effect that when facing higher prices, poorer consumers may substitute into lower cost services such as self-service or doit-yourself remedies, because low-quality doctors are denied entry into the market. ${ }^{130}$ Some empirical evidence also shows that substitution into selfprovided services does exist. ${ }^{131}$

\subsubsection{Is Licensing an Optimal Way to Ensure Quality?}

In practice, it is questionable whether licensing requirements can ensure a desirable level of professional competence or service quality.

First, it is questionable whether students or training institutions are induced to provide the socially optimal amount of education and training. ${ }^{132}$ Students only want enough education to pass the examination and training institutions want to maximise profits (either through high tuition or through high volume). ${ }^{133}$ Many members of the medical profession themselves do not believe the examination is an effective tool to eliminate incompetent professionals, ${ }^{134}$ and some empirical evidence in the US suggests that academic grades are a strong predictor of learning ability but not of professional competence. ${ }^{135}$ The American Medical Association (hereinafter AMA) has long criticised that most "new or unorthodox training programs" are not intended to train high-quality professionals. ${ }^{136}$ Better and perhaps more effective ways that can be used to evaluate physician competence may include actual assessment of aspiring applicants' performance in the course of

129 Trebilcock 1983, p. 97; Curran 1993, p. 57. This argument does not seem to fit into the classic accident models, since it treats as "medical accidents" cases where patients cause damage to themselves when performing self-remedies. Evidently, it is impossible for physicians to prevent these "medical accidents" out of their reach. However, this unfavourable substitution effect should not be ignored when designing legal instruments aiming at preventing medical malpractice. In other words, a legal regime primarily aiming at accident prevention may result in prohibitive adverse distributional consequences as side-effects. Such a regime should not be treated as desirable, unless these distributional consequences could be better tackled by other mechanisms such as social security. See Calabresi 1970, pp. 78-80.

$130 \quad$ Id.

$131 \quad$ See generally Muris \& McChesney 1979; Carroll \& Gaston 1981.

$132 \quad$ Curran 1993, p. 58.

133 Id.

$134 \quad$ Hogan 1983, p. 122.

135 See generally Price et al. 1964; McClelland 1973.

$136 \quad$ Id. 
residency training. In addition, governmental restrictions on entry into the training business may not be effective at tackling the problem, since schools may "use their relationship with the government to lobby for increases in educational requirements not justified by the quality needs of the licensed occupation." 137

Second, a good education and training level do not necessarily result in a high quality of services provided. ${ }^{138}$ To begin with, since human capital depreciates over time, this assumed correlation will become weaker over the provider's career. ${ }^{139}$ As Friedman put it long ago, "A man's ability to pass an examination twenty or thirty years earlier is hardly assurance of quality now ..."140 Nevertheless, license renewal, which is subject to certain conditions such as mandatory periodic revaluation or continuing medical education (CME), may relieve this problem. ${ }^{141}$ Empirical evidence shows that CME is especially successful when specific problems that were identified in practice are the main focus of the education. ${ }^{142}$ In other words, there should be a connection between the requirements of input regulation and the examination of actual performance. ${ }^{143}$

Third, even if licensing could guarantee physician competence, it could not ensure that competent physicians will not betray the trust of patients. Licensing per se cannot disclose all information on providers' (esp. subsequent) competence and service quality to patients, and hence in the long run the problem of information asymmetry cannot be fully tackled through licensing alone. Due to any remaining asymmetric information, providers may still be able to lower the quality of services by sending false market signals. ${ }^{144}$

\subsection{SUMMARY AND EVALUATION}

Section 4 examined the most widely adopted form of input controls regarding the regulation of the medical profession. Proponents of licensing defend the idea that licensing can ensure service quality by resolving the problems of asymmetric information, externalities, and quality deterioration. First, it resolves the imperfect information problem by providing consumers with

Curran 1993, p. 59.

Trebilcock 1983, p. 96; Curran 1993, p. 58.

Id.

Friedman 1962, p. 158.

Dewees, Duff \& Trebilcock 1996, p. 126.

See generally Chassin \& McCue 1986; Davis et al. 1990.

See generally Brown \& Uhl 1970.

Curran 1993, p. 59. 
some information about physician competency. Second, it prevents external costs from being spread to third parties by ensuring a minimum level of professional competency. Third, it lowers the marginal cost of providing service. The aforesaid case for licensing is normally applicable to cases where health care is provided in a free market. However, even in a non-marketbased health care system, licensing is useful because, at least, it does purport to guarantee a minimum level of professional competence.

Besides these benefits yielded, licensing may have several drawbacks. First, it may lower the aggregate quality of care due to the substitution effect and decrease the choices for consumers due to the monopoly effect. Second, licensing requirements may have little connection with professional competency or service quality. Third, agency costs are high because licensing cannot effectively guarantee that providers will not cease investing in patient-specific treatment at the expense of uninformed patients. ${ }^{145}$

After weighing up the pros and cons of licensing, Trebilcock remarked that

\begin{abstract}
These weaknesses of an occupational licensing system are formidable and suggest that licensure should be reserved for professional markets characterized by high costs of error by providers, high information costs faced by consumers, and/or substantial and widespread negative thirdparty effects not fully compensable in damages, and for situations where there is a reasonably high correlation between prescribed training inputs and desired service outputs. ${ }^{146}$
\end{abstract}

In view of Trebilcock's foregoing criteria, the benefits of licensing as a mechanism to ensure service quality may exceed its social costs in the health care market. First, the costs of medical errors are considerable relative to that of errors in other types of professional markets, since disability or death is often the consequence of medical errors. Second, information costs confronted by patients are also prohibitive because quality uncertainty and asymmetric information are characteristic of the health care market. Third, the potential negative externalities to third parties such as an epidemic of diseases due to low-quality medical services can be very substantial and widespread. Fourth, substantial investment in medical expertise is essential to the provision of optimal treatment. It is virtually impossible for a poorly trained professional to provide high-quality medical services. Therefore, licensing does serve the purpose of reducing primary accident costs.

145 In this last respect, output regulation or liability rules that are intended to ensure the quality of care directly may be indispensable.

146 Trebilcock 1983, p. 99. 
Given the goals of primary and tertiary cost avoidance together, it appears that licensing can be a potentially useful complement, to rather than a perfect substitute for, tort liability. On the one hand, it is a nice complement in the sense that it can reinforce medical professionals' incentives to invest substantially in human capital before and after they begin their careers. Obviously, initial investment in human capital is the prior condition for obtaining a license. Licensed professionals will also be induced to make subsequent investment in human capital, because of periodic relicensing ${ }^{147}$ or because their licenses may be suspended or revoked by regulators for professional incompetence, ${ }^{148}$ although in practice disciplinary sanctions may be less effective due to low rates of identification and enforcement. ${ }^{149}$ Without a license, anyone practising medicine may be subject to criminal penalties. ${ }^{150}$ Although tort liability can also induce health care providers to make extensive investment in patient safety, which includes but is not limited to professional expertise, it may incur more administrative costs than licensing and re-licensing. ${ }^{151}$ On the other hand, licensing is not a perfect substitute for tort liability. Although licensing reduces the marginal cost of providing optimal treatment, it does not necessarily ensure that providers will exercise sufficient patient-specific care. Besides inducing providers to make investments in patient safety, tort liability also incentivizes providers to exercise optimal care in a single treatment, which is beyond the

147 Of course, as mentioned before, to set passing periodical evaluations or taking continuing medical education as the conditions for re-licensing may be a potential way to generate continuing incentives to update professional expertise. However, these measures may not be very effective at improving quality if they are not problem-oriented.

148 For instance, the usual grounds for revocation of license in the US may include "professional incompetence, bad character, immorality, professional misconduct, dishonourable conduct, conviction of criminal offence, and gross negligence." USLegal 2016. In should be noted that revocation can not only be used to ensure subsequent professional competence, but also have punitive effects on doctors who, deliberately or accidently, committed gross medical negligence even if they are relatively competent. Hence, on the one hand, revocation of license is part of input regulation; on the other hand, it can be viewed as a sanction under output regulation. The double role of revocation of license itself can be explained by the fact that licensing is intended to ensure professional competence, which is in turn aimed at guaranteeing the minimum level of service quality.

149 See supra Section 3.3.4.C.

150 In the US, for example, practising medicine without a license is illegal in all states and anyone who commits such a crime may be subject to imprisonment and fines. See generally e.g. Suszek 2016; Theoharis 2016.

151 It should be noted that the imposition of disciplinary sanctions such as suspension or revocation of a license is ex post in nature, which is the same as tort law. Thus, although ex ante (re)licensing may have a cost advantage over tort liability administratively; disciplinary sanctions do not seem to have this advantage over tort liability. 
reach of licensing. The foregoing analyses suggest that it may be socially optimal to use the licensing system and tort liability jointly.

\section{OUTPUT CONTROLS: IS QUALITY REGULATION A DESIRABLE ALTERNATIVE?}

\subsection{INTRODUCTION}

While the major target of input regulation is to ensure professional competence, output regulation focuses on how to "ensure individual compliance with pre-determined standards." ${ }^{152}$ Quality regulation - the typical form of output regulation - usually refers to the regulator's control over goods/service quality directly through prescribing and enforcing safety rules by either public regulatory agencies or delegated professional bodies. ${ }^{153}$

In order for quality assurance to be effective, three requirements must be satisfied: (1) appropriate "norms, standards, and criteria" should be developed in order to ensure an efficient level of care; (2) practitioners who are below "acceptable minimum quality standards" should be identified; and (3) sanctions should also be appropriate and effective. ${ }^{154}$

The following section will outline the theories of quality regulation and relevant empirical evidence. In Section 5.2, I will contrast ex ante regulation with ex post regulation and try to answer which is more desirable in the context of medical quality regulation. In Section 5.3, I will explore the question as to how to design an optimal regime of sanctions for medical quality assurance. A summary and evaluation will be given in Section 5.4.

\subsection{THE FORMS OF QUALITY REGULATION}

\subsubsection{Introduction}

In order to ensure a minimum level of quality, the state or professional bodies should set regulatory standards that medical professionals have to comply

$152 \quad$ Dewees, Duff \& Trebilcock 1996, p. 131.

153 Curran 1993, p. 51; Van den Bergh 1993, pp. 37-43. Sometimes, tort liability is also regarded as a way of regulation. In this dissertation, we distinguish the medical malpractice litigation system from safety regulation of the medical profession which is administered by regulatory bodies rather than courts.

154 Dewees, Duff \& Trebilcock 1996, pp. 131-134. 
with. ${ }^{155}$ In terms of precision, regulatory standards can be either "rules" or "standards." 156 "Rules" denote those standards the content of which is specifically defined ex ante through collective decisions (e.g. the head should be covered), whereas the content of "standards" is determined ex post by an adjudicator (e.g. what behaviour adversely affect the reputation of doctors). ${ }^{157}$ Their distinction is significant in that while the former is intended to be used as the means of ex ante (safety) regulation which is triggered before any accident occurs, the latter tends to be treated as the way of ex post regulation which is activated after an accident happens. ${ }^{158}$

In the health care sector, "rules" often manifest themselves in various professional codes of conduct, practice rules, and clinical guidelines. ${ }^{159}$ Theoretically, it is possible that regulatory agents (or delegated professional bodies) may identify those providers who contravene safety standards ("rules") before any accident occurs and levy an act-based administrative/disciplinary sanction (e.g. a warning, suspension/revocation of the license, or a civil penalty) on them.

In the literature, ex post regulation is often understood as (fault-based) liability in tort, ${ }^{160}$ under which judges resolve claims filed by victims through the civil procedure and damages awarded to victims are considered as "sanctions" levied on tortfeasors. Nonetheless, ex post regulation may also be administered by regulatory agents (or delegated professional bodies) via the administrative procedure under which harm-based administrative/disciplinary sanctions (e.g. a warning, suspension/revocation of the license, or a civil penalty) may be imposed.

Criminal law is also relevant to regulation. In case of severe contraventions, either ex ante or ex post regulation may be backed up by criminal penalties (e.g. fines or imprisonment) which are imposed by the court through criminal proceedings. Criminal penalties are unique in that they "may be imposed if no harm is done or conditional on its occurrence."161 Those serious violations of regulatory standards are often labelled as

$155 \quad$ Curran 1993, p. 52.

156 For legal or economic analyses of "rules" and "standards," see generally e.g. Ehrlich \& Posner 1974; Diver 1983; Schlag 1985; Kaplow 1992. In ought to be noted that quotation marks are used to emphasise the distinction between "rules" and "standards" in order to be precise, while regulatory standards (without quotation marks) can refer to both "rules" and "standards."

$157 \quad$ Kaplow 1992, p. 559.

$158 \quad$ Shavell 1987a, p. 278; Posner 2014, § 14.1.

159 See e.g. Taylor 2010, pp. 75-76.

160 See e.g. Shavell 1984a; 1984b; Charles, Thomas \& Gary 1990; Hiriart, Martimort \& Pouyet 2004; Innes 2004

161 Shavell 1987a, p. 279. 
"regulatory offences,"162 "public-welfare offences"163 or "administrative crimes"164 in the common law systems.

The preceding forms of quality regulation can be presented in Table 9.1 as follows:

Table 9.1: EX Ante and Ex Post Regulatory Measures for Quality Assurance ${ }^{165}$

\begin{tabular}{|c|c|c|}
\hline \multirow{2}{*}{ How initiated } & \multicolumn{2}{|c|}{ When applied } \\
\hline & Ex ante & Ex post \\
\hline By victims & - & $\begin{array}{l}\text { Liability: } \\
\text { - breaching the standard of } \\
\text { care } \\
\text { - causing harm } \\
\text { - harm-based damages }\end{array}$ \\
\hline By the state & $\begin{array}{l}\text { Safety regulation by regulators: } \\
\text { - contravening "rules" } \\
\text { - causing no harm but risks } \\
\text { - act-based administrative } \\
\text { sanctions }\end{array}$ & $\begin{array}{l}E \boldsymbol{x} \text { post regulation by } \\
\text { regulators: } \\
\text { - contravening "standards" } \\
\text { - causing harm } \\
\text { - harm-based administrative } \\
\text { sanctions }\end{array}$ \\
\hline $\begin{array}{l}\text { Victims or the } \\
\text { state }\end{array}$ & $\begin{array}{l}\text { Criminal sanctions: } \\
\text { - contravening "rules" } \\
\text { - conduct of serious risks } \\
\text { ("conduct crimes") } \\
\text { - act-based penalties }\end{array}$ & $\begin{array}{l}\text { Criminal sanctions: } \\
\text { - contravening "standards" } \\
\text { - serious result ("result } \\
\text { crimes") } \\
\text { - harm-based penalties }\end{array}$ \\
\hline
\end{tabular}

The next Section 5.2.2 will only discuss the respective desirability of ex ante and $e x$ post regulation. The choice among various sanctions will be addressed in Section 5.3.

\subsubsection{EX-Ante versus EX Post Regulation by Regulators}

In the light of Calabresi's goals of primary and tertiary cost avoidance, ex ante and ex post regulation by regulators can be contrasted in several aspects:

- Ensuring compliance. Generally, "rules" are better than "standards" at inducing potential injurers to comply with regulations, since "rules" make a clear distinction between what is forbidden and what is

\footnotetext{
$162 \quad$ Brown 1992, p. 692.

163 See generally Sayre 1933; Borre 1961.

164 See generally Schwenk 1943.

165 Table 9.1 is built upon Shavell 1987a, p. 278, Table 12.1.
} 
Part II. Economic Theories and Empirical Evidence

permitted. ${ }^{166}$ The ex-ante approach makes legal obligations that potential injurers have to discharge easier to understand and hence probably promotes "better compliance (fewer inadvertent violations)." ${ }^{167}$

- Enactment costs. "Rules" can be "centrally designed" by a single administrative agency once and for all, while "standards" have to be crystallised by many adjudicators in a decentralised adjudication system. ${ }^{168}$ Hence, the cost of promulgating a "rule" $e x$ ante is easily "outweighed by the benefit of having avoided additional costs repeatedly incurred" in applying a "standard" ex post on a case-by-case basis. ${ }^{169}$

- $\quad$ The insolvency risk. As far as monetary sanctions are concerned, ex ante regulation will be less affected by the lawbreaker's insolvency risk than ex post regulation, because a "rule" can be enforced by "light penalties" (equal to expected rather than actual harm). ${ }^{170}$ However, when nonmonetary sanctions are employed, the lawbreaker's insolvency risk will become irrelevant. ${ }^{171}$

- Enforcement costs. Since the cost of enforcing "standards" is normally incurred only after a loss was caused by an accident while the cost of enforcing "rules" is incurred whenever there is non-compliance, there will be an enforcement cost advantage of "standards" over "rules."

When it comes to the choice between ex ante and ex post regulation of safety and health, Posner maintained that the dominant form of regulation of treatment should be ex post regulation, because in an individual case only one patient is likely to be injured and it is "not feasible to require physicians to seek approval from a regulatory agency for every procedure they perform."173 However, as summarised above, ex ante regulation seems superior to ex post regulation in the first three aspects, whereas the latter may be better than the former in the fourth aspect. Hence, it can be argued that the joint use of $e x$ ante and ex post regulation in the health care sector may be optimal. While ex post regulation is indispensable as a "fail-safe" device against the failure of $e x$ ante regulation, ex ante regulation should be encouraged insofar as the

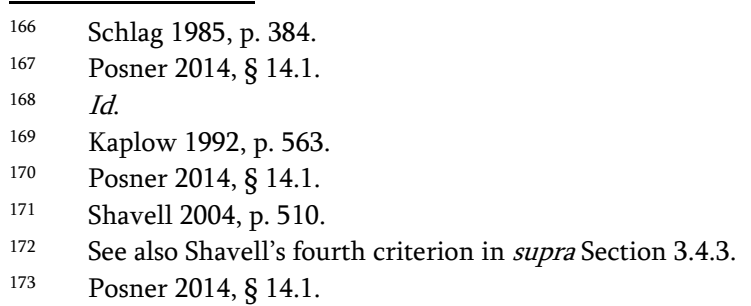


conditions of patients and their responses to medications are homogeneous in order to improve regulatory efficiency.

\subsubsection{Regulation versus Liability}

\subsubsection{Ex-Ante Safety Regulation versus Liability}

Shavell conducted a thorough economic analysis of the relative desirability of liability and safety regulation in terms of the maximisation of social welfare and proposed four criteria for safety regulation. ${ }^{174}$ This model was frequently applied and expanded by later scholars. ${ }^{175}$ Shavell's four criteria are briefly presented as follows:

- Information asymmetry. If regulators (e.g. those who are selected from the profession) possessed better information than private parties or the court, then regulation would be superior to liability in that errors in setting regulatory standards would be minimised.

- Insolvency risk. Under liability, insolvent parties may take less than the optimal level of care due to limited assets. Under regulation, it would be irrelevant whether private parties are insolvent or not, since if they failed to take required precautions they could be sanctioned by nonmonetary penalties.

- $\quad$ The threat of liability suits. If the threat of suit were lowered due to various factors, ${ }^{176}$ then the incentives for parties to take optimal care would be diluted. However, it would not affect (ex-ante) safety regulation, since it is solely activated by non-compliance with a

$174 \quad$ See generally Shavell 1984a; $1984 \mathrm{~b}$.

175 For the application of this model to environmental damage, see e.g. Faure \& Grimeaud 2003, pp. 40-42. For the application of the same model to damage caused by medical malpractice, see e.g. Faure 2004a, pp. 31-35. For an extension of the same model, see e.g. Epstein 2013, pp. 609-611. Epstein extended Shavell's criteria from four determinants to six factors: (1) differential knowledge, (2) private parties' funds, (3) number of victims, (4) number of tortfeasors, (5) the detection rates, and (6) soundness of the regulators and courts. To be fair, Epstein's addition of two factors has not fundamentally altered Shavell's model, for Epstein's third, fourth and fifth factors seem to be a decomposition of Shavell's third determinant.

176 Possible reasons that defendants may escape liability include: (1) that damage is widely dispersed (can be cured through class actions), (2) that damage manifests itself a long period of time after the accident (evidence stale or potential tortfeasors out of business), and/or (3) that there is great uncertainty over causation due to non-tortious factors or indeterminate defendants. 
regulatory standard irrespective of whether a particular harm was caused by a risk-creator.

- Administrative costs. Liability, as a form of ex post regulation, may save more administrative costs than safety regulation, since it is triggered infrequently (only when damage occurs). This enforcement cost advantage of liability over safety regulation implies that the examination of behaviour under fault-based liability could be more detailed than under regulation, even if regulation is enforced on the basis of probability. ${ }^{177}$

After applying Shavell's four criteria to the context of medical malpractice, Faure maintained that "liability rules alone cannot suffice to prevent harm" because all the first three of the four criteria point to safety regulation in the health care sector ${ }^{178}$ Therefore, "some form of (government regulation)" of medical practice is necessary. ${ }^{179}$ Although the first three criteria imply a strong preference for $e_{x}$ ante regulation of medical quality, the fourth criterion still suggests that liability has an enforcement cost advantage over safety regulation even in the context of medical malpractice. Hence, in order to better control malpractice risks, an optimal solution should combine liability and regulation together.

\subsubsection{Ex Post Regulation by Regulators versus Liability}

$E_{X}$ post regulation by regulators is not necessarily superior to liability; vice versa. On the one hand, regulatory adjudicators (esp. self-regulated disciplinary boards) may have an information advantage over judges. On the other hand, judges are supposedly more impartial, authoritative, and better able to administer an adversarial system of justice. It follows that, in cases where ex ante regulation failed, it would economise more on administrative costs if duplicate decisions on the same issue - whether the physician concerned has breached the standard of care - could be avoided.

There are for example several alternative arrangements that may be well worth considering: (1) that courts recognise prior regulatory decisions as prima facie evidence for establishing (gross) negligence unless persuasive contradictory evidence is produced; ${ }^{180}$ (2) that regulators recognise judicial

\footnotetext{
177 Shavell briefly addressed this point in 1984 and later thoroughly demonstrated it in 2013 see Shavell 2013.

$178 \quad$ Faure 2004a, pp. 34-35.

$179 \quad$ Id.

180 In many countries such as France, the Netherlands and Spain, although disciplinary decisions are not directly binding on courts, judges often make reference to medical codes
} 
decisions as conclusive evidence for (gross) negligence which constitutes cause for disciplinary sanctions; ${ }^{181}$ or (3) that regulators and courts may work together in deciding the standard of care. ${ }^{182}$ Other issues such as the imposition of disciplinary sanctions upon providers and the award of damages to victimised patients should be left to regulators and courts respectively.

\subsection{THE CHOICE OF SANCTIONS}

\subsubsection{Introduction}

Deterrence may be generated either by monetary sanctions (e.g. fines) or by non-monetary sanctions (e.g. imprisonment or revocation of a license). In most western countries, the traditional form of regulation of medical practice is self-regulation. Hence, medical practitioners whose performance falls beneath professional standards are primarily subject to disciplinary sanctions: suspension or revocation of a license. ${ }^{183}$ Licensing sanctions are primarily employed both to ensure subsequent professional fitness for medical practice, and to induce licensed practitioners to invest optimally in patient-specific

of conduct or practice guidelines when deciding medical malpractice. See e.g. Rubio \& Garcia 2010, p. 171; Taylor 2010, p. 76; Hondius 2010a, p. 136. Nonetheless, it is conceivable that judges will make a decision more easily and faster when they are provided with a disciplinary determination that has already presented persuasive arguments and evidence for that particular decision than when they themselves have to weigh the evidence and arguments from the beginning.

181 For instance, in the UK, medical practitioners' tribunals hear evidence and decide whether a doctor's fitness to practice is impaired. The tribunal must accept a certificate of a conviction or determination as "conclusive evidence that the offence was committed, or that the facts are as found by the determination." General Medical Council 2016, p. 34.

182 For example, it may be the case that medical disciplinary boards invite judges to assist in deciding malpractice issues before any litigation is initiated. Then, this disciplinary determination will become much more admissible to the court. It may also be the case that disciplinary boards send some members to audit in the trial and provide the judge with expert testimony about medical malpractice.

183 For instance, in the UK, a doctor's registration may be suspended (for up to 12 months) if he/she e.g. seriously breaches good medical practice but this is not fundamentally incompatible with his/her continued registration, while his/her name may be erased from the medical register if $\mathrm{s} /$ he e.g. seriously departs from good medical practice which is fundamentally incompatible with being a doctor or he/she shows a deliberate or reckless regard for good medical practice or s/he does serious harm to others deliberately. General Medical Council 2016, pp. 28-32. In the US, adverse licensure actions normally include limitations, suspension, surrender or revocation of a medical license. "Negligence" accounted for $9 \%$ of all the specified reasons for medical board actions for the period 2010-2014. Harris \& Byhoff 2016. In France, the sanctions available against medical practitioners include "a warning, a blame, a temporary ban from practising, or striking off the register." Taylor 2010, p. 76. 
treatment. Besides licensing sanctions, we can also see in many legal systems that physicians who cause fatal medical accidents due to (gross) medical negligence begin to be subject to criminal penalties. It should be noted that fines can also be a "civil penalty" which is imposed simply for a violation of a statute or regulation (a civil wrong) rather than for a crime. ${ }^{184}$

From the perspective of optimal deterrence, it will be socially optimal if the enforcement of regulatory standards in the health care sector can effectively reduce the incidence of (preventable) adverse events without incurring too high costs of safety precautions (Calabresi's primary goal), while at the same time it economises on administrative costs (Calabresi's tertiary goal). Specifically, the social welfare objective is to minimise the total social costs due to non-compliance, which is the sum of "damages, costs of apprehension and conviction, and costs of carrying out the punishments imposed." 185 The next section will address how the size of sanctions should be set and then compare the relative desirability of applying fines, licensing sanctions and imprisonment to quality regulation.

\subsubsection{Optimal Size of Sanctions}

The costs of correcting market failure and preventing accidents through regulation should be smaller than the benefits of the regulation. Various forms of sanctions generate different levels of deterrence and incur different sizes of costs. Hence, both the magnitude and the type of sanctions are relevant to efficient regulation.

When it comes to the size of sanctions, if employed alone, the optimal magnitude of fines should be determined on the basis of actual factors. First, if lawbreakers can be identified with certainty at zero cost, it is socially optimal to set fines equal to harm (or expected harm in the case of act-based enforcement). ${ }^{186}$ Second, if the probability of identification is fixed in practice, the magnitude of fines should be increased to offset the likelihood of escaping sanctions. ${ }^{187}$ Third, if the probability of identification also needs to be optimally determined, then it will be socially desirable to choose a low probability-high sanction enforcement strategy, with a view to economising on enforcement costs without diluting the deterrent effect. ${ }^{188}$

If employed alone, the optimal magnitude of imprisonment can be determined in a way that is similar to that of fines, because the cost of

\footnotetext{
$184 \quad$ Garner 2014, p. 1247.

185 Becker 1968, p. 207.

186 Shavell 2004, pp. 474-478.

187 Shavell 2004, pp. 482-484.

188 Shavell 2004, pp. 484-487.
} 
imprisonment - "the discounted sum of the earnings foregone and the value placed on the restrictions in consumption and freedom" - can be converted into monetary values. ${ }^{189}$ Hence, it can be found that the cost of imprisonment is positively correlated to what the lawbreaker could earn outside prison and for the length of the sentence. ${ }^{190}$ Another implication is that when sanctions are non-monetary, fault-based liability is superior to strict liability, because under the former less actual imprisonment will be imposed. ${ }^{191}$ It is socially costly to impose non-monetary sanctions. ${ }^{192}$ Since deterrence can be generated by less frequent enforcement of sanctions under fault liability than under strict liability, the fault system economises on enforcement costs more than strict liability. ${ }^{193}$

By the same token, if employed alone, the optimal magnitude of license suspension can be designed in a similar way to fines. Thus, the cost of license suspension can be adjusted in line with the lawbreaker's earning capability and the length of suspension. In contrast, the magnitude of license revocation is fixed to each provider - the loss of all future earnings his or his/her job will yield. Hence, the deterrent effect generated by license revocation is normally greater than license suspension.

As far as the choice of sanctions is concerned, regulation should not limit market entry or competition too much. As Philipsen maintained, "regulation should be both justified (in order to cure the problem at hand) and proportional." 194 Hence, when licensing sanctions work, one should not impose criminal sanctions. This is consistent with the idea of marginal deterrence. Other things being equal, "it is socially desirable that enforcement policy creates marginal deterrence, so that those who are not deterred from committing harmful acts have a reason to moderate the amount of harm that they cause." 195 Hence, "sanctions should rise with the magnitude of harm" and "most sanctions should be less than maximal."196

The next part will discuss the choice among licensing sanctions, fines, and imprisonment.

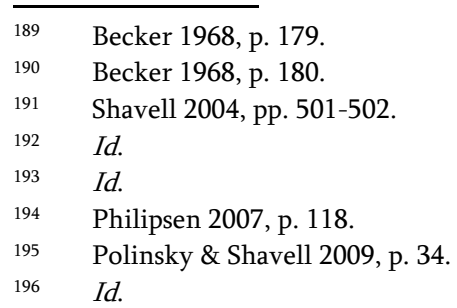


Part II. Economic Theories and Empirical Evidence

\subsubsection{Licensing Sanctions}

An ideal regime of licensing should not only induce aspiring physicians to make sufficient investment in human capital before entering the health care market by meeting certain ex ante requirements, but also ensure that licensed physicians keep the currency of their professional competency after they begin their careers through disciplinary sanctions. Once a practitioner is identified as unfit to practice, some remedial programs or procedures should have to be taken in order to ensure patient safety. ${ }^{197}$ If the detected practitioner is not systematically incompetent, disciplinary boards may suspend his/her license for a certain period and order him/her to take Continuing Medical Education (CME). This action is optimal if and only if, as calculated by the regulator, the marginal benefit of enforcing $\mathrm{CME}$ - reduced future adverse events - exceeds the marginal cost of implementing CME. ${ }^{198}$

CME may dilute the deterrent effect of suspension of a license, for the lawbreaker may feel the "sting of the sanction may be lessened" because he/she will "learn valuable skills" during the process. ${ }^{199}$ In this case, an appropriate amount of civil penalty may be needed to supplement the deterrence. Nevertheless, the deterrent effect of revocation of a license, as examined in the next sub-section, remains intact. In other words, s/he will take CME and expertise promotion seriously for fear of losing his or her license for good. If after reassessment his/her competence has been promoted to the required level, then the restriction on his/her license may be removed.

In contrast, if a licensed practitioner is regarded as systematically unfit to practice even after taking CME, meaning he/she has an unchanging propensity to commit medical errors, ${ }^{200}$ he/she should be prohibited from practising medicine. Revocation of a license may serve as a deterrent to those practitioners who are not systematically incompetent. It is intended to induce them to promote their professional expertise continuously. Obviously, providers benefit from licensing, because they can enjoy high profits and returns to investments in medical training. ${ }^{201}$ If their licenses are terminated, they will lose these benefits immediately. ${ }^{202}$ Hence, from the perspective of deterrence, revocation of a license will induce providers to make subsequent

Council on Medical Service 1988.

This is a direct application of Shavell's basic model of enforcement and rehabilitation. See Shavell 2004, p. 535

Shavell 2004, p. 536.

Shavell 2004, p. 532.

Svorny 2000, p. 307

Id. 
investment in professional expertise continuously given that they are not systematically unfit to practice.

\subsubsection{Administrative Sanctions versus Criminal Penalties}

Licensing sanctions and civil penalties belong to the category of administrative (or disciplinary) sanctions, whereas fines and imprisonment are criminal penalties. ${ }^{203}$ Administrative sanctions differ from criminal penalties in two aspects. First, the former can economise in administrative costs, since it is much more difficult, costly, and time-consuming to pursue a criminal prosecution. ${ }^{204}$ The enforcement of imprisonment also consumes considerable social resources, whereas the imposition of licensing sanctions incurs very few costs (similar to fines). Second, "a criminal conviction carries a stigma, even when the only punishment is a fine, that may impair the defendant's human capital, as well as trigger collateral consequences such as being banned from future employment." ${ }^{205}$ In contrast, administrative sanctions only impose a restriction or ban on medical practice or a loss of certain amount of money. Even when a medical practitioner is expelled from the health service market, he/she may well get a new job in other occupations. In view of tertiary cost avoidance, it is normally more efficient to impose administrative sanctions than criminal penalties.

Sometimes, however, administrative sanctions may fail to deter noncompliance. License revocation may fail to deter those practitioners who themselves know they are so incompetent that their expertise cannot be promoted by taking any CME but who wilfully do not quit the market in order to enjoy the benefits of being a medical professional. It is impossible for those people to respond to any deterrent incentives generated by licensing sanctions, for the consequence of quitting the market voluntarily and that of being deprived of a license involuntarily are the same - losing the benefit the medical profession yields. Without other forms of sanctions, they may well choose to stay in the market instead of quitting the market voluntarily.

Suppose licensing sanctions fail to deter non-compliance, we need to consider the possibility of fines (a civil penalty or a criminal fine) or

\footnotetext{
203 In common law systems, licensing sanctions are part of the disciplinary proceeding, meaning an "action brought to reprimand, suspend, or expel a licensed professional or other person from a profession or other group because of unprofessional, unethical, improper, or illegal conduct." Garner 2014. In civil law systems, licensing sanctions may be one form of "administrative sanctions," which denotes those "sanctions imposed by the regulator without intervention by a court or tribunal." Lynott \& Cullinane 2010.

204 Lynott \& Cullinane 2010.

$205 \quad$ Posner 2014, § 7.1.
} 
imprisonment. The use of fines and imprisonment has already been fully examined in the literature. ${ }^{206}$ The general conclusion is that it is not socially advantageous to imprison someone until fines fail to deter undesirable acts in that it is almost costless for the state to collect fines. ${ }^{207}$ Fines can be imposed either by regulatory agents or criminal courts. While a civil penalty incurs lower tertiary costs than a criminal fine, the latter may generate greater deterrent effects since more stigma is attached to the latter than the former. However, non-monetary sanctions may be more desirable when fines per se cannot adequately deter socially undesirable acts in cases where the lawbreaker is insolvent. ${ }^{208}$ Therefore, non-monetary sanctions seem only fit for medical quality regulation in cases where both licensing sanctions and fines fail to deter.

When it comes to the criteria for criminal penalties, it seems that they should be based on fault rather than strict liability in order to avoid considerable enforcement costs. ${ }^{209}$ It is generally agreed that criminal law is intended "to constrain certain behaviour that could not otherwise adequately be controlled," ${ }^{210}$ because criminal penalties are exceptionally costly and harsh. It would be significantly disproportional to impose criminal penalties in cases where liability or administrative sanctions already suffice. Of course, any provider, who wilfully contravenes regulatory standards and does severe harm to patients deliberately, is punishable in criminal law. However, this is a case of murder, not of malpractice in the course of providing treatment. As far as medical malpractice is concerned, the more proper question is how should the mens rea of a negligent provider be set. For primary cost avoidance, criminal penalties may be levied on licensed practitioners who themselves know that they are systematically incompetent but still want to stay in the market in order to enjoy the benefit of being a practitioner, but who do not intend to murder patients. This requirement implies that the mens rea should be at least "recklessness"211 rather than merely (gross)

206 See generally e.g. Becker 1968; Polinsky \& Shavell 1984; Shavell 1985b; 1987b; Polinsky \& Shavell 1994.

207 Becker 1968, p. 180; Shavell 2004, p. 509; Cooter \& Ulen 2012, p. 478; Posner 2014, § 7.1.

208 Shavell 1985b, pp. 1236-1238.

209 Shavell 2004, p. 501.

$210 \quad$ Shavell 2004, p. 543

211 In common law countries, recklessness is one of the levels of mens rea which has a greater degree of fault than negligence but a lesser degree of fault than intent. Garner, 2014. Basically, it denotes a state of mind where "the actor does not desire harmful consequences but nonetheless foresees the possibility and consciously takes the risk." Id. In civil law countries such as Germany, there is no category of means rea that is perfectly an equivalence of "recklessness" under common law. Bohlander 2009, p. 63. Recklessness is argued to be a lesser degree of fault than conditional intent (dolus eventualis) but a greater degree of fault than advertent negligence. Id. 
negligence. It follows that licensed medical practitioners who merely inadvertently contravene a regulatory standard should not be sanctioned by criminal law.

The optimal choice of various sanctions is summarised in Table 9.2 as follows:

Table 9.2: Optimal Sanctions for Medical Quality Regulation

\begin{tabular}{|c|c|c|}
\hline $\begin{array}{l}\text { Medical errors committed by providers } \\
\text { who: }\end{array}$ & Consequence & Sanctions \\
\hline \multirow{2}{*}{$\begin{array}{l}\text { - are relatively competent but } \\
\text { inadvertently committed errors }\end{array}$} & $\begin{array}{l}\text { - Adverse } \\
\text { events }\end{array}$ & $\begin{array}{l}\text { - Liability for } \\
\text { compensation }\end{array}$ \\
\hline & - Near misses & - None \\
\hline \multirow{2}{*}{$\begin{array}{l}\text { - failed to maintain subsequent } \\
\text { competency but their expertise can be } \\
\text { enhanced }\end{array}$} & $\begin{array}{l}\text { - Adverse } \\
\text { events }\end{array}$ & $\begin{array}{l}\text { - Liability for } \\
\text { compensation } \\
\text { - License suspension } \\
(\mathrm{CME})^{*}\end{array}$ \\
\hline & - Near misses & $\begin{array}{l}\text { - License suspension } \\
\text { (CME) and a civil } \\
\text { penalty }\end{array}$ \\
\hline \multirow{2}{*}{$\begin{array}{l}\text { - failed to maintain subsequent expertise } \\
\text { but also fail to enhance expertise after } \\
\text { taking CME }\end{array}$} & $\begin{array}{l}\text { - Adverse } \\
\text { events }\end{array}$ & $\begin{array}{l}\text { - Liability for } \\
\text { compensation } \\
\text { - License revocation* }\end{array}$ \\
\hline & - Near misses & - License revocation \\
\hline \multirow{2}{*}{$\begin{array}{l}\text { - know they are systematically incompe- } \\
\text { tent but still wilfully choose to stay in the } \\
\text { market, but who do not intend to murder } \\
\text { patients }\end{array}$} & $\begin{array}{l}\text { - Adverse } \\
\text { events }\end{array}$ & $\begin{array}{l}\text { - Liability for } \\
\text { compensation } \\
\text { - License revocation } \\
\text { - Fines or } \\
\text { Imprisonment** }\end{array}$ \\
\hline & - Near misses & $\begin{array}{l}\text { - License revocation } \\
\text { - Fines or } \\
\text { imprisonment }\end{array}$ \\
\hline
\end{tabular}

\subsection{SUMMARY AND EVALUATION}

Section 5 addressed the question of whether quality regulation is a desirable alternative to malpractice liability. Quality regulation can be either ex ante regulation based on "rules" or ex post regulation based on "standards." "Rules" are detailed regulatory standards that are enacted collectively before any accident occurs, whereas "standards" must be determined by an adjudicator 
after an accident occurs. "Rules" are likely to be more efficient than "standards" in that the former promote greater compliance, ${ }^{212}$ economise on costs of enactment (centrally designed), and are more resilient to insolvency risks (enforced ex ante). In contrast, "standards" are superior to "rules" as far as enforcement costs are concerned. Hence, ex ante and ex post regulation should be jointly used. In the light of information asymmetry, insolvency risk, and the threat of liability suits, ex ante regulation is more efficient than malpractice liability. In contrast, regarding administrative costs, malpractice liability is more desirable than ex ante regulation. Hence, ex ante regulation and malpractice liability should be jointly used.

For the purpose of primary cost avoidance, both monetary sanctions (fines) and non-monetary sanctions (license suspension/revocation or imprisonment) can be employed and their joint use might be socially desirable. Licensing sanctions are preferable to criminal sanctions in most of the cases. Nonetheless, in the case where license suspension may not be enough to deter, civil penalties may be warranted. In the case where licensing revocation may fail to deter, fines (civil or criminal) or imprisonment may be necessary. Fines should always be employed before imprisonment. However, if insolvency risks are high, imprisonment is more desirable. Fault liability is more efficient than strict liability for imposing criminal penalties on providers. It will be socially desirable if the mens rea is set at least equal to "recklessness" (in the common law systems) or "advertent negligence" (in the civil law systems). Where the liable provider is not systematically incompetent, then a civil penalty should be avoided if he/she is supposed to pay compensation to the victim.

\section{PUBLIC REGULATION VERSUS SELF- REGULATION}

Self-regulation is characteristic of the medical profession in most legal systems. ${ }^{213}$ The level of care required of a physician is normally determined by professional associations and backed by disciplinary sanctions. ${ }^{214}$ Why do not the governments in these countries regulate the quality of medical care directly?

\footnotetext{
212 Potential injurers may find it easier to comply with "rules" than with "standards." However, if the behaviour of potential injurers is not properly monitored or "rules" are not properly enforced, then "rules" may fail to promote greater compliance.

213 See generally Faure et al. 1993; Johnson, Larkin \& Saks 2015.

$214 \quad$ Faure 2004a, p. 36.
} 
This can be explained by two limitations imposed on direct government regulation, which may prevent the government from regulating health-service quality effectively and optimally. First, it is not easy to prescribe regulatory safety standards optimally. Although regulatory agencies have the advantage of data gathering, statistical calculation capacity, and centralised decision-making power over courts, ${ }^{215}$ they still suffer from the problem of imperfect information in the health care market. One problem is that the cost and benefit analysis is easier said than done. ${ }^{216}$ Causation or the probability of the accident is hard to predict and the costs and benefits of precautions are difficult to calculate. ${ }^{217}$ For instance, placing a monetary value on lives saved is a daunting task and can incur considerable administrative costs. ${ }^{218}$ Another problem is that safety standards are dynamic rather than static. ${ }^{219}$ Due to "bureaucratic resistance to the evolution of new standards," direct regulation is likely to "introduce undesirable rigidities" into medical quality assurance, because medical knowledge and technology are developing and improving rapidly in modern times. ${ }^{220}$ Consequently, safety standards prescribed by the government may become "obsolete" very soon. ${ }^{221}$

Second, it is also very demanding to enforce regulatory standards costeffectively. One problem is that it is usually difficult to monitor quality of care sufficiently on account of considerable transaction costs faced by regulators of monitoring "a multitude of widely diverse services."222 For example, regulators, who are monitoring medical practice from a distance, may feel it virtually impossible to observe accurately how much time and effort each physician invests in treatment or how sophisticated the physician is when making medical judgements. ${ }^{223}$ If regulators intervened in routine medical practice too much by closer observation, more practice reviews or quality audits, it would not only incur prohibitive administrative costs, but would also do great harm to the trust patients placed on providers. ${ }^{224}$ Consequently, only a limited number of areas, which may not have the greatest implications for quality assurance, can be effectively monitored by

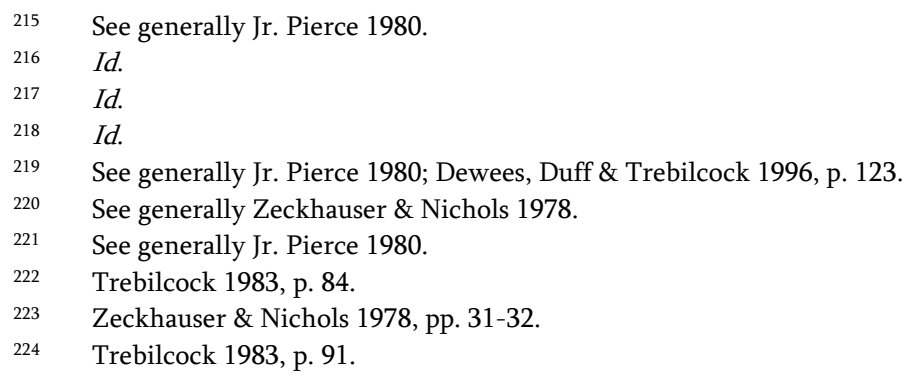


regulators, and providers may therefore be induced to over-invest in those areas. $^{225}$

The foregoing disadvantages of public regulation may call for selfregulation, which can be a potential alternative to public regulation. Miller argued that self-regulation has three advantages. First, self-regulated professions have the best information about the quality of services and the costs and benefits of accident prevention, because they can obtain the required information at lower costs than regulatory agencies and the combined role of the regulator and the expert save costs. ${ }^{226}$ Second, selfregulation is more flexible in that ineffective and inefficient old rules will be altered more quickly and hence it facilitates innovation and provides more consumer choices.227 And last but not least, self-regulation economises on government expenditures, since the costs of self-regulation are fully borne by the professions themselves and self-regulators are induced to minimise the costs of both enforcement and compliance. ${ }^{228}$

However, Miller's case for self-regulation has its limitations. Curran maintained that Miller's arguments are not compelling theoretically for three reasons. First, Miller neglected the possible costs of the rent-seeking in selfregulation, since public interest will be harmed due to both wealth transfer from the general public to the profession and the costs of rent-seeking. ${ }^{229}$ Second, the rent-seeking also makes the flexibility of self-regulation problematic, because rent-seeking reduces market competition and more efficient rules will be resisted by the rent seekers. ${ }^{230}$ Third, the costs of selfregulation may not be split efficiently between providers and purchasers on account of the absence of continuous monitoring from consumers. ${ }^{231}$

In addition to the foregoing concerns over serious agency costs, Dewees, Duff and Trebilcock pointed out another difficulty with selfregulation: the "development of professional norms and allegiances" may discourage disciplinary boards from enforcing regulatory standards actively since the revelation of gross misconduct will damage the reputation of the medical profession as a whole. ${ }^{232}$

It follows from the above analyses that neither public regulation nor self-regulation alone is perfect for quality assurance. From the perspective of

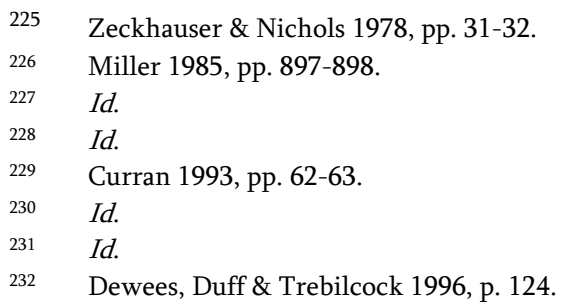


public interest and primary cost avoidance, it would be more efficient if the two mechanisms could be optimally combined. A mixed regulatory structure would be optimal if it could be sensitive to two conflicting tensions simultaneously: "(1) the need for objective decisions made in the public's interest and (2) the need for decision-making based on the best available technical expertise. ${ }^{233}$

\section{EMPIRICAL EVIDENCE}

\subsection{DETECTION OF NON-COMPLYING PROVIDERS}

Ideally, in the absence of administrative costs, if every substandard or negligent provider could be identified and sanctioned, professional competency and service quality of the whole profession would be perfectly ensured. ${ }^{234}$ In practice, the optimal rate of identification is less than $100 \%$ in order to reduce enforcement costs. Neither should it be too low, because the efficacy of enhancing expertise through $\mathrm{CME}$ and discouraging noncompliance depends upon a relatively high rate of apprehension.

Since it is virtually impossible for only a handful of members of a licensing board to monitor each and every provider within its jurisdiction, the only workable way is to rely on information collected elsewhere. For instance, some available sources of information concerning substandard providers in the US include individual reporting, courts and malpractice insurance companies, medical societies, hospital review committees, and peer review organisations (PROs). ${ }^{235}$ However, the efficacy of these sources of information has their limitations. Based on available empirical studies, some of the problems faced by these reporting measures are summarised as follows: ${ }^{236}$

- Individual reporting is not practically efficacious. First, due to asymmetrical information, the lay public are often unable to detect a substandard practitioner when they do meet one. ${ }^{237}$ Second, sometimes

\footnotetext{
233 Cohen 1980, p. 303.

234 This theoretical assumption underlies much of the discussion in Dewees, Duff \& Trebilcock 1996, pp. 128-131.

235 Law \& Polan 1978, pp. 41-42.

236 Some early empirical studies were summarised in Dewees, Duff \& Trebilcock 1996, pp. 121-131. A few recent empirical studies are added to the discussion.

237 Dolan \& Urban 1983, p. 206.
} 
those patients who do identify an incompetent provider may not know to whom they could make a complaint. ${ }^{238}$ A 1976 New York survey showed that the lay public often do not know that they could file a complaint against their physicians to the medical licensing board. ${ }^{239}$ Third, the lay public are not incentivized to report simply because patients would not obtain compensation through the incident reporting procedure. $^{240}$

- $\quad$ The association between malpractice claims and physicians' fitness to practice is relatively low. Empirical evidence shows that many, if not most, medical errors are committed accidentally by physicians who are not systematically incompetent. ${ }^{241}$ Therefore, records of malpractice claims, although they may reflect practitioners' potential proneness to commit medical errors to some extent, ${ }^{242}$ are not good indicators for lack of professional fitness to practice. ${ }^{243}$

- Practitioners are understandably reluctant to report sub-standard colleagues. First, practitioners may not be subject to any penalty if they fail to report. Sometimes the reporting is mandatory, but no penalty has been prescribed. ${ }^{244}$ Second, practitioners may be discouraged from reporting their colleagues for fear of being sued by those who they are supposed to report. ${ }^{245}$ One solution to relieving this problem is to provide practitioners with evidentiary privilege and immunity from defamation. ${ }^{246}$ Empirical evidence in Arizona showed that the introduction of such an immunity increased the incidence of reporting fourfold. ${ }^{247}$ Nonetheless, practitioners still hesitate to report their colleague' mistakes on account of the fear that "they are sending their colleague to 'gaol'."'48 Third, the professional culture in the health care sector may prevent practitioners from reporting peers. Reporting violations of clinical protocols to a superior may be regarded by medical professionals as "a threat to their professional autonomy," and "whistle

Law \& Polan 1978, pp. 44-45.

Dolan \& Urban 1983, p. 206.

Goldman 1987. See also supra Sub-Section 8.2.1.3.

See generally e.g. Rolph 1981a; Nye \& Hofflander 1988; Luft, Katz \& Pinney 1991; Rolph

1991; Bovbjerg \& Petronis 1994.

Dewees, Duff \& Trebilcock 1996, p. 129.

Kusserow, Handley \& Yessian 1987, p. 823.

See generally Derbyshire 1983.

Law \& Polan 1978, p. 44; Derbyshire 1983, p. 199.

Derbyshire 1983, p. 199.

Brazier et al. 2007, p. 24. 
blowing is taboo."249 In addition, other common barriers to reporting include time constraints, unsatisfactory processes, inadequate feedback, etc. $^{250}$

- Hospitals systematically fail to report data on substandard practitioners. In 2009, Public Citizen published an extensive report on hospital incident reporting. ${ }^{251}$ This report disclosed that hospitals in the US systematically under-report substandard practitioners to the National Practitioner Data Bank (NPDB). ${ }^{252}$ For instance, since the end of 2007, about half of US hospitals had never submitted a single report on hospital privilege sanctions to the NPDB. ${ }^{253}$ The average number of annual reports to the NPDB for the period 1990-2007 was only 650, which is roughly one-eighth of the government estimate $(5,000)$ and one-sixteenth of the industry estimate $(10,000) .{ }^{254}$ To avoid reporting, hospitals bypass the law in many ways, such as imposing shorter disciplinary periods that do not need to be reported, or changing their bylaws or having practitioners take "leave of absence."255 Peer review and discipline of sub-standard physicians may be blocked for the reason that hospitals earn handsome profits from surgeries performed by those physicians. ${ }^{256}$ Consequently, many hospital clinical privilege sanctions will not be reported to licensing boards. ${ }^{257}$ The report found that about 1,000 sub-standard practitioners who had been subject to clinical privilege sanctions at least twice were not sanctioned by licensing boards subsequently. ${ }^{258}$

Hence, although incident reporting is widely used in many systems, it misses "the vast majority of events and cannot provide stable estimates of the true underlying defect rates." ${ }^{259}$ Recently, in order to better detect adverse events, more and more innovative methods, such as chart review, direct observation, patient interviews, combined modalities, automated detection systems, and

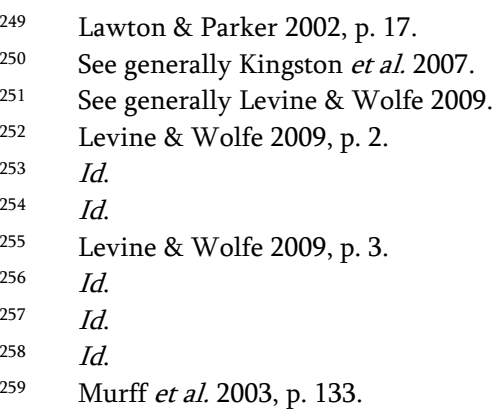


cognitive frameworks, have been developing in the US.260 Although these new methods look promising, they are not the focus of this thesis.

\subsection{LICENSING SANCTIONS}

Remedial actions against substandard or negligent practitioners may be less than optimal in that they are much less effective than expected. There are basically two types of remedial actions: (1) if possible, license suspension together with CME should be taken with a view to promoting the professional competence of the identified sub-standard provider to the desired level; or (2) if there is evidence of egregious misconduct that displays a systematically low level of professional competence which is unlikely to be improved, the identified substandard provider's practice should be banned (e.g. revocation of a license) by licensing boards. ${ }^{261}$ Empirical evidence shows that both types of remedial action may call for further improvement:

- Sub-standard practitioners who are identified may fail to improve their professional competence through CME. First, sometimes it may not be set as a mandatory obligation to take CME. ${ }^{262}$ Under such a regime, there would be little incentive for sub-standard practitioners to upgrade their expertise through educational programs. Second, if it were mandatory for incompetent practitioners to upgrade their expertise through educational programs, such CME programs would be ineffective if they did not clearly target specific problems. ${ }^{263}$

- Disciplinary actions are extremely rare. Although it is estimated that between $2 \%$ and $10 \%$ of all US physicians are unfit to practice, ${ }^{264}$ a 1971 study reported that disciplinary actions taken by Medical Boards were "insignificant in terms of the universe of practising physicians," and "data indicate a tendency toward leniency even in the relatively few cases that result in formal board action."265 For the period 1969-1981, less than $0.14 \%$ of all licensed US doctors had been disciplined. ${ }^{266} \mathrm{~A}$ recent study by USA TODAY indicated that this situation had not been

\footnotetext{
$260 \quad$ See generally Murff et al. 2003; Montesi \& Lechi 2009.

261 Dewees, Duff \& Trebilcock 1996, p. 130.

262 For example, by the end of 2013, some US States (Colorado, Indiana, Montana, New York, South Dakota) had not made taking CME a mandatory requirement for licensure reregistration yet. All of the remaining US States do require a minimum number of CME Credits per year. American Medical Association 2013, pp. 65-69.

263 See supra Section 3.3.3.1.

264 Law \& Polan 1978, pp. 43-44.

265 US Department of Health, Education, and Welfare 1971, p. 33.

266 See generally Derbyshire 1983.
} 
improved: (1) for the period 2001-2011 in the US, although about 6,000 doctors' clinical privileges had been restricted or revoked by their hospitals, more half of them had never been disciplined by Medical Boards; (2) and roughly 250 of them were regarded as an immediate threat to health and safety, but they were still allowed to practice. ${ }^{267}$ Some similar evidence in Canada also shows that the low rate of disciplinary action is not unique to the US. ${ }^{268}$

Dewees, Duff and Trebilcock summarised several reasons that may explain the foregoing deficiencies in remedial action:269 first, medical boards are unwilling to impose severe sanctions such as suspension or revocation of a license, especially when physician misconduct is not extreme; ${ }^{270}$ second, medical boards lack sufficient resources to investigate and prosecute all substandard practitioners; ${ }^{271}$ third, disciplinary procedures may incur considerable administrative costs due to the length of time, higher standards of proof (requiring clear and convincing rather than a preponderance of evidence) and complexity in medical judgements, ${ }^{272}$ and fourth, the dominance of medical professionals siting on medical boards may reduce the effectiveness of monitoring. ${ }^{273}$

To summarise, although in theory suspension/revocation of a license is a socially desirable mechanism to ensure subsequent investment in professional competence and in care, it is far from being optimal in practice due to extremely low rates of identification and enforcement.

\subsection{CRIMINAL PENALTIES}

In many legal systems, negligent providers may not only be financially responsible for compensating injuries suffered by patients, but also be subject to criminal penalties in cases where there are severe consequences.

In some common law systems, although the criteria for imposing criminal penalties on providers is gross negligence, ${ }^{274}$ empirical evidence

\footnotetext{
267 See generally Eisler \& Hansen 2013.

268 See generally Coyte, Dewees \& Trebilcock 1991.

269 Dewees, Duff \& Trebilcock 1996 p. 131.

270 Brook, Brutoco \& Williams 1975, p. 1224.

271 Derbyshire 1983, p. 199; Kusserow, Handley \& Yessian 1987, p. 820.

Kusserow, Handley \& Yessian 1987, p. 823.

Law \& Polan 1978, pp. 46-48.

274 In England, doctors who commit egregious medical errors that lead to the patient's death may be convicted of gross negligence/manslaughter. See generally e.g. Quick 2006; Brazier et al. 2007; Quick 2007. In New Zealand, since 1997, the level of negligence for a conviction of manslaughter has followed the English criterion. See NZ-CA 1961, Section
} 
shows that many, if not most, providers who were convicted of manslaughter merely committed errors due to ordinary negligence. Ferner and McDowell identified 85 doctors charged with manslaughter in England for the period 1795 and 2005, and found that the number had dramatically increased since $1990 .{ }^{275}$ Of all the 85 doctors, 60 (70.59\%) were acquitted, 22 (25.88\%) were convicted, and 3 pleaded guilty. ${ }^{276} \mathrm{~A}$ significant proportion (63.53\%) of the doctors were charged due to mistakes $(\mathrm{n}=37 ; 43.53 \%)$ or slips $(\mathrm{n}=17 ; 20 \%)$, whereas the remaining were on account of deliberately violating rules $(\mathrm{n}=16$; 18.82\%). ${ }^{277}$ Ferner and McDowell supported the prosecution of doctors who clearly violate safety rules but argued against the criminalization of medical errors since unconscious errors are hard to prevent.. ${ }^{278}$ By 2004, ten providers in New Zealand had been charged with manslaughter for alleged negligence and in the majority of the cases the level of negligence was very low..$^{279}$

In the US, however, medical malpractice cases are typically handled by civil courts. Recent evidence suggests that the number of US physicians facing criminal charges over wrongful drug prescription is growing. ${ }^{280}$ However, the overall rate of criminal charges against physicians is relatively low. For the period 2001-2011, only 37 criminal charges against physicians were reported. ${ }^{281}$ Some precedential authority in the US indicates the test for punishing physicians in criminal law is not ordinary negligence but "reckless and wanton and of such character as shows an utter disregard for the safety of others under circumstances likely to cause death." 282

Whereas common law systems set the mens rea for prosecuting physicians as gross negligence or recklessness, civil law systems are inclined to criminalise ordinary medical negligence. In civil law countries, doctors may be charged with crimes of homicide due to negligence ${ }^{283}$ or bodily injuries due to negligence. ${ }^{284}$

150A (amended by NZ-CAA 1997, Section 2(1) and NZ-CAA 2011, Section 6). See also Merry 2007, p. 78.

$275 \quad$ Ferner \& McDowell 2006, p. 309.

276 Id.

277 Id.

278 Ferner \& McDowell 2006, p. 314.

279 Merry 2007, p. 74

280 See generally Baynes 2011; Join Together Staff 2011.

281 Id.

282 State v. Weiner, 194 A.2d 467, 469-70 (N.J. 1963). See also Van Grunsven 1997, pp. 52-54; US Model Penal Code, § 2.02(3).

283 See e.g. German StGB, § 227; French C. pén., art. 221-6; Italian C.p., art. 43, para. 3 \& art. 575; Spanish C.P., art. 142, para. 3.

284 See e.g. German StGB, § 229; French C. pén., arts. 222-19 and 222-10; Italian C.p., art. 43 , para. 3 \& art. 582; Spanish C.P., art. 152, para. 3. 
As a notable example in Europe, a rise in criminal lawsuits was reported in Spain. Rodriguez-Vazquez reviewed a total of 297 criminal cases where doctors were concerned for the period 2000-2004..$^{285}$ Of all the 297 cases, $31 \%$ were associated with charges of negligent homicide, while $54 \%$ with charges of negligent injuries (the remaining $15 \%$ with other charges). ${ }^{286}$ The number of total charges increased from 44 in 2000 to 90 in 2004, with an average growth rate of almost $20 \% .{ }^{287}$ In about $12.5 \%$ of all the cases, defendant-doctors were convicted. ${ }^{288}$ The most striking example of criminalising medical malpractice in the world is perhaps Taiwan, where "the judges, using criminal law in $79 \%$ of the medical disputes, punish physicians in addition to the money damages." ${ }^{289}$ For the period 2000-2007, of all the 74 cardiac surgical specialists in Taiwan, 6 had been prosecuted and the rate of conviction was $16.7 \%{ }^{290}$ This unique phenomenon can be explained by the fact that criminal litigation costs are borne by the state and victims have an increased access to evidence. ${ }^{291}$

It follows from the foregoing descriptions that most common law systems (except the US) set the criteria for mens rea as gross negligence, whereas most civil law systems take ordinary negligence as the criteria for both civil malpractice liability and criminal penalties. Civil law systems tend to impose criminal penalties on providers more readily than common law systems. It was also argued that the rising trend of criminal charges against providers had contributed to the problem of defensive medicine, ${ }^{292}$ and the more criminal charges the more administrative costs. Hence, more primary and tertiary accident costs may be incurred due to the low level of negligence for criminal penalties. In this regard, the American test for mens rea recklessness - appears more efficient.

\section{CONCLUSIONS}

This Chapter, has examined two alternative regimes to the fault-based malpractice liability as far as quality assurance (prevention of medical errors) is concerned - the contractual approach and regulation. The general

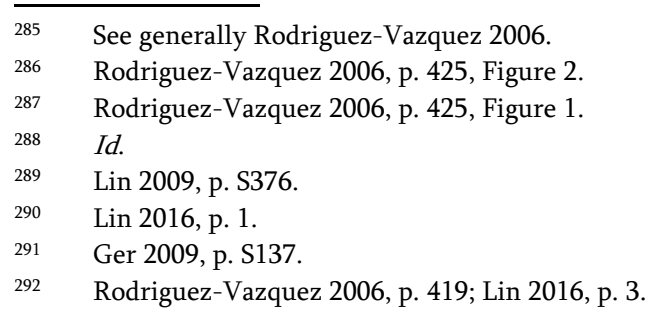


conclusion is that neither of them is a perfect substitute for malpractice liability. The contractual approach is likely to be inferior to malpractice liability whereas regulation may be a desirable complement to, rather than a substitute for, malpractice liability. The contractual approach is less efficient than malpractice liability, not only because its key assumption of perfect information is often not valid in the health care sector, but also in that a shift from tort liability to the contractual approach would not replicate the same deterrence benefits which the tort system generates but would incur much greater social costs. The reason why regulation is merely a complement instead of an alternative to tort liability is that neither of them is better than the other in all aspects. Hence, a joint use of regulation and malpractice liability would be socially optimal. 


\section{CHAPTER 10 THE FAULT-BASED COMPENSATION MECHANISMS FOR IATROGENIC INJURIES}

\section{INTRODUCTION}

Unlike the previous three chapters (7-9) where particular attention is paid to prevention of medical malpractice (primary and tertiary cost avoidance), this chapter (and also the next) is intended to answer Sub-question (2-a) from the perspective of compensation (secondary cost avoidance). While this chapter is concerned only with the fault-based compensation mechanisms (tort law alone, the fault-liability-insurance system, and self-insurance), the next Chapter 11 will deal with compensation instruments that are not based on fault (first-party insurance, no-fault compensation funds, and social security).

Secondary costs are defined as "the social dislocation costs of the accident," "the costs of social and economic dislocations which all too often follow the immediate accident, especially if the initial cost burden is left unspread,"2 or simply "the societal costs resulting from accidents."3 Although the secondary goal is sometimes referred to as compensation, it is different from the legal notion of "corrective compensation."4 According to Calabresi, not only the costs of accident reduction should be reduced in the first place,

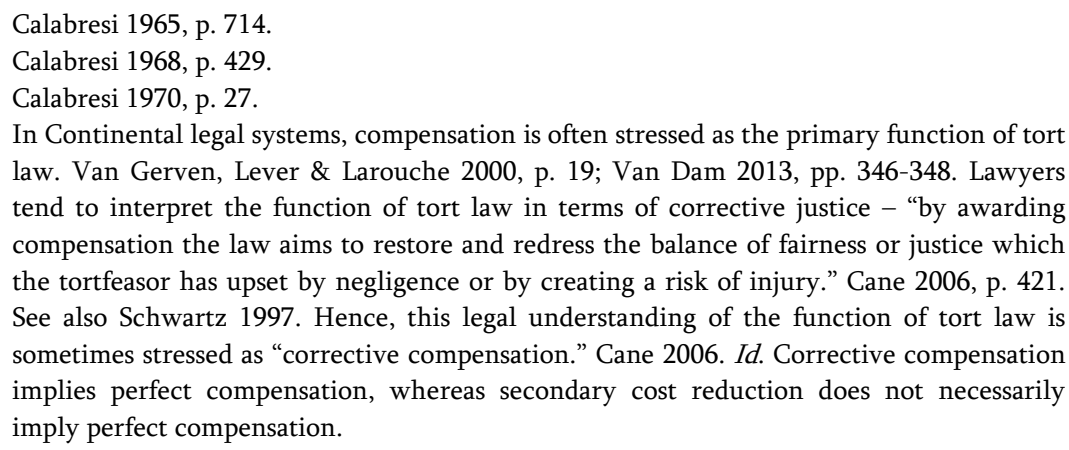


but the secondary costs resulting from accidents which nonetheless occur need to be reduced as well. ${ }^{5}$ However, the pursuit of secondary cost reduction may adversely affect the primary goal of accident law. The preventive incentives generated by tort liability may be diluted by the presence of various compensation instruments. ${ }^{6}$ Hence, the issues of prevention and compensation are often intertwined.

In addition, the benefits of primary and secondary cost avoidance must be counter-balanced by tertiary costs - "those costs involved in regulating primary and secondary costs." In practice, tertiary costs may include litigation costs and the costs of operating courts and prisons, regulatory bodies, and various institutions that are in charge of risk spreading (e.g. costs incurred by insurance companies when investigating the damage). ${ }^{8}$ The goal of tertiary cost reduction is equally important because if primary or secondary cost reduction "costs more than it saves," there will be a waste of scarce social resources. ${ }^{9}$ Social optimum will be obtained if the sum of all the three costs, together with the costs of precaution, is minimised..$^{10}$

There are many instruments that can be employed to compensate victims of medical malpractice. This Chapter will focus on compensation via tort law, liability insurance, and self-insurance. All these instruments are fault-based. No-fault compensation mechanisms (first-party insurance, compensation funds, and social security) will be addressed in Chapter 11. The next will first describe the basic theories regarding secondary cost avoidance in Section 2. Then, it will discuss the desirability of compensation via tort law alone in Section 3. Thereafter, compensation via liability insurance will be examined in Section 4. After that, the question of whether self-insurance is a perfect alternative to liability insurance will be explored in Section 5 . The final Section 6 concludes.

\section{BASIC THEORIES OF SECONDARY COST AVOIDANCE}

Calabresi maintained that secondary costs can be reduced by loss spreading in that it is socially desirable to place one large loss on many people rather than

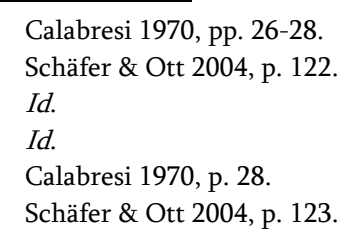


on one person..$^{11} \mathrm{He}$ further claimed that the foregoing proposition is based on the "diminishing marginal utility of money theory" and firmly believed that as long as "a five-dollar loss divided among five people necessarily hurts less than the same loss placed on one person, the basic justification for loss spreading remains strong." ${ }^{\prime 2}$ A variant of the proposition is the "deep pocket" notion - secondary costs could be better reduced if the rich, who are "least likely to suffer substantial social or economic dislocations," were required to bear those costs. ${ }^{13}$ Thus, the deep pocket approach suggests that sometimes "partial spreading can reduce secondary costs better than total spreading if the right people are made to pay." 14

In light of the expected utility theory, later economists treat secondary cost reduction as a problem of "the allocation of risk"15 or "risk spreading."16 In this context, the "risk" exactly refers to the possibility of suffering secondary costs. In a market setting, risk spreading is achieved primarily through insurance. Ideally, social welfare optimum will be achieved and hence secondary costs are reduced if "the sum of the insurance premiums that its members are willing to pay for an uncertain loss is at least equal to the expected value that each would receive in the event of the loss (plus administrative costs)." ${ }^{17}$

The fundamental assumption underpinning insurance is that most people are risk averse - they prefer to suffer a certain loss with a small magnitude than to suffer an uncertain loss with a large magnitude. ${ }^{18}$ The attitude of risk aversion is strictly equivalent to an increasing utility of wealth function with a diminishing marginal utility of wealth. ${ }^{19}$ The extent of risk aversion is normally affected by both personal assets and personal needs. Put another way, when facing the same magnitude of losses, the poor in need of money may be treated as risk averse whereas the rich may be considered as risk neutral. ${ }^{20}$ Social welfare will be improved if the risk faced by the riskaverse can be somehow reduced or eliminated.

In terms of risk aversion, Calabresi's methods of loss spreading and deep pocket can be justified as welfare-enhancing mechanisms. On the one hand, loss/risk spreading is normally efficient because if risks are shared

Calabresi 1970, p. 39.

Calabresi 1970, pp. 39-40.

Calabresi 1970, p. 40.

Calabresi 1970, pp. 40-41.

Shavell 1987a, pp. 186-191.

Schäfer \& Ott 2004, pp. 117-122.

Schäfer \& Ott 2004, p. 117.

Cooter \& Ulen 2012, p. 45.

Schäfer \& Ott 2004, p. 118.

Shavell 1987a, p. 189. 
among the risk averse, the magnitude of losses confronting each of them is reduced, supposing there are no significant differences in their marginal utility of wealth. ${ }^{21}$ Social welfare (the sum of parties' expected utilities) will be enhanced if loss/risk spreading can be achieved through e.g. a risk sharing agreement. ${ }^{22}$ In addition to interpersonal loss spreading, inter-temporal loss spreading - spreading losses "over the victim's past and future earnings" may sometimes be more desirable if interpersonal spreading is impossible or more costly. ${ }^{23}$ On the other hand, the deep pocket method is also desirable because the same magnitude of losses will reduce the expected utility of the risk averse greater than that of the risk neutral (or from more to the less risk averse), given that they have the same marginal utility at the beginning. ${ }^{24}$ Hence, social welfare will be raised if risks are moved from the former to the latter through e.g. insurance. ${ }^{25}$ Specifically, the primary systems of accident loss distribution may include "social insurance, private risk pooling (insurance), and enterprise liability." 26

The above analysis appears applicable to secondary cost reduction in the context of iatrogenic injuries. The classic model of malpractice liability assumes that parties are risk neutral. The available empirical evidence - the fact that patients with fewer personal assets suffer disproportionately large numbers of iatrogenic injuries, ${ }^{27}$ the extensive purchase of malpractice liability insurance, ${ }^{28}$ and the prevalence of defensive medicine ${ }^{29}$ - does suggest that many, if not most, health care providers and patients may be risk averse rather than risk neutral. ${ }^{30}$ Hence, the methods of risk spreading discussed above are fit for the health care sector.

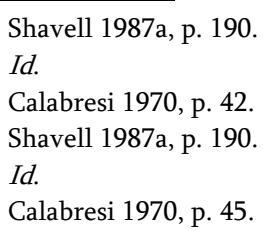

Whether most people are risk neutral or risk averse is ultimately an empirical question. Available empirical literature suggests that risk aversion may be more prevalent than risk neutrality in everyday life. Binswanger conducted an experimental work in rural India and reported that "at high payoff levels, virtually all individuals are moderately risk-averse with little variation according to personal characteristics." Binswanger 1980. With a different research design, Kachelmeier and Shehata conducted several experiments in China and concluded that risk aversion increases with the prize value. Kachelmeier \& Shehata 1992. Smith and Walker examined subjects' risk preferences in the context of the first price sealed bid auction and found "an overwhelming tendency for subjects to bid above the risk-neutral prediction (as if risk averse)." Smith \& Walker 1993. After 


\section{COMPENSATION VIA TORT LAW ALONE}

\subsection{INTRODUCTION}

Tort law is unique in that it is a mixed system that is aimed at both accident prevention and victim compensation. ${ }^{31}$ The preventive function of tort law is fulfilled by the workings of liability rules that are intended to $e x$ ante induce risk-creators to exercise optimal precautions to avoid accidents in the first place. As shown in Chapters 7-9, tort liability is still critically important for the goal of primary cost reduction.

Be that as it may, the essential role played in prevention does not necessarily mean that tort law can perform the function of compensation equally well. The desirability of reducing secondary costs through tort law alone will be examined in this sub-section. To begin with, it will explore the question of whether enterprise liability promotes secondary cost avoidance in Section 3.2. After that, the desirability of treating tort law as an insurance mechanism will be evaluated in Section 3.3. A summary will be provided in Section 3.4.

\subsection{ENTERPRISE LIABILITY}

Broadly speaking, enterprise liability refers to the tort doctrine that "losses to society created or caused by an enterprise or, more simply, by an activity, ought to be borne by that enterprise or activity." ${ }^{32}$ In the context of an individual (e.g. a doctor) acting on behalf of an enterprise (e.g. a hospital), "enterprise liability" specifically denotes that "the enterprise is liable while the agent is not." ${ }^{\prime 33}$ As far as medical malpractice is concerned, the notion of "enterprise medical liability" (hereinafter EML) was proposed to describe a regime where "health care organisations bear responsibility for medical malpractice ... instead of individual health professionals." ${ }^{34}$ As demonstrated

observing subjects' choices under both low- and high-money payoffs, Holt and Laury found that even under low-money payoffs (below \$4.00), the vast majority (two-thirds) of the subjects still exhibit risk aversion. Holt \& Laury 2002. Their findings were also consistent with the previous three studies in that when payoffs are raised risk aversion rises dramatically.

$31 \quad$ See generally Calabresi 1970, pp. 239-243; Schwartz 1997.

$32 \quad$ Klemme 1976, p. 158.

$33 \quad$ Kornhauser 1982, p. 1345.

$34 \quad$ Sage 1997, p. 159. See also generally Abraham \& Weiler 1994; Sage, Hastings \& Berenson 1994. 
before, for the purpose of minimising primary and tertiary costs, EML is more desirable than individual physician liability. ${ }^{35}$

In the light of secondary cost reduction, Calabresi maintained that two types of the so-called "enterprise liability" can be employed to achieve wide spreading of accident risks. The first type places losses on those categories of parties who are most likely to insure or ablest to self-insure against secondary losses. In contrast, the second type places losses on those who are in the best position to pass losses on to consumers or factors of production (e.g. labour and capital). ${ }^{36}$ In the light of this analysis, it appears that EML could reduce secondary costs more than individual provider liability. First, health care organisations are usually more solvent than individual providers, so that they are more able to purchase insurance or self-insure. Second, health care organisations have a larger number of consumers, so that they are able to pass added costs on to consumers through the price mechanism (decreased output and higher prices) in a free health market. As employers, they may also respond to added costs by "lower payments to, and decreased use of, those resources giving rise to the extra cost." ${ }^{37}$

Enterprise liability cannot be justified only by its function as a regime of "semi-compulsory spreading," for social insurance can achieve the broadest possible loss spreading (and deep pocket) much more cheaply. ${ }^{38}$ Conversely, enterprise liability is primarily intended to achieve optimal primary cost reduction in that society decides to place losses specifically on those who are more able to prevent accidents. ${ }^{39}$ Hence, enterprise liability can induce optimal incentives to take care, and it aims at reducing secondary costs to some extent at the same time. Moreover, the radical demand for enterprise liability, which is more compulsory than private insurance, indicates that "people do not individually insure voluntarily to the degree necessary to provide for the spreading of losses that collectively they consider best for society." ${ }^{40}$

As demonstrated above, in the absence of first-party or third-party insurance, both types of enterprise liability predict that health care organisations themselves can achieve loss spreading either through selfinsurance or by acting as an "insurer." It suffices here to say that EML is superior to individual liability in that the former better facilitates effective

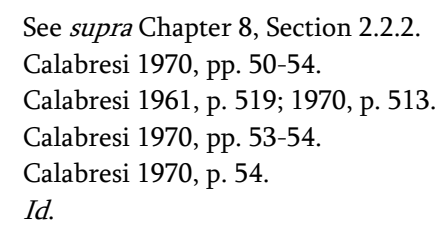


self-insurance. Whether it is desirable to treat medical liability itself as insurance will be examined in the next sub-section.

\subsection{OPTIMAL COMPENSATION}

\subsubsection{The Insurance Theory}

It is worth examining how EML works as a way of "semi-compulsory spreading." Due to a lack of universal coverage of first party patient insurance, ${ }^{41}$ tort liability is often regarded as a way to provide those uninsured patients with some protection against at least negligent iatrogenic injuries. If exculpatory agreements are forbidden, the tort system can be seen as a system of "compulsory insurance," which is publicly administered via court decisions concerning liability and quantum rules. ${ }^{42}$ Accordingly, the optimal magnitude of liability should be determined by insurance theories. According to Shavell, optimal compensation for iatrogenic injuries should be determined in the light of the following criterion:

Whether publicly or privately provided, compensation for a medical accident ought to reflect the insurance coverage against the accident that a rational, well-informed individual with a socially acceptable level of income would have bought ... the determination of optimal compensation ought to reflect a hypothetical decision about the purchase of insurance. ${ }^{43}$

Hence, some argued that victims should receive optimal compensation instead of full compensation and optimal compensation usually would not make a victim whole. ${ }^{44}$ In other words, they believe full compensation is normally socially inefficient regarding either deterrence or compensation, at least in the case where the victim suffered severe disability. ${ }^{45}$

According to this model, a rational patient would like to choose a level of coverage $c^{*}$ to maximise his/her expected utility. The utility of money to an individual depends on his or his/her life style. It may increase, decrease, or remain unchanged, after the individual suffers a personal injury. ${ }^{46}$ If an accident does not lead to a permanent disability that may affect the patient's life style, meaning the utility of money to him/her will not be affected by the

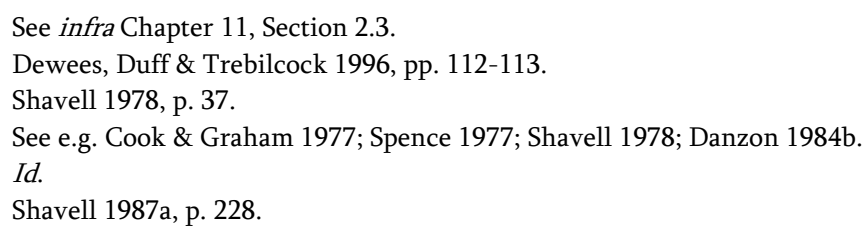


accident, it will be optimal for him or her to purchase a level of coverage $c^{*}$ which equals pecuniary losses. ${ }^{47}$ If the utility to the patient increases after the patient suffered a modest disability (that is, he/she is badly in need of money), he/she will choose a level of coverage $c^{*}$ which is somewhere between pecuniary losses and full compensation, i.e. the sum of full pecuniary losses and some non-pecuniary losses. ${ }^{48}$ However, if the utility of money to him/her decreases due to severe disability (e.g. because he/she is in a vegetative state and unable to enjoy the basic aspects of life), he/she will choose $c^{*}$ which falls short of even pecuniary losses. ${ }^{49}$ Therefore, from the perspective of secondary cost reduction, the full compensation principle is unlikely to be optimal, especially in cases where seriously disabling injuries constitute "irreplaceable losses." ${ }^{50}$ Given the fact that the loading on malpractice insurance is high, optimal compensation tends to be lower. ${ }^{51}$

In the above insurance model, although non-pecuniary losses are actual harm, there is normally no need for recovery of such losses, since "non-pecuniary losses do ex post not create a demand for additional money, the victim has no willingness to pay a premium to cover for this nonpecuniary loss ex ante. ${ }^{.52}$ Conversely, empirical studies show that injuries are most likely to reduce the marginal utility of wealth, i.e. victims gain less from the same amount of money ${ }^{53}$ In such a case, people would not be willing to purchase insurance against non-pecuniary losses before the accident, because "the premium costs more utility than the expected coverage yields." 54 Other empirical evidence also suggests that full compensation of tort law "far exceeds the coverage people are prepared to pay for." ${ }^{35}$ However, this conclusion may be inconsistent with the goal of primary cost avoidance.

\subsubsection{Decoupled Liability}

If optimal compensation falls short of full compensation, a problem of underdeterrence may arise from the perspective of deterrence..$^{56}$ To resolve this problem, some scholars proposed to employ a regime of "decoupled" liability, where "the plaintiff is awarded an amount different from what the defendant

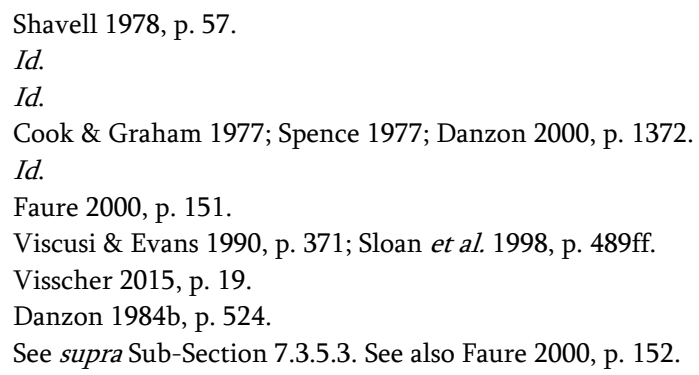


is made to pay." ${ }^{57}$ Specifically, the government should impose on the defendant an optimal deterrence fine, which is equal to the victim's uncompensated loss after receiving optimal compensation. This would be in addition to the compensatory award..$^{58}$ Given optimal compensation, the magnitude of the optimal deterrence fine will be decided by patients' willingness to pay for injury reduction..$^{59}$ In general, the more the medical prices internalise patients' willingness to pay for injury reduction, and the more defendants fear uninsurable non-financial malpractice risk, the larger the magnitude of the optimal deterrence fine. ${ }^{60}$ The state should collect the fine and then spend it on the health care system, with the intention of maintaining "appropriate relative prices." 61

Be that as it may, decoupled liability is not flawless. This approach was looked upon with disfavour by some economists because it would "even worsen the position of the victims: they pay an increased price (because the injurer is liable for the non-pecuniary losses), but they do not receive coverage!" 62 Instead, they maintained that the ex ante willingness to pay (hereinafter WTP) to avoid non-pecuniary losses forms a better basis to measure recovery for non-pecuniary losses than the insurance theory on two major grounds. On the one hand, the insurance theory does not always hold true. ${ }^{63}$ First, although the victim's marginal utility after the accident may not change or even decrease, the victim may still want to insure against nonpecuniary losses because receiving money after suffering non-pecuniary losses may enhance the victim's overall utility to some extent. ${ }^{64}$ Second, the victim's marginal utility of wealth does not necessarily decrease after the accident since her "baseline utility" may be too low. ${ }^{65}$ Third, there may be some demand for insurance against non-pecuniary losses, but no insurers want to provide such insurance due to problems of adverse selection or moral hazard. ${ }^{66}$ Fourth, there may be no demand for such insurance precisely because tort damages already include non-pecuniary losses in practice. ${ }^{67} \mathrm{On}$ the other hand, the ex ante WTP "shows how many resources the victim

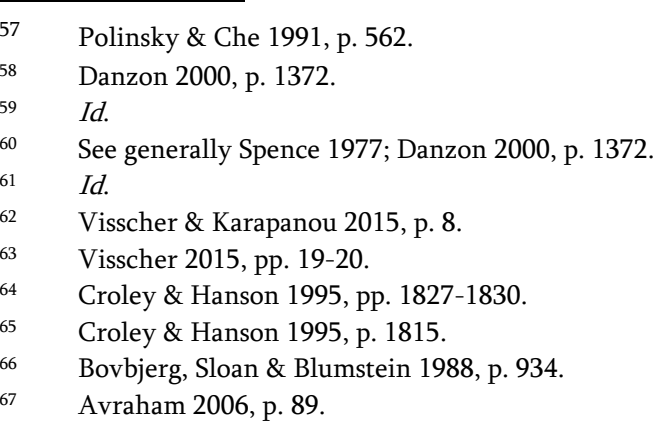


found equivalent (ex ante) to suffering the loss." 68 To victims themselves, their utility would indeed be reduced in the future, if they were willing to pay to avoid non-pecuniary losses before the accident. ${ }^{69}$

\subsubsection{Inefficiencies of Treating Tort Law as an Insurance Scheme}

Theoretically speaking, liability rules alone give no guarantee that losses suffered by victims will be sufficiently compensated when compared with market insurance. First, there may be no swift compensation. The compensation function of liability rules may work better under strict liability while it does not work well under the negligence rule, for victims have to prove the fault of injurers. ${ }^{70}$ In contrast, benefits under a (first-party) insurance plan are normally paid once an insured risk materialises. A considerable delay "creates another source of secondary costs based on the delay itself." "11 Second, there may be no sufficient compensation. If the insolvency risk is high, it is less likely that victims' losses will be sufficiently compensated..$^{72}$ Nevertheless, it would be less problematic if EML were employed, since health care organisations are normally considered to be more solvent than an individual provider.

Based on the available empirical evidence, Dewees, Duff and Trebilcock also concluded that although "distributive inequality and market failures appear to justify some form of compensation for the victims of medical injuries, civil liability is not an optimal instrument for accomplishing this objective." ${ }^{73}$ Empirically speaking, the inefficiency of tort liability as an insurance system can be explained by several factors. First, there is no optimal deterrence fine in practice to cure the problem of under-deterrence. Second, many eligible patients with meritorious claims do not sue or are denied compensation. ${ }^{74}$ Third, administrative costs are very high. ${ }^{75}$ Fourth, there is a regressive character to tort compensation (paying same premiums, receiving different compensation corresponding to income levels). ${ }^{76}$ Therefore, it is reasonable to conclude that "no rational consumer would voluntarily

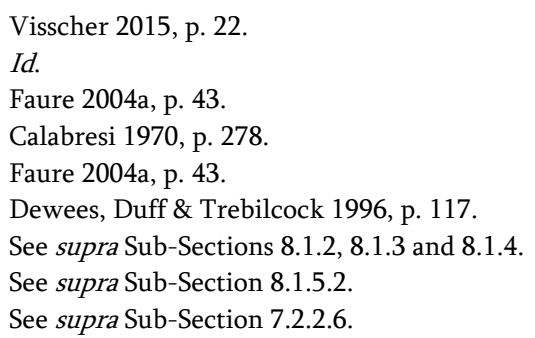


purchase the insurance that is implicitly offered through the civil liability system." 77

\subsection{SUMMARY}

Traditional tort theorists, familiar with the notion of corrective justice, treat compensation (loss shifting) as the primary function of tort law. ${ }^{78}$ In contrast, economists normally stress the deterrence function of tort law. The primary goal of accident law is to reduce the number and severity of accidents in the first place. Be that as it may, economists also pay attention to the secondary goal of reducing the social and economic dislocations of victims due to accidents that nonetheless happen.

Tort law could be designed to reduce secondary costs if EML were employed. Two types of enterprise liability are available. The first type shifts losses to those who are most able to self-insure (or insure), while the second type spreads losses to consumers by treating the tort system as insurance. Although treating the tort system alone as an insurance regime does reduce some secondary costs, it achieves this goal at the expense of the goals of primary and tertiary cost avoidance. Hence, it may be better to employ EML in the sense that it better facilitates self-insurance. Tort damages should be determined in light of the victim's ex ante WTP, which takes into account both primary and secondary cost avoidance. In contrast, insurance systems may outperform tort law regarding optimal secondary cost reduction, and this will be addressed in the remaining sections.

\section{COMPENSATION VIA LIABILITY INSURANCE}

\subsection{INTRODUCTION}

In previous chapters, we have demonstrated that tort law alone can be justified primarily on its deterrence function ${ }^{79}$ which has been corroborated by empirical evidence. ${ }^{80}$ In the previous section, we have also shown that tort law could not be fully justified if its sole function were compensation, although EML, which places losses on hospitals because they are able to self-

\footnotetext{
$77 \quad$ Dewees, Duff \& Trebilcock 1996, p. 117.

78 Of course, there are lawyers who stress the deterrent function of tort law as well. Faure 2004a, p. 7.

79 See supra Chapter 7.

$80 \quad$ See supra Chapter 8.
} 
insure, may induce hospitals to take optimal self-insurance plans to reduce secondary costs. Hence, more efficient instruments that can achieve greater levels of secondary cost reduction through e.g. interpersonal loss spreading may be warranted.

As far as iatrogenic risks are concerned, private insurance can be either (third-party) medical liability insurance (hereinafter MLI) or (first-party) patient insurance. In this Chapter, we will only examine MLI, which is traditionally the dominant form of compensation in the health care sector. First-party patient insurance will be discussed in Section 5.

In many legal systems, the medical malpractice system is the "faultliability-insurance" system (hereinafter FLIS), under which the negligence rule and MLI are jointly used. ${ }^{81}$ Under the MLI scheme, the insurer provides cover in respect of the insured's tort liability for harm done to third parties. ${ }^{82}$ In other words, claims for medical malpractice are determined by tort law while damage awards are ultimately paid by liability insurers. From the perspective of law and economics, MLI primarily serves to offer protection for risk-averse injurers whereas potential victims are only protected indirectly. ${ }^{83}$ Nevertheless, from the perspective of victims, losses due to medical malpractice will be transferred from them to the negligent health care provider and eventually spread to all the insured providers through the insurance mechanism (loss spreading) ${ }^{84}$ In this way, secondary costs resulting from negligent adverse events are reduced via the FLIS. Without MLI, secondary costs of negligent iatrogenic injuries may not be reduced due to the injurer's insolvency risks. It should, however, be noted that under the FLIS, secondary losses not resulting from medical malpractice, i.e. risks of nonnegligent iatrogenic injuries or non-iatrogenic injuries, are not covered by MLI. These risks fall within the patient's own scope of responsibility. Nonetheless, risk-averse patients may purchase first-party insurance to cover these non-malpractice risks in particular or the risk of suffering personal injuries in general.

The following section will first examine the economic rationale behind private insurance and discuss the desirability of applying it to risk spreading in the health care sector in Section 4.2. Since the FLIS is based on the negligence rule, more attention will be paid to the classic model of liability insurance under negligence. Then, empirical evidence concerning the FLIS will be reviewed in Section 4.3. A summary will be made in Section 4.4.

OECD 2006, p. 10.

Faure 2004a, p. 55

Faure 2004a, p. 47

Cane 2013, p. 44. For a thorough discussion on the relationship between tort law and liability insurance, see e.g. Schwartz 1990. 


\subsection{THE RATIONALE OF LIABILITY INSURANCE}

\subsubsection{Loss Distribution and Private Insurance}

From the perspective of society, (private) insurance such as MLI is an economic instrument for accident loss distribution. It is meant to reduce secondary accident costs through risk spreading, the predominate form of which is pooling - "combining a sufficient number of homogeneous exposures into a group to make the losses predictable for the group as a whole." 85 Insurance is socially appealing because it is politically the "freest" way of risk spreading. ${ }^{86}$ Two features are characteristic of insurance: first, it is a combination of inter-temporal and inter-personal loss spreading; and second, unless the government intervenes, it does not reflect the aim of the deep pocket method (i.e. the rich pay more premiums than the poor). ${ }^{87}$ Insurance is a method of inter-temporal loss spreading to the extent that all those insured have an equal risk potential. ${ }^{88}$ Similar to saving, those insured pay premiums in advance, in return for future insurance benefits when accidents occur. ${ }^{89}$ However, insurance is more than just saving. ${ }^{90}$ It can also achieve limited interpersonal loss spreading insofar as there are some differences among the insured. On the one hand, it spreads risk from those who face greater accident costs to those who face fewer accident costs. ${ }^{91}$ On the other hand, it spreads risk from those who suffer accidents sooner to those who suffer accidents later. ${ }^{92}$

\subsubsection{The Demand for Insurance}

\subsubsection{Risk Aversion and Insurance}

From the perspective of individuals, Insurance is a special kind of contract, which is "an exchange of money now for money payable contingent on the occurrence of certain events. ${ }^{193}$ As previously demonstrated, ${ }^{94}$ many injurers

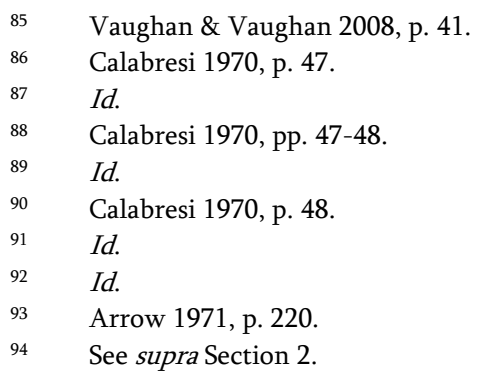


are averse towards a risk with a substantially large magnitude when it occurs, although the probability of its occurrence may be relatively low. In the health care sector, risk-aversion can be assumed as a general attitude of medical professionals, since even those "who are modestly wealthy and earn well above average would be ruined financially if confronted by an obligation to compensate victims for severe personal injuries." 95 Such a risk creates disutility for risk-averse health care providers, which is inefficient. Hence, they have a high demand for risk shifting or risk sharing. Theoretically, riskaverse injurers prefer to pay a certain small amount of money (insurance premiums) in exchange for shifting the possibility of a larger loss to riskneutral insurers, which increases the former's utility. ${ }^{96}$

According to the theory of diminishing marginal utility of wealth, "it is fair to assume risk-aversion as a general attitude of human beings. ${ }^{97}$ Health care providers and patients are not exceptions. For instance, the extensive practice of defensive medicine implies that physicians are averse towards malpractice risks. ${ }^{98}$

\subsubsection{Demand for MLI under the Negligence Rule}

Be that as it may, according to the negligence-based malpractice model, there should have been no demand for MLI given perfect information concerning due care. ${ }^{99}$ It would be less costly to escape liability by simply exercising due care than to purchase MLI because premiums would be too high due to all negligently acting providers. ${ }^{100}$ Traditionally, however, MLI is used to provide protection for risk-averse health care professionals, who take out almost complete insurance against malpractice liability. ${ }^{101}$

This apparent paradox can be explained by several factors as follows. First, information about the standard of care is highly uncertain, and risks may nevertheless be imposed on health care providers if due care is set higher than optimal care. ${ }^{102}$ Also, real-life judges may erroneously find providers liable due to their personal inclination towards plaintiff-patients, hindsight bias, and errors in applying the economic calculus. ${ }^{103}$ Moreover, to err is

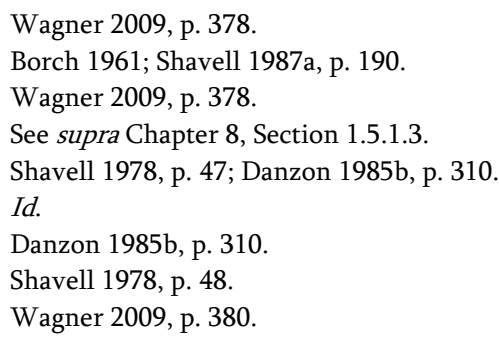


human, and many physicians may inadvertently breach their duty to exercise due care. ${ }^{104}$

Consequently, the risk of being held liable for iatrogenic injuries erroneously or accidentally committing errors is not insignificant even though physicians make their best endeavours to provide optimal treatment. It follows that, even under the negligence rule, physicians may be willing to insure against potential malpractice liability. ${ }^{105}$

\subsubsection{Institutional Providers}

In most legal systems, hospitals may be held liable either directly due to their own fault or vicariously due to fault on the part of their medical staff members. ${ }^{106}$ Hospitals would be the sole defendant if EML were employed. ${ }^{107}$ Hence, it is questionable whether healthcare organisations such as hospitals have a demand for MLI.

As enterprises, hospitals normally have relatively large assets compared to physicians. While it is fairly reasonable to regard individual providers as risk-averse parties, it is somewhat strange to believe enterprises are riskaverse. The whole idea of EML is that hospitals are "deep pockets" that do not hurt very much when losses are placed on them instead of on physicians. ${ }^{108}$ They may simply choose self-insurance which is less expensive than market insurance and spread risks through the price mechanism. ${ }^{109}$ However, practice shows that "even large firms favour market insurance over selfinsurance." 110 This phenomenon can be explained by three reasons. First, enterprises normally rely on the expertise of liability insurers in handling claims, ${ }^{111}$ which reduces transaction costs. ${ }^{112}$ Second, they may also want to reduce the variance in enterprise performance by purchasing liability insurance. ${ }^{113}$ Third, although firms may be risk-neutral, firm managers are usually risk-averse towards losses that may ultimately reduce their own salaries. ${ }^{114}$ According to the above analysis, it is highly likely that hospitals

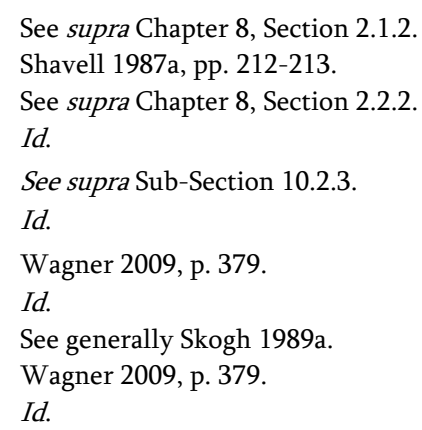


have a demand for MLI as well. Nonetheless, there is a trade-off between the demand for MLI and that for self-insurance. ${ }^{115}$

\subsubsection{Coverage for Non-Pecuniary Losses}

Many economists maintain that risk-averse parties do not have a demand for insurance against non-pecuniary losses. ${ }^{116}$ Some scholars, however, do not endorse this argument. ${ }^{117}$ Under the FLIS, insurance coverage usually takes the scope of liability as the upper limit. Since recovery for non-pecuniary losses can be justified from the perspective of optimal deterrence and the ex ante WPT, there is no reason to exclude non-pecuniary losses from liability insurance coverage. Indeed, scope of liability and hence MLI coverage is an issue that "must be solved by legislation in the area of tort law and not within the sphere of insurance law." 118

\subsubsection{The Supply of Insurance}

\subsubsection{Pooling, Re-insurance, and Co-Insurance}

The previous subsection explained why there is a demand for MLI. The next question is why insurers are willing to take on the insured's risks. As profitmaximisers, they must be able to ensure that the risk is insurable, and their operation is profitable; otherwise, the private insurance market would not be sustainable.

The usual technique employed by insurers to spread risks is pooling, ${ }^{119}$ meaning the spreading of losses suffered by the few over the entire group of homogeneous and independent people insured. ${ }^{120}$ The larger the group, the fewer risks faced by each insured member of the group on average. ${ }^{121}$ Another reason why the group should be sufficiently large is that the larger the number, the more accurate the estimate and thus the insurability of the risks. ${ }^{122}$ The method of pooling generally applies to both MLI and patient insurance.

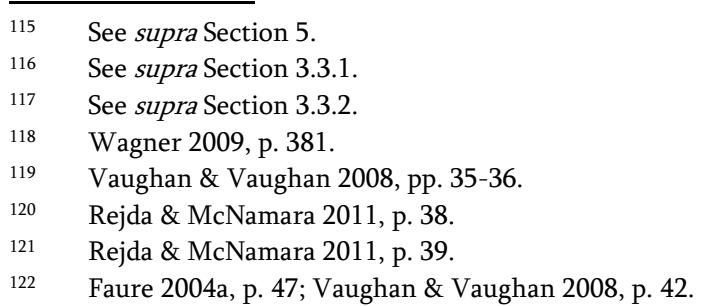


Unlike individuals, insurance companies can predict future losses within a particular group of the insured based on the Law of Large Numbers. ${ }^{123}$ According to this Law, "as the number of trials of a random experiment increases, the percentage difference between the expected and actual numbers of successful outcomes goes to zero."124 In practice, the underlying probability can be obtained a posteriori by observing past accidents that have occurred, making use of statistical inference. ${ }^{125}$ Hence, pooling can transform "the uncertainty of outcome in every single trial into a certainty with regard to the sum of all trials" and the "risks have cancelled each other out." ${ }^{126}$

With the help of the Law of Large Numbers, an insurer is able to calculate insurance premiums. Apart from administrative costs, the insurer may pay its way by charging the insured the actuarially fair premium, which is equal to the expected value of payment under the policy. ${ }^{127}$ In practice, there will be loading costs (an additional charge for overhead costs). ${ }^{128}$ Also, the profit-maximizing insurer will add a profit margin to the premium. ${ }^{129}$ Therefore, the insurance premium is normally larger than the actuarially fair rate. However, since the risk-averse insured person "has a strict preference for the actuarially fair policy over assuming the risks himself, he/she will still have a preference for an actuarially unfair policy," provided that "it is not too unfair." 130

Sometimes, insurers still face some residual risks even after pooling in that the real outcome may depart from their predictions. ${ }^{31}$ In response, the insurance markets have developed some non-pooling mechanisms such as reinsurance $^{132}$ and co-insurance. ${ }^{133}$

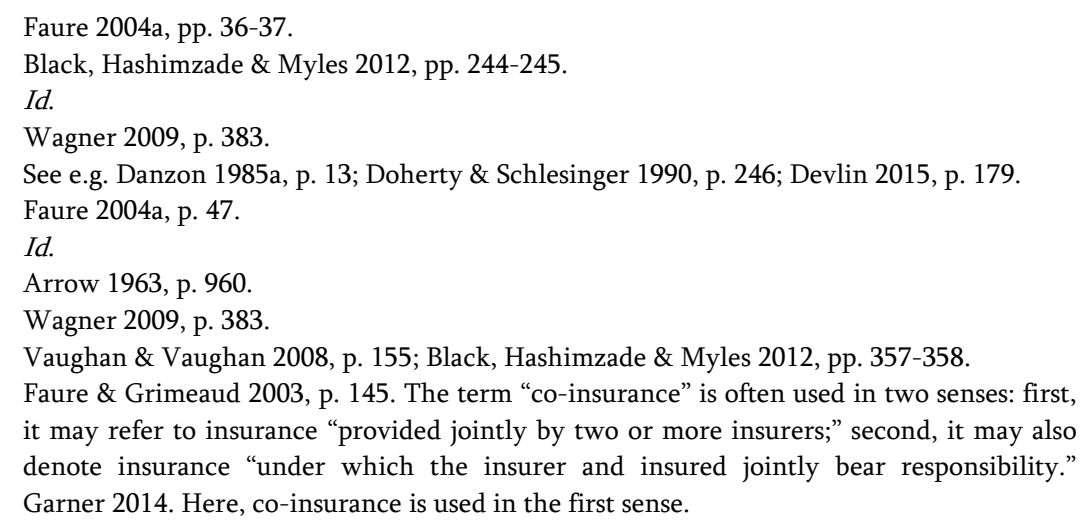




\subsubsection{The Insurability of the Medical Malpractice Risk}

Elements of Insurability. As mentioned in the prior sub-section, insurers will often not sell an insurance policy unless they consider the risk concerned is insurable. A sufficiently large number of homogeneous exposure units is only one of several elements of the notion of insurability. Insurability is described by Wagner as "a term of art in insurance economics and insurance practice," denoting "the minimum requirements a certain category of risk must satisfy in order to be eligible for coverage." 134 In a rough sense, insurability refers to the extent to which a risk can be foreseen and calculated. ${ }^{135}$ Specifically, an insurable risk must be accidental, determinable and measurable, independent, and non-catastrophic. ${ }^{136}$

As far as the malpractice risk is concerned, the last of the foregoing four elements can be easily satisfied. Evidently, unlike catastrophic losses due to e.g. a natural disaster or war that may well lead to a financial catastrophe for an insurer, an iatrogenic injury resulting from a wrongful treatment is non-catastrophic. However, it is hard to meet the other three elements perfectly.

Accidental nature of malpractice risks. The risk of an accident may be affected by moral hazard and adverse selection. Iatrogenic injuries are by definition unintended harm that is due to medical errors committed by physicians accidentally. Medical malpractice liability is based on the law of negligence rather than intentional torts. Hence, MLI excludes coverage for losses due to intentional torts. Be that as it may, MLI coverage may raise the problems of moral hazard and adverse selection, both of which suggest that part of the probability of loss may be affected by the insured's behaviour. ${ }^{137}$ The insured's incentives to take care may be reduced once he/she obtains coverage (moral hazard) and low-risk insureds may choose not to buy any insurance (adverse selection), both of which will increase the probability of loss. However, this may not make the malpractice risk uninsurable; otherwise, there would be no MLI available in practice. ${ }^{138}$

Determinability and measurability of malpractice risks. This requirement is also difficult to be fulfilled. First, the pool of potential policyholders may be relatively small, so that it would be difficult to predict

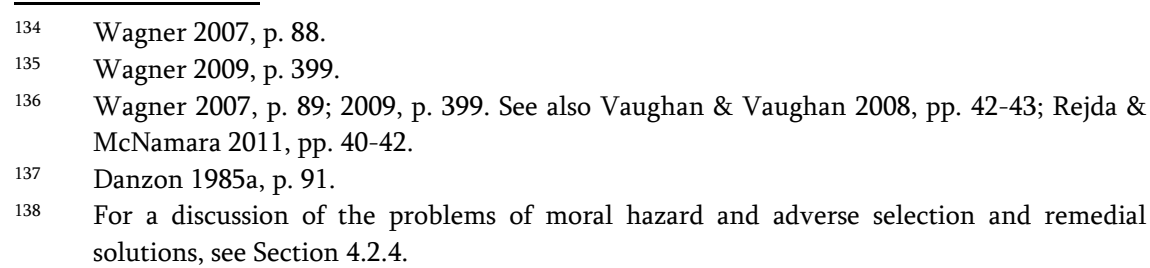


the frequency of malpractice claims accurately. ${ }^{139}$ Second, there may be considerable volatility in the frequency and severity of malpractice claims. ${ }^{140}$ Third, there may be the well-known problem of the "long tail on losses." ${ }^{141}$ Fourth, some special liability sub-rules may make liability risks less predictable as well..$^{142}$

One may wonder whether there is a real long tail problem in the MLI market, since e.g. most surgical injuries are apparent after the treatment. However, some treatment injuries may "take a longer time to manifest themselves, as many as several years in some cases." ${ }^{143}$ Also, although most "negligent mistakes become apparent to patients or their families shortly after they occur, a few remain undiscoverable for an extended length of time." ${ }^{144}$ Even after injuries and errors are identified, it may take several more years for victims to win the case through the litigation system. ${ }^{145}$ If liability for these injuries is covered by insurance on an occurrence basis, then the insurers have to bear "all risk arising from socio-legal and financial trends affecting future claims." 146 This problem will make it extremely difficult for insurers to calculate premiums. Many insurers in the US "found themselves paying 1970 losses with 1950 premiums." ${ }^{147}$

All these problems will lead to the so-called problem of "insurer ambiguity." ${ }^{148}$ However, ambiguity does not necessarily mean uninsurability. Where there is ambiguity regarding the probability or magnitude of the loss, insurers will charge an additional "risk premium" to off-set against the unpredictability. ${ }^{149}$ The insurer should at least have some information to "make more than an educated guess concerning the risk premium he/she has to charge." ${ }^{150}$ However, due to the competitive nature of the medical liability insurance market, the insurer may still be willing to provide liability insurance even when it is not possible to charge the risk premium. ${ }^{151}$ Nonetheless, many insurers "would prefer not to provide insurance against

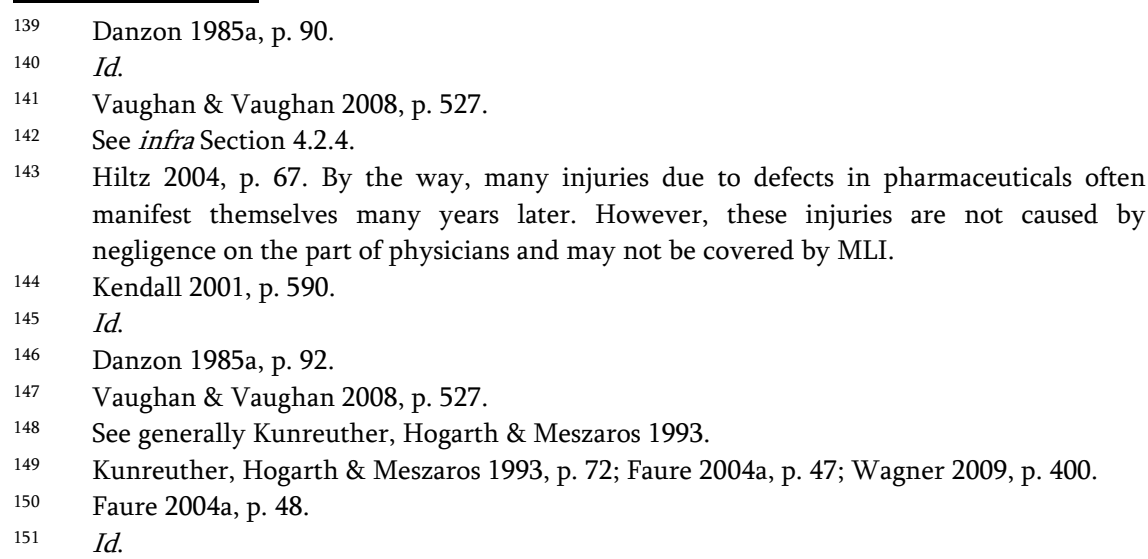


risks where there is considerable ambiguity and uncertainty." 152 Indeed, if the risk premium were too considerable, the insurance premium would well exceed "the price potential customers are willing to pay."153

A specific way to tackle the long tail problem is to move from occurrence policies to claims-made policies. Occurrence policies "provide coverage for insured events occurring during the policy period, regardless of the length of time that passes before the insurance company is notified of the claim." 154 In contrast, claims-made policies "provide coverage for insured events occurring on or after the specified policy's retroactive date, when the insured events are reported during the policy period." 155 Hence, a claimsmade policy will effectively transfer the risk associated with the long tail on losses from the insurer to the insured, which makes it easier to calculate premiums accurately. ${ }^{156}$

Independence of malpractice risks. Some malpractice risks are not independent. Adverse events normally occur on a case-by-case basis. Hence, malpractice risks are basically independent of one another. It is highly unlikely that many physicians in the same pool would simultaneously cause negligent iatrogenic injuries. However, "multiple claims against an individual physician are not independent, to the extent that they arise out of systematic characteristics of his practice." 157 More problematic is the fact that "claims against physicians as a group are not independent." ${ }^{158}$ For instance, changes in legal doctrines may affect each patient's incentive to file a claim and eventually the magnitude of damage awards. ${ }^{159}$ Also, due to the long tail in malpractice claims, risks may accumulate and materialise simultaneously. ${ }^{160}$

When it comes to cumulative risks, several strategies can be employed to render these risks insurable. For instance, re-insurance can be used by the insurer to transfer part or all of the potential losses to the re-insurer, who is then responsible for the payment of these losses. ${ }^{161}$ Instead of re-insurance, primary insurers may also share the risks among themselves by co-insurance - the "pooling of risks and premiums in a common fund run in the name of all insurance companies which participate." ${ }^{162}$ Moreover, as mentioned above,

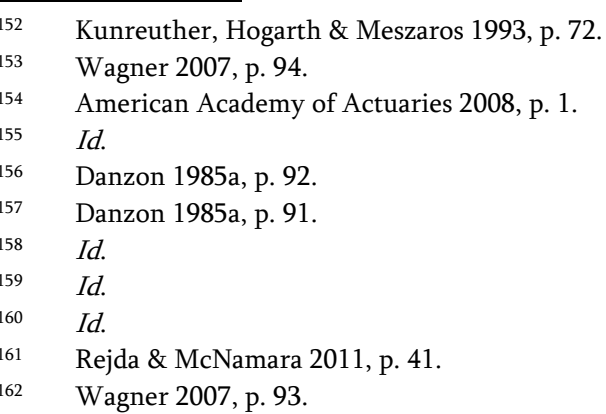


a shift from occurrence policies towards claims-made policies reduces the cumulative risks due to long tails in malpractice claims.

\subsubsection{Informational Problems in the Insurance Market}

\subsubsection{Moral Hazard}

Since the insured injurers can shift their risks of tort liability to insurers via the purchase of liability insurance, the insureds' incentives to invest in precautions may be reduced. This concerns a well-known problem of "moral hazard," 163 meaning the insured injurers' motive to prevent injury will be altered if the risk is shifted to an insurer. ${ }^{164}$ This behaviour alteration is "a result not of moral perfidy, but of rational economic behaviour." 165 The cause of moral hazard is information asymmetry - the insurer does not have perfect information concerning the insured's behaviour. ${ }^{166}$ This problem is not unique to the private insurance relationship but is characteristic of the principal-agent relationship. ${ }^{167}$

Regarding liability insurance, Shavell contended that injurers' preventive incentives will not necessarily be diluted, since insurers in a competitive market will incorporate within their insurance policies "an appropriate substitute (but not necessarily equivalent) set of incentives to reduce accident risks," 168 i.e. making the premium accurately reflect the insured's expected loss. ${ }^{169}$ Faure also argued that if moral hazard is perfectly controlled, the insured injurer will again behave as if there were no insurance while his disutility imposed by risk can still be removed. ${ }^{170}$ Basically, two partial solutions to the problem of moral hazard are proposed:171 (a) monitoring the insured injurer's level of care and (b) exposing the insured injurer to risk.

163 In mainstream insurance textbooks, a hazard is usually defined as a condition that may generate or increase the probability of a loss resulting from a given peril. "Moral hazard" denotes dishonest tendencies such as fraud whereas "attitudinal hazard" or "morale hazard" refers to a careless or indifferent attitude toward preventing losses. See e.g. Vaughan \& Vaugha 2008, p. 5 and Rejda \& McNamara 2011, pp. 22-23. This chapter does not make this distinction and "moral hazard" is used to cover both cases.

164 Shavell 1979, p. 541.

165 Pauly 1968 , p. 535.

166 Wagner 2009, p. 386.

$167 \quad$ Id. See also Arrow 1985.

168 Shavell 1982, pp. 121-122.

169 Danzon 2000, p. 1360.

$170 \quad$ Faure 1997, p. 196.

171 See generally Shavell 1979. See also Faure 2004a, pp. 48-49. 
The first best solution is that insurers can ideally overcome the insured's adverse incentives through detailed control of the insured's behaviour. ${ }^{172}$ In the real world, however, this ideal control is impracticable because it is very costly to observe the injurer's care level accurately. ${ }^{173}$ In practice, nevertheless, two operable measures based on risk differentiation have been developed to monitor the insured's care as accurately as possible: $e_{X}$ ante screening and $e_{X}$ post experience rating. ${ }^{174} E_{X}$ ante screening associates a higher premium for certain groups of the insured with higher risks before the sale of insurance policies. ${ }^{175} E_{X}$ post experience rating alters the premium according to the insured's past claims or loss experience. ${ }^{176}$ When care concerns risk-reducing activity that is variable (e.g. driving) rather than an expenditure on assets that fixed (e.g. smoke detectors), ex post experience rating is preferable to or as good as ex ante screening. ${ }^{177}$

The second best solution is to expose the insured injurers to risk through partial coverage. ${ }^{178}$ Partial coverage makes sure that only part of the insured's risk is removed. The insured injurers will still have some incentives to prevent injury. This approach is "second best" because the insured's liability risks are not fully covered by insurance. ${ }^{179}$ The most widely used devices to implement incomplete coverage are deductibles and coinsurance. ${ }^{180} \mathrm{~A}$ deductible subtracts a certain amount from the insurance benefits that insurers would otherwise have to pay, whereas co-insurance requires the insured to pay a certain percentage of each covered loss. ${ }^{181}$

These two solutions may be optimally used in combination. How to combine the use of both monitoring and exposing the insured to risk depends on upon two factors: information costs and the value of the insurance policy. ${ }^{182}$ One the one hand, if information costs are high, it may be better to adopt more deductibles. ${ }^{183}$ On the other hand, if the value of the insurance is high, the insurer may be induced to make a "nicely tailored insurance

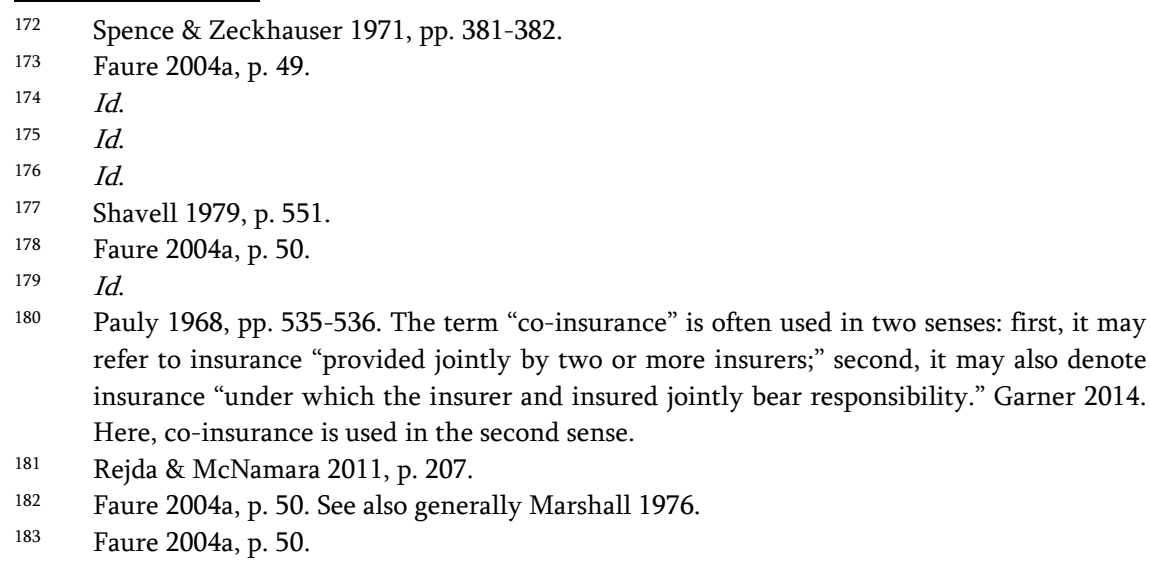


policy." 184 The control of moral hazard is not only beneficial to the parties but to society as well, for it will guarantee the insured's incentives to risk prevention. ${ }^{185}$

\subsubsection{Adverse Selection}

A second problem in the insurance market is adverse selection. ${ }^{186}$ Adverse selection denotes the phenomenon that when the average premium in a risk pool is relatively high because the pool is constructed so broadly, low-risk members of the pool will be forced to leave the group. ${ }^{187}$ Adverse selection is also the result of information asymmetry between insurers and the insureds. ${ }^{188}$ The insured may "fail to disclose their true risk profile appropriately" which may prevent the risk group from being constructed as narrowly as possible. ${ }^{189}$ Should insurers have perfect information and be able to distinguish precisely between high-risk insureds and low-risk insureds, then insurers could charge the insureds in the light of their risk categories, and eventually adverse selection could be prevented. ${ }^{190}$ Adverse selection may be remedied "by discriminating between different groups of insureds and by setting the premium in proportion to the risk represented by the average member of the different groups." ${ }^{111}$ In so doing, the risk pools could be constructed as narrowly as possible. ${ }^{192}$

\subsubsection{Risk Differentiation}

The problems of both moral hazard and adverse selection may be cured by risk differentiation..$^{193}$ If it were possible to connect policy terms to the risk profile of individual insureds, the problem of moral hazard would be controlled. ${ }^{194}$ If low-risk insureds and high-risk insureds could be perfectly distinguished, adverse selection would never arise. ${ }^{195}$ An appropriate risk differentiation should provide remedies to moral hazard and adverse selection

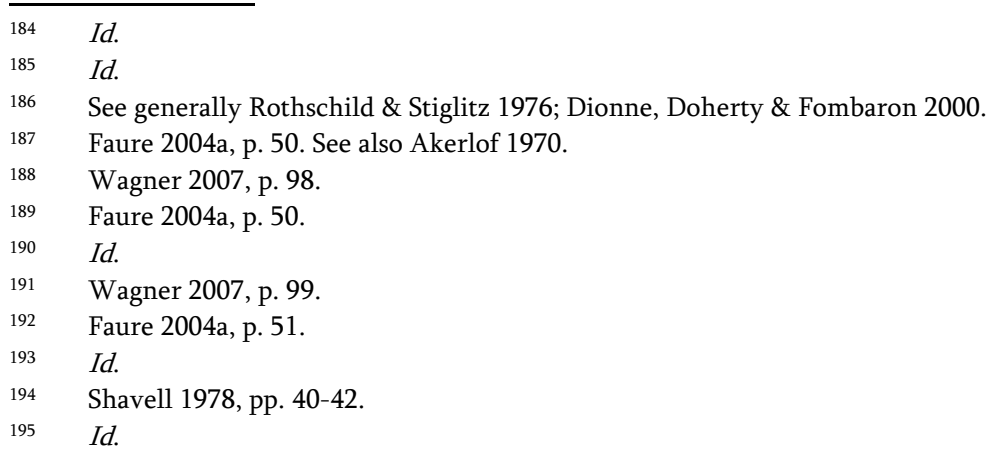


since the more the risk is differentiated, the easier it is for injurers to narrow the risk group and to set the premium that can reflect the risk of the average member of the pool. ${ }^{196}$

The efficiency of liability insurance is also based on the assumption that "there is perfect competition within the insurance market."197 If monopolistic premiums can be set under the context of a high concentration on insurance markets, insurers will have fewer incentives to match their premiums to the risk profiles of the insureds. ${ }^{198}$ In that case, the moral hazard problem cannot be cured, and more accidents may occur. ${ }^{199}$

It is widely argued that experience rating can redress the moral hazard problem plaguing malpractice insurance. ${ }^{200}$ Boccara explained that experience rating is based on the bonus-malus principle - if the insured health care provider exercises due care the premium will decrease (bonus) whereas if he/she deviates from due care the premium will increase (malus).

\subsubsection{Impact of Special Liability Sub-Rules on Insurability}

\subsubsection{Causal Uncertainty}

The issue of causal uncertainty has been addressed in Chapter $7^{201}$ and elsewhere. ${ }^{202}$ In medical malpractice cases, it may be tremendously difficult to establish causation because there is often "scientific uncertainty concerning the causal relationship" 203 between a faulty treatment and an iatrogenic injury. Besides faulty treatments, injuries suffered by patients may result from two non-tortious factors: (1) the normal outcome of the patient's underlying or pre-existing medical condition, or (2) therapeutic risks inherent in treatment beyond physicians' control. ${ }^{204}$ Hence, it is often uncertain whether

$196 \quad$ Faure \& Hartlief 1998, pp. 697-699.

$197 \quad$ Faure 2004a, p. 53.

198 See generally Faure \& Van den Bergh 1995.

$199 \quad$ Faure 2004a, p. 53.

200 Boccara 2009; Van Velthoven \& Van Wijck 2012

$201 \quad$ See supra Chapter 7, Sections 7.2.2.5 and 7.3.3.2.

202 For an extensive examination of the issues of causal uncertain in the context of Chinese medical malpractice law, see generally Yu 2016. For another similar discussion on the attribution of liability from the perspective of comparative law and economics, see generally Faure 2016.

$203 \quad$ Young, Faure \& Fenn 2004, p. 507.

204 Khoury 2006, pp. 51-52. Uncontrollable therapeutic risks, though partly triggered by medical interventions, can be legitimately regarded as direct consequences of pre-existing conditions. Hence, it is not problematic to say that an injury suffered by a patient in the course of treatment can be attributable to two factors - either the tortious factor (the faulty treatment) or the non-tortious factor (the patient's pre-existing conditions). 
or to what extent the faulty treatment or the pre-existing condition has contributed to the victim's injury, which makes it very hard for insurers to predict the likelihood and magnitude of malpractice liability. It is highly likely that, at the end of the day, insurers would not only have to cover the losses of their own insured parties but also the losses that might have been caused by other factors, ${ }^{205}$ i.e. the patient's pre-existing conditions in the context of health care. Hence, in the case of causal uncertain, liability risks would become less insurable, especially under a so-called rule of reversal of the burden of proving causation. ${ }^{206}$ There would be no such problem of being unable to find insurance if proportional liability were adopted to tackle causal uncertainty issues. ${ }^{207}$

\subsubsection{Channelling under EML}

If EML were employed, then the locus of liability would be exclusively placed on hospitals, and joint and several liability would not apply.208 In other words, the sole defendant in medical malpractice cases would become hospitals, although the plaintiff-patient's injury was caused by a physician. This particular arrangement is also called "channelling of liability." Unlike joint and several liability, "under channelling the liability is attached to one party who then becomes fully liable for the damage ... [t] he victim can only sue the 'channelled injurer' and not another party who might have contributed to the loss as well." ${ }^{209}$ This channelling would be inefficient if the channelled injurer could not monitor the behaviour of another party who could affect the accident risk or if there were no right of recourse, because the third party would have no incentive to take care in the absence of liability. ${ }^{210}$

As far as medical liability is concerned, channelling is not necessarily inefficient. If there were an employment contract between hospitals and physicians, "a liability could be passed on the basis of contract" and "such a reallocation complies with the principles of the Coase theorem." physician were an independent contractor who utilizes the facilities and staff members of the hospital, the law could grant the hospital a right of recourse against physicians at fault alongside the imposition of enterprise liability.

Faure \& Grimeaud 2003, p. 163.

Id.

See supra Chapter 7, Sections 7.2.2.5 and 7.3.3.2.

See supra Chapter 8, Section 2.2.2.

Faure \& Grimeaud 2003, p. 165.

Id.

Id. 
Will channelling improve the insurability of malpractice risks? If the channelled injurer and the third party are totally independent of each other, channelling will make the former's liability risks less insurable because it shifts the latter's liability risks to the former. ${ }^{212}$ In other words, channelling "creates a greater risk exposure for the operator and therefore creates higher uncertainty for the insurer." 213

In the context of EML, however, the conclusion may be reversed. On the one hand, hospitals and physicians work within hospital facilities are not completely independent of each other. In many cases, hospitals have the opportunity to monitor treatment procedures, implement clinical guidelines and treatment protocols, provide training, coordinate the work of medical teams, and so on. Hospitals are in a better position to prevent system failures that may account for a significant proportion of human errors. In this respect, channelling does not seem to generate a greater exposure risk for hospitals since these individual malpractice risks are not completely separate from hospitals' under-investment in patient safety. The group of third parties associated with each hospital is relatively certain and the aggregate malpractice risks of all physicians within a hospital are much more predictable than individual malpractice risks.

On the other hand, hospitals are "better able than physicians to manage the volatility of insurance premiums and better able to obtain insurance or to make alternative risk transfer arrangements under even the most difficult market conditions." ${ }^{14}$ Baker even argued that if EML were to be rejected, "enterprise insurance" could be employed which would "provide much of the deterrence benefit of an enterprise liability regime." 215 Therefore, it seems that the insurability of malpractice risks may be enhanced rather than decreased by the adoption of channelling under EML.

\subsubsection{Retroactive Liability}

Retroactive (or retrospective) liability refers to the situation where new liability rules apply to accidents which occurred earlier and were not considered as torts in the light of then liability rules. ${ }^{216}$ In medical malpractice cases, it is often seen that an iatrogenic injury will not be discovered until after several years. One important implication of this "potential long time between the wrongful event and the damage is that this

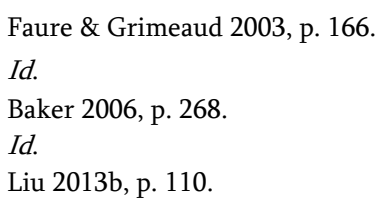


may result in retrospective liability." ${ }^{217}$ Retroactive liability is inefficient because imposing liability according to new rules ex post will not provide potential injurers with incentives to take precautions ex ante. ${ }^{218}$

One important element of insurability is that the risk should be predictable. Retroactive liability will make long-tail risks less insurable, because

if the insurer were not aware that the behaviour of this insured party might potentially have been considered wrongful, no premium would have been charged for this risk, no preventive measures would have been required in the policy conditions and no reserves against losses would have been set aside. ${ }^{219}$

Although when facing "insurer ambiguity" insurers may charge an additional risk premium to cover the risk of changing liability rules, this risk is so unpredictable that insurers in practice normally do not take it into account $e x$ ante when designing policies. ${ }^{220}$ Hence, retroactive liability is socially undesirable in the light of either deterrence or insurability.

\subsubsection{Financial Limits on Liability}

Lawyers argue that there is a necessity of imposing financial caps on the amount of compensation if the injurer is relatively poor or the amount of compensation is tremendously large. ${ }^{221}$ In such a case, it would be unjust to hold the injurer fully liable for harm done. ${ }^{222}$ However, from the perspective of primary cost avoidance, setting damages lower than full harm will lead to under-compensation and eventually under-deterrence. ${ }^{223}$ Hence, caps on liability will undesirably dilute potential injurers' incentives to take precautions. ${ }^{224}$ Another problem of caps is that they constitute "an indirect subsidy of that particular industry," for this industry enjoy the "benefit of limitation of liability."225 This is an indirect subsidy because "if caps are set lower than the actual damage, the latter will have to be covered by public

\footnotetext{
$217 \quad$ Faure \& Grimeaud 2003, p. 167.

$218 \quad$ Id.

$219 \quad$ Faure \& Grimeaud 2003, p. 169.

$220 \quad$ Faure \& Grimeaud 2003, p. 170.

221 Faure \& Grimeaud 2003, pp. 195-196.

222 Id.

223 Faure \& Grimeaud 2003, pp. 197-198.

224 Id.

225 Faure \& Grimeaud 2003, pp. 198-199.
} 
funds." ${ }^{226}$ Be that as it may, caps can be justified if "injurers are risk averse and no liability insurance is available." 227

One may wonder whether caps on liability will help guarantee the insurability of liability risks. Economists have demonstrated that "it is usually not the amount of the expected damages that causes uninsurability of risks, but more often the unpredictability of certain risks." ${ }^{228}$ Facing unpredictable risks, injurers would be "ambiguous and averse towards these risks," and may respond by "requiring an additional risk premium." 229 The amount of liability is also not a problem because competitive insurance markets have developed various instruments such as re-insurance, co-insurance, or pooling of risks to deal with large risks. ${ }^{230}$ Hence, the considerable amount of losses itself "does not make certain industrial accidents uninsurable per se."231 In this regard, caps on liability do not seem to enhance the insurability of risks too much while they usually bring about under-deterrence.

Even if available insurance coverage in the market is limited, it is not necessarily true that caps on liability are warranted. It can be the case that partial coverage which is available is purchased and the uninsured part of liability will induce potential injurers to take at least some care. ${ }^{232}$ Thus, an alternative - limiting the duty to insure - is more desirable: "to introduce a duty to insure up to the available amount of insurance coverage, but to keep the liability of the injurer unlimited." ${ }^{233}$ Also, unlimited liability is essential for making potential injurers partially liable for the risk, which is considered as a device to control moral hazard. If caps are imposed on liability, it would be difficult for insurers to control moral hazard. ${ }^{234}$

\subsubsection{Compulsory Insurance}

\subsubsection{The Case for Compulsory Liability Insurance}

The previous discussion has shown that there are many problems with the free MLI market on account of uncertainty over the pricing of insurance and imperfect information concerning potentially liable parties' malpractice risks.

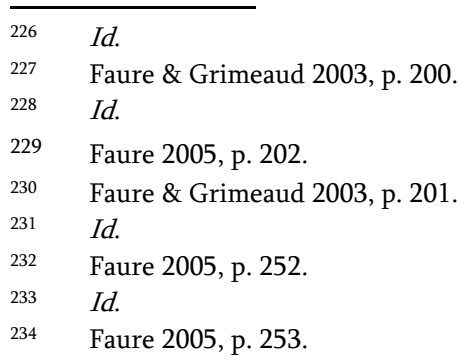


As Calabresi warned long ago, "free individual decisions about insurance are not likely to bring about the amount and type of loss spreading we collectively want" and "private insurance gives inadequate risk spreading." ${ }^{235}$ Hence, compulsory liability insurance is often argued in the literature as a potential remedy to the problems of the free insurance market. ${ }^{236}$ The most essential three arguments for compulsory insurance are summarised as follows:

The possibility of under-estimating the risk. Individuals often do not have perfect data on how risky their activities are and how much harm they may suffer or be held liable when accidents happen. ${ }^{237}$ Hence, potentially liable parties may not be able to evaluate liability risks they are exposed to and the benefits of purchasing liability insurance. ${ }^{238}$ There is a great danger that potential injurers may under-estimate the risk of liability payment and thus wrongfully decide that it is not necessary to purchase liability insurance. ${ }^{239}$ The introduction of a general duty to insure would paternalistically protect the best interest of the insureds who under-rate liability risks.

- Judgement-proof injurers. Lawyers often maintain that compulsory insurance is an effective guarantee of compensation to victims, because victims will have little hope of obtaining compensation if injurers are insolvent and uninsured. ${ }^{240}$ Also, from the perspective of secondary cost avoidance, there will be greater loss spreading if the law mandates that every potential injurer should buy liability insurance. ${ }^{241}$ In addition, without insurance, the judgement proof problem will lead to undercompensation and thus under-deterrence. ${ }^{242}$ If liability insurance is available, potential injurers who have limited assets will only purchase liability insurance up to the size of their assets. ${ }^{243}$ Hence, there will be under-insurance which in turn will not completely eliminate the risk of under-deterrence. ${ }^{244}$ In other words, in cases where insolvency risks are highly possible, compulsory insurance might be socially desirable.

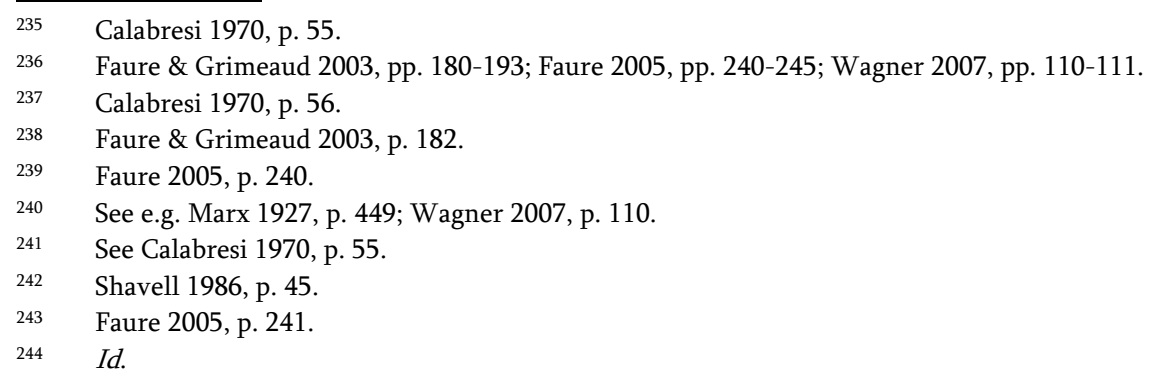


Part II. Economic Theories and Empirical Evidence

- Adverse selection. Under the compulsory liability scheme, every potential party is required by law to purchase liability insurance. Hence, low-risk injurers have no choice but to participate in the same pool with high-risk injurers. In this way, "compulsory insurance eliminates the dynamic workings of adverse selection and thus prevents the failure of the private insurance market." 245 It is indeed questionable "why the good risks should stay to give a subsidy to the bad risks." ${ }^{246}$ This may be explained by the goal of secondary cost reduction - social welfare will be enhanced if "the man who has above average accident costs spreads a portion of them to the man who has fewer than the average" in a sufficiently large insurance pool. ${ }^{247}$

\subsubsection{Some Warnings}

Be that as it may, there are a few warnings against the use of compulsory insurance. First, there may be the problem of moral hazard. ${ }^{248}$ Under compulsory insurance, deductibles are usually not allowed. ${ }^{249}$ If the monitoring of the insured's behaviour is administratively costly, the problem of moral hazard will not be controlled..$^{250}$ Second, the problem of moral hazard may be worse if there is concentration on insurance markets. ${ }^{251}$ Indeed, monopolistic insurers would be less incentivized to set premiums in the light of the individual insured's behaviour, and hence "there is less control of the moral hazard problem." 252 Third, compulsory insurance would make the insured more dependent on the insurance industry. ${ }^{253}$ There may be an undesirable situation where "the legislator would introduce a duty to take out compulsory insurance, but that the market would refuse to provide such coverage." 254 It is highly problematic to make "the availability of insurance coverage a pre-requisite" for market entry, because insurers would de facto become the licensor of the profession, especially in a monopolistic market. ${ }^{255}$

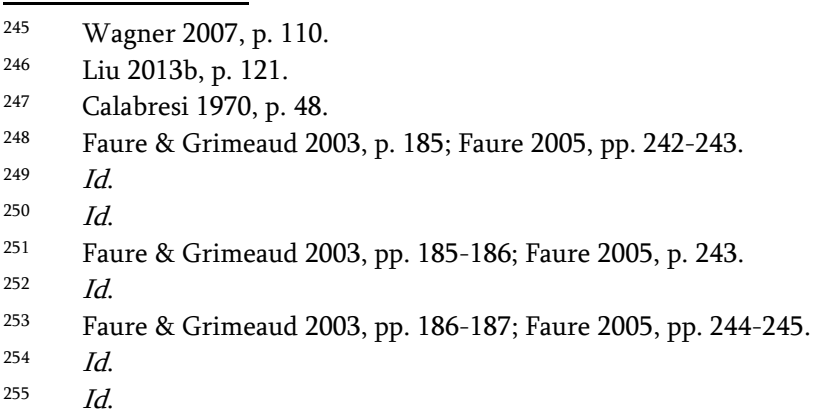




\subsection{EMPIRICAL EVIDENCE}

\subsubsection{Rating and Partial Coverage}

\subsubsection{Risk Differentiation in Practice (Experience Rating)}

Although experience rating is a first-best solution to the problem of moral hazard in the malpractice insurance market, ${ }^{256}$ malpractice premiums in practice are generally not experience-rated. In Canada, the CMPA membership fees are determined on the basis of the type of work and the region. ${ }^{257}$ In the US, although some insurance firms have implemented experience rating schemes, the majority of them have either completely abandoned experience rating or only maintained a plan of limited scope. ${ }^{258}$ In most cases, malpractice insurance rates are "a multiplicative function of limits of coverage (for example, \$1 million per occurrence, \$3 million total for the policy year); medical speciality; and geographic location." ${ }^{259}$ In contrast, hospital insurance premiums in the US are often experience rated to some extent (up to 20-25\% above or below the average premium). ${ }^{260}$ Also in Piedmont of Italy, each hospital has to pay premiums to a regional malpractice liability fund for all public hospitals depending on its claims history. ${ }^{261}$

Some argued that there should be more experience rating because the distribution of malpractice claims is not random. Several studies found that a small proportion of insured physicians account for a large number of claims. ${ }^{262}$ This result contradicts the hypothesis that "malpractice claims are randomly distributed among the physicians within each specialty class."263 Therefore, the heterogeneity of physicians within the same specialty provides the case for experience rating. To insurers, this heterogeneity may lead to several problems. First, placing highly heterogeneous insureds in the same pool will make it harder to predict the average liability risk. ${ }^{264}$ Second, it will be unfair on physicians with relatively low risks to make them subsidise those

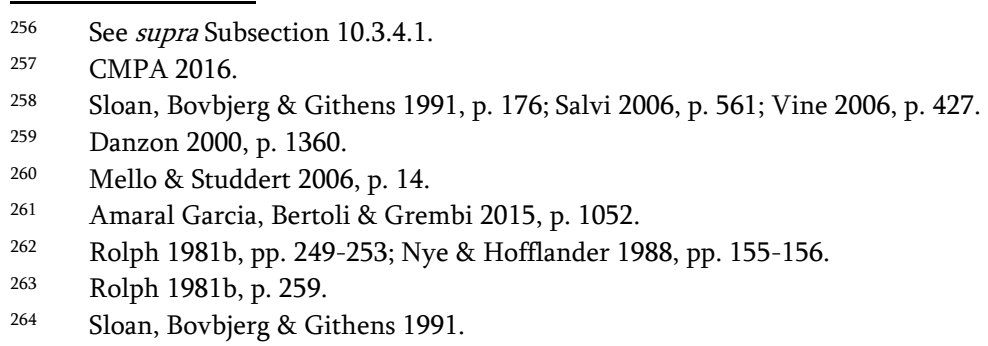


relatively high-risk physicians. ${ }^{265}$ Third, without experience rating, there may be the problem of adverse selection. ${ }^{266}$ In the extreme, adverse selection may give risk to the "unravelling" of the insurance market. ${ }^{267}$ Last but not the least, there may be the problem of moral hazard that dilutes loss prevention incentives. ${ }^{268}$

\subsubsection{Why Is Detailed Risk Differentiation Not Widely Accepted?}

If experience rating is theoretically desirable, why do insurance firms normally hesitate to systematically implement it in the field of individual physician liability? This puzzling fact can be explained by several reasons as follows.

First, although the frequency of malpractice claims has risen sharply in the past, it is still "far too small for what would be considered necessary for actuarially sound experience rating."269 Ellis, Gallup and McGuire found that five years of experience would move prices only modestly towards the actuarially fair premium on average. ${ }^{270}$

Second, the distribution of malpractice claims may not be a good predictive index of a physician's care level. The distribution may be affected not only by the care level of individual physicians but also by "treatment procedures, the severity of the injuries when they occur, the likelihood that lawyers can be found to bring suit, and the readiness of jurors to uphold claims against doctors and to assess generous damages." ${ }^{271}$ For instance, the frequency of claims per physician for surgeons may far exceed that for nonsurgeons. However, this difference in the rate of claims does not seem to suggest that surgeons are systematically less careful than non-surgical physicians. Rather, it may be explained by the fact that "surgical errors are more likely to be severe, and causal connections to treatment are more obvious." 272

Third, past claims history is not a reliable predictor of accidentproneness in the future. In Florida, for instance, it was found that "more than half the individual doctors in the early highest-risk category had no claims at all in the second period, during which time they would be paying a hefty

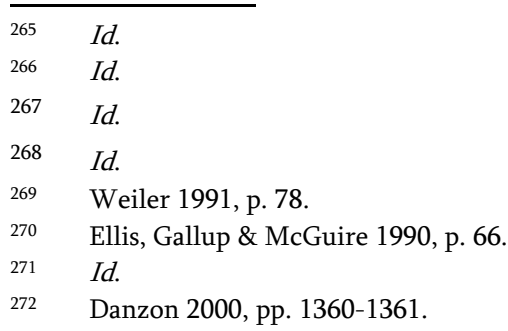


surcharge under a hypothetical experience-rating program."273 Rolph also found that 5 years' prior claims experience is only a modest predictor of future claims experience. ${ }^{274}$

Fourth, non-malpractice costs associated with defending malpractice claims may already provide sufficient incentives to take care. Physicians will lose several working days and thus suffer financial costs if they have to respond to malpractice claims. In addition, they may suffer reputational harm and psychological stress when defending in the court. For this reason, "an experience-rated program that eventually adds a finite surcharge to malpractice premiums is not likely to alter fundamentally the incentives already felt by doctors under the present flat-rate system."275

In order to better rate malpractice risks, some proposed that independent reviews should be conducted instead of relying on court decisions on malpractice claims. ${ }^{276}$ This peer review scheme is advantageous in that it provides "a better informed appraisal of a particular incidence of malpractice as well as the broader practice pattern of the physician."277 However, independent reviews may be very difficult to conduct, since health care providers themselves may not be willing to accept the idea of risk differentiation, because it "may be desirable for the medical profession to keep the 'bad apples' hidden."278 "A detailed individualization of premiums which would show which professionals are the good and which are the bad risks, would be contrary to the independence and dignity of professionals."279 In addition, commercial insurers may not feel that they are competent to monitor members of "a respectable profession." 280 Self-regulated professions may utilize their monopolistic positions to protect their own interests rather than public interest. ${ }^{281}$ In other words, hospitals may hesitate to disclose information on "bad apples" to insurers with a view to avoiding the information from being publicised. Without real data from hospitals, insurers would find it tremendously difficult to implement any meaningful risk differentiation.

Others argued that there may be greater demand for "community-rate" policies which can be employed to insure against "the risk of error by

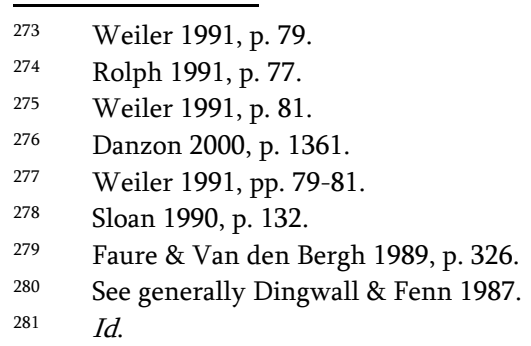


claimants, the courts and the settlement process." ${ }^{282}$ Some evidence shows that community-rate policies may not adversely affect the deterrent effective of liability rules. For instance, recently Amaral Garcia, Bertoli and Grembi assessed the impact of an increase in malpractice pressure (premiums of hospital liability insurance) on obstetrics and found that "an increase in malpractice pressure decreases the average incidence of $\mathrm{C}$-sections by $7 \%$ to 11.6\%." 283

\subsubsection{Partial Coverage}

Although economic theories predict that partial coverage through deductibles or co-insurance is a second-best solution to the problem of moral hazard, it is a mystery that in practice malpractice liability insurers seldom employ partial coverage to control moral hazard. ${ }^{284}$ Danzon provided four reasons to explain this puzzle. First, physicians have to suffer uninsurable costs of time, anxiety and damage to reputation associated with being sued. ${ }^{285}$ Second, the possibility that the court grants damages awards which exceed the policy limit, generates additional uninsured risk. ${ }^{286}$ Third, since liability insurance covers both costs of defence and indemnity payments, the implementation of a deductible would dilute the insurer's incentives to "defend claims that could be settled within the limits of a deductible." 287 Fourth, classifying physicians into groups can be used as a crude form of experience rating, as long as "lower priced insurers with stringent underwriting standards reject physicians with bad prior claims experience." 288

\subsubsection{A Typical Case: The American Malpractice Crisis}

The United States offers a classic example of how a free health care market has been hit by several rounds of medical malpractice crises and what the many US States have done to tackle the crisis. The first crisis erupted in the middle of the 1970s, involving both a dramatic surge in malpractice premiums (up to 500 percent) in some states and the withdrawal of some commercial insurers from the market entirely. ${ }^{289}$ Compared with erratic

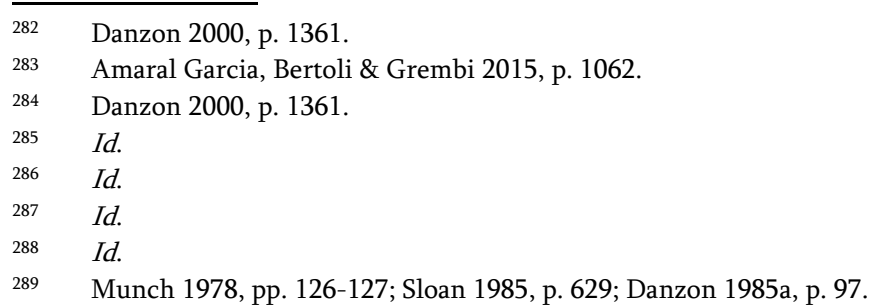


premium rises, the "contraction of availability" was more serious. ${ }^{290}$ Hence, the 1970s were described as "a crisis of availability." ${ }^{291}$ Danzon argued that the primary cause of the sudden increase in premiums from 1974 to 1975 was the increasing claim costs over the previous five years and the inability to raise premiums accordingly. ${ }^{292} \mathrm{He} / \mathrm{she}$ also maintained that the direct cause of the availability crisis was state interventions that held rates below the adequate level and denied the move towards claims-made policies. ${ }^{293}$

In order to ease the crisis, many states implemented legislative reforms: traditional tort reforms and the reform of insurance provisions. ${ }^{294}$ Tort reforms will be addressed in the next subsection. Let us first look at what reforms were put in place in the insurance market: ${ }^{295}$

- Allowing physician-owned carriers. In many states, physicians were allowed to establish their own carriers such as mutuals or reciprocals and hospitals chose to self-insure and to establish captives or special pooled trusts, by which state insurance regulation could be circumvented. Although mutuals are inferior to commercial carriers in terms of loss spreading, they have comparative advantages in two areas: reducing claim costs and decreasing uncertainty over pricing. The key difference between mutuals and commercial carriers is that the incentives to monitor and control physician behaviour are greater when the policyholders are shareholders of mutuals as well.

- Allowing claims-made policies. Whereas occurrence policies cover all claims resulting from accidents that happened in the policy year, claimsmade policies only cover claims filed during the policy year. Since longtail claims are commonly seen in medical malpractice cases, claimsmade policies will greatly reduce the uncertainty over pricing and effectively shift the risk of uncertain future claims from the insurer to the insured. In addition, claims-made policies facilitate individual rating and may help tackle the problem of moral hazard.

- Creating joint under-writing associations. Non-profit joint underwriting associations (JUAs) are a pooling arrangement that consist of commercial carriers in the state, which had been established in several states and are run on a self-sustaining basis. JUAs may be an effective

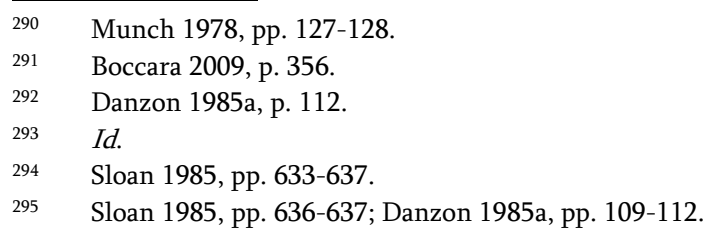


solution for availability crisis, but they may not be a desirable solution for the cost problem.

In the second half of the 1970s, both claim costs and insurance premiums began to decrease. ${ }^{296}$ However, malpractice premiums increased dramatically again in the mid 1980s. ${ }^{297}$ This second crisis was often called the crisis of affordability. ${ }^{298}$ Dewees, Duff, and Trebilcock found that the average real cost of basic malpractice coverage for American physicians tripled, from $\$ 6,350$ in 1974 to around $\$ 17,000$ in $1988 .{ }^{299}$ Viscusi et al. reported that "malpractice premiums escalated by 56\% from 1984 to 1985 and an additional $26 \%$ from 1985 to 1986 ." 300 They also maintained that "this two-year period accounted for $62 \%$ of the total growth in medical malpractice premiums from 1981 to 1990." 301 The second crisis led more states to adopt tort reforms aiming at limiting malpractice insurers' costs. ${ }^{302}$

After an "unusually long period of flat or modest increases in premium rates and widespread availability of insurance," ${ }^{303}$ the third crisis occurred in the early 2000s. ${ }^{304}$ As Danzon found, the average premium increase from 0$2 \%$ in $1996-97$ to $17-18 \%$ in 2003 , even reaching $60 \%$ in some states in $2001-$ $02{ }^{305}$ Some of the largest malpractice insurers such as St. Paul Travellers, PHICO and Frontier Insurance Group decided to withdraw from the market. ${ }^{306}$ Thorpe also illustrated that the median surge in malpractice premiums ranged between 15 and 30 percent. ${ }^{307}$ Rate increases in e.g. Pennsylvania ranged from 26 to 73 percent in 2003. ${ }^{308}$

To conclude, it is often claimed that the three malpractice crises that occurred in the US can be explained as follows: "the increasing number of claims entail increasing damage awards which entail increased malpractice

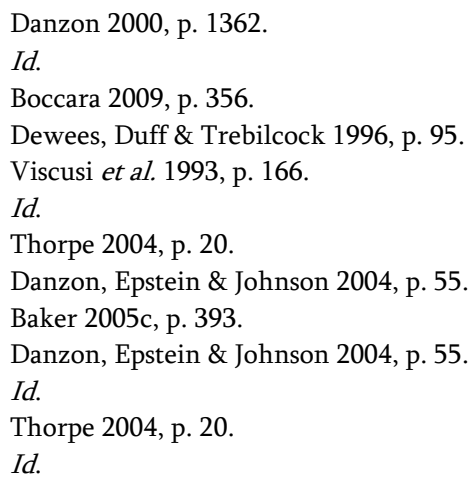


premiums." ${ }^{309}$ Hence, it is essential to examine whether traditional tort reforms are fit for overcoming the malpractice crisis.

\subsubsection{Traditional Tort Reforms}

\subsubsection{Content of the Reforms}

In order to deal with the malpractice crisis, most US states have implemented tort reforms. ${ }^{310}$ The fundamental goal of these traditional tort reforms is to "reduce the overall costs of malpractice litigation." ${ }^{111}$ The most common reforms adopted by states are listed as follows: ${ }^{312}$

- $\quad$ statutes of limitation: to limit the amount of time a patient has to file a malpractice claim, typically to two or three years;

- attorney contingency-fee reform: to limit the amount of a malpractice award that a plaintiff's attorney may take in a contingent-fee arrangement;

- pre-trial screening panels. to establish pre-trial screening panels to review a malpractice case at an early stage and provide an opinion about whether a claim has sufficient merit to proceed to trial;

- caps on damages. to limit the amount of money that a plaintiff can take as an award in a malpractice suit, which may apply to non-pecuniary damages, total damages or only punitive damages;

- collateral-source rule reform: to eliminate the traditional rule that if an injured plaintiff receives compensation for her injury from other sources such as insurance, that payment should not be deducted from the damage award;

- joint-and-several liability reform: to limit the financial liability of each defendant to the percentage fault of that defendant;

- periodic payment. to allow insurers to pay out malpractice awards over a long period of time instead of a lump sum.

In addition, there are less commonly employed tort reforms by some states, such as to limit the use of the res ipsa loquitur doctrine, to clarify the

309 Boccara 2009, p. 358. Of course, there are other explanations for the US malpractice crisis, which will be dealt with in Section 4.3.4.

310 For the latest information on tort reforms in all US states, see American Tort Reform Association 2015.

$311 \quad$ Mello 2006, p. 6

312 Mello 2006, p. 7. See also Thorpe 2004, pp. 25-26; Van Velthoven \& Van Wijck 2012, pp. 39-40. 
informed consent doctrine, to eliminate the ad damnum clause, to impose a locality rule, and to allow for binding arbitration. ${ }^{313}$

\subsubsection{Impact of the Reforms}

Literature on the effect of tort reforms on the frequency and size of claims and on malpractice premiums is extensive. Mello conducted a detailed review of the available studies ${ }^{314}$ and reached several conclusions: ${ }^{315}$

- $\quad$ Aside from caps on damages, most of these reforms have had limited efficacy.

- The efficacy of caps on damages has been hotly disputed, and much of the evidence used in the policy debate is not based on rigorous analysis.

- Good evidence shows that caps on damages reduce average award size by 20-30 percent, but there is no evidence that they decreased claims frequency.

- $\quad$ The best studies suggest that caps are associated with a small increase in physician supply.

- $\quad$ The most recent controlled studies show that caps moderately constrain the growth of premiums.

Recently, Paik, Black and Hyman conducted an in-depth study on the effect of damage caps adopted in the 1990s and 2000s on malpractice claim rates and payouts. ${ }^{316}$ They pointed out that most prior studies do not allow for the gradual phase-in ${ }^{317}$ of damage caps, which normally applies only to claims or injuries filed after the reform's effective date. ${ }^{318}$ Once allowing for phase-in, they found strong evidence that damage caps reduce both frequency and severity of malpractice claims, and more stringent caps have a larger impact on large claims. ${ }^{319}$ Nevertheless, they also found a receding tide of malpractice

314 Danzon 1984a; Sloan 1985; Danzon 1986; Zuckerman, Bovbjerg \& Sloan 1990; Viscusi et al. 1993; Hellinger \& Encinosa 2003; Klick \& Stratmann 2003; Danzon, Epstein \& Johnson 2004; Thorpe 2004; Encinosa \& Hellinger 2005; Viscusi \& Born 2005; Matsa 2005. Matsa's 2005 working paper has been published as Matsa 2007.

315 Mello 2006, pp. 9-12.

316 See generally Paik, Black \& Hyman 2013a; 2013b.

317 Allowing for the phase-in (meaning "a gradual introduction") of damage caps implies that the researchers had taken into account the lag between the earlier day when the reforms became effective and the later day when a claim was closed. Most prior studies ignored the lag, which would bias the predicted effects of the reforms toward zero. Paik, Black \& Hyman 2013a, p. 640. 
claims in all states and tort reforms cannot explain why malpractice claims are decreasing in no-cap states as well. ${ }^{320}$ This finding suggests that some other factors may account for the malpractice crisis better than claim costs.

Even if it could be demonstrated that caps on damages would help decrease malpractice premiums significantly, financial limits on liability are socially disadvantageous from the perspective of deterrence. ${ }^{321}$ As Danzon pointed out, most of the traditional tort reforms are intended to "reduce measurable claim costs," which may at best simply shift costs from health care providers to patients and taxpayers. ${ }^{322}$ At worst, "total social costs may actually increase if, for example, deterrence incentives are weakened." 323

\subsubsection{Other Causes of the Malpractice Crisis}

Priest argued that the adverse selection process due to an information asymmetry between the insurer and the insured led to the malpractice crisis in the American liability insurance market. ${ }^{324}$ Long tails of liability faced by various medical specialities had so expanded the variance of malpractice liability risks that defeated any meaningful risk differentiation. ${ }^{325}$ Eventually, insurers found it difficult to distinguish between good risks and bad risks. ${ }^{326}$ Facing high premiums, good risks would leave the pool and ultimately there would be a total unravelling of risk pools. ${ }^{327}$ The final crisis of unavailability of malpractice insurance would lead to a negative redistribution - although premiums were increased primarily due to higher income groups, lower income groups were harmed more greatly by the crisis. ${ }^{328}$

However, other economists did not agree. Some studies indicated that litigation behaviour and malpractice claim payments did not alter significantly between 1970 and 1975, between 1981 and 1986, or between 1996 and 2001. ${ }^{329}$ Danzon, Epstein and Johnson also found that "state-specific premium rate increases are not significantly related to prior increases in statespecific losses paid or incurred." 330 Baker found that there had been changes in insurance market conditions, the investment and cost projections which

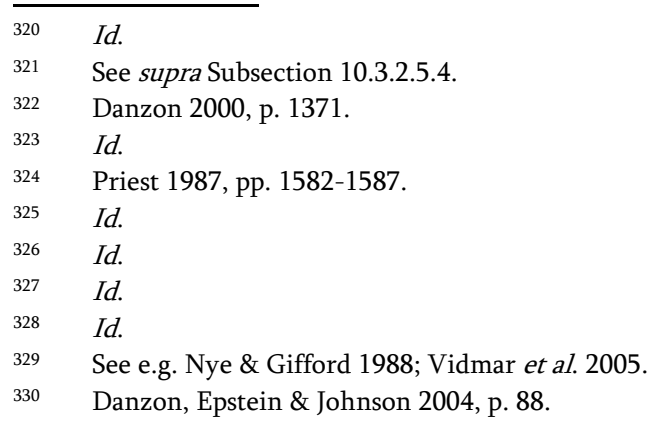


account for part of malpractice premiums. ${ }^{331}$ In other words, insurers who "had offered low prices based on rosy scenarios in 1970, 1981, and 1996 switched to high prices based on pessimistic scenarios in 1975, 1986, and 2001." 332 Hence, Baker argued that the medical malpractice crisis in the US is an insurance crisis rather than a tort crisis. The real problem is not the total cost of malpractice premiums but the "disruptive effect of rapid price increases, and the related unfairness of asking a few, hospital-based speciality groups ... to bear the brunt of those increases."333

The cyclical occurrence of the malpractice crisis can be better explained by the insurance under-writing cycle, denoting "alternating periods in which insurance is priced below cost (a 'soft' market) and periods in which insurance is priced above cost (a 'hard' market)." 334 Two reasons may account for the severity of this cycle: first, there is a long tail - the period between the date when premiums are paid and the date when the insured malpractice claims are filed; and second, malpractice losses are much more difficult to predict than many other types of losses. ${ }^{335}$ Baker pointed out that changes in the investment climate may also contribute to the underwriting cycle, since when interest rates decline, the insurer's investment income falls. ${ }^{336}$ Danzon, Epstein and Johnson also found that "premium increases were positively related to upward revisions of reserves following initial under-reserving and that firms with large prior forecast errors were more likely to exit." 337 A malpractice insurance crisis occurs "when insurers are too optimistic about future losses for too long." 338 Consequently, insurers fail to charge enough premiums. When future losses exceed what insurers expected, insurers will attempt to increase their reserves dramatically. ${ }^{339}$ When premiums are increased, insurers will ultimately reduce the amount of insurance supply. ${ }^{340}$

To conclude, the American malpractice crisis is more an insurance crisis than a medical liability crisis. The medical malpractice insurance underwriting cycle may not be a bad thing at all, since it "may promote patient safety by drawing attention to the problem of medical malpractice in a manner that makes medical liability more salient and induces greater efforts

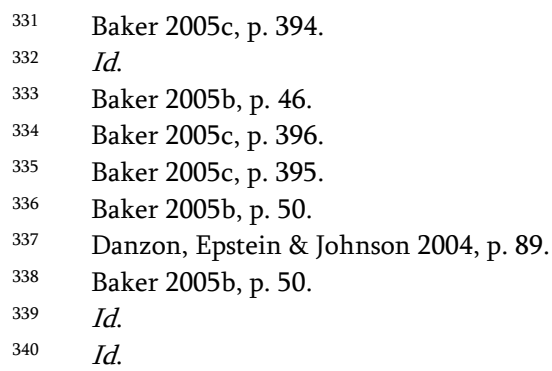


to prevent medical injuries." ${ }^{341}$ Recently, Rodwin, Silverman and Merfeld asked why the medical malpractice crisis persists even when malpractice insurance premiums fall. ${ }^{342}$ According to them, two reasons may account for this phenomenon: first, physicians mistakenly perceive a crisis; and second, key actors such as the AMA, politicians, and many journalists have an interest in maintaining the perception of a crisis. ${ }^{343}$

\subsection{SUMMARY}

Section 4 examined the question whether compensation via liability insurance is a socially optimal compensation device in the context of medical malpractice. In many legal systems, MLI is employed to cover the risk of malpractice liability. Hence, MLI works together with the fault-based malpractice liability system, which covers only the risk of negligent iatrogenic injuries. This implies that the risk of non-negligent iatrogenic injuries and non-iatrogenic injuries should be borne by patients or be covered by other first-party insurance schemes.

MLI can be used to reduce secondary accident costs in that it helps promote both inter-personal and inter-temporal loss spreading. There is a real demand for MLI because many, if not most, practitioners are risk averse and there is great uncertainty over the standard of care under negligence. Hospitals may also be in need of MLI on account of operational reasons. Although proponents of the traditional insurance theory do not believe that it is efficient for MLI to cover the risk of liability for non-pecuniary losses, opponents argue that cover for non-pecuniary losses is justified in light of optimal deterrence and the ex ante WPT.

The supply of MLI is possible in that insurers rely on the technique of pooling and the Law of Large Numbers. Sometimes when pooling is not possible, insurers may nonetheless provide coverage with the help of reinsurance or co-insurance. For a risk to be insurable, it must be accidental, determinable and measurable, independent, and non-catastrophic. Various instruments, such as risk differentiation, claims-made policies, re-insurance, and co-insurance, have been developed to guarantee the insurability of malpractice liability risks.

Informational problems - moral hazard and adverse selection - may have adverse implications for the MLI market. Moral hazard may dilute the insured's incentives to take precautions. The first best solution for MLI may

\begin{tabular}{ll}
\hline 341 & Baker 2005c, p. 436. \\
342 & See generally Rodwin, Silverman \& Merfeld 2015. \\
343 & Rodwin, Silverman \& Merfeld 2015, pp. 222-226.
\end{tabular} 
be ex post experience rating. The second best solution may be deductibles or co-insurance. Adverse selection may lead to the breakdown of the MLI market. The common solution to moral hazard and adverse selection is risk differentiation, especially through experience rating.

Regarding some liability sub-rules, the proportional approach in the case of causal uncertainty and channelling of liability under EML may enhance the insurability of MLI without adversely affecting the deterrent function of malpractice liability. In contrast, retroactive liability is inefficient regarding either deterrence or insurability. Caps on liability would not enhance insurability too much but they would lead to under-deterrence.

Compulsory MLI may be warranted in three cases where potential liable parties underestimate the risk of malpractice liability, where potential liable parties are judgement-proof, and where the risk of adverse selection is considerable.

Empirical evidence from North America shows that neither experience rating nor partial coverage is adopted by MLI insurers. Three rounds of malpractice crisis occurred in the US in the mid-1970s, the mid-1980s, and early 2000s. Both the insurance market and the malpractice system have been reformed in order to resolve the malpractice crisis. However, recent evidence shows that the costs of malpractice claims are not the main cause of crisis. The malpractice crisis is more an insurance crisis due to the underwriting cycle than a malpractice liability crisis.

\section{SELF-INSURANCE: A PERFECT ALTERNATIVE TO MARKET MLI?}

\subsection{INTER-TEMPORAL LOSS SPREADING AND SELF- INSURANCE}

An important way of achieving inter-temporal spreading is self-insurance, ${ }^{344}$ which is widely used by many firms in risk management programs. ${ }^{345}$ Broadly speaking, self-insurance denotes retention, meaning that "the firm retains part or all of the losses that can result from a given loss." ${ }^{346}$ A narrowly defined self-insurance (or self-funding) is "a special form of planned retention

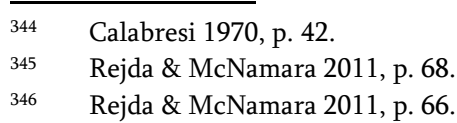


by which part or all of a given loss exposure is retained by the firm." ${ }^{347}$ Typically methods used for paying losses include (1) current net income, (2) an unfunded reserve (a bookkeeping account) and (3) a funded reserve (the setting aside of liquid funds). ${ }^{348}$ Although constituting "a nice word," selfinsurance lacks the essential feature of traditional market insurance (interpersonal) "loss spreading after an accident happens." ${ }^{349}$ Hence, "selfinsurance is not an insurance scheme, but a system whereby potentially responsible parties make reserves for future losses. ${ }^{350}$

The ability to self-insure constitutes a strong argument for EML. The justification for the first type of EML is that losses should be placed on those who are abler to (self-)insure risks. Hence, the locus of medical liability ought to be placed solely on health care organisations (usu. hospitals), because they are in a better financial position than individual providers. When EML is less available, many hospitals, e.g. in the Netherlands, have moved to selfinsurance. $^{351}$ Even in legal systems such as the US where EML is not systematically adopted, medical professionals, if they find MLI difficult to obtain or too expensive to buy in the market, are allowed to form new mutuals, risk retention groups or captive insurers to self-insure their liability loss exposures. ${ }^{352}$ Although self-insurance is not insurance proper, it nonetheless constitutes a way of reducing secondary costs.

\subsection{SELF-INSURANCE VERSUS MARKET MLI}

Market insurance re-distributes income (ultimately consumption opportunities) towards the less well-endowed states ${ }^{353}$ of the world, and selfinsurance redistributes income in a similar way. ${ }^{354}$ In the case of "full insurance," incomes would be equalised both in the state of the world with the accident and in the one without the accident given diminishing marginal utility of income, and hence, the insured would be indifferent as to which state happened. ${ }^{355}$ Facing rare losses, potentially liable parties would be less incentivized to self-insure than to purchase market insurance, because "the

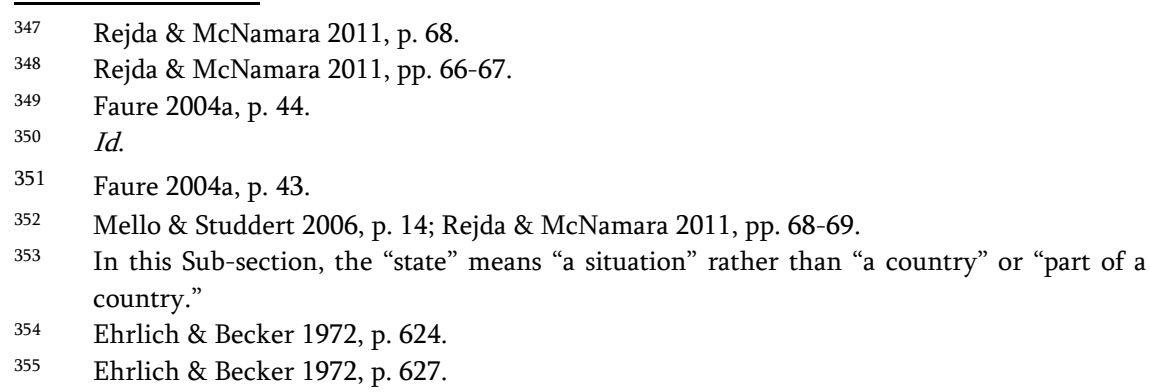


loading factor of self-insurance is larger for rare losses." ${ }^{356}$ More importantly, they demonstrated that market insurance and self-insurance are substitutes to each other - an increase in premiums would decrease the demand for market insurance and enhance the demand for self-insurance. ${ }^{357}$

Self-insurance has a major advantage over market insurance in that it may economise on more tertiary costs. First, the premium of market insurance normally exceeds actuarially fair value of the risk, because the insurer usually charges loading costs to "cover the administrative functioning of its service." ${ }^{358}$ Second, the process of negotiating the insurance coverages may incur considerable costs of time and effort. ${ }^{359}$ All these costs could be avoided if potentially liable parties made their own reserves for future losses. Another reason why self-insurance is desirable to them is that these reserves (also called "captives") are made for future compensation claims so that they will not be taxed as hidden profit. ${ }^{360}$

However, self-insurance is normally inferior to market liability insurance for four reasons. ${ }^{361}$ First, self-insurance does not guarantee against the insolvency risk, unless regulatory measures can guarantee that the reserved money is sufficient for paying future compensation. ${ }^{362}$ Second, selfinsurance does not have the advantage of "economies of scale" by a risk spreading, while under liability insurance the insurer may gather similar but unrelated risks together which increase the expected utility of all the insured who are risk averse. ${ }^{363}$ Third, self-insurance does not have the advantage of efficient insurance policies which may lead to an optimal reduction in medical malpractice risk whereas, under efficient insurance policies, specialised insurers may encourage health care providers to take efficient precautions using policy provisions. ${ }^{364}$ Fourth, self-insurance may lead to problems of re-distribution. For example, public hospitals may pass the costs on to taxpayers instead of those who enjoy benefits from the health service, which may distort the market completion between public and private hospitals. 365

When applying the above analysis to the health care sector, it is important to note that the type of losses is highly relevant. It would be more

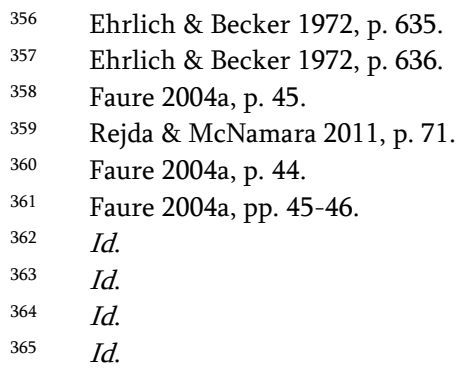


appropriate to employ self-insurance if loss frequency and severity were relatively low while market insurance would be more suited for lowfrequency, high-severity losses. ${ }^{366}$ In the first case where both loss frequency and loss severity are low, it may be cheaper to retain the expected loss than to purchase costly market insurance. ${ }^{367}$ In the second case, although loss severity is high, low less frequency suggests that purchasing insurance is financially feasible. ${ }^{368}$ Moreover, risk spreading is needed to insure against catastrophic loss. ${ }^{369}$ Given the fact that physicians are not sued frequently and that damages awards may be very considerable, ${ }^{370}$ it seems to be more efficient to purchase MLI than to self-insure.

However, whether it is feasible to purchase market MLI also depends on market conditions. For instance, some argued that the medical malpractice crisis in the US is not a malpractice lawsuit crisis but a medical malpractice insurance crisis. ${ }^{371}$ There is an under-writing cycle, meaning the "cyclical pattern in under-writing standards, the amount of premiums charged, and profitability in the industry." 372 In a "hard" market where insurers face declining profits, they will increase premiums. Consequently, it will be very expensive or difficult to obtain market insurance. ${ }^{373}$ In contrast, in a "soft" market where profitability is improving, insurers will reduce premiums, and hence it will be less expensive or easier to purchase market insurance. ${ }^{374}$ In this regard, if the current malpractice insurance market were "hard," health care institutions would have no choice but retain some risks of malpractice claims. Nonetheless, they may still choose to combine the use of both instruments by self-insuring most risks but purchasing "excess insurance for high amounts" given such an insurance market does exist. ${ }^{375}$ Without interpersonal loss-spreading, small losses in the aggregate can be so sizable that they exceed potentially liable parties' assets (insolvency risk). ${ }^{376}$ 


\subsection{SUMMARY}

To sum up, although self-insurance is not insurance proper, it is a legitimate instrument for reducing secondary costs. However, although self-insurance saves on tertiary costs, it is by and large inferior to market insurance, because it does not spread losses and hence cannot prevent against insolvency risks given that losses due to medical malpractice are normally highly severe. Nonetheless, self-insurance can be justified in cases where market insurance is too expensive or hardly available. In such a case, a combined use of selfinsurance (against small losses) and market insurance (against large losses) may be socially optimal. In any case, "self-insurance can only be considered an effective financial security if guarantee can be provided through regulation that the reserves set aside will effectively be used for the potential losses for which they are meant." 377

\section{CONCLUSIONS}

Chapter 10 examined the question of whether tort law per se, MLI and selfregulation can be socially optimal devices for compensating damage due to medical malpractice The first conclusion is that tort law per se is an undesirable instrument for compensation in that insurance can achieve faster compensation without incurring too many tertiary costs. Nevertheless, it would be optimal to place the locus of liability on hospitals rather than physicians had EMI been employed. Hospitals are more able than physicians to self-insure or buy MLI. However, it is inefficient to treat the tort system as an insurance scheme because it may result in under-deterrence.

The second conclusion is that MLI per se is a socially optimal instrument to spread the risk of negligent injuries. MLI is superior to the tort system in that it achieves a wider degree of loss spreading and protects the victim against a judgement-proof defendant and it does not necessarily dilute the deterrent effect of malpractice liability. The malpractice crisis that occurred in the US may be better explained by the insurance underwriting cycle than by the costs of claims.

The third conclusion is that although self-insurance is not insurance proper, it is a legitimate mechanism of inter-temporal risk spreading. Selfinsurance is not a perfect substitute for but a nice complement to MLI. If MLI were available and affordable, self-insurance is inferior to MLI because the

\footnotetext{
$377 \quad$ Faure 2004a, p. 46.
} 
latter can achieve a greater degree of interpersonal loss spreading. However, in a hard market where MLI is unavailable or unaffordable, self-insurance is a second best solution.

It ought to be noted that both MLI and self-insurance work on the basis of the fault-based liability system. Hence, the heavy costs incurred by the tort litigation system should be taken into consideration when comparing MLI or self-insurance to other no-fault compensation mechanisms. 



\section{CHAPTER 11}

\section{MEDICAL COMPENSATION MECHANISMS NOT BASED ON FAULT}

\section{INTRODUCTION}

It has previously been demonstrated that the fault rule can be justified as a relatively efficient mechanism in that the deterrence benefits that it generates are likely to exceed the tertiary costs that it incurs. ${ }^{1}$ As far as compensation is concerned, however, the fault-based malpractice liability alone is inefficient because it cannot guarantee swift and sufficient compensation whenever a patient suffers an iatrogenic injury. ${ }^{2}$ Many eligible victimised patients do not sue and many patients who did file a claim may still face tremendous difficulties in establishing fault and causation and may not obtain compensation until several years later.

There are also deficiencies in compensation mechanisms relying on the tort regime such as self-insurance and liability insurance, not only because of the deficiencies of the traditional malpractice liability but also because they have problems of their own. ${ }^{3}$ While self-insurance does not work well in the case of insolvency risks, liability insurance suffers from problems such as moral hazard, adverse selection, and severe underwriting cycles. Hence, one may wonder whether there is any alternative mechanism that can achieve the three goals of accident law simultaneously: (1) optimal deterrence (primary cost avoidance), (2) optimal compensation (secondary cost avoidance), and (3) being administratively cost-effective (tertiary cost avoidance).

For this reason, many scholars proposed and several legal systems have already developed the so-called "no-fault" compensation system (or scheme) (hereinafter NFCS) as an alternative to the traditional fault-based malpractice

See supra Chapter 8, Section 1.5.3.

See supra Chapter 10, Section 2.

See supra Chapter 10, Sections 3 and 4. 
liability regime. Broadly speaking, NFCSs denote insurance programs that "provide compensation on proof of loss without any need to identify another party that caused the loss or prove their fault." ${ }^{\prime 4}$ Two common features are characteristic of these no-fault schemes: first, victimised patients normally do not have to prove providers' fault to obtain compensation; and second, costly malpractice lawsuits can usually be avoided. In a broad sense, no-fault schemes include first-party patient insurance, a special compensation fund covering iatrogenic injuries or social security that provides benefits for patients and the disabled in general. ${ }^{5}$ In practice, however, an NFCS specifically refers to a compensation fund that provides cover for personal injuries or iatrogenic injuries. ${ }^{6}$

The NFCS should be distinguished from strict liability. Strict liability is usually described as "liability without fault," meaning that the defendant will be held liable for any damage that he/she has caused irrespective of whether he/she was at fault or not. ${ }^{7}$ Hence, no-fault schemes are similar to strict liability insofar as the element of fault is not required for claiming compensation. However, no-fault schemes differ from strict liability in at least two significant ways. First, strict liability is one form of tort liability which should be enforced through the tort litigation system, whereas no-fault schemes are normally detached from the tort system. ${ }^{8}$ Second, victims under strict liability are usually compensated by injurers, while those under no-fault schemes are normally paid by various insurance funds directly. ${ }^{9}$

This chapter will review theoretical and empirical studies regarding no-fault compensation schemes. Specifically, it will examine the basic features of the three typical forms of no-fault schemes - first-party insurance (Section 2), compensation funds (Section 3), and social security (Section 4) respectively, and evaluate how efficient they are in achieving optimal deterrence and compensation without incurring considerable tertiary costs. Section 5 will examine NFCSs in several legal systems and check whether these NFCSs are structured in light of efficiency. The final Section 6 concludes.

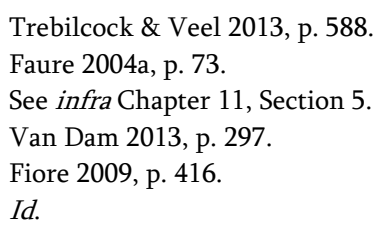




\section{FIRST-PARTY INSURANCE}

\subsection{THE RATIONALE OF FIRST-PARTY INSURANCE}

Since there are deficiencies in self-insurance (i.e. insolvency risks) and liability insurance (i.e. moral hazard, adverse selection, and severe underwriting cycles), alternatives such as first party patient insurance may be well worth considering. Under (third-party) liability insurance, the insurer provides coverage in respective of the insured health care provider's tort liability for negligent iatrogenic injuries done to third parties (patients). ${ }^{10}$ Under (first-party) patient insurance, however, the insurer directly compensates iatrogenic injuries suffered by the insured (patients) provided that it is the insured risk that causes the injuries. ${ }^{11}$ Hence, a shift from malpractice insurance towards patient insurance entails a potential expansion of coverage. While under malpractice insurance only liability for negligent iatrogenic injuries is insured, under patient insurance both negligent and non-negligent iatrogenic injuries are directly covered. Another difference is that first-party insurance is purchased directly by victims (patients), whereas third-insurance is bought by potential injurers (health care providers) for the purpose of compensating patients for their injuries. Since both third-party insurance and first-party insurance are market insurance, much of the core rationale of liability insurance described in Chapter 10 applies to first-party insurance.

First-party patient insurance differs from the malpractice liability in several ways. First, under the former it is free for patients to choose the amount of coverage they desire, whereas under the latter the amount of coverage is normally determined by the court in light of malpractice liability rules. ${ }^{12}$ Second, the former normally requires the insured to bear part of the loss through an upper limit (or ceiling) or a deductible, while the latter is intended to provide full compensation. ${ }^{13}$ Third, the former does not require negligence on the part of the insured, whereas the latter does. ${ }^{14}$ Fourth, nonpecuniary losses are rarely covered by the former but usually covered by the latter. ${ }^{15}$

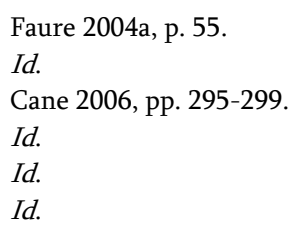


First-party insurance has a comparative advantage over third-party insurance in terms of saving tertiary costs. First-party insurance enables a better risk differentiation than the latter because "the victim can signal all his characteristics on whether he/she is a high or a low-risk individual directly to the insurer." 16 In contrast, it is tough for insurers to predict $e x$ ante the risk that their insureds will harm a third party, which is highly uncertain when considering the long tail problem. ${ }^{17}$ In other words, it is easier and more accurate to calculate the actuarially fair premium by the risk of iatrogenic injuries than by negligent iatrogenic injuries. Also, third-party insurance is expensive because it relies on the tort system to determine eligibility for coverage, which incurs considerable legal and administrative costs. ${ }^{18}$ Therefore, in an ideal world, patient insurance alone should be more efficient than the fault-liability-insurance system (FLIS) regarding tertiary cost reduction.

From the perspective of victimised patients, they may not necessarily be able to receive compensation more easily under patient insurance than under malpractice insurance. It is true that patients do not have to establish health care providers' fault in order to claim insurance benefits. However, they still have to show that their losses resulted from the provision of health services, i.e. they suffered iatrogenic injuries rather than non-iatrogenic injuries due to their pre-existing conditions. This requirement of causation is essential because the "compensation system should not be constructed in such a way that the patient is compensated as soon as he/she is dissatisfied with the result of the medical treatment." ${ }^{19}$ Without this requirement, the borderline between patient insurance and health insurance would be blurred.

\subsection{THE RELATIONSHIP WITH THE FAULT-LIABILITY- INSURANCE SYSTEM (FLIS)}

Bearing in mind the differences between first-party insurance and the FLIS above, we now discuss the relationship between them in three scenarios: ${ }^{20}$

- $\quad$ Scenario 1: Suppose the FLIS were totally replaced with the first-party insurance scheme. To the patient, he/she will receive compensation with more certainty, because he/she will not be supposed to prove

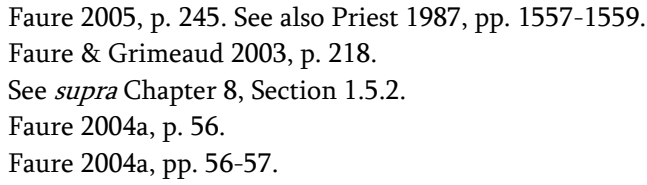


negligence on the part of the health care provider although he/she will still have to prove the causal link. Secondary accident costs will be reduced more quickly and more extensively under patient insurance than under MLI. Although the amount of compensation he/she could receive is normally lower than full compensation under tort law, this result is still optimal since the amount under patient insurance represents the victim's willingness to insure against her own losses. However, from the perspective of primary accident cost avoidance, eliminating the FLIS is inefficient, because the health care provider's incentives to take precautions may be diluted. On balance, it is socially undesirable to substitute first-party insurance for the FLIS, unless the provider's preventive incentives can be largely maintained by alternative mechanisms such as regulation.

- Scenario 2: Suppose both the FLIS and patient insurance are retained and parallel to each other, but there is no subrogation. To the patient, he/she will receive compensation both from the health care provider (or the liability insurer) and from her own insurer, which will lead to a cumulation of insurance. This result is inefficient not because it does not reduce secondary costs but because it reduces secondary costs too much (double compensation) and incurs more tertiary costs. However, in light of deterrence, to retain both systems is efficient since the provider's preventive incentives are kept. On balance, the joint use of the two systems may be more efficient than using the FLIS alone. The increase in tertiary costs may be well exceeded by the benefits of reduction in primary and secondary costs. Hence, patient insurance can be used as a complement to rather than a substitute for MLI.

- Scenario 3: Suppose both the FLIS and patient insurance are retained and parallel to each other, and there is subrogation. Under the principle of subrogation, the first-party insurer that has paid benefits to a victimised patient under a patient insurance policy is entitled to all the rights and remedies belonging to the insured patient against the health care provider that treated the patient. To the patient, he/she will not be allowed to file a claim against the provider for any injury that has been compensated for by the first-party insurer. Hence, the problem of double compensation will not arise. To the provider, he/she (or her liability insurer) will have to pay full damages either to the patient or the patient's first-party insurer (through subrogation). From the perspective of primary cost avoidance, the result is efficient because the provider's incentives to take precautions will not be diluted. As far as secondary cost avoidance is concerned, the result is socially desirable in that patients are able to obtain adequate compensation quickly. When it comes to tertiary cost avoidance, however, the result is undesirable 
since more administrative costs are incurred due to the cumulation of insurance.

It seems that none of the above three scenarios are socially optimal when Calabresi's three costs are considered at the same time. Notwithstanding, it is not difficult to find that the third scenario is the most efficient one among all the three scenarios.

\subsection{EMPIRICAL EVIDENCE CONCERNING THE (VOLUNTARY) FIRST-PARTY INSURANCE MARKET}

According to the classic model of malpractice liability, not all risks of iatrogenic injuries are borne by health care providers. From the perspective of society, it is sometimes too costly to eliminate a certain risk. Under the negligence rule, patients have to endure the costs of non-negligent iatrogenic injuries in order to enjoy the benefits of medical care. ${ }^{21}$ Empirical evidence also shows that many patients with meritorious claims either do not sue or are denied compensation. ${ }^{22}$ Therefore, many costs of negligent iatrogenic injuries are actually borne by patients due to the imperfect operation of the malpractice system in practice. Theoretically, risk-averse patients would enhance their utility if they insured against the risk of suffering an iatrogenic injury without any compensation from health care providers. ${ }^{23}$

In practice, such an insurance market, where patients fully insure against (non-negligent) iatrogenic injuries, is not universally developed in the US or other legal systems. Exceptionally, first-party patient insurance, which covers iatrogenic injuries in general, has been developing in some countries such as New Zealand and Sweden for decades. ${ }^{24}$ However, this no-fault approach has not been widely accepted in most legal systems. ${ }^{25}$ Dewees, Duff, and Trebilcock provided several reasons to explain why the objective of universal coverage is impeded. On the one hand, due to limited purchase power, imperfect information, and a persistent tendency to understate the risk of accidents with low probabilities, patients' demand for both Medical Adversity Insurance and Accidental Death and Disability Insurance may not be strong enough. ${ }^{26}$ On the other hand, due to imperfect information, the

Dewees, Duff \& Trebilcock 1996, pp. 112-113.

See supra Chapter 8, Sections 1.2, 1.3 and 1.4.

Shavell 1978, p. 36; 1987a, p. 212.

OECD 2006, pp. 348-349.

Koch \& Koziol 2004, p. 417. See also infra Chapter 11, Sections 3 and 4.

Dewees, Duff \& Trebilcock 1996, pp. 112-113. 
supply side of the market is only willing to provide incomplete insurance. ${ }^{27}$ For this reason, these kinds of insurance may not be universally available. Some evidence also indicates that people are more willing to purchase liability insurance than personal accident insurance. ${ }^{28}$

\subsection{SOLUTION: A COMPULSORY FIRST-PARTY INSURANCE SCHEME?}

As demonstrated previously, it may be socially desirable to use first-party patient insurance as a complement to the FLIS (the foregoing Scenario 3). However, it is also shown in the preceding subsection that the market for private patient insurance has not been universally developed yet. One may wonder whether compulsory first-party insurance is more desirable than voluntary first-party insurance. Compulsory patient insurance may be justified on two grounds. First, due to imperfect information potential victims may underestimate major medical risks. ${ }^{29}$ Hence, this information problem may justify regulatory intervention through compulsory first-party insurance (or social security). ${ }^{30}$ People are more averse towards large risks (e.g. paying a hospitalisation bill) than small risks (e.g. paying for a visit to the doctor). ${ }^{31}$ Hence, compulsory insurance should be restricted to cover larger risks instead of smaller risks. ${ }^{32}$ Second, uninsured patients who e.g. are unable to pay the medical bill after receiving highly costly treatment may externalise their costs to society at large. ${ }^{33}$ Therefore, in order to tackle the information problem and to avoid externalities, the purchase of patient insurance should be mandated.

Nevertheless, two caveats deserve careful consideration. On the one hand, there may be a negative redistribution of benefits from the good risk (those who have smaller demand for all-inclusive coverage) to the bad risk (those who have larger demand for all-inclusive coverage). ${ }^{34}$ On the other hand, adequate competition and the control of moral hazard are also essential to the efficiency of first party insurance. ${ }^{35}$

\begin{tabular}{ll}
\hline 27 & Id. \\
28 & Calabresi 1970, p. 56. \\
29 & Faure 2005, p. 246. \\
30 & Id. \\
31 & Id. \\
32 & Id. \\
33 & Id. \\
34 & Id. \\
35 & Id.
\end{tabular}




\subsection{SUMMARY AND EVALUATION}

First-party patient insurance has advantages over the FLISs in terms of secondary and tertiary cost reduction. Under patient insurance, victimised patients could obtain compensation much more extensively (covering both negligent and non-negligent iatrogenic injuries) and more quickly (in the absence of a duty to establish the provider's negligence). Patient insurance economises on tertiary costs more than the FLIS in that the former facilitates better risk-differentiation and avoids costly tort litigation procedures.

However, the use of patient insurance alone is inefficient because it may dilute health care providers' incentives to take precautions and increase primary accident costs dramatically. Hence, it may be socially optimal to use patient insurance as a complement to the FLIS although it would incur high tertiary costs due to a cumulation of insurance mechanisms.

On account of imperfect information and concerns for externalities, compulsory patient insurance may be warranted, especially for covering large risks.

Be that as it may, one may still wonder whether there is any alternative mechanism that could better guarantee fair and efficient compensation while it would not dilute providers' incentives to take precautions and would not incur too many tertiary costs.

\section{THEORIES OF COMPENSATION FUNDS}

\subsection{DEFINING COMPENSATION FUNDS}

Since the traditional fault-and-liability system fails to provide victimised patients with adequate compensation efficiently ${ }^{36}$ and it is difficult for firstparty insurance schemes to maintain deterrent incentives, ${ }^{37}$ one may wonder whether there is any other alternative regime that can provide fair and efficient compensation while keeping deterrent incentives at the same time. Compensation funds are thus proposed as such a potentially fair and efficient alternative compensation instrument. ${ }^{38}$

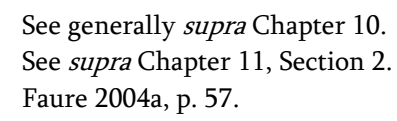


A fund is usually defined as "a sum of money or other liquid assets established for a specific purpose." ${ }^{\text {" I }}$ In practice, funds may take various forms and have different functions. Faure summarised four types of widely used funds as follows: ${ }^{40}$

- Limitation funds. A limitation fund applies to the situation where serial or mass damage (e.g. DES) is caused by similar products or services. It has three essential features. First, the liable enterprise's liability is limited to a certain amount. Second, there is no risk spreading with other potential injurers and the fund is only financed by the liable enterprise. Third, it is intended to "have an adequate instrument to divide the available proceeds among the victims in case of serial damage." ${ }^{41}$ Thus, the limitation fund plays a bigger role in compensating serial damage caused by pharmaceuticals, but less a role in compensating medical injuries caused by malpractice.

- Advancement funds. An advancement fund is constructed for "longlasting civil procedures and insurance coverage issues that can last much longer than the life of the victim." ${ }^{\prime 2}$ Especially in the case of asbestos victims, Faure argued that "it is highly unfair that (relatives of) victims only receive compensation post mortem because of the relatively short time between the discovery of the illness and their death. ${ }^{"}{ }^{3}$ In contrast, compensation funds are often proposed on the grounds that some risks are uninsurable or victims find it difficult to obtain compensation under liability rules rather than on account of long-lasting procedures. In this sense, advancement funds are insufficient to cure the above problems.

- Guarantee funds. A guarantee fund is meant to "protect victims against the possible insolvency of a liable injurer or his insurer." ${ }^{\prime 4}$ It only intervenes if all other compensation schemes have failed. For instance, it can be employed to protect victims against excess risk - "the risk for which in the specific case for various reasons no insurance coverage is available." ${ }^{45}$

- A general medical compensation fund. It is intended as a substitute for the traditional FLIS. Under this scheme, a sum of money will be established specifically for compensating eligible accident victims.

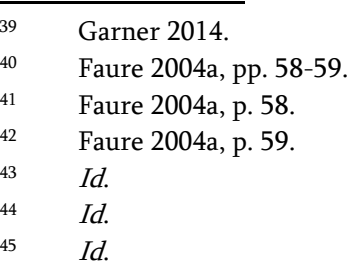


Part II. Economic Theories and Empirical Evidence

This last type of compensation fund is actually what most no-fault compensation schemes are concerned with. In the remaining part if this section, we will primarily touch upon the general medical compensation fund, and examine whether it can provide fair and efficient compensation.

\subsection{FAIR AND EFFICIENT COMPENSATION}

In order for a compensation fund to be fair and efficient, Faure maintained that it must follow three principles: ${ }^{46}$

- Principle 1: the incentives for health care providers to prevent medical malpractice should not be undermined. In other words, "a duty to compensate should in principle only rest upon the one who actually contributed to the risk." 47 If potentially liable parties did not have to bear any accident costs, their incentives to take precautions might be diluted significantly.

- Principle 2: the duty of contribution should also correspond with the extent to which the risk has been caused by the specific treatment or hospital. This principle is enshrined in the causation requirement under tort law. The collectivization of compensation entails that injurers only contribute financially to the collection in proportion to the weight their wrongful treatment contributed to the risk. Hence, risk differentiation (through e.g. experience rating) is needed in order to guarantee that bad risks pay a higher contribution than good risks with a view to avoiding negative redistribution.

- Principle 3: as a matter of principle, "only those who actually contributed to the risk should contribute to the fund." On the one hand, however, the difficult issue of causation will become a barrier to the building of an efficient compensation fund. On the other hand, if the fund were financed by the State (eventually by the general taxpayers), it would be questionable why victims of a specific type of accident (medical malpractice) should be treated better than victims of other types of accidents. Hence, how to define compensable events and how to finance the fund are questions that cannot be easily answered.

Faure argued that these principles are beneficial to both the efficiency goal (keeping incentives) and the fairness goal (avoiding negative redistribution). ${ }^{48}$

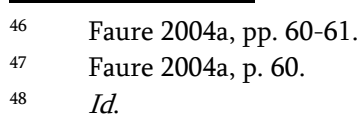


Therefore, the ability to obtain sufficient information on risk profiles (aiming at a differentiation of the contributions due) and to establish causation (insuring that the fund only intervenes in case of malpractice) really matters. ${ }^{49}$ Since compensation funds are defined as a way of loss spreading that is aimed at secondary cost avoidance, Faure's three principles are mainly meant to maintain the deterrent function in cases where the tort-liabilityinsurance system is replaced by a compensation fund.

Apart from efficiency in reducing primary costs, Faure also stressed the importance of avoiding unfairness (negative redistribution). Although accident law is less an appropriate instrument to redistribute income than progressive taxation, a compensation fund that leads to severe negative redistribution is socially undesirable. However, since risk differentiation cannot be perfect in practice, a certain level of effects arising from redistribution may be tolerable as long as the compensation fund can achieve a high level of efficiency.

\subsection{CAUSATION: HOW SHOULD IATROGENICITY BE DEFINED?}

\subsubsection{Defining Iatrogenic Injuries}

Under a no-fault compensation fund, the eligibility of a victim for compensation is based on causation rather than fault. In medical cases, there may be multiple causes that lead to final injuries, because "the patient who enters a hospital is already suffering from an underlying illness, which may itself be capable of producing the disabling losses in question." ${ }^{50}$ Hence, as a baseline, compensable events should be limited to injuries that are attributable to medical intervention..$^{51}$ In other words, injuries that were wholly or substantially caused by other factors than medical intervention should not be covered by a special compensation fund for iatrogenic injuries. By analogy with workers' compensation plans, some proposed that the test for compensable events should be the injury "arose out of and in the course of" medical treatment. ${ }^{52}$

However, this test is not desirable, because not all consequences of medical treatment should be compensable under a no-fault plan. Hence, the fact that the patient's injury was caused by medical intervention is not

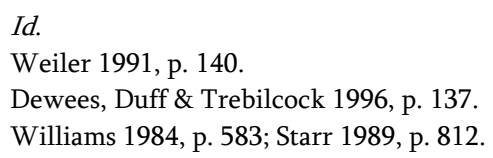


sufficient. Iatrogenic injuries must be interpreted as "unintended or unexpected result of treatment." ${ }^{\prime 53}$ This stricter requirement of iatrogenicity is to prevent no-fault compensation for "purely medical injuries" from becoming "a general insurance scheme for disability however caused." 54 Against this benchmark, injuries such as the following cases should be regarded as attributable to the underlying conditions rather than to medical interventions: ${ }^{55}$

- $\quad$ temporary disability for a medically obligatory period of convalescence after surgery,

- permanent disability associated with a medically necessary removal of a limb or an organ, or

- commonly encountered side effects that are medically necessary to treat the patient's underlying condition.

However, temporary disability lasting for a period longer than minimally required after a surgery and permanent disability as a result of unnecessary removal of a limb or an organ are examples of iatrogenic injuries. ${ }^{56}$

To summarise, adverse events will become compensable iatrogenic injuries "when they are more severe than expected," ${ }^{57}$ or "when they represent the random manifestation of a serious low-probability risk inherent in a medically necessary method of treatment." ${ }^{158}$

\subsubsection{Iatrogenicity versus Due Care}

The test of iatrogenicity differs from a fault standard in two ways. On the one hand, while the standard of care is measured against customary practice or reasonable man under fault liability, a standard of medical possibility applies to no-fault schemes. ${ }^{59}$ On the other hand, whereas only information available before the treatment is relevant to the determination of due care under fault liability, an event will be compensable if subsequent information after the treatment reveals that the procedure concerned was unnecessary or inappropriate. ${ }^{60}$

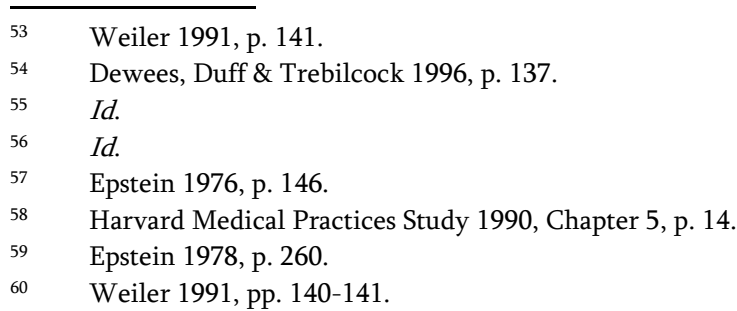




\subsubsection{Iatrogenicity and Omissions}

Iatrogenicity may involve both active medical interventions and omissions. An omission occurs "when a disability is caused or aggravated by a failure to prevent or minimise the patient's condition at a stage when it was medically possible to do so." ${ }^{61}$ For instance, the failure to diagnose and treat avoidable blindness from glaucoma or a curable cancer can be regarded as iatrogenic injury rather than as a natural progression of the pre-existing condition. ${ }^{62}$ However, "if diagnosis is medically impossible until the condition is virtually untreatable (or if the patient fails to seek medical attention until corrective measures are no longer possible)," the outcome is a non-iatrogenic injury. ${ }^{63}$

One reason that Epstein argued against a no-fault plan for medical injuries is that the no-fault plan cannot eliminate the negligence issue. ${ }^{64} \mathrm{An}$ omission already implies a duty of performance and the defendant would try to prove that the treatment was non-negligent in order to demonstrate that the real cause of the injury is more likely to be the patient's pre-existing condition. ${ }^{65}$ However, a standard of medical possibility should be distinguished from due care in cases where an omission is involved. Under no-fault schemes, an injury is compensable as long as the patient's condition could have been diagnosed and treated medically, no matter how high the cost of the treatment (the highest care level). ${ }^{66}$ In contrast, under fault liability the fault on the part of the defendant would not be established if the condition could not have been diagnosed and treated at a socially optimal cost (efficient care level). ${ }^{67}$ Hence, the "causal question of whether a correct diagnosis could have been made is conceptually distinct from the normative question of whether an accurate diagnosis should have been made." 68

\subsubsection{Causal Uncertainty}

Since medical science is often probabilistic in nature ${ }^{69}$ and iatrogenicity is typically only one element in a complex causal chain leading to the patient's injury, any injury suffered by the patient may be attributable both to the

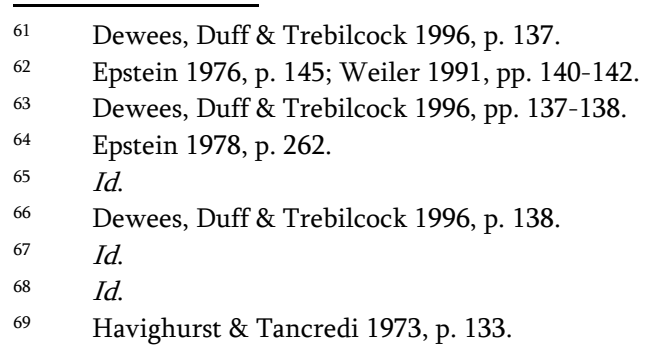


medical intervention and to the patient's pre-existing condition..$^{70}$ One may wonder to what extent patients can claim compensation from the compensation fund in cases where there is uncertainty over causation. Epstein was concerned that the complexities of establishing causation would not be substantially reduced by changing from the fault rule to a no-fault plan. ${ }^{71}$

Two solutions may be well worth considering:

- Solution 1: It can be required that medical care is both "a probable cause of the adverse outcome" and "a significant or material cause of the resulting disability." ${ }^{\prime} 2$ For example, it can be provided that only costs incurred by the patient after a fixed period (perhaps six months following the treatment) are compensable. ${ }^{73}$ However, it still remains a difficult issue that how to define "significance" or "materiality."

- Solution 2: Since no-fault plans are similar to strict liability in that all costs of iatrogenic injuries are internalised by the health care industry, the proportional approach to causation may well apply to no-fault schemes. If the proportional approach were employed, health care providers would react as if there were no uncertainty over causation. ${ }^{74}$ In so doing, either over-deterrence or under-deterrence may be avoided.

From the perspective of primary cost avoidance, the second solution is more efficient than the first "or-all-nothing" approach. In the case of causal uncertainty, patients should only obtain compensation to the extent that the injury was due to medical interventions rather than to pre-existing conditions.

\subsection{FUNDS VERSUS INSURANCE}

Faure compared funds vis-à-vis insurance in terms of risk differentiation and costs respectively. ${ }^{75}$ As far as risk differentiation is concerned, there is no reason why compensation funds should be preferred to the tort-liabilityinsurance system when both of them cover the same risk. ${ }^{76}$ If there is

Dewees, Duff \& Trebilcock 1996, p. 138.

Epstein 1978, p. 261.

Dewees, Duff \& Trebilcock 1996, p. 138

Harvard Medical Practices Study 1990, Chapter 8, p. 6.

See supra Chapter 7, Section 3.2.

Faure 2004a, pp. 61-62.

Faure 2004a, p. 61. 
competition in insurance markets, liability insurance should be preferred. ${ }^{77}$ Insurers are better able to conduct risk differentiation since they are specialised in such issues. ${ }^{78}$ In contrast, in the absence of competition in insurance markets (shortage of supply of coverage or excessively high premiums), a preference for compensation funds managed by governmental administrators may be justifiable. ${ }^{79}$ Nonetheless, it would be still questionable whether administrators are able to recognise good and bad risks in order to properly carry out risk differentiation. ${ }^{80}$ If "highly technical risks" are to be differentiated and health care providers are in a much better position than the insurers to monitor each other, a regime of mutual risk sharing (e.g. MediRisk in the Netherlands) may be preferred. ${ }^{81}$ Where compensation funds and liability insurance cover different risks, there is no need to compare them because they are not alternative to each other. ${ }^{82}$

Regarding costs, if compensation funds were run by regulatory authorities, insurance would be less costly than compensation funds for three reasons. First, liability insurance policies are concluded for a whole set of risks, not for only one risk. Second, the costs of risk spreading incurred by insurers (who are specialised in risk differentiation) may be lower than by compensation funds. Third, liability insurance may reduce transaction costs more than compensation funds do, because insurers and the insureds are able to negotiate on risk distribution ex ante. ${ }^{83}$ If, on the other hand, compensation funds were run by private entities, market competition is needed to provide incentives to reduce costs. ${ }^{84}$ Those compensation funds (e.g. limitation funds or guarantee funds) that are intended to complement rather than replace liability insurance, may save more costs. ${ }^{85}$

\subsection{SUMMARY AND EVALUATION}

A carefully designed and well-functioning no-fault plan offers excellent potential for achieving fair and efficient compensation without incurring too much administrative cost. Regarding primary cost avoidance, risk differentiation would link the cost of iatrogenic injuries to risk-creators so

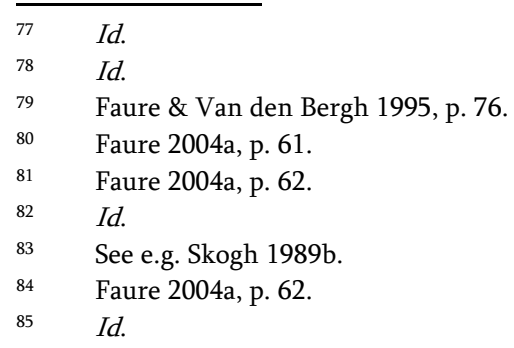


that their incentives to invest in care would be maintained. In this regard, nofault schemes are more efficient than either first-party insurance or social security. Moreover, because doctors would rarely be sued before the court under no-fault plans, they would no longer react by over-complying. Hence, unnecessary costs of defensive medicine could be avoided. In this respect, nofault schemes might save more primary costs than the tort system.

Be that as it may, this advantage of saving primary costs may be mitigated to some extent by the fact that many iatrogenic injuries that are currently unavoidable at a socially optimal cost (medical mishaps) would be covered by no-fault schemes as well. Although holding providers liable for currently unavoidable injuries would not alter their incentives to take care, they would react to increased accident costs by reducing their activity levels. Since health care services generate considerable positive externalities that benefit society as a whole, it would be socially undesirable if the health care industry suffered a severe contraction. However, Weiler et al. maintained that in the long run it makes economic sense to impose the costs of some currently unavoidable injuries on the health care industry ${ }^{86}$ As they argued, the development of medicine is dynamic and currently unavoidable risks will become readily avoidable in the future. ${ }^{87}$ Hence, providers would be incentivized to continually invest in research and innovation. ${ }^{88}$

As far as secondary cost avoidance is concerned, no-fault schemes are also desirable because the risk of iatrogenic injuries is spread broadly within the health care industry. Since most no-fault plans are mandatory social insurance, the extent of risk spreading under no-fault schemes is likely to be greater than that under the FLIS. Moreover, no-fault plans are intended to provide compensation for the victim's losses rather than to offer those in need a minimum level of subsistence. ${ }^{89}$ Thus, no-fault schemes are more directed at reducing secondary losses resulting from adverse events than social security.

In terms of tertiary cost avoidance, comprehensive no-fault schemes, similar to first-party insurance and social security, would entail lower administrative costs than the tort system. Under no-fault schemes, legal and litigation costs and the cost of determining fault could be avoided. Hence, in a single case, the administrative costs of no-fault schemes tend to be lower than those of the tort system. Admittedly, total administrative costs under no-fault schemes may be greater, given that the number of claims would rise substantially after a shift from fault towards no-fault. Nevertheless, the increase in total administrative costs might well be justified by the

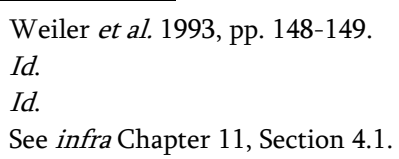


considerable reduction in total secondary costs since more victims would be compensated more quickly.

\section{THEORIES OF SOCIAL SECURITY}

\subsection{THE RATIONALE OF SOCIAL SECURITY}

Broadly speaking, "social security law" and "social security systems" or "agencies" can be understood to mean regulations set and maintained by the state, and schemes or agencies which are state-controlled, and which carry out in whatever manner the task of granting benefits on the basis of personal injuries. ${ }^{90}$

The rationale behind social security is the "doctrine or belief that the government should provide a minimum level of economic security and social welfare for citizens and their families." ${ }^{91}$ Social security systems began to develop in the West in the 19th century, first for workers and then for other parts of the population. ${ }^{92}$ The main model was Bismarck's social insurance legislation in Germany, which provided that a state agency funded by employers and employees jointly was intended to offer benefits to employees once they suffered work-related injuries or become old. ${ }^{93}$ Gradually, it became widely recognised that to provide citizens with social security against the risks of life should be the primary task of the modern welfare state. ${ }^{94}$ Today, various social security programs are growing fast in many developing nations worldwide. ${ }^{95}$

Although both social security and compensation funds are no-fault schemes, they still differ significantly in two ways. First, social security schemes are mainly intended to provide a limited compensation for the protected persons in need of help, while compensation funds are meant to provide victims with fair and efficient compensation as a substitute for tort liability. Second, social security funds are mainly financed by the protected persons according to their income and partly subsidised by the state, whereas compensation funds are primarily financed according to potential liable parties' accident-proneness (and sometimes also subsidised by the state).

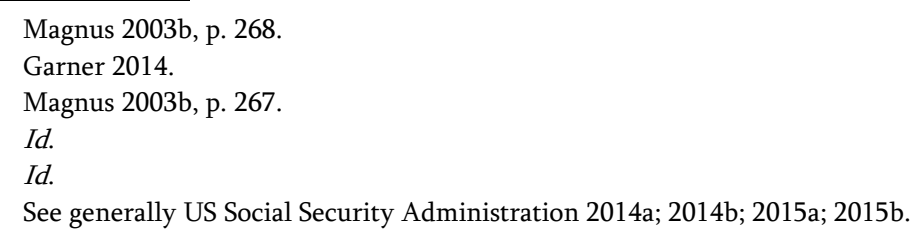


Thus, compensation funds are designed to achieve both the goal of compensation and that of deterrence.

In Europe, for instance, no country seems to employ only a single and comprehensive social security program to cover all kinds of personal injury risks. ${ }^{96}$ Many countries have a very complicated system of social security, consisting of various single schemes. ${ }^{97}$ For example, the Netherlands has a very extensive social security system that "provides the general population with modest financial protection against various risks of life, e.g., sickness or disability, unemployment, death of breadwinner, old age and cost of children." ${ }^{98}$ However, other schemes such as employees insurance co-exist with the national insurance scheme. ${ }^{99}$

A social security scheme is usually operated subject to three basic requirements: ${ }^{100}$ first, there should be a state organised insurance scheme; second, the claimant should belong to the protected group of people; and third, the claimant often has to contribute to the social security fund. In a pure social insurance scheme, the insured claimants have to contribute to the fund fully. ${ }^{101}$ Sometimes, however, an entirely state financed scheme through taxation where the protected persons do not have to contribute to the fund does exist. ${ }^{102}$ In the majority of the cases, social security schemes are cofunded by both citizens and the state. ${ }^{103}$ If first-party insurance coverage is made compulsory, then the effect is "more or less the same as under a social insurance scheme with full contributions of the covered group." ${ }^{104}$ In this respect, social security could be and sometimes is replaced by private insurance. ${ }^{105}$

Social security law is intended to provide financial support for "the weakest in society, whether or not their position results from accident or illness." 106 The pre-requisite for joining a social security scheme is normally low and the amount of compensation is usually limited. ${ }^{107}$ Hence, social security is more "Existenzsicherung," ${ }^{108}$ aiming at providing a source of

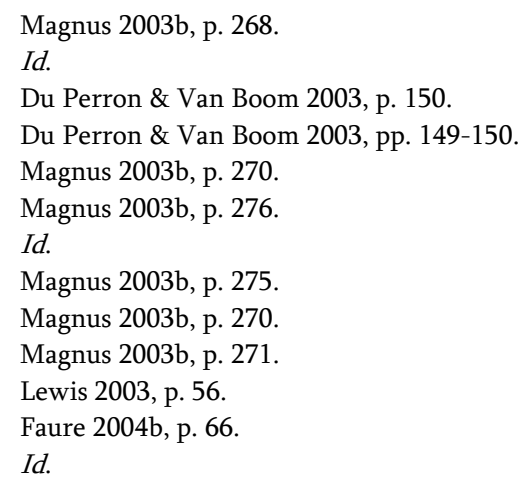


livelihood. Social security normally covers a wide range of risks of life, such as old age, disability, sickness, maternity, work injury and unemployment. ${ }^{109}$ Obviously, not all of these risks are related to accidents. Social security benefits for personal injury are "only a part (although an important one) of all benefits granted under the heading of social security." 110 In order to draw a comparison between tort law and social security, the focus will be on personal injury losses resulting from accidents, since "tort law traditionally is limited to the situation whereby personal injury is the result of a wrongful act following an accident caused by a third party." 111 In many countries, social security plays a leading role in compensating damage caused by medical malpractice. ${ }^{12}$ Social security may cover the costs of additional medical care and loss of earnings, no matter what has caused these losses. ${ }^{113}$

\subsection{DISTINCTION BETWEEN SOCIAL SECURITY AND TORT LIABILITY}

Social security differs from tort liability in the requirements and scope of compensation, the rationale, and basic goals: ${ }^{114}$

- Requirements of compensation. Both tort liability and social security require that the claimant has suffered some personal injuries. Besides damage, tort liability has much stricter requirements than social security. In order for fault-based tort liability to be established, the claimant still has to prove that the injury he/she suffered was due to fault on the part of the defendant. Hence, fault and causation are essential elements for e.g. medical malpractice liability. In contrast, fault is not required under social security schemes. Causation is not required under non-causal social insurance schemes (general social insurance), but it is a requirement of causal social insurance schemes (e.g. for workrelated injuries). Therefore, causation is relevant in the sense that "the damage of the bodily impaired person must be linked to the insured risk through a chain of causation." 115

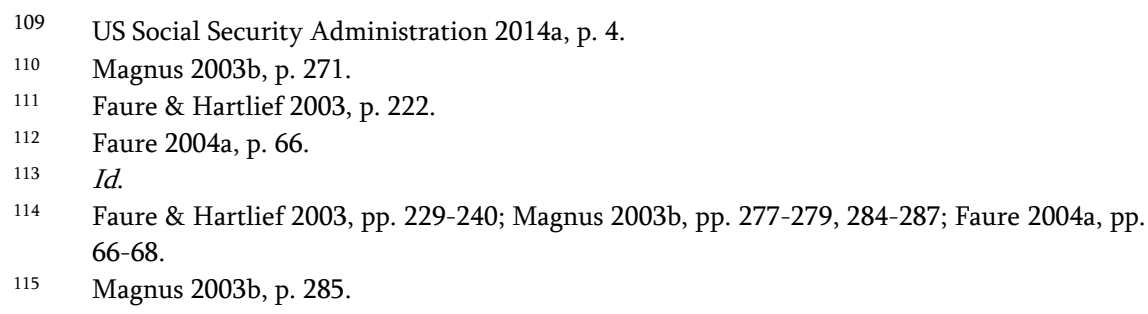


Part II. Economic Theories and Empirical Evidence

- Scope of compensation. Tort law is intended to provide full compensation, including recovery for non-pecuniary losses. However, social security is not directly relevant to the financial loss of the victim but often to the income earned by the victim, which generally excludes coverage for non-pecuniary damages. Hence, social security is meant to "provide the necessary help in a situation of need."116 In principle, tort damages are reduced by contributory negligence on the part of the victim, while social security benefits are not affected by contributory negligence.

- Rationale. Social security is aimed at promoting solidarity between citizens and protecting those "who are otherwise - due to hardship or other occurrences - at risk of being reduced to a life of need and poverty." ${ }^{117}$ In contrast, tort law is not intended to promote solidarity between injurers and victims. Sometimes, there is solidarity between all the insured injurers under (liability) insurance. However, this is only a way of risk spreading, which is based on risk differentiation instead of income dependence solidarity.

- $\quad$ Basic goals. The primary goal of tort law as understood by economists is to prevent accidents (deterrence), ${ }^{118}$ whereas social security is mainly used to provide (limited) compensation for protected claimants.

\subsection{INTERPLAY BETWEEN SOCIAL SECURITY AND TORT LIABILITY}

\subsubsection{Compensation Models}

Supposing tort liability and social security are complete alternatives to each other, two ideal models of reaching the goals of both deterrence and compensation through either social security or tort law could be designed as follows: ${ }^{119}$

- Safety regulation + social security. If secondary cost avoidance were the only goal, social security seems to be the most appealing instrument in that "it allows for just the degree of risk spreading or deep pocket we

$16 \quad$ Magnus 2003b, p. 286.

117 Magnus 2003b, p. 279

118 Lawyers may disagree and they generally hold that the primary function of tort law is compensation. Notwithstanding, the compensatory goal of tort law is full compensation, which is often more generous than social security benefits.

119 See generally Skogh 1982; 1989b. For a brief summary, see Faure 2004a, pp. 68-69. 
want and permits us to achieve it in a remarkably inexpensive way." ${ }^{20}$ Then, it would be most efficient if a general social insurance funded by taxation and covering all accident risks could be established. ${ }^{121}$ However, secondary cost avoidance is not the only goal, and primary cost avoidance is of equal importance. Ideally, if social security could provide adequate compensation, then it would be unnecessary for victims to claim compensation through tort law. Some instruments other than tort law should be employed to guarantee that those riskcreators take sufficient precautions. Hence, it is argued that safety regulation serves the goal of deterrence in the absence of tort law.

- Tort liability + insurance. ${ }^{122}$ If primary cost avoidance were the sole goal, then tort liability would be efficient since it could ex ante induce risk-creators to invest in precautions. However, to reduce secondary costs through risk spreading is also socially desirable from an ex post perspective. Tort law alone is not so effective at broad loss spreading. Hence, liability insurance and first-party insurance may be employed to spread accident risks among the insured injurers or victims.

\subsubsection{Combined Use in Practice}

In practice, however, to replace social security completely by tort liability or vice versa is virtually unrealistic. On the one hand, tort liability is often indispensable in that it is sometimes difficult to use ex ante safety regulation to control risky behaviour effectively and social security benefits are often rather limited. Hence, in the absence of a tort-liability-insurance system, safety regulation may fail to generate sufficient incentives to take precautions and social security may not be able to provide adequate compensation.

On the other hand, social security is not absolutely replaceable because it can achieve wider risk spreading at less expenses than the tort system. Under the tort-liability-insurance system, tort litigation and risk differentiation under third-party insurance incur larger administrative costs than first-party insurance. Potential victims may also lack enough incentives to purchase first-party insurance. In addition, social security is also intended to promote other important goals such as social solidarity, which is outside the ambit of tort law.

It follows from the above analysis that tort liability and social security may co-exist and affect each other to a certain extent in practice. ${ }^{123}$

\footnotetext{
$120 \quad$ Calabresi 1970 , p. 46.

121 Id.

122 See generally supra Chapter 10.

$123 \quad$ Faure \& Hartlief 2003, p. 227.
} 
Comparative studies also show that except New Zealand, no other country has implemented a comprehensive social security scheme that is intended to replace the traditional tort system. ${ }^{124}$ What is often found in many legal systems is "a partial replacement of tort law through social security law."125

Then, how do legal systems handle the situation where part of tort damages is also recoverable under social security schemes? There are basically two tendencies. On the one hand, some legal systems such as England and Wales and the Netherlands choose to leave tort liability fully intact, subject to the collateral source set-off rule - the part of damages that is already covered by social security schemes should be deducted from total tort damages. ${ }^{126}$ Then, a right of recourse must be granted to social security agencies so that tortfeasors have to contribute to the schemes. ${ }^{127}$ On the other hand, some legal systems such as France, Greece, Italy, Austria, and Germany decide to abolish tort law in the field of occupational accidents and diseases because the privileged tortfeasor has paid for being immune. ${ }^{128}$

In cases where tort damages and social security benefits overlap, it may be socially efficient to grant a right of recourse to social security agencies. As a general rule, three goals should be borne in mind in order for the joint use of tort liability and social security to be optimal: ${ }^{129}$ first, victims should be fully compensated - either over-compensation or under-compensation should be avoided; second, tortfeasors should not be subsidised in the form of paying less than full compensation; and third, administrative costs should be minimised.

Against these benchmarks, the combination of the collateral source set-off rule and a right of recourse or subrogation is efficient. On the one hand, the victim will get full compensation, consisting of benefits received from social security schemes and properly reduced tort damages from the tortfeasor. There will be neither over-compensation nor under-compensation. On the other hand, the tortfeasor will have to pay part of the damages to the victim and the remaining part to social security agencies. Hence, there will be neither under-deterrence nor over-deterrence.

The foregoing analysis shows that the joint use of tort liability and social security is not only practically inevitable but also socially optimal as long as the collateral source set-off rule and a right of recourse are employed in combination as well. Both the goals of compensation and deterrence can be

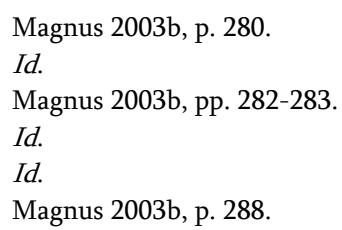


achieved. Victims will seek "the best of both worlds" within tort law: "they seek the low threshold for compensation of social security, to be combined with full compensation under tort law." ${ }^{130}$ For instance, social security benefits are relatively high, so that victims only need to receive compensation for the top of their income (which is not covered by social security) and for non-pecuniary loss. ${ }^{131}$ Tort law thus becomes a "luxury" system! ${ }^{132}$ With the expansion of social security benefits, secondary accident costs could be further reduced while deterrent incentives could be kept intact. The other way around, it is expected that "if the government withdrew from the compensation of personal injury via social security, victims would be forced to make an increasing use of tort law and insurance to meet this same goal."133

\section{EMPIRICAL EVIDENCE ON NO-FAULT COMPENSATION SCHEMES IN PRACTICE}

\subsection{INTRODUCTION}

Currently, there are five legal systems that have implemented a comprehensive NFCS for personal injuries in general or iatrogenic injuries in particular for some time: New Zealand and four Scandinavian countries Sweden, Finland, Norway and Denmark.

New Zealand was the first country in the world that established a comprehensive NFCS for personal injuries in general in 1974. New Zealand's NFCS (hereinafter NZ-NFCS) is based on an insurance model that provides coverage for all victims of accidents without resorting to the fault-based tort system. The NZ-NFCS's model was proposed by the Royal Commission of Inquiry, which produced the well-known Woodhouse Report, ${ }^{134}$ named after its chairman, Mr. Justice Woodhouse. In the Report, the Commission came to the conclusion that tort law does not have a deterrent effect and the negligence action is a form of lottery. ${ }^{135}$ Hence, the Commission recommended that the tort system should be replaced by "a unified and comprehensive scheme of accident prevention, rehabilitation, and

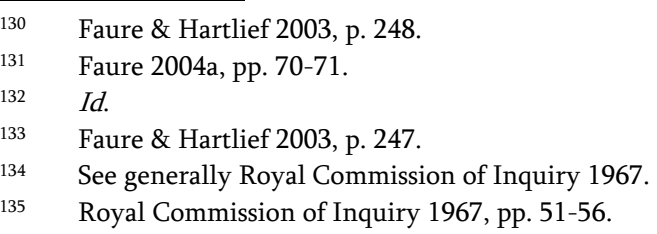


compensation which will avoid the disadvantages of the present processes."136 This scheme must be guided by five principles: community responsibility, comprehensive entitlement, complete rehabilitation, real compensation, and administrative efficiency. ${ }^{137}$

New Zealand's legislature accepted this recommendation and enacted the Accident Compensation Act 1972 (hereinafter NZ Act 1972), which took effect in 1974. After 1974, the NZ Act 1972 has undergone several major amendments in 1982, 1992, 1998, and 2001.138 Compensation for iatrogenic injuries has been covered since the NZ Act 1982. In 2005, a significant amendment was made by the Injury Prevention, Rehabilitation, and Compensation Amendment Act 2005 (hereinafter NZ Amendment Act 2005) to the NZ Act 2001 concerning the definition of medical injury. The latest major amendment to the NZ Act 2001 was the Accident Compensation Amendment Act 2010. ${ }^{139}$

The Scandinavian countries have also developed NFCSs since the 1970s. ${ }^{140}$ Scandinavian NFCSs differ from NZ NFCS in that while the former only apply to injuries in the health care sector the latter provides cover for all kinds of personal injuries. ${ }^{141}$ Sweden was the first Scandinavian country that established a patient insurance for treatment-related injury in $1975 .{ }^{142} \mathrm{~A}$ similar patient insurance scheme was introduced in Finland in 1984, in Norway in 1988, and in Denmark in 1992. ${ }^{143}$ Currently, Scandinavian NFCSs are governed by patient injury acts as follows:

- $\quad$ Sweden: Patient Injury Act $1996^{144}$ (hereinafter Swedish PIA);

- $\quad$ Finland: Patient Injury Act $1986^{145}$ (hereinafter Finish PIA);

$136 \quad$ Royal Commission of Inquiry 1967, p. 107.

137 Royal Commission of Inquiry 1967, p. 20.

138 For more studies on NZ-NFCS, see generally e.g. Harris 1974; Brown 1985; Palmer 1994; Todd 2000; Yang 2000; Dew 2002; Davis et al. 2003; Howell 2004; Skegg 2004; Hitzhusen 2005; Oliphant 2007; Kachalia et al. 2008; Schuck 2008; Todd 2011; 2013.

139 For a list of the amendments to the NZ Act 2001, see Accident Compensation Act 2001 (2016 Reprint). Available at: <www.legislation.govt.nz/act/public/2001/0049/latest/whole.html $>$ (accessed on 31 May 2016).

140 For more information on the Swedish NFCS, see generally e.g. Cohen \& Korper 1976; Oldertz 1984; Hellner 1985; Calabresi 1986; Hellner 1986; Oldertz 1986; Danzon 1994a; 1994c; Hellner 2001; Yang 2001; Wendel 2004; Johansson 2010; on the Finnish NFCS, see generally e.g. Mikkonen 2001; 2004a; 2004b; on the Norwegian NFCS, see generally e.g. Jorstad 2002; and on the Danish NFCS, see generally e.g. Ulrich 1994; Erichsen 2001; Hartlev 2011. For a comprehensive analysis of all the four Scandinavia NFCSs, see generally e.g. Dute 2004; Ulfbeck, Hartlev \& Schultz 2013.

$141 \quad$ Dute 2004, p. 447.

$142 \quad$ Cohen \& Korper 1976, p. 70.

143 Von Eyben 2001, pp. 201-202.

144 Patientskadelag [Patient Injury Act] (Svensk författningssamling [SFS] 1996:799) (Swed.). 
- Norway: Patient Injury Act $2001^{146}$ (hereinafter Norwegian PIA);

- Denmark: Law on the Right to Complain and Receive Compensation within the Health Service 2010 $0^{147}$ (hereinafter Danish KEL).

The remainder of this section primarily examines the core features of these NFCSs and reviews some relevant empirical data (Section 5.2). Thereafter, it will evaluate these NFCSs in terms of Calabresi's primary, secondary and tertiary costs (Section 5.3).

\subsection{CORE FEATURES OF THE NFCS: A COMPARATIVE} ANALYSIS

\subsubsection{Eligibility}

\subsubsection{New Zealand}

Defining treatment injury. In New Zealand, the original notion of compensable adverse events was medical misadventure. NZ Act 1982 Section 2 provided that personal injury by accident includes "medical, surgical, dental, or first aid misadventure." However, NZ Act 1982 itself had not clarified what medical misadventure means. Nevertheless, courts soon developed a two-limb test - either medical negligence or medical mishap. ${ }^{148}$ Negligence is generally regarded as misadventure. ${ }^{149}$ It normally includes cases such as "insufficient or wrong treatment, failure to inform, misdiagnosis, misrepresentation (innocent or fraudulent) or administrative shortcomings." 150 Medical mishap is defined as a "quite unforeseeable adverse consequence of treatment which had been properly administered and did not involve negligence." 151 The two-limb approach was confirmed in Child v. Hillock. ${ }^{152}$ There is a need to distinguish patients who are eligible for

\footnotetext{
145 Potilasvahinkolaki [Patient Injury Act] No. 585, July 25, 1986 (Fin.).

146 Lov om erstatning ved pasientskader mv. (Pasientskadeloven) [Patient Injury Act] No. 53, June 15, 2001 (Nor.).

147 Lov om klage- og erstatningsadgang inden for sundhedsvæsenet [Law on the Right to Complain and Receive Compensation within the Health Service] No. 706, June 25, 2010 (Den.).

148 ACC v. Auckland Hosp. Bd. [1980] 2 NZLR 748 (HC), 751; Bridgeman v. ACC [1993] NZAR 199 (HC).

149 Green v. Matheson [1989] 3 NZLR 564 (CA), 572-573.

$150 \quad$ Todd 2013, p. 293.

151 Id. See also ACC v. Auckland Hosp. Bd. [1980] 2 NZLR 748 (HC), 751.

$152 \quad$ Child v. Hillock [1994] 2 NZLR 65, 72 (CA).
} 
compensation and those who are not. Thus, medical misadventure should be unexpected or "accident-like." 153 In Section 5(1) of NZ Amendment Act 1993, medical misadventure was interpreted as including medical error and medical mishap. "Medical error" was defined as meaning medical negligence, and "medical mishap" as meaning an adverse consequence of properly administered treatment that was "rare" and "severe." 154 The original NZ Act 2001 followed the preceding definition of medical misadventure. A complication was considered to be rare if it does not occur in more than $1 \%$ of cases. ${ }^{155}$ An injury was said to be severe only if it results in dying, hospitalisation for more than 14 days or serious physical handicap. ${ }^{156}$

This notion of medical misadventure was criticised as unsatisfactory for two reasons. First, it is rather anomalous for patients to prove a medical error in the context of a no-fault scheme. ${ }^{157}$ This notion of medical errors will lead to the same kinds of difficulties under the tort system and incurs considerable administrative costs and delay. ${ }^{158}$ Second, the notion of the medical mishap is also "confusing and arbitrary," which often bears "little relationship to the circumstances of the patient, resulting in claimants unfairly missing out on cover." 159 It was recommended that the notion of medical misadventure be abandoned and all unintended injuries in the treatment process should be compensable. ${ }^{160}$ In other words, "all adverse medical events, whether or not preventable, provided they were unintended or, on another formulation, outside the expected and likely range of consequences of treatment" are coverable. ${ }^{161}$ For this reason, NZ Amendment Act 2005 employs the new notion of "treatment injury" to replace "medical misadventure."162 The primary purpose of this shift is to remove any requirement of fault. ${ }^{163}$ It is hoped as well that providers would be induced to "cooperate in the claims process" and promote better reporting, creating "a climate of learning" and protect public safety. ${ }^{164}$

Treatment injury is defined as personal injury that is (a) suffered by a patient, (b) caused by treatment, and (c) not a necessary part, or ordinary

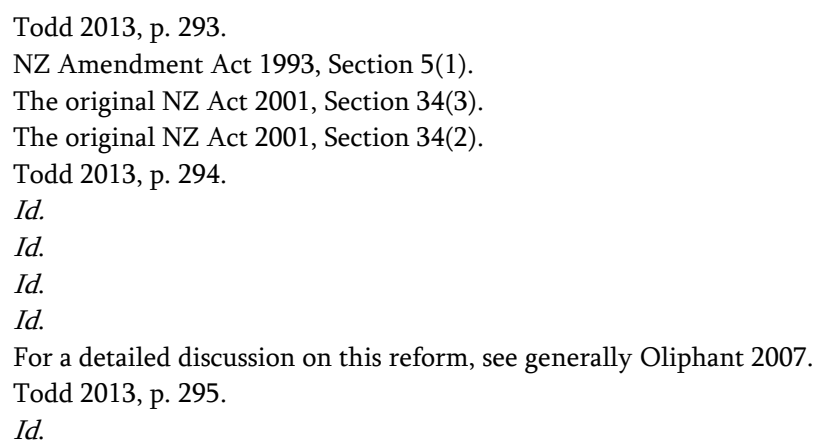


consequence, of the treatment, given (i) the patient's underlying condition, and (ii) the clinical knowledge at the time of the treatment. ${ }^{165}$ Treatment injury does not include personal injury that is (a) wholly or substantially caused by a patient's underlying condition, (b) solely attributable to a resource allocation decision, or (c) a result of a patient unreasonably withholding or delaying their consent to undergo treatment. ${ }^{166}$ The fact that treatment did not achieve a desired result does not of itself constitute treatment injury. ${ }^{167}$ Coverage for infection is extended to secondary victims. ${ }^{168}$ Treatment intervention may include (a) the giving of treatment, (b) a diagnosis of a condition, (c) a decision on the treatment to be provided (including a decision not to provide treatment), (d) failure or delay in providing treatment, (e) obtaining or failing to obtain a person's consent to treatment, (f) the provision of prophylaxis, (g) the failure of any equipment used as part of the treatment process, and (h) the application of any support systems used by the organisation responsible for providing the treatment. ${ }^{169}$

It is evident from the foregoing description that the notion of "treatment injury" has abolished any reference to either a "medical mishap" or a "medical error."170 Nevertheless, the concept of treatment injury can be understood in the light of updated notions of mishap and error. As far as mishap is concerned, there is no coverage for personal injury that is a necessary part or ordinary consequence of treatment, e.g. a surgical incision during an operation. ${ }^{171}$ Are all recognised but unwanted side effects a necessary part or ordinary consequence of treatment? The Accident Compensation Corporation (hereinafter ACC) maintains that known complications may be compensable. ${ }^{172}$ Ultimately, the court should determine whether complications are not "necessary" or "ordinary." ${ }^{173}$ In this regard, the amended NZ Act 2001 "has reverted from detailed definition back to judicial discretion." ${ }^{174}$

Regarding error, the injury should not be wholly or substantially attributable to the patient's underlying condition. ${ }^{175}$ Supposing there is a failure to treat and the patient's condition gets worse, or treatment does not

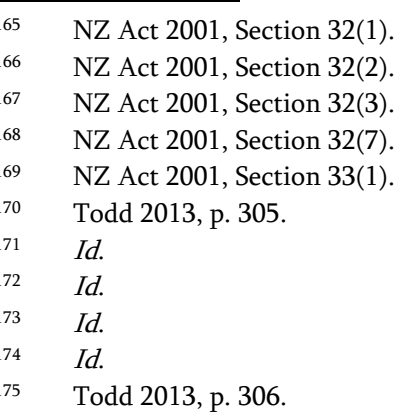


alleviate a condition, is the continuing injury due to the treatment or the underlying condition? In New Zealand, it is currently necessary to examine the causal potency of the underlying condition relative to that of treatment. ${ }^{176}$ The claimant has to show that "the health professional should have treated or should have treated differently" and this is equivalent with proving the fault on the part of the professional. ${ }^{177}$ In other words, that desired results are not achieved does not make it a treatment injury, unless a wrong treatment is given. Therefore, the notion of negligence is still hidden in the operation of NZ-NFCS. As Todd put it, "While negligence is not formally required ... it necessarily re-appears in deciding whether treatment injury can be shown to exist."178

Treatment injury claims in practice. Before 2005, there were about 3,000 medical misadventure claims each year, of which $86 \%$ were mishaprelated and $14 \%$ error-related. ${ }^{179}$ These claims constituted only a small proportion $(0.05 \%$ in 2003$)$ of all accident injuries but took much longer than the average to resolve. ${ }^{180}$ After 2005, there was a dramatic surge in the number of claims (1,434 treatment injury claims in 2004-05, 2,846 in 2005$06,3,974$ in 2006-07, 5,472 in 2008-09), and a small decrease to 5,210 in 200910. ${ }^{181}$ In contrast, the total number of no-fault accident claims has risen slowly during the same period. ${ }^{182}$ There was a doubling of the acceptance rate, $70.6 \%$ were declined in $2004-05$, whereas only $35.5 \%$ were denied in 2008 09. ${ }^{183}$ It takes a short average time for a claim to be resolved after 2005: from about 5 months before 2005 to 37 days in 2009. ${ }^{184}$

Based on the preceding data, Todd made three observations. First, the concepts of a mishap and an error are still inherent in the notion of treatment injury ("adverse events"). ${ }^{185}$ Second, it is highly likely that the surge in claims after 2005 is due to "the lowering of the threshold for what qualifies as a mishap."186 It seems that the requirement of an unnecessary part or extraordinary consequence of treatment is less strict than that of a "rare" and "severe" mishap. ${ }^{187}$ Third, negligent error is still significant in establishing

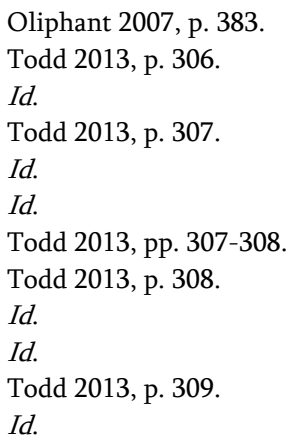


treatment injury and "every case of negligent treatment will constitute treatment injury." 188

Hence, although the amended NZ Act 2001 avoids making any reference to negligence, the actual working of the no-fault scheme still partly relies on the notion of negligence. Also, the court may find it difficult to decide whether an injury is not a necessary part, or ordinary consequence, of the treatment. Although the determination of this causation test is difficult, it is theoretically indispensable. As Todd rightly pointed out: ${ }^{189}$

\begin{abstract}
Medical injury frequently lies near the dividing line between accident and illness. For as long as the accident compensation scheme provides cover for accidents but not for illness (save for occupational disease), it will remain necessary to search for an unexpected accident or event which can separate a medical injury from ordinary treatment of an illness or disease.
\end{abstract}

\title{
5.2.1.2. Scandinavia
}

Scope of coverage. In contrast to NZ-NFCS where a unified notion of treatment injury is defined, the cover under the Scandinavian NFCSs is based on detailed lists of compensable and excluded injuries. Table 11.1 summarises the cover under the NFCSs in the four Scandinavian countries.

The adverse consequence of treatment is the primary form of a compensable event. In the majority of the Scandinavian systems (Sweden, Finland and Denmark), the claim for compensation for iatrogenic injury is based on two requirements. First, the injury must occur in the course of or arise out of treatment. Second, the injury must be medically avoidable. In Norway, however, the avoidable aspect is not required, and any adverse event caused by failure when providing health care suffices. In Sweden, Finland, and Denmark, whether an injury is avoidable is determined against the test of the experienced specialist standard. The "experienced specialist" is based on an optimus vir (best man) standard, denoting "the best doctor in the particular field." 190 In contrast, under the negligence rule an injury would be attributable to the tortfeasor only if a reasonable man could avoid the injury in a similar situation. ${ }^{191}$

Obviously, the level of care exercised by the best doctor is much greater than that exercised by the reasonable doctor. Suppose tort law adopted the best man as the standard of care to determine fault. If an injury

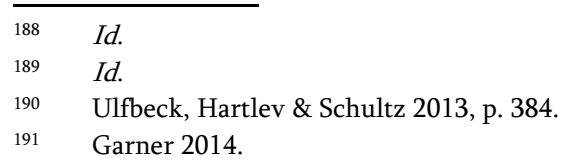


could be avoided only by the level of care taken by the best doctor, then doctors who are below the best would automatically be at fault in that they would never reach the best-man level of care.

Table 11.1: Scandinavian No-Fault Compensation Systems: Cover ${ }^{192}$

\begin{tabular}{|c|c|c|c|}
\hline $\begin{array}{l}\text { Sweden } \\
\text { (Swedish PIA) }\end{array}$ & $\begin{array}{l}\text { Finland } \\
\text { (Finnish PIA) }\end{array}$ & $\begin{array}{l}\text { Norway } \\
\text { (Norwegian PIA) }\end{array}$ & $\begin{array}{l}\text { Denmark } \\
\text { (Danish KEL) }\end{array}$ \\
\hline Injury resulting from: & $\begin{array}{l}\text { Injury resulting } \\
\text { from: }\end{array}$ & $\begin{array}{l}\text { Injury resulting } \\
\text { from: }\end{array}$ & Injury resulting from: \\
\hline $\begin{array}{l}\text { 1. treatment, but only } \\
\text { if avoidable by a } \\
\text { different performance } \\
\text { or by an alternative } \\
\text { procedure done by an } \\
\text { experienced specialist } \\
(\S 6, \text { para. } 1 \text {, item } 1 \& \\
\text { para.2) }\end{array}$ & $\begin{array}{l}\text { 1. treatment, but } \\
\text { only if avoidable by } \\
\text { a different } \\
\text { performance done } \\
\text { by an experienced } \\
\text { specialist ( } \$ 2 \text {, para. } \\
1 \text {, item } 1)\end{array}$ & $\begin{array}{l}\text { 1. treatment failure, } \\
\text { even if no one can be } \\
\text { blamed ( } \S 2 \text {, para. } 1 \text {, } \\
\text { item a) }\end{array}$ & $\begin{array}{l}\text { 1. treatment, but only } \\
\text { if avoidable by a } \\
\text { different performance } \\
\text { or by an alternative } \\
\text { procedure done by an } \\
\text { experienced specialist } \\
(\S 20 \text {, para. } 1 \text {, items } 1 \\
\& 3)\end{array}$ \\
\hline $\begin{array}{l}\text { 2. defects in } \\
\text { equipment ( } \S 6 \text {, para. } \\
1 \text {, item } 2)\end{array}$ & $\begin{array}{l}\text { 2. defects in } \\
\text { equipment ( } \$ 2 \text {, } \\
\text { para. 1, item 2) }\end{array}$ & $\begin{array}{l}\text { 2. failure of } \\
\text { equipment ( } \S 2 \text {, para. } \\
1 \text {, item b) }\end{array}$ & $\begin{array}{l}\text { 2. failure of equipment } \\
(\S 20 \text {, para. } 1 \text {, item } 2)\end{array}$ \\
\hline $\begin{array}{l}\text { 3. an incorrect } \\
\text { diagnosis that could } \\
\text { be avoided by an } \\
\text { experienced specialist } \\
(\S 6 \text {, para. } 1 \text {, item } 3 \& \\
\text { para.2) }\end{array}$ & - & - & $\begin{array}{l}\text { 3. an incorrect } \\
\text { diagnosis leading to } \\
\text { failure in performing a } \\
\text { chosen procedure or } \\
\text { using apparatus ( } \S 21 \text {, } \\
\text { para. } 1)\end{array}$ \\
\hline $\begin{array}{l}\text { 4. an infection that } \\
\text { should not be } \\
\text { reasonably tolerated } \\
(\$ 6 \text {, para. } 1 \text {, item } 4 \& \\
\text { para. } 3)\end{array}$ & $\begin{array}{l}\text { 3. an infection that } \\
\text { should not be } \\
\text { reasonably } \\
\text { tolerated by the } \\
\text { patient ( } \$ 2 \text {, para. } 1 \text {, } \\
\text { item } 3)\end{array}$ & $\begin{array}{l}\text { 3. an infection that is } \\
\text { not mainly due to } \\
\text { the patient's } \\
\text { underlying condition } \\
\text { (§ 2, para. } 1 \text {, item c) }\end{array}$ & $\begin{array}{l}\text { 4. infections or } \\
\text { complications that } \\
\text { should not be } \\
\text { reasonably tolerated } \\
\text { by the patient ( } § 20 \text {, } \\
\text { para. } 1 \text {, item } 4 \text { ) }\end{array}$ \\
\hline $\begin{array}{l}\text { 5. premises-related } \\
\text { accidents (e.g. a fire } \\
\text { in the hospital) ( } \S 6 \text {, } \\
\text { para. } 1 \text {, item } 5)\end{array}$ & $\begin{array}{l}\text { 4. premises-related } \\
\text { accidents ( } \S 2 \text {, para. } \\
1 \text {, item } 4) \text {, } \\
\text { including a fire ( } \S \\
2 \text {, para. } 1 \text {, item } 5)\end{array}$ & $\begin{array}{l}\text { 4. conditions that } \\
\text { entail medical } \\
\text { malpractice under } \\
\text { tort law ( } \S 2 \text {, para. } 1 \text {, } \\
\text { item e) }\end{array}$ & $\begin{array}{l}\text { 5. premises-related } \\
\text { accidents (hospitals } \\
\text { assumed to be at fault) } \\
(\S 21, \text { para. } 2)\end{array}$ \\
\hline $\begin{array}{l}\text { 6. incorrect } \\
\text { medication (not side- } \\
\text { effects) ( } \S 6 \text {, para. } 1 \text {, } \\
\text { item } 6)\end{array}$ & $\begin{array}{l}\text { 5. incorrect } \\
\text { medication }(\S 2, \\
\text { para. } 1 \text {, item } 6)\end{array}$ & $\begin{array}{l}\text { 5. vaccination }(\S 2, \\
\text { para. } 1, \text { item d) }\end{array}$ & - \\
\hline
\end{tabular}

192 Table 11.1 is based on Dute 2004, pp. 451-452, Table 1, with necessary updates. 


\begin{tabular}{|c|c|c|c|}
\hline- & $\begin{array}{l}\text { 6. unreasonable } \\
\text { permanent and } \\
\text { severe disability or } \\
\text { death ( } \S 2 \text {, para. } 1 \text {, } \\
\text { item } 7)\end{array}$ & $\begin{array}{l}\text { 6. particularly severe } \\
\text { or particularly } \\
\text { unexpected adverse } \\
\text { events that should be } \\
\text { considered as an } \\
\text { unacceptable risk to } \\
\text { the patient ( } \$ 2 \text {, para. } \\
\text { 3) }\end{array}$ & - \\
\hline Exclusions: & Exclusions: & Exclusions: & Exclusions: \\
\hline $\begin{array}{l}\text { 1. a consequence of a } \\
\text { necessary procedure } \\
\text { without which } \\
\text { patients would die or } \\
\text { become severely } \\
\text { disabled ( } \$ 7 \text {, para. } 1 \text {, } \\
\text { item } 1 \text { ) }\end{array}$ & - & $\begin{array}{l}\text { 1. injuries due to } \\
\text { inadequate } \\
\text { resources, if the } \\
\text { distribution of } \\
\text { resources has been } \\
\text { prudent and business } \\
\text { keeps a proper } \\
\text { standard ( } § 2 \text {, para. } \\
2 \text { ) }\end{array}$ & - \\
\hline $\begin{array}{l}\text { 2.side-effects of } \\
\text { correct medication ( } \S \\
7 \text {, para. } 1 \text {, item } 2)\end{array}$ & $\begin{array}{l}\text { 1. side-effects of } \\
\text { correct medication } \\
(\S 2, \text { para. } 2)\end{array}$ & - & $\begin{array}{l}\text { 1. injuries resulting } \\
\text { from medication }(\S 21 \text {, } \\
\text { para. } 3)\end{array}$ \\
\hline
\end{tabular}

Under tort law, this result would effectively change the negligence rule into strict liability to all less than best doctors. Fault under traditional tort law is determined by answering the question whether the injury is avoidable by the reasonable man rather than by the best man. In this regard, although Scandinavian NFCSs employ the concept of avoidability to limit the scope of compensable adverse events, the notion of fault as defined under tort law does not play any role here and "the overall question is if the patient has received the treatment, which according to medical science and experience, would have been the best for him." ${ }^{193}$ In Sweden, the test of avoidability appears less stringent because it is assessed "retroactively"194 rather than prospectively. Accordingly, an injury is still compensable if subsequent information after the treatment indicates that it was medically avoidable, although doctors did not have enough information to make the right decision before the treatment.

The scope of compensation seems more extensive in Sweden and Denmark than in Finland in that an injury that can be avoided by an alternative treatment is compensable as well in the former. The "alternative treatment rule" provides that an injury would be compensable if it could have been avoided, on the basis of "a subsequent evaluation," if the provider had chosen another available treatment measure that "would have satisfied the

$\begin{array}{ll}193 & \text { Ulfbeck, Hartlev \& Schultz 2013, p. } 384 . \\ 194 & \text { Swedish PIA, 2, para. 1, item 1. }\end{array}$ 
need of treatment in a less hazardous way" 195 or "would have been just as effective in treating the patient's illness." 196 This alternative treatment rule is not a fault-based rule since it does not ex ante require that the provider should have chosen the alternative treatment measure. ${ }^{197}$ Hence, both information available at the time of the treatment and information that becomes available after the treatment are essential to the application of the alternative treatment rule with hindsight. ${ }^{198}$ Two points need to be emphasised: first, the alternative measure must have been available at the time of the treatment; and second, it the alternative measure requires superior skill, the doctor must refer the patient to a more skilful doctor. ${ }^{199}$

In Sweden and Denmark, an incorrect diagnosis is singled out as a separate compensable event. Whether a diagnosis is correct or not is also determined by the experienced specialist standard. It is unclear whether Finland and Norway recognise this event as compensable. If we accepted that "examination, treatment or other similar action"200 and "providing health care"201 had already covered diagnosis, then there would be no reason why injury due to incorrect diagnosis should not be included under Finnish and Norwegian NFCSs.

Not only injuries due to incorrect treatment behaviour (e.g. diagnosis, examination and surgery) are compensable, but injuries resulting from the failure of apparatus are coverable as well under all four Scandinavian NFCSs. Whereas Sweden and Finland employ the same test as under products liability (i.e. defects in equipment), Norway and Denmark adopt a more lenient test - merely malfunction or failure of any equipment suffices for claiming compensation. Hence, patients in Norway and Denmark may find it easier to obtain compensation for injury due to equipment than patients in Sweden and Finland.

In addition to injury arising out of treatment or equipment failure, some other types of accidents occurring within the hospital may be compensable as well. In Sweden and Finland, an accident such as a fire at the hospital is recoverable. In Denmark and Norway, however, an accident occurring at the hospital is compensable only if the hospital may be liable under tort law. Thus, the notion of fault still plays a role in premises-related accidents under the Danish and Norwegian NFCSs.

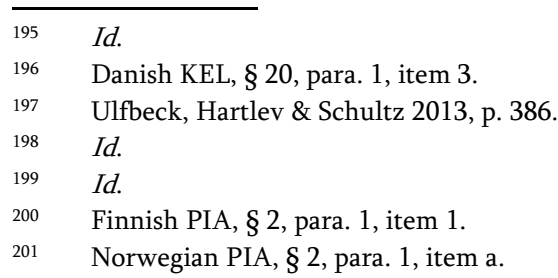


Injury due to an infection is also singled out as a separate iatrogenic injury. However, no infection is compensable. In Sweden, Finland, and Denmark, an injury arising out of an infection is compensable only if it should not be reasonably tolerated by the patient. The reasonableness is normally tested against several factors as follows: (a) the predictability of the infection, (b) the degree of severity of the injury, (c) the nature or difficulty of the illness or impairment, or (d) the patient's overall health. ${ }^{202}$ In Norway, although the preceding factors are not provided, it is still required that the infection is not mainly due to the patient's underlying condition. These two tests are the two sides of the same coin. Indeed, an infection that is not primarily the result of the patient's pre-existing condition should not be reasonably tolerated by the patient; and vice versa. Nonetheless, the former three systems provide for detailed factors against which the reasonableness can be assessed.

Be that as it may, regarding the test of reasonableness, Norway remarkably has a general reasonableness rule for all types of iatrogenic injuries:

Although there is no basis for liability under subsections, compensation may be granted exceptionally where there has been an adverse event that is particularly large or particularly unexpected, and which cannot be considered as the outcome of a risk that the patient must accept. Emphasis should be on whether there is adequate disclosure in advance. ${ }^{203}$

Strikingly, Finland also has a similar general reasonableness rule but only for "permanent, severe illness or impairment, or death." 204

It ought to be noted that the reasonableness rule under Scandinavian NFCSs has nothing to do with the notion of reasonable man under tort law. The former rule is intended to demarcate the risk that the patient must accept from the one that the patient should not accept, whereas the latter test is meant to determine whether the provider has breached the duty of care. The wording "reasonableness" here does not imply any notion of fault. Irrespective of whether the reasonableness rule applies only to injury due to an infection or to general iatrogenic injuries, the rationale behind this rule is that patients have to bear risks of their underlying conditions. ${ }^{205}$ Hence, "the

\footnotetext{
202 Swedish PIA, § 6, para. 3; Finnish PIA§ 2, para. 1, item 3; Danish KEL, § 20, para. 1, item 4.

$203 \quad$ Norwegian PIA, § 2, para. 3.

$204 \quad$ Finnish PIA, § 2, para. 1, item 7.

205 Ulfbeck, Hartlev \& Schultz 2013, p. 387.
} 
more serious the initial disease, the more substantial complications must be accepted."206

As far as injury due to medication is concerned, both Sweden and Finland require that the injury is compensable only if the prescription or provision of pharmaceuticals is in contravention of regulations. However, Norway and Denmark do not have similar provisions concerning incorrect medication. Nevertheless, in Norway, injury resulting from vaccination is compensable no matter whether any regulation is violated.

In addition to the foregoing compensable events, some events are explicitly excluded from the scope of compensation under Scandinavian NFCSs. In Sweden, injuries due to a consequence of a necessary procedure without which patients would die or become severely disabled are not compensable. In both Sweden and Finland, injuries resulting from side-effects of correct medication, and in Denmark, all injuries resulting from medication, are not coverable. In Norway, injuries due to inadequate resources, if the distribution of resources has been prudent and business keeps a proper standard, are not covered by the NFCS.

Iatrogenic injury claims in practice. The number of claims and the compensation awarded annually has been increasing under some of the four Scandinavian NFCSs during these years. In Denmark, the number of claims rose from 5, 519 in 2008 to 7,489 in 2010, of which around 35.3\% to $35.7 \%$ were successful. ${ }^{207}$ In Sweden, the number of claims increased from 9,000 in 2005 to 12,000 in 2011, of which about $44 \%$ were successful. ${ }^{208}$ In Norway, the number of claims rose from 2,332 in $2003^{209}$ to 4,352 in 2010, of which roughly $44 \%$ were successful. ${ }^{210}$ However, in Finland, where the success rate was about 30\%, there was a decline in 2009 and 2010 compared to previous years. ${ }^{211}$ Nonetheless, the number increased again from 6,696 in 2012, to 7,659 in 2013 and 8,502 in 2014..$^{212}$

\subsubsection{Comparison and Summary}

The eligibility of victimised patients for compensation is the primary feature that distinguishes an NFCS from the tort system. After examining the detailed requirements of compensation for iatrogenic injuries under both the NZ-

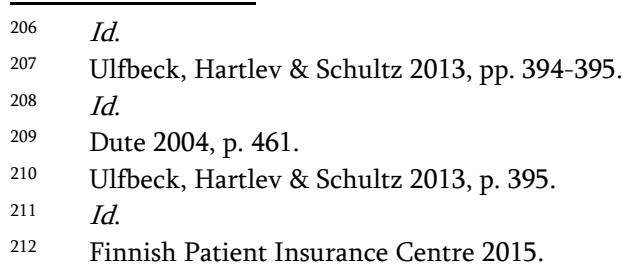


NFCS and the Scandinavian NFCSs, we can see that the former appears more patient-friendly than the latter.

First, regarding the definition of the compensable event, the current NZ Act 2001 provides that an injury caused by treatment is readily compensable unless it is a necessary part, or ordinary consequence of the treatment. In other words, many known complications, even if they are not rare or severe, are likely to be compensable under the NZ-NFCS. In contrast, in most Scandinavian systems, a special requirement of avoidability has to be satisfied. This stringent requirement is intended to limit compensable events to those that can be avoided by the experienced specialist (the best doctor). Thus, many known complications are not compensable in that even the best doctor cannot prevent it.

Second, as far as the scope of compensable events is concerned, almost all the events enumerated under the Scandinavian NFCSs are also covered by the NZ-NFCS. ${ }^{213}$ Moreover, the NZ-NFCS provides the patient with compensation for injuries due to failure in obtaining informed consent, which does not seem to be a compensable event under the Scandinavian NFCSs.

The preceding analysis may explain why currently the success rate under the NFCS is about $60 \%$ in New Zealand, while roughly only $40 \%$ in Scandinavia.

\subsubsection{Other Features}

\subsubsection{Benefits}

Categories of benefits. The benefits granted by the NFCSs in both New Zealand and the four Scandinavian systems are summarised in Table 11.2. As far as the relationship between the NFCSs and tort law is concerned, in New Zealand and Denmark, to the extent injuries are covered by NZ Act 2001 and the Danish KEL, tort claims are not allowed. ${ }^{214}$

$213 \quad$ See supra Chapter 11, Section 5.2.1.1.

214 NZ Act 2001, Section 317(1); Danish KEL, § 26. 
Part II. Economic Theories and Empirical Evidence

Table 11.2: No-Fault Compensation Systems: Scope of Benefits ${ }^{215}$

\begin{tabular}{|c|c|c|c|c|}
\hline New Zealand & Sweden & Finland & Norway & Denmark \\
\hline $\begin{array}{l}\text { Only pecuniary } \\
\text { losses: (NZ Act } \\
\text { 2001) }\end{array}$ & $\begin{array}{l}\text { In principle, } \\
\text { applying law on } \\
\text { tort damages } \\
\text { (Swedish PIA, § } \\
\text { 8) }\end{array}$ & $\begin{array}{l}\text { In principle, } \\
\text { applying law on } \\
\text { tort damages } \\
\text { (Finnish PIA, § } \\
\text { 3) }\end{array}$ & $\begin{array}{l}\text { In principle, } \\
\text { applying law on } \\
\text { tort damages } \\
\text { (Norwegian } \\
\text { PIA, § 4) }\end{array}$ & $\begin{array}{l}\text { In principle, } \\
\text { applying law on } \\
\text { tort damages } \\
\text { (Danish KEL, } \S \\
24 \text {, para. } 1 \text { ) }\end{array}$ \\
\hline $\begin{array}{l}\text { 1. expenses of } \\
\text { treatment and } \\
\text { rehabilitation } \\
(\text { Section } 69(1)(a))\end{array}$ & $\begin{array}{l}\text { 1. medical costs } \\
\text { and other } \\
\text { necessary } \\
\text { expenses } \\
\text { (Swedish Tort } \\
\text { Act, Chapter } 5 \text {, } \\
\S 1 \text {, para. } 1 \text { ) }\end{array}$ & $\begin{array}{l}\text { 1. medical costs } \\
\text { and other costs } \\
\text { (Finnish Tort } \\
\text { Act, § 2) }\end{array}$ & $\begin{array}{l}\text { 1. the damage } \\
\text { suffered } \\
\text { (Norwegian } \\
\text { Damages Act, § } \\
\text { 3-1) }\end{array}$ & $\begin{array}{l}\text { 1. recovery costs } \\
\text { and other losses } \\
\text { (Danish Damages } \\
\text { Act, } § 1 \text {, para. 1) }\end{array}$ \\
\hline $\begin{array}{l}\text { 2. earnings- } \\
\text { related } \\
\text { compensation } \\
\text { (Section } \\
69(1)(b)-(c))\end{array}$ & $\begin{array}{l}\text { 2. loss of } \\
\text { income } \\
\text { (Swedish Tort } \\
\text { Act, Chapter 5, } \\
\S 1 \text {, para. } 2 \text { ) }\end{array}$ & $\begin{array}{l}\text { 2. loss of } \\
\text { income } \\
\text { (Finnish Tort } \\
\text { Act, § 2) }\end{array}$ & $\begin{array}{l}\text { 2. loss of future } \\
\text { earnings } \\
\text { (Norwegian } \\
\text { Damages Act, § } \\
3-1 \text { ) }\end{array}$ & $\begin{array}{l}\text { 2. loss of } \\
\text { earnings (Danish } \\
\text { Damages Act, } \S \\
1 \text {, para. } 1 \& \S 2 \text { ) }\end{array}$ \\
\hline $\begin{array}{l}\text { 3. lump sum } \\
\text { compensation } \\
\text { for permanent } \\
\text { impairment } \\
\text { (Section } \\
69(1)(d))\end{array}$ & $\begin{array}{l}\text { 3. permanent } \\
\text { disability } \\
\text { (Swedish Tort } \\
\text { Act, Chapter } 5 \text {, } \\
\S 1 \text {, para. } 3 \text { ) }\end{array}$ & $\begin{array}{l}\text { 3. invalidity } \\
\text { and other } \\
\text { permanent } \\
\text { handicap } \\
\text { (Finnish Tort } \\
\text { Act, § 2) }\end{array}$ & - & $\begin{array}{l}\text { 3. permanent } \\
\text { injury (Danish } \\
\text { Damages Act, } \S \\
1 \text {, para. } 2 \& \S 4 \text { ) }\end{array}$ \\
\hline $\begin{array}{l}\text { 4. death benefits } \\
\text { (Section } 69(1)(e))\end{array}$ & $\begin{array}{l}\text { 4. death } \\
\text { benefits } \\
\text { (Swedish Tort } \\
\text { Act, Chapter 5, } \\
\S 2 \text { ) }\end{array}$ & $\begin{array}{l}\text { 4. death } \\
\text { benefits } \\
\text { (Finnish Tort } \\
\text { Act, } \S \S 3-4 a \text { ) }\end{array}$ & $\begin{array}{l}\text { 3. death } \\
\text { benefits } \\
\text { (Norwegian } \\
\text { Damages Act, § } \\
3-4 \text { ) }\end{array}$ & $\begin{array}{l}\text { 4. death benefits } \\
\text { (Danish Damages } \\
\text { Act, } \S \S 13-14 \text { ) }\end{array}$ \\
\hline - & $\begin{array}{l}\text { 5. (temporary) } \\
\text { pain and } \\
\text { suffering } \\
\text { (Swedish Tort } \\
\text { Act, Chapter 5, } \\
\S 1 \text {, para. } 3 \text { ) }\end{array}$ & $\begin{array}{l}\text { 5. pain and } \\
\text { suffering } \\
\text { (Finnish Tort } \\
\text { Act, § 2) }\end{array}$ & - & $\begin{array}{l}\text { 5. pain and } \\
\text { suffering (capped } \\
\text { to DKK } 130 \text { per } \\
\text { day for a sick } \\
\text { man; at most } \\
\text { DKK 50,000 for a } \\
\text { non-sick man) } \\
\text { (Danish Damages } \\
\text { Act, §3) }\end{array}$ \\
\hline
\end{tabular}

215 Table 11.2 is based on Dute 2004, p. 460, Table 2, with necessary updates. 
Medical Compensation Mechanisms Not Based on Fault

\begin{tabular}{|c|c|c|c|c|}
\hline Limitations: & Limitations: & Limitations: & Limitations: & Limitations: \\
\hline $\begin{array}{l}\text { 1. excluded in } \\
\text { cases of wilfully } \\
\text { self-inflicted } \\
\text { personal injuries } \\
\text { and suicide } \\
\text { (Section 119) }\end{array}$ & $\begin{array}{l}\text { 1. reduced only } \\
\text { if the injured } \\
\text { party } \\
\text { intentionally or } \\
\text { through gross } \\
\text { negligence } \\
\text { contributed to } \\
\text { the harm } \\
\text { (Swedish Tort } \\
\text { Act, Chapter 6, } \\
\S 1 \text { ) }\end{array}$ & $\begin{array}{l}\text { 1. reduced only } \\
\text { if the injured } \\
\text { party acted } \\
\text { wilfully or } \\
\text { through } \\
\text { negligence } \\
\text { (Finnish PIA, § } \\
\text { 3) }\end{array}$ & $\begin{array}{l}\text { 1. recovery for } \\
\text { non-pecuniary } \\
\text { losses is } \\
\text { excluded } \\
\text { (Norwegian } \\
\text { PIA, § 4, para. } \\
\text { 1) }\end{array}$ & $\begin{array}{l}\text { 1. reduced only } \\
\text { if the patient } \\
\text { contributed to } \\
\text { the injury } \\
\text { wilfully or } \\
\text { through gross } \\
\text { negligence } \\
\text { (Danish KEL, § } \\
\text { 25) }\end{array}$ \\
\hline $\begin{array}{l}\text { 2. excluded in } \\
\text { cases of some } \\
\text { crimes or } \\
\text { offenders } \\
\text { (Sections } 120 \text { - } \\
122 \text { ) }\end{array}$ & $\begin{array}{l}\text { 2. deduction } \\
\text { (one twentieth } \\
\text { of the base } \\
\text { amount be } \\
\text { deducted) } \\
\text { (Swedish PIA, § } \\
\text { 9) }\end{array}$ & $\begin{array}{l}\text { 2. minor } \\
\text { injuries are not } \\
\text { compensable } \\
\text { (Finnish PIA, § } \\
\text { 3) }\end{array}$ & $\begin{array}{l}\text { 2. losses below } \\
10,000 \text { crowns } \\
\text { are not } \\
\text { compensable } \\
\text { (Norwegian } \\
\text { PIA, § 4, para. } \\
\text { 1) }\end{array}$ & $\begin{array}{l}\text { 2. compensation } \\
\text { for loss of } \\
\text { earnings and } \\
\text { pain and } \\
\text { suffering is } \\
\text { excluded unless } \\
\text { the injury was } \\
\text { lasting more } \\
\text { than a fixed } \\
\text { period up to } \\
\text { three months } \\
\text { (Danish KEL, § } \\
\text { 24, para. 2) }\end{array}$ \\
\hline $\begin{array}{l}\text { 3. cover for non- } \\
\text { pecuniary losses } \\
\text { are excluded } \\
\text { unless it is } \\
\text { mental injury (a } \\
\text { clinically } \\
\text { significant } \\
\text { dysfunction) } \\
\text { (Section 27) }\end{array}$ & $\begin{array}{l}\text { 3. caps (at most } \\
1,000 \text { times the } \\
\text { base amount } \\
\text { per event; } 200 \\
\text { times the base } \\
\text { amount per } \\
\text { injured patient } \\
\text { per event) } \\
\text { (Swedish PIA, § } \\
\text { 10) }\end{array}$ & - & - & $\begin{array}{l}\text { 3. injuries must } \\
\text { exceed DKK } \\
\text { 10,000 (Danish } \\
\text { KEL, § 24, para. } \\
\text { 2) }\end{array}$ \\
\hline $\begin{array}{l}\text { 4. exemplary } \\
\text { damages } \\
\text { excluded }\end{array}$ & & & & \\
\hline
\end{tabular}

In New Zealand, is it argued that victims waive their right to tort claims in return for no-fault compensation. ${ }^{216}$ In Denmark, the rationale behind this arrangement is "to channel liability to the patient insurance." 17 Contrariwise, the other three Scandinavian systems allow patients to file an ordinary tort

216 Queenstown Lakes District Council v. Palmer [1999] 1 NZLR 549 (CA).

217 Ulfbeck, Hartlev \& Schultz 2013, p. 383. 
claim as an alternative to the NFCSs. ${ }^{218}$ Be that as it may, very few patients choose to obtain compensation through the tort system due to the difficult burden of proof for loss, causation and fault. ${ }^{219}$ Patients already enjoy a considerably better position within the patient insurance scheme than under tort law. 220

Pecuniary losses are compensable in all the five legal systems surveyed, whereas non-pecuniary losses are only completely compensable under the Swedish and Finnish NFCSs. Under the NZ-NFCS, only mental injury, which is defined as a clinically significant behavioural, cognitive, or psychological dysfunction, is compensable. In other words, non-pecuniary losses without dysfunctional results (e.g. pain and suffering for a short period) are not recoverable. Cover for non-pecuniary losses is totally excluded under the Norwegian NFCS. In Denmark, compensation for pain and suffering is excluded unless the injury lasted more than a fixed period up to three months. Hence, patients seeking non-pecuniary losses are worse off in New Zealand and Denmark, since access to tort litigation is blocked under the NFCSs there. ${ }^{221}$ The other three systems seem less problematic since they allow patients to file tort claims as an alternative to the NFCSs.

Regarding the amount of compensation, there are several types of limitations. One common form of limitation in all the surveyed systems except Norway is that the patient herself contributed to her injury intentionally or through gross negligence. In such a case, patients will lose their entitlement to compensation in New Zealand, while they will only be entitled to reduced compensation in Sweden, Finland, and Denmark. Moreover, in New Zealand, a claim for compensation under the NFCS will be denied as well if a patient is involved in some crimes.

Another form of limitation characteristic of all the four Scandinavian NFCSs is that compensation is normally deducted or capped. In Sweden, one twentieth of the base amount under the National Insurance Act, i.e. SEK 2,225 in 2015,222 should be deducted from patient compensation when the amount is determined. In Finland, minor injuries are not compensable, although the Finish PIA does not provide for a figure for the deductible element. In contrast, the deductible is stipulated explicitly in other systems 10,000 crowns in Norway and DKK 10,000 in Denmark. Financial caps are also imposed on compensation in Sweden, where at most 1,000 times the base

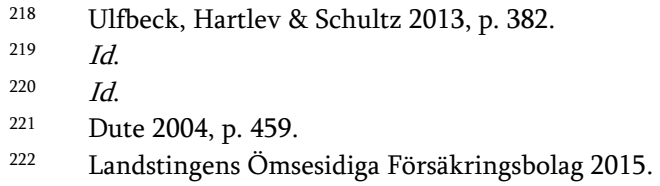


amount could be granted per event, and 200 times the base amount per injured patient per event.

Benefits actually paid. In New Zealand, the benefits paid out were increasing dramatically from $\$ 48.6 \mathrm{~m}$ in $2004-05$ to $\$ 56.5 \mathrm{~m}$ in $2005-5006$, $\$ 69.2 \mathrm{~m}$ in $2006-07, \$ 86.3 \mathrm{~m}$ in $2007-08, \$ 109.8 \mathrm{~m}$ in $2008-09$, and $\$ 106 \mathrm{~m}$ in $2009-10.223$ A shift from compensating medical misadventure to compensating treatment injury was estimated to lead to an annual increase of $\$ 8.7 \mathrm{~m} .{ }^{224}$ The escalating costs of the treatment injury account dwarfed funding. The account deficit rose from $\$ 332.5$ million in 2004-05 to $\$ 1.4$ billion in 2009$10 .{ }^{225}$ To sum up, the accident compensation in New Zealand is facing financial problems, which is "driven by years of significant increases in costs and increasing numbers of claims." 226 Todd explained that this difficulty reflects "a shift from ACC being a public insurance scheme to it becoming an extension of the welfare state."227

Available data in the Scandinavian systems showed the same trend. For instance, in Denmark, total compensation rose from 437.6 million DKR in 2008 to 660.5 million DKR in 2010, with an average compensation of 183.56 DKR for the period 2008-2010.228 In Norway, total annual compensation was 818.4 million NKR in 2010, which was higher than that in Denmark. ${ }^{229}$ In Finland, indemnities paid altogether rose from $€ 30,975 \mathrm{~m}$ in 2009 , to $€ 32.645 \mathrm{~m}$ in 2010 , €32.972m in 2011, €34.596m in 2012, €38.853m in 2013, and $€ 40.144 \mathrm{~m}$ in $2014 .{ }^{230}$

\subsubsection{Procedures}

In New Zealand, the claimant may make a claim for cover for her treatment injury. ${ }^{231}$ The patient's provider may lodge a claim on behalf of her with authorization. ${ }^{232}$ On receiving the claim for cover, the ACC must decide whether it accepts that the patient has cover and provide her with information about the role of the Health and Disability Commissioner (hereinafter HDC). ${ }^{233}$ The patient must make a claim within 12 months after

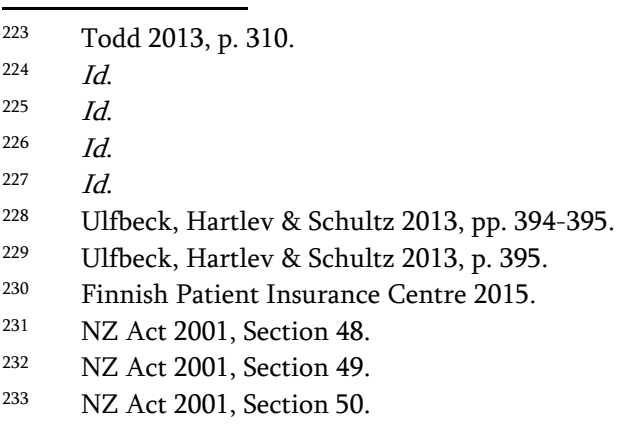


the later of the date that the injury was first considered by a registered health professional as a treatment injury. ${ }^{234}$ The ACC must make decisions in time and give reasons if it decides against the claimant. ${ }^{235}$ An appeal may be filed before the District Court. ${ }^{236}$

In Sweden, all county councils and regions are insured under a common insurer, Landstingens Ömsesidiga Försäkringsbolag (hereinafter LÖF) (The County Council's Mutual Insurance Company). ${ }^{237}$ An injured patient must make a claim within three years from learning that a claim could be made, and in any case within ten years from the time when the injury occurred. ${ }^{238}$ The LÖF in turn commissions the company Personskadereglering $\mathrm{AB}$ (PSR) to handle the claims for compensation. ${ }^{239}$ More than $90 \%$ of all patient injury claims are processed by the PSR. ${ }^{240}$ In addition, the Patientskadenämnden (Patient Claims Panel) (hereinafter PCP) is established to provide advisory opinions on matters concerning patient injury compensation, in order to "promote uniform and fair application" of the Swedish PIA. ${ }^{241}$ The PCP is composed of a chairman, three members representing patients' interests, one medical expert, one specialist on medical care issues and one specialist on claims adjustment. ${ }^{242}$ Review by the PCP is free of charge and remains confidential. ${ }^{243}$ Once a patient is not satisfied with the decision of the LÖF, he/she can request that her claim be reviewed by the PCP. ${ }^{24}$ The PCP will process the claim and formulate a decision. ${ }^{245}$ The opinion of the PCP is advisory, which means that the LÖF is not obliged to comply with the opinion but this is almost always what happens. ${ }^{246}$

In Finland, all insurance companies are entitled to provide patient insurance under the Finnish NFCS. ${ }^{247}$ All those insurance companies that issue patient insurance policies in Finland must be members of Potilasvakuutuskeskus (Finnish Patient Insurance Centre) (hereinafter $\mathrm{PVK}){ }^{248} \mathrm{PVK}$ settles patient injury claims and may issue insurance on behalf

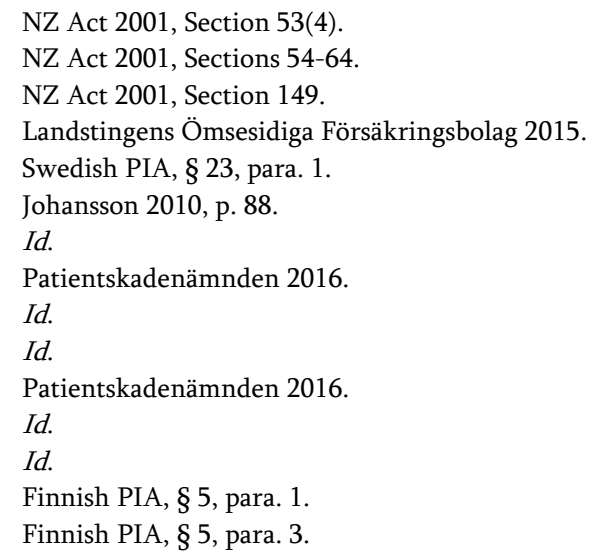


of its member companies. ${ }^{249} \mathrm{PVK}$ also has to settle claims made to any member company that become bankrupt. ${ }^{250}$ In addition, PVK promotes patient safety through conducting research, collecting data, and making predictions. ${ }^{251}$ The claim should be presented to the PVK within three years since the injured patient learned or should have learned of the injury and the patient will in any case lose her entitlement to compensation if he/she makes the claims ten years after the adverse event. ${ }^{252}$ The Government appoints Potilasvahinkolautakunta (Patient Injuries Board) (hereinafter PVLTK) to issue recommendations for decisions on individual claims at the request of a claimant, the PVK, a provider or an insurer. ${ }^{253}$ Claims are processed by PVLTK in accordance with the Administrative Procedure Act (434/2003) and are free of charge. ${ }^{254}$ Decisions made by PVLTK are recommended decisions that are not subject to appeal. 255

In Norway, the Ministry of Health has established the Norsk Pasientskadeerstatning (Norwegian System of Patient Injury Compensation) (hereinafter NPE) to process claims from injured patients, the proceedings of which are free of charge. ${ }^{256} \mathrm{NPE}$ investigates the matter and decides whether to grant the benefits. ${ }^{257}$ Compensation should be granted immediately after the case is settled.258 NPE's decision can be appealed to Pasientskadenemnda (Patient Injury Compensation Board) (hereinafter PSN) within three weeks. ${ }^{259}$

In Denmark, administrators of public hospitals, pre-hospital care, regional dental care, university schools of dentistry, and regions of a patient or where a privately practising provider is located should be liable to pay compensation. ${ }^{260}$ These potentially liable bodies may insure against patient injury claims. ${ }^{261}$ The annual cover amounts are determined by the Minister of the Interior and Health. ${ }^{262}$ However, the Government, Regional and district/city councils shall be exempt from the legal duty to insure against patient injury claims. ${ }^{263}$ In other words, they may choose to self-insure.

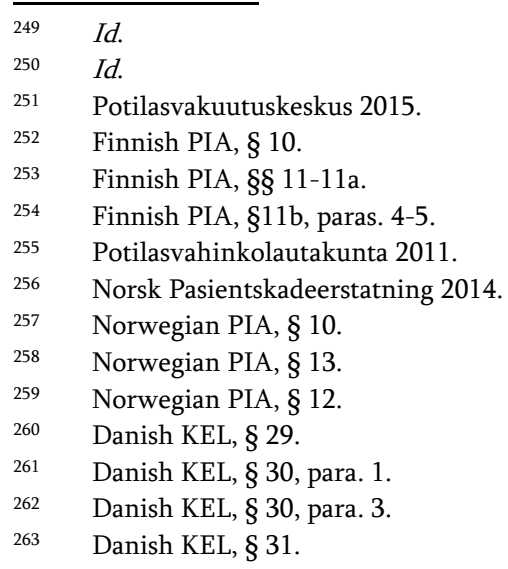


"Patient insurance"264 companies and self-insuring regional and district/city councils have jointly set up Patienterstatningen (Patient Insurance Association) (hereinafter PEBL), the task of which is to help patients injured in connection with treatment. ${ }^{265}$ The PEBL will receive, elucidate and decide all compensation claims and may arrange for the district court to question witnesses. ${ }^{266}$ The relevant insurer, the Government or the self-insuring regional council or district/city councils should then pay out benefits on the basis of the PEBL's decisions. ${ }^{267}$ An appeal may be lodged before the Patients' Complaints Board of Appeal. ${ }^{268}$

\subsubsection{Financing}

In some systems surveyed, NFCSs are funded by general taxation. Under the NZ-NFCS, the Treatment Injury Account has not been funded by health care providers directly; rather, it is funded from the Earner's and Non-Earners' Accounts, which are ultimately financed by earners and general taxation. ${ }^{269}$ In Norway, state, regional health authorities, counties and municipalities provide grants to the NPE to cover compensation for patient injuries caused by public health care providers. ${ }^{270}$

In the other systems surveyed, NFCSs are funded by the health care industry. Under the Swedish NFCS, health care providers have to contribute to the patient insurance fund. ${ }^{271}$ The insurance policy is actually held by the regions, not by single doctors (enterprise liability). ${ }^{272}$ In Finland, health care providers are obliged to purchase patient insurance against liability under the NFCS. ${ }^{273}$ In Denmark, administrators of health care providers and regions of resident have to make contributions to the NFCS fund. ${ }^{274}$ Interestingly, although cover for injuries arising out of public health care is financed by the

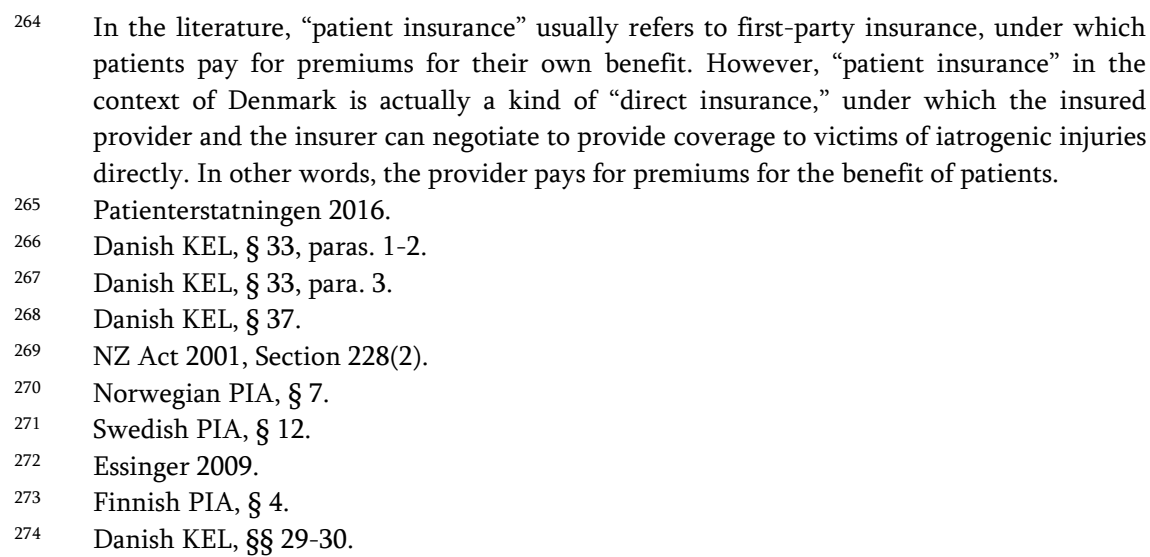


government in Norway, private health care providers have to contribute to the NPE themselves. ${ }^{275}$

Be that as it may, none of these systems has ever attempted to link the cost of a patient injury directly to a particular health care provider. ${ }^{276}$ Risk differentiation through experience rating does not apply to these NFCSs.

\subsubsection{Costs}

Costs in a single case. Dewees, Duff, and Trebilcock gave four reasons to explain why the comprehensive NFCS is able to "reduce delays and administrative costs below levels" existing under the current tort system in a single case, as follows:277

- The NFCS is likely to process claims more quickly and less costly than the current malpractice system does since the adversarial character of the tort system is avoided.

- Periodic payments eliminate the delays and costs involved in the assessment of lump sum damages.

- Restrictions imposed on or schedules applied to the evaluation of nonpecuniary losses economises on administrative costs since these intangible losses are difficult to measure.

- It is less burdensome to determine only causation than to determine both causation and fault.

It should be noted that, regarding the last feature, some scholars did not believe that substituting causation for the negligence rule would significantly reduce administrative costs in that causation issues in medical cases per se are very complicated due to the patient's pre-existing conditions. ${ }^{278}$ However, the Harvard Medical Practice Study Group reported that it is indeed less costly to evaluate causation than to determine negligence - only $14.2 \%$ of adverse events were found to involve close calls whereas $25.7 \%$ of negligent adverse events were considered close calls. ${ }^{279}$

Empirical evidence demonstrates that the NFCS saves greater administrative costs than does the fault-based malpractice system in a single claim. Dewees, Duff, and Trebilcock reported that most claims for medical misadventure in New Zealand were paid without much delay and that

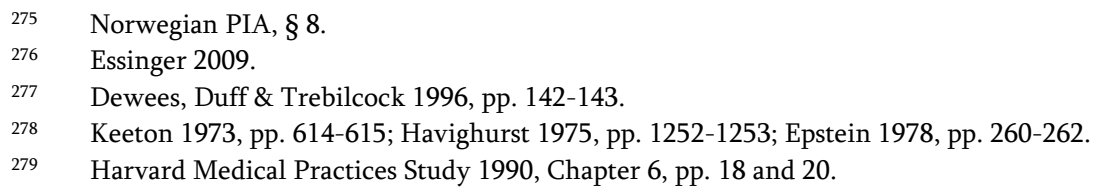


"administrative costs accounted for less than $10 \%$ of total premium dollars collected" under the NZ-NFCS before 1992. ${ }^{280}$ This number seems rather stable even today. In 2009, the NZ-NFCS's administrative costs equalled to $13.4 \%$ of claims paid. ${ }^{281}$ In Sweden, about $14 \%$ to $17.5 \%$ of total insurance premiums were reported to be spent on administration. ${ }^{282}$ In contrast, about $55 \%-60 \%$ of one premium dollar were due to administrative costs under the traditional malpractice system in the US. ${ }^{283}$ Recently, Essinger reported that in the US $72 \%$ of the premium is spent on legal services and administration, whereas only $28 \%$ of the premium is paid to the victimised patient. ${ }^{284}$ In the UK, about $45 \%$ of the compensation award was swallowed up in the administration of the tort system. ${ }^{285}$ In Sweden, about $58 \%$ of patient injury claims were resolved within five months of filing and $80 \%$ within seven months, whereas it took an average of 3 years to resolve a malpractice claim in the US. ${ }^{286}$

The increased costs of shifting from fault towards no-fault. Some empirical evidence indicated that between $17 \%$ and $27.6 \%$ of all iatrogenic injuries were due to provider negligence and only between $6.25 \%$ and $8 \%$ of these negligently injured patients obtain any compensation through the tort system. ${ }^{287}$ Based on these data, Dewees, Duff, and Trebilcock predicted that "no-fault patient compensation would be expected to compensate between 45 and 94 times as many injured patients as does the existing tort system."288

That being said, it is possible for a comprehensive no-fault scheme to limit compensation for non-pecuniary losses (e.g. under the New Zealand Scheme) and deduct collateral benefits from other sources, or even introduce deductibles or co-insurance that "effectively restrict eligibility to only the most severely injured patients." 289

\subsection{EVALUATION}

As far as primary cost avoidance is concerned, efficiency entails that the incentives for health care providers to prevent medical malpractice should

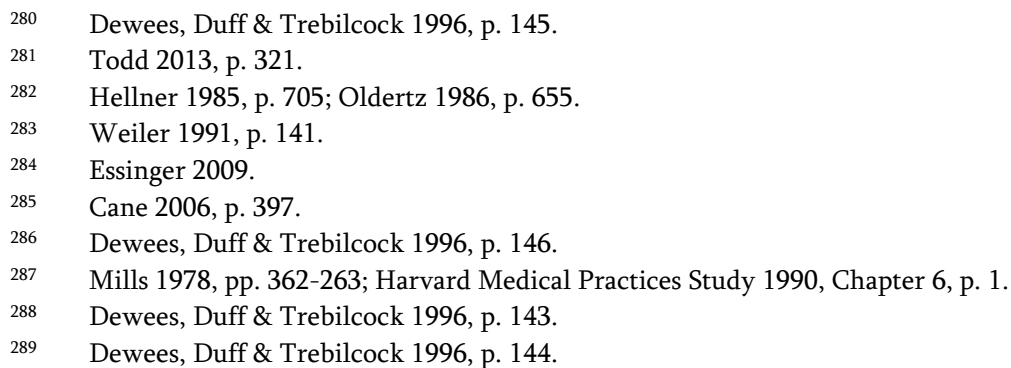


not be undermined. Hence, the expected accident costs should still be imposed on the risk creator or only those who actually contribute to the risk should contribute to the no-fault insurance fund. In New Zealand and Norway, however, expected accident costs are borne by the state rather than by the individual wrongdoer or the health care industry. In the absence of regulation, the incentives for providers to invest in expertise and care will be diluted. In contrast, in Sweden, Finland, and Denmark, at least the accident costs are imposed on the health care industry. Since there is a lack of risk differentiation, the incentives for providers to take precautions may still be mitigated.

Regarding secondary cost avoidance, all the preceding no-fault schemes are able to provide more victims of AEs with quick compensation. Many deductibles and caps are imposed in the four Scandinavian systems, which may be justified by the intention to help those who are severely injured to obtain more compensation. Although the New Zealand scheme does not impose similar deductibles or caps, it excludes compensation for non-pecuniary losses. Overall, these NFCSs are highly efficient at providing quick and relatively sufficient compensation to victims of AEs.

When it comes to tertiary cost avoidance, it seems that claims under these no-fault schemes are resolved much faster than in the traditional malpractice system. Although the total number of compensable events may be much higher than medical malpractice claims, the tertiary costs incurred per claim would be lower under the NFCSs than under the tort system. In this regard, the NZ-NFCS appear more administratively efficient than its counterpart in the Scandinavian systems since the element of avoidability has been eliminated.

Overall, we may find that comprehensive NFCSs are effective at compensating more injured patients more quickly than under the tort system without substantially increasing tertiary costs. However, one may still have concern for the reduced incentives for providers to excise care under these NFCSs.

\section{CONCLUSIONS}

Chapter 11 has examined theories and empirical evidence pertaining to various no-fault compensation schemes that cover iatrogenic injuries. In theory, both voluntary first-party patient insurance and no-fault compensation schemes are able to provide quick compensation to more victims without incurring too many tertiary costs when compared to the tort system. However, many of these alternative compensation schemes may 
Part II. Economic Theories and Empirical Evidence

inevitably dilute incentives for providers to take optimal precautions due to a lack of causal link or risk differentiation. In addition, the joint use of tort liability and social security is not only practically inevitable but also socially desirable. 
PART III

APPLYING THE ECONOMIC

OBSERVATIONS TO CHINA 



\section{INTRODUCTORY NOTE}

On the one hand, this part is aimed at answering part of the second main research question - Are the current legal remedies for medical malpractice in China efficient when measured against economic benchmarks? (Sub-question (2-b)) Chapter 12 will evaluate the Chinese legal remedies for medical malpractice in the light of the economic benchmarks developed in Part II .

On the other hand, this part will also answer the third main research question - If the foregoing legal remedies in China are not efficiently structured, how can we improve them? Chapter 13 will summarise all major findings in the preceding chapters and try to formulate some policy recommendations concerning how to improve the Chinese legal remedies for medical malpractice. 



\section{CHAPTER 12}

\section{AN ECONOMIC ANALYSIS OF THE CHINESE MEDICAL MALPRACTICE SYSTEM}

\section{INTRODUCTION}

Much legislative endeavour has been made to build a credible medical malpractice liability system in China. The system is very young. It was formally established in the second half of the 1980s, and has been drastically reformed twice since then. ${ }^{1}$ Voluminous literature regarding the Chinese medical malpractice liability reforms is currently available, most of which has attempted to evaluate the old and/or the current medical malpractice liability system from the perspective of legal doctrine. ${ }^{2}$ Some have focused on the medical malpractice law in action and tried to explain why medical dispute resolution in China is often associated with violent malpractice mobs. ${ }^{3}$ However, none of these studies can tell us whether the Chinese medical

$1 \quad$ See supra Chapter 3, Section 2.

2 See e.g. Dai 2003 (discussing early development of the doctrine of informed consent in China); Harris \& Wu 2005 (discussing the pros and cons of the AR-Medical Accidents 1987, 2002); Ren \& Wang 2004 (discussing the problems of the AR-Medical Accidents 2002 and its impact on medical ethical principles); Xi \& Yang 2011 (discussing the bifurcated medical negligence system in China for the period 2002-2010 and the legislative reform of medical liability in 2010); Wang \& Oliphant 2012 (summarizing the history of medical liability in China from 1949 onwards and evaluating main provisions of the AR-Medical Accidents 1987, 2002 and the currently applicable Tort Law 2009); Zhu, Li \& Li 2011 (discussing criminal penalties for medical malpractice); Ding 2012 (discussing and evaluating the old and the current medical negligence system in China from a legal doctrinal perspective); Zhao 2012 (discussing the doctrine of informed consent from the perspective of comparative law); Min \& Peng 2013 (discussing the current status and legal treatment of medical disputes in China).

3 See e.g. Liebman 2013 (arguing that "increased innovation and competence are not providing greater authority for the courts" and medical disputes "highlight largely unobserved trends in both law and governance in China, in particular state overresponsiveness to individual grievances"). 
malpractice liability system is efficient at preventing medical errors and compensating victims of medical malpractice or not.

Be that as it may, a minority of studies have touched upon the medical malpractice issues in China from the perspective of law and economics. Several journal articles in Chinese have briefly introduced the classic model of tort liability and made some comments on how to improve the Chinese medical malpractice liability law. ${ }^{4}$ Two theses have explained the classic model of tort law in detail, applied the model to evaluate the sub-rules of Chinese medical malpractice law systematically and made some recommendations on how the current law might be improved. ${ }^{5}$ However, all these studies have only examined the medical malpractice law in the books without paying attention to the law in action. As was presented in Chapter 4, there are marked variations between the law in books and the law in action in the context of Chinese medical malpractice law. Hence, it is insufficient to evaluate the medical malpractice liability system without looking at the empirical evidence.

One article published in English has attempted to evaluate the new Chinese medical malpractice law provided for in the Tort Law 2009 on the basis of some empirical evidence. ${ }^{6}$ This article deserves serious attention because its author Kearney strongly argued as follows,

China's new law is unlikely to cause any substantial decrease in the level of malpractice in the country. The Tort Liability Law is an inefficient model, the burden of which will be borne by under-funded hospitals and patients who are already under-served. ${ }^{7}$

However, some empirical data, on the basis of which Kearney made this critical remark, were either too old (almost a decade ago) ${ }^{8}$ or reported anecdotally. ${ }^{9}$ This lack of updated empirical data on the functioning of the Chinese medical malpractice liability system may weaken several of Kearney's remarks and predictions.

See e.g. Liu, Fan \& Lu 2003; Zhang 2004; Li 2005; Wang 2006; Li \& Wang 2008; Wei \& Wang 2011.

5 Chen 2012 (a Master's thesis); Yang, J. 2013 (a PhD thesis published as a monograph).

6 Kearney 2012 (opining that the new Tort Law 2009 would fail to achieve its goals of efficient deterrence and fair compensation).

$7 \quad$ Kearney 2012, p. 1077.

8 One secondary source that Kearney relied heavily on was Harris \& Wu 2005, which was over ten years ago.

9 Remarkably, Kearney only cited some English news reports as the main source of empirical data. 
On the basis of currently available empirical data, ${ }^{10}$ Chapter 12 is primarily intended to add to existing literature on the Chinese medical malpractice liability system with existing economic models and empirical evidence (from Chapter 7 to Chapter 10). Since so far China has not implemented any no-fault compensation fund for medical malpractice as addressed in Chapter 11, the desirability of adopting such a compensation fund will be discussed as a policy recommendation for China in Chapter 13 . Hence, this chapter mainly focuses on the question of whether the tort system can achieve deterrence and compensation efficiently. Besides tort law, Chapter 12 also touches upon the efficiency of the regulatory quality assurance system, insurance, and social security in China, which was largely ignored by the existing studies.

The structure of this Chapter is modelled on Dewees, Duff, and Trebilcock's framework for empirical evaluations of tort law. ${ }^{11}$ Section 2 and Section 3 evaluate the efficiency of the Chinese medical tortious law in terms of prevention of medical errors and victim compensation respectively. Section 4 and Section 5 evaluate the regulatory system and alternative compensation schemes respectively. Section 6 will discuss the impact of $Y i$ Nao incidents on the Chinese malpractice system. The final Section 7 concludes.

\section{TORT LAW: PREVENTION (DETERRENCE)}

\subsection{INTRODUCTION}

Based on Chapter 3 (substantive rules), Chapter 4 (empirical evidence on China), Chapter 7 (the economic model), and Chapter 8 (empirical evidence on the economic model and the updated model), this will evaluate the medical malpractice liability under Chinese tort law in terms of the prevention of medical errors (deterrence) in this Section. First of all, it will examine the Chinese medical malpractice liability system (both law in the books and law in action) in light of the (updated) economic model of tort law in Section 2.2. Then, it will address the issue of whether the Chinese medical malpractice liability system does or may produce the intended deterrent effect in Section 2.3. A summary will be made in Section 2.4.

See supra Chapter 4.

See generally Dewees, Duff \& Trebilcock 1996. 
Part III. Applying the Economic Observations to China

\subsection{INPUT ANALYSIS}

\subsubsection{Introduction}

This Section evaluates to what extent the actual medical malpractice system in China shows the structural features necessary for deterrence. In general, economic efficiency demands that health care providers should exercise patient-specific care and make investments in patient safety (expertise, training, equipment, system design, etc.) to the extent where the marginal cost of error prevention equals the marginal benefit of injury reduction. ${ }^{12}$ Hence, liability and quantum rules (law of damages) should be optimally set (Sections 2.2.2 and 2.2.3), all meritorious claims should be filed and resolved correctly (Sections 2.2.4 and 2.2.5), expected accident costs should not be passed from health care providers on to others (Section 2.2.6), and health care providers should be able to respond to economic incentives appropriately (Section 2.2.7). ${ }^{13}$ A summary will be made in Section 2.2.8.

\subsubsection{Liability Rules}

\subsubsection{Negligence versus Strict Liability}

As demonstrated before, it is highly likely that the negligence rule is fitter than strict liability for quality assurance in the health care sector. ${ }^{14}$ In this respect, the fault liability adopted by article 54 of the Tort Law 2009 is efficient.

Since article 59 of the Tort Law imposes strict liability for medical products in hospitals, one may wonder whether article 59 is efficient or not. As a general rule, it seems wrong to impose liability on hospitals which cannot prevent the defects in medical products that are produced by manufacturers. However, article 59 grants hospitals a right of recourse against liable manufacturers. Hence, there will be no over-deterrence in that hospitals are not ultimately liable for damage due to defective medical products. Damages will be paid by liable manufacturers, who will be induced to take socially optimal precautions.

In cases where manufacturers from whom medical products were purchased were insolvent, hospitals would have to bear the risk of not being able to exercise the right of recourse and might thus be over-deterred due to

$12 \quad$ See supra Chapter 7, Section 2; Chapter 8, Section 3.

13 Dewees, Duff \& Trebilcock 1996, p. 97.

$14 \quad$ See supra Chapter 7, Section 3.2.4. 
article 59. Without article 59, however, victims would have to bear such a risk. One may ask whether it is better for hospitals or victims to bear such a risk.

One important feature of treatment is that it involves both the techniques implemented by providers and the use of medical products. Therefore, any adverse event may be due to either provider negligence in the use of medical products or defects in medical products themselves, or both. Victims may be confronted with considerable information costs and may not know who should be sued. Compared to victims, hospitals are professional institutions and clearly have better information concerning the quality and the use of medical products than victims. That is to say, between hospitals and victims, the former are the least cost avoider and the best information provider. By imposing strict liability on hospitals, article 59 will induce hospitals not only to use equipment or administer pharmaceuticals properly, but also to select manufacturers very carefully. In this respect, article 59 is socially desirable as well.

\subsubsection{Standards of Care}

Technical malpractice. As demonstrated before, efficiency requires that the Learned Hand Rule should apply to medical malpractice liability cases in order to induce providers to make cost-justified investments in injury prevention. ${ }^{15}$ In theory, article 57 of the Tort Law 2009 establishes the reasonable doctor standard of care ("the duty of medical care corresponding to the then medical standard") in China. ${ }^{16}$ In practice, however, the court usually defines the "medical standard" as statutory standards, standardised written treatment norms, and customary practices. ${ }^{17}$ Whether these standards, norms or customs can be regarded as the standards of care required of a reasonable doctor will be determined by expert testimony on a case-bycase basis. Therefore, in China, the standard of care is determined in two steps. First, the court and expert witnesses will look for statutory standards or written norms published or recognised by the government and decide whether these regulatory standards contradict the reasonable doctor standard. Second, if there is no such regulatory standard, they will decide whether a customary practice conforms to the reasonable doctor standard.

The preceding approach is theoretically efficient for two reasons. On the one hand, since many professional standards are already summarised and

See supra Chapter 7, Section 3.3.1.

See supra Chapter 3, Section 3.2.1.

See supra Chapter 4, Section 3.3.2. 
published by statutes or clinical guidelines, it will save considerable administrative costs of the cost and benefit analysis if the court can rely on these regulatory standards. ${ }^{18}$ On the other, article 57 (the reasonable doctor standard) serves as a fail-safe device in the sense that when regulatory standards or customary practices deviate from the due care level, the court has a chance to adjust the standards. In theory, it seems that Chinese courts may apply the Learned Hand Rule to determine provider negligence.

Some empirical evidence suggests that the standard of care in China may often be set higher than the optimal level because clinical expert witnesses, who are high-ranking doctors from high-level hospitals, tend to testify against those low-ranking doctors from low-level hospitals, which goes against the principle of "peer review." 19 However, this deviation from the economic model is caused by defects in the expert ascertainment system rather than by article 57 of the Tort Law 2009 .

Ethical malpractice. In practice, Chinese courts apply the "double-test standards" to information disclosure. ${ }^{20}$ Given the fact that the patient group is often heterogeneous, the specific patient should be allowed to play a role in what information ought to be disclosed and the information should reflect the cost and benefit confronted by each patient. ${ }^{21}$ In this way, the utility of patients can be maximised. ${ }^{22}$ However, to find out each patient's subjective preference in detail may incur considerable transaction costs. Hence, to save tertiary costs, it may be desirable first to look at what a reasonable doctor would be willing to disclose and what a reasonable patient wants to know. ${ }^{23}$ Then, attention should be paid to the particular preference of the specific patient. ${ }^{24}$ In this regard, the "double-test standard" of information disclosure is efficient.

Regarding the types of ethical malpractice, some unfavourably commented that "these laws will not have much effect on maintaining the quality they strive to protect, and people who are harmed by them will receive no compensation." ${ }^{25}$ In particular, article 61 (duty of medical record keeping) ${ }^{26}$ and article 63 (prohibiting unnecessary examinations) ${ }^{27}$ of the Tort

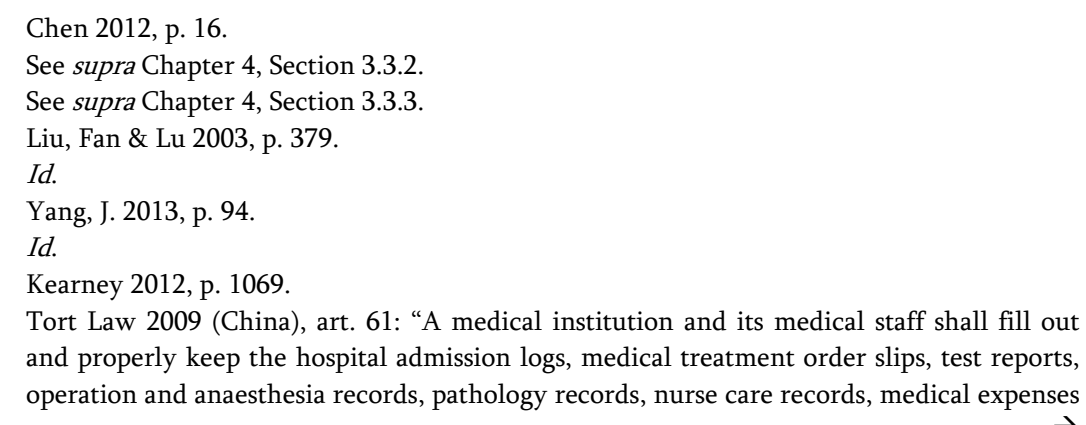
and properly keep the hospital admission logs, medical treatment order slips, test reports, operation and anaesthesia records, pathology records, nurse care records, medical expenses 
Law 2009 were heavily criticised, because "neither provision mentions financial liability for the violation." ${ }^{28}$

It is true that article 61 and article 63 have not mentioned compensation. However, it should be noted that Chapter VII of the Tort Law 2009 (titled "Liability for Iatrogenic Injury") is a complete system for medical malpractice issues, where article 54 serves as the general clause under which all fault-based medical torts can be subsumed. ${ }^{29}$ Also, article 58 plays a special role in transforming some categories of illegal acts into fault..$^{30}$

Hence, if a patient is injured due to unnecessary examinations conducted by the defendant-hospital, the defendant will be presumed to be at fault in accordance with article 58, sub-para. (1), and it will be held liable for the iatrogenic injury in light of article 54 if it cannot rebut the presumption of fault.

In case the defendant-hospital conceals or refuses to provide medical records, ${ }^{31}$ or forges or tampers the records, ${ }^{32}$ the defendant will also be presumed to be at fault in light of article 58, sub-paras. (2) and (3) and it will have to pay compensation according to article 54 .

Hence, Kearney's worry about the under-enforcement of article 61 and article 63 is unfounded.

sheets and other medical history data according to the relevant provisions. Where a patient files a request for consulting or copying the medical history data in the preceding paragraph, the medical institution shall provide the data."

27 Tort Law 2009 (China), art. 63: "A medical institution and its medical staff shall not conduct unnecessary examinations in violation of the procedures and standards for diagnosis and treatment."

$28 \quad$ Kearney 2012, p. 1069.

$29 \quad$ Tort Law 2009 (China), art. 54: "Where a patient sustains any harm during diagnosis and treatment, if the medical institution or any of its medical staff is at fault, the medical institution shall assume the compensatory liability."

30 Tort Law 2009 (China), art. 58: "Under any of the following circumstances, a medical institution shall be presumed to be at fault for any harm caused to a patient: (1) violating a law, administrative regulation or rule, or any other provision on the procedures and standards for diagnosis and treatment; (2) concealing or refusing to provide the medical history data related to a dispute; or (3) forging, tampering or destroying any medical history data."

$31 \quad$ See e.g. Zhang v. Shang (China); Wang \& Wang v. Ningxia Fourth Hospital (China); Yao v. Songshan Hospital \& Ping an Insurance Co., Ltd (China); Zhang v. Employees Hospital (China).

32 See e.g. Deng v. Anji Hospital (China); Ouyang v. Suzhou Hospital (China); Shan v. Shuanmiao Health Centre (China); Liu v. Gong'an Traditional Chinese Hospital(China). 


\subsubsection{Feasance versus Nonfeasance}

One of the essential reasons that the Tort Law 2009 may lead to undercompensation is that patients who suffer iatrogenic injury due to physician inaction (non-feasance) may not be protected by the Law. One the one hand, the Law is "silent about what a physician's obligation will be in the event that a person is harmed by physician inaction when the person cannot pay for treatment." ${ }^{\prime 33}$ On the other, even if the Law did impose liability in case of physician inaction, plaintiffs would not be protected because it would be unlikely that they could afford litigation costs when they could not pay for medical bills. ${ }^{34}$

It is true that the Tort Law has not said anything about "inaction." However, this argument may be undermined by two reasons as follows.

First, physician inaction normally leads to tort liability (and even administrative/criminal sanctions). China is largely a civil law country, where not only promulgated statutes matter but also dominant legal doctrines count. In China, it is a widely accepted doctrine that a tortious act can be done by either feasance or non-feasance. ${ }^{35}$ Non-feasance means that the tortfeasor breaches an affirmative duty to act, which is usually imposed by statutory provisions, professional codes of conduct or contracts. ${ }^{36}$ The law has already imposed an affirmative duty on providers to rescue and treat critically ill patients and providers must not refuse to admit such patients. ${ }^{37}$ Any provider who fails to fulfil this duty shall be subject to administrative punishments and/or criminal penalties. ${ }^{38}$ Some empirical evidence shows that providers rarely breach this statutory duty and as a result many public hospitals face the problem of unpaid medical bills. ${ }^{39}$ After the patient is admitted, any unreasonable failure to treat the patient after admitting her to the hospital may contravene the standard of care defined by article 57 and establish liability. Some local courts argued that the hospital's refusal to provide treatment is only justified when the termination of the contract will not contravene humanitarianism, the patient refuses to pay for medical bills, and expert witnesses testify that the patient's conditions have already met the standards for leaving the hospital. ${ }^{40}$

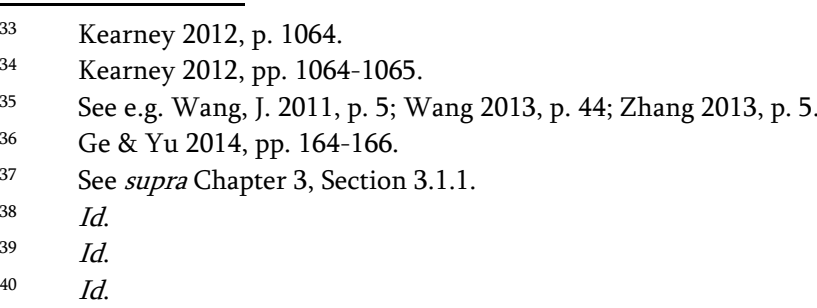


Second, even when there are cases of physician inaction in practice, this problem should not be exaggerated. Some anecdotal evidence suggests that hospitals would suspend further treatment but would provide a minimum level of medical care if the patient refused to pay for medical bills. ${ }^{41}$ Hence, it is likely that some poor patients may receive a reduced level of care in practice. That being said, these non-paying patient now only represent the minority. With the development of the social security schemes, currently more than $95 \%$ of the Chinese population are covered under the BMIS ${ }^{42}$ and more and more extremely poor patients are covered under the URMAS as well. ${ }^{43}$ It is expected that this problem of under-investment in care for nonpaying will be relieved with the development of the social security schemes. In any case, it is not appropriate for tort law to resolve this social problem.

\subsubsection{Causation and Proof Rules}

Causation. The Tort Law 2009 is silent on the definition of causation and issues of causal uncertainty. Nevertheless, the conditio sine qua non test for causation in fact and the adequacy test for causation in law, and proportional liability in case of severe uncertainty over factual causation that are adopted by Chinese courts are efficient. ${ }^{44}$

Proof Rules. The reversal of the burden of proof regarding fault and causation that was once adopted by Chinese courts has been abandoned by the Tort Law 2009. Currently, the onus is in principle on the plaintiff to establish medical malpractice liability (article 54). The only exception is article 58 of the Law, which applies the presumption of fault in three limited scenarios. ${ }^{45}$

The old reversal rule was widely criticised as being too harsh for health care providers, which ultimately led to defensive medicine. ${ }^{46}$ In cases where the defendant was not able to rebut the presumption of fault, the reversal rule would become strict liability. As demonstrated before, in the

$41 \quad$ Iktsuarpok 2015; Today's Headlines 2016.

$42 \quad$ See supra Chapter 2, Section 3.3.

43 See supra Chapter 5, Section 3.3.2.2.

44 See supra Chapter 3, Section 3.2.3.2; Chapter 4, Section 3.4; Chapter 7, Sections 3.4.13.4.2.

45 Tort Law 2009 (China), art. 58: "Under any of the following circumstances, a medical institution shall be presumed to be at fault for any harm caused to a patient: (1) violating a law, administrative regulation or rule, or any other provision on the procedures and standards for diagnosis and treatment; (2) concealing or refusing to provide the medical history data related to a dispute; or (3) forging, tampering or destroying any medical history data."

$46 \quad$ Wang 2006, pp. 135-136; Chen 2012, pp. 25-27. 
health care sector, negligence is more efficient than strict liability ${ }^{47}$ Hence, the reversal rule is inefficient.

Article 58 presumes fault in three factual scenarios, which are widely recognised as typical evidence of fault. This presumption rule is efficient in that it is intended to minimise litigation and error costs. ${ }^{48}$

Some may argue that article 58 does not relieve the burden of proof imposed on the plaintiff since it is very difficult for the plaintiff to prove e.g. that the defendant has contravened any statutory standard or treatment norm in the first place. ${ }^{49}$ Also, the plaintiff has to discharge the burden of proving causation, which has not been presumed by article 58 .

This problem of inability to produce evidence in medical malpractice lawsuits can be resolved by the expert witness system. In almost all court cases, expert testimonies would be provided through the MATAS and/or the JAS. ${ }^{50}$ The very existence of the expert witness system dwarfs the importance of the burden of proof rules in that experts are supposed to give a definite opinion on whether medical malpractice liability can be established. Hence, the burden of proof rules actually matter insofar as who should pay medical ascertainment fees in advance is concerned. The party who bears the burden of proof should pay ascertainment fees in advance and the party who loses the case shall ultimately pay the fees.

Therefore, the current burden of proof rules (article 54 and article 58) are designed efficiently. However, their advantage over the old reversal rule is greatly lessened by the expert witness system.

\subsubsection{A Contractual Waiver of or Alteration to Tort Liability?}

In China, any agreement that is intended to waive tort liability or vary the standard of care is null and void. ${ }^{51}$ Also, patients and public hospitals are not allowed to negotiate on service prices, which are set by the government. Hence, the contractual approach strongly recommended by Professor Richard Epstein $^{52}$ does not seem to fit into the current legal and health care framework in China.

However, whether China should employ Epstein's proposal and change the legal and health care system accordingly is another question. As addressed before, due to severe information asymmetry and the loss of the

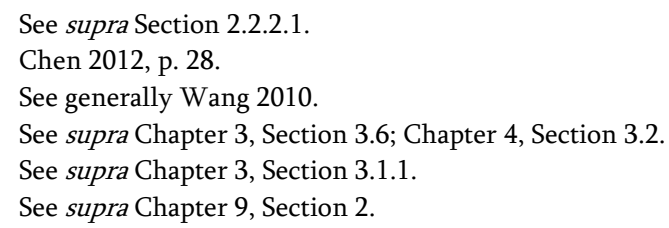


benefits of collective care generated by the malpractice system, the contractual approach seems inferior to statutorily defined medical malpractice liability. ${ }^{53}$

\subsubsection{Quantum Rules}

Some argued that the Tort Law 2009 will under-compensate victims of medical malpractice because it is "silent as to whether it affects the value of the compensation the courts will hand out" and it will not "bring about an increase in compensation" compared to the AR-Medical Accidents 2002.54

However, this argument is unfounded for ignoring one of the most significant judicial interpretations for tort cases in China - the JI-Personal Injury 2003..$^{55}$ Even in the period 2002-2009 when the compensation part of the AR-Medical Accidents 2002 was applicable, empirical evidence shows that the court would apply quantum rules defined by the AR-Medical Accidents in less than $10 \%$ of all medical malpractice cases. ${ }^{56}$ The court would apply the JI-Personal Injury 2003 in more than 90\% of all medical malpractice cases before 2010 and only apply the JI-Personal Injury after 2010.57 Since patients usually obtain more compensation under the JIPersonal Injury than under the AR-Medical Accidents, it is baseless to claim that patients were systematically under-compensated from 2004 to 2009. After 2010, all courts in China now apply the JI-Personal Injury to medical malpractice cases. Hence, the advent of the Tort Law will increase victim compensation to some extent in that now $100 \%$ victims obtain compensation under the JI-Personal Injury.

Efficient deterrence requires that compensation should be full - both pecuniary and non-pecuniary losses should be compensable. While article 16 of the Tort Law and the JI-Personal Injury are intended to provide quantum rules for calculating pecuniary damages (for medical expenses, lost earnings, permanent disability, wrongful death, etc.), ${ }^{58}$ article 24 of the Tort Law and the JI-Emotional Damage 2001 are meant to offer a legal basis for measuring non-pecuniary damages. ${ }^{59}$ As far as the category of compensation items is

53 Id. This information problem may be relieved if health insurers, who have better information than patients, decide to step in and enter into a service contract with health care providers on behalf of patients (like the managed care system in many Western countries). However, this is currently not the case in China.

Kearney 2012, p. 1065.

See supra Chapter 3, Section 3.7.2.

See supra Chapter 4, Section 2.4.

Id.

See supra Chapter 3, Section 3.7.2.

See supra Chapter 3, Section 3.7.3. 
concerned, the Tort Law, supplemented with the preceding two judicial interpretations, providers fairly full compensation. The objective method of the calculation of damages for permanent disability and wrongful death ${ }^{60} \mathrm{can}$ also be justified in terms of tertiary cost avoidance. ${ }^{61}$

When it comes to compensation for permanent disability, death, or non-pecuniary losses, the JI-Personal Injury and the JI-Emotional Damage's approach may lead to under-compensation and ultimately under-deterrence. As demonstrated before, the newly developed notion of "quality-adjusted life years" (QALYs) seems more complete than the traditional approach to the measure of compensation for wrongful death and pain and suffering. ${ }^{62}$ While the criteria for compensating for disability and death in China focus only on how much earnings the victim would lose in the future because of her disability or death, QALYs pay more attention to the value of lost quality of life in the light of the victim's $e x$ ante willingness to pay (WTP). If China adopted the approach of QALYs, compensation for disability, death, and pain and suffering would be highly likely to increase considerably compared to the current compensation regime, under which a cap of 20 years applies to compensation for disability and death ${ }^{63}$ and a cap of 50,000 yuan is imposed on non-pecuniary damages. ${ }^{64}$

Hence, although the inception of the Tort Law 2009 produces an increase in compensation in comparison to the AR-Medical Accidents 2002, its silence on detailed quantum rules and the actual reliance on the JIPersonal Injury 2003 mean that it will still lead to under-compensation in terms of the economic criteria of QALYs. Consequently, health care providers may systematically be under-deterred due to under-compensation. Be that as it may, the Tort Law's role played in abolishing the AR-Medical Accidents should be welcomed. Also, its silence on detailed quantum rules makes it possible that the Supreme People's Court (SPC) may raise compensation for fatal injury, death, and pain and suffering through new judicial interpretations in the future when the SPC sees fit. The QALY-approach can be a potentially desirable option for the SPC.

In addition, the proportional apportionment rule that excludes noniatrogenic injury from the scope of liability and the collateral benefit set-off

See supra Chapter 3, Section 3.7.2.2.

See supra Chapter 7, Section 3.6.3.1.

See supra Chapter 7, Sections 3.6.3.2 and 3.6.3.3.

See supra Chapter 3, Section 3.7.2.3.

See supra Chapter 3, Section 3.7.3. 
rule applying to social insurance employed by Chinese courts ${ }^{65}$ are efficient as well. ${ }^{66}$

\subsubsection{Claims Initiation}

Optimal deterrence entails that all negligent AEs can be detected, all negligently injured patients file claims, and no non-negligently injured patients file claims.$^{67}$ Currently in China, however, data on the ratio of the number of medical malpractice claims initiated to the total number of negligent AEs are unavailable. Neither could such data be generated from the analysis of court decisions or semi-structured interviews.

As mentioned before, where a medical error is severe or easily identifiable, the rate of claims initiation should not be extremely low, though it is far less than $100 \%{ }^{68}$ Data from the US show that about 3.3 to 10 negligent AEs would lead to one initiated medical malpractice claim. ${ }^{69}$ The relatively low rate of claims initiation may be attributable to the problem of "claims consciousness" and high transaction costs. ${ }^{70}$

Hence, the deterrent effect of tort law may be reduced due to the low rate of claims initiation.

\subsubsection{Claims Resolution}

Optimal deterrence requires that medical malpractice claims should be resolved accurately - all meritorious claims will be supported, and all nonmeritorious claims will be denied. Data from the US show that a plaintiff was roughly 2 to 8 times more likely to obtain compensation if the defendant had provided sub-standard care than if the defendant had not, which "should provide a significant deterrent effect, despite the high overall error rate in claiming." 71

In general, however, detailed empirical evidence on the accuracy of claims disposition is currently unavailable. However, Chinese courts rely heavily on expert testimony to decide essential issues such as fault, causation, and scope of liability. The well-organised expert witness system in China may

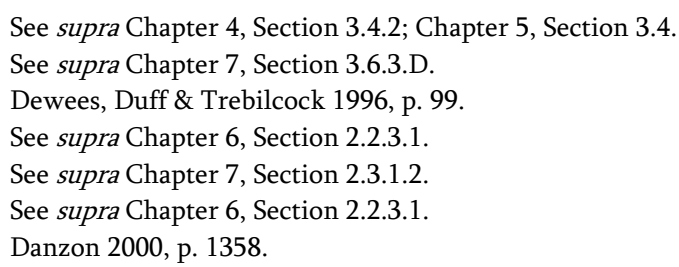


help in guaranteeing the accuracy of claims disposition. ${ }^{72}$ Most of the US studies on the accuracy of claims resolution have also relied on peer review to determine whether a claim is meritorious or not. Hence, a speculative prediction is that most medical malpractice claims are resolved relatively accurately through litigation in China.

That being said, one may still wonder whether the resolution of the remaining more than $80 \%$ medical malpractice claims that are settled out of court in China is accurate or not. It is often reported that, when facing Yi NaO incidents, hospitals would give in and pay some damages not because they are at fault but because they want to restore hospital order as quickly as possible. ${ }^{73}$ However, it is also possible that patients yield to a low amount of compensation even when they have meritorious claims because they are so poor that they cannot afford litigation and they desperately need quick compensation. Therefore, it is very difficult to judge whether or not victimised patients with meritorious claims are more likely to obtain compensation than patients with non-meritorious claims do. Overall, at least as far as medical malpractice claims resolved in court are concerned, the accuracy of claims resolution may not be extremely low in China.

\subsubsection{Medical Liability Insurance (MLI)}

In theory, MLI would not affect economic incentives faced by insured health care providers if explicit co-payment mechanisms and/or experience-rating were adopted. ${ }^{74}$ Currently, in China, cost externalisation by MLI is not a serious problem. On the one hand, medical liability insurance (MLI) is rather under-developed (covering less than $10 \%$ of all hospitals) for the time being. ${ }^{75}$ Hence, the majority of Chinese hospitals still have to self-insure against medical malpractice liability. On the other hand, some local jurisdictions in China that have initiated MLI schemes do recognise the importance of experience-rating (e.g. in Shanghai and Nanjing) and co-payment (e.g. in Yunnan, Shanghai, Beijing, Shenzhen, Ningbo, and Nanjing). ${ }^{76}$

$72 \quad$ See supra Chapter 6, Section 2.2.3.2. One may question whether these expert witnesses (essentially physicians) are so honest that they do not cover for their peers. In China, although clinical expert witnesses are often under suspicion of protecting their colleagues or peers simply because they belong to the same profession, there is currently no compelling evidence showing that they do so.

73 Id.

$74 \quad$ See supra Chapter 10, Section 4.2.4.

75 See supra Chapter 6, Section 2.2.3.3.

76 See supra Chapter 5, Section 2.3.8. 
Since it will still take some years for China to develop MLI schemes nationwide, it is too early to say that economic incentives faced by Chinese health care providers will be diluted by MLI. Nevertheless, the three rounds of malpractice insurance crisis that occurred in the US should teach China a salutary lesson when developing its own MLI schemes.

\subsubsection{Defendant Responsiveness}

Given the fact that most medical errors are accidental rather than deliberate and are ultimately due to system failures instead of human errors, imposing liability exclusively on hospitals through EML is more efficient than individual physician liability. ${ }^{77}$

Article 54 of the Tort Law 2009 defines the hospital as the sole defendant in medical malpractice litigation and thus imposes the costs of medical malpractice exclusively on the institutional provider, which is more efficient than physician liability. In some cases, however, medical malpractice may primarily be due to human errors. Will EML lead to under-deterrence in such cases where these negligent providers may escape liability? The answer is "No" for two reasons.

On the one hand, as summarised before, based on recent empirical evidence on the causes of medical malpractice, most medical errors are accidental, and system failures account for a large proportion of these errors. ${ }^{78}$ Hence, medical errors should be prevented at the institutional level, and hospitals should be induced to invest in staff training, medical equipment, technology, fail-safe systems, etc. optimally through EML.

On the other hand, those providers who primarily contribute to a negligent $\mathrm{AE}$ are not necessarily under-deterred because of the implementation of EML. Since 2002, Chinese public hospitals have begun to have the authority to hire and fire (now at least $95 \%$ of) their medical staff members $^{79}$ and may impose various internal sanctions (e.g. fines, and restrictions on promotion prospects and prescription privileges) on those staff members who cause negligent iatrogenic injuries to patients..$^{80}$ Therefore, the possibility of imposing internal sanctions on negligent providers after hospitals pay compensation to victimised patients ensures that individual providers are still incentivized to exercise the optimal level of care.

See supra Chapter 8, Section 3.

See supra Chapter 8, Section 3.2.2.

See supra Chapter 2, Section 2.3.

See supra Chapter 4, Section 3.3.1. 
Part III. Applying the Economic Observations to China

For the reasons above, one can conclude that EML adopted by article 54 of the Tort Law 2009 is largely efficient in terms of injury prevention.

\subsubsection{Summary}

Remarkably, many aspects of the Chinese medical malpractice system embody the features of efficiency. First, liability rules, including causation and proof rules, are largely optimally defined by either the Tort Law 2009 or Chinese courts. Second, the resolution of claims in litigation seems accurate with the help of expert witnesses. Third, economic incentives faced by Chinese health care providers do not seem to be so much diluted by MLI in China for the time being. Fourth, that EML places the locus of liability solely on hospitals and hospitals have full authority to monitor and sanction their staff members may help encourage optimal injury precautions at the organisational level.

However, some problems plaguing the Chinese medical malpractice system may prevent it from achieving optimal deterrence. First, although compensation for disability and death has been increased by the Tort Law 2009 in all medical malpractice cases, the amount of compensation is still greatly limited, which may result in under-deterrence. Second, the rate of claims initiation is still low which may also lead to under-deterrence.

Overall, the new Chinese medical malpractice system seems well constituted to induce optimal injury prevention except for the quantum rules and barriers to lawsuits. The Chinese medical malpractice system may even appear more efficient than its US counterpart in that the latter does not have well-defined liability rules and has not adopted EML but has to face reduced economic incentives due to cost externalisation by malpractice insurance.

\subsection{OUTPUT ANALYSIS}

Data from the US show that the increased threat of malpractice liability results in defensive medicine ${ }^{81}$ and ultimately reduces the injury rate. ${ }^{82}$ The cost of the malpractice system can be justified by the benefit of injury reduction..$^{83}$

However, since the medical malpractice system in China is fairly young and few Chinese scholars pay attention to the deterrent effect of tort law, empirical statistical evidence on the impact of civil liability on medical

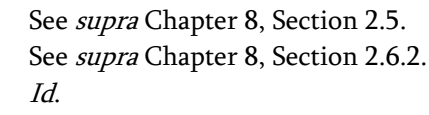


practice and that of practice changes on the injury rate are currently unavailable.

That being said, based on some direct surveys of and interviews with physicians, we know that defensive medicine (both PDM and NDM) is likely to be prevalent in China as well. ${ }^{84}$ Some of the defensive practices may be due to the increased threat of medical malpractice liability, but some of them may be explained by the epidemic of $\mathrm{Yi}$ Nao incidents and the pursuit of economic profits. ${ }^{85}$

The next question is whether the empirical findings originating largely from the US can be directly transferred to China. This question should be answered on the basis of the differences and similarities between China and the US as far as legal remedies for medical malpractice and relevant social contexts are concerned.

There are important differences in contexts. First, the US is a litigious society $^{86}$ while China has a long tradition of resolving disputes through community mediation (People's Mediation) out of court. ${ }^{87}$ Second, the US belongs to the common law world whereas China largely follows the Continental legal tradition. Third, administrative costs of the malpractice system in the US ${ }^{88}$ are much higher compared to those in China. ${ }^{89}$ Fourth, in the US physicians are self-regulated ${ }^{90}$ while in China the medical profession is regulated by the government directly. ${ }^{91}$ Fifth, medical liability insurance (MLI) in the US has been fully developed ${ }^{92}$ whereas MLI in China is still in the initial stages. ${ }^{93}$ Sixth, the American health care system looks better than the Chinese counterpart as far as the benefits that patients may enjoy are concerned. ${ }^{94}$

Notwithstanding the above differences, there are at least two similarities. On the one hand, both China and the US adopted the fault-based tort liability to handle medical malpractice issues. On the other hand, victims

\footnotetext{
$84 \quad$ See supra Chapter 4, Section 3.9.1.

85 See supra Chapter 4, Section 3.9.2.

$86 \quad$ See generally Howard 1987.

$87 \quad$ Zeng 2009.

$88 \quad$ See supra Chapter 8, Section 2.6.1.

$89 \quad$ See supra Chapter 4, Section 3.7.2.

$90 \quad$ See supra Chapter 9, Section 6.

$91 \quad$ See supra Chapter 2, Section 4.4.

92 See supra Chapter 10, Section 4.3.

93 See supra Chapter 5, Section 2.

94 After comparing health care systems in Europe, the US, and China, Rose concluded that health care systems in Europe are the good, the American health care system is the bad and the Chinese one is the ugly. See Rose 2011.
} 
rely heavily on the tort system to obtain compensation in that they cannot obtain much compensation under social security schemes.

When it comes to China, given the fact that there are differences in specific contexts, what can we still learn from these empirical findings from the US? One of the issues, of course, is that the evidence shows that stakeholders, especially physicians, react to incentives. Different liability regimes affect their behaviour, so tort law has a deterrent effect, which is of course relevant to China as well.

Given the similarities between the Chinese malpractice system and its US counterpart, it is reasonable to predict that the Chinese one may also be efficient at reducing negligent iatrogenic injury. However, this is a very tentative conclusion which needs to be substantiated by future empirical studies conducted in China.

\subsection{SUMMARY}

As far as the input of the Chinese medical malpractice system (Tort Law 2009 and law in action) is concerned, liability rules (standard of care, causation, and proof rules) and enterprise medical liability (EML) are efficient. The accuracy of claims resolution through litigation is relatively high, although patients may sometimes be either over-compensated (when hospitals give in to patients with non-meritorious claims for fear of Yi Nao incidents) or under-compensated (when extremely poor patients with meritorious claims yield to hospitals to obtain quick compensation) if they decide to resolve disputes through ADRs. Since medical liability insurance (MLI) is still in its initial stage in China, there are currently few worries about its adverse impact on economic incentives for health care providers to take precautions. And many MLI schemes that were recently initiated in some local jurisdictions in China have already adopted co-payment mechanisms or experience-rating.

The only two factors that may lead to under-deterrence are a low rate of claims initiation and low levels of compensation for disability, death, and pain and suffering compared to the QALYs approach.

When it comes to the output of the Chinese medical malpractice system, there is only some evidence showing that defensive medicine is prevalent and that the threat of medical malpractice liability partly contributes to this change in physician practice. However, there is currently no empirical evidence on the impact of the malpractice system on injury reduction. Data from the US show that the malpractice system is effective at cost-justified injury precaution. Since the Chinese medical malpractice system looks similar to its US counterpart in several respects, it is reasonable to predict that the former may be efficient in injury prevention as well. 
Overall, the Chinese medical malpractice system has made substantial advances recently in terms of optimal deterrence. These advances would have been impossible without the advent of the Tort Law 2009 and the flexibility and creativity shown by Chinese courts in interpreting and applying legal rules. The Tort Law has repealed the inefficient reversal of the burden of proof rule and the quantum rules defined by the AR-Medical Accidents 2002 that provided a lower level of compensation. Although the Tort Law is silent on causation issues, Chinese courts systematically apply proportional liability to medical malpractice cases where uncertainty over causation is considerable.

\section{TORT LAW: COMPENSATION}

\subsection{INTRODUCTION}

In cases where AEs nonetheless occur, patients may suffer secondary costs the social dislocation costs of the accident. According to Calabresi, the secondary goal of accident law is to reduce these dislocation costs through the deep-pocket approach and loss spreading. ${ }^{95}$ The deep-pocket approach entails that accident losses should be placed on those who are in the best position to (self-)insure against these losses. ${ }^{96}$ The EML approach adopted by article 54 of the Tort Law 2009 is more efficient than individual liability in that hospitals are more able than individual providers to self-insure against medical malpractice liability. ${ }^{97}$

Regarding loss spreading, in addition to tort law, social insurance and private insurance may provide victims of medical malpractice with some compensation. In China, neither social insurance nor private insurance plays a significant role in compensating victims of medical malpractice On the one hand, not all Chinese residents are covered by social insurance, and the level of compensation provided by social insurance is limited. When people are old, totally disabled, or sick, they may enjoy social insurance benefits under the pension (BPIS) ${ }^{98}$ or health insurance schemes (BMIS). ${ }^{99}$ Extremely poor people may receive some state assistance. ${ }^{100}$ However, medical bills added

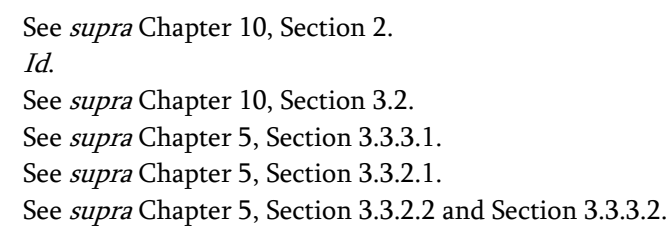


because of negligent AEs are excluded from the cover under the BMIS. Those victims of medical malpractice who are not approaching retirement, who are not totally disabled, and who are not extremely poor are unable to receive any benefit from social security schemes. Those who do receive some benefit from these schemes are far from being fully compensated, in that social security schemes are only meant to provide a minimum level of compensation. On the other hand, the role played by private insurance is rather limited. For instance, private health insurance only covered a small proportion (3.57\%) of the whole population (almost 1.4 billion). ${ }^{101}$ Therefore, tort law still serves as the primary source of victim compensation in China.

In China, any agreement that is intended to waive tort liability or vary the standard of care is null and void. ${ }^{102}$ Hence, where "exculpatory agreements are legally barred or practically impossible, defendants are effectively compelled to serve as a source of injury compensation" - "a scheme of compulsory insurance." 103

The next several sections will examine whether the Chinese medical malpractice system is efficient in terms of secondary cost avoidance.

\subsection{BENEFIT LEVELS}

The insurance theory demonstrates that optimal compensation for damage should "reflect the insurance coverage against the accident that a rational, well-informed individual with a socially acceptable level of income would have bought." 104 In light of this insurance theory, the full compensation principle will lead to over-compensation and there should be no need to grant non-pecuniary damages. ${ }^{105}$

Contrary to what was found in the US, ${ }^{106}$ tort compensation rules in China do not seem to pay considerably higher benefits than would be provided under optimal insurance. First, although dominant tort doctrines in China purport to employ the full compensation principle, the SPC de facto adopts limited compensation for negligently caused disability and wrongful death with a cap of 20 years. ${ }^{107}$ In addition, local courts tend to impose a cap of 50,000 yuan on non-pecuniary damages. ${ }^{108}$ Hence, it is hard to decide

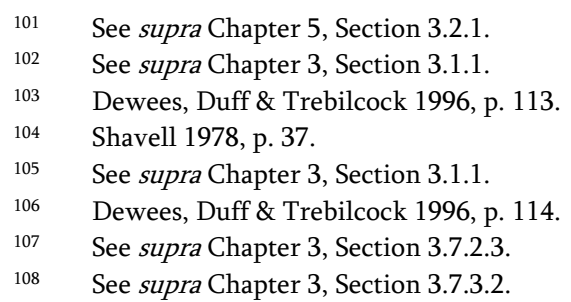


whether compensation for a particular iatrogenic injury under tort law will surely be excessive from the perspective of secondary cost avoidance. Second, although plaintiffs are able to receive non-pecuniary damages, these damages (not more than 50,000 yuan or about 7,500 US dollars ${ }^{109}$ ) are rather modest compared to some "multimillion-dollar damage awards involving significant payments for non-economic loss" in the US. ${ }^{110}$ Finally, since public health insurance benefits are effectively deducted from damages awards and only a minority of people in China purchase private insurance, the number of cases where victimised patients receive duplicate compensation is relatively low in China. For the reasons above, quantum rules in China do not seem to deviate very far from the insurance theory.

That being said, from the perspective of primary cost avoidance, this low level of compensation is likely to lead to under-deterrence.

\subsection{ELIGIBILITY CRITERIA}

Although the benefit levels under the Chinese medical malpractice system may not contradict the insurance theory too much, the eligibility criteria are surely inappropriate. First, a rational consumer will tend to purchase insurance when it is relatively easy to receive benefits when the insured accident occurs. However, malpractice doctrines require that patients have to establish both fault and causation, which can be very difficult for most patients. Second, a rational consumer may insure only against severe losses, ${ }^{111}$ while both minor and severe losses are recoverable under tort law. Data from the Gulou Court show that of all the 190 judgements with some awards, about $38.95 \%$ involved minor injuries and $14.21 \%$ emotional distress only. ${ }^{112}$

Hence, a rational consumer's willingness to buy a policy with the foregoing eligibility criteria may be relatively low.

\footnotetext{
109 This was based the exchange rate of RMB to US dollars on August 14, 2016.

110 Dewees, Duff \& Trebilcock 1996, p. 114.

111 Theoretically, only risk-averse consumers will purchase insurance because they prefer a certain small loss (premiums) to an uncertain large loss (accident harm). Risk attitudes depend upon the size of losses in relation to parties' assets. Shavell 1987a, pp. 207-208. Hence, when consumers face severe losses, they are more likely to be risk-averse; conversely, whey they face minor losses, they are more likely to be risk-neutral. However, this is only a theoretical prediction. In the Netherlands, for example, many people may nonetheless voluntarily insure against minor risks such as dentist visits. But it may be another story in China where many people are not willing to insure against even major risks. That is one of the important reasons why the first-party insurance market is still under-developed in China. See supra Chapter 5, Section 3.2.

$112 \quad$ See supra Chapter 4, Section 2.7.
} 


\subsection{CLAIMS DISPOSITION}

Optimal insurance requires that all eligible consumers should receive compensation promptly. However, the rate of claims initiation is relatively low. ${ }^{113}$ Moreover, due to high legal costs (litigation costs and attorney fees) and the difficulties created by the proof rules, compensation through the tort system is fairly slow (about 173 days) ${ }^{114}$ compared to compensation under private insurance schemes (not more than 30 days $^{115}$ ), and many patients are forced to accept a lower level of compensation through settlement out of court (about $25 \%$ of what would otherwise have been payable in court). ${ }^{116}$ It is argued that "this settlement process operates in a highly regressive manner by placing the greatest pressure to settle on those with the fewest resources and the most severe injuries." 117 Hence, from the perspective of secondary cost avoidance, this problem of delayed compensation and undercompensation is socially undesirable, although settlement out of court economises on tertiary costs. In addition, under-compensation will also lead to the problem of under-deterrence.

\subsection{ADMINISTRATIVE COSTS}

The Gulou Data show that for every 28.81 yuan damages, 1 yuan would be spent on litigation procedures, ${ }^{118}$ while in the US of one-dollar malpractice insurance premium, roughly 40 cents will be received by plaintiff-patients as compensation, about 40 cents will be spent on litigation costs and the remaining 20 cents are insurance overheads. ${ }^{119}$ In this regard, it seems that the burden of litigation costs on litigants in China is modest. However, the administrative costs of the medical malpractice system may still far exceed the insurance overheads in that malpractice litigation generates "substantial investigation costs and precludes the development of economies of scale in claims assessment." 120

\footnotetext{
113 See supra Section 3.4.

114 See supra Chapter 4, Section 3.7.1.

115 Insurance Law 2009 (China), art. 23.

116 See supra Chapter 4, Section 3.8.3.

117 Dewees, Duff \& Trebilcock 1996, p. 115.

118 See supra Chapter 4, Section 3.7.2.

119 See supra Chapter 8, Section 2.6.1.

120 Dewees, Duff \& Trebilcock 1996, p. 116.
} 


\subsection{FINANCING}

In the US, it is claimed that the way in which the medical malpractice system is financed may be very regressive - "low-income patients in effect subsidise the insurance coverage of high-income patients" - since "all patients pay the same implicit insurance premium regardless of income while benefits are strongly influenced by income-related pecuniary losses." ${ }^{.121}$

In China, however, this regressive effect should not be overstated. The main reason is that China adopts an abstract/objective approach to the calculation of damages for negligently caused disability and wrongful death, where the same criteria apply to all victims regardless of their income levels before the accident. ${ }^{122}$

\subsection{SUMMARY}

From the perspective of secondary cost avoidance, optimal compensation should reflect a rational consumer-patient's hypothetical decision about the purchase of insurance. The medical malpractice system in China is not an efficient mechanism of optimal compensation in that eligibility criteria are too complex and restricted, many victims do not receive compensation or obtain a low level of compensation, and the payment is very slow. Although the Chinese medical malpractice system seems to have fewer problems than its US counterpart under which benefit levels are exceedingly high and the regressive effect is considerable, a rational consumer-patient may still be reluctant to purchase such an "insurance." If available, insurance schemes should be more appropriate for compensating victims more promptly and sufficiently. ${ }^{123}$

As far as primary cost avoidance is concerned, under-compensation may lead to the problem of under-deterrence. ${ }^{124}$

When it comes to tertiary cost avoidance, the Chinese malpractice system incurs modest administrative costs, though these costs may still exceed insurance overheads.

\footnotetext{
$121 \quad$ Dewees, Duff \& Trebilcock 1996, p. 117.

122 See supra Chapter 3, Section 3.7.2.1.

123 See supra Chapter 10, Section 3.4.

$124 \quad$ See also supra Section 2.2.
} 


\section{PENAL AND REGULATORY ALTERNATIVES: PREVENTION (DETERRENCE)}

Regulation can be justified as an instrument for the promotion of public interest, which is intended to remedy the four sources of market failure: asymmetric information, externalities, public goods, and market power. ${ }^{125}$ As far as medical quality assurance is concerned, asymmetric information and externalities seem more severe than market power. ${ }^{126}$ In the health care sector, regulation can be either the input control (licensing) ${ }^{127}$ and the output control (quality regulation). ${ }^{128}$ Output controls may consist of ex ante safety regulation and ex post regulation. ${ }^{29}$

In order for licensing to be effective in ensuring competency, at least two conditions should be met. First, requirements for medical student education and training should be set based on the quality needs of the licensed profession. ${ }^{130}$ Second, there should be a mandatory periodic reevaluation of actual performance or continuing medical education (CME) that are directed at specific problems in practice to ensure subsequent competency. ${ }^{131}$ In China, taking five years of education at medical schools and passing the national exam for practising doctors are two essential prerequisites for obtaining a license. Recently, China initiated a nationwide mandatory scheme of the RSTR in order to provide residents with sufficient training in clinical practice. ${ }^{132}$ In theory, these medical education and training programmes should provide aspiring providers with incentives to invest sufficient time and effort in building professional competency at the beginning of their career. However, the RSTR may not be very effective in that evaluations of residents after training mainly take the form of examinations which focus on theoretical knowledge rather than on clinical techniques. ${ }^{133}$

For output controls to be effective in quality assurance, regulatory standards should be well defined and effectively enforced. ${ }^{134}$ In China, many

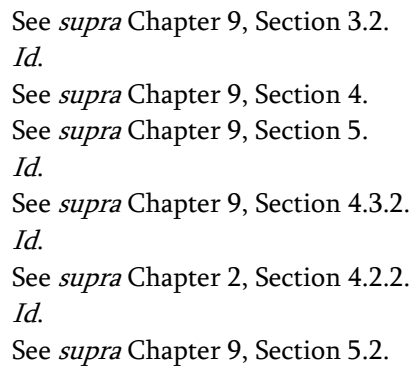


codes of conduct for health care providers are enacted by statutes, the violation of which may lead to administrative punishments (license suspension or revocation) and/or criminal penalties (imprisonment). ${ }^{135}$ These regulatory standards may be enforced either ex ante (before an $\mathrm{AE}$ occurs) or ex post (after an AE occurs). Since the medical profession in China is regulated directly by the government and it is very difficult for governmental officials to monitor provider behaviour easily and routinely, ex ante safety regulations may be enforced more through the peer review process periodical doctor assessment (PDA). However, some evidence suggests that the PDA is not very effective at enhancing doctors' expertise because in practice it focuses too much on theoretical knowledge and most doctors find it easy to pass the PDA. ${ }^{136}$ Ex post regulations rely heavily on the mandatory incident reporting system. Providers are required to report all medical quality-safety incidents (MQSI) to the public health authorities. ${ }^{137}$ However, empirical evidence shows that the rate of reporting MQSIs is exceedingly low. ${ }^{138}$ Therefore, both ex ante safety regulations and ex post regulations regarding medical quality assurance seem relatively under-enforced.

Regulatory standards are enforced by penal or administrative sanctions, which should be optimally designed as well. ${ }^{139}$ In the light of efficiency, when a less severe sanction is sufficient to deter an unlawful act, it is unnecessary to impose a more severe sanction. ${ }^{140}$ License suspension should be sufficient to deter those providers who fail to maintain subsequent competency but their expertise can be enhanced. ${ }^{141}$ License revocation should be sufficient to deter those providers who fail to maintain subsequent expertise but also fail to enhance expertise after taking CME. ${ }^{142}$ Imprisonment should only be imposed on those who know they are systematically incompetent but still willfully choose to stay in the market, but who do not intend to murder patients (recklessness or dolus eventualis). ${ }^{143}$

In China, in cases where a medical accident (an AE with obvious personal injury) occurs, the negligent provider may be subject to license suspension, license revocation, and/or imprisonment depending on the degree of negligence on the part of the provider and the seriousness of the

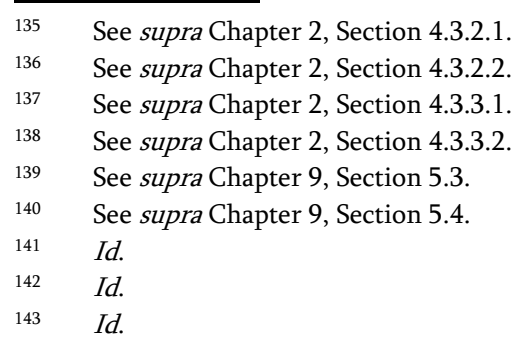


consequences. ${ }^{144}$ The criteria for the Crime of Medical Accidents (CMA) gross negligence ("seriously irresponsible") - seem too broad, since many of those who cause serious AEs due to gross negligence may be doctors who are relatively competent but commit errors inadvertently ${ }^{145}$ and who can be sufficiently deterred by license revocation, together with medical malpractice liability. Hence, the imposition of the CMA, in addition to medical malpractice liability and licensing sanctions, on providers who (grossly) negligently cause injury or death to patients is highly likely to result in overdeterrence.

Economic theories demonstrate that ideally a low probability-high sanction enforcement strategy can economise on enforcement costs without diluting the deterrence effect. ${ }^{146}$ However, in order to generate marginal deterrence, sanctions should be increased along with the size of harm and most sanctions should be set less than maximal. Therefore, with a view to maintaining sufficient deterrence, the rate of detection and prosecution should not be too low. The under-enforcement of regulatory standards in the Chinese health care sector suggests that there may be under-deterrence. Nevertheless, this problem of under-deterrence may not be so severe. Since regulation and tort liability are jointly used in China, the two regimes may well complement each other in terms of medical quality assurance. ${ }^{147}$

\section{ALTERNATIVE COMPENSATION MECHANISMS: COMPENSATION}

\subsection{MEDICAL LIABILITY INSURANCE (MLI)}

In China, MLI is still developing and may become the primary source of compensation for iatrogenic injury in the near future. ${ }^{148}$ From the perspective of law and economics, MLI primarily serves to offer protection for risk-averse injurers whereas potential victims are only protected indirectly. ${ }^{149}$ Nevertheless, from the perspective of victims, losses due to medical malpractice will be transferred from them to the negligent health care

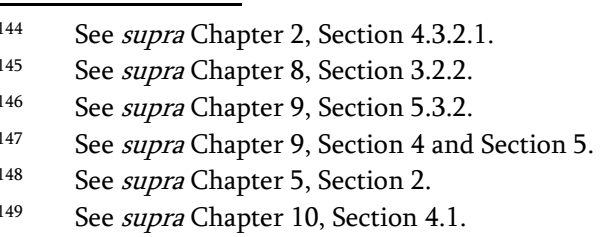


provider and eventually spread to all the insured providers through the insurance mechanism (loss spreading). ${ }^{150}$ In this way, secondary costs resulting from negligent adverse events are reduced via the fault-liabilityinsurance system (FLIS). ${ }^{151}$

For MLI to be successful, it ought to be guaranteed that the risk of medical malpractice liability is insurable. The theoretical issues concerning the insurability of malpractice risks have been extensively discussed in Chapter 10. ${ }^{152}$ After examining the medical malpractice system and several MLI schemes in China, it can be found that the many aspects of the Chinese FLIS fit into these theories. First, most (five out of six) of the MLI schemes are claims-made with a view to tackling the long tail problem. ${ }^{153}$ Second, all of these six MLI schemes employ some solutions to resolve the problem of moral hazard. Caps on insurance benefits (under-insurance) are adopted by all, coinsurance by one, deductibles by two, and experience-rating by two. Third, Chinese courts employ proportional liability to tackle causation uncertainty issues, which will not lead to a problem of un-insurability. ${ }^{154}$ Fourth, channelling of liability adopted by article 54 of the Tort Law 2009 (EML) will enhance rather than decrease the insurability of malpractice risks. ${ }^{155}$ Fifth, article 57 of the Tort Law ("the then medical standard") excludes the possibility of retroactive liability, which will not lead to uninsurability. ${ }^{156}$

Be that as it may, the current MLI schemes in China still face some problems. Although these MLI schemes claim to be compulsory, they lack the necessary sanctions to enforce this obligation. Hence, many low-risk hospitals do not purchase MLI or only purchase MLI for high-risk specialties, leading to the problem of adverse selection. ${ }^{157}$ Due to this problem, the premiums for MLI are often high and sometimes even higher than the total malpractice damages paid annually, which discourage many hospitals from purchasing MLI continually. ${ }^{158}$

Overall, although many aspects of the Chinese FLIS fit into economic theories, the MLI schemes will not develop well unless the problem of adverse selection has been tackled. Risk differentiation (e.g. experience-

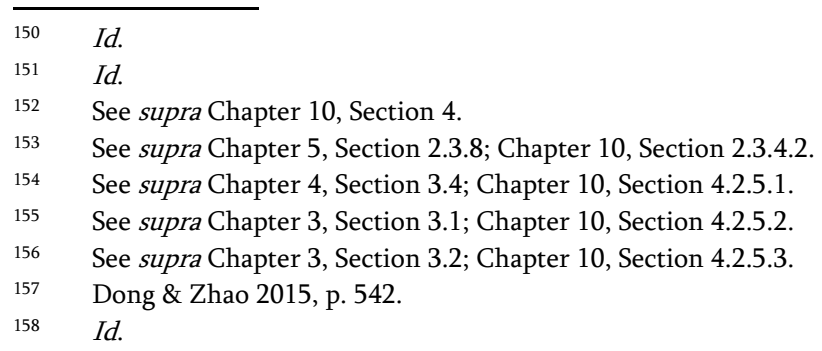


rating) $)^{159}$ and compulsory MLI with effective enforcement mechanisms ${ }^{160}$ are clearly warranted.

\subsection{FIRST-PARTY INSURANCE AND SOCIAL SECURITY}

In China, the first-party insurance that covers iatrogenic injuries is underdeveloped. Hence, it is difficult to assess whether it is able to provide victims with adequate and quick compensation.

Social security is developing rapidly and covers the majority of the population in China now. However, it only provides a minimum level of economic security. Hence, in practice, it is jointly used with tort law. The current combination of social security and tort law seems to over-compensate victims of medical malpractice because the law does not provide for the collateral source set-off rule and a right of recourse except for cases where public health insurance is involved. ${ }^{161}$ It is difficult to understand why the Social Insurance Law 2010 has provided for the collateral source set-off rule for claims under the BMIS while it has not mentioned this rule under the BPIS. ${ }^{162}$ Neither has the administrative assistance regime adopted this rule. ${ }^{163}$

\section{THE IMPACT OF YI NAOINCIDENTS ON THE MALPRACTICE SYSTEM}

The above analysis demonstrates that there is the problem of undercompensation in the malpractice system in China due to the low rate of claims initiation and the low level of compensation. According to economic theories, under-compensation will lead to under-deterrence. In China, however, available evidence suggests that providers are often over-deterred and defensive medicine is prevalent. Why is that so?

The primary reason, of course, is that there is great uncertainty over the standard of care and providers react by over-complying.

The second reason may be that the regulatory and penal regimes provide physicians with additional deterrent incentives. However, the low rate of detection of those at fault and the under-enforcement of regulatory

See supra Chapter 10, Section 4.2.4.3.

See supra Chapter 10, Section 4.2.6.

See supra Chapter 11, Section 4.3.2.

See supra Chapter 5, Section 3.4.

Id. 
standards in the health care sector call into question the effectiveness of such alternative regimes.

Another reason may be that, empirically speaking, $Y i$ Nao incidents provide such additional deterrent incentives. In China, not only to the indirect risks of medical malpractice liability pose a threat (internal sanctions) to individual providers, but also the direct risks of getting involved in $\mathrm{Yi} \mathrm{NaO}$ incidents generate a chill of fear. Although negligent providers do not have to appear in court as the defendant, they will directly face any potentially violent consequences of a $\mathrm{Yi}$ Nao incident triggered by a medical dispute. The threat of $Y i$ Nao incidents even partly accounts for the epidemic of defensive medicine in China.

That being said, this does not mean to say that $\mathrm{Yi}$ Nao incidents are socially desirable. Yi Nao incidents per se are illegal activities that incur considerable social costs. They should be banned beyond doubt. In the long run, when $Y i$ Nao incidents are effectively dealt with by the police, ${ }^{164}$ this chilling effect generated by $\mathrm{Yi}$ Nao incidents may be considerably lessened or removed.

\section{CONCLUSIONS}

Chapter 12 has evaluated the entire Chinese legal remedies in relation to medical malpractice prevention and victim compensation from the perspective of law and economics. The primary purpose is to answer the question whether the Chinese medical malpractice liability system is efficient in terms of both deterrence and compensation. In addition, alternative regimes such as regulation and MLI have also been evaluated briefly in the light of economic theories.

The main conclusion is that most aspects of the Chinese medical malpractice system are efficient in terms of injury prevention, except for under-compensation due to the caps on compensation for disability, death, and emotional distress and the low rate of claims initiation. However, Chinese health care providers may not be under-deterred when two factors are taken into account. First, uncertainty over the standard of care will

164 Recently, China enacted the N-Crackdown on Yi Nao Incidents 2016 (China), and initiated a one-year crackdown on Yi Nao incidents from August 2016 to April 2017. The police are required to intervene and stop $Y i$ Nao incidents as quickly as possible. Those $Y_{i}$ Nao mobs who assault providers or damage hospital facilities will be arrested and prosecuted promptly. It seems that it is now impossible for the police to act as onlookers when a Yi Nao incident occurs. However, it still remains to be seen whether the $\mathrm{Yi} \mathrm{NaO}$ problem will be eliminated by the state crackdown in the future. 
normally induce providers to over-comply. Second, the potential risk of being criminally charged with the CMA or being subject to license revocation poses some threats to providers. Hence, for the time being, it is unlikely that Chinese health care providers will be under-deterred. On the contrary, providers may be over-deterred as evidenced by the prevalence of defensive medicine.

In addition, medical disputes are often associated with violent $Y i \mathrm{NaO}$ incidents, which may produce an unintended deterrent to providers. However, $Y i$ Nao incidents are illegal and should be tackled by the police in the future. The effect of the elimination of $\mathrm{Yi} \mathrm{NaO}$ incidents in the future on provider incentives still remains to be seen.

From the perspective of optimal compensation, however, the Chinese medical malpractice system is inefficient mainly due to the complex and restricted eligibility criteria, a low rate of claims initiation, and systematic under-compensation through settlement out of court.

The regulatory system of medical quality assurance may lead to underdeterrence due to under-enforcement of regulatory standards. This problem may not be severe, since regulation and liability may complement each other as far as injury prevention is concerned.

MLI is still in its preliminary stage in China. Although most local MLI schemes adopt co-payment mechanisms to tackle the problem of moral hazard, only a minority employ experience-rating. Hence, many of these local MLI schemes face the problem of adverse selection. Although most of these MLI schemes claim to be compulsory insurance, no law or regulation has ever provided a sanction to enforce this compulsory obligation to purchase MLI.

Tort law and social security are jointly used in practice. Apart from the BMIS, other social security schemes may lead to over-compensation in that they have not employed the collateral source set-off rule. 


\section{CHAPTER 13 \\ CONCLUDING REMARKS AND POLICY RECOMMENDATIONS}

\section{INTRODUCTION}

The primary purpose of this thesis was to answer the following main research questions:

(1) Are the current legal remedies for medical malpractice in China sound from the legal perspective?

(2) Are these legal remedies also efficient when measured against economic benchmarks?

(3) If not, how can we improve these systems?

Chapter 1 has provided the background to this research, defined the above research questions and explained the research methods. Chapters 2 to 12 have answered the first two main research questions. The general conclusion is that although many aspects of the Chinese legal remedies for medical injury prevention and patient compensation are relatively effective and efficient, there is still plenty of room for improvement. Section 2 will summarise the main findings of the previous Chapters in the light of sub-questions derived from the first main research question. Policy recommendations for improvement (i.e. answers to the third main research question) will be made in Section 3. Although the topics covered by this thesis are extensive, the thesis has its limitations, which will be highlighted in Section 4 . The final Section 5 will point out some directions for future research. 
Part III. Applying the Economic Observations to China

\section{A SUMMARY OF MAIN FINDINGS}

\subsection{SUB-QUESTION 1-A: WHAT ARE THE LEGAL REMEDIES CURRENTLY AVAILABLE IN CHINA THAT ARE AIMED AT THE PREVENTION OF MEDICAL MALPRACTICE AND VICTIM COMPENSATION?}

\subsubsection{Introduction}

This sub-question has been answered in Part I (Chapter 2 to Chapter 5). Although ex post compensation is essential to victims of medical malpractice, the avoidance of the victimisation in the first place is the best way to protect victims. Hence, not only legal instruments that are intended to provide victimised patients with compensation but also those that are meant to prevent medical malpractice (or medical errors) should be examined.

China has established some legal remedies pertaining to medical malpractice prevention and victim compensation, which can be summarised as follows.

\subsubsection{Regulation}

The regulatory framework for the assurance of medical quality (or injury prevention) in China has been described in Chapter 2. Regulation is primarily concerned with injury prevention instead of victim compensation.

In China, all health care services are provided by institutional providers ("medical institutions" including hospitals, health care centres, and clinics) for patients. Individual providers (doctors, nurses, pharmacists, technicians, etc.) are medical staff members employed by various medical institutions.

The medical profession - both institutional and individual providers is directly regulated by the government, mainly by the public health authorities. Both the health care input (entry into the medical profession) and the health care output (the quality of care) are controlled and monitored by the authorities.

Both institutional and individual providers have to obtain a license from the authorities before they can practice medicine. If they practice without a license, they will be subject to administrative punishments and/or criminal penalties. 
The authorities basically employ the command-and-control method to ensure the quality of care. Providers must comply with professional codes of conduct that are provided for by relevant laws, regulations, and medicaltechnical norms. Violation of these codes of conduct will lead to administrative and/or criminal sanctions.

In order to ensure subsequent expertise, hospital accreditation and periodical doctor assessment have been implemented.

In addition, providers are supposed to report adverse incidents (MQSIs) to the authorities. In the light of the seriousness of the reported incident, the authorities may decide to employ regulatory threats rather than sanctions to induce hospital managers to make corrections.

Since the medical profession in China is tightly controlled by the government, there is currently little room for self-regulation.

\subsubsection{The Medical Malpractice Liability System}

Chapter 3 has described the substantive system of private law compensation for iatrogenic injuries in China. The liability system is unique in that it is aimed at both deterrence and compensation.

Although it is possible for victimised patients to claim compensation under either contract law or tort law, few patients choose the former because detailed quantum rules, medical expert ascertainment, and non-pecuniary damages are only available under the latter.

The medical malpractice tort system was established in 1987 (ARMedical Accidents 1987) and was substantially reformed in 2002 (AR-Medical Accidents 2002) and 2009 (Tort Law 2009).

The AR-Medical Accidents 1987 was abandoned because it only provided victims with an extremely limited scope of liability and level of compensation. The AR-Medical Accidents 2002 was replaced by the Tort Law in that the former's scope of liability and level of compensation were still limited compared to the general civil law (Principles 1986 and relevant judicial interpretations).

The current medical malpractice liability system is based on the Tort Law 2009, together with the JI-Emotional Damage 2001 and the JI-Personal Injury 2003. In general, China employs the fault-based enterprise medical liability (EML) to medical malpractice issues (article 54 Tort Law), where medical institutions are the sole defendant in medical malpractice litigation.

Any fault on the part of medical staff members is directly considered as the medical institutions' own fault.

The current medical malpractice liability can be classified into technical malpractice (breach of standards of care regarding medical 
techniques) and ethical malpractice (breach of standards of care regarding medical ethics).

Ethical malpractice can be sub-divided into disclosure malpractice (breach of the duty of disclosing information and obtaining consent, article 55 Tort Law), breach of confidence (article 62 Tort Law), and conducting unnecessary examinations (article 63 Tort Law).

The standard of care regarding medical techniques is defined as the "then medical standard" (article 57 Tort Law).

Regarding the burden of proof, the onus currently is in principle placed on the plaintiff-patient, although in the period 2002-2009 it was mainly placed on the defendant-hospital. However, in cases where the provider contravenes a regulatory standard, refuses to provide or forges medical records, the defendant will be presumed to be at fault (a rebuttable presumption).

Besides technical malpractice and ethical malpractice, hospitals are strictly held liable for injury due to defects in medical products. After paying damages to victims, hospitals are entitled to have recourse to manufacturers/blood banks that are ultimately liable.

The determination of fault and causation relies heavily on the two parallel expert witness systems - the MATAS (clinical experts organised by medical associations) and the JAS (forensic pathologists).

Quantum rules (law of damages) are defined roughly by the Tort Law (article 16 and article 22) and specified in detail by the JI-Emotional Damage 2001 and the JI-Personal Injury 2003. The measure of future damage due to disability or death is based on the abstract/standardised approach, i.e. the average annual earnings multiplied by a fixed period (usu. not more than 20 years).

\subsubsection{Medical Liability Insurance (MLI)}

Chapter 5 has described the development of MLI in China. MLI is an insurance scheme, based on the medical malpractice liability system, that can provide victims with adequate compensation in cases where the defendant is insolvent.

The current legal basis for MLI is article 65 and article 66 of the Insurance Law 2009. The insurer is allowed to pay benefits to the third-party victim. The victim is entitled to claim benefits directly from the insurer if the insured fails to make such a request in time.

All necessary and reasonable costs of litigation or arbitration will be covered by the insurer as well. These rules apply to all types of liability insurance.

There is currently no legal provision specifically intended for MLI. 


\subsubsection{First-Party Private Insurance}

Chapter 5 has also described the legal basis for first-party private insurance the Insurance Law 2009. Patients may decide to purchase private health insurance or medical mishap insurance to insure against the risk of iatrogenic injury.

\subsubsection{Social Security Schemes}

In addition to MLI and first-party private insurance, some of the losses suffered by victims of medical malpractice may be covered under various social security schemes as depicted in Chapter 5 .

Social security is intended to provide a minimum level of compensation to the vulnerable groups.

Added treatment costs due to medical malpractice may be covered under the public health insurance schemes (BMIS) or administrative assistance schemes for the poor.

Consequential losses due to disability or death may be covered under the basic pension scheme or the administrative assistance schemes for the poor.

\subsection{SUB-QUESTION 1-B: ARE THESE REMEDIES SOUND ACCORDING TO LEGAL DOCTRINES?}

\subsubsection{Introduction}

This sub-question has been answered in Part I (Chapter 2, Chapter 4 to Chapter 6). The soundness (legal certainty, effectiveness, and fairness) of these legal remedies are assessed on the basis of traditional legal doctrines and currently available empirical evidence, part of which were first-hand data collected by the author (mainly presented in Chapter 4) and part which concerns findings of existing empirical studies. The results of the assessment are summarised as follows.

\subsubsection{Regulation}

Empirical evidence about the effectiveness of regulation has been addressed in Chapter 2.

Overall, the effectiveness of the regulatory quality assurance system needs to be enhanced for five reasons. First, the licensing law is underenforced in rural and suburban areas. Second, the hospital accreditation 
scheme has been suspended several times. Third, the PDA evaluates physician competency based on theoretical knowledge rather than actual performance and ethics. Fourth, adverse incidents (MQSIs) are considerably underreported. Fifth, regulatory threats do not generate any deterrent effect.

\subsubsection{The Medical Malpractice Liability System}

Chapter 4 has presented the results of the analysis of court decisions and semi-structured interviews, which are compared and contrasted with prior studies.

The general conclusion is that although many aspects of the substantive medical malpractice liability law are undefined or unclear (e.g. the meaning of "the then medical standard," standard of disclosure, causation issues, the applicability of equitable liability, the measure of non-pecuniary damages), Chinese courts have developed a consistent approach to these undefined or unclear aspects.

For instance, they often interpret the "then medical standard" as written regulatory standards or customary practices if there are no such written standards. They employ the "double-test doctrine" to define the standard of information disclosure. They restrict the applicability of equitable liability only to cases where the patient is injured by substandard blood but neither the plaintiff nor the defendant is at fault. They apply proportional liability to cases where uncertainty over causation is considerable.

All these endeavours made by Chinese courts ensure that the substantive medical malpractice liability system is functioning well in dispute resolution through litigation.

The medical malpractice system also plays a role in disputes resolved through negotiation and mediation out of court, since liability rules and quantum rules often serve as a useful starting point for bargaining between hospitals and patients.

Hence, the Chinese medical malpractice liability system is relatively effective in practice. Be that as it may, its effectiveness needs to be improved in that the rate of claims initiation is low in practice.

In addition, some features of the system may go against the principles of corrective justice. For instance, an abstract approach is adopted to the measure of compensation and some financial caps are imposed. The low rate of claims initiation also goes against corrective justice. 


\subsubsection{Medical Liability Insurance (MLI)}

MLI is rather under-developed in China, where only about $10 \%$ of all medical institutions purchase MLI policies. Six local MLI schemes have been described and compared in Chapter 5.

Many of these schemes face the problem of a contraction of the market. Four reasons may explain this contraction. First, although many local MLI schemes require that at least public hospitals purchase MLI policies, it is difficult to enforce this obligation due to a lack of statutorily imposed sanctions. Second, large hospitals are not willing to purchase MLI policies because they prefer self-insurance to paying high MLI premiums and MLI insurers are unable to help resolve the problem of $\mathrm{Yi}$ NaO incidents. Third, some hospitals do not purchase MLI because they want to conceal medical accidents which may lead to administrative punishments and/or criminal penalties. Fourth, many insurance companies are not willing to sell MLI policies because of considerable uncertainty over legal standards for the period 2002-2009.

The second and the fourth reasons may become less convincing for the time being in that $\mathrm{Yi} \mathrm{NaO}$ incidents may have been reduced by the joint effort of the police crackdown and people's mediation, and the Tort Law 2009 has already unified the substantive medical malpractice rules. Overall, the effectiveness of MLI is currently rather limited in China.

\subsubsection{First-Party Private Insurance}

Currently in China, first-party patient insurance is even less developed than MLI. Patients are often not willing to purchase either private health insurance or medical mishap insurance.

\subsubsection{Social Security Schemes}

Recently, China has made relatively successful endeavours to build a social security network for its population. Currently, about $95 \%$ of the population has been covered by the public health insurance (BMIS) and $80 \%$ by pension insurance (BPIS). The legal doctrine of subrogation applies under the BMIS but not under the BPIS.

Extremely poor people are entitled to receive some benefits from the government via administrative assistance schemes.

These schemes are relatively effective in practice but they only provide a minimum level of compensation for eligible residents. Hence, social security schemes in China may play a supplementary rather than an alternative role in compensating victims of medical malpractice compared to the tort system. 
Part III. Applying the Economic Observations to China

\subsection{SUB-QUESTION 2-A: HOW SHOULD THE LEGAL REMEDIES BE STRUCTURED IN ORDER TO PREVENT MEDICAL MALPRACTICE AND COMPENSATE VICTIMS FOR IATROGENIC INJURIES EFFICIENTLY IN THE LIGHT OF ECONOMIC BENCHMARKS AND} AVAILABLE EMPIRICAL EVIDENCE?

\subsubsection{Introduction}

This sub-question can further be divided into two parts. First, how should legal remedies be designed in order to prevent medical errors (medical malpractice) efficiently? Second, how should legal remedies be structured in order to compensate victims for iatrogenic injuries efficiently?

Answers provided by economists to these questions are normally based on Calabresi's analytical framework. According to Calabresi, the principle function of accident law is to reduce the expected accident costs and the cost of precautions ("injury prevention"). The sum of these costs is often referred to as Calabresi's primary costs. Also, Calabresi stressed the importance of secondary cost avoidance - in cases where accidents nonetheless occur victims should be compensated quickly and adequately in order to reduce the economic dislocation due to accidents. Moreover, the tertiary costs of administering the prevention and compensation systems should not exceed the benefits of injury prevention and victim compensation. Social welfare will be maximised when the sum of these three types of costs is minimised.

The two legal instruments that are used to prevent iatrogenic injuries are the tort system (Chapter 7 and Chapter 8) and regulation (Chapter 9). In contrast, some regard the contractual approach as the best way to maximise the welfare of patients (Chapter 9).

Various legal instruments - tort law, liability insurance, self-insurance, first-party insurance, compensation funds, and social security - may be used to provide victims with compensation for iatrogenic injuries. Chapter 10 has examined tort law and those compensation mechanisms that are based on fault-based tort system (liability insurance and self-insurance). In contrast, Chapter 11 has addressed various no-fault compensation schemes - first-party insurance, compensation funds, and social security. 


\subsubsection{How Should Legal Remedies Be Designed in Order to Prevent Medical Errors (Medical Malpractice) Efficiently?}

\subsubsection{Tort Law}

Economic theories and empirical studies on the deterrent effect of medical malpractice liability law have been addressed in Chapter 7 (theoretical models) and Chapter 8 (empirical evidence).

Economic Theories. Chapter 7 has explained the unilateral accident model of tort law and applied the model to medical malpractice liability. As to the choice between negligence and strict liability, although the model predicts that strict liability is superior to negligence when activity levels are taken into account, concerns for other factors such as positive externalities generated by health care activities and insolvency risks suggest that we should be cautious about imposing strict liability.

Regarding the standard of care, it is optimal to impose a higher level of due care on providers rather than on ordinary citizens and a uniform level of due care should be adopted for the same or similar group of providers in order to economise on tertiary costs. Uncertainty over the standard of care is likely to result in defensive medicine. One way to reduce this uncertainty is to rely on customary practices which are developed by the medical profession. Regulatory standards can also be referred to. A contravention of regulatory standards should automatically establish negligence, whereas compliance with regulatory standards should not automatically exclude a finding of negligence.

When it comes to causation, in cases where it is uncertain whether the provider's faulty treatment or other non-tortious factors (therapeutic risks or pre-existing conditions) have caused the patient's injury, proportional liability is more efficient than the traditional threshold approach. As regards proof rules, a reversal of the burden of proof is akin to strict liability, which is socially undesirable when taking into account the considerable positive externalities generated by health care activities.

Full compensation is essential to the deterrent effect of tort liability. In order to save tertiary costs, damages should be assessed objectively rather than subjectively. With a view to better assessing the value of a loss of life or pain and suffering, the QALY approach is highly recommended. While the collateral-source set-off rule should be applied to cases where part of damages are paid under social insurance, the collateral-source rule should be applied to cases where part of the damages is paid under private health. In light of the off-setting benefits rule, non-negligence iatrogenic injuries and noniatrogenic injuries should be excluded from the scope of liability. 
Finally, a settlement that could mirror a court decision is socially desirable in that it saves tertiary costs.

Empirical evidence. Chapter 8 has examined empirical evidence on the deterrent effect of the fault-based medical malpractice liability and discussed the modification of the classic model of medical malpractice liability in the light of new evidence pertaining to the causes of iatrogenic injuries. The general conclusion is that although the costs of the malpractice system are quite high, the huge deterrence benefits of reduced iatrogenic injuries are highly likely to pay for the expenses incurred by the malpractice system.

Moreover, new empirical evidence supports the view that medical negligence is mostly accidental rather than deliberate and most medical errors can be better prevented at the institutional level instead of the individual level. The updated and empirically-grounded model of malpractice liability requires that health care providers should be induced to invest in both care and patient safety and the locus of liability should be placed on institutional providers alone.

\subsubsection{Regulation}

In the light of the public interest theory, regulation can be a legitimate instrument for the promotion of public interest. Regulation may be able to remedy the four sources of market failure: asymmetric information, externalities, public goods, and market power. In the context of health care, regulation can be either input control through licensing and output control through quality regulation.

Licensing can be used to ensure service quality by resolving the problems of asymmetric information, externalities, and quality deterioration. Licensing may have several drawbacks, but at least it can be justified as serving the purpose of primary cost avoidance - ensuring the initial investment in professional competency - and constituting a useful complement to the tort system.

Quality regulation can be either ex ante safety regulation based on rules before any accident occurs or ex post regulation based on standards after an accident occurs. While $e x$ post regulation is indispensable as a "fail-safe" device against the failure of $e_{x}$ ante regulation, the latter should be encouraged, insofar as the conditions of patients and their responses to medications are homogeneous, in order to improve regulatory efficiency. Neither ex ante regulation nor ex post regulation is a perfect alternative to tort law. Hence, regulation and tort liability should be jointly used in practice. 
We should be cautious about the criminalization of medical malpractice since the enforcement of imprisonment is highly costly and the social stigma attached to being criminally punished may persist even after being discharged from prison. Since most medical errors are committed inadvertently by relatively competent physicians, medical malpractice liability is sufficient to deter, and criminal penalties should not be imposed in the majority of the cases. In cases where the physician fails to maintain subsequent competency and also fails to enhance it after taking CME, her license should be revoked and criminal penalties are not warranted. Only in cases where the physician knows that he/she is systematically incompetent but still deliberately chooses to stay in the market, criminal penalties should be imposed to deter her from continuing medical practice.

Neither direct governmental regulation alone nor self-regulation alone is socially desirable. The government may lack sufficient information to set regulatory standards and may be unable to enforce regulatory standards costeffectively. However, self-regulation also has its limitations such as rentseeking, limitations on market competition, and professional protectionism. From the perspective of public interest and primary cost avoidance, it would be more efficient if the two mechanisms could be optimally combined.

Empirical evidence from North America shows that the rate of detection of non-complying providers is relatively low and regulators are often not willing to impose licensing sanctions. Under-enforcement of regulatory standards may lead to under-deterrence.

In some common law systems (England and New Zealand), although the criterion for imposing criminal penalties on providers is gross negligence, empirical evidence shows that many, if not most, providers who were convicted of manslaughter merely committed errors due to ordinary negligence. As a notable example in Europe, a rise in criminal lawsuits was reported in Spain. The over-criminalization of medical malpractice may lead to over-deterrence.

\subsubsection{The Contractual Approach}

Proponents of the contractual approach criticise the traditional fault-based malpractice liability for it is an expensive "lottery" that has little deterrent benefits. Instead, they maintain that fully informed parties should be allowed to negotiate on the extent of liability by private contracts, for they know better than others what is best for themselves. However, their fundamental assumption that parties have perfect information concerning malpractice risks is directly challenged by many opponents because serious uncertainty about quality and information asymmetry are characteristic of the health care sector. 
Moreover, opponents also raise objections to the contractual approach even when parties were fully informed. Patients would be systematically worse off if they opted out of statutory liability or varied the statutory standard of care. A patient would only care about her own best interests in a private contract. He/she would neglect the benefits of collective care to other patients and ignore learning and network benefits to providers. The availability of extensive social welfare provision in some legal remedies may render the contractual approach less attractive.

\subsubsection{How Should Legal Remedies Be Structured in Order to Compensate Victims for Iatrogenic Injuries Efficiently?}

\subsubsection{Tort Law Per Se}

Traditional tort theorists, based on the notion of corrective justice, treat compensation (loss shifting) as the primary function of tort law. In contrast, economists normally stress the deterrence function of tort law.

Tort law could be designed to reduce secondary costs if EML were employed. Two types of enterprise liability are available. The first type transfers losses to those who are most able to self-insure (or insure), while the second type spreads losses to consumers by treating the tort system as insurance.

Although treating the tort system alone as an insurance regime does reduce some secondary costs, it achieves this goal at the expense of the goals of primary and tertiary cost avoidance.

Hence, it may be better to employ EML in the sense that it better facilitates self-insurance.

Tort damages could be determined in the light of the victim's ex ante WTP, which takes into account both primary and secondary cost avoidance.

\subsubsection{Liability Insurance}

MLI can be used to reduce secondary accident costs in that it helps promote both inter-personal and inter-temporal loss spreading. The supply of MLI is possible in that insurers rely on the technique of pooling and the Law of Large Numbers.

Informational problems - moral hazard and adverse selection - may have adverse implications for the MLI market. Moral hazard may dilute the insured's incentives to take precautions.

The first best solution for MLI may be ex post experience rating. 
The second best solution may be deductibles or co-insurance. Adverse selection may lead to the breakdown of the MLI market.

The common solution to moral hazard and adverse selection is risk differentiation, especially through experience rating.

Regarding some liability sub-rules, the proportional approach in the case of causal uncertainty and channelling of liability under EML may enhance the insurability of MLI without adversely affecting the deterrent function of malpractice liability. In contrast, retroactive liability is inefficient regarding either deterrence or insurability. Caps on liability would not enhance insurability too much but they would lead to under-deterrence.

Compulsory MLI may be warranted in three cases where potentially liable parties under-estimate the risk of malpractice liability, where potentially liable parties are judgement-proof, and where the risk of adverse selection is considerable.

Recent evidence shows that the costs of malpractice claims are not the main cause of the crisis. The malpractice crisis is more an insurance crisis due to the underwriting cycle than a malpractice liability crisis.

\subsubsection{Self-Insurance}

Although self-insurance saves on tertiary costs, it is by and large inferior to market insurance, because it does not spread losses and hence cannot prevent insolvency risks given that losses due to medical malpractice are normally high.

Nonetheless, self-insurance can be justified in cases where market insurance is too expensive or hardly available. In such a case, a combined use of self-insurance (against small losses) and market insurance (against large losses) may be socially optimal.

However, regulation is needed to guarantee that the reserves set aside will be used to insure against potential malpractice risks.

\subsubsection{First-Party Insurance}

First-party patient insurance has advantages over the FLISs (FLIS) in terms of secondary and tertiary cost reduction. Under patient insurance, victimised patients could obtain much more extensive compensation and relatively more quickly. Patient insurance economises on tertiary costs more than the FLIS in that the former facilitates better risk-differentiation and avoids costly tort litigation procedures.

However, the use of patient insurance alone is inefficient because it may dilute health care providers' incentives to take precautions and increase primary accident costs dramatically. 
Hence, it may be socially optimal to use patient insurance as a complement to the FLIS. On account of imperfect information and concerns for externalities, compulsory patient insurance may be warranted.

\subsubsection{Compensation Funds}

Under a general medical compensation fund, a sum of money will be established specifically for compensating eligible accident victims.

In order for a compensation fund to be fair and efficient, it must meet three principles: (1) the incentives for health care providers to prevent medical malpractice should not be undermined; (2) the duty of contribution should also correspond with the extent to which the risk has been caused by the specific treatment or hospital; and (3) only those who actually contribute to the risk should contribute to the fund.

Adverse events will become compensable iatrogenic injuries when they are more severe than expected, or when they represent the random manifestation of a serious low-probability risk inherent in a medically necessary method of treatment.

In case of causal uncertainty, the proportional approach to causation may avoid either over-deterrence or under-deterrence.

Empirical evidence shows that comprehensive NFCSs (e.g. in New Zealand, and Scandinavian countries) are effective at compensating a greater number of injured patients more quickly than under the tort system without substantially increasing tertiary costs.

However, one may still have concern for the reduced incentives for providers to exercise care under these NFCSs.

\subsubsection{Social Security}

Social security is intended to provide a minimum level of economic security and social welfare for citizens and their families.

A social security scheme is usually operated subject to three basic requirements: first, there should be a state organised insurance scheme; second, the claimant should belong to the protected group of people; and third, the claimant often has to contribute to the social security fund.

Supposing tort liability and social security were completely alternative to each other. Then, two ideal models of reaching the goals of both deterrence and compensation through either social security or tort law could be designed as follows: (1) safety regulation + social security; and (2) tort liability + insurance.

In practice, however, to replace social security completely by tort liability or vice versa is virtually unrealistic. 
In cases where tort damages and social security benefits overlap, it may be socially efficient to grant a right of recourse to social security agencies. The combination of the collateral source set-off rule and a right of recourse is efficient.

\subsection{SUB-QUESTION 2-B: ARE THESE LEGAL REMEDIES FOR IATROGENIC INJURY PREVENTION AND PATIENT COMPENSATION IN CHINA EFFICIENT AS WELL?}

\subsubsection{Legal Remedies for Injury Prevention}

\subsubsection{The Medical Malpractice Liability System}

Many elements of the Chinese medical malpractice system are structured efficiently. First, it is primarily fault-based, except for medical products liability which is based on strict liability. Since health care activities generate considerable external benefits to society, it is more desirable to apply negligence to medical malpractice liability. The fault liability rule adopted by article 54 of the Tort Law is efficient. Second, article 57 adopts the objective reasonable doctor test (the "then medical standard") as the standard of care regarding medical techniques. The reasonable doctor test is theoretically compatible with the economic notion of the optimal level of care. In practice, although regulatory standards or customary practices may be relied upon to determine fault, courts may disregard them if due care entails different standards. The "double-test doctrine" adopted by courts for the standard of information disclosure is also efficient. Third, as regards causal uncertainty, courts adopt the proportional approach to factual causation, which is efficient. Fourth, the reversal of the burden of proof rule, which is akin to strict liability, has been abandoned by the Tort Law. Fifth, damage due to non-tortious factors (pre-existing conditions or therapeutic risks) is excluded from the scope of liability, which is compatible with the re-stated negligence rule. Sixth, the collateral benefit set-off rule applying to cases where public health insurance (BMIS) is involved reduces tertiary costs due to dual compensation.

However, some aspects of the medical malpractice systems may lead to under-deterrence. First, there are caps imposed on damages for disability, death or emotional distress which may cause under-compensation systematically compared to the QALY's approach. Second, the rate of claims 
initiation is relatively low due to the problem of claims consciousness or high transaction costs.

That being said, two factors may enhance economic incentives for providers to take precautions. First, uncertainty over the standard of care may induce providers to over-comply. Second, the potential risk of being criminally charged with CMA or being subject to license revocation may pose some threat to providers. Hence, for the time being, it is unlikely that Chinese health care providers will be under-deterred too much. Instead, they may be over-deterred, evidenced by the epidemic of defensive medicine. In addition, medical disputes are often associated with violent $Y i$ Nao incidents, which may generate an unintended deterrent to providers. However, these $Y i$ Nao incidents are illegal activities which should be prevented.

There is a want of empirical statistical studies in China on the impact of the threat of medical malpractice liability on the rate of iatrogenic injury directly. Since China's input of the medical malpractice system appears similar to its US counterpart in many respects, we may, based upon the extensive empirical studies in the US, speculate that the Chinese medical malpractice system is likely to be effective at reducing iatrogenic injuries as well.

\subsubsection{Regulation}

The regulation of the medical profession in China faces the problem of underenforcement, ${ }^{1}$ which may lead to the problem of under-deterrence. This problem may not be so severe since the tort system also generates additional incentives for providers to take precautions.

When it comes to the choice of sanctions, since license revocation has already proved sufficient to deter many negligent providers who are relatively competent, the CMA should be restricted to extreme cases where providers, who know they are systematically incompetent but still want to stay in the market, causes serious damage to patients (dolus eventualis).

\subsubsection{Legal Remedies for Victim Compensation}

\subsubsection{The Medical Malpractice Compensation System}

From the perspective of secondary cost avoidance, the Chinese medical malpractice system exhibits some features of efficiency. First, it adopts EML (article 54 Tort Law) which places the locus of liability exclusively on

See supra Section 2.2 . 
hospitals. This is efficient (the deep pocket approach) because it places accident losses on the party who is in the best position to self-insure against malpractice risks in that hospitals have more assets than individual providers. Second, benefit levels are relatively low because of the caps on compensation for disability, death, and pain and suffering, which may not deviate from the optimal compensation defined by the insurance theory. Third, claims disposition is relatively accurate because most decisions on fault and causation are based on expert testimonies (peer review). Fourth, the Chinese medical malpractice system incurs a relatively low size of administrative costs (28.81-yuan compensation to 1-yuan litigation costs) compared to its US counterpart (40-cent compensation to 40-cent litigation costs). Fifth, the Chinese medical malpractice system is not financed regressively since the same abstract criteria for compensation apply to all victims alike, which is different from its US counterpart where pecuniary losses are income-related.

Be that as it may, the Chinese medical malpractice system is inefficient at optimal compensation in other aspects. First, the eligibility criteria (fault and causation) are too complex and restricted. It is difficult for eligible victims to obtain compensation easily and quickly. Second, many victims do not receive any compensation because they fail to file a claim or receive a low level of compensation through settlement out of court. Although the Chinese medical malpractice system has fewer problems than its US counterpart under which benefit levels are exceedingly high and the regressive effect is considerable, a rational consumer-patient may still be reluctant to purchase such an "insurance."

\subsubsection{Medical Liability Insurance (MLI)}

After examining the medical malpractice system and several MLI schemes in China, it can be found that the many aspects of the Chinese FLIS fit into these theories. First, most (five out of six) of the MLI schemes are claims-made with a view to tackling the long tail problem. Second, all of these six MLI schemes employ some solutions to resolve the problem of moral hazard. Caps on insurance benefits (under-insurance) are adopted by all, co-insurance by one, deductibles by two, and experience-rating by two. Third, Chinese courts employ proportional liability to tackle causation uncertainty issues, which will not lead to a problem of uninsurability. Fourth, channelling of liability adopted by article 54 of the Tort Law 2009 (EML) will enhance rather than decrease the insurability of malpractice risks. Fifth, article 57 of the Tort Law ("the then medical standard") excludes the possibility of retroactive liability, which will not lead to uninsurability.

Be that as it may, the current MLI schemes in China still face some problems. Although these MLI schemes claim to be compulsory, they lack the 
necessary sanctions to enforce this obligation. Hence, many hospitals do not purchase MLI or only purchase MLI for high-risk specialities, leading to the problem of adverse selection. Due to this problem, the premiums for MLI are often high and sometimes even higher than the total malpractice damages paid annually, and this discourages many hospitals from purchasing MLI continually.

Overall, although many aspects of the Chinese FLIS fit into economic theories, the MLI schemes will not develop well unless the problem of adverse selection has been tackled.

\subsubsection{Social Security}

Social security only provides a minimum level of economic security in China. In practice, it is jointly used with the tort system. The current combination of social security and tort law may over-compensate victims of medical malpractice because the law does not provide for the collateral source set-off rule and a right of recourse except for cases where public health insurance is involved. Hence, victims of medical malpractice who suffer disability, or close relatives of deceased patients, may have dual compensation - full compensation from the defendant-hospital and benefits under the pension scheme or administrative assistance schemes.

\section{POLICY RECOMMENDATIONS: HOW CAN WE IMPROVE THESE SYSTEMS? (MAIN QUESTION 3)}

\subsection{INTRODUCTION}

After summarizing the main findings of previous chapters, it is time to return to the second main research question - Are the current legal remedies for medical quality assurance and victim compensation in China efficient? The answer is yes and no. The answer is yes because many aspects of the Chinese legal remedies are likely to be efficient at deterrence and compensation. The answer is no in that some aspects of the systems are inefficient, which can be improved in the light of economic benchmarks discussed in Chapter 7 to Chapter 11 .

Hence, it is indeed necessary to answer the third main research question - "If not, how can we improve these legal remedies?" Some policy recommendations will be formulated in the light of two different approaches 
- reforming the current remedies piecemeal (Section 3.2) or no-fault compensation schemes (Section 3.3) - and discuss their desirability in the context of China.

\subsection{REFORMING THE TORT AND RELEVANT SYSTEMS PIECEMEAL}

The first proposal is that China should continue to develop the fault-liabilityinsurance system (FLIS). The FLIS consists of the medical malpractice tort system and MLI. While the former has developed in China since the 1980s, MLI is still in its experimental stage and currently under-developed. In order for the medical malpractice liability system to be more efficient, some reforms in the tort system and relevant legal remedies need to be introduced as follows:

The standard of care. As far as technical malpractice is concerned, article 57 of the Tort Law $2009^{2}$ should expressly define the standard of care in light of the reasonable doctor or the Learned Hand Rule ${ }^{3}$ instead of providing for an ambiguous term "the then medical standard." In this regard, Article 7:453 of the Dutch BW (Civil Code) provides an interesting example, which reads:

In providing the medical treatment, the care provider must observe the standards of a prudent care provider and, in doing so, he/she has to act in conformity with the responsibilities laid upon him by the professional standard for care providers.

Although many Chinese courts in practice interpret the "then medical standard" as the reasonable doctor standard, which is in theory compatible with the Learned Hand Rule, two problems may arise. First, some courts may interpret the "then medical standard" as exclusively meaning regulatory standards or customary practice. Second, even when courts correctly interpret the "then medical standard" as the reasonable doctor standard, they may still fail to employ the cost and benefit analysis to determine the optimal level of care in a given case.

Hence, it would be desirable if Chinese lawmakers could adopt the Learned Hand Rule definitely or the Supreme People's Court (SPC) could

\footnotetext{
$2 \quad$ Tort Law 2009 (China), art. 57: "Where any medical staff member fails to fulfil the duty of medical care corresponding to the then medical standard and causes any harm to a patient, the medical institution shall assume the compensatory liability."

$3 \quad$ See supra Chapter 7, Section 3.3.1.
} 
define it as the Learned Hand Rule in the forthcoming judicial interpretation. Perhaps the Learned Hand Rule should not only apply to the determination of medical malpractice but also to that of negligence in other fault-based torts. The definition of "negligence" provided for in the US Restatement (Third) of Torts serves as a useful example, which reads:

\begin{abstract}
A person acts negligently if the person does not exercise reasonable care under all the circumstances. Primary factors to consider in ascertaining whether the person's conduct lacks reasonable care are the foreseeable likelihood that the person's conduct will result in harm, the foreseeable severity of any harm that may ensue, and the burden of precautions to eliminate or reduce the risk of harm. ${ }^{4}$
\end{abstract}

When it comes to disclosure malpractice, the "double-test doctrine" (the objective physician + the objective/subjective patient) that has been developed by some local courts should also be incorporated into article 55 of the Tort Law 2009 or into its judicial interpretations.

Statutes, custom, and medical records. Article 58 of the Tort Law 20095 should be modified. First, since statutory standards and treatment norms (published or recognised by the government) are often set at a minimum level, it is better to adopt the negligence per se rule - a violation of the statutory standard or treatment norm automatically leads to a finding of negligence. Hence, either the SPC should interpret the "presumption of fault" as an "irrebuttable presumption" or lawmakers should change the "presumption of fault" into the "conclusive evidence of fault." Also, because these standards are probably set at the minimum level, article 58 should make it clear that compliance with a statutory standard or treatment norm does not preclude a finding of negligence.

Second, article 58 has ignored "customary practice" (常规), which had been expressly employed as the standard of care in the AR-Medical Accidents 1987, 2002. The current article 58, para. 1 only mentions statutory standards and treatment norms (诊疗规范) but is silent on how to deal with custom in the health care sector. Since the number of statutory standards and treatment norms is fairly limited and these written standards may be out of date rather quickly, health care providers often rely on medical custom to provide treatment services. In order to reduce uncertainty over negligence and save

US Restatement (Third) of Torts: Phys. \& Emot. Harm, § 3.

Tort Law 2009 (China), art. 58: "Under any of the following circumstances, a medical institution shall be presumed to be at fault for any harm caused to a patient: (1) violating a statutory standard provided for by laws, administrative regulations, or rules, or a treatment norm; (2) concealing or refusing to provide the medical history data related to dispute; or (3) forging, tampering with, or destroying any medical history data." 
information costs, it is efficient for article 58 to provide that compliance with custom is prima facie evidence of non-negligence and departure from custom is prima facie evidence of negligence. Whether a particular custom is higher or lower than the optimal level of care should be decided on a case-by-case basis.

Third, the last two sub-paragraphs of article 58 are concerned with the consequences of hiding or forging essential evidentiary documents in medical malpractice litigation - medical history data that record any information concerning the patient's condition and the treatment procedures. Without these medical records, even expert witnesses will be unable to produce any evidence. Therefore, it is efficient to presume the defendant-hospital is at fault in such cases because it is less costly for the defendant to bear the burden of proving non-negligence. However, article 58 is defective because it has not mentioned the burden of proof regarding causation. If the defendant refuses to provide medical records or provides fake ones, it is impossible for the plaintiff to prove causation. Thus, article 58 should provide that medical malpractice liability (both fault and causation) be presumed to be established in cases where medical records are unavailable or not authentic.

Causation. Lawmakers or the SPC should endorse local judicial practices in relation to the definition of causation ${ }^{6}$ and proportional liability into the Tort Law or its judicial interpretations.

Equitable liability. In practice, some courts apply equitable liability to medical products liability cases where neither the defendant nor the plaintiff is at fault. This practice cannot be justified from the perspective of prevention. It may be justified in terms of secondary cost avoidance since it is often believed that hospitals have much greater assets (deep pocket) than individual patients and hospitals can spread accident costs broadly through the price mechanism. However, applying equitable liability to medical malpractice cases may lead to some problems. First, public hospitals are not allowed to increase service prices freely. Second, many small-scale hospitals or clinics are not very rich. For instance, a health centre only earned about 100,000 yuan annually in $2010 .{ }^{8}$ If a health centre faces one or two medical accidents, almost all the annual earnings will be paid to victimised patients. Third, if there are better ways of compensation that can achieve broader loss spreading such as social security or compensation funds, why should these losses due to non-negligent AEs only be apportioned between hospitals and patients. For these reasons, one can argue against the application of equitable

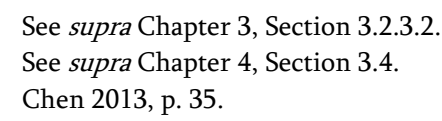


liability to medical malpractice cases. The Tort Law should clarify the scope of cases to which equitable liability shall apply.

Expert evidence. Since the standard of care is measured against a reasonable doctor, it is justifiable to employ expert witnesses to produce testimony (peer review). The debate in China is not whether a regime of expert witnesses is warranted, but whether it is better to keep the two parallel systems - the MATAS and the JAS - unchanged or to find a way to merge them. From the perspective of legal certainty and efficiency, it is socially desirable if the two systems will be somehow merged in the future. ${ }^{9}$

Quantum rules (law of damages). The goal of primary cost avoidance may conflict with that of secondary cost avoidance when it comes to the scope of compensation. While optimal deterrence requires full compensation, ${ }^{10}$ the insurance theory normally suggests that non-pecuniary losses should be excluded from the scope of compensation. ${ }^{11}$ In order to resolve this conflict, decoupled liability was proposed under which victimised patients obtain damages in the light of the insurance theory while the state imposes fines equal to the difference between full compensation and optimal compensation on the defendant. ${ }^{12}$ However, decoupled liability has been challenged by an approach under which non-pecuniary losses are compensable and should be measured by victims' ex ante willingness to pay (WTP). ${ }^{13}$

This ex ante WTP approach also applies to the measure of compensation for wrongful death, where recovery for loss of life should be measured on the basis of quality adjusted life years (QALYs). The QALY approach is applicable to compensation for disability as well.

It is accepted that the foregoing ex ante WTP approach has not been accepted in other legal systems either. However, theoretically, this approach is more efficient than the "arbitrary" approach that is currently used in China. Hence, the efficiency of the Chinese medical malpractice system would be enhanced if China adopted this ex ante WTP approach to the measure of compensation for disability, death, and pain and suffering.

Claims initiation. One of the important reasons that many victimised patients do not file a medical malpractice lawsuit is that legal costs (esp. attorney fees and expert ascertainment fees) are considerable and they simply cannot afford the costs. According to the Gulou Data, plaintiff-patients are

See generally Xiao 2014

See supra Chapter 7, Section 3.6.2.

See supra Chapter 10, Section 3.3.1.

See supra Chapter 10, Section 3.3.2.

Id. 
not represented by lawyers in almost $40 \%$ of the medical malpractice cases. ${ }^{14}$ Very few (2 out of 461) plaintiff-patients get legal aid free of charge, although China established a legal aid system in 2003. ${ }^{15}$ Hence, in order to help more victims of medical malpractice, especially those who are poor, to obtain attorney services, it may be desirable for China to lift the ban on charging contingency fees in medical malpractice claims. Although these poor victims may have to pay a significant portion of damages to their attorneys, it would be better than the case where they lose the lawsuit or never file a claim due to a lack of attorneys. In addition, more attorneys should be encouraged by the state to practise as public interest lawyers. ${ }^{16}$

The rules on charging expert ascertainment fees should be changed in order to increase victims' access to justice. It would be naïve to argue that litigation fees should be abolished or wholly subsidised by the state. Litigation fees, combined with the rule that the losing party bears all litigation fees (the rule of "losers pay all"), plays a significant role in tertiary cost avoidance through stopping frivolous lawsuits. However, litigation fees should not be set too high. Otherwise, victims would not file a claim and the deterrent effect of tort law would be undermined. Victims would only file a claim when the expected value of the legal claim (EVC) exceeds the filing costs (FC). ${ }^{17}$ Therefore, at least two reforms on the ascertainment fees could be made. First, China could reduce the fees charged under the JAS. Currently, the fees charged under the MATAS (often 2,200 yuan) are about four to five times lower than under the JAS (often 10,000 yuan). There is no reason why clinical experts and forensic pathologists charge so differently when they actually do the same job. Since 2,200 yuan under the MATAS is already relatively high to most poor victims, 10,000 yuan is wholly unjustified, which may stop many victims from filing claims and may ultimately lead to underdeterrence. Second, another method of increasing access to justice for the poor is that ascertainment fees "could be assigned on a sliding scale based on income." 18

Regulation. The regulatory system of medical quality assurance is primarily confronted with a problem of under-enforcement. This may be largely because the medical profession is directly regulated by the government which lacks sufficient medical professional expertise and manpower to set efficient standards and conduct effective routine

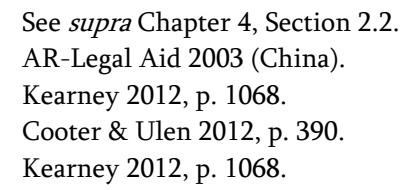


monitoring. ${ }^{19}$ China should pay more attention to the benefits of selfregulation and adopt a mixed approach to the regulation of health care where both the government and the medical profession play a role in quality assurance. ${ }^{20}$

The current criteria for imposing license sanctions or criminal penalties on negligent providers are ambiguous or too broad, which may go against the goal of marginal deterrence. Marginal deterrence requires that sanctions should rise with the size of harm and most sanctions should be less than maximal. It is suggested that license revocation only applies to those providers whose expertise cannot be enhanced even after taking CME and imprisonment; (CMA) only applies to those providers who know they are systematically incompetent but still wilfully choose to stay in the market to enjoy the benefit of being a licensed provider. The mens rea for establishing the CMA should be set as "recklessness" or "dolus eventualis" rather than a simple or gross negligence.

Medical liability insurance (MLI). In China, MLI is still underdeveloped due to the problem of adverse selection and the "compulsory" obligation to purchase MLI cannot be enforced by any legal sanctions. In order to tackle this problem, compulsory MLI is clearly warranted. Lawmakers (NPC and SC-NPC) or the State Council should enact national laws or administrative regulations to impose legal sanctions on hospitals who fail to purchase MLI and these law and regulations should be effectively enforced in practice.

Alternative dispute resolution (ADR). The new form of ADR for resolving medical malpractice claims - medical dispute people's mediation (MDPM) - seems rather effective at settling a claim quickly. The MDPM should be encouraged if it may reduce the tension between patients and hospitals and may potentially reduce the frequency of $\mathrm{Yi} \mathrm{NaO} \mathrm{incidents.} \mathrm{The}$ police should also stop $\mathrm{Yi} \mathrm{NaO}$ incidents in time and prosecute those patients, their family members or professional mobs who intend to obtain compensation through coercive measures.

Collateral source set-off and social security benefits. All kinds of social security benefits should be deducted from tort damages awards in order to reduce tertiary costs due to dual compensation. Hence, either lawmakers should add the collateral source set-off rule to the Tort Law or the SPC should provide for this rule in judicial interpretations. 


\subsection{NO-FAULT COMPENSATION SCHEMES}

Chapter 11 has introduced various no-fault compensation schemes such as first-party insurance, comprehensive compensation funds, and social security. Next there is a discussion of their desirability in the context of China as follows.

First-party insurance. Although first-party insurance has a comparative advantage over third-party insurance in terms of saving tertiary costs, it should be used jointly with the FLIS in order to keep economic incentives for health care providers to take precautions. ${ }^{21}$ However, as discussed before, patients in China are often not willing to purchase voluntary first-party insurance to cover either medical bills or other losses caused by disability. ${ }^{22}$ Many of them may underestimate the risk of iatrogenic injuries due to imperfect information while the premiums for first-party insurance may not be low. ${ }^{23}$ In addition, uninsured patients may externalise their costs to society at large. ${ }^{24}$ Therefore, it may be desirable for China to introduce compulsory first-party insurance. Since patients may be more averse towards large risks than small risks, it would be optimal if compulsory first-party insurance covered only large risks of iatrogenic injuries.

The problem is that some extremely poor patients may still find it difficult to afford the premiums. These patients should obtain assistance from the state under social security schemes (e.g. their premiums for the insurance would be paid by the state).

Compensation funds. The above plan of reforming the FLIS piecemeal or the plan of using the FLIS and compulsory first-party insurance is still based on the fault-based tort system. Due to considerable tertiary costs and delays in compensation associated with the FLIS, one may wonder whether the tort system should be dispensed with, as least as far as medical malpractice liability is concerned, and establish a compensation fund to cover all iatrogenic injuries instead. However, this narrowly defined no-fault compensation scheme (NFCS) should not dilute economic incentives for health care providers to take precautions. Hence, compensation funds should be constructed on the basis of economic principles in order to provide fair and efficient compensation. ${ }^{25}$ Although current NFCSs implemented in New Zealand and Scandinavian countries are effective at compensating victims of

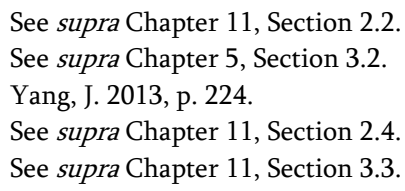


AEs quickly and without significant administrative costs, they are ineffective at inducing health care providers to invest in treatment optimally.

When taking into account the current tension between health care providers and patients in China, the NFCS seems extremely desirable since in most of the Yi Nao incidents what most patients care about is compensation rather than whether the hospital is at fault or not. This is also one of the reasons why many patients do not file a lawsuit because litigation procedures pay more attention to the merit of the claim (i.e. whether there are fault and causation) rather than what the patients need. When facing Yi Nao incidents, hospitals often give in to patients and pay a modest amount of "compensation" (buchang) irrespective of whether they are at fault. Thus, it seems that there is a great demand for the NFCS under which both hospitals and patients' needs would be satisfied. Hence, an NFCS that provides extensive cover for iatrogenic injuries may help relieve the current tension between providers and patients and provide a quick, even if limited, remedy for victims of AEs.

In order to maintain economic incentives for providers to take precautions, it is necessary that each hospital should contribute to the compensation fund and the premium should be experience-rated. In order to reduce secondary and tertiary costs, eligibility under the NFCS should be restricted to only the most severely injured patients and the benefits should be lower than tort damages awards. In addition, the effectiveness of regulation should be increased in order to provide additional deterrence.

Some victims may still want to be compensated through the tort system. Hence, China may take the Swedish NFCS as the model and allow victims to choose between the tort system and the NFCS.

Social security. China may also learn from New Zealand's experience and adopt a comprehensive NFCS for all types of accidents. This would the most radical reform plan which has only been implemented in New Zealand. This radical plan may find itself confronted by massive opposition in the context of China. The first reason for the opposition is that bearing liability for damage that you cause to others is a traditional Chinese value which even has impressed American scholars such as Baker. ${ }^{26}$ China is in the process of building a credible legal system and making people accountable for their own wrongful actions. In this context, a radical no-fault plan is not likely to be accepted by Chinese government officials and citizens. Second, social security often spreads accident losses broadly and does not place accident costs on a specific group of people. The New Zealand model may dilute economic incentives for providers to take precautions significantly. This problem

26 Baker 2005b, pp. 115-116. 
cannot be easily tackled unless China will be able to enhance the effectiveness of its regulatory system of quality assurance. Third, if China adopted a special social security scheme for compensation of iatrogenic injuries that would place accidents costs on hospitals, this would soon become the compensation fund approach as discussed above.

Since it is highly impractical if not impossible for China to adopt this radical social security reform, it may be desirable to keep the current social security system as a supplement to the FLIS or a special compensation fund that covers iatrogenic injuries.

\subsection{A COMPARISON OF THE DIFFERENT REFORM PLANS}

After discussing the desirability of the foregoing reform plans, it seems that compulsory first-party insurance or no-fault plans such as the Swedish model could be employed by China to provide victimised patients with fair and efficient compensation. Piecemeal reforms on the FLIS will not be enough since victims of non-negligent iatrogenic injuries are not compensated. Especially when taking into consideration the epidemic of $Y i$ Nao incidents, these dissatisfied patients may pose a great threat to public order and may induce providers to practice defensive medicine. Therefore, some no-fault schemes targeted at these patients may be a workable solution to the problems in the Chinese malpractice system. Whatever reform plan China chooses, economic incentives for providers to invest in treatment and patient safety optimally should not be undermined.

\section{LIMITATIONS}

This thesis is the first research that evaluates the Chinese legal remedies for medical malpractice prevention and victim compensation both from the perspective of law and economics and on the basis of empirical evidence. It has arrived at many new conclusions compared to prior studies. However, it still has its limitations, which are listed as follows.

First, due to limited time and finances, firsthand empirical data collected for this research are restricted to court decisions and semistructured interviews. It is difficult to have access to hospital records or insurance claims records. Hence, firsthand data on medical malpractice claims settled out of court are unavailable. It follows that it is currently impossible to conduct any research into the impact of tort law on the rate of iatrogenic injuries. Therefore, any deterrent effect of the Chinese medical malpractice 
system on primary cost reduction is a theoretical prediction based on empirical data from the US.

Second, due to limited language skills, it is difficult to access foreign literature that is not written in English. Hence, when discussing no-fault schemes in Scandinavian countries, there was no access to recent data on the functioning of these schemes. It follows that any information presented in this thesis about these schemes may be out of date.

Third, many conclusions of this thesis about China are based on economic theories that have been developed and tested empirically in the context of the United States. Although both countries rely on the fault-based medical malpractice system, they differ in many other aspects such as the health care system, social security system, insurance market, and traditional values. The transferability of the US experience to China needs to be further examined.

\section{FUTURE RESEARCH}

Directions for future research can be identified from prior discussions on policy recommendations and limitations.

First, more empirical research should be conducted into the epidemiology of medical injury and its relationship with claims initiation. Currently, there are no large-scale studies on the frequency, severity, and causes of iatrogenic injury and the rate of initiated claims. Without these data, it is also impossible to measure the actual effect of tort law on injury reduction.

Second, more attention should be paid to the notion of full compensation. Although losses due to disability or death are recoverable under the current Chinese tort law, compensation for these losses is groundlessly limited. For instance, the cap of 20 years is rather arbitrary. It may be interesting to see whether the ex ante WPT or QALY approach to the measure of compensation for disability, death or pain and suffering is desirable in the context of China.

Third, although many Chinese scholars have discussed the desirability of implementing compulsory MLI, few have discussed the possibility of nofault schemes. In the discussion on policy recommendations, their feasibility for China has already been discussed. However, the discussion is rather short and more scholarly attention should to paid to this topic.

Fourth, a prior assumption of this thesis is that if the Chinese legal system were effective and efficient at preventing medical errors (or quality assurance) and compensating victims of medical malpractice adequately, there would be a substantial reduction in medical disputes, AEs, violence 
against doctors and $\mathrm{Yi}$ NaO incidents. This assumption should be tested empirically in the future when the input system concerning injury prevention and victim compensation in China will have been structured efficiently in theory and enforced effectively in practice. 



\section{SUMMARY}

This book examines the legal remedies for preventing medical errors and compensating victims of medical malpractice in China from the perspective of law and economics. Those legal remedies generally include, inter alia, tort liability, regulation, insurance and social security.

After the Introduction (Chapter 1), Part I (Chapter 2 to Chapter 6) examines the legal remedies for medical quality assurance and victim compensation in China. Subsequently, Part II (Chapter 7 to Chapter 11) is primarily concerned with economic theories and relevant empirical evidence pertaining to medical malpractice and adverse events. Finally, Part III (Chapter 12 and Chapter 13) evaluates the legal remedies for medical quality assurance and victim compensation in China from the perspective of law and economics (Chapter 12) and tries to make a few concluding remarks and to formulate some policy recommendations (Chapter 13). The central thesis is that many aspects of the legal remedies in China are consistent with the economic model of accident law as far as primary accident cost avoidance is concerned, but they still need to be greatly improved when it comes to secondary accident cost avoidance.

Overall, this book provides a thorough examination of the legal remedies for medical malpractice in China, especially taking into account the latest development in economic theories and new empirical findings. Hence, it will be of interest to legal and economic scholars, lawyers, insurers and policy makers responsible for ensuring the quality of medical care. 



\section{BIBLIOGRAPHY}

Abel, R.L. (1987). The Real Tort Crisis - Too Few Claims. Ohio State Law Journal, 48, pp. 443-467.

Abraham, K.S. (1977). Medical Malpractice Reform: A Preliminary Analysis. Maryland Law Review, 36(3), pp. 489-532.

Abraham, K.S. (1992). What Is a Tort Claim-An Interpretation of Contemporary Tort Reform. Maryland Law Review, 51, pp. 172-204.

Abraham, K.S. \& Weiler, P.C. (1994). Enterprise Medical Liability and the Evolution of the American Health Care System. Harvard Law Review, 108(2), pp. 381-435.

Adler, M. \& Posner, E.A. (2008). Happiness Research and Cost-Benefit Analysis. The Journal of Legal Studies, 37(S2), pp. S253-S292.

Agresti, A. \& Franklin, C. (2013). Statistics: The Art and Science of Learning from Data. Boston et al: Pearson.

Ai, E. \& Fang, B. (2010). The Research Report Concerning the Application of Law for the Medical Malpractice Compensation Cases of China. Hebei Law Science, 28(2), pp. 121-131.

Akerlof, G.A. (1970). The Market for 'Lemons': Quality Uncertainty and the Market Mechanism. The Quarterly Journal of Economics, 84(3), pp. 488500.

Amaral Garcia, S., Bertoli, P. \& Grembi, V. (2015). Does Experience Rating Improve Obstetric Practices? Evidence from Italy. Health Economics, 24(9), pp. 1050-1064.

American Medical Association (1969). Medical Malpractice: The Patient versus the Physician. Washington D.C.: US Government Printing Office.

American Medical Association (2013). State Medical Licensure Requirements and Statistics 2014. Chicago: American Medical Association.

American Tort Reform Association (2015). ATRA Tort Reform Record. Available at: <http://atra.org/sites/default/files/documents/Record\%20625-15.pdf $>$ (accessed on 13 May 2016).

An, J. (ed.) (2009). A Commentary on the Insurance Law of the People's Republic of China (2009 Amendment). Beijing: Law Press-China. 
Bibliography

Andrews, L.B., Stocking, C., Krizek, T., Gottlieb, L., Krizek, C., Vargish, T. \& Siegler, M. (1997). An Alternative Strategy for Studying Adverse Events in Medical Care. Lancet, 349(9048), pp. 309-313.

Andrews, L. (2005). Studying Medical Error in SITU: Implications for Malpractice Law and Policy. DePaul Law Review, 54(2), pp. 357-392.

Aranaz-Andres, J.M., Aibar-Remon, C., Vitaller-Murillo, J., Ruiz-Lopez, P., Limon-Ramirez, R. \& Terol-Garcia, E. (2008). Incidence of adverse events related to health care in Spain: results of the Spanish National Study of Adverse Events. Journal of Epidemiology \& Community Health, 62(12), pp. 1022-1029.

Arlen, J. (1985). An Economic Analysis of Tort Damages for Wrongful Death. New York University Law Review, 60, p. 1113-1136.

Arlen, J. (2006). Private Contractual Alternatives to Malpractice Liability. In: Sage, W.M. \& Kersh, R. (eds.), Medical Malpractice and the U.S. Health Care System (pp. 245-266). Cambridge et al:: Cambridge University Press.

Arlen, J. (2010). Contracting over Liability: Medical Malpractice and the Cost of Choice. University of Pennsylvania Law Review, 158(4), pp. 957-1023.

Arlen, J. (2013). Economic Analysis of Medical Malpractice Liability and Its Reform. In: Arlen, J. (ed.), Research Handbook on the Economics of Torts (pp. 33-68). Cheltenham \& Northampton, MA: Edward Elgar.

Arlen, J. (2014). Reality Check: How Malpractice Facts Changed Malpractice Liability Theory. In: Chang, Y. (ed.), Empirical Legal Analysis: Assessing the Performance of Legal Institutions (The Economics of Legal Relationships) (pp. 21-62). London/New York: Routledge.

Arlen, J. \& Macleod, B. (2003). Malpractice Liability for Physicians and Managed Care Organisations. New York University Law Review, Vol. 78(6), pp. 1929-2006.

Arlen, J. \& Macleod, W.B. (2005). Torts, Expertise, and Authority: Liability of Physicians and Managed Care Organisations. The Rand Journal of Economics, 36(3), pp. 494-519.

Arrow, K.J. (1963). Uncertainty and the Welfare Economics of Medical Care. American Economic Review, 53(5), pp. 941-973.

Arrow, K.J. (1971). Insurance, Risk and Resource Allocation. In: Dionne, G. \& Harrington, S.E. (eds.), Foundations of Insurance Economics: Readings in Economics and Finance (pp. 220-229). Reprint: Springer Science+Business Media, LLC, 1992.

Arrow, K.J. (1985). The Economics of Agency. In: Pratt, J.W. \& Zeckhauser, R.J. (eds.), Principals and Agents: The Structure of Business (pp. 37-54). Boston: Harvard Business School Press.

Ashenfelter, O. (2006). Measuring the Value of a Statistical Life: Problems and Prospects. Economic Journal, 116(1976), pp. 10-23. 
Avraham, R. (2006). Putting a Price on Pain-and-Suffering Damages: A Critique of the Current Approaches and a Preliminary Proposal for Change. Northwestern University Law Review, 100(1), pp. 87-119.

Avraham, R. (2007). An Empirical Study of the Impact of Tort Reforms on Medical Malpractice Settlement. The Journal of Legal Studies, 36(52), pp. S183-S229.

Baczyk-Rozwadowska, K. (2013). Medical Malpractice and Compensation in Poland. In: Oliphant, K. \& Wright, R.W. (eds.), Medical Malpractice and Compensation in Global Perspective (Tort and Insurance Law Vol 32) (pp. 327-376). Berlin/Boston: De Gruyter.

Bagenstos, S.R. \& Schlanger, M. (2007). Hedonic Damages, Hedonic Adaptation, and Disability. Vanderbilt Law Review, 60(3), pp. 745-797.

Bai, T. (2015). 80\% of the Population Has Been Covered under the Basic Pension Insurance Scheme. People's Daily, 1 July, 10.

Bai, Z. \& Pei, Y. (2016) A Report on the Trial of Medical Malpractice Cases. Available at: <http://tjbdfy.chinacourt.org/article/detail/2016/07/id/2020429.shtml $>$ (accessed on 19 July 2016).

Baicker, K. \& Chandra, A. (2005a). The Effect of Malpractice Liability on the Delivery of Health Care. Frontiers in Health Policy Research, 8(4), pp. 127.

Baicker, K. \& Chandra, A. (2005b). Defensive Medicine and Disappearing Doctors?. Regulation, 28(3), pp. 24-31.

Baicker, K., Fisher, E.S. \& Chandra, A. (2007). Malpractice Liability Costs and the Practice of Medicine in the Medicare Program. Health Affairs, 26(3), pp. 841-852.

Baker, G.R., Norton, P.G., Flintoft, V., Blais, R., Brown, A., Cox, J., Etchells, E., Ghali, W.A., Hébert, P., Majumdar, S.R., O’Beirne, M., PalaciosDerflingher, L., Reid, R.J., Sheps, S. \& Tamblyn, R. (2004). The Canadian Adverse Events Study: The Incidence of Adverse Events among Hospital Patients in Canada. Canadian Medical Association Journal, 170(11), pp. 1678-1686.

Baker, T. (2005a). Reconsidering the Harvard Medical Malpractice Study Conclusions about the Validity of Medical Malpractice Claims. Journal of Law, Medicine and Ethics, 33, pp. 501-514.

Baker, T. (2005b). The Medical Malpractice Myth. Chicago \& London: The University of Chicago Press.

Baker, T. (2005c). Medical Malpractice and the Insurance Underwriting Cycle. DePaul Law Review, 54, pp. 393-438.

Baker, T. (2006). Medical Malpractice Insurance Reform: "Enterprise Insurance" and Some Alternatives. In: Sage, W.M. \& Kersh, R. (eds.), Medical Malpractice and the U.S. Health Care System (pp. 267-290). Cambridge et al: Cambridge University Press. 
Bibliography

Baker, T. \& Lytton, T.D. (2010). Allowing Patients to Waive the Right to Sue for Medical Malpractice: A Response to Thaler and Sunstein. Northwestern University Law Review, 104(1), pp. 233-252.

Baldwin, L.M., Hart, L.G., Lloyd, M., Fordyce, M. \& Rosenblatt, R.A. (1995). Defensive Medicine and Obstetrics. The Journal of the American Medical Association, 274(20), pp. 1606-1610.

Baldwin, R., Cave, M. \& Lodge, M. (2013). Understanding Regulation: Theory, Strategy, and Practice. Oxford/New York: Oxford University Press.

Bandao.cn (2014). Have You Offered a Hongbao to Your Doctors? Available at: <http://vote.bandao.cn/view_result.php?id=490> (accessed on 20 July 2016).

Baumol, W.J. \& Oates, W.E. (1988). The Theory of Environmental Policy. Cambridge: Cambridge University Press.

Baynes, T. (2011). More U.S. Doctors Facing Charges over Drug Abuse. Available at: <www.reuters.com/article/us-jackson-malpracticeidUSTRE78D3P620110914> (accessed on 8 July 2016).

Beam, C. (2014). Under the Knife: Why Chinese Patients Are Turning against Their Doctors. The New Yorker, 25 August.

Becker, G. (1968). Crime and Punishment: An Economic Approach. Journal of Political Economy, 76(2), pp. 169-217.

Becker, G.S. (1983). A Theory of Competition Among Pressure Groups for Political Influence. The Quarterly Journal of Economics, 98(3), pp. 371400.

Beijing Haidian District People's Court (2008). A Report on the Application of Rules in Medical Dispute Cases. Journal of Law Application, 7, pp. 62-67.

Beijing High People's Court First Civil Chamber (2006). Cases concerning Disputes over Compensation for Medical Injury: The Trial, the Problems and the Countermeasures. In: Wang, L. (ed.), Research on Court Judgements and Decisions (pp. 41-53). Beijing: People's Court Press.

Beijing High People's Court (2011). Issues on and Countermeasures to the Trials of Medical Malpractice Compensation Disputes under the New Situation. Evidence Science, 19(3), pp. 377-384.

Ben-Shahar, O. (2009). Causation and Foreseeability. In: Faure, M.G. (ed.), Tort law and Economics (Encyclopedia of Law and Economics Vol. 1) (pp. 83-108). Cheltenham \& Northampton, MA: Edward Elgar.

Bernzweig, E.P. (1973). Defensive Medicine. In: US Department of Health, Education and Welfare (ed.), Appendix: Report of the Secretary's Commission on Medical Malpractice (DHEW Publication No. (OS) 73-89) (pp. 38-40). Washington, D.C.: U.S. Government Printing Office.

Berwick, D.M. (1989a). Continuous Improvement as an Ideal in Health Care. New England Journal of Medicine, 25, pp. 320-321. 
Berwick, D.M. (1989b). E.A. Codman and the Rhetoric of Battle: A Commentary. The Milbank Quarterly, 67(2), pp. 262-267.

Binswanger, H.P. (1980). Attitudes toward Risk: Experimental Measurement in Rural India. American Journal of Agricultural Economics, 62(3), pp. 395-407.

Black, B., Silver, C., Hyman, D.A. \& Sage, W.M. (2005). Stability, Not Crisis: Medical Malpractice Claim Outcomes in Texas, 1988-2002. Journal of Empirical Legal Studies, 2(2), pp. 207-259.

Black, J., Hashimzade, N. \& Myles, G. (2012). A Dictionary of Economics. 4th edn., Oxford: Oxford University Press.

Boccara, S. (2009). Medical Malpractice. In: Faure, M.G. (ed.), Tort Law and Economics (Encyclopedia of Law and Economics Volume 1) (pp. 341-374). Cheltenham \& Northampton, MA: Edward Elgar.

Bohlander, M. (2009). Principles of German Criminal Law. Oxford \& Portland, Oregon: Hart Publishing.

Borch, K. (1961). The Utility Concept Applied to the Theory of Insurance. ASTIN Bulletin, 1, pp. 245-255.

Borre, G.V. (1961). Public Welfare Offences: A New Approach. The Journal of Criminal Law, Criminology, and Police Science, 52(4), pp. 418-422.

Boundless (2015). Externalities in the Health Care Market. Available at: $<$ https://www.boundless.com/economics/textbooks/boundless-economicstextbook/health-care-economics-35/introducing-health-care-economics135/externalities-in-the-health-care-market-534-12631/> (accessed on 29 July 2016).

Bovbjerg, R.R. (1995). Medical Malpractice: Problems and Reforms. Washington D.C., The Urban Institute.

Bovbjerg, R.R. \& Petronis, K.R. (1994). The Relationship Between Physicians' Malpractice Claims History and Later Claims: Does the Past Predict the Future?. The Journal of American Medical Association, 272(18), pp. 14211426.

Bovbjerg, R.R., Sloan, F.A. \& Blumstein, J.F. (1988). Valuing Life and Limb in Tort: Scheduling Pain and Suffering. Northwestern University Law Review, 83, pp. 908-976.

Brazier, M., Allen, N., Brazier, M. \& Allen, N. (2007). 2. Criminalizing Medical Malpractice. In: Erin, C.A. \& Ost, S. (eds.), The Criminal Justice System and Health Care (pp. 15-28). Oxford/New York: Oxford University Press.

Brody, W.R. (2004). Dispelling Malpractice Myths. Available at: <www.washingtonpost.com/wp-dyn/articles/A46795-2004Nov12.html> (accessed on 1 August 2016). 
Bibliography

Brook, R.H., Brutoco, R.L. \& Williams, K.N. (1975). The Relationship between Medical Malpractice and Quality of Care. Duke Law Journal, 6, pp. 1197-1231.

Brown, C. (1985). Deterrence in Tort and No-Fault: The New Zealand Experience. California Law Review, 73(3), pp. 976-1002.

Brown, C.R. \& Uhl, H.S.M. (1970). Mandatory Continuing Education - Sense or Nonsense. The Journal of American Medical Association, 213(10), pp. 1660-1668.

Brown, J.P. (1973). Toward an Economic Theory of Liability. The Journal of Legal Studies, 2(2), pp. 323-349.

Brown, R.M. (1992). Administrative and Criminal Penalties in the Enforcement of Occupational Health and Safety Legislation. Osgoode Hall Law Journal, 30(3), pp. 691-735.

Burkitt, L. (2015). China to Cut Hospital Drug Dependency. Available at: $<$ www.wsj.com/articles/china-to-cut-hospital-drug-dependency1432289756> (accessed on 14 July 2016).

Burris, J.F., Little, N., Brennan, T.A., Leape, L.L., Laird, N.M., Localio, A.R., Hebert, L., Lawthers, A.G., Weiler, P.C., Newhouse, J.P. \& Hiatt, H.H. (1991). Incidence of Adverse Events and Negligence in Hospitalised Patients: Results of the Harvard Medical Practice Study I. The New England Journal of Medicine, 324(6), pp. 370-376.

Burrows, P. (1999). Combining Regulation and Legal Liability for the Control of External Costs. International Review of Law and Economics, 19(2), pp. 227-244.

Calabresi, G. (1961). Some Thoughts on Risk Distribution and the Law of Torts. The Yale Law Journal, 70(4), pp. 499-553.

Calabresi, G. (1965). The Decision for Accidents: An Approach to Nonfault Allocation of Costs. Harvard Law Review, 78(4), pp. 713-745.

Calabresi, G. (1968). Does the Fault System Optimally Control Primary Accident Costs. Law \& Contemporary Problems, 33(3), pp. 429-464.

Calabresi, G. (1970). The Costs of Accidents: A Legal and Economic Analysis. New Haven \& London: Yale University Press.

Calabresi, G. (1978). The Problem of Malpractice - Trying to Round out the Circle. In: Rottenberg, S. (ed.), The Economics of Medical Malpractice (pp. 233-244). Washington, D.C: American Enterprise Institute for Public Policy Research.

Calabresi, G. (1986). Policy Goals of the 'Swedish Alternative'. The American Journal of Comparative Law, 34(4), pp. 657-667.

Cane, P. (2006). Atiyah's Accidents, Compensation and the Law. Cambridge: Cambridge University Press. 
Cane, P. (2013). Atiyah's Accidents, Compensation and the Law. 8th edn. Available at: <www.amazon.de/Atiyahs-Accidents-Compensation-LawContext-ebook/dp/B00B4V6HTC/ref=sr_1_1?ie=UTF8\&qid=1461165502\&sr=8-1\&keywords=Atiyah\%27s+Accidents\%2C+Compensation+and+the+Law (Downloaded on 20 April 2016).

Cane, P. \& Kritzer, H.M. (eds.) (2010). The Oxford Handbook of Empirical Legal Research. Oxford/New York: Oxford University Press.

Cao, H. (2004). On the Certainty and Uncertainty of Law. Journal of Northwest University of Political Science and Law, 22(3), pp. 13-18.

Cao, Z. \& Chen, L. (2014. Practical Analysis of the Influence of Medical Dispute on Defensive Medicine Behaviour of Physicians. Chinese Hospital Management, 34(9), pp. 9-11.

Cao, Z. \& Wu, M. (2014a). Study Scheme of Measurement and Formation Mechanism of Defensive Medicine Behaviour of Physician. Chinese Hospital Management, 34(9), pp. 4-5.

Cao, Z. \& Wu, M. (2014b). Analysis of Influence Mechanism of Defensive Medicine Behaviour from the Perspective of Law Economics. Chinese Hospital Management, 34(9), pp. 6-8.

Cao, Z. \& Wu, M. (2014c). Measurement and Analysis of Defensive Medicine Behaviour of Physicians Based on Clinical Pathway. Chinese Hospital Management, 34(9), pp. 12-14.

Carrier, E.R., Reschovsky, J.D., Mello, M.M., Mayrell, R.C. \& Katz, D. (2010). Physicians' Fears of Malpractice Lawsuits Are not Assuaged By Tort Reforms. Health Affairs, 29(9), pp. 1585-1592.

Carroll, S.L. \& Gaston, R.J. (1981). Occupational Restrictions and the Quality of Service Received: Some Evidence. Southern Economic Journal, 47(4), pp. 959-976.

Cascão, R. \& Hendrickx, R. (2007). Shifts in the Compensation of Medical Adverse Events. In: Van Boom, W.H. \& Faure, M.G. (eds.), Shifts in Compensation Between Private and Public Systems (Tort and Insurance Law Vol. 22) (pp. 115-142). WienNewYork: Springer.

Cave, M. (1985). Market Models and Consumer Protection. Journal of Consumer Policy, 8(4), pp. 335-351.

Chai, H. \& Jia, X. (2013). Hospital Accreditation: Where to Go? Available at: $<$ www.infzm.com/content/88448> (accessed on 23 June 2016).

Charles, D.K., Thomas, S.U. \& Gary, V.J. (1990). Ex Post Liability for Harm vs. Ex Ante Safety Regulation: Substitutes or Complements? American Economic Review, 80(4), pp. 888-901.

Chassin, M.R. \& Mccue, S.M. (1986). Randomized Trial of Medical Quality Assurance: Improving Physicians' Use of Pelvimetry. The Journal of American Medical Association, 256(8), pp. 1012-1016. 
Bibliography

Chen, D., Wang, Q. \& Liu, Y. (2004). The Reversal of the Burden of Proof and Defensive Medicine. Hospital Administration Journal of PLA, 11(1), pp. 20-22.

Chen, L. (2016). Temporary Assessment of the Standardised Training of Residents in Shanghai. Human Resource Management, 1, pp. 148-149.

Chen, L. \& Dai, Z. (2011). The Conditions for and the Legal Consequences of Cancelling A Hospitalisation Medical Service Contract Because the Patient Refuses to Pay for Medical Bills. People's Judicature, 12, pp. 25-28.

Chen, P. \& Yuan, J. (2011). On the Medical Practising Insurance System in Our Country - An Empirical Analysis on the Medical Liability Insurance Pilot in Ningbo. Medicine and Jurisprudence, 3(1), pp. 60-63.

Chen, Q. (2011). Research on the Problems of Medical Fault Identifying Criterion. Unpublished Master thesis. Peking University.

Chen, Q., Tian, M. \& Lu, Y. (2015). Practice and Appraisal on Medical Doctor Regular Evaluation in Shanghai. Hospital Administration Journal of Chinese People's Liberation Army, 22(11), pp. 1078-1079.

Chen, S. (2012). Law and Economic Analysis of Medical Liability for Damage - Medical Tort as the Main Content. Unpublished Master thesis. Southeast University.

Chen, Y. (2013). On Legal Issues of Medical Malpractice Insurance. Unpublished $\mathrm{PhD}$ thesis. Wuhan University.

Chen, Y., Shen, C. \& Wei, M. (2010). Discussion on Classification of Defensive Medicine. Medicine \& Philosophy(A), 31(5), pp. 32-33.

Cheney, F.W., Posner, K., Caplan, R.A. \& Ward, R.J. (1989). Standard of Care and Anesthesia Liability. Journal of American Medical Association, 261(11), pp. 1599-1603.

Cheng, H. (2007). Legal Matters of Medical Service Contract. Journal of Liaoning Medical University (Social Science Edition), 15(4), pp. 17-20.

Cheng, H., Chen, G., Cai, Z., Liu, X. \& Wang, J. (2003). The Investigation and Analysis of 512 Physicians' Defensive Medicine. Chinese Hospital Management, 23(6), pp. 8-10.

Chengdu Jingjiang District People's Court, First Civil Chamber (2011). On the Issue of Ascertainment in Disputes over Compensation for Iatrogenic Injuries - Taking the Double Tracks of Medical Injury Ascertainment as the Starting Point. Journal of Sichuan Administration College, 1, pp. 5357.

China Economic Net (2014). Data Summary: An Overview of the Consumer Price Index in China (by July 2014). Available at: <http://intl.ce.cn/specials/zxxx/201408/11/t20140811_3330614.shtml> (accessed on 23 July 2016). 
Chinese Government Network (2016). The Burden of Paying for Out-ofPocket Expenses Are Reduced in Shaanxi Province. Available at: <www.mohrss.gov.cn/SYrlzyhshbzb/dongtaixinwen/dfdt/gzdt/201605/t20 160510_239696.html> (accessed on 21 June 2016).

Chinese Hospital Association (2004). Survey on and Analysis of Medical Disputes after the Implementation of 'Regulation on Handling Medical Accidents'. Chinese Hospitals, 8(3), pp. 12-15.

Chinese Hospital Association (2011). Chinese Hospital Association Statutes. Available at: <www.cha.org.cn/plus/list.php?tid=283 > (accessed on 11 June 2016).

Chinese Medical Association (2010) The Chinese Medical Association's Statutes (2010 Edition). Available at: <www.cma.org.cn/gyxh/xhzc/20101122/1290386400875_1.html\#> (accessed on 11 July 2016).

Chinese Medical Doctor Association (2012). Chinese Medical Doctor Association Statutes. Available at: <www.cmda.net/xiehuijieshao/xhzc.html> (accessed on 11 July 2016).

Christensen, J.F., Levinson, W. \& Dunn, P.M. (1992). The Heart of Darkness: The Impact of Perceived Mistakes on Physicians. Journal of General Internal Medicine, 7(4), pp. 424-431.

Civil Affairs Bureau of Jiangning District of Nanjing Municipal (2015) Minimum Subsistence Guarantee. Available at: <www.jnqmzj.gov.cn/n50c12.aspx> (accessed on 6 August 2016).

Classen, D.C., Resar, R., Griffin, F., Federico, F., Frankel, T., Kimmel, N., Whittington, J.C., Frankel, A., Seger, A. \& James, B.C. (2011). 'Global Trigger Tool' Shows That Adverse Events in Hospitals May Be Ten Times Greater Than Previously Measured. Health Affairs, 30(4), pp. 581-589.

CMPA (2016). Fees and Payment. Available at: <https:/www.cmpa-acpm.ca/fees-and-payment $>$ (accessed on 11 May 2016).

CNTV (2013). Focus Interview: "Professional Mobs" Running Wild. Available at: <http://news.cntv.cn/2013/12/24/VIDE1387886530502367.shtml> (accessed on 27 July 2016).

Coase, R.H. (1960). The Problem of Social Cost. The Journal of Law and Economics, 3, pp. 1-44.

Coglianese, C. \& Mendelson, E. (2010). Meta-Regulation and Self-Regulation. In: Baldwin, R., Cave, M. \& Lodge, M. (eds.), The Oxford Handbook of Regulation (pp. 147-169). New York: Oxford University Press, pp. 147169.

Cohen, E.D. \& Korper, S.P. (1976). The Swedish No-Fault Patient Compensation Program: Provisions and Preliminary Findings. Insurance Law Journal, 2, pp. 70-80. 
Bibliography

Cohen, H. (1980). On Professional Power and Conflict of Interest: State Licensing Boards on Trial. Journal of Health Politics, Policy and Law, 5(2), pp. 291-308.

Cook, P.J. \& Graham, D.A. (1977). The Demand for Insurance and Protection: The Case of Irreplaceable Commodities. The Quarterly Journal of Economics, 91(1), pp. 143-156.

Cooter, R. (2003). Hand Rule Damages for Incompensable Losses. San Diego Law Review, 40(4), pp. 1097-1122.

Cooter, R. \& De Pianto, D. (2013). Damages for Incompensable Harms. In: Arlen, J. (ed.), Research Handbook on The Economics of Torts (pp. 439459). Cheltenham \& Northampton, MA: Edward Elgar.

Cooter, R. \& Ulen, T. (2012). Law \& Economics. Boston et al.: AddisonWesley.

Council on Medical Service (1988). Guidelines for Quality Assurance. The Journal of American Medical Association, 259(17), pp. 2572-2573.

Coyte, P.C., Dewees, D.N. \& Trebilcock, M.J. (1991). Canadian Medical Malpractice Liability: An Empirical Analysis of Recent Trends. Journal of Health Economics, 10(2), pp. 143-168.

Cranberg, L.D., Glick, T.H. \& Sato, L. (2007). Do the Claims Hold Up? A Study of Medical Negligence Claims Against Neurologists. Journal of Empirical Legal Studies, 4(1), pp. 155-162.

Crane, M. (2014). All-Time Craziest Frivolous Lawsuits. Available at: <www.medscape.com/features/content/6006313> (accessed on 1 August 2016).

Craswell, R. \& Calfee, J.E. (1986). Deterrence and Uncertain Legal Standards. Journal of Law, Economics, and Organisation, 2(2), pp. 279-303.

Croley, S.P. \& Hanson, J.D. (1995). The Nonpecuniary Costs of Accidents: Pain-and-Suffering Damages in Tort Law. Harvard Law Review, 108(8), pp. 1785-1917.

Curran, C. (1993). The American Experience with Self-Regulation in the Medical and Legal Professions. In Faure, M.G., Finsinger, J., Siegers, J. \& Van den Bergh, R. (eds.), Regulation of Professions: A Law and Economics Approach to the Regulation of Attorneys and Physicians in the US, Belgium, The Netherlands, Germany and the UK (pp. 47-87). Antwerp: MAKLU.

Currie, J. \& Macleod, W.B. (2008). First Do No Harm? Tort Reform and Birth Outcomes. Quarterly Journal of Economics, 123(2), pp. 795-830.

Dachen Collection (2015). The List of Chinese Hospitals that Have Passed the JCI Accreditation. Available at: <http://news.hc3i.cn/art/201510/34853.htm $>$ (accessed on 24 June 2016).

Dai, Q. (2003). Informed Consent in China: Status Quo and Its Future. Medical Law International, 6(1), pp. 53-71. 
Danzon, P.M. (1984a). The Frequency and Severity of Medical Malpractice Claims. The Journal of Law \& Economics, 27(1), pp. 115-148.

Danzon, P.M. (1984b). Tort Reform and the Role of Government in Private Insurance Markets. The Journal of Legal Studies, 13(3), pp. 517-549.

Danzon, P.M. (1985a). Medical Malpractice: Theory, Evidence, and Public Policy. Cambridge, MA \& London: Harvard University Press.

Danzon, P.M. (1985b). Liability and Liability Insurance for Medical Malpractice. Journal of Health Economics, 4(4), pp. 309-331.

Danzon, P.M. (1986). The Frequency and Severity of Medical Malpractice Claims: New Evidence. The Journal of Law \& Economics, 27(1), pp. 115148.

Danzon, P.M. (1987). The Effects of Tort Reforms on the Frequency and Severity of Medical Malpractice Claims. Ohio State Law Journal, 48, pp. 413-417.

Danzon, P.M. (1994b). The Swedish Patient Compensation System: Lessons for the United States. The Journal of Legal Medicine, 15(2), pp. 199-247.

Danzon, P.M. (1994c). The Swedish Patient Compensation System: Myths and Realities. International Review of Law and Economics, 14(4), pp. 453466.

Danzon, P.M. (2000). Liability for Medical Malpractice. In: Culyer, A.J. \& Newhouse, J.P. (eds.), Handbook of Health Economics (Volume 1B) (pp. 1339-1404). North-Holland: Elsevier.

Danzon, P.M. \& Lillard, L.A. (1983). Settlement out of Court: The Disposition of Medical Malpractice Claims. The Journal of Legal Studies, 12(2), pp. 345-377.

Danzon, P.M., Epstein, A.J. \& Johnson, S.J. (2004). The 'Crisis' in Medical Malpractice Insurance. Brookings-Wharton Papers on Financial Services, 96, pp. 55-96.

Davis, D.A., Norman, G.R., Painvin, A., Lindsay, E., Ragbeer, M.S. \& Rath, D. (1990). Attempting to Ensure Physician Competence. The Journal of American Medical Association, 263(15), pp. 2041-2042.

Davis, P., Lay-Yee, R., Briant, R. \& Scott, A. (2003). Preventable In-Hospital Medical Injury under the 'No Fault' System in New Zealand. Quality \& Safety in Health Care, 12, pp. 251-256.

Davis, P., Lay-Yee, R., Briant, R., Ali, W., Scott, A. \& Schug, S. (2002a). Adverse Events in New Zealand Public Hospitals I: Occurrence and Impact. New Zealand Medical Journal, 115(1167), pp. 1-9.

Davis, P., Lay-Yee, R., Briant, R., Ali, W., Scott, A. \& Schug, S. (2002b). Adverse Events in New Zealand Public Hospitals II: Preventability and Clinical Context. New Zealand Medical Journal, 116(1183), pp. U624U624. 
Bibliography

De Vries, H., Sanderson, P., Janta, B., Rabinovich, L., Archontakis, F., Ismail, S., Klautzer, L., Marjanovic, S., Patruni, B., Puri, S. \& Tiessen, J. (2009). International Comparison of Ten Medical Regulatory Systems. RAND EUROPE.

De Mot, J. \& Faure, M. (2016). Discretion and the Economics of Defensive Behaviour by Public Bodies. Maastricht Journal of European and Comparative Law, 23(4), pp. 595-610.

Dekker, S.W.A. \& Leveson, N.G. (2015). The Systems Approach to Medicine: Controversy and Misconceptions. BMJ Quality \& Safety, 24(1), pp. 7-9.

Den Hertog, J. (1993). An Economic Analysis of the (Self-)Regulation of Physicians in the Netherlands. In: Faure, M.G., Finsinger, J., Siegers, J. \& Van den Bergh, R. (eds.), Regulation of Professions (pp. 195-204). Antwerp: MAKLU.

Den Hertog, J. (2000). General Theories of Regulation. In: Bouckaert, B. \& Geest, G.D. (eds.), Regulation of Contracts (pp. 223-270). Cheltenham: Edward Elgar.

Deng, H., Li, X. \& Chen, Y. (2007). The Drawbacks of Applying the 'Equitable Responsibility' Principle to Settle the Medical Accident and the Measure to Deal with it. Journal of Kunming Medical College, 28(6), pp. 119-122.

Deng, J. (2015). The Guiding Case System in Mainland China. Frontiers of Law in China, 10(3), pp. 1-26.

Deng, L. (2014). The Chinese Medical Doctor Association: Our Opinion on $\mathrm{Xu}$ Feng's Case of the 'Crime of Medial Accident'. Available at: <http://news.haoyisheng.com/14/1203/310106890.html> (accessed on 26 June 2016).

Derbyshire, R.C. (1983). How Effective Is Medical Self-Regulation. Law and Human Behaviour, 7(2/3), pp. 193-202.

Devlin, A. (2015). Fundamental Principles of Law and Economics. London \& New York: Routledge.

Dew, K. (2002). Accident Insurance, Sickness, and Science: New Zealand's No-Fault System. International Journal of Health Services, 32(1), pp. 163178.

Dewees, D.N., Mathewson, G.F. \& Trebilcock, M.J. (1983). The Rationale for Government Regulation of Quality. In: Dewees, D.N. (ed.), The Regulation of Quality Products, Services, Workplaces, and the Environment (pp. 3-26). Toronto: Butterworths.

Dewees, D., Duff, D. \& Trebilcock, M. (1996). Exploring the Domain of Accident Law: Taking the Facts Seriously. New York \& Oxford: Oxford University Press.

Di, X. \& Wu, Y. (2009). The Developing Trend of the People's Mediation in China. Sociological Focus, 42(3), pp. 228-245. 
Ding, C. (2012). Medical Negligence Law in Transitional China. Cambridge, Antwerp \& Portland: Intersentia.

Dingwall, R. \& Fenn, P. (1987). 'A Respectable Profession'? Sociological and Economic Perspectives on the Regulation of Professional Services. International Review of Law and Economics, 7(1), pp. 51-64.

Dionne, G., Doherty, N. \& Fombaron, N. (2000). Adverse Selection in Insurance Markets. In: Dionne, G. (ed.), Handbook of Insurance (pp. 185243). Dordrecht: Springer Netherlands.

Diver, C.S. (1983). The Optimal Precision of Administrative Rules. The Yale Law Journal, 93(1), pp. 65-109.

Doherty, N.A. \& Schlesinger, H. (1990). Rational Insurance Purchasing: Consideration of Contract Nonperformance. The Quarterly Journal of Economics, 105(1), pp. 243-253.

Dolan, A.K. \& Urban, N.D. (1983). The Determinants of the Effectiveness of Medical Disciplinary Boards: 1960-1977. Law and Human Behaviour, 7(2/3), pp. 203-217.

Dong, C. (2015). On the Distributor's Defense Right of Product Liability From the Perspective of 3 Defense Rigths of Article 41 'Product Quality Law'. Commercial Research, 1, pp. 186-192.

Dong, W. (2012). The Regime of Hospital Accreditation: To Be Annulled or Reshaped?. China Youth Daily, 18 September, 5.

Dong, W. (2014). Medical Liability Insurance: Can It Be a Amulet for Doctors and Patients. The Hospital Leadership Decision-making Reference, 16, pp. 16-19.

Dong, W. \& Zhao, L. (2015). Current Medical Liability Insurance in China. In: Cui, J. (ed.), China: Views from Young Scholars (pp. 527-578). Beijing: Social Sciences Academic Press (China).

Dranove, D. \& Gron, A. (2005). Effects of the Malpractice Crisis on Access to and Incidence of High-Risk Procedures: Evidence from Florida. Health Affairs, 24(3), pp. 802-810.

Dranove, D. \& Watanabe, Y. (2009). Influence and Deterrence: How Obstetricians Respond to Litigation against Themselves and Their Colleagues. American Law and Economics Review, 12(1), pp. 69-94.

Du, Q. \& Liu, Y. (2009). The Reasons for the Illegal Practice of Repeated Research and Corresponding Measures. China Health Law, 17(3), pp. 2426.

Dubay, L., Kaestner, R. \& Waidmann, T. (1999). The Impact of Malpractice Fears on Caesarian Section Rates. Journal of Health Economics, 18(4), pp. 491-522.

Dubay, L., Kaestner, R. \& Waidmann, T. (2001). Medical Malpractice Liability and Its Effect on Prenatal Care Utilisation and Infant Health. Journal of Health Economics, 20(4), pp. 591-611. 
Bibliography

Du Perron, C.E.D. \& Van Boom, W.H. (2003). The Impact of Social Security Law on Tort Law in the Netherlands. In: Magnus, U. (ed.), title (pp. 149164). Wien/NewYork: Springer.

Dute, J. (2004). A Comparison of No-Fault Compensation Schemes. In: Dute, J., Faure, M.G. \& Koziol, H. (eds.), No-Fault Compensation in the Health Care Sector (Tort and Insurance Law Vol. 8) (pp. 444-484). Wien/NewYork: Springer.

Dute, J., Faure, M.G. \& Koziol, H. (eds.) (2004). No-Fault Compensation in the Health Care Sector (Tort and Insurance Law Vol. 8). Wien/NewYork: Springer.

Ehrlich, I. \& Becker, G.S. (1972). Market Insurance, Self-Insurance, and SelfProtection. Journal of Political Economy, 80(4), pp. 623-648.

Ehrlich, I. \& Posner, R.A. (1974). An Economic Analysis of Legal Rulemaking. The Journal of Legal Studies, 3(1), pp. 257-286.

Eijlander, P. (2005). Possibilities and Constraints in the Use of Self-regulation and Co-Regulation in Legislative Policy: Experiences in the Netherlands Lessons to Be Learned for the EU?. Electronic Journal of Comparative Law, 9(1), pp. 1-25.

Eisler, P. \& Hansen, B. (2013). Thousands of Doctors Practising Despite Errors, Misconduct. Available at: <www.usatoday.com/story/news/nation/2013/08/20/doctors-licenses-medical-boards/2655513/> (accessed on 2 April 2016).

Ellis, R.P., Gallup, C.L. \& Mcguire, T.G. (1990). Should Medical Professional Liability Insurance Be Experience Rated?. The Journal of Risk and Insurance, 57(1), pp. 66-78.

Encinosa, W.E. \& Hellinger, F.J. (2005). Have State Caps on Malpractice Awards Increased the Supply of Physicians?. Health Affairs, 24(4), pp. 1186-1194.

Epstein, L. \& Martin, A.D. (2014). An Introduction to Empirical Legal Research. Oxford/New York: Oxford University Press.

Epstein, R.A. (1976). Medical Malpractice: The Case for Contract. American Bar Foundation Research Journal, 1(1), pp. 87-150.

Epstein, R.A. (1977). Contracting Out of the Medical Malpractice Crisis. Perspectives in Biology and Medicine, 20(2), pp. 228-245.

Epstein, R.A. (1978). Medical Malpractice: Its Cause and Cure. In: Rottenberg, S. (ed.), The Economics of Medical Malpractice (pp. 245-268). Washington, D.C: American Enterprise Institute for Public Policy Research.

Epstein, R.A. (1984). In Defense of the Contract at Will. University of Chicago Law Review, 51, pp. 947-982. 
Epstein, R.A. (1986). Medical Malpractice, Imperfect Information, and the Contractual Foundation for Medical Services. Law and Contemporary Problems, 49(2), pp. 201-212.

Epstein, R.A. (1988). Market and Regulatory Approaches to Medical Malpractice: The Virginia Obstetrical No-Fault Statute. Virginia Law Review, 74(8), pp. 1451-1474.

Epstein, R.A. (1995). Simple Rules for a Complex World. Cambridge et al: Harvard University Press.

Epstein, R.A. (2005). Contractual Principle versus Legislative Fixes: Coming to Closure on the Unending Travails of Medical Malpractice. DePaul Law Review, 54, pp. 503-526.

Epstein, R.A. (2013). Alternatives and Complements: Liability and Regulation as Remedies for Physical Injury. In: Arlen, J. (ed.), Research Handbook on the Economics of Torts (pp. 608-632). Cheltenham \& Northampton, MA: Edward Elgar.

Epstein, R.A. \& Sykes, A.O. (2001). The Assault on Managed Care: Vicarious Liability, ERISA Preemption, and Class Actions. The Journal of Legal Studies, 30(S2), pp. 625-659.

Erichsen, M. (2001). The Danish Patient Insurance System. Medicine and Law, 20(3), pp. 355-370.

Essinger, K. (2009). The Swedish Medical Injury Insurance. Available at: <www.vm.gov.lv/images/userfiles/phoebe/ministrija_sabiedribas_lidzdalib a_ab75e1a6c38b637dc22573d800293aaa/zviedrijas_traumu_apdrosin.pdf> (accessed on 19 May 2016).

Fan, C., Wang, J., Xu, Q. \& Ji, L. (2013). 'Analysis of 1,069 Sanitary and Administrative Penalty Cases of Medical Institutions in Anhui Province from 2011 to 2012', Anhui Medical Journal, 34(10), pp. 1546-1549.

Fang, M. \& Yang, N. (2011). Investigation Analysis of Medical Dispute Appraisal for 192 Cases. Chinese Journal of Social Medicine, 28(3), pp. 215-217.

Farber, H.S. \& White, M.J. (1991). Medical Malpractice: An Empirical Examination of the Litigation Process. The Rand Journal of Economics, 22(2), pp. 199-217.

Farber, H.S. \& White, M.J. (1994). A Comparison of Formal and Informal Dispute Resolution in Medical Malpractice. The Journal of Legal Studies, 23(2), pp. 777-806.

Faure, M.G. (1997). Interdependencies between Tort law and Insurance. Risk Decision and Policy, 2(2), pp. 193-210.

Faure, M.G. (2000). Compensation of Non-Pecuniary Loss: An Economic Perspective. In: Magnus, U. \& Spier, J. (eds.), European Tort Law: Liber Amicorum for Helmut Koziol (pp. 143-159). Frankfurt et al.: Peter Lang International Academic Publishers. 
Bibliography

Faure, M.G. (2004a). Economic Observations Concerning Optimal Prevention and Compensation of Damage Caused by Medical Malpractice. In: Dute, J., Faure, M.G. \& Koziol, H. (eds.), No-Fault Compensation in the Health Care Sector (pp. 5-87). Wien/NewYork: Springer.

Faure, M.G. (2004b). Alternative Compensation Mechanisms as Remedies for Uninsurability of Liability. Geneva Papers on Risk and Insurance - Issues and Practice, 29(3), pp. 455-489.

Faure, M.G. (2005). The View from Law and Economics. In: Wagner, G. (ed.), Tort Law and Liability Insurance (Tort and Insurance Law Vol. 16) (pp. 239-274). Wien/NewYork: Springer.

Faure, M.G. (2007). Economic Analysis of Tort and Regulatory Law. In: Van Boom, W.H., Lukas, M. \& Kissling, C. (eds.), Tort and Regulatory Law (Tort and Insurance Law Vol. 19) (pp. 399-415). Wien/NewYork: Springer.

Faure, M.G. (2016). Attribution of Liability: An Economic Analysis of Various Cases. Chicago-Kent Law Review, 91(2), pp. 603-635.

Faure, M.G., Finsinger, J., Siegers, J. \& Van den Bergh, R. (eds.) (1993). Regulation of Professions: A Law and Economics Approach to the Regulation of Attorneys and Physicians in the US, Belgium, The Netherlands, Germany and the UK. Antwerp: MAKLU.

Faure, M. \& Grimeaud, D. (2003). Financial Assurance Issues of Environmental Liability. In: Faure, M.G. (ed.), Deterrence, Insurability, and Compensation in Environmental Liability: Future Developments in the European Union (pp. 7-255). Wien/NewYork: Springer.

Faure, M.G. \& Hartlief, T. (1998), Remedies for Expanding Liability. Oxford Journal of Legal Studies, 18(4), pp. 681-706.

Faure, M. \& Hartlief, T. (2003). Social Security versus Tort Law as Instruments to Compensate Personal Injuries: A Dutch Law and Economics Perspective. In: Magnus, U. (ed.), The Impact of Social Security Law on Tort Law (Tort and Insurance Law Vol. 3) (pp. 222-265). Wien/NewYork: Springer.

Faure, M. \& Van den Bergh, R. (1989). Compulsory Insurance for Professional Liability. The Geneva Papers on Risk and Insurance, 14(53), pp. 308-330.

Faure, M. \& Van den Bergh, R. (1995). Restrictions of Competition on Insurance Markets and the Applicability of EC Antitrust Law. Kyklos, 48(1), pp. 65-85.

Federation of State Medical Boards (2016). State - Specific Requirements for Initial Medical Licensure. Available at: <https://www.fsmb.org/policy/public-resources/state_specific $>$ (accessed on 12 March 2016).

Fei, F. (2010). Defensive Medicine - An Assistance for Excessive Medication. Capital Food Medicine, 1, pp. 24-25. 
Feng, Q., Zhu, Y. \& Xie, Y. (2013). An Analysis of 103 Cases of Administrative Punishments on Medical Institutions in Futian District. China Health Industry, 11, pp. 47-48.

Feng, Y., Zhang, J. \& Zeng, L. (2013). Analysis of 250 Cases of Administrative Punishments on Medical Institutions in Shenzhen for the Period 20102012. China Health Industry, 31, pp. 37-39.

Ferner, R.E. \& Mcdowell, S.E. (2006). Doctors Charged with Manslaughter in the Course of Medical Practice, 1795-2005: A Literature Review. Journal of the Royal Society of Medicine, 99(6), pp. 309-314.

Finnish Patient Insurance Centre (2015). Statistics 2015. Available at: $<$ www.pvk.fi/en/statistics/> (accessed on 8 June 2016).

Fiore, K. (2009). No-Fault Compensation Systems. In: Faure, M.G. (ed.), Tort Law and Economics (Encyclopedia of Law and Economics Volume 1) (pp. 406-432). Cheltenham \& Northampton, MA: Edward Elgar.

Florida Centre for Health Information and Policy Analysis (2012). Hospitals Reported Malpractice Claims by Area Office 2012. Available at: <https://ahca.myflorida.com/SCHS/RiskMgtPubSafety/Statistics/docs/2011 /AnnualData/MalpracticeClaimsReportedStateWide2012.pdf> (accessed on 8 June 2016).

Florida Centre for Health Information and Policy Analysis (2013). Statewide Malpractice Claims Reported State-Wide 2013. Available at: <https://ahca.myflorida.com/SCHS/RiskMgtPubSafety/Statistics/docs/2013 /RMPS_REPORT_ANNUAL_STATEWIDE_2013.pdf> (accessed on 8 June 2016).

Florida Centre for Health Information and Policy Analysis (2014). Statewide Malpractice Claims Reported State-Wide 2014. Available at: $<$ https://ahca.myflorida.com/SCHS/RiskMgtPubSafety/Statistics/docs/2014 /RMPS_REPORT_ANNUAL_STATEWIDE_2014.pdf> (accessed on 8 June 2016).

Friedman, D. (1982). What Is 'Fair Compensation' for Death or Injury?. International Review of Law and Economics, 2(1), pp. 81-93.

Friedman, M. (1953). Essays in Positive Economics. Chicago \& London: The University of Chicago Press.

Friedman, M. (1962). Capitalism and Freedom. Chicago \& London: The University of Chicago Press.

Gao, S. (2012). The Unreal Joint and Several Liability between the Producer and the Seller in the Context of Product Liability. Legal Forum, 27(2), pp. 16-22.

Garcia, C.A. (2011). Quantifying the Economics of Medical Malpractice: A View from $A$ Civil Law Perspective. Unpublished $\mathrm{PhD}$ thesis. Erasmus University Rotterdam. 
Bibliography

Garner, B.A. (ed.) (2014). Black's Law Dictionary. 10th edn. Available at: $<$ https://itunes.apple.com/us/app/blacks-law-dictionary-10th/id985199462? mt=8 (Downloaded on15 April 2016.

Gawande, A.A., Zinner, M.J., Studdert, D.M. \& Brennan, T.A. (2003). Analysis of Errors Reported by Surgeons at Three Teaching Hospitals. Surgery, 133(6), pp. 614-621.

Ge, G. (2016). Could Letting the Police Stationed in Hospitals Stop Yi-Nao Incidents? Naive!. Available at: <http://news.gmw.cn/201607/11/content_20905917.htm> (accessed on 27 July 2016).

Ge, J. \& Yu, X. (2014). Copycat Torts Committed by Minors - Comments on the Xi Yang Yang Case. SJTU Law Review, (4), pp. 159-174.

General Medical Council (2016). Sanctions Guidance. Available at: <www.gmc-uk.org/DC4198_Sanctions_Guidance_23008260.pdf> (accessed on 27 March 2016).

Ger, J. (2009). Why Can Taiwan Utilize Criminal Law to Discipline Physicians?. Legal Medicine, 11(Suppl. 1), pp. S135-S137.

Giesen, I. \& Engelhard, E. (2011). Medical Liability in the Netherlands. In: Koch, B.A. (ed.), Medical Liability in Europe: A Comparison of Selected Jurisdictions (Tort and Insurance Law Vol. 29) (pp. 361-410). Berlin/Boston: De Gruyter.

Gilead, I. (1997). Tort Law and Internalization: The Gap between Private Loss and Social Cost. International Review of Law and Economics, 17(4), pp. 589-608.

Gilead, I., Green, M.D. \& Koch, B.A. (eds.) (2013). Proportional Liability: Analytical and Comparative Perspectives (Tort and Insurance LaW Vol. 33). Berlin/Boston: De Gruyter.

Gius, M.P. (2000). An Examination of the Determinants of Physician Supply at the State Level. The Journal of Business and Economic Studies, 6(1), pp. 73-79.

Givelber, D.J., Bowers, W.J. \& Blitch, C.L. (1984). Tarasoff, Myth and Reality: An Empirical Study of Private Law in Action. Wisconsin Law Review, 1(2), pp. 443-497.

Goldberg, V.P. (1974). The Economics of Product Safety and Imperfect Information. The Bell Journal of Economics and Management Science, 5(2), pp. 683-688.

Goldman, B. (1987). Quality Assurance Will Play Key Role in Reducing Malpractice Suits: CMPA. CMAJ: Canadian Medical Association Journal, 137(5), pp. 447-448.

Goyert, G.L., Bottoms, S.F., Treadwell, M.C. \& Nehra, P.C. (1989). The Physician Factor in Caesarian Birth Rates. The New England Journal of Medicine, 320(11), pp. 706-709. 
Graddy, E. (1991). Toward a General Theory of Occupational Regulation. Social Science Quarterly, 72(4), pp. 676-695.

Grant, D. \& McInnes, M.M. (2004). Malpractice Experience and the Incidence of Caesarian Delivery: A Physician-Level Longitudinal Analysis. Inquiry, 41(2), pp. 170-188.

Gray, D.E. (2014). Doing Research in the Real World. $3^{\text {rd }}$. edn., Los Angeles et al.: SAGE.

Greenwald, B.C.N. \& Mueller, M.W. (1978). Medical Malpractice and Medical Costs. In: Rottenberg, S. (ed.), The Economics of Medical Malpractice (pp. 65-86). Washington, D.C: American Enterprise Institute for Public Policy Research.

Grober, E.D. \& Bohnen, J.M.A. (2005). Defining Medical Error. Canadian Journal of Surgery, 48(1), pp. 39-44.

G'Sell-Macrez, F. (2013). Medical Malpractice and Compensation in France. In: Oliphant, K. \& Wright, R.W. (eds.), Medical Malpractice and Compensation in Global Perspective (Tort and Insurance Law Vol. 32) (pp. 131-178). Berlin/Boston: De Gruyter.

Gu, J. \& Zhuang, L. (2008). On the Defensive Medical Treatment. Chinese Medical Ethics, 21(1), pp. 73-75.

$\mathrm{Gu}$, X. (2014). Problems of Pharmaceutical Pricing Regulation in China and Study of Countermeasures. In: Wen, X. \& Pang, Z. (eds.), Annual Report on Reform of Medical and Health System in China (2014-2015) (pp. 156185). Beijing: Social Sciences Academic Press (China).

Guiding Case Office of the Supreme People's Court (2015). Understanding and Application of Guiding Case No. 24. People's Judicature, 12, pp. 9-12.

Guo, J. (2015). A Comparison and Contrast of the Expert Witness Systems for Medical Malpractice Claims Organised by Medical Associations and Judicial Expertise Institutions. Science \& Technology Vision, 10, pp. 295296.

Guo, J. (2013). Hospital Accreditation Suspended Again. Medical Community, 12, pp. 1-2.

Guyatt, G.H., Feeny, D.H. \& Patrick, D.L. (1993). Measuring Health-Related Quality of Life. Annals of Internal Medicine, 118(8), pp. 622-629.

Ha, W., Zhou, Y., Gu, M. \& Wang, Z. (2009). Review on the Reporting System of Medical Adverse Events. Chinese Hospital Management, 29(1), pp. 20-22.

Han, C., Li, Y., Han, C., Zhang, Z., Cao, Z., Zhang, X., Zhao, Y. \& Du, H. (2013). Research on the Status of Medical Dispute and Impact for Diagnosis and Treatment Behaviours in A Hospital of Chengde. The Chinese Health Service Management, 30(8), pp. 573-575.

Han, S. (2005). On the Incomplete Performance of Medical Service Contracts and the Remedy Thereof. Chinese Journal of Law, 2005(6), pp. 89-104. 
Bibliography

Han, S. (2014). Culpa in Contrahendo in Chinese Contract Law. Tsinghua China Law Review, 6(2), pp. 157-170.

Harris, C.T., Peeples, R. \& Metzloff, T.B. (2008). Does Being a Repeat Player Make a Difference? The Impact of Attorney Experience and Case-Picking on the Outcome of Medical Malpractice Lawsuits. Yale Journal of Health Policy, Law, and Ethics, 8(2), pp. 253-282.

Harris, D.M. \& Wu, C.C. (2005). Medical Malpractice in the People's Republic of China: The 2002 Regulation on the Handling of Medical Accidents. The Journal of Law, Medicine \& Ethics, 33(3), pp. 456-477.

Harris, D.R. (1974). Accident Compensation in New Zealand: A Comprehensive Insurance System. The Modern Law Review, 37(4), pp. 361-376.

Harris, J.A. \& Byhoff, E. (2016). Variations by State in Physician Disciplinary Actions by US Medical Licensure Boards. BMJ Quality \& Safety, 0, pp. 1-9.

Hartlev, M. (2011). Forwards or Backwards - New Directions in Danish Patients' Rights Legislation. European Journal of Health Law, 18(4), pp. 365-374.

Harvard Medical Practices Study (1990). Patients, Doctors, and Lawyers: Medical Injury, Malpractice Litigation, and Patient Compensation in New York: The Report of the Harvard Medical Practice Study to the State of New York. Cambridge, MA: Harvard University Press.

Havighurst, C.C. (1975). 'Medical Adversity Insurance': Has Its Time Come?. Duke Law Journal, 6, pp. 1233-1280.

Havighurst, C.C. (1983). Decentralizing Decision Making: Private Contract versus Professional Norms. In: Meyer, J.A. (ed.), Market Reforms in Health Care Current Issues, New Directions, Strategic Decisions (pp. 2245). Washington: American Enterprise Institute for Public Policy Research.

Havighurst, C.C. (1986). Private Reform of Tort-Law Dogma: Market Opportunities and Legal Obstacles. Law and Contemporary Problems, 49(2), pp. 143-172.

Havighurst, C.C. \& Tancredi, L.R. (1973). 'Medical Adversity Insurance': A No-Fault Approach to Medical Malpractice and Quality Assurance. The Milbank Memorial Fund quarterly. Health and Society, 51(2), pp. 125-168.

Hay, B.L. (1997). Allocating the Burden of Proof. Indiana Law Journal, 72(3), pp. 651-680.

He, J. (2014). Defensive Medicine and Its Contributing Factors of Public Hospitals in China: Research Findings from A Physician Survey in A City of Guangdong Province. Chinese Journal of Health Policy, 7(10), pp. 3339. 
Helland, E. \& Showalter, M.H. (2009). The Impact of Liability on the Physician Labour Market. The Journal of Law and Economics, 52, pp. 635663.

Hellinger, F.J. \& Encinosa, W.E. (2003). The Impact of State Laws Limiting Malpractice Awards on the Geographic Distribution of Physicians. U.S. Department of Health and Human Services, Available at: $<$ http://citeseerx.ist.psu.edu/viewdoc/download;jsessionid=DA72411136B2 B39E83C3E526E76D7F42?doi=10.1.1.397.460\&rep=rep1\&type=pdf > (accessed on 14 May 2016).

Hellinger, F.J. \& Encinosa, W.E. (2006). The Impact of State Laws Limiting Malpractice Damage Awards on Health Care Expenditures. American Journal of Public Health, 96(8), pp. 1375-1381.

Hellner, J. (1985). Sweden. In: Deutsch, E. \& Schreiber, H.L. (eds.), Medical Responsibility in Western Europe: Research Study of the European Science Foundation (pp. 685-728). Berlin et al.: Springer-Verlag.

Hellner, J. (1986). Compensation for Personal Injury: The Swedish Alternative. The American Journal of Comparative Law, 34(4), pp. 613633.

Hellner, J. (2001). Compensation for Personal Injuries in Sweden-A Reconsidered View. Scandinavian Studies in Law, 41, pp. 249-277.

Hesketh, T., Wu, D., Mao, L. \& Ma, N. (2012). Violence against Doctors in China. The BMJ, 345, pp. e5730-e5730.

Hilfiker, D. (1984). Facing Our Mistakes. The New England Journal of Medicine, 310, pp. 118-122.

Hiltz, P.L. (ed.) (2004). Medical Malpractice: Issues and Law. New York: Nova Science Publishers Inc.

Hiriart, Y., Martimort, D. \& Pouyet, J. (2004). On the Optimal Use of Ex Ante Regulation and Ex Post Liability. Economics Letters, 84(2), pp. 231-235.

Hitzhusen, M. (2005). Crisis and Reform: Is New Zealand's No-Fault Compensation System a Reasonable Alternative to the Medical Malpractice Crisis in the United States. Arizona Journal of International and Comparative Law, 22(3), pp. 649-690.

Hogan, D.B. (1983). The Effectiveness of Licensing: History, Evidence, and Recommendations. Law and Human Behaviour, 7(2/3), pp. 117-138.

Holt, C.A. \& Laury, S.K. (2002). Risk Aversion and Incentive Effect. The American Economic Review, 92(5), pp. 1644-1655.

Hondius, E. (2010a). The Development of Medical Liability in the Netherlands. In: Hondius, E. (ed.), The Development of Medical Liability (pp. 132-159). Cambridge: Cambridge University Press.

Hondius, E. (2010b). General Introduction. In: Hondius, E. (ed.), The Development of Medical Liability (pp. 1-26). Cambridge: Cambridge University Press. 
Hondius, E. (ed.) (2010c). The Development of Medical Liability. Cambridge: Cambridge University Press.

Hong, X. \& Wang, H. (2014). The First Case of the Crime of Medical Accident. Legal Evening News, 24 November, A4.

Howard, A.E.D. (1987). Our Litigious Society. South Carolina Law Review, 38, pp. 365-379.

Howell, B. (2004). Medical Misadventure and Accident Compensation in New Zealand: An Incentives-Based Analysis. Victoria University of Wellington Law Review, 35, pp. 857-878.

Hu, T. \& Zhao, H. (2013). A Survey on Awareness, and Behaviour on Law of Tort Liability Compensation for Medical Damage of Primary Hospitals and Its Medical Staff in Changsha. Modern Hospital, 13(10), pp. 80-83.

Hu, X. (ed.) (2001). Watching the Tide with an Air of Detachment: On the Contentious Issues as regards Health Law. Nanjing: Southeast University Press.

Hu, X. \& Shi, H. (2016). A Report on Cases of Disputes over Medical Injury Liability After the Inception of the Tort Law. Shandong Justice, 32(2), pp. 112-116.

Huang, H. (2013). Enlightens of Healthcare Organisation Accreditation in America. Hospital Directors' Forum, 2013(5), pp. 59-63.

Huang, S. (ed.) (2004). An Understanding and Application of the Interpretation of the Supreme People's Court on Some Issues concerning the Application of Law for the Trial of Cases on Compensation for Personal Injury. Beijing: People's Court Press.

Hutchinson, T. (2013). Doctrinal Research: Researching the Jury. In: Watkins, R. \& Burton, M. (eds.), Research Methods in Law (pp. 7-34). London: Routledge.

Hyman, D.A. \& Silver, C.M. (2013). Medical Malpractice and Compensation in Global Perspective: How Does the U.S. Do It?. In: Oliphant, K. \& Wright, R.W. (eds.), Medical Malpractice and Compensation in Global Perspective (Tort and Insurance Law Vol. 32) (pp. 473-512). Berlin/Boston: De Gruyter.

Iktsuarpok (2015). What Should Hospitals Do When Patients Are Unable to Pay for Medical Bills? Available at: <www.zhihu.com/question/24809030> (accessed on 13 August 2016).

Inman, W.H.W. (1986). Risks in Medical Intervention: Balancing Therapeutic Risks and Benefits. In: Worden, A.N., Parke, D.V. \& Marks, J. (eds.), The Future of Predictive Safety Evaluation (Vol. 1) (pp. 43-62). Lancaster et al: MTP Press Limited.

Innes, R. (2004). Enforcement Costs, Optimal Sanctions, and the Choice Between Ex-Post Liability and Ex-Ante Regulation. International Review of Law and Economics, 24(1), pp. 29-48. 
International Committee of the Red Cross (ICRC) (2012). Violent Incidents Affecting Health Care: Health Care in Danger. Available at: <https://www.icrc.org/eng/assets/files/reports/4050-002_violent-incidentsreport_en_final.pdf> (accessed on 7 August 2016).

Ison, T.G. (1967). The Forensic Lottery: A Critique on Tort Liability as a System of Personal Injury Compensation. London: Staples Press.

Jena, A.B., Seabury, S., Lakdawalla, D. \& Chandra, A. (2011). Malpractice Risk According to Physician Specialty. New England Journal of Medicine, 365(7), pp. 629-636.

Jia, X., Zhou, H., Zhao, Y., Zheng, L., Wei, Q. \& Zheng, X. (2014). Investigation on Hospital Violence during 2003 to 2012 in China. Chinese Hospitals, 18(3), pp. 1-3.

Jian, F. (2014). More Than 3,000 Medical Dispute Mediation Organisations Established, Success Rate 88\%. Available at: <www.chinanews.com/gn/2014/05-06/6135670.shtml> (accessed on 27 July 2016).

Jiang, C. (2006). On the Patient's Right to Informed Consent: Cases Survey and Thinking. Nanjing University Law Review, (2), pp. 113-134.

Jiang, Q. (2010). Joint and Several Liability, Imperfect Joint and Several Liability in the Tort Liability Law and Applicable Procedures. Journal of Law Application, 2010(7), pp. 15-20.

Jiang, Q. (2015). 60 Doctors Had Been Sanctioned Due to Taking the Hongbao in Anhui Province. Available at: <www.51esou.com/Disease_art.php?articleID=46013> (accessed on 20 July 2016).

Jiangsu Nanjing Gulou District People's Court, First Civil Chamber (2014). Essential Issues Regarding the Trial of Cases of Disputes over Liability for Iatrogenic Injuries (on file with author).

Jiangsu Nanjing Intermediate People's Court, First Civil Chamber (2014). On the Issues Regarding the Application of Legal Rules to Cases of Disputes over Liability for Iatrogenic Injuries (on file with author).

Jiangsu Nantong Intermediate People's Court, First Civil Chamber (2013). A Report on the Trial of Medical Injury Cases. Available at: <www.ntfy.gov.cn/contents/565/1787.html> (accessed on 19 July 2016).

Jiangsu Provincial Commission of Health and Family Planning (2014). Jiangsu Health Yearbook (2014). Available at: <www.jswst.gov.cn/jsswshjhsywyh/fzgk/jsws/jsnj/qw/2014/10/22151230390.html> (accessed on 10 June 2016).

Jilin Workers' Daily (2015). Oxygen 72 Hours A Day, the Hospital Overcharges Too Outrageously. Jilin Workers' Daily, 10 April, A.

Jin, Y. (2014). Research on Improving Operational Mode of Medical Liability Insurance in Shanghai, China. Unpublished Master thesis. Fudan University.

Johansson, H. (2010). The Swedish System for Compensation of Patient 
Bibliography

Injuries. Upsala Journal of Medical Sciences, 115(2), pp. 88-90.

Johnson, T., Larkin, G. \& Saks, M. (eds.) (2015). Health Professions and the State in Europe. London \& New York: Routledge.

Johnson, V.R. \& Gunn, A. (2009). Studies in American Tort Law. 4th edn. Durham: Carolina Academic Press.

Join Together Staff (2011). Small but Growing Number of Doctors Face Criminal Charges Over Prescription Drugs. Available at: <wwwdrugfree.org/join-together/small-but-growing-number-of-doctors-facecriminal-charges-over-prescription-drugs/> (accessed on 8 July 2016).

Jorstad, R.G. (2002). The Norwegian System of Compensation to Patients. Medicine and Law, 21(4), pp. 681-696.

Jr. Pierce, R.J. (1980). Encouraging Safety: The Limits of Tort Law and Government. Vanderbilt Law Review, 33(6), pp. 1281-1332.

Ju, L. \& Ma, C. (2012). On the Improvement of the Calculation of Death Compensation in China. Qinghai Social Sciences, 2012(5), pp. 97-102.

Kachalia, A.B., Mello, M.M., Brennan, T.A. \& Studdert, D.M. (2008). Beyond Negligence: Avoidability and Medical Injury Compensation. Social Science \& Medicine, 66(2), pp. 387-402.

Kachelmeier, S.J. \& Shehata, M. (1992). Examining Risk Preferences Under High Monetary Incentives: Experimental Evidence from the People's Republic of China. American Economic Review, 82(5), pp. 1120-1141.

Kahan, M. (1989). Causation and Incentives to Take Care Under the Negligence Rule. Journal of Legal Studies, 18(2), pp. 427-448.

Kakalik, J.S. \& Robyn, A.E. (1982). Costs of the Civil Justice System: Court Expenditures for Processing Tort Cases. Rand: The Institute for Civil Justice.

Kaplow, L. (1992). Rules versus Standards: An Economic Analysis. Duke Law Journal, 42(3), pp. 557-629.

Kaplow, L. (2012). Burden of Proof. The Yale Law Journal, 121(4), pp. 739859.

Kaplow, L. \& Shavell, S. (1996). Accuracy in the Assessment of Damages. The Journal of Law and Economics, 39(1), pp. 191-191.

Karapanou, V. \& Visscher, L.T. (2010). Towards a Better Assessment of Pain and Suffering Damages. Journal of European Tort Law, 1(1), pp. 48-74.

Kearney, J. (2012). Why China's 2010 Medical Malpractice Reform Fails to Reform Medical Malpractice. Emory International Law Review, 26(2), pp. 1039-1078.

Keeton, R.E. (1973). Compensation for Medical Accidents. University of Chicago Law Review, 121(3), pp. 590-617.

Keeton, R.E., Sargentich, L.D. \& Keating, G.C. (2004). Tort and Accident Law: Cases and Materials. 4th edn., Saint Paul: Thomson (West).

Kendall, K. (2001). Latent Medical Errors and Maine's Statute of Limitations 
for Medical Malpractice: A Discussion of the Issues. Maine Law Review, 53(2), pp. 589-626.

Kessler, D.P., Sage, W.M. \& Becker, D.J. (2005). Impact of Malpractice Reforms on the Supply of Physician Services. The Journal of American Medical Association, 293(21), pp. 2618-2625.

Kessler, D. \& McClellan, M. (1993). The Effects of Malpractice Pressure and Liability Reforms on Physicians' Perceptions of Medical Care. Law and Contemporary Problems, 60(1), pp. 81-106.

Kessler, D. \& McClellan, M. (1996). Do Doctors Practice Defensive Medicine?. Quarterly Journal of Economics, 111, pp. 353-390.

Kessler, D. \& McClellan, M. (2002a). How Liability Law Affects Medical Productivity. Journal of Health Economics, 21(6), pp. 931-55.

Kessler, D. \& McClellan, M. (2002b). Malpractice Law and Health Care Reform: Optimal Liability Policy in an Era of Managed Care. Journal of Public Economics, 84(2), pp. 175-197.

Khoury, L. (2006). Uncertain Causation in Medical Liability. Oxford \& Portland, Oregon: Hart Publishing.

Kim, B. (2007). The Impact of Malpractice Risk on the Use of Obstetrics Procedures. The Journal of Legal Studies, 36(S2), pp. S79-S119.

Kingston, M., Evans, S., Smith, B. \& Berry, J. (2007). Attitudes of Doctors and Nurses Towards Incident Reporting: A Qualitative Analysis. Medical Journal of Australia, 181(1), pp. 36-39.

Kleiner, M.M. (2000). Occupational Licensing. The Journal of Economic Perspectives, 14(4), pp. 189-202.

Klemme, H.C. (1976). The Enterprise Liability Theory of Torts. University of Colorado Law Review, 47(2), pp. 153-232.

Klick, J. \& Stratmann, T. (2003). Does Medical Malpractice Reforms Help States Retain Physicians and Does it Matter? Available at: <https://www.researchgate.net/publication/241095910_Does_Medical_Ma lpractice_Reform_Help_States_Retain_Physicians_and_Does_it_Matter> (accessed on 14 May 2016).

Klick, J. \& Stratmann, T. (2007). Medical Malpractice Reform and Physicians in High-Risk Specialties. Journal of Legal Studies, 36(2), pp. S121-S142.

Klingman, D., Localio, A.R., Sugarman, J., Wagner, J.L., Polishuk, P.T. \& Wolfe, L. (1996). Measuring Defensive Medicine Using Clinical Scenario Surveys. Journal of Health Politics, Policy and Law, 21(2), pp. 185-220.

Koch, B.A. (ed.) (2011). Medical Liability in Europe: A Comparison of Selected Jurisdictions (Tort and Insurance Law Vol. 29). Berllin/Boston: De Gruyter. 
Bibliography

Koch, B.A. (2013). Medical Malpractice in Austria. In: Oliphant, K. \& Wright, R.W. (eds.), Medical Malpractice and Compensation in Global Perspective (Tort and Insurance Law Vol. 32) (pp. 7-34).Berlin/Boston: De Gruyter.

Koch, B.A. \& Koziol, H. (2004). Comparative Report and Conclusions. In: Dute, J., Faure, M.G. \& Koziol, H. (eds.), No-Fault Compensation in the Health Care Sector (pp. 417-443). Wien/NewYork: Springer.

Kohn, L.T., Corrigan, J.M. \& Donaldson, M.S. (eds.) (2000). To Err Is Human: Building a Safer Health System. Washington, D.C.: National Academy Press.

Kong, D., Wu, X., Shi, F., Han, H., Li, X., Liu, Y. \& Xu, Y. (2016). Analysis of Administrative Punishments of Medical Institutions from 2010 to 2014 in Haidian District, Beijing. China Health Law, 24(2), pp. 41-45, 54.

Kong, X. (1994). Imperfect Joint and Several Liability. Peking University Law Journal, 1994(3), pp. 19-24.

Kornhauser, L.A. (1982). An Economic Analysis of the Choice between Enterprise and Personal Liability for Accidents. California Law Review, 70(6), pp. 1345-1392.

Kovacs, E., Schmidt, A.E., Szocska, G., Busse, R., Mckee, M. \& LegidoQuigley, H. (2014). Licensing Procedures and Registration of Medical Doctors in the European Union. Clinical Medicine, Journal of the Royal College of Physicians of London, 14(3), pp. 229-238.

Koziol, H. \& Zhu, Y. (2010). Background and Key Contents of the New Chinese Tort Liability Law. Journal of European Tort Law, 1(3), pp. 328361.

Kraakman, R.H. (2009). Vicarious and Corporate Civil Liability. In: Faure, M.G. (ed.), Tort law and economics (Encyclopedia of Law and Economics Vol. 1) (pp. 134-150). Cheltenham \& Northampton, MA: Edward Elgar.

Kunreuther, H., Hogarth, R. \& Meszaros, J. (1993). Insurer Ambiguity and Market Failure. Journal of Risk and Uncertainty, 7(1), pp. 71-87.

Kusserow, R.P., Handley, E.A. \& Yessian, M.R. (1987). An Overview of State Medical Discipline. The Journal of American Medical Association, 257(6), pp. 820-824.

Kysar, D.A., Mcgarity, T.O. \& Sokol, K. (2006). Medical Malpractice Myths and Realities: Why an Insurance Crisis Is Not a Lawsuit Crisis. Loyola of Los Angeles Law Review, 39, pp. 785-818.

Landrigan, C.P., Parry, G.J., Bones, C.B., Hackbarth, A.D., Goldmann, D.A. \& Sharek, P.J. (2010). Temporal Trends in Rates of Patient Harm Resulting from Medical Care. The New England Journal of Medicine, 363(22), pp. 2124-2134.

Landstingens Ömsesidiga Försäkringsbolag (2015). If You Are Injured in Healthcare. Available at: <http://lof.se/wp-content/uploads/1011_Om-duskadas-i-v\%C3\%A5rden_engelska.pdf> (accessed on 9 June 2016). 
Langfitt, F. (2013). In Violent Hospitals, China's Doctors Can Become Patients. Available at: <www.npr.org/sections/parallels/2013/11/06/242344329/in-violent-hospitals-chinas-doctors-can-become-patients > (accessed on 7 August 2016).

Law, S.A. \& Polan, S. (1978). Pain and Profit: The Politics of Malpractice. New York: Harper \& Row.

Lawton, R. \& Parker, D. (2002). Barriers to Incident Reporting in A Healthcare System. Quality and Safety in Health Care, 11(1), pp. 15-18.

Leape, L.L. (1994). Error in Medicine. The Journal of American Medical Association, 272(23), pp. 1851-1857.

Leape, L.L., Brennan, T.A., Laird, N., Lawthers, A.G., Localio, A.R., Barnes, B.A., Hebert, L., Newhouse, J.P., Weiler, P.C. \& Hiatt, H. (1991). The Nature of Adverse Events in Hospitalised Patients. Results of the Harvard Medical Practice Study II. The New England Journal of Medicine, 324(6), pp. 377-384.

Leape, L., Bates, D., Cullen, D., Cooper, J., Demonaco, H., Gallivan, T., Hallisey, R., Ives, J., Laird, N. \& Laffel, G. (1995). Systems Analysis of Adverse Drug Events. The Journal of American Medical Association, 274(1), pp. 33-43.

Leeuw, F.L. \& Schmeets, H. (2016). Empirical Legal Research. Cheltenham \& Northampton, MA: Edward Elgar Publishing.

Leffler, K.B. (1978). Physician Licensure: Competition and Monopoly in American Medicine. Journal of Law and Economics, 21(1), pp. 165-186.

Lei, J. (2003). Protective Medicine Different from Defensive Medicine. Health News, 29 July, 1.

Leland, H.E. (1979). Quacks, Lemons, and Licensing: A Theory of Minimum Quality Standards. Journal of Political Economy, 87(6), pp. 1328-1328.

Levine, A. \& Wolfe, S. (2009). Hospitals Drop the Ball on Physician Oversight: Failure of Hospitals to Discipline and Report Doctors Endangers Patients. Available at: <www.citizen.org/documents/18731.pdf> (accessed on 1 April 2016).

Levinson, D. (2010). Adverse Events in Hospital: National Incidence among Medicare Beneficiaries. US Department of Health and Human Services, Office of Inspector General, November 2010 (OEI-06-09-00090). Available at: <http://oig.hhs.gov/oei/reports/oei-06-09-00090.pdf> (accessed on 31 July 2016).

Lewis, R. (2003). The Impact of Social Security Law on Tort Law in England and Wales. In: Magnus, U. (ed.), The Impact of Social Security Law on Tort Law (pp. 56-73). Wien/NewYork: Springer.

Li, D. (2013). The Survey Report on the Medical Disputes in the Four Primary Hospitals in Dongguan. Evidence Science, 21(2), pp. 199-214. 
Bibliography

Li, G. (ed.) (2002). Understanding and Application of the Some Provisions of the Supreme People's Court on Evidence in Civil Procedures. Beijing: China Legal Publishing House.

Li, G. (2005). An Economic Analysis of Medical Malpractice Liability - the Hand Formula. Medicine and Society, 18(3), pp. 19-22.

Li, H. (1999). Rethinking of the Standard of Proof for Civil Proceedings. Studies in Law and Business, 5, pp. 19-21.

Li, H. (2014). Who Should Be Responsible for the Arrears of Medical Bills. Hospital Leadership Decision Reference, 20, pp. 5-8.

Li, H. \& Zhang, J. (2013). The Relation Between Efficiency and Fairness After China Laungched Its Reform And Opening-Up Policy. Inheritance \& Innovation, 4, pp. 72-73.

Li, H., Wu, X., Sun, T., Li, L., Zhao, X., Liu, X., Gao, L., Sun, Q., Zhang, Z. \& Fan, L. (2014). Claims, Liabilities, Injuries and Compensation Payments of Medical Malpractice Litigation Cases in China from 1998 to 2011. BMC Health Services Research, 14(1), pp. 1-9.

Li, Q. (2011). Beijing City Set up Hospital Administration Bureau to Administrate All Public Hospitals. The Beijing Times, 28 July 2011, A21.

$\mathrm{Li}$, R. (2015). The Discussion on the Status Quo and the Promotional Countermeasures of Medical Liability Insurance. Journal of Baotou Medical College, 31(3), pp. 118-120.

Li, R., Wu, X. \& Luo, D. (2007). The Reasons of Persistent Practising without A License and Countermeasures. Chinese Journal of Public Health Management, 23(5), pp. 438-439.

Li, T. (2014). Hospitals Attempted to Advocate "Surgical Mishap Insurance" But Failed. Available at: <http://news.xinhuanet.com/fortune/201403/22/c_126301235.htm> (accessed on 6 August 2016).

$\mathrm{Li}$, X. (2012). The Goals of the Three-Year Medical Reform Has Been Achieved, and the Total Coverage of the Basic Medical Insurance Has Exceeded 95\%. China Insurance News, 20 June 2012, 01.

Li, X. \& Song, J. (2012). Interpreting 'Serious Irresponsibility' in the Crime of Medical Accidents. People's Procuratorial Semimonthly, 2012(21), pp. 1419.

Li, X. \& Wang, F. (2008). A Legal-Economic Analysis of Responsibility Assignment of Medical Accidents. Journal of Shandong University (Philosophy and Social Sciences), 2008(4), pp. 129-134.

Li, Y. (1987). Medical Disputes. Tianjin: Nankai University Press.

Liang, H. (1998). Identification and Legal Handling of Medical Accidents. Beijing: Law Press.China.

Liang, W., Zheng, J. \& He, L. (2004). Social Causes of Defensive Medicine. Chinese Journal of Hospital Administration, 20(3), pp. 132-134. 
Liao, T., Yang, X., Ding, B., Song, Y., Huo, J. \& Yu, H. (2010). An Investigation and Reflection on the Issue of Medical Ascertainment in Medical Malpractice Cases. Journal of Hotan Teachers College, 29(2), pp. 2-3.

Liebman, B.L. (2013). Malpractice Mobs: Medical Dispute Resolution in China. Columbia Law Review, 113, pp. 181-264.

Lin, P. (2016). Empirical Study on Criminal Medical Liability in Taiwan. Biomedical Journal of Chang Gung University, 30(9), pp. 1-3.

Lin, P.J. (2009). Criminal Judgements to Medical Malpractice in Taiwan. Legal Medicine, 11(Suppl. 1), pp. S376-S378.

Lin, Z., Li, Y., Liu, H. \& Jiang, B. (2016). Exploration on Practice of Medical Liability Insurance in Nanjing. Medicine and Philosophy, 37(3A), pp. 6771.

Liu, C. (2014). The Research of Physician Regular Assessment. Unpublished Master thesis. Zhengzhou University.

Liu, C., Yang, X. \& Hu, Z. (2006). Research Progress and Inspiration of Defensive Medicine. Medicine \& Philosophy(B), 27(8), pp. 58-59.

Liu, D. (2013a). NGOs Emerge in China, But Face More Challenges. Available at: <http://news.trust.org//item/20131007121609-glxo2/> (accessed on 11 July 2016).

Liu, J. (2013b). Compensating Ecological Damage. Antwerp: Intersentia.

Liu, D., Fan, Z. \& Lu, G. (2003). Economic Essence Analysis of Medical Malpractice. Hospital Administration Journal of PLA, 10(4), pp. 378-379.

Liu, J., Hu, X., Shen, Z. \& Zhao, T. (2012). On the Medical Quality-Safety Incident Reporting System. Jiangsu Healthcare Administration, 23(01), pp. 9-10.

Liu, J. \& Li, M. (2002). Discussions on Law of Doctor-patient Relationship. Beijing: CITIC Publishing House.

Liu, L., Chen, T. \& Zhao, R. (2014). The Status Quo and Causes of Medical Disputes in China and Countermeasures. In: Wen, X. \& Pang, Z. (eds.), Annual Report on Reform of Medical and Health System in China (20142015) (pp. 209-243). Beijing: Social Sciences Academic Press (China).

Liu, R. \& Feng, Y. (2013). Survey and Reflections on Medical Disputes in Public Hospitals. Health Economics Research, 1, pp. 60-62.

Liu, X. (2012). Disputes over Medical Interest - Status Quo, Cases, and Countermeasures. Beijing: People's Publishing Security University China Press.

Liu, X. (2014). On Medical Injury Technical Authentication. Beijing: China University of Political Science and Law Press.

Liu, X., Wang, S. \& Zhang, Y. (2014). An Investigation into the Issuance of Court Decisions on Line. The Twenty-First Century, 19 March, 07. 
Bibliography

Liu, Y. (2014) .What Are the Relationship between Doctors and Hospitals?. Chinese Community Doctors, 2014(14), pp. 44-44.

Liu, Y., Liu, Y., Cheng, Y., He, Y., Guo, Q., Yue, D., Lin, J. \& Cheng, X. (2012a). Current Situation Survey of Medical Malpractice Identification Working in Shandong Province. Soft Science of Health, 26(9), pp. 826830.

Liu, Y., Lin, J., Liu, Y., Yue, D., Cheng, Y., Cheng, X., Guo, Q. \& He, Y. (2012b). Economic Operation Investigation of 9 Medical Malpractice Identification Institutions in Shandong Province. Soft Science of Health, 26(11), pp. 921-925.

Liu, Y. \& Song, W. (2013). A Report on the Cases of Disputes over Medical Damage Liability. Shandong Justice, 29(1), pp. 53-56.

Liu, Y. (2010). On the Civil Liability for Breach of the Duty of Mandatory Contracting. Available at: <http://hhhjfy.chinacourt.org/public/detail.php?id=21> (accessed on 12 August 2016).

Localio, A.R., Lawthers, A.G., Bengtson, J.M., Hebert, L.E., Weaver, S.L., Brennan, T.A. \& Landis, J.R. (1993). Relationship Between Malpractice Claims and Caesarian Delivery. The Journal of American Medical Association, 269(3), pp. 366-373.

Localio, A.R., Lawthers, A.G., Brennan, T.A., Laird, N.M., Hebert, L.E., Peterson, L.M., Newhouse, J.P., Weiler, P.C. \& Hiatt, H.H. (1991). Relation between Malpractice Claims and Adverse Events due to Negligence: Results of the Harvard Medical Practice Study III. The New England Journal of Medicine, 325(4), pp. 599-605.

Luft, H.S., Katz, P.P. \& Pinney, D.G. (1991). Risk Factors for Hospital Malpractice Exposure: Implications for Managers and Insurers. LaW and Contemporary Problems, 54(2), pp. 43-64.

Luo, Z. (2016). Why Will It Be Difficult to Enforce the Criminal Charge against Yi-Nao Mobs? Available at: <http://news.163.com/16/0531/02/BOC4GRBC00014Q4P.html> (accessed on 27 July 2016).

Lynott, J.D. \& Cullinane, R. (2010). Administrative Sanctions. Available at: <www.slideshare.net/DLynott/administrative-sanctions> (accessed: 6 April 2016).

Ma, H., Du, Y., Liu, Y. \& Cao, Z. (2015). A Survey of the Status Quo of Defensive Medicine in Hospitals in Hebei Province. Industrial \& Science Tribune, 14(12), pp. 98-100.

Magnus, U. (2000). Causation in German Tort Law. In: Spier, J. (ed.), Unification of Tort Law: Causation (Principles of European Tort Law Vol. 4) (pp. 63-73). The Hague, London \& Boston: Kluwer Law International. 
Magnus, U. (2001a). Comparative Report on the Law of Damages.In: Magnus, U. (ed.), Unification of Tort Law: Damages (Principles of European Tort Law Vol. 5) (pp. 185-217). The Hague, London \& Boston: Kluwer Law International.

Magnus, U. (2001b). Comparative Report on the Law of Damages. In: Magnus, U. (ed.), Unification of Tort Law: Damages (Principles of European Tort Law Vol. 5) (pp. 185-217). The Hague, London \& Boston: Kluwer Law International.

Magnus, U. (ed.) (2003a). The Impact of Social Security Law on Tort Law. Wien/NewYork: Springer.

Magnus, U. (2003b). Impact of Social Security Law on Tort Law Concerning Compensation of Personal Injuries - Comparative Report. In: Magnus, U. (ed.), The Impact of Social Security Law on Tort Law (Tort and Insurance Law Vol. 3) (pp. 266-306). Wien/NewYork: Springer.

Manner, P.A. (2007). Practising Defensive Medicine-Not Good for Patients or Physicians. American Academy of Orthopedic Surgeons, (JanuaryFebruary), pp. 1-7.

Marshall, J.M. (1976). Moral Hazard. The American Economic Review, 66(5), pp. 880-890.

Marx, R.S. (1927). Compulsory Automobile Insurance. University of Cincinnati Law Review, 1(4), pp. 445-455.

Matsa, D. (2005). Does Malpractice Liability Keep the Doctor A way. Evidence from Tort Reform Damage Caps, Xerox, Dept. of Economics, Massachusetts Institute of Technology.

Matsa, D.A. (2007). Does Malpractice Liability Keep the Doctor Away? Evidence from Tort Reform Damage Caps. The Journal of Legal Studies, 36(S2), pp. S143-S182.

McConnell, C.R., Brue, S.L. \& Flynn, S.M. (2009). Economics: Principles, Problems, and Policies. 18th edn. Boston et al.: McGraw-Hill \& Irwin.

Mcclanahan, S., Goodwin, S.T. \& Perlin, J.B. (2011). Chapter 1 A Formula for Errors: Good People + Bad Systems. In: Spath, P.L. (ed.), Error Reduction in Health Care: A Systems Approach to Improving Patient Safety (pp. 320). New Jersey et al: John Wiley \& Sons.

McClelland, D.C. (1973). Testing for Competence Rather Than Intelligence. American Psychologist, 28(1), pp. 1-1.

Mckie, J., Singer, P. \& Richardson, J. (1998). The Allocation of Health Care Resources: An Ethical Evaluation of the 'QALY' Approach. Aldershot et al:: Routledge. 
Bibliography

Mello, M.M. (2006). Medical Malpractice: Impact of the Crisis and Effect of State Tort Reforms. Robert Wood Johnson Foundation, Research Synthesis Report No. 10. Available at: <https://folio.iupui.edu/bitstream/handle/10244/526/no10_researchreport.pdf?sequence $=2>$ (accessed on 14 May 2016).

Mello, M.M. \& Studdert, D.M. (2006). The Medical Malpractice System. In: Sage, W.M. \& Kersh, R. (eds.), Medical Malpractice and the U.S. Health Care System (pp. 11-29). Cambridge et al: Cambridge University Press.

Mello, M.M. \& Studdert, D.M. (2008). Deconstructing Negligence: The Role of Individual and System Factors in Causing Medical Injuries. Georgetown Law Journal, 96(2), pp. 599-623.

Mello, M.M., Chandra, A., Gawande, A.A. \& Studdert, D.M. (2010). National Costs of the Medical Liability System. Health Affairs, 29(9), pp. 15691577.

Mello, M.M., Studdert, D.M., Desroches, C.M., Peugh, J., Zapert, K., Brennan, T.A. \& Sage, W. M. (2005). Effects of a Malpractice Crisis on Specialist Supply and Patient Access to Care. Annals of Surgery, 242(5), pp. 621-628.

Merry, A.F. (2007). 5. When Are Errors a Crime? - Lessons from New Zealand. In: Erin, C.A. \& Ost, S. (eds.), The Criminal Justice System and Health Care (pp. 67-97). Oxford/New York: Oxford University Press.

Michel, P., Quenon, J.L., de Sarasqueta, A.M. \& Scemama, O. (2004). Comparison of Three Methods for Estimating Rates of Adverse Events and Rates of Preventable Adverse Events in Acute Care Hospitals. BMJ (Clinical research ed.), (box 1), pp. 199-204.

Michigan OFIR (2009). Evaluation of the Michigan Medical Professional Liability Insurance Market, available at <https://www.michigan.gov/documents/dleg/Michigan_Medical_Liability_Ins_Rpt_297694_7.pdf> (accessed 28 June 2016).

Mikkonen, M. (2001). Nordic Model: Finnish Experiences of the Patient Injury Act in Practice. Medicine and Law, 20(3), pp. 347-354.

Mikkonen, M. (2004a). Compensation in the Finnish Health Care Sector. In: Dute, J., Faure, M.G. \& Koziol, H. (eds.). No-Fault Compensation in the Health Care Sector (Tort and Insurance Law Vol. 8) (pp. 186-209). Wien/NewYork: Springer.

Mikkonen, M. (2004b). Prevention of Patient Injuries: The Finnish Patient Insurance Scheme. Medicine and Law, 23(2), pp. 251-258.

Miller, J.C. (1985). The FTC and Voluntary Standards: Maximizing the Net Benefits of Self-Regulation. Cato Journal, 4(3), pp. 897-903.

Mills, D.H. (1978). Medical Insurance Feasibility Study: A Technical Summary. The Western Journal of Medicine, 4(128), pp. 360-365. 
Min, Z. \& Peng, T. (2013). Current Status and Legal Treatments of Medical Disputes in China. In: Beran, G.R. (ed.).], Legal and Forensic Medicine (pp. 1445-1457). Berlin, Heidelberg: Springer Berlin Heidelberg.

Missiouri DIFP (2014). 2013 Missouri Medical Professional Liability Insurance Report. Available at: <http://insurance.mo.gov/reports/medmal/documents/2013MissouriMedicalProfessionalLiabilityInsuranceR eport.pdf $>$ (accessed on 1 August 2016).

Mommsen, F. (1853). Beiträge zum Obligationenrecht: Abth. zur Lehre von dem Interesse, C.A. Schwetschke und Sohn (M. Bruhn).

Montesi, G. \& Lechi, A. (2009). Prevention of Medication Errors: Detection and Audit. British Journal of Clinical Pharmacology, 67(6), pp. 651-655.

Moore, M.J. \& Viscusi, W.K. (1988). The Quantity-Adjusted Value of Life. Economic Inquiry, 26(3), pp. 369-388.

Moran, M. (2002). The Health Professions in International Perspective. In: Allsop, J. \& Saks, M. (eds.), Regulating the Health Professions (pp. 19-30). London, Thousand Oaks \& New Delhi: SAGE Publications.

Munch, P. (1978). Causes of the Medical Malpractice Insurance Crisis: Risks and Regulation. In: Rottenberg, S. (ed.), The Economics of Medical Malpractice (pp. 125-154). Washington, D.C: American Enterprise Institute for Public Policy Research.

Murff, H.J., Patel, V.L., Hripcsak, G. \& Bates, D.W. (2003). Detecting Adverse Events for Patient Safety Research: A Review of Current Methodologies. Journal of Biomedical Informatics, 36(1-2), pp. 131-143.

Muris, T.J. \& Mcchesney, F.S. (1979). Advertising and the Price and Quality of Legal Services: The Case for Legal Clinics. American Bar Foundation Research Journal, 4(1), pp. 179-207.

Murthy, K., Grobman, W.A., Lee, T.A. \& Holl, J.L. (2007. Association between Rising Professional Liability Insurance Premiums and Primary Caesarian Delivery Rates. Obstetrics and Gynecology, 110(6), pp. 12641269.

Nanjing Gulou District Bureau of Statistics (2015). Statistics in 2014. Available at: <http://tjj.njgl.gov.cn/art/2015/5/13/art_5028_2238324.html> (accessed on 22 July 2016).

National Bureau of Statistics of China (ed.) (2010). China's 2010 Population Census Data. Beijing: China Statistics Press.

National Bureau of Statistics of China (ed.) (2015). China Statistical Yearbook 2015. Beijing: China Statistics Press.

National Bureau of Statistics of China (2016). Total Population by Year. Available at: <http://data.stats.gov.cn/easyquery.htm?cn=C01> (accessed on 17 June 2016). 
Bibliography

National Health and Family Planning Commission (2014). What We Do. Available at: <http://en.nhfpc.gov.cn/2014-05/07/c_46917.htm> (accessed on 22 June 2016).

National Health and Family Planning Commission (ed.) (2015). Yearbook of China Health and Family Planning Statistics (2015). Beijing: Beijing Union Medical University Press.

Neale, G., Woloshynowych, M. \& Vincent, C. (2001). Exploring the Causes of Adverse Events in NHS Hospital Practice. Journal of the Royal Society of Medicine, 94(7), pp. 322-330.

Nelson, P. (1970). Information and Consumer Behaviour. Journal of Political Economy, 78(2), pp. 311-329.

Norsk Pasientskadeerstatning (2014). About NPE. Available at: $<$ www.npe.no/en/About-NPE/> (accessed on 10 June 2016).

Nye, B.F. \& Hofflander, A.E. (1988). Experience Rating in Medical Professional Liability Insurance. The Journal of Risk and Insurance, 55(1), pp. 150-157.

Nye, D.J. \& Gifford, D.G. (1988). The Myth of the Liability Insurance Claims Explosion: An Empirical Rebuttal. 41 Vanderbilt Law Review, 41, pp. 909922.

O’Donoghue, T. \& Rabin, M. (2000). The Economics of Immediate Gratification. Journal of Behavioural Decision Making, 13(2), pp. 233-250.

OECD (2006). Medical Malpractice: Prevention, Insurance and Coverage Options. Paris et al:: OECD Publishing.

Ogburn, P.L., Julian, T.M., Brooker, D.C., Joseph, M.S., Butler, J.C., Williams, P.P., Anderson, M.L., Shepard, A.C., Ogburn, S.L. \& Preisler, W.C. (1988). Perinatal Medical Negligence Closed Claims from the St. Paul Company, 1980-1982. The Journal of Reproductive Medicine, 33(7), pp. 608-611.

Ogus, A. (2007). The Relationship Between Regulation and Tort Law: Goals and Strategies. In: Van Boom, W.H., Lukas, M. \& Kissling, C. (eds.), Tort and Regulatory Law (Tort and Insurance Law Vol. 19) (pp. 377-389). Wien/NewYork: Springer.

Oldertz, C. (1984). The Swedish Patient Insurance System - 8 Years of Experience. The Medico-Legal Journal, 52(1), pp. 43-59.

Oldertz, C. (1986). Security Insurance, Patient Insurance, and Pharmaceutical Insurance in Sweden. The American Journal of Comparative Law, 34(4), pp. 635-656.

Oliphant, K. (2007). Beyond Misadventure: Compensation for Medical Injuries in New Zealand. Medical Law Review, 15(3), pp. 357-391.

Oliphant, K. (2012). Uncertain Causes: The Chinese Tort Liability Law in Comparative Perspective. In: Chen, L. \& van Rhee, C.H.R. (eds.), Towards a Chinese Civil Code: Comparative and Historical Perspectives (pp. 395408). Leiden \& Boston: Martinus Nijhoff Publishers. 
Oliphant, K. (2013). Medical Malpractice and Compensation: Comparative Observations. In: Oliphant, K. \& Wright, R.W. (eds.), Medical Malpractice and Compensation in Global Perspective (Tort and Insurance Law Vol. 32) (pp. 513-574). Berlin/Boston: De Gruyter.

Oliphant, K. \& Wright, R.W. (eds.) (2013). Medical Malpractice and Compensation in Global Perspective (Tort and Insurance Law Vol 32). Berlin/Boston: De Gruyter.

Olsen, R.N. (1996). The Reform of Medical Malpractice Law: Historical Perspectives. The American Journal of Economics and Sociology, 55(3), pp. 257-275.

Olsen, R.N. (2000). Regulation of Medical Professions. In: Bouckaert, B. \& Geest, G.D. (eds.), The Regulation of Contracts (Encyclopedia of Law and Economics, Vol. III) (pp. 678-714). Cheltenham: Edward Elgar.

Ottenwess, D.M., Lamberti, M.A., Ottenwess, S.P. \& Dresevic, A.D. (2011). Medical Malpractice Tort Reform. Radiology Management, 33, pp. 30-35.

Paik, M., Black, B.S., Hyman, D.A., Sage, W.M. \& Silver, C.M. (2012). How Do the Elderly Fare in Medical Malpractice Litigation, Before and After Tort Reform? Evidence from Texas. American Law and Economics Review, 14(2), pp. 561-600.

Paik, M., Black, B. \& Hyman, D. (2013a). The Receding Tide of Medical Malpractice Litigation: Part 2-Effect of Damage Caps. Journal of Empirical Legal Studies, 10(4), pp. 639-669.

Paik, M., Black, B. \& Hyman, D. (2013b). The Receding Tide of Medical Malpractice Litigation: Part 1-National Trends. Journal of Empirical Legal Studies, 10(4), pp. 612-638.

Palmer, G. (1994). New Zealand's Accident Compensation Scheme: Twenty Years on. The University of Toronto Law Journal, 44(3), pp. 223-273.

Parkin, M. (2014). Microeconomics. Boston et al:: Pearson.

Patienterstatningen (2016). About The Danish Patient Compensation Association. Available at: <http://patienterstatningen.dk/en/Om-PEBL> (accessed on 10 June 2016).

Patientskadenämnden (2016). The Patient Claims Panel. Available at: <www.patientskadenamnden.se/system/in-english/> (accessed on 9 June 2016).

Pauly, M.V. \& Satterthwaite, M.A. (1981). The Pricing of Primary Care Physicians Services: A Test of the Role of Consumer Information. The Bell Journal of Economics, 12(2), pp. 488-506.

Pauly, M. (1968). The Economics of Moral Hazard: Comment. The American Economic Review, 58(3), pp. 531-537.

Peeples, R., Harris, C.T. \& Metzloff, T.B. (2002). The Process of Managing Medical Malpractice Cases: The Role of Standard of Care. Wake Forest Law Review, 37(3), pp. 877-902. 
Bibliography

Peltzman, S. (1976). Toward a More General Theory of Regulation. The Journal of Law \& Economics, 19(2), pp. 211-240.

Peng, K. \& Huang, Y. (2015). Survey of the Distribution and Causes of Defensive Medicine of Physicians in One District of Shenzhen City. Military Medical Journal of South China, 29(5), pp. 385-387.

Peters, P.G. (2000) 'The Quiet Demise of Deference to Custom: Malpractice Law at the Millennium', Washington and Lee Law Review, 57(1), pp. 163205.

Philipsen, N.J. (2003). Regulation of and by Pharmacists in the Netherlands and Belgium: An Economic Approach. Antwerp \& Groningen: Intersentia.

Philipsen, N.J. (2007). The Law and Economics of Professional Regulation: What Does the Theory Teach China?. In: Eger, T., Faure, M. \& Zhang, N. (eds.), Economic Analysis of Law in China (pp. 112-150). Cheltenham \& Northampton, MA: Edward Elgar.

Pocincki, L.S., Dogger, S.J. \& Schwartz, B.P. (1973). The Incidence of Iatrogenic Injuries. In: US Department of Health, Education and Welfare (ed.), Appendix: Report of the Secretary's Commission on Medical Malpractice (pp. 50-64). Washington, D.C.: DHEW Publication.

Polinsky, A.M. \& Che, Y. (1991). Decoupling Liability: Optimal Incentives for Care and Litigation. RAND Journal of Economics, 22(4), pp. 562-570.

Polinsky, A.M. \& Shavell, S. (1984). The Optimal Use of Fines and Imprisonment. Journal of Public Economics, 89(4-5), pp. 823-835.

Polinsky, M. \& Shavell, S. (1994). Should Liability Be Based on the Harm to the Victim or the Gain to the Injurer?. Journal of Law, Economics \& Organisation, 10(2), pp. 427-437.

Polinsky, A.M. \& Shavell, S. (2009). Public Enforcement of Law. In: Garoupa, N. (ed.), Criminal Law and Economics (Encyclopedia of Law and Economics Vol. 3) (pp. 1-59). Cheltenham et al:: Edward Elgar.

Pollack, L.M. (1987). Medical Maloccurrence Insurance: A First Party NoFault Insurance Proposal for Resolving the Medical Malpractice Insurance Controversy. University of Michigan Journal of Law Reform, 20(4), pp. 1245-1292.

Pollack, L.M. (1988). Medical Maloccurrence Insurance (MMI): A First-Party, No-Fault Insurance Proposal for Resolving the Medical Malpractice Controversy. Tort \& Insurance Law Journal, 23(3), pp. 552-588.

Porat, A. (2007). Offsetting Risks. Michigan Law Review, 106(2), pp. 243-276.

Posner, E.A. \& Sunstein, C.R. (2005). Dollars and Death. University of Chicago Law Review, 72(2), pp. 537-598.

Posner, R.A. (1970). Book Review: Reviewing Guido Calabresi, The Cost of Accidents: A Legal and Economic Analysis (1970). The University of Chicago Law Review, 37, pp. 636-648. 
Posner, R.A. (1974). Theories of Economic Regulation. The Bell Journal of Economics and Management Science, 5(2), pp. 335-358.

Posner, R.A. (2005). Guido Calabresi's the Costs of Accidents: A Reassessment. Maryland Law Review, 64, pp. 12-23.

Posner, R.A. (2011). Economic Analysis of Law. 8th edn. Austin et al.: Wolters Kluwer (Law \& Business).

Posner, R.A. (2014). Economic Analysis of Law. Available at: <www.amazon.com/Economic-Analysis-Eighth-Edition-Casebooksebook/dp/B00AR6A7NM> (downloaded on 23 March 2016).

Potilasvahinkolautakunta (2011). Patient Injuries Board. Available at: $<$ www.finanssivalvonta.fi/en/Financial_customer/Customer_protection/As sistance/Appeals/Patient_Injuries_Board/Pages/Default.aspx $>$ (accessed on 10 June 2016).

Potilasvakuutuskeskus (2015). Patient Insurance Centre. Available at: <www.pvk.fi/en/patient-insurance-centre/> (accessed on 10 June 2016).

Price, P.B., Taylor, C.W., Richards, J.M. \& Jacobsen, T.L. (1964). Measurement of Physician Performance. Journal of Medical Education, 39(2), pp. 203-210.

Priest, G.L. (1987). The Current Insurance Crisis and Modern Tort Law. The Yale Law Journal, 96(7), pp. 1521-1590.

Project (1971). The Medical Malpractice Threat: A Study of Defensive Medicine. Duke Law Journal, 1971, pp. 939-993.

Qiang, M. (2010). On Sharing Liability for Compensation for Medical Injury. Beijing: Intellectual Property Publishing House.

Qianzhan Net (2015). Jiangsu Province: The Average Per capita Consumption Expenditure. Available at: <http://d.qianzhan.com/xdata/buystep1> (accessed on 26 July 2016).

Quick, O. (2006). Prosecuting 'Gross' Medical Negligence: Manslaughter, Discretion, and the Crown Prosecution Service. Journal of Law and Society, 33(3), pp. 421-450.

Quick, O. (2007). 3. Medical Manslaughter: The Rise (and Replacement) of a Contested Crime?. In: Erin, C.A. \& Ost, S. (eds.), The Criminal Justice System and Health Care (pp. 29-47). Oxford/New York: Oxford University Press.

Rauhala, E. (2015). Chinese Doctors to Disgruntled Patients: Please Stop Stabbing Us. The Washington Post, 22 July.

Reason, J. (1995). Understanding Adverse Events: Human Factors. Quality in Health Care, 4(2), pp. 80-89.

Reason, J. (2004). Beyond the Organisational Accident: The Need for "Error Wisdom" on the Frontline. Quality and Safety in Health Care, 13(suppl_2), pp. ii28-ii33.

Rejda, G.E. \& Mcnamara, M.J. (2011). Principles of Risk Management and 
Bibliography

Insurance. Boston et al.: Pearson.

Ren, D. (2015). The Success Rate for Medical Dispute People's Mediation Is 90\%. Available at: <http://news.163.com/15/1123/03/B9300JVQ00014Q4P.html> (accessed on 27 July 2016).

Ren, L. \& Bai, J. (2011). From Hospital Violator and Defensive-Medicine to Explore Harmonious Doctor-Patient Relationship. Chinese Journal of Women and Children Health, 2(5), pp. 226-228.

Ren, R. \& Wang, M. (2004). On the Legal System of Medical Malpractice Management in China and Its Impact on Medical Ethics. International Journal of the Computer, the Internet and Management, 12(3), pp. 73-80.

Ren, W., Shuai, C., Sun, X., Xiao, H. \& Gao, H. (2016). Yi-Nao Incidents Doing Harm to the Doctor-Patient Relationship, Why the Criminalization Does Not Work? Available at: <http://china.huanqiu.com/hot/201607/9128827.html > (accessed on 27 July 2016).

Reynolds, R.A., Rizzo, J.A. \& Gonzalez, M.L. (1987). The Cost of Medical Professional Liability. The Journal of the American Association, 257(20), pp. 2776-2781.

Right Diagnosis (2016). Underlying Condition Misdiagnosis. Available at: <www.rightdiagnosis.com/intro/underly.htm> (accessed on 21 July 2016).

Robertson, G.B. (1984). Informed Consent in Canada: An Empirical Study. Osgoode Hall Law Journal, 22(1), pp. 139-161.

Robertson, G.B. (1991). Informed Consent Ten Years Later: The Impact of Reibl v. Hughes. The Canadian Bar Review, 70(3), pp. 423-447.

Robertson, G.B. (2003). Informed Consent 20 Years Later. Health Law Journal, 60, pp. 153-160.

Robinson, G.O. (1986). Rethinking the Allocation of Medical Malpractice Risks Between Patients and Providers. Law and Contemporary Problems, 49(2), pp. 173-199.

Rodriguez-Vazquez, V. (2006. Doctors in Spanish Criminal Law: Medical Criminal Responsibility for Deaths and Injuries Caused by Negligence in Present-Day Spain. Medicine and Law, 25(3), pp. 411-426.

Rodwin, M.A., Silverman, J. \& Merfeld, D. (2015). Why the Medical Malpractice Crisis Persists Even When Malpractice Insurance Premiums Fall. Health Matrix, 25, pp. 163-226.

Rogers, W.V.H. (2001a). Comparative Report of a Project Carried Out by the European Centre for Tort and Insurance Law. In: Rogers, W.V.H. (ed.), Damages for Non-Pecuniary Loss in a Comparative Perspective (Tort and Insurance Law Vol. 2) (pp. 245-296). Wien/NewYork: Springer.

Rogers, W.V.H. (2001b). Damages for Non-Pecuniary Loss in a Comparative Perspective (Tort and Insurance Law Vol. 2). Wien/NewYork: Springer.

Rolph, J.E. (1981a). Some Statistical Evidence on Merit Rating in Medical Malpractice Insurance. The Journal of Risk and Insurance, 48(2), pp. 247- 
260.

Rolph, J.E. (1981b). Some Statistical Evidence on Merit Rating in Medical Malpractice Insurance. The Journal of Risk and Insurance, 48(2), pp. 247260.

Rolph, J.E. (1991). Merit Rating for Physicians' Malpractice Premiums: Only a Modest Deterrent. Law and Contemporary Problems, 54(2), pp. 65-86.

Rose-Ackerman, S. (1992. Rethinking the Progressive Agenda: The Reform of the American Regulatory State. Available at: <www.amazon.de/Rethinking-Progressive-Agenda-English-Rose-Ackerman-ebook/dp/B003DYGNSS/ref=sr_1_1_twi_kin_2?ie=UTF8\&qid=1459116909\&sr=8$1 \&$ keywords=Rethinking+the+Progressive+Agenda\%3A+The+Reform + of + the+American+Regulatory+State $>$ (downloaded on 27 March 2016).

Rose, C. (2011. The Good, The Bad, and The Ugly: A Health Care Comparison of Three Nations. Available at: <www.amazon.com/The-Good-Bad-UglyComparison-ebook/dp/B006C9N84I> (accessed on 5 September 2015).

Rosenblatt, R.A. \& Hurst, A. (1989). An Analysis of Closed Obstetric Malpractice Claims. Obstetrics \& Gynecology, 74(5), pp. 710-714.

Rosenblatt, R.A. \& Wright, C.L. (1987). Rising Malpractice Premiums and Obstetric Practice Patterns. Western Journal of Medicine, 146(2), pp. 246248.

Rothschild, M. \& Stiglitz, J.E. (1976). Equilibrium in Competitive Insurance Markets: An Essay on the Economics of Imperfect Information. The Quarterly Journal of Economics, 90(4), pp. 630-49.

Rowe, A. \& García-Barbero, M. (2005). Regulation and Licensing of Physicians in the WHO European Region. Copenhagen: WHO Regional Office for Europe.

Royal Commission of Inquiry (1967). Compensation for Personal Injury in New Zealand: Report of the Royal Commission of Inquiry. Wellington: Government Printer.

Rubin, R.J. \& Mendelson, D.N. (1993). Defensive Medicine and Medical Liability Reform: Estimating Costs and Potential Savings. Fairfax,VA: Lewin-VHI.

Rubio, M.P.G. \& Garcia, B.T. (2010). The Development of Medical Liability in Spain. In: Hondius, E. (ed.), The Development of Medical Liability (pp. 160-187). Cambridge et al:: Cambridge University Press.

Rui, L., Shen, S., Xiao, S. \& Wei, J. (2006). Comparative Analysis of National Medical Liability Insurance Model. Chinese Hospitals, 10(1), pp. 35-37. 
Bibliography

Runciman, W.B., Webb, R.K., Helps, S.C., Thomas, E.J., Sexton, E.J., Studdert, D.M. \& Brennan, T.A. (2000). A Comparison of Iatrogenic Injury Studies in Australia and the USA II: Reviewer Behaviour and Quality of Care. International Journal for Quality in Health Care, 12(5), pp. 379-388.

Sage, W.M. (1997). Enterprise Liability and the Emerging Managed Health Care System. Law and Contemporary Problems, 60(2), pp. 159-210.

Sage, W.M., Hastings, K.E. \& Berenson, R.A. (1994). Enterprise Liability for Medical Malpractice and Health Care Quality Improvement. American Journal of Law and Medicine, 20, pp. 1-28.

Saine, C.D. (1997). Preserving the Collateral Source Rule: Modern Theories or Tort Law and a Proposal for Practical Application. Case Western Reserve Law Review, 47(3), pp. 1075-1120.

Saks, M.J. (1992). Do We Really Know Anything about the Behaviour of the Tort Litigation System. And Why Not?. University of Pennsylvania Law Review, 140(2), pp. 1147-1292.

Salvi, P.A. (2006). Why Medical Malpractice Caps Are Wrong. Northern Illinois University Law Review, 26(3), pp. 553-562.

Sayre, F.B. (1933). Public Welfare Offences. Columbia Law Review, 33(1), pp. 55-88.

Schäfer, H.B. \& Ott, C. (2012). Lehrbuch der ökonomischen Analyse des Zivilrechts. 5th edn. Springer Berlin Heidelberg.

Schäfer, H. \& Müller-Langer, F. (2009). Strict Liability versus Negligence. In: Faure, M. (ed.), Tort law and Economics (Encyclopedia of Law and Economics Vol. 1) (pp. 3-45). Cheltenham \& Northampton, MA: Edward Elgar.

Schäfer, H. \& Ott, C. (2004. The Economic Analysis of Civil Law. Cheltenham \& Northampton, MA: Edward Elgar.

Schap, D. \& Feely, A. (2008). The Collateral Source Rule: Statutory Reform and Special Interests. Cato Journal, 28(1), pp. 83-100.

Schimmel, E.M. (1964). The Hazards of Hospitalisation. Annals of Internal Medicine, 60(1), pp. 100-110.

Schiøler, T., Lipczak, H., Pedersen, B.L., Mogensen, T.S., Bech, K.B., Stockmarr, A., Svenning, A.R. \& Frølich, A. (2001). Danish Adverse Event Study: Incidence of Adverse Events in Hospitals. A Retrospective Study of Medical Records. Ugeskrift for laeger, 163(39), pp. 5370-5378.

Schlag, P.J. (1985). Rules and Standards. UCLA Law Review, 33(2), pp. 379430.

Schnakenberg, E. (2015). What Is the Meaning of Underlying Medical Condition? Available at: <www.answers.com/Q/What_is_the_meaning_of_underlying_medical_condition> (accessed on 21 July 2016). 
Schuck, P.H. (2008). Tort Reform, Kiwi-Style. Yale Law \& Policy Review, 27(1), pp. 187-203.

Schwartz, A. \& Wilde, L.L. (1983). Imperfect Information in Markets for Contract Terms: The Examples of Warranties and Security Interests. Virginia Law Review, 69(8), pp. 1387-1485.

Schwartz, G.T. (1990). The Ethics and the Economics of Tort Liability Insurance. Cornell Law Review, 75, pp. 313-365.

Schwartz, G.T. (1997). Mixed Theories of Tort Law: Affirming Both Deterrence and Corrective Justice. Texas Law Review, 75(7), pp. 18011834.

Schwartz, W.B. \& Komesar, N.K. (1978). Doctors, Damages and Deterrence An Economic View of Medical Malpractice. The New England Journal of Medicine, 298(23), pp. 1282-1289.

Schwenk, E.H. (1943). The Administrative Crime, Its Creation and Punishment by Administrative Agencies. Michigan Law Review, 42(1), pp. 51-86.

Selden, W.K. (1970). Licensing Boards Are Archaic. The American Journal of Nursing, 70(1), pp. 124-126.

Selznick, P. (1985). Focusing Organisational Research on Regulation. In: Noll, R.G. (ed.), Regulatory Policy and the Social Sciences (pp. 363-367). Berkeley/Los Angeles/London: University of California Press.

Shanley, M.G. \& Peterson, M.A. (1987). Posttrial Adjustments to Jury Awards. RAND: The Institute for Civil Justice, R-3511-ICJ. Available at: <www.rand.org/content/dam/rand/pubs/reports/2007/R3511.pd> (accessed on 1 August 2016).

Shao, Y. (2013). Analysis of the Location of Burden of Proof in Medical Malpractice Lawsuits. Journal of Heilongjiang Administrative Cadre Institute of Politics and Law, 2, pp. 104-106.

Shapiro, C. (1986). Investment, Moral Hazard, and Occupational Licensing. The Review of Economic Studies, 53(5), pp. 843-862.

Shavell, S. (1978). Theoretical Issues in Medical Malpractice. In: Rottenberg, S. (ed.), The Economics of Medical Malpractice (pp. 35-64). Washington, D.C: American Enterprise Institute for Public Policy Research.

Shavell, S. (1979). On Moral Hazard and Insurance. The Quarterly Journal of Economics, 93(4), pp. 541-562.

Shavell, S. (1980). Strict Liability versus Negligence. The Journal of Legal Studies, 9(1), pp. 1-25.

Shavell, S. (1982). On Liability and Insurance. The Bell Journal of Economics, 13(1), pp. 120-132.

Shavell, S. (1984a). Liability for Harm versus Regulation of Safety. The Journal of Legal Studies, 13(2), pp. 357-374. 
Bibliography

Shavell, S. (1984b). A Model of the Optimal Use of Liability and Safety Regulation. RAND Journal of Economics, 15(2), pp. 271-280.

Shavell, S. (1985a). Uncertainty over Causation and the Determination of Civil Liability. The Journal of Law and Economics, 28(3), pp. 587-609.

Shavell, S. (1985b). Criminal Law and the Optimal Use of Non-Monetary Sanctions as A Deterrent. Columbia Law Review, 85(6), pp. 1232-1262.

Shavell, S. (1986). The Judgement Proof Problem. International Review of Law and Economics, 6(1), pp. 45-58.

Shavell, S. (1987). Economic Analysis of Accident Law. Cambridge, MA \& London: Harvard University Press.

Shavell, S. (2004). Foundations of Economic Analysis of Law. Cambridge, MA \& London: The Belknap Press of Harvard University Press.

Shavell, S. (2013). A Fundamental Enforcement Cost Advantage of the Negligence Rule over Regulation. The Journal of Legal Studies, 42(2), pp. 275-302.

Shen, G. (2016). Regulation of Cross-Border Establishment in China and the EU: A Comparative Law and Economics Approach. Antwerp: Intersentia.

Shen, G. (2005). The Application of the Principle of Equality of Arms to Medical Malpractice Lawsuits. The Taiwan Law Review, 127, pp. 28-49.

Shen, L. (2013). Changes in Administrative Districts in Nanjing City. Available at: <http://news.xinhuanet.com/politics/2013-02/21/c_124370358.htm> (accessed on 22 July 2016).

Shenzhen HFPC (2013). Yearbook of Shenzhen Health and Family Planning Statistics (2012). Available at: <www.szhfpc.gov.cn/xxgk/tjsj/zxtjxx/201310/t20131015_2222897.htm> (accessed on 24 June 2016).

Sher, N. (2007). New Differences Between Negligence and Strict Liability and Their Implications on Medical Malpractice Reform. Southern California Interdisciplinary Law Journal, 16, pp. 335-377.

Shi, X. \& Yan, W. (2016). Clarification and Reconstruction: The Chinese Approach to the Standard of Proof in Civil Cases. The 27th Academic Seminar of Chinese Courts. Beijing, China.

Shreve, J., Gray, J.V.D.B., Rustagi, M.H.K. \& Ziemkiewicz, E. (2010). The Economic Measurement of Medical Errors. Society of Actuaries' Health Section, Available at: <https://www.soa.org/files/research/projects/research-econ-measurement.pdf> (accessed on 1 August 2016).

Shu, G. (2008). Empirical Analysis on the Application of Administrative Mediation in Present Medical Disputes - with A Certain City in Anhui Province As An Example. Journal of Anhui University (Philosophy \& Social Sciences), 32(6), pp. 41-44.

Shu, J. (1998). Application of Medical Action and Principle of Fair Obligation. The Journal of Law \& Medicine, 5(2), pp. 71-75. 
$\mathrm{Si}, \mathrm{A}$. (1985). Some Comments on Reforming the Current Labour Insurance System. China Labour, 1985(8), pp. 22-23.

Siems, M. (2014). Comparative Law. Cambridge et al: Cambridge University Press.

Signorili, I. (2007). I Am a Professional Hospital Trouble Maker. Available at: $<\mathrm{http} / / /$ bbs.tianya.cn/post-free-902082-1.shtml> (accessed on 27 July 2006).

Skegg, P. (2004). Compensation in the New Zealand Health Care Sector. In: Dute, J., Faure, M.G. \& Koziol, H. (eds.), No-Fault Compensation in the Health Care Sector (Tort and Insurance Law Vol. 8) (pp. 298-333). Wien/NewYork: Springer.

Skogh, G. (1982). Public Insurance and Accident Prevention. International Review of Law and Economics, 2(1), pp. 67-80.

Skogh, G. (1989a). The Transactions Cost Theory of Insurance: Contracting Impediments and Costs. The Journal of Risk and Insurance, 56(4), pp. 726732.

Skogh, G. (1989b). The Combination of Private and Public Regulation of Safety. In: Faure, M. \& Van den Bergh, R. (eds.), Essays in Law and Economics Corporations, Accident Prevention and Compensation for Losses (pp. 87-102). Antwerp-Apeldoorn: MAKLU.

Sloan, F.A. (1985). State Responses to the Malpractice Insurance "Crisis" of the 1970s: An Empirical Assessment. Journal of Health Politics, Policy and Law, 9(4), pp. 629-646.

Sloan, F.A. (1990). Experience Rating: Does It Make Sense for Medical Malpractice Insurance?. The American Economic Review, 80(2), pp. 128133.

Sloan, F.A. \& Chepke, L.M. (2008). Medical Malpractice. Cambridge, MA \& London: The MIT Press.

Sloan, F.A. \& Shadle, J.H. (2009). Is There Empirical Evidence for "Defensive Medicine"? A Reassessment. Journal of Health Economics, 28(2), pp. 481491.

Sloan, F.A., Bovbjerg, R.R. \& Githens, P.B. (1991). Insuring Medical Malpractice. New York \& Oxford: Oxford University Press.

Sloan, F.A., Entman, S.S., Reilly, B.A., Glass, C.A., Hickson, G.B. \& Zhang, H.

H. (1997). Tort Liability and Obstetricians' Care Levels. International Review of Law and Economics, 17(2), pp. 245-260.

Sloan, F.A., Viscusi, W.K., Chesson, H.W., Conover, C.J. \& WhettenGoldstein, K. (1998). Alternative Approaches to Valuing Intangible Health Losses: The Evidence for Multiple Sclerosis. Journal of Health Economics, 17(4), pp. 475-497. 
Bibliography

Sloan, F.A., Whetten-Goldstein, K., Githens, P.B. \& Entman, S.S. (1995). Effects of the Threat of Medical Malpractice Litigation and Other Factors on Birth Outcomes. Medical Care, 33(7), pp. 700-714.

Smith, V.L. \& Walker, J.M. (1993). Rewards, Experience and Decision Costs in First Price Auctions. Economic Inquiry, 31(2), pp. 237-244.

Smith-Bindman, R., Mcculloch, C.E., Ding, A., Ding, A., Quale, C. \& Chu, P. W. (2011). Diagnostic Imaging Rates for Head Injury in the ED and States' Medical Malpractice Tort Reforms. The American Journal of Emergency Medicine, 29(6), pp. 656-64.

Sohu News (2010). Bad Law Inducing Drivers to Kill Pedestrians. Available at: <http://news.sohu.com/s2010/dianji515/> (accessed on 18 July 2016).

Sommella, L., de Waure, C., Ferriero, A., Biasco, A., Mainelli, M., Pinnarelli, L., Ricciardi, W. \& Damiani, G. (2014). The Incidence of Adverse Events in an Italian Acute Care Hospital: Findings of A Two-Stage Method in A Retrospective Cohort Study. BMC Health Services Research, 14(1), pp. 358-365.

Song, X. (2011). Research of Yueyang Medical Disputes. Unpublished Master thesis. Hunan University.

Soop, M., Fryksmark, U., Köster, M. \& Haglund, B. (2009). The Incidence of Adverse Events in Swedish Hospitals: A Retrospective Medical Record Review Study. International Journal for Quality in Health Care: Journal of the International Society for Quality in Health Care/ISQua, 21(4), pp. 28591.

Sousa, P., Uva, A., Serranheira, F., Nunes, C. \& Leite, E.S. (2014). Estimating the Incidence of Adverse Events in Portuguese Hospitals: A Contribution to Improving Quality and Patient Safety. BMC Health Services Research, 14(1), pp. 311-316.

South China Metropolis Daily (2006). Doctors Claiming a Hongbao Before A Surgery, Saying Refusal to Pay Will Lead to More Accidents. South China Metropolis Daily, 16 October.

Southwick, L. \& Young, G.J. (1992). Lawyers and Medical Torts: Medical Malpractice Litigation as a Residual Option. Applied Economics, 24(9), pp. 989-998.

Spence, M. (1977). Consumer Misperceptions, Product Failure and Producer Liability. The Review of Economic Studies, 44(3), pp. 561-572.

Spence, M. \& Zeckhauser, R. (1971). Insurance, Information, and Individual Action. The American Economic Review, 61(2), pp. 380-387.

Starr, D.S. (1989). The No-Fault Alternative to Medical Malpractice Litigation: Compensation, Deterrence, and Viability Aspects of a Patient Compensation Scheme. Texas Tech Law Review, 20(3), pp. 803-840. 
Stauch, M. (2008). The Law of Medical Negligence in England and Germany: A Comparative Analysis. Oxford \& Portland, Oregon: Hart Publishing.

Stauch, M.S. (2013). Medical Malpractice and Compensation in Germany. In: Oliphant, K. \& Wright, R.W. (eds.), Medical Malpractice and Compensation in Global Perspective (Tort and Insurance Law Vol. 32) (pp. 179-210). Berlin/Boston: De Gruyter.

Steel, K., Gertman, P.M., Crescenzi, C. \& Anderson, J. (1981). Iatrogenic Illness on a General Medical Service at a University Hospital. The New England Journal of Medicine, 304(11), pp. 638-642.

Stevenson, A. (2010). Oxford Dictionary of English. 3rd edn. Available at: <www.oxfordreference.com/view/10.1093/acref/9780199571123.001.0001/ acref-9780199571123> (downloaded on 21 July 2016).

Steves, M.F. (1976). A Proposal to Improve the Cost to Benefit Relationships in the Medical Professional Liability Insurance System. Duke Law Journal, 6, pp. 1305-1333.

Stigler, G.J. (1971). The Theory of Economic Regulation. The Bell Journal of Economics and Management Science, 2(1), pp. 3-21.

Studdert, D.M., Brennan, T.A. \& Thomas, E.J. (2000). Beyond Dead Reckoning: Measures of Medical Injury Burden, Malpractice Litigation, and Alternative Compensation Models from Utah and Colorado. Indiana Law Review, 33(4), pp. 1643-1686.

Studdert, D.M., Mello, M.M., Gawande, A.A. \& Gandhi, T.K. (2006). Claims, Errors, and Compensation Payments in Medical Malpractice Litigation. The New England Journal of Medicine, 354(19), pp. 2024-2033.

Studdert, D.M., Mello, M.M., Sage, W.M., Desroches, C.M., Peugh, J., Zapert, K. \& Brennan, T.A. (2005). Defensive Medicine Among High-Risk Specialist Physicians in a Volatile Malpractice Environment. The Journal of American Medical Association, 293(21), pp. 2609-2617.

Sudworth, J. (2014). China Sees Wave of Violence against Hospital Staff. Available at: <www.bbc.com/news/world-asia-china-26364133> (accessed on 7 August 2016).

Suk, H. (2007). The Standard for Determining Medical Negligence. In: Liang, H. (ed.), Civil and Commercial Law Review (Vol. 37) (pp. 261-284). Beijing: Law Press.China.

Sun, D. (2011). Looking for A New Tort Theory with More Explanatory Power - Corrective Justice and Law and Economics. Contemporary Law Review, 2, pp. 77-83.

Sun, T., Li, G., Fan, L., Li, L., Gao, L., Liu, X. \& Zhang, Z. (2014. An Analysis of the Type Distribution of Medical Injury Compensation and the Tendency in the Awarding of Damages in China. International Symposium on Health Law and Bioethics. Beijing, China. 
Sun, Y. (2016) 'The Chinese Civil Code Is Ready to Come Out', People's Daily (Overseas Edition), 28 June, 04.

Sunstein, C.R. (2004). Lives, Life-Years, and Willingness to Pay. Colorectal Disease, 104(2), pp. 205-252.

Sunstein, C.R. \& Thaler, R.H. (2003. Libertarian Paternalism Is Not an Oxymoron. The University of Chicago Law Review, 70(4), pp. 1159-1202.

Suszek, A. (2016). Practising Medicine Without a License: Criminal \& Civil Liability. Available at: <www.alllaw.com/articles/nolo/medicalmalpractice/practising-without-license-criminal-civil-liability.html> (accessed on 27 March 2016).

Svorny, S. (2000). Licensing, Market Entry Regulation. In: Bouckaert, B. \& Geest, G.D. (eds.), Regulation of Contracts (Encyclopedia of Law and Economics, Vol. III) (pp. 296-328). Cheltenham: Edward Elgar.

Swain, W. (2010). The Development of Medical Liability in England and Wales. In: Hondius, E. (ed.), The Development of Medical Liability (pp. 27-53). Cambridge et al.: Cambridge University Press.

Sykes, A.O. (1981). An Efficiency Analysis of Vicarious Liability under the Law of Agency. The Yale Law Journal, 91(1), pp. 168-206.

Sykes, A.O. (1984). The Economics of Vicarious Liability. The Yale Law Journal, 93(7), pp. 1231-1280.

Talley, E.L. (2013). Law, Economics, and the Burden(s) of Proof. In: Arlen, J. (ed.), Research Handbook on the Economics of Torts (pp. 305-329). Cheltenham \& Northampton: Edward Elgar.

Tan, H. \& Yang, J. (2009). Fault Liability from the Perspective of Corrective Justice. Social Scientist, 2009(2), pp. 88-90.

Tan, X. (2007). Study on the Objective Requisites of Crime of Medical Malpractice. The Journal of Law \& Medicine, 14(2), pp. 122-126.

Tan, X. (2008). On Medical Liability Insurance. Shanghai: Shanghai University of Finance and Economics Press.

Tan, Y. (2011). Cause Analysis and Countermeasures of Defensive Medicine. Chinese Medical Ethics, 24(2), pp. 160-171.

Tang, X., Duan, H., Lv, X., Shi, J. \& Xiao, W. (2012). A Study on Judicial Cognizance of Medical Negligence: Evidence from 243 Civil Trial of Lawsuit for Medical Damage Compensation. Chinese Journal of Health Policy, 5(5), pp. 62-65.

Taragin, M.I., Willett, L.R., Wilczek, A.P., Trout, R. \& Carson, J.L. (1992). The Influence of Standard of Care and Severity of Injury on the Resolution of Medical Malpractice Claims. Annals of Internal Medicine, 117(9), pp. 780-784.

Taylor, R.B. (2015). Errors, Uncertainty, and Ethical Issues. In: Taylor, B.R. (ed.), On the Shoulders of Medicine's Giants: What Today's Clinicians Can Learn from Yesterday's Wisdom (pp. 192-211). New York, NY: Springer. 
Taylor, S. (2010). Medical Liability in France. In: Hondius, E. (ed.), The Development of Medical Liability (pp. 70-107). Cambridge et al: Cambridge University Press.

Taylor, S. (2015). Medical Accident Liability and Redress in English and French Law. Cambridge et al: Cambridge University Press.

Thaler, R.H. \& Sunstein, C.R. (2003). Libertarian Paternalism. The American Economic Review, 93(2), pp. 175-179.

Thaler, R.H. \& Sunstein, C.R. (2008). Nudge: Improving Decisions About Health, Wealth, and Happiness. New Haven \& London: Yale University Press.

The Drafting Group (ed.) (2002). A Commentary on the Regulation on Handling Medical Accidents. Beijing: China Legal Publishing House.

The Economist (2012). Heartless Attacks: Medical Staff Are Fearful as Anger against Their Profession Grows. Available at: <www.economist.com/node/21559377> (accessed on 7 August 2016).

The Economist (2013). Murder Mysteries: Official Figures Showing a Sharp Drop in China's Murder Rate Are Misleading. Available at: <www.economist.com/news/china/21575767-official-figures-showingsharp-drop-chinas-murder-rate-are-misleading-murder-mysteries $>$ (accessed on 7 August 2016).

The Lancet Editorial (2014). Violence against Doctors: Why China? Why now? What next?. Lancet, 383(9922), pp. 1013-1013.

The State Council Information Office (2012). The White Paper: Medical and Health Services in China. Available at: <www.uschinahcp.org/sites/default/files/State\%20Council\%20White\%20Paper\%20\%20Medical\%20an d\%20Health\%20Services\%20in\%20China\%20(Dec\%2026).pdf> (accessed 16 June 2016).

The Supreme People's Court (ed.) (2015). Guiding Cases Published by the Supreme People's Court (The First Batch to the Nineth Batch). Beijing: People's Court Press.

Theoharis, M. (2016). Practising Medicine Without a License. Available at: $<$ www.criminaldefenselawyer.com/resources/practising-medicinewithout-a-license.htm > (accessed on 27 March 2016).

Thomas, E.J., Studdert, D.M., Burstin, H.R., Orav, E.J., Zeena, T., Williams, E.J., Howard, K.M., Weiler, P.C. \& Brennan, T. (2000a). Incidence and Types of Adverse Events and Negligent Care in Utah and Colorado. Medical Care, 38(3), pp. 261-271.

Thomas, E.J., Studdert, D.M., Newhouse, J.P., Zbar, B.I.W., Howard, K.M., Williams, E.J. \& Brennan, T.A. (1999). Costs of Medical Injuries in Utah and Colorado. Inquiry, 36(3), pp. 255-264. 
Bibliography

Thomas, E.J., Studdert, D.M., Runciman, W.B., Webb, R.K., Sexton, E.J., Wilson, R.M., Gibberd, R.W., Harrison, B.T. \& Brennan, T.A. (2000b). A Comparison of Iatrogenic Injury Studies in Australia and the USA. I: Context, Methods, Casemix, Population, Patient and Hospital Characteristics. International Journal for Quality in Health Care, 12(5), pp. 371-8.

Thomas, J.W., Ziller, E.C. \& Thayer, D.A. (2010). Low Costs of Defensive Medicine, Small Savings from Tort Reform. Health Affairs, 29(9), pp. 1578-1584.

Thorpe, K.E. (2004). The Medical Malpractice 'Crisis': Recent Trends and the Impact of State Tort Reforms. Health Affairs, 23(2), pp. 20-30.

Today's Headlines (2016). Should Hospitals Stop Treatment When Patients Are Unable to Pay for Medical Bills? Available at: <http://toutiao.com/i6314211225584534017/> (accessed on 13 August 2016).

Todd, S. (2000). Privatisation of Accident Compensation: Policy and Politics in New Zealand. Washburn Law Journal, 39(3), pp. 404-495.

Todd, S. (2011). Forty Years of Accident Compensation in New Zealand. Thomas M. Cooley Law Review, 28(2), pp. 189-218.

Todd, S. (2013). Treatment Injury in New Zealand. In: Oliphant, K. \& Wright, R.W. (eds.), Medical Malpractice and Compensation in Global Perspective (Tort and Insurance Law Vol. 32) (pp. 275-325). Berlin/Boston: De Gruyter.

Trebilcock, M.J. (1983). Regulating Service Quality in Professional Markets. In: Dewees, D.N. (ed.), The Regulation of Quality: Products, Services, Workplaces, and the Environment (pp. 83-107). Toronto: Butterworths.

Trebilcock, M. \& Veel, P. (2013). No-fault Accident Compensation Systems. In: Arlen, J. (ed.), Research Handbook on the Economics of Torts (pp. 588607). Cheltenham \& Northampton, MA: Edward Elgar.

Tucker, J.D., Cheng, Y., Wong, B., Gong, N., Nie, J.B., Zhu, W., Mclaughlin, M.M., Xie, R., Deng, Y., Huang, M., Wong, W.C., Lan, P., Liu, H., Miao, W. \& Kleinman, A. (2015). Patient-Physician Mistrust and Violence against Physicians in Guangdong Province, China: A Qualitative Study. BMJ Open, 5(10), pp. 1-10.

Tussing, A.D. \& Wojtowycz, M.A. (1992). The Caesarian Decision in New York State, 1986: Economic and Noneconomic Aspects. Medical Care, 30(6), pp. 529-540.

Tussing, A.D. \& Wojtowycz, M.A. (1997). Malpractice, Defensive Medicine, and Obstetric Behaviour. Medical Care, 35(2), pp. 172-191.

Twitchett, D. \& Fairbank, J.K. (eds.) (1987). The Cambridge History of China (Vol. 14 The People's Republic, Part I : The Emergence of Revolutionary China 1949-1965). Cambridge et al:: Cambridge University Press. 
Ulfbeck, V., Hartlev, M. \& Schultz, M. (2013). Malpractice in Scandinavia. In: Oliphant, K. \& Wright, R.W. (eds.), Medical Malpractice and Compensation in Global Perspective (Tort and Insurance Law Vol. 32) (pp. 377-396). Berliln/Boston: De Gruyter.

Ulrich, A. (1994). An Evalution of the Danish No-Fault System for Compensating Medical Injuries. Annals of Health Law, 3, pp. 243-282.

US Congressional Budget Office (2004) Limiting Tort Liability for Medical Malpractice. Available at: <https://www.cbo.gov/sites/default/files/108thcongress-2003-2004/reports/01-08-medicalmalpractice.pdf $>$ (accessed on 2 August 2016).

US Department of Health, Education, and Welfare (1971). Report on Licensure and Related Health Personal Credentialing (DHEW Publ. No. (HSM) 72-11). Washington: U.S. Government Printing Office.

US General Accounting Office (1987). Medical Malpractice: Characteristics of Claims Closed in 1984 (GAO/HRD-87-55). Washington, D.C.: United States General Accounting Office.

US Office of the Assistant Secretary for Planning and Evaluation (2003). Addressing the New Health Care Crisis: Reforming the Medical Litigation System. US Department of Health and Human Services, Assistant Secretary for Planning and Evaluation Office of Disability, Aging and Long-Term Care Policy, March 2003. Available at: <http://aspe.hhs.gov/sites/default/files/pdf/72871/medliab.pdf $>$ (accessed on 2 August 2016).

US Office of the Technology Assessment (OTA) (1994). Defensive Medicine and Medical Malpractice (OTA-H--602). Washington, D.C.: U.S. Government Printing Office.

US Social Security Administration (2014a). Social Security Programs Throughout the World: Europe. SSA Publication No. 13-11801. Available at: <https://www.ssa.gov/policy/docs/progdesc/ssptw/2014-2015/europe/ssptw14europe.pdf $>$ (accessed on 26 May 2016).

US Social Security Administration (2014b) Social Security Programs Throughout the World: Asia and the Pacific. SSA Publication No. 1311802. Available at: <https://www.ssa.gov/policy/docs/progdesc/ssptw/2014-2015/asia/ssptw14asia.pdf> (accessed on 26 May 2016).

US Social Security Administration (2015a) Social Security Programs Throughout the World: Africa. SSA Publication No. 13-11802. Available at: <https://www.ssa.gov/policy/docs/progdesc/ssptw/2014-2015/africa/ssptw15africa.pdf $>$ (accessed on 26 May 2016). 
Bibliography

US Social Security Administration (2015b). Social Security Programs Throughout the World: The Americas. SSA Publication No. 13-11802. Available at: <https:/www.ssa.gov/policy/docs/progdesc/ssptw/20142015/americas/ssptw15americas.pdf> (accessed on 26 May 2016).

USLegal (2016). Revocationd and Suspension of Physician Licenses. Available at: <http://physicians.uslegal.com/revocation-and-suspension-ofphysician-licenses/> (accessed on 27 March 2016).

Van Dam, C. (2013). European Tort Law. Oxford/New York: Oxford University Press.

Van den Bergh, R. (1993). Self-Regulation in the Medical and Legal Professions and the European Internal Market. In: Faure, M.G., Finsinger, J., Siegers, J. \& Van den Bergh, R. (eds.), Regulation of Professions: A Law and Economics Approach to the Regulation of Attorneys and Physicians in the US, Belgium, The Netherlands, Germany and the UK (pp. 21-45). Antwerp: MAKLU.

Van Dijck, G. (2015). Should Physicians Be Afraid of Tort Claims? Reviewing the Empirical Evidence. Journal of European Tort Law, 2015(6), pp. 282303.

Van Gerven, W., Lever, J. \& Larouche, P. (2000). Tort Law. Oxford \& Portland, Oregon: Hart Publishing.

Van Grunsven, P.R. (1997). Medical Malpractice or Criminal Mistake--An Analysis of Past and Current Criminal Prosecutions for Clinical Mistakes and Fatal Errors. DePaul Journal of Health Care Law, 2(1), pp. 1-54.

Van Velthoven, B.C.J. \& Van Wijck, P.W. (2012). Medical Liability: Do Doctors Care?. Recht der Werkelijkheid, 33(2), pp. 28-47.

Van Wijck, P. \& Winters, J.K. (2001). The Principle of Full Compensation in Tort Law. European Journal of Law and Economics, 11(3), pp. 319-332.

Vaughan, E.J. \& Vaughan, T.M. (2008). Fundamentals of Risk and Insurance. New Jersey et al:: John Wiley \& Sons.

Vidmar, N., Lee, P., Mackillop, K. \& Mccarthy, K. (2005). Uncovering the 'Invisible' Profile of Medical Malpractice Litigation: Insights from Florida. DePaul Law Review, 54(2), pp. 315-356.

Vincent, C., Neale, G. \& Woloshynowych, M. (2001). Adverse Events in British Hospitals: Preliminary Retrospective Record Review. British Medical Journal (Clinical Research Ed.), 322(7285), pp. 517-519.

Vine, C.L. (2006). Addressing the Medical Malpractice Insurance Crisis: Alternatives to Damage Caps. Northern Illinois University Law Review, 26(2), pp. 413-438.

Viscusi, W.K. \& Aldy, J.E. (2003). The Value of a Statistical Life: A Critical Review of Market Estimates Throughout the World. Journal of Risk and Uncertainty, 27(1), pp. 5-76. 
Viscusi, W.K. \& Born, P.H. (2005). Damages Caps, Insurability, and the Performance of Medical Malpractice Insurance. Journal of Risk and Insurance, 72(1), pp. 23-43.

Viscusi, W.K. \& Evans, W.N. (1990). Utility Functions That Depend on Health Status: Estimates and Economic Implications. The American Economic Review, 80(3), pp. 353-374.

Viscusi, W.K., Zeckhauser, R.J., Born, P. \& Blackmon, G. (1993). The Effect of 1980s Tort Reform Legislation on General Liability and Medical Malpractice Insurance. Journal of Risk and Uncertainty, 6(2), pp. 165-186.

Visscher, L.T. (2009). Tort Damages. In: Faure, M.G. (ed.), Tort Law and Economics (Encyclopedia of LaW and Economics Vol. 1) (pp. 153-200). Cheltenham \& Northampton, MA: Edward Elgar.

Visscher, L.T. (2015). Debated Damages (Erasmus Law Lectures). The Hague: Eleven International Publishing.

Visscher, L.T. \& Karapanou, V. (2015). Non-pecuniary Losses in the Economic Analysis of Torts: a Plea for Ex Ante Determined Damages. The Chinese Journal of Comparative Law, 3(2), pp. 1-22.

Von Eyben, B.E. (2001. Alternative Compensation Systems. Scandinavian Studies in Law, 41, pp. 194-233.

Wagner, G. (2007). (Un)insurability and the Choice between Market Insurance and Public Compensation Systems. In: Van Boom, W.H. \& Faure, M.G. (eds.), Shifts in Compensation between Private and Public Systems (Tort and Insurance Law Vol. 22) (pp. 87-112). Wien/NewYork: Springer.

Wagner, G. (2009). Tort Law and Liability Insurance. In: Faure, M.G. (ed.), Tort Law and Economics (Encyclopedia of Law and Economics Vol. 1) (pp. 377-405). Cheltenham \& Northampton, MA: Edward Elgar.

Wang, A., Huang, M. \& Li, L. (2013). On the Legal Definition of Excessive, Protective and Preventive Medical Treatment. Medicine \& Philosophy $(A)$, 34(5A), pp. 67-69.

Wang, C. (2010). An Empirical Analysis of the Legal Regulation of Medical Torts - A Comment on Chapter Seven of the Tort Liability Law. China Legal Science, 5, pp. 113-122.

Wang, D. (2008). Resolve Medical Disputes to Construct a Harmonious Relationship between Doctors and Patients Based on the Game Theory. Unpublished Master thesis. Southern Medical University.

Wang, D. \& Yang, Y. (2007). A Retrospective Analysis of 315 Medical Disputes Occurring in A General Hospital. Sun Yatsen University Forum, 27(11), pp. 32-36.

Wang, F. (2006). The Analysis on the Principle of Medical Accident - At the Angle of Law and Economics. Shandong University Law Review, 2006(00), pp. 130-139. 
Bibliography

Wang, H. (2011). A Monographic Study on Atypical Contract. Beijing: China Press of Democracy and Legality.

Wang, H. \& Tussing, D. (2011). Understanding China's Healthcare Reform in a Global Context. APSA 2011 Annual Meeting Paper, Available at: <http://ssrn.com/abstract=1901049> (accessed on 15 June 2016).

Wang, H., Tan, X., Ma, J., Li, M., Tong, J., Yu, J. \& Dai, W. (2006). A Search for Law: An Investigative Report on a Medical Tangle Case of the People's Court of Wuhou District. Journal of SWUPL, 8(5), pp. 54-77.

Wang, H. \& Chen, S. (2014). Research on the Mechanism of Sharing Medical Injury. Hangzhou: Zhejiang Industry and Commerce University Press.

Wang, L. (2011). The Research on Tort Liability Law (Book 1). Beijing: China Remin University Press.

Wang, L. \& Su, Y. (2009). The Investigation and Analysis of the Status of Credibility of Malpractice Appraisement in Hainan Province. Medicine and Society, 22(11), pp. 42-44.

Wang, P. (2014). On the Difficulties Facing the Developing Commercial Health Insurance in China and the Countermeasures. Shanghai Insurance, 2014(3), pp. 9-24.

Wang, Q. (2012). On the Influence of Defensive Medicine from Perspective of Medical Students' Growth and Development: Investigation of Medical Students' Cognition and Attitude on Defensive Medicine. Medicine and Philosophy, 33(6), pp. 71-73.

Wang, Q. \& Wang, F. (2004). Discussion on Defensive Medicine from Onus Proof Conversion. Journal of Nanjing Medical University (Social Sciences), 4(3), pp. 189-192.

Wang, S. (ed.) (2013). A Commentary on the Tort Law of the People's Republic of China. 2nd edn. Beijing: Law Press.China.

Wang, Y. (2014). Solutions to the Problem of Unvertainty of Causality in Medical Malpractice. Unpublished Master thesis. East China University.

Wang, Y. \& Xu, L. (2008). A Review of Current Studies on Defensive Medicine in China. Chinese Health Service Management, 25(11), pp. 742744.

Wang, Z. \& Oliphant, K. (2012). Yangge Dance: The Rhythm of Liability for Medical Malpractice in the People's Republic of China. Chicago-Kent Law Review, 87(1), pp. 21-52.

Wang, Z. (2009). On the Application of Statutory Imperfect Joint and Several Liability to the Fields of Strict Liability. Renmin University Law Review, 1, pp. 163-172.

Wei, J. \& Wang, J. (2011). Analysis About the Proficiency of Liability System of the Medical Damage. Law Science Magazine, 32(7), pp. 54-58.

Wei, L. (1997). Judicial Interpretation in China. Willamette Journal of International Law and Dispute Resolution, 5, pp. 87-112. 
Wei, L., Liu, Y., Ji, L., Zheng, X., Chen, T. \& Wang, X. (2013). Survey on Medical Damage Liability Juridical Practice. Chinese Hospitals, 17(5), pp. 18-23.

Wei, M. \& Shen, C. (2009). China-US Studies System of Defensive Medicine: Comparative Analysis and Enlightenment. Medicine \& Philosophy (A), 30(5), pp. 49-51.

Wei, Z. (1987). The Nature and Application of Compensatory Liability for Emotional Damage. Political Science and Law, 1987(6), pp. 24-27.

Weiler, P.C. (1991). Medical Malpractice on Trial. Cambridge, MA \& London: Harvard University Press.

Weiler, P.C., Hiatt, H.H., Newhouse, J.P., Johnson, W.G., Brennan, T.A. \& Leape, L.L. (1993). A Measure of Malpractice: Medical Injury, Malpractice Litigation, and Patient Compensation. Cambridge, MA \& London: Harvard University Press.

Weinstein, M.C. (2005). Spending Health Care Dollars Wisely: Can CostEffectiveness Analysis Help? Centre for Policy Research, Maxwell School of Citizenship and Public Affairs, Paper 13. Available at: $<$ http://ssrn.com/abstract=1822505> (accessed on 19 April 2016).

Weinstein, N.D. (1982). Unrealistic Optimism about Susceptibility to Health Problems. Journal of Behavioural Medicine, 5(4), pp. 441-460.

Wendel, L. (2004). Compensation in the Swedish Health Care Sector. In: Dute, J., Faure, M.G. \& Koziol, H. (eds.), No-Fault Compensation in the Health Care Sector (Tort and Insurance Law Vol. 8) (pp. 367-391). Wien/NewYork: Springer.

Weng, K., Fan, L. \& Sun, Q. (2005). A Survey of High Amount of Damages in Medical Accident Cases. China Journal of Public Health, 21(4), pp. 107108.

Wiley, J. (1982). The Impact of Judicial Decisions on Professional Conduct: An Empirical Study. Southern California Law Review, 55(2), pp. 345-398.

Williams, P.C. (1984). Abandoning Medical Malpractice. Journal of Legal Medicine, 5(4), pp. 549-594.

Wilson, R.M., Runciman, W.B., Gibberd, R.W., Harrison, B.T., Newby, L. \& Hamilton, J.D. (1995) 'The Quality in Australian Health-Care Study', Medical Journal of Australia, 163(9), pp. 458-471.

Winthers, M. (2016). The Difference between A Pre-Existing Condition and A Pre-Disposition. Available at: <www.colorado-law.net/the-differencebetween-a-pre-existing-condition-and-a-pre-disposition $>$ (accessed on 21 July 2016).

World Health Organisation (2006). Constitution of the World Health Organisation. Available at: <www.who.int/governance/eb/who_constitution_en.pdf $>$ (accessed on 17 April 2016). 
Bibliography

World Health Organisation (2011). World Health Statistics 2011. Geneva et al.: WHO Press.

Wu, C. (2008). Unreal Joint and Several Liability between Manufacturers and Sellers in the 'Tainted Milk' Case. Legal Science, 11, pp. 21-24.

Wu, S., Gai, Y., Wei, L., Xu, X., Liu, X. \& Chen, D. (2013). Practice Summary on the Periodical Assessment Work of Doctors. Chinese Medical Record, 14(12), pp. 30-31.

Wu, T. (2011). Agency Threats. Duke Law Journal, 60, pp. 1841-1857.

Wu, T., Xiong, Z. \& Lu, L. (2012). Agency Threats. Administrative Law Review, 4, pp. 136-144.

Wu, X. \& Jin, Y. (2015). On the Problems of Periodical Physician Assessment and Suggestions. Journal of Bethune Military Medical College, 13(6), pp. 667-669.

Wu, Y. (2013). People's Mediation in China. In: Cao, L., Sun, I.Y. \& Hebenton, B. (eds.), The Routledge Handbook of Chinese Criminology (pp. 116-129). London/New York: Routledge.

$\mathrm{Wu}, \mathrm{Z}$. (2013). The Standard of Proof for Civil Procedure in Chinese Law. Tsinghua Law Review, 7(1), pp. 73-88.

Xi, C. \& Yang, L. (2011). Medical Liability Laws in China: The Tale of Two Regimes. Tort Law Review, 19, pp. 65-75.

Xi, X. \& The Supreme People's Court (eds.) (2010). Understanding and Application of the Tort Liability Law of the People's Republic of China. Beijing: People's Court Press.

Xia, Y. (2007). Compensation Law for Medical Accidents - From the Perspective of Japanese Law. Beijing: Law Press.China.

Xia, Y. \& Tian, K. (2015). Data Analysis of 2589 Cases of Medical Quality Safety Events in Jiangsu Province: Comment on Medical Quality Safety Events Reporting System. Chinese Hospital Management, 35(8), pp. 29-31.

Xiamen Intermediate People's Court \& Siming District People's Court (2008). Report on the Legal Issues concerning the Trial of Medical Dispute Cases. Southeast Justice Review, pp. 71-92.

Xi'an Daily (2010). Who Created the 'Sewed Annul Incident'?. Xi'an Daily, 6 August, 6.

Xiao, L. (2011). Comparative Study of Medical Injury Identification System in Jiangsu Model and Beijing Model - Based on the Implementation of 'Tort Liability Act'. Evidence Science, 19(3), pp. 290-298.

Xiao, L. (2012). Economic Analysis of Defensive Medicine. Law Science Magazine, 33(8), pp. 140-144.

Xiao, L. (2014). Positive Study on the Unification of Medical Damage Appraisal. Modern Law Science, 36(4), pp. 176-183. 
Xiao, X. \& Qiao, N. (2003). Defensive Medicine from the Perspective of the Reversal of the Burden of Proof. China Contemporary Medicine, 9(11), pp. 33-36.

Xiaoxiaosweety (2011). Administrative Affiliation System versus Employment System and Contract System. Available at: <www.360doc.com/content/11/0211/12/5703837_92111772.shtml> (accessed on 13 August 2016).

Xie, H. (2009). The Investigate and Analysis of Dispute to Medical Treatment and Preventive Countermeasure. Unpublished Master thesis. Xinjiang Medical University.

Xiong, S. (2012). Rankings Based on Accreditation, Past and Present. Minsheng Weekly.

$\mathrm{Xu}, \mathrm{H}$. (2004). The Limitation of Applying 'Equitable Responsibility' Principle to Medical Cases. Journal of Anhui TV University, 1, pp. 20-22.

Xu, J. (2010). The Distinction between Treatment Norms and Customary Practices in Light of the Tort Law. China Pharmaceutical News, 11 May, B06.

Xu, L. (2016). Discussion on the Relationship between Defensive Medical Behaviours and Excessive Medical Treatment. Medicine and Society, 29(2), pp. 41-43.

Xu, X. \& Lu, R. (2008). Violence and Mistrust: Research on Violence in Medical Treatment in Transforming China (2000 2006). Legal and Social Development, 1, pp. 82-101.

Xu, Y., Wan, L., Zhu, J., Yang, S. \& Peng, T. (2010). Study on 151 Cases of Judicial Identification of Medical Dispute. Medicine and Philosophy (Humanistic \&Social Medicine Edition), 31(10), pp. 64-65.

Xu, Z., Xie, Q., Liang, J. \& Luo, P. (2012). An Analysis of 917 Cases of Administrative Punishments on Medical Institutions in Yudu County. Chinese Journal of Public Health Management, 28(2), pp. 213-215.

Yang, G. (2013). Corrective Justice: Essential Conditions for Justifying Tort Liability. Academic Research, 6, pp. 54-59.

Yang, H. (2000). A Return to Fault: The New Zealand Lesson for Taiwan's Medical Injury Compensation. National Taiwan University Law Review, 64, pp. 97-119.

Yang, H. (2001). A Comparative Study of Swedish Patient Compensation System: Lessons for Taiwan. National Taiwan University Law Journal, 30(6), pp. 165-194.

Yang, H. (2002). Definition, Causes, and Imputation Principles of Medical Disputes. Taiwan Law Journal, 10, pp. 121-131.

Yang, H., Zhao, H. \& Bao, L. (2006). A Survey of Medical Disputes in Huangshi City of Hubei Province. LiShiZhen Medicine and Materia Medica Research, 17(9), pp. 1861-1862. 
Bibliography

Yang, J. (2013). An Economic Analysis of Medical Torts. Beijing: Law Press $\cdot$ China.

Yang, L. (2008). The Rule of Causal Potency Applying to Compensatory Liability for Medical Malpractice. Studies in Law and Business, 6, pp. 3744.

Yang, L. (2009a). The Research on Medical Injury Liability. Beijing: Law Press.China.

Yang, L. (2009b). Proving Causation and the Burden of Proof in Medical Malpractice Cases. Law Science, 1, pp. 35-44.

Yang, L. (2012). Specific Judgements on the Constitutive Requirements for Liability for Medical Injury. Journal of Law Application, 4, pp. 19-27.

Yang, L. (2014). Tort Law. Beijing: Peking University Press.

Yang, L., Deng, Z. \& Dong, Y. (2009). On Administrative Punishments on Providers. Chinese Journal of Health Inspection, 14(1), pp. 44-46.

Yang, L. \& Yang, Z. (2013). Applying Chinese Law to Products Liability Cases. Northern Legal Science, 7(5), pp. 5-17.

Yang, T.T., Studdert, D.M., Subramanian, S.V. \& Mello, M.M. (2008). A Longitudinal Analysis of the Impact of Liability Pressure on the Supply of Obstetrician-Gynecologists. Journal of Empirical Legal Studies, 5(1), pp. 21-53.

Yang, Y.T., Mello, M.M., Subramanian, S.V. \& Studdert, D.M. (2009). Relationship Between Malpractice Litigation Pressure and Rates of Caesarian Section and Vaginal Birth After Caesarian Section. Medical Care, 47(2), pp. 234-242.

Yang, Y.T., Studdert, D.M., Subramanian, S.V. \& Mello, M.M. (2012). Does Tort Law Improve the Health of Newborns, or Miscarry? A Longitudinal Analysis of the Effect of Liability Pressure on Birth Outcomes. Journal of Empirical Legal Studies, 9(2), pp. 217-245.

Ye, M. (2012). The Decline of the Theory of Medical Contractual Liability Taking French Law as an Example. Journal of Gansu Institute of Political Science and Law, 6, pp. 53-62.

Yi, W. (2014). To Put a Damper on Medical Dispute People's Mediation. Available at: <www.66law.cn/domainblog/61378.aspx> (accessed on 27 July 2016).

Yin, H. \& Wang, H. (2006). Why Is Practising Medicine without A License Persistent. Guangming Daily, 8 December, 06.

Ying, S. (ed.) (2011). Administrative Law and Administrative Procedure Law. 2nd edn. Beijing: China University of Political Science and Law Press.

You, M. \& Chen, G. (2006). 200 Medical Violent Incidents Occurred in Guangdong in the First Half of 2006, of Which 129 Resolved Behind the Scenes. Available at: <http://news.sohu.com/20060910/n245256467.shtml> (accessed on 27 July 2016). 
Young, R., Faure, M. \& Fenn, P. (2004). Causality and Causation in Tort Law. International Review of Law and Economics, 24, pp. 507-523.

Yu, S., Lai, L., Cai, M. \& Wu, J. (2011). An Analysis of 214 Cases of Administrative Punishments on Medical Institutions in Longgang District. Guide of China Medicine, 9(3), pp. 170-171.

$\mathrm{Yu}, \mathrm{X}$. (2009). The Difficult Implementation of Law from the Certainty of Law. Cards World, 13(6), pp. 69-70.

$\mathrm{Yu}, \mathrm{X}$. (2016). Causal Uncertainty in Chinese Medical Malpractice Law When Theories Meet Facts. Tsinghua China Law Review, 9(1), pp. 23-62.

Yuan, D. \& Zhang, Y. (2008). The Prevalence of Practising Medicine without A License, the Borderline between Innocence and Guilt. Legal Daily, 13 May, 5.

Yuan, L. (2013). On the Relationship between Social Medical Insurance and Commercial Medical Insurance. China Business Update, 22, pp. 117-119.

Zang, D. (2002). Research on Crime of Medical Accident. Unpublished PhD thesis. Wuhan University.

Zeckhauser, R. \& Nichols, A.L. (1978). Lessons from the Economics of Safety. In: Rottenberg, S. (ed.), The Economics of Medical Malpractice (pp. 1933). Washington, D.C: American Enterprise Institute for Public Policy Research.

Zegers, M., De Bruijne, M.C., Wagner, C., Hoonhout, L.H.F., Waaijman, R., Smits, M., Hout, F.A.G., Zwaan, L., Christiaans-Dingelhoff, I., Timmermans, D.R.M., Groenewegen, P.P. \& Van der Wal, G. (2009). Adverse Events and Potentially Preventable Deaths in Dutch Hospitals: Results of a Retrospective Patient Record Review Study. Quality and Safety in Health Care, 18(4), pp. 297-302.

Zeng, X. (2009). Mediation in China-Past and Present. Asia Pacific Law Review, 17, pp. 1-29.

Zeng, E., Chen, B., Deng, Z. \& Chen, H. (2015). The Basis of Medical Injury Identification by Forensic Doctor. Journal of North Sichuan Medical College, 30(4), pp. 552-556.

Zhang, C. (2010). There Had Been 80,000 Applications for Medical Accident Technical Ascertainment in the Past 8 Years. Health Weekly, 5 July, 003.

Zhang, C. \& Chen, M. (2013). The Current Status, Problems, and Future of Medical Injury Ascertainment - A Synthesis of the First Academic Seminar on Medical Injury Ascertainment. Evidence Science, 21(2), pp. 240-247. 
Bibliography

Zhang, G. \& Dai, L. (2016). The Regulation of the Determination of the Crime of Medical Accidents and Room for Improvement. Available at: $<$ http://mp.weixin.qq.com/s?src=3\&timestamp=1466836784\&ver=1\&signat ure=X8yBCzwbHQoyJvNkpCLPMzeotcKGN3Zt7eV4kqpM6MSq2WJ3O WMvvCmUE05kDn1b9RDJqDb*nldOFnJWm4C4JX81FqtrJOVezNzZNks6MUToqi-gHfy6HUWTuwHmru3lPG1pmgApE5hcsi5yFXGAjOpZqfm1KaHncZKmxRANcA=> (accessed on 25 June 2016).

Zhang, H., Zheng, H., Liu, J., Zhang, Y. \& Zhang, C. (2015). Comparative Study on the Influence of Medical Dispute to Medical Staffs' Defensive Medical Behaviour. Soft Science of Health, 29(5), pp. 295-298.

Zhang, L. \& Ma, Y. (eds.) (2011). Research on Chinese Health Delivery System Reform Using Evidence-informed Policy Making. Beijing: Science Press.

Zhang, M. (2011). Tort Liabilities and Torts Law: The New Frontier of Chinese Legal Horizon. Richmond Journal of Global Law and Business, 10(4), pp. 415-495.

Zhang, Q., Cai, W., Wang, W. \& Wang, H. (2013). A Research on Analyzing Reasons and Providing Suggestions of Medical Treatment Arrearages in Shandong Province. Chinese Health Service Management, 3(1), pp. 46-48.

Zhang, W., Zhao, J., Li, L. \& Liu, H. (2011). The Contribution of Periodic Doctor Assessment to the Improvement of the Quality of Care. Guide of Chinese Medicine, 9(28), pp. 395-396.

Zhang, W. (ed.) (2011). Jurisprudence. 4th edn. Beijing: High Education Press.

Zhang, X. (2013). Tort Liability Law. 3rd edn. Beijing: China Remin University Press.

Zhang, Y. (2004). Research of Medical Tort by Economic Method. Chinese Hospital Management, 24(5), pp. 15-17.

Zhang, Y., Liu, G., Tian, H. \& Shi, X. (2007). Retrospective Analysis of the Medical Professional Liability Insurance in Yunnan Province. Chinese Journal of Hospital Statistics, 14(2), pp. 101-104.

Zhang, Y. \& Zhang, C. (2015). Present Situation and Countermeasures of Illegal Medical Practice in China - With Case Statistics as Analysis Perspective. Medicine and Jurisprudence, 7(4), pp. 47-50.

Zhang, Y., Liu, G., Zhao, X., Zhou, F. \& Wei, G. (2007). Status of medical responsibility insurance in China. Chinese Hospitals, 11(9), pp. 1-5.

Zhang, Z. (2001). On Legal Attributes of Medical Relations. Medicine and Philosophy, 22(4), pp. 3-7.

Zhao, B. \& Zeng, C. (1998). On the Features of the Requirements of the Crime of Medical Accidents. Jurists' Review, 5, pp. 29-45.

Zhao, H. \& Feng, X. (2010). Health-Care Reform in China. Chinese Economy, 43(3), pp. 31-36. 
Zhao, X. (2012). The New Tort Liability Law and the Journey towards Informed Consent in China. Medical Law International, 12, pp. 156-187.

Zhao, X. (2013). The Duty of Medical Practitioners and CAM TCM Practitioners to Inform Competent Adult Patients about Alternatives. Verlag, Berlin \& Heidelberg: Springer.

Zhejiang Hangzhou Intermediate People's Court (2015). A Report on the Trial of Medical Malpractice Cases in Hangzhou City. Available at: $<$ www.hzcourt.cn/art/2015/10/9/art_51_12480.html> (accessed on 19 July 2016).

Zhejiang High People's Court, First Civil Chamber (2010). The Report on the Trial of Medical Dispute Cases in Our Province. Research on Rule of Law, 8, pp. 91-97.

Zhejiang Ningbo Intermediate People's Court, First Civil Chamber (2013). A Report on the Trial of Medical Dispute Cases After the Implementation of the Tort Liability Law. People's Judicature, 9, pp. 77-82.

Zheng, L., Jin, K., Yan, X., Chen, Y., Dong, L., Jin, H. \& Tang, J. (2006). A Survey of 111 Medical Dispute Cases. Chinese Journal of Hospital Administration, 22(4), pp. 250-252.

Zheng, X., Deng, L. \& Chen, C. (2002) 'An Investigation on the Medical Dissensions and Infringement Events in 326 Medical Institutions', Chinese Hospitals, 6(6), pp. 25-31.

Zheng, X., Gao, S., Wang, J., Cao, Y., Le, Q., Wen, X. \& Liu, F. (2012). Investigation on the Mechanism for Third-Party Mediation in Medical Dispute in Some Provinces. Chinese Hospitals, 16(7), pp. 5-7.

Zheng, X., Wei, L., Zhang, B., Wang, X. \& Wang, X. (2007). Medical Dispute Survey in China and Medical Dispute Solution Overseas. Chinese Hospitals, 11(7), pp. 2-4.

Zhou, W. (2005). The Subjective Requirements of Medical Malpractice and the Crime of Medical Accidents. People's Procuratorial Semimonthly, 3, pp. 37-40.

Zhu, S., Li, L. \& Li, Y. (2011). China's Criminal Penalty for Medical Malpractice: Too Lenient or Not?. Legal Medicine, 13(3), pp. 116-119.

Zippelius, R. (2008). Juristische Methodenlehre (Introduction to German Legal Methods). Translated by Junker, K.W. \& Roy, P.M., Durham, North Carolina: Carolina Academic Press.

Zuckerman, S. (1984). Medical Malpractice: Claims, Legal Costs, and the Practice of Defensive Medicine. Health Affairs, 3(3), pp. 128-134.

Zuckerman, S., Bovbjerg, R.R. \& Sloan, F. (1990). Effects of Tort Reforms and Other Factors on Medical Malpractice Insurance Premiums. Inquiry, 27(2), pp. 167-182. 



\section{APPENDIX 1: LEGISLATION}

China $^{1}$

AR-BMI for Urban Employees 1998 (China)

Decision on Establishing the Urban Employees' Basic Medical Insurance System 关于建立城镇职工基本医疗保险制度的决定 (Dec. 14, 1998).

AR-BMI for Urban Residents 2007 (China)

Guiding Opinions about the Pilot Urban Resident Basic Medical Insurance 关于开展城镇居民基本医疗保险试点的指导意见 (Jul. 10, 2007).

AR- Five Guarantees 2006 (China)

Regulations on the Work of Providing Five Guarantees 农村五保供养工作条例 (Mar. 1, 2006).

AR- General Practitioners 2011 (China)

Guiding Opinion on the Establishment of the Regime of General Practitioners 关于建立全科医生制度的指导意见 (Jul. 1, 2011).

1 In this thesis, regarding the Constitution and national laws (法律) promulgated by the NPC and the SC-NPC, no letter has been prefixed to the abbreviations of the statutes. Other inferior and secondary statutes or policy documents have been prefixed with letters as follows: "AR-" stands for "administrative regulations" (行政法规) enacted by the State Council, "DR-" for "departmental/ministry rules" (部门规章) by ministries of the State Council, "LR-" for “local regulations" (地方性法规) by local people's congresses, "GR-" for “local governmental rules" (地方政府规章) by local governments at or above the largemunicipality level, "N-" for non-enforceable "other normative legal documents" (其他规范性文件) by various state organs, “JI-” for “judicial interpretations” (司法解释) by the SPC, and "LJI-" for "local documents of a nature of judicial interpretations" (地方司法解释性文件) by local appellate courts. 
Appendix 1

\section{AR-Government-Funded Medical Insurance 1952 (China)}

A Directive on the Implementation of the Government-Funded Medical Insurance System for all National Public Servants Working at Various Levels of the People's Government, Political Parties, Societies and Affiliated Public Institutions 关于全国各级人民政府、党派、团体及所属事业单位的国家工 作人员实行公费医疗预防的指示 (Feb. 26, 1951, amended Jan. 2, 1953).

AR-Labour Insurance 1953 (China)

Labour Insurance Regulations 劳动保险条例 (Jan. 2, 1953).

AR-Legal Aid 2003 (China)

Regulation on Legal Aid 法律援助条例 (Jul. 21, 2003).

AR-Litigation Costs 2007 (China)

Measures for Paying Litigation Costs 诉讼费用交纳办法 (Apr. 1, 2007).

AR-Medical Accidents 1987 (China)

Measures for the Handling of Medical Accidents医疗事故处理办法 (Jun. 29, 1987).

AR-Medical Accidents 2002 (China)

Regulation on the Handling of Medical Accidents 医疗事故处理条例 (Sep. 1, 2002).

AR- Minimum Subsistence for Rural Residents 2007 (China)

Notice on Establishing the System of Guaranteeing Minimum Subsistence for Rural Residents across the Nation 关于在全国建立农村最低生活保障制度的 通知 (Jul. 11, 2007).

AR-Minimum Subsistence for Urban Residents 1999 (China)

Regulations on Guaranteeing Minimum Subsistence for City Residents 城市 居民最低生活保障条例 (Oct. 1, 1999).

AR-Medical Institutions 1994 (China)

Regulations on the Administration of Medical Institutions 医疗机构管理条例 (Sep. 1, 1994).

AR-Nurses 2008 (China)

Nurses Regulation 护士条例 (May 12, 2008). 
AR- Road Traffic Accidents 1991 (China)

Measures for the Handling of Road Traffic Accidents 道路交通事故处理办法 (Sep. 22, 1991, effective Jan. 1, 1992).

\section{AR- Social Assistance 2014 (China)}

Interim Measures for Social Assistance 社会救助暂行办法 (May 1, 2014).

Civil Procedure Law 1982 (China)

Civil Procedure Law (For Trial Implementation) 民事诉讼法(试行) (Oct. 1, 1982).

Civil Procedure Law 1991 (2012 Amendment) (China)

Civil Procedure Law 民事诉讼法 (Apr. 9, 1991, amended Aug. 31, 2012).

\section{Constitution 2004 (China)}

The Constitution of the People's Republic of China 中华人民共和国宪法 (Dec. 4, 1982, amended Mar. 14, 2004).

Consumer Law 1993 (China)

Law on the Protection of Consumer Rights and Interests 消费者权益保护法 (Oct. 31, 1993, effective Jan. 1, 1994.

Contract Law 1999 (China)

Contract Law 合同法 (Oct. 1, 1999).

Criminal Law 1997 (China)

Criminal Law 刑法 (Oct. 1, 1997).

Doctors Law 1998 (China)

Law on Practising Doctors 执业医师法 (June 26, 1998, effective May 1, 1999).

DR-Accident Ascertainment 2002 (China)

Interim Measures for Medical Accident Technical Ascertainment 医疗事故技术鉴定暂行办法 (Sep. 1, 2002).

DR-Accreditation Expert Database 2011 (China)

Measures for the Administration of Hospital Accreditation Expert Database (Trial) 医院评审专家库管理办法(试行) (Dec. 21, 2011). 
Appendix 1

DR-Administrative Dissuasion 2011 (China)

Interim Measures for Medical Quality and Safety Dissuasion and Conversation System 医疗质量安全告诫谈话制度暂行办法 (Jan. 7, 2011).

DR-Criteria for Medical Institutions 1994 (China)

The Basic Criteria for Establishing Medical Institutions (Trial) 医疗机构基本 标准(试行) (Sep. 2, 1994).

DR- Designated Medical Institutions 1999 (China)

Notice on the Promulgation of the Interim Measures for the Administration of Designated Medical Institutions under the Basic Medical Insurance for Urban Employees 关于印发城镇职工基本医疗保险定点医疗机构管理暂行 办法的通知 (May 11, 1999).

DR-Detailed Rules-Medical Institutions 2006 (China)

Detailed Rules for the Implementation of the Regulations on the Administration of Medical Institutions 医疗机构管理条例实施细则 (Sep. 1, 1994, amended Dec. 1, 2006).

DR-Disability Pension 2013 (China)

Measures for the Administration of Disability Pension 伤残抚恤管理办法 (Jul. 5, 2007, amended Jun. 27, 2013).

DR- Doctors' Routine Assessment 2007 (China)

Administrative Measures for Doctors' Routine Assessment 医师 定期考核管理办法 (Feb. 9, 2007).

DR-Draft-General Hospitals Ranking 1989 (China)

Criteria for the Administration of General Hospitals Based on Their Rankings (Trial Draft) 综合医院分级管理标准(试行草案) (1989).

DR-Employment Contracts in Public Institutions 2002 (China)

Notice on Opinions on Implementing the Regime of Employment Contracts in Public Institutions on a Trial Basis 关于在事业单位试行人员聘用制度意 见的通知 (Jul. 6, 2002).

DR-Hospital Accreditation 1998 (China)

Notice on the Hospital Accreditation 关于医院评审工作的通知 (Aug. 11, 1998).

DR-Hospital Accreditation 2011 (China)

Interim Measures for Hospital Accreditation (Year 2011-2015) 医院评审暂行办法(2011-2015年) (Sep. 21, 2011). 
DR-Hospital Ranking 1989 (China)

Measures for the Administration of Hospitals in Accordance with Their Ranking (Trial) 医院分级管理办法(试行) (Nov. 29, 1989).

\section{DR-Incident Reporting 2011 (China)}

Interim Provisions on the Reporting of Medical Quality Safety Incidents 医疗 质量安全事件报告暂行规定 (Jan 14, 2011).

DR-Increase in BMIUR \& NRCMC Premiums 2014 (China)

Notice on the Increase in BMIUR and NRCMC Premiums in 2014 关于提高 2014年新型农村合作医疗和城镇居民基本医疗保险筹资标准的通知 (Apr. 25, 2014).

DR-Licensed Pharmacists 1999 (China)

Interim Provisions on the Regime of Licensed Pharmacists 执业药师资格制 度暂行规定 (Apr. 1, 1999).

DR-Maintaining Order In Medical Institutions 2012 (China)

Notice on Maintaining the Order in Medical Institutions 关于维护医疗机构 秩序的通告 (Apr. 30, 2012).

DR- Medical Assistance Funds 2013 (China)

Measures for the Administration of the Urban-Rural Medical Assistance Funds 城乡医疗救助基金管理办法 (Dec. 23, 2013).

DR- Medical Assistance System 2009 (China)

Opinion on the Further Improvement of the Urban-Rural Medical Assistance System 关于进一步完善城乡医疗救助制度的意见 (Jun. 11, 2009).

DR-MoH Report-Hospitals Running at a Loss 1981 (China)

Report on the Question as to How to Resolve the Problem of Hospitals Running at a Loss 关于解决医疗赔本问题的报告 (Feb. 16, 1981).

DR-Neo-Rural Cooperative 2003 (China)

Opinions on Establishing the New-Type Rural Cooperative Medical System 关于建立新型农村合作医疗制度的意见 (Jan. 10, 2003).

DR-Nurse Examination 2010 (China)

The Measures for the Nurse Practising Qualification Examination 护士执业 资格考试办法 (Jul. 1, 2010). 
Appendix 1

\section{DR-Prehospital Emergency Care 2013 (China)}

Measures for the Management of Prehospital Emergency Medical Care 院前 医疗急救管理办法 (Feb. 1, 2014).

\section{DR-Promotion of the BMIUR 2016 (China)}

Notice on the Promotion of the Basic Medical Insurance for Urban Residents in 2016 关于做好 2016年城镇居民基本医疗保险工作的通知 (Apr. 29, 2016).

\section{DR-Promotion of MLI 2007 (China)}

Notice on the Issues pertaining to the Promotion of Medical Liability Insurance 关于推动医疗责任保险有矢问题的通知 (Jun. 21, 2007).

\section{DR- Sino-Foreign Medical Institutions 2000 (China)}

Interim Measures for the Administration of Sino-foreign Equity Joint and Cooperative Joint Medical Institutions 中外合资、合作医疗机构管理暂行办 法 (Jul. 1, 2000).

\section{DR-Standardised Training of Residents 1993 (China)}

Pilot Measures for Standardised Training of Clinical Residents 临床住院医师 规范化培训试行办法 (Feb. 17, 1993).

\section{DR-Standardised Training of Resident 2014 (China)}

Regulatory Measures for Standardised Training of Resident (Trial) 住院医师 规范化培训管理办法(试行) (Aug. 22, 2014).

\section{DR-Unregistered Interns 2004 (China)}

Reply to the Question about Whether Unregistered Interns Who Have Already Obtained the Qualifications for Practising Doctors Are Allowed to Practice 关于取得医师资格但未经执业注册的人员开展医师执业活动有矢 问题的批复 (Jun. 3, 2004).

\section{Enterprise Income Tax Law 2007 (China)}

Enterprise Income Tax Law 企业所得税法 (Mar. 16, 2007, effective Jan. 1, 2008).

\section{GR-Jiangsu Attorney Fees (China)}

Detailed Rules for the Implementation of the Measures for the Administration of Lawyers' Fees in Jiangsu Province 江苏省《律师服务收费 管理办法》实施细则 (Jan. 1, 2007). 
GR-Jiangsu Criteria for Attorney Fees (China)

Criteria for Attorney Fees in the Jiangsu Province 江苏省律师服务收费标准 (Dec. 13, 2013).

\section{Insurance Law 1995 (China)}

Insurance Law 保险法 (Oct. 1, 1995).

Insurance Law 2009 (China)

Insurance Law 保险法 (Oct. 1, 2009).

\section{JI-Application of Tort Law 2010 (China)}

Notice on Certain Issues concerning the Application of the Tort Law 关于适 用《侵权责任法》若干问题的通知 (Jun. 30, 2010).

\section{JI-Causes of Civil Action 2001 (China)}

Notice on Issuing the Provisions on Causes of Action in Civil Cases (Trial) 关 于印发《民事案件案由规定(试行)》的通知 (Oct. 30, 2000).

\section{JI-Causes of Civil Action 2008 (China)}

Notice on Issuing the Provisions on Causes of Action in Civil Cases 关于印发 《民事案件案由规定》的通知 (Apr. 1, 2008).

\section{JI-Causes of Civil Action 2011 (China)}

Notice on Issuing the Revised Provisions on Causes of Action in Civil Cases 关于印发修改后的《民事案件案由规定》的通知 (Apr. 1, 2011).

\section{JI-Application of Civil Procedure Law 2015 (China)}

Interpretation on the Application of the Civil Procedure Law of the People's Republic of China 关于适用《中华人民共和国民事诉讼法》的解释 (Feb. 4, 2015).

\section{JI-Criminal Filing Standards 2008 (China)}

Provisions (I) on the Standards for Filing Criminal Cases under the Jurisdiction of the Public Security Organs For Investigation and Prosecution 关于公安机关管辖的刑事案件立案追诉标准的规定(一) (Jun. 25, 2008).

\section{JI-Emotional Damage 2001 (China)}

Interpretation of Several Issues regarding the Ascertainment of Compensation Liability for Emotional Damage in Civil Torts 关于确定民事侵权精神损害赔 偿责任若干问题的解释 (Mar. 10, 2001). 
Appendix 1

\section{JI-No Compensation Shall Be Granted 1964 (China)}

Official Reply to the Issue that Economic Compensation Shall not Be Granted in Handling Medical accidents Cases 关于处理医疗事故案件不应当判给经济 补偿问题的批复 (Jan. 18, 1964).

\section{JI-Notice on Referring to the RHMA 2003 (China)}

Notice on Trying Civil Cases on Medical Disputes by Referring to the “Regulation on Handling Medical Malpractices” 关于参照《医疗事故处理条 例》审理医疗纠纷民事案件的通知 (Jan. 6, 2003).

\section{JI-Personal Injury 2003 (China)}

Interpretation of Some Issues concerning the Application of Law for the Trial of Cases on Compensation for Personal Injury 关于审理人身损害赔偿案件适 用法律若干问题的解释 (Dec. 4, 2003, effective May 1, 2004).

\section{JI-Rules of Evidence 2001 (China)}

Some Provisions on Evidence in Civil Procedures 关于民事诉讼证据的若干 规定(Dec. 21, 2001, effective Apr. 1, 2002).

Judicial Ascertainment Administration 2005 (China)

Decision on the Administration of Judicial Ascertainment 关于司法鉴定管理 问题的决定 (Oct. 1, 2005).

\section{Labour Contract Law 2012 (China)}

Labour Contract Law 劳动合同法 (Jun. 29, 2007, amended Dec. 28, 2012).

Law on Administrative Penalty 1996 (China)

Law on Administrative Penalty 行政处罚法 (Oct. 1, 1996).

\section{LGR-Ningbo Medical Dispute Resolution 2007 (China)}

Interim Measures for Preventing and Handling Medical Disputes in Ningbo City 宁波市医疗纠纷预防与处置暂行办法 (Nov. 20, 2007, effective Mar. 1, 2008).

\section{LGR-Yunnan Iatrogenic Injury Incidents 1998 (China)}

Provisions on the Handling of Iatrogenic Injury Incidents in the Yunnan Province 云南省医疗损害事件处理规定 (Oct. 15，1988， effective Jan. 1, 1999).

LJI-Anhui Guide to Malpractice (2011)

Guiding Opinions on Several Issues concerning the Trial of Medical Dispute Cases 关于审理医疗纠纷案件若干问题的指导意见 (Nov. 22, 2011). 
LJI-Beijing Guide to Malpractice 2010 (China)

Guiding Opinions on Several Issues concerning the Trial of Cases of Disputes over Compensation for Medical Injury (Trial) 关于审理医疗损害赔偿纠纷案 件若干问题的指导意见(试行) (Nov. 18, 2010).

\section{LJI-Jiangsu Guide to Injury Ascertainment 2010 (China)}

Several Opinions on the Medical Injury Ascertainment Work (Trial) 关于医 疗损害鉴定工作的若干意见(试行) (Oct. 11, 2010).

\section{LJI-Jiangsu Notice on Injury Ascertainment 2010 (China)}

Notice on the Proper Conduct of Medical Injury Ascertainment after the Coming into Force of the PRC Tort Liability Law 关于做好《中华人民共和 国侵权责任法》实施后医疗损害鉴定工作的通知 (Jul. 9, 2010).

\section{LJI-Jiangsu Guide to Torts 2011 (China)}

A Trial Guide to the Trial of Cases of Compensation for Damage Caused by Torts 侵权损害赔偿案件审理指南 (2011).

\section{LJI-Shanghai Guide to Malpractice 2005 (China)}

Guide to the Trial of Cases of Disputes over Compensation for Injury Caused by Medical Malpractice 医疗过失赔偿纠纷案件办案指南 (2005).

\section{LJI-Xinjiang Guide to Malpractice (2011)}

Guiding Opinions on Several Issues concerning the Trial of Cases of Compensation for Medical Injury (Trial) 关于审理医疗损害赔偿案件若干问 题的指导意见(试行) (Sep. 29, 2011).

\section{LJI-Zhejiang Guide to Malpractice (2010)}

Opinions on Several Issues concerning the Trial of Medical Dispute Cases (Trial) 关于审理医疗纠纷案件若干问题的意见(试行) (Jul. 1, 2010).

\section{LR-Jiangsu Legal Aid 2001 (China)}

Regulations on Legal Aid in the Jiangsu Province 江苏省法律援助条例 (Oct. 1, 2001).

\section{LR-Jiangsu Legal Aid 2001 (2005 Amendment, China)}

Regulations on Legal Aid in the Jiangsu Province (2005 Amendment) 江苏省 法律援助条例(2005年修订) (Dec. 1, 2005).

\section{N-Assistance for Non-Paying Emergencies 2013 (China)}

Guiding Opinions on the Establishment of the Regime of Assistance for NonPaying Emergencies 关于建立疾病应急救助制度的指导意见 (Feb. 22, 2013). 
Appendix 1

N-Beijing Medical Liability Insurance 2004 (China)

Notice concerning the Enactment of the Opinions on Implementing Medical Liability Insurance in Beijing City 关于下发《北京市实施医疗责任保险的意 见》的通知 (Sep. 1, 2004).

N-Crackdown on Yi Nao Incidents 2016 (China)

A Campaign for the Crackdown on Hospital Order-Related Crimes 关于严厉 打击涉医违法犯罪专项行为方案 (Jun. 30, 2016).

N-Criteria for Ascertaining the Degree of Disability 2005 (China)

Criteria for Ascertaining the Degree of Disability (Trial) 人体损伤残疾程度鉴 定标准(试行) (May 1, 2005).

N-Deepening of Health Reform 2009 (China)

Opinions on Deepening the Reform of the Medical and Health Care System 关于深化医药卫生体制改革的意见 (Mar. 17, 2009).

N-Establishment of Standardised Training of Residents 2013 (China)

Guiding Opinions on the Establishment of Standardised Training of Residents 关于建立住院医师规范化培训制度的指导意见 (Dec. 31, 2013).

N-Jiangsu Accident Ascertainment Fees 2002 (China)

A Reply to the Criteria for Charging Medical Accident Technical Ascertainment 关于医疗事故技术鉴定等收费试行标准的批复 (Oct. 14, 2002).

N-Private Medical Institutions 2010 (China)

Notice on the Opinions on Further Encouraging and Guiding the Establishment of Medical Institutions by Social Capital 关于进一步鼓励和引 导社会资本举办医疗机构意见的通知 (Dec. 26, 2010).

N-Shanghai Medical Liability Insurance 2002 (China)

On the Reply to the Opinion on Implementing Medical Liability Insurance in Shanghai City 关于同意《关于本市实施医疗责任保险的意见》的批复 (Aug. 23, 2002).

N-Shanghai Medical Liability Insurance Implementation Schemes 2002 (China)

Implementation Schemes for Medical Accident Liability Insurance in Shanghai City 上海市医疗事故责任保险实施方案(试行) (Aug. 23, 2002). 
N-Shenzhen Medical Professional Risk Insurance 2004 (China)

Measures for Administrating Medical Professional Risk Insurance in Shenzhen City 深圳市医疗执业风险保险管理办法 (Jan. 8, 2004).

\section{Principles 1986 (China)}

General Principles of the Civil Law 民法通则 (Apr. 12, 1986, effective Jan. 1, 1987).

Public Security Administration Punishments Law 2006 (China)

Public Security Administration Punishments Law 治安管理处罚法 (Mar. 1, 2006).

\section{State Compensation Law 1994 (China)}

State Compensation Law 国家赔偿法 (May 12, 1994, effective Jan. 1, 1995).

Social Insurance Law 2010 (China)

Social Insurance Law 社会保险法 (Oct. 28, 2010, effective Jul. 1, 2011).

Tort Law 2009 (China)

Tort Law 侵权责任法 (Dec. 26, 2009, effective Jul. 1, 2010).

People's Mediation Law 2010 (China)

People's Mediation Law 人民调解法 (Aug. 28, 2010, effective Jan. 1, 2011).

Product Quality Law 2000 (China)

Product Quality Law 产品质量法 (Feb. 22, 1993, amended Jul. 8, 2000).

Property Law 2007 (China)

Property Law 物权法 (Oct. 1, 2007).

\section{Denmark}

\section{Danish KEL:}

Lov om klageog erstatningsadgang inden for sundhedsvæsenet [Law on the Right to Complain and Receive Compensation within the Health Service] No. 706, June 25, 2010 (Den.), translated by the Patienterstatningen.

\section{Danish Damages Act:}

Bekendtgørelse af lov om erstatningsansvar [Liability for Damages Act] No. 885, September 20, 2005 (Den.), translated by the Patienterstatningen. 
Appendix 1

\section{France}

French C. pén:

Code pénal (Penal Code), translation at <www.legislationline.org/documents/section/criminal-codes/country/30> (Fr.).

French Law 2002-303 of March 4 :

Loi 2002-303 du 4 mars 2002 relative aux droits malades et à la qualité du système de santé [Law 2002-303 of March 4, 2002 on Patients' Rights and the Quality of the Health System], Journal Officiel de la Republique Française [J.O.] [Official Gazette of France], Mar. 5, 2002, p. 4118 (Fr.)

\section{Finland}

\section{Finish PIA:}

Potilasvahinkolaki [Patient Injury Act] No. 585, July 25, 1986 (Fin.), translated by the Finnish Patient Insurance Centre.

\section{Finish Tort Act:}

Vahingonkorvauslaki [Tort Liability Act] No. 412, May 31, 1974 (Fin.), translated by the Finlex.

\section{Germany}

\section{German StGB:}

Strafgesetzbuch (Penal Code), translation at <https://www.gesetze-iminternet.de/englisch_stgb/index.html> (Ger.)

Italy

Italian C.p.:

Codice penale (It.).

Spain

Spanish C.P.:

Código Penal (Criminal Code) (Spain).

\section{The Netherlands}

Dutch BW:

Burgerlijk Wetboek (Civil Code) (established in 1992) (Neth.), translated in (Internet Site of Dutch Civil Law).

\section{New Zealand}

\section{Code: NZ-HDC-CHDSCRR 1996}

The HDC Code of Health and Disability Services Consumers' Rights Regulation 1996 (N.Z.) 
NZ Act 1972:NZ-ACA 1972

Accident Compensation Act 1972 (N.Z.).

NZ Act 1982:NZ-ACA 1982

Accident Compensation Act 1982 (N.Z.).

NZ Amendment Act 1993:NZ-ARCIAA 1993

Accident Rehabilitation and Compensation Insurance Amendment Act 1993 (N.Z.).

\section{NZ Act 2001:NZ-ACA 2001}

Accident Compensation Act 2001 (N.Z.).

NZ-CA 1961:

Crimes Act 1961 (N.Z.)

NZ-CAA 1997:

Crimes Amendment Act 1997 (N.Z.)

NZ-CAA 2011:

Crimes Amendment Act 2011 (N.Z.)

NZ HDC Act 1994:NZ-HDCA 1994

Health and Disability Commissioner Act 1994 (N.Z.).

NZ-IPRCAA 2001:

Injury Prevention, Rehabilitation, and Compensation Amendment Act 2001 (N.Z.).

\section{NZ Amendment Act 2005:NZ-IPRCAA 2005}

Injury Prevention, Rehabilitation, and Compensation Amendment Act 2005 (N.Z.).

\section{Norway}

Norwegian PIA:

Lov om erstatning ved pasientskader mv. (Pasientskadeloven) [Patient Injury Act] No. 53, June 15, 2001 (Nor.).

Norwegian Damages Act:

Lov om skadeserstatning (skadeserstatningsloven) [Damage Compensation Act] No. 26, June 13, 1969 (Nor.). 
Appendix 1

\section{Sweden}

Swedish PIA:

Patientskadelag [Patient Injuries Act] (Svensk författningssamling [SFS] 1996:799) (Swed.), translated by Carl Espersson.

Swedish Tort Act:

Skadeståndslag [Tort Liability Act] (Svensk författningssamling [SFS] 1972:207) (Swed.).

\section{The United States}

US Model Penal Code:

Model Penal Code (Am. Law Inst., Proposed Official Draft 1962).

US Restatement (Second) of Torts:

Restatement (Second) of Torts (Am. Law Inst. 1979).

US Restatement (Third) of Torts: Phys. \& Emot. Harm:

Restatement (Third) of Torts: Liability for Physical and Emotional Harm (Am. Law Inst. 2010). 


\section{APPENDIX 2:}

\section{CASES}

\section{China}

Chen v. Stomatological Hospital (China)

Chen Bo v. Stomatological Hospital of Jiangsu Province 陈博诉江苏省口腔医院, (on file with author) (Jiangsu Nanjing Gulou District People's Court Dec. 12, 2003) (China)

Children's Hospital v. Pang et al. (China)

Chongqing Medical University Affiliated Children's Hospital v. Pang Kunchuan, Pang Haikuan \& Chen Shiling 重庆医科大学附属儿童医院诉庞坤川、庞海宽和陈石玲, (Chinalawinfo) (Chongqing Yuzhong District People’s Ct. 2009) (China).

Chongqing Children's Hospital v. Pang et al. (China) Chongqing Medical University Affiliated Children's Hospital 重庆医科大学附属儿童医院, (Chinalawinfo) (Chongqing Yuzhong District People's Court 2009) (China).

Deng v. Anji Hospital (China)

Deng Moumou v. Anji County People’s Hospital 邓某某诉安吉县人民医院, (Chinalawinfo) (Zhejiang Huzhou Intermediate People's Court 2015) (China).

Feng \& Xue v. Drum Tower Hospital (China)

Feng Zenglin \& Xue Huailan v. Nanjing Drum Tower Hospital 冯增林、薛怀兰诉南京市鼓楼医院, (on file with author) (Jiangsu Nanjing Gulou District People's Court Dec. 14, 2006) (China).

Gu v. Drum Tower Hosp. \& Shanghai RAAS Co., Ltd. (China) Gu Yeqin v. Nanjing Drum Tower Hosp. \& Shanghai RAAS Blood Products Co., Ltd. 顾业勤诉南京市鼓楼医院、上海莱士血制品有限公司, (on file with author) (Jiangsu Nanjing Gulou District People’s Court Dec. 16, 2005) (China). 
He v. A Chongqing Hospital (China)

He Mou Jia v. A Hospital in Chongqing City 何某甲诉重庆市某医院, (Chinalawinfo) (Chongqing the Fifth Intermediate People's Court Jul. 24, 2005) (China).

Huang v. Chen (China)

Huang Tujian v. Chen Longsheng 黄土坚诉陈龙生医疗事故损害赔偿纠纷案, (Chinalawinfo) (Guangdong High People's Court Jan. 19, 2015) (China).

Li v. Shaoyang Hospital (China)

Li Yinxian et al. v. Shaoyang Central Hospital 李银先等与邵阳市中心医院医疗损害责任纠纷上诉案, (Chinalawinfo) (Hunan Shaoyang Intermediate People's Court Dec. 5, 2012) (China).

Liang $v$. The Third Hospital et al. (China)

Liang Haoming $v$. The Third Affiliated Hospital of Sun Yat-Sen University et al. 梁浩明诉中山大学附属第三医院等, (Caseshare) (Guangdong Guangzhou Intermediate People's Court Dec. 20, 2010) (China).

Liu v. Datong Clinic (China)

Liu Ying v. Ürümchi New Urban District Datong Trade Firm Traditional Chinese Clinic 刘颙诉乌鲁木齐新市区大同贸易商行中医门诊部, (Chinalawinfo) (Ürümchi Intermediate People’s Court April 24, 1992) (China).

Liu v. Pingdingshan Hospital (China)

Liu Shuhua v. Pingdingshan Coal Mine Group 12 Hospital 刘树华与平煤集团十二矿医院医疗过失损害赔偿纠纷案， (Chinalawinfo) (Pingdingshan Weidong District People's Court Apr. 20, 2009) (China).

Liu v. Gong'an Traditional Chinese Hospital(China)

Liu Liangrong v. Gong'an County Traditional Chinese Hospital 刘良容诉公安县中医医院, (Chinalawinfo) (Hubei Gong'an County People's Court 2014) (China).

Lü v. Drum Tower Hospital (China)

Lü Ruijin v. Nanjing Drum Tower Hospital \& Renji Hospital of Shanghai Jiaotong University School of Medicine 吕瑞今诉南京市鼓楼医院、上海交通大学医学院附属仁济医院, (on file with author) (Jiangsu Nanjing Gulou District People's Court Jun. 11, 2006) (China). 
Ouyang v. Suzhou Hospital(China)

Ouyan Lanying V. Suzhou Municipal Hospital 欧阳兰英诉宿州市立医院, (Chinalawinfo) (Anhui Suzhou Yongqiao District People's Court 2015) (China).

Qi \& Qi v. Stomatological Hospital(China)

Qi Jianzhong \& Qi Enxuan v. Stomatological Hosp. Jiangsu Province 戚建中、戚恩瑄诉江苏省口腔医院, (on file with author) (Jiangsu Nanjing Gulou District People's Court Mar. 26, 2008) (China).

Qian v. Zhongda Hospital (China)

Qian Lijuan v. Zhongda Hospital Affiliated to Southeast University 钱莉娟诉东南大学附属中大医院, (on file with author) (Jiangsu Nanjing Gulou District People's Court Sep. 15, 2011) (China).

Rong v. Wang \& Yongcheng Insurance Ltd. (China)

Rong Baoying v. Wang Yang \& Yongcheng Property Insurance Ltd., Jiangyin Branch 荣宝英诉王阳、永诚财产保险股份有限公司江阴支公司, (Chinalawinfo) (Jiangsu Wuxi Binhu District People's Court. Feb. 8, 2013) (China).

Shan v. Shuanmiao Health Centre (China)

Shan Xiuying v. Xiajin County Shuangmiao Health Centre 单秀英诉夏津县双庙中心卫生院, (China-lawinfo) (Shandong Dezhou Xiajin Intermediate People’s Court 2015) (China).

Shan v. Third Hospital (China)

Shan Yeping v. Nanjing Third Hospital 单业平诉南京市第三医院, (on file with author) (Jiangsu Nanjing Gulou District People's Court Mar. 11, 2003) (China).

Shen v. A Hospital (China)

Shen et al. v. A Hospital 沈某等诉某医院人身损害赔偿纠纷案, (Chinalawinfo) (Shanghai Luwan District People's Court Feb. 14, 2008) (China).

Sun et al. v. Ansheng Tianping Ltd. (China)

Sun Qinghao et al. v. Ansheng Tianping Property Ins. Ltd, Jinan Cent. Branch 孙钦浩等诉安盛天平财产保险股份有限公司济南中心支公司, (Chinalawinfo) (Jinan Intermediate People’s Court Mar. 5, 2015) (China). 
Wang v. Brain Hospital (China)

Wang Gang et al. v. Nanjing Brain Hospital 王刚等诉南京脑科医院, (on file with author) (Jiangsu Nanjing Gulou District People's Court Dec. 11, 2006) (China).

Wang v. Drum Tower Hospital (China)

Wang Fengqin v. Nanjing Drum Tower Hospital 王凤琴诉南京市鼓楼医院, (on file with author) (Jiangsu Nanjing Gulou District People's Court May 16, 2005) (China).

Wang v. Nantong Affiliated Hospital (China)

Wang Huajie v. Affiliated Hospital of Nantong University et al. 王华杰诉南通医学院附属医院等医疗损害赔偿案, (Chinalawinfo) (Jiangsu Nantong Intermediate People's Court Oct. 10, 1999) (China).

Wang et al. v. Jiangsu Hospital (China)

Wang Wenqing et al. v. Jiangsu Province Hospital 王文清诉江苏省人民医院, (on file with author) (Jiangsu Nanjing Gulou District People's Court Mar. 11, 2011) (China)

Wang \& Wang v. Ningxia Fourth Hospital (China)

Wang Jincheng \& Wang Dong v. The Fourth People's Hospital of Ningxia Hui Autonomous Region 王进成、王东诉宁夏回族自治区第四人民医院, (Chinalawinfo) (Ningxia Yinchuan Xizia District People's Court 2014) (China).

Xiong v. Drum Tower Hospital (China)

Xiong Huarong v. Nanjing Drum Tower Hospital 熊化荣诉南京市鼓楼医院, (on file with author) (Jiangsu Nanjing Gulou District People's Court Jun. 27, 2006) (China).

Xu v. Changge Hospital (China)

$\mathrm{Xu}$ Xiuhua ${ }^{\mathrm{N}}$. Changge East City Hospital 胥秀花与长葛市东城医院医疗过错损害赔偿纠纷上诉案, (Chinalawinfo) (Henan Xuchang Intermediate People's Court Dec. 31, 2014) (China).

Yan v. Zhu \& Beijing Bus Co. Ltd. (China)

Yan Sixian v. Zhu Yuqin \& Beijing Bus Co. Ltd. 晏思贤诉朱玉琴、北京巴士股份有限公司, <http://news.xinhuanet.com/legal/2007-11/26/content_7148244.htm> (accessed on 18 July 2016) (Beijing First Intermediate People's Ct. 2007) (China). 
Yang v. Ruijing Hospital (China)

Yang Yong v. Ruijin Hospital Affiliated to Shanghai Second Medical University et al. 杨涌诉上海第二医科大学附属瑞金医院等人身损害赔偿案, (Chinalawinfo) (Shanghai Changning District People's Court Nov. 25, 2002) (China).

Yang v. Shanghai MCC20(China)

Yang Wenwei v. Shanghai Baoshan Steel MCC20 Co., Ltd. 杨文伟诉上海宝钢二十冶企业开发公司， (Chinalawinfo) (Shanghai $2^{\text {nd }}$ Intermediate People's Cour June 30, 2006) (China).

Yang v. Shantou Affiliated Hospital(China)

Mrs. Yang v. An Affiliated Hospital to the Shantou University Medical College 杨某枝与汕头大学医学院第某附属医院医疗服务合同纠纷上诉案, (Chinalawinfo) (Guangdong Shantou Intermediate People's Court Dec. 18, 2012) (China).

Yao v. Songshan Hospital \& Ping An Insurance Co., Ltd(China)

Yao Zhenhai v. Chifeng Songshan Hospital \& China Ping An Property

Insurance Co., Ltd. Chifeng Branch

姚振海诉赤峰市松山医院、中国平安财产保险股份有限公司赤峰中心支公

司, (Chinalawinfo) (Inner Mongolia Chifeng Songshan District People’s Court 2015) (China).

Yin \& Li v. PICC (China)

Yin Baohai \& Li Lanxiu v. Xue Jiaxin \& PICC P\&C Ltd., Zhijiang Branch 尹保海、李兰修诉薛家新、中国人民财产保险股份有限公司枝江支公司, (Chinalawinfo) (Hebei Sheng Zhijiang People’s Ct. Nov. 17, 2013) (China).

Zeng et al. v. Drum Tower Hospital (China)

Zeng Guoying et al. v. Nanjing Drum Tower Hospital 曾国英等诉南京市鼓楼医院, (on file with author) (Jiangsu Nanjing Gulou District People's Court Dec. 15, 2006) (China).

Zhang v. Employees Hospital(China)

Zhang Erfeng v. Employees Hospital of the Henan Zhongyuan Neipei Co., Ltd. 张二凤诉河南省中原内配股份有限公司职工医院, (Chinalawinfo) (Henan Mengzhou People's Court 2015) (China).

Zhang v. Shang (China)

Zhang Mou v. Shang Moumou 张某诉上某某, (Chinalawinfo) (Shanghai Minxing District People's Court 2014) (China). 
Appendix 2

Zheng \& Chen v. Jiangsu Hospital (China)

Zheng Xuefeng and Chen Guoqing v. People's Hospital of Jiangsu Province 郑雪峰、陈国青诉江苏省人民医院，2004(8) SUP. PEOPLE'S CT. GAZ. 4 (Nanjing Intermediate People's Court November 18, 2003) (China).

Zhou \& Jin v. Children's Hopital (China)

Zhou Jibing \& Jin Guozhen v. Nanjing Children's Hospital 周继兵、晋国珍诉南京市儿童医院, (on file with author) (Jiangsu Nanjing Gulou District People’s Court May 5, 2014) (China).

\section{New Zealand}

ACC v. Auckland Hosp. Bd. [1980] 2 NZLR 748 (HC).Bridgeman v. ACC [1993] NZAR 199 (HC).

Child v. Hillock [1994] 2 NZLR 65, 72 (CA).

Green v. Matheson [1989] 3 NZLR 564 (CA).

Queenstown Lakes District Council v. Palmer [1999] 1 NZLR 549 (CA).

\section{The United Kingdom}

Livingstone v. Rawyards Coal Co. (1880) 5 App Cas 25.

\section{The United States}

State v. Weiner, 194 A.2d 467 (N.J. 1963).

U.S. v. Carroll Towing Co., 159 F. 2d 169, 173 (2d Cir. 1947) 


\section{APPENDIX 3: SEMI-STRUCTURED INTERVIEWS}

\section{Interview-2013-1}

Interview with $\mathrm{Hu}$ Xiaoxiang (胡晓着翔) \& Liu Junning (刘俊宁), Division Chiefs, Nanjing Health Bureau, Jiangsu Province, China (Aug. 30, 2013).

\section{Interview-2014-1}

Interview with Yang Bingquan (杨冰泉), Associate Chief Physician, Zhongda Hospital at Southeast University, Nanjing, Jiangsu Province, China (Jul. 1, 2014).

\section{Interview-2014-2}

Interview with Gu Liubao (顾刘宝), Attending Doctor, Jiangsu Province Official Hospital, China (Jul. 1, 2014).

\section{Interview-2014-3}

Interview with Yang Weimin (杨伟民), Office Director, Office for Reconciliation between Doctors and Patients, Zhongda Hospital at Southeast University, Nanjing, Jiangsu Province, China (Jul. 1, 2014).

\section{Interview-2014-4}

Interview with Zhu Jian (朱建), Assoc. Chief Physician, Zhongda Hospital at Southeast University, Nanjing, Jiangsu Province, China (Jul. 1, 2014).

\section{Interview-2014-5}

Interview with Ms. A (alias), Resident Doctor, Zhongda Hospital at Southeast University, Nanjing, Jiangsu Province, China (Jul. 2, 2014).

\section{Interview-2014-6}

Interview with Huo Mingdong (霍明东), Attending Doctor, Zhongda Hospital at Southeast University, Nanjing, Jiangsu Province, China (Jul. 2, 2014). 


\section{Interview-2014-7}

Interview with Teng Shichao (滕世超) \& Yu Kai, Office Director, Office for Reconciliation between Doctors and Patients, Jiangsu Province Hospital of TCM, Nanjing, Jiangsu Province, China (Jul. 3, 2014).

\section{Interview-2014-8}

Interview with Mr. A (alias), People's Mediator, Yizheng Social Conflicts and Disputes Mediation Service Centre, Yangzhou, Jiangsu Province, China (Jul. 8, 2014).

\section{Interview-2014-9}

Telephone Interview with Mr. Qiu, Manager, Nanjing Branch of PICC Property\& Casualty Co Ltd., Nanjing, Jiangsu Province, China (Jul. 11, 2014).

\section{Interview-2014-10}

Interview with Li Zimu (李子木), Division Chief Judge, Nanjing Gulou District People's Court, Jiangsu Province, China (Jul. 14, 2014).

\section{Interview-2014-11}

Telephone Interview with Mr. B (alias), Manager, An Insurance Corporation in Yangzhou, Jiangsu Province, China (Jul. 14, 2014).

\section{Interview-2014-12}

Interview with Mr. Shen, Div. Chief, Grass-Root Work Department, Nanjing Bureau of Justice, Jiangsu Province, China (Jul. 16, 2014).

\section{Interview-2014-13}

Interview with Ms. A (alias), Assistant Judge, Nanjing Intermediate People's Court, Jiangsu Province, China (Jul. 17, 2014).

\section{Interview-2014-14}

Interview with Jiang Tao (江涛), Office Director, Office for Medical Authentication, Nanjing Medical Association, Jiangsu Province, China (Jul. 22, 2014).

\section{Interview-2014-15}

Interview with Liu Junning (刘俊宁), Division Chief, Medical Administration Department, Nanjing Health Bureau, Jiangsu Province, China (Aug. 30, 2013).

\section{Interview-2015-1}

Interview with Dai Qingkang (戴庆康), Assoc. Professor, Southeast University, Law School \& Assistant to the President, Xuzhou Intermediate People's Court, Nanjing \& Xuzhou, China (Jan. 3, 2015). 
Semi-Structured Interviews

\section{Interview-2015-2}

Interview with Bai Xiuyan (白秀艳), Lawyer, DeHeng (TaiYuan) Law Offices, Taiyuan, Shanxi Province, China (Jan. 5, 2015).

\section{Interview-2015-3}

Interview with Gu Yihua (顾益华), Lawyer, Jiangsu Jianxing Law Firm, Nantong, Jiangsu Province, China (Jan. 5, 2015).

\section{Interview-2015-4}

Interview with Zeng Fanlin (曾凡林), Lawyer, Hunan Jinzhou (Changde) Law Firm, Changde, Hunan Province, China (Jan. 6, 2015).

\section{Interview-2016-1}

Interview with Chen Zhihua (陈志华), Lawyer, Huan'an First People's Hospital, Huan'an, Jiangsu Province, China (Feb. 26, 2016). 



\section{VALORISATION ADDENDUM}

\section{1) What is the social relevance of your research results?}

The troubled relationship between doctors/hospitals and patients is a topical subject in China. In particular, Chinese doctors complain that they are under threat from violence. Violence against doctors is a worldwide problem. However, what is unique to China is that the nature of violence is extreme and part of the violent events is labeled as Yi Nao incidents. Many patients and their family members use violence or a threat of violence to coerce hospitals into paying compensation. They may also employ $Y i$ Nao gangs to help them to carry out $\mathrm{Yi} N \mathrm{No}$ incidents. These groups would threaten and assault hospital personnel, damage facilities, and equipment, and disturb the normal activities of the hospital, which has been widely reported in both Chinese and English media. In addition to the costs of medical malpractice, those violent $Y i$ Nao incidents incur considerable social costs.

Various factors may account for the tension between doctors/hospitals and patients, such as deteriorating medical quality and ethics, bad communications between doctors and patients, low coverage of social security, and high medical bills. One of the causal factors that is pertinent to this thesis is that patients resort to $\mathrm{Yi} \mathrm{Nao}$ incidents because they do not trust the legal remedies for medical malpractice in China. Hence, this thesis has explored what the legal remedies are in China, how good they are both from a legal perspective and from a law and economics perspective, and how we can improve them.

The research results show that the Chinese legal remedies for preventing medical malpractice and compensating victims of medical malpractice need to be further improved, although many aspects of the remedies are in line with economic benchmarks. At the end of this thesis, several policy recommendations are proposed in order for optimal deterrence and compensation to be achieved. The wider social relevance of these results is that if health care providers would be induced to invest optimally in care and patient safety and victimised patients could obtain sufficient compensation quickly, more medical malpractice would be prevented in the first place and fewer serious medical disputes would arise. A decreased rate of medical malpractice, iatrogenic injury, medical disputes, and $Y i \mathrm{Nao}$ incidents would surely economise on social costs and thus enhance social welfare. 
2) To who, in addition to the academic community, are your research results of interest and why?

In additional to scholars, the research results of this thesis may be interesting to many other groups. First and foremost, policy recommendations proposed at the end of the thesis are of relevance for Chinese policy makers. In China, important decisions are generally made by the national legislature (NPC and SC-NPC) and sometimes by the central government (State Council). The legal remedies for medical malpractice have been changed several times and further reforms are still pending. If Chinese policy makers set the minimization of accident costs as a legitimate policy goal, then it would be helpful if they could take into account the policy recommendations that I put forward in my thesis. Overall, China should continue to improve the faultliability-insurance system (FLIS) in order to provide physicians with sufficient incentives to take precautions at the moment. Besides, in order to provide victims with fast and fair compensation, China may conduct some experiments in the no-fault compensation scheme (NFCS) in some local jurisdictions and strengthen quality regulation at the same time. Any further reform proposal should be based on a careful comparison between the FLIS and the NFCS.

Also, this book may be of interest to businesses, especially liability insurance companies. China has reformed the medical malpractice liability regime drastically by enacting the new Tort Liability Law 2009. This book has examined not only how the law in books is written, but also how the law is applied in practice. The empirical data collected in this book should be able to help liability insurance companies, especially those from other countries, to assess the risk of medical malpractice in China and make informed decisions.

In addition to policy makers and businesses, this book may be interesting to judges, especially those from other countries. In modern times, especially within the member states of the European Union, judges more frequently make references to foreign case-law or legal doctrines in their decisions. This book provides foreign judges with an interesting example of how Chinese judges handle medical malpractice issues. After all, the problem of medical malpractice is not unique to China. Besides, the detailed information summarised in this book on how to construct an efficiencyoriented malpractice system may give judges fascinating insights into how to apply and interpret the law in a better way, irrespective of the particularity of jurisdictions. 
3) Into which concrete products, services, processes, activities or commercial activities will your results be translated and shaped?

First, the results of my research will be published into a book by the Intersentia in its EDLE series (devoted to Law and Economics). This book will be available for researchers, students and other readers who are interested in topics such as medical malpractice law, tort law, health care regulation and law and economics. By reading this book, they will have a clear understanding of the legal remedies for medical malpractice in China, the latest developments in economic theories concerning medical malpractice and extensive empirical evidence.

Second, some parts of this thesis have already been published in law journals. For example, the Tsinghua China Law Review has published the article "Causal Uncertainty in Chinese Medical Malpractice Law - When Theories Meet Facts" in Volume 9, Number 1, 2016. In addition to this article, there is a plan to transform other parts of the thesis into articles in the near future.

Third, during the period between 2012 and 2016, some preliminary results were presented at several conferences and workshops, such as the METRO Seminar Series, the Joint Seminar "The Future of Law and Economics" in Paris and the "Liability and Insurance" Workshop at the $20^{\text {th }}$ Ius Commune Congress in 2015. Feedback from the audience greatly facilitated the improvement of my research.

4) To what degree can your results be called innovative in respect to the existing range of products, services, processes, activities and commercial activities?

This research is innovative in two aspects. On the one hand, it generates new empirical findings pertaining to how the medical malpractice regime actually works in China. For the purpose of examining how the law is working in practice, a total of 592 court decisions have been analyzed and some semistructured interviews conducted. These empirical data show that there is a gap between what the law says and what the law is applied in practice. Hence, it would be too superficial if only the substantive rules were addressed. On the other hand, it looks at the medical malpractice issue from the perspective of law and economics. Although the economic analysis of malpractice liability has been extensively carried out in the West, it is still relatively new to apply this approach to the analysis of the Chinese one. In particular, the book has summarised a lot of empirical evidence in favour of the deterrent effect of medical malpractice liability, which has laid a solid foundation for normative arguments. 
5) How will these plans for valorization be shaped? What is the schedule, are there risks involved, what market opportunities are there and what are the costs involved?

First, social media, such as newspapers and blogs, are wonderful platforms to make the research results accessible to a wider public audience. The general public will read those results and acquire a better understanding of various disputes over medical malpractice. Readers, who find law and economics theories convincing or unconvincing, may try to participate in the discussions and put forward their own opinions.

Second, it may be helpful to provide legal advisers or commercial insurers with some handbooks or brochures, which include the introduction to the Chinese medical malpractice regime and major findings of this research. That is particularly important for international insurance companies who want to do businesses in China but who are unfamiliar with the Chinese legal system.

Third, the key findings of this research will be spread to policy makers, judges, scholars and the public through various conferences and workshops. In addition to the presentations in Europe mentioned before, the research results are going to be presented on new occasions in China in the near future. 


\section{CURRICULUM VITAE}

Xiaowei Yu was born in the Yizheng City of the Jiangsu Province, China. He attended schools in Yizheng and graduated from the Yizheng High School in 2005. Upon graduation, he went to Southeast University (Nanjing, China) and obtained the degree of Bachelor of Law in 2009 and subsequently the degree of Master of Law in 2012. In September 2012, Xiaowei started his PhD research into medical malpractice liability in China at the Maastricht Institute for Transnational Legal Research (METRO). 